\title{
Geschichte im Dienst für das Vaterland
}

Traditionen und Ziele der russländischen Geschichtspolitik seit 2000 
V\&R 


\section{Schnittstellen}

Studien zum östlichen und südöstlichen Europa

Herausgegeben von

Martin Schulze Wessel und Ulf Brunnbauer

Band 11 
Philipp Bürger

\section{Geschichte im Dienst für das Vaterland}

Traditionen und Ziele der russländischen Geschichtspolitik seit 2000

Vandenhoeck \& Ruprecht 
Gedruckt mit freundlicher Unterstützung der Graduiertenschule für

Ost- und Südosteuropastudien der Ludwig-Maximilians-Universität München.

Bibliografische Information der Deutschen Nationalbibliothek:

Die Deutsche Nationalbibliothek verzeichnet diese Publikation in

der Deutschen Nationalbibliografie; detaillierte bibliografische Daten

sind im Internet über http://dnb.de abrufbar.

(c) 2018, Vandenhoeck \& Ruprecht GmbH \& Co. KG, Theaterstraße 13, D-37073 Göttingen Alle Rechte vorbehalten. Das Werk und seine Teile sind urheberrechtlich geschützt. Jede Verwertung in anderen als den gesetzlich zugelassenen Fällen bedarf der vorherigen schriftlichen Einwilligung des Verlages.

Umschlagabbildung: Lenin eingerüstet, Moskau 2015 @ Foto: Philipp Bürger

Satz: textformart, Göttingen | www.text-form-art.de

Vandenhoeck \& Ruprecht Verlage | www.vandenhoeck-ruprecht-verlage.com

ISBN (Print): 978-3-525-37067-4

ISBN (PDF): 978-3-666-37067-0

https://doi.org/10.13109/9783666370670

Dieses Material steht unter der Creative-Commons-Lizenz Namensnennung -

Nicht kommerziell - Keine Bearbeitungen 4.0 International. Um eine Kopie dieser Lizenz zu sehen, besuchen Sie http://creativecommons.org/licenses/by-nc-nd/4.0/.

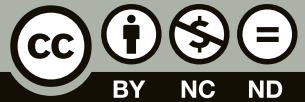




\section{Inhalt}

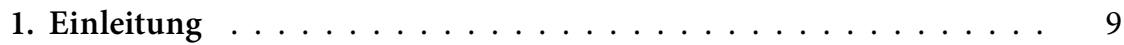

1.1 Theorie und Methode . . . . . . . . . . . . . . . . . 11

1.1.1 Gedächtnis, Erinnerung und Erinnerungskultur . . . . . . 11

1.1.2 Geschichts- und Erinnerungspolitik . . . . . . . . . . . 14

1.1.3 Weitere Begriffe: Narrativ und Event . . . . . . . . . . 20

1.1.4 Methode . . . . . . . . . . . . . . . . . . . . . 23

1.2 Struktur der Arbeit $\ldots \ldots \ldots \ldots \ldots \ldots$

1.3 Eingrenzung $\ldots \ldots \ldots \ldots \ldots \ldots \ldots \ldots \ldots \ldots$

1.4 Forschungsstand $\ldots \ldots \ldots \ldots \ldots \ldots \ldots \ldots \ldots \ldots$

1.5 Quellen . . . . . . . . . . . . . . . . . 31

2. Patriotismus und Erinnerungspolitik $\ldots \ldots \ldots \ldots \ldots$

2.1 Die Programme zur Patriotischen Erziehung . . . . . . . . . . 33

2.1.1 Die Programme zur Patriotischen Erziehung . . . . . . . 35

2.1.2 Budgets und Struktur . . . . . . . . . . . . . . . . . 45

2.1.3 Patriotismus-Begriff und Identität . . . . . . . . . . . 50

2.2 Neugestaltung der Feiertage . . . . . . . . . . . . . . . 55

2.2.1 Tage des militärischen Ruhmes _ . . . . . . . . . . 58

2.2.2 Reform der Novemberfeiertage _. . . . . . . . . . . 62

2.2.3 Einführung der Gedenktage . . . . . . . . . . . . . . . . 67

2.2.4 Neue Gedenktage seit 2007 . . . . . . . . . . . . . . . . 70

2.3 Die Veteranenparaden am 7. November . . . . . . . . . . . . 74

2.3.1 Neugestaltung der Parade . . . . . . . . . . . . . . . . 75

2.3.2 Emotionale Aktualisierung . . . . . . . . . . . . . . 77

2.3.3 Kontinuierung: Der Schwur der Jugend . . . . . . . . . . . 78

2.3.4 Verbindung der Zeiten: Von 1612 bis 2012 . . . . . . . . . 81

2.3.5 Zivile Gegenwart? . . . . . . . . . . . . . . . . . . . . 87

2.3.6 Leistungsschau der Erinnerungspolitik . . . . . . . . . . 89

2.4 Neue Akteure - Kooperationen der Patriotischen Erziehung . . . . 91

2.4.1 Prosveščenie - Karte der Erinnerungen _. . . . . . . . 92

2.4.2 Bike-Shows und Patriotische Erziehung . . . . . . . . . . . 95

2.4 .3 Bike-Show $»$ Stalingrad $2013 « \ldots \ldots$. . . . . . . . . . . . . 98 
2.5 Ausrichtung auf das Web - Helden der Timelines . . . . . . . . 111

2.5.1 Wir erinnern uns! . . . . . . . . . . . . . . . . . . . 112

2.5.2 Nationale Helden auf YouTube . . . . . . . . . . . . . . . 113

2.6 Zusammenfassung: Patriotismus und Erinnerungspolitik _. . . 119

3. Schulbücher, Bildungspolitik - Geschichtspolitik . . . . . . . . 123

3.1 Geschichte und Perestrojka . . . . . . . . . . . . . . . 123

3.2 Pluralität und Stagnation in den 1990er Jahren . . . . . . . . . . 124

3.3 Bildungspolitik und Schulbücher in den 2000er Jahren _ . . . . 129

3.3.1 Regulierungen der 2000er Jahre . . . . . . . . . . . . 130

3.3.2 Einflussnahmen in den 2000er Jahren . . . . . . . . . . 135

3.3.3 Die Schulbuchgeneration Ende der 2000er Jahre . . . . . . 138

3.4 Der 2013er Standard - Geschichte mit offizieller Bewertung? . . 149

3.5 Der Lehrmethodenkomplex Geschichte . . . . . . . . . . . . . 152

3.5.1 Konzeptionelle Grundlagen . . . . . . . . . . . . . . . 153

3.5.2 Der »historisch-kulturelle Standard» . . . . . . . . . . . . 158

3.5.2.1 Neue Perspektiven? . . . . . . . . . . . . . . . . . . . . 159

3.5.2.2 Die Zeit der Wirren . . . . . . . . . . . . . . . . . . . 160

3.5.2.3 Modernisierung und Imperium . . . . . . . . . . . . 161

3.5.2.4 Die großen Erschütterungen . . . . . . . . . . . . . 162

3.5.2.5 Sowjetunion und Stalinismus . . . . . . . . . . . 164

3.5.2.6 Der Große Vaterländische Krieg . . . . . . . . . 167

3.5.2.7 Stalin . . . . . . . . . . . . . . . . . . . . . . 169

3.5.2.8 Tauwetter, Stagnation und Perestroika _ . . . . . . 170

3.5.2.9 Die Russländische Föderation . . . . . . . . . . . 171

3.5.3 Die »schwierigen Fragen der russländischen Geschichte« . . 173

3.5.4 Resümee zum Lehrmethodenkomplex . . . . . . . . . . 176

3.6 Die Schulbücher für das Schuljahr 2015/2016 _ . . . . . . . . . 178

3.6.1 Die Zeit der Wirren . . . . . . . . . . . . . . . . . . . 181

3.6.2 Reformen und multiethnisches Imperium ‥ . . . . . 182

3.6.3 Eine Sowjetische Erfolgsgeschichte? . . . . . . . . . . . . . 183

3.6.4 Der Große Vaterländische Krieg . . . . . . . . . . . . . . 185

3.6.5 Neueste Geschichte in den Büchern 2015/2016 . . . . . . . 187

3.6.6 Resümee: Die aktuellen Schulbücher _ . . . . . . . . . . . 188

3.7 Zusammenfassung: Bildungspolitik und Schulbücher . . . . . . . . 190 
4. Erinnerungspolitik in Präsidentenreden _. . . . . . . . . . . 193

4.1 Formen der Erinnerungspolitik in öffentlichen Reden _ . . . . 193

4.2 Der 9. Mai in Präsidentenreden: Die Siegesparaden bis 1999 . . . 196

4.2.1 Die Parade als Rettung für das System? Das Jahr 1990 _ . . . 199

4.2.2 Eine Pause. Die 1990er und die Entsowjetisierung . . . . . 202

4.2.3 Die Wiederkehr: 1995 . . . . . . . . . . . . . . . . . . 204

4.2.4 Vom 9. Mai zum Wahltag: Zuspitzung 1996 . . . . . . . . 209

4.2.5 Resümee: Die Siegesparaden bis 1999 . . . . . . . . . . . . 212

4.3 Reden und Paraden am 9. Mai von 2000 bis 2015 . . . . . . . . . 213

4.3.1 Terroristische Bedrohung und internationale Kooperation . 214

4.3.2 Tagespolitische Ausrichtungen . . . . . . . . . . . . 216

4.3.3 Sicherheitspolitik und Konfrontation 2007 . . . . . . . . 218

4.3.4 Pragmatismus und militärische Stärke

bei Dmitrij Medvedev . . . . . . . . . . . . . . . . 220

4.3.5 Putins Rückkehr 2012: Eine patriotische Wende? . . . . . . 223

4.3.6 Wende nach innen 2014 . . . . . . . . . . . . . . . . . 225

4.3.7 Rückkehr zu appellativen Traditionen 2015 . . . . . . . . . 226

4.3.8 Kriegsnarrativ und Inszenierung . . . . . . . . . . . 228

4.3 .9 Resümee: Reden und Siegesparaden . . . . . . . . . . . . 231

4.4 Reden vor der Föderalversammlung . . . . . . . . . . . . . . 232

4.4.1 Die 1990er und die "Stabil'nost'" . . . . . . . . . . . . . . . 234

4.4 .2 Patriotismus und Katharsis? . . . . . . . . . . . . . . . . . 239

4.4.3 Dmitrij Medvedev und die 1990er . . . . . . . . . . . . . 242

4.4.4 Die Rückkehr Putins . . . . . . . . . . . . . . . . . . . 243

4.4.5 Resümee: Reden vor der Föderalversammlung . . . . . . 249

4.5 Reden zum Tag des Vaterlandsverteidigers _. . . . . . . . . . 251

4.6 Reden am Tag der Einheit des Volkes _. . . . . . . . . . . 258

4.7 Reden am Tag Russlands . . . . . . . . . . . . . . . . . 264

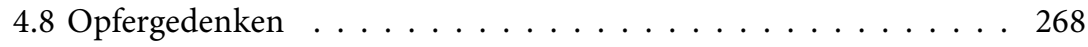

4.9 Zusammenfassung: Erinnerungspolitik in Präsidentenreden . . 274

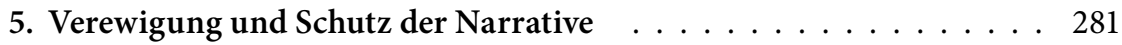

5.1 Geschichtliche Entwicklung des Schutzes der Narrative _. . . . 282

5.2 Förderung und Fixierung der richtigen Geschichte . . . . . . 283

5.3 Delegitimierung von Geschichte und Kampf gegen Fälschung . . 286 
5.4 Staatliches Handeln gegen `alternative` oder auch ffalsche` Geschichte

5.5 Zusammenfassung: Schutz der Geschichte oder Schutz der Narrative?

Resümee: Geschichte im Dienst für das Vaterland 301

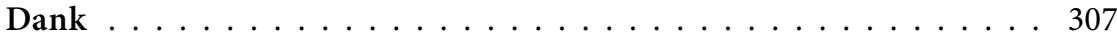

Quellen- und Literaturverzeichnis ． . . . . . . . . . . . . . . . . . . 309

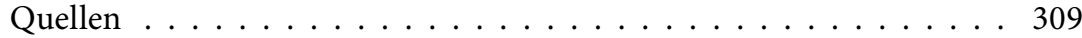

Forschungsliteratur . . . . . . . . . . . . . . . 329

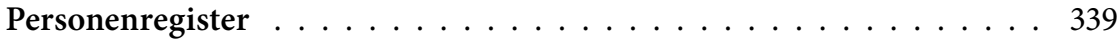




\section{Einleitung}

Ende des 20. Jahrhunderts wurde die Frage nach der geschichtlichen Selbstverortung in vielen Staaten Mittel- und Osteuropas wieder aktuell. Nach dem Zerfall der Sowjetunion wurden Sowjetrepubliken zu unabhängigen Staaten, Ostmitteleuropa löste sich aus seiner Abhängigkeit. Für alle Staaten der ehemaligen Sowjetunion und des Warschauer Paktes bedeutete diese Zeit die Möglichkeit zur geschichtlichen Neuausrichtung, zur Konstruktion neuer Geschichtsbilder. Die meisten postsowjetischen Staaten nutzten diese Möglichkeit, um sich selbst in Abgrenzung zur sowjetischen Geschichte neu zu erfinden. Aus der Perspektive der Spätmoderne vermeintlich obsolet gewordene Bilder nationaler ethnischer Identität als politische Argumentationsstrategien erwiesen sich als wirkmächtige Integrationsfaktoren auch auf gesellschaftlicher Ebene. ${ }^{1}$

In der Russländischen ${ }^{2}$ Föderation war der Blick auf die Geschichte weit weniger eindeutig als in vielen anderen ehemaligen Sowjetrepubliken. Die Zeit Ende der 1980er und Anfang der 1990er war auf der einen Seite von Veröffentlichungen über bis dahin unbekannte Schrecken der sowjetischen Zeit geprägt - mit den Hoffnungen auf eine bessere Zukunft ging auch eine Distanzierung von der sowjetischen Geschichte einher. Auf der anderen Seite waren jedoch auch die beharrenden sowjetisch-kommunistischen Kräfte weiterhin einflussreich. Sinnbildlich für diese Spaltung steht die Parade am 1. Mai 1990 in Moskau. Aus dem ersten Teil der Demonstration über den Roten Platz wurden Gorbačëv und die politische Führung von sowjetisch-konservativen Kräften kritisiert, aus dem zweiten, reformorientierten Teil folgte liberale antisowjetische Kritik an der Politik Gorbačëvs. Auch bei vielen anderen Anlässen

1 Vgl. Binder, Beate/Niedermüller, Peter/Kaschuba, Wolfgang: Inszenierungen des Nationalen - einige einleitende Bemerkungen. In:Binder, Beate/Niedermüller, Peter/Kaschuba, Wolfgang (Hg.): Inszenierungen des Nationalen. Geschichte, Kultur und die Politik der Identitäten am Ende des 20. Jahrhunderts. Köln 2001, $7 \mathrm{f}$.

2 Der Begriff »russländisch « wird in der Arbeit von dem ethnisch-kulturellen Begriff »russisch« unterschieden. Russländisch (russ.: rossijskij) beschreibt die gesamtstaatliche und territoriale Dimension des multiethnischen Staates - der Russländischen Föderation. Der Begriff »russisch « wird in Bezug auf die ethnischen Russen verwendet. Vgl. Luchterhand, Galina: Die politischen Parteien im neuen Rußland. Dokumente und Kommentare. Bremen 1993, 13 f. und ausführlich zur heutigen Bedeutung der Unterscheidung und zum Entstehungskontext vgl. Lutz-Auras, Ludmila: >Auf Stalin, Sieg und Vaterland!.. Politisierung der kollektiven Erinnerung an den Zweiten Weltkrieg in Russland. Wiesbaden 2013, $46 \mathrm{f}$. 
zeigte sich auf der Straße diese Polarisierung zwischen Reformern und Konservativen, die schließlich im Laufe des Jahres 1993 immer weiter eskalierte.

Die konservativ-sowjetnostalgischen Kräfte kultivierten ein Geschichtsbild von untergegangener Größe und Macht, von einem verlorengegangenen Imperium und vom Verlust des Weltmachtstatus. Gleichzeitig zeigte sich, dass sich die Zukunftsversprechen der Reformer für weite Teile der Gesellschaft nicht erfüllten und stattdessen ein Absinken des Lebensstandards spürbar wurde.

Boris El'cin konnte für große Teile seiner Geschichtspolitik, die sich in den ersten Jahren darauf richtete, vorsowjetische Bezugspunkte zu etablieren, keine breite Unterstützung und parlamentarische Legitimität einwerben. Seine Ansätze waren geprägt von der Auseinandersetzung mit den innenpolitischen Gegnern.

Geschichts- und Symbolpolitik bewegten sich in dem Spannungsfeld zwischen gesamtgesellschaftlicher Kohäsionswirkung und Exklusion der Legitimationsressourcen der politischen Gegner - zwischen Versuchen, neue, nichtsowjetische Anknüpfungspunkte in der Geschichte zu finden, und den Versuchen, den Sieg im >Großen Vaterländischen Krieg ‘ ${ }^{3}$ als sinn- und identitätsstiftendes Ereignis nicht dem konservativ-sowjetischen Lager zu überlassen.

Vladimir Putin machte bereits in seiner Antrittsrede im Jahr 2000 deutlich, dass er dem Thema Geschichtspolitik ein größeres Gewicht beimessen und einen anderen Ansatz verfolgen würde. »[...] Wir dürfen keine Ivane sein, die ihre Herkunft nicht kennen. ${ }^{4}$

Dieser Ausspruch stellt einen der zentralen Begriffe des Geschichtsdiskurses der El'cin-Jahre dar. ${ }^{5}$ Anders als in seinem ursprünglichen Kontext zu Beginn der 1990er Jahre, als der Ausdruck die Forderung unterstrich, die sowjetische Geschichtslosigkeit zu überwinden und sich der vorsowjetischen Geschichte zuzuwenden, benutzt ihn Putin, um der Forderung Nachdruck

3 Der in dieser Arbeit verwendete Begriff »Großer Vaterländischer Krieg« stellt den in der russländischen Gesellschaft wie auch in der russländischen Historiographie etablierten Begriff für die Kriegshandlungen zwischen dem 22. Juni 1941 und dem 9. Mai 1945 dar. Dieser Fokus auf die Folgeereignisse des deutschen Überfalls auf die Sowjetunion unterscheidet ihn vom Begriff Zweiter Weltkrieg und macht seine Verwendung in der Beschreibung russländischer Geschichtspolitik, auch angesichts seines Entstehungs- und Verwendungskontextes und der damit verbundenen Implikationen, sinnvoll. Für eine präzise Problematisierung des Entstehungskontextes und der diesbezüglichen Diskussionen in der russländischen Historiografie vgl. Lutz-Auras, Ludmila: `Auf Stalin, Sieg und Vaterland!r. Politisierung der kollektiven Erinnerung an den Zweiten Weltkrieg in Russland. Wiesbaden 2013, $43 \mathrm{ff}$.

4 Putin, Vladimir: Vystuplenie na ceremonii vstuplenija v dolžnost' Prezidenta Rossii. 7 maja 2000 goda. Moskva. Online: http://kremlin.ru/events/president/transcripts/21399.

5 Vgl. de Keghel, Isabelle: Die Rekonstruktion der vorsowjetischen Geschichte. Identitätsdiskurse im neuen Russland. Hamburg 2006, $137 \mathrm{f}$. 
zu verleihen, alle Epochen der Geschichte zu erinnern - sowjetische und vorsowjetische - und so die >Verbindung der Zeiten`, die geschichtliche Kontinuität wiederherzustellen.

Die umfangreiche Implementation und Institutionalisierung dieser Ankündigung direkt in der ersten Phase seiner Präsidentschaft machen deutlich, dass er diesen Politikbereich - im Gegensatz zu El'cin - als zentral betrachtete.

Für diese Arbeit stellen sich daher die Fragen: Wie wird diese neue staatliche Geschichtspolitik gemacht? Was sind die entscheidenden rechtlichen und organisatorischen Rahmenbedingungen, wie verlaufen die politischen Prozesse? Wer sind die Akteure und in welchem Verhältnis stehen sie zueinander? Was sind wichtige Vermittlungspraktiken und Kommunikationskanäle?

Neben diesen strukturellen, institutionellen und akteursbezogenen Fragen müssen auch die prägenden Inhalte der neuen Geschichtspolitik in den Blick genommen werden. Welche historischen Narrative werden eingesetzt, wie wird an ihrem Zuschnitt und an ihrer Bedeutung für die Gegenwart gearbeitet? Lassen sich in verschiedenen Bereichen etwa ähnliche Ausrichtungen und Dynamiken feststellen? Wo knüpft die offizielle Politik nach der Jahrtausendwende an Traditionen an, wo bestehen tatsächliche Innovationen, sowohl strukturell als auch inhaltlich?

\subsection{Theorie und Methode}

\subsubsection{Gedächtnis, Erinnerung und Erinnerungskultur}

Ausgangspunkt für Überlegungen müssen Fragen nach Gedächtnis, Erinnerung, Identität und Erinnerungskultur sein. Erinnerung und Gedächtnis stehen in enger Verbindung. Das Gedächtnis stellt die Gesamtheit erinnerbarer Erfahrungen dar, wobei sich die Auswahl dieser Erfahrungen nicht bewusst oder gezielt, sondern durch das Nicht-Vergessen ergibt. Gedächtnisinhalte sind dadurch nicht die Folge von freier Selbstreflexion des Bewusstseins, sondern das Resultat einer Eigenlogik, die bisher als weitgehend unerforscht gelten muss. ${ }^{6}$ Erinnerung stellt eine situative Auswahl aus dem Gedächtnisinhalt dar. Situativ in dem Sinne, dass sich Erinnerung immer in einer bestimmten Situation mit einem bestimmten Kontext abbildet. Zudem bettet sich die Erinnerung, als Aktualisierung in der Gegenwart, in einen Ereignishorizont ein, der in der eigentlich >erinnerten Vergangenheit noch nicht existierte: Die Aktualisierung der Gegenwart ist bedingt durch eine Fülle von Kausalzusam-

6 Vgl. Hahn, Alois: Inszenierung und Erinnerung. In: Paragrana. Internationale Zeitschrift für Historische Anthropologie. 9/2 (2000), 21. 
menhängen, Kontexten und weiteren Ereignissen, die ursprünglich in der $\mathrm{Zu}$ kunft der zu erinnernden Vergangenheit lagen. Aus dieser vielfachen Bedingtheit und den kontingenten Entstehungsprozessen resultiert die Beschreibung von Erinnerungen als Konstrukten »nicht im Sinn von Erfindungen, aber im Sinn von Gestaltungen [...]. . ${ }^{7}$

Diese Feststellung gründete sich auf den Thesen von Maurice Halbwachs über die vielfältige Bedingtheit und die soziale Konstruktion von Erinnerung. ${ }^{8}$ Anknüpfend bezeichnete Aleida Assmann das individuelle Gedächtnis als das sozial gestützte »dynamische Medium subjektiver Erfahrungsverarbeitung. «"

Ungleich kontroverser werden bis heute die von Emile Durkheims Ansatz des >kollektiven Bewusstseins ${ }^{10}$ beeinflussten Begriffe des 'kollektiven Gedächtnis` und der `kollektiven Erinnerung ${ }^{11}{ }^{11}$ von Maurice Halbwachs diskutiert, da sie sich noch offensichtlicher einem direkten Zugriff entziehen.

Betrachtet man kollektives Gedächtnis und kollektive Erinnerung jedoch unter dem Vorbehalt, dass es sich nicht um fassbare Manifestationen handelt, sondern um einen fluiden Bestand an Elementen des individuellen Bewusstseins, der von einem Individuum als gemeinsamer Bestand mit anderen angesehen wird, so schärfen die Begriffe den Blick für den hochgradig konstruierten Charakter von individuellen oder kollektiven Selbstzuschreibungen. Aber auch hier gilt: Sie werden nicht ausschließlich im Sinne von Erfindungen konstruiert. Sie sind vielmehr noch als ihre individuellen Pendants die Produkte sozialer Interaktion und Bedingtheit. Sie bilden und verfestigen sich durch den Austausch von Erfahrungen und die Kommunikation, sei es zwischen den Menschen oder in den Medien.

Diese Perspektive hat in den 1980er Jahren zu einer Vielzahl von Studien geführt, die bis heutige grundlegende Begriffe wie `Erinnerungsorte $\triangleleft$, Symbolpolitikı, `Gefallenenkult ‘ oder `kommemorative Praktiken` geprägt haben. ${ }^{12}$

7 Kocka, Jürgen: Erinnerung und Politik. In: Oldenhage, Klaus (Hg.): Archiv und Geschichte. Düsseldorf 2000, 966.

8 Vgl. Halbwachs, Maurice: Das Gedächtnis und seine sozialen Bindungen. Frankfurt a. M. 1985.

9 Assmann, Aleida: Der lange Schatten der Vergangenheit. Erinnerungskultur und Geschichtspolitik. Bonn 2007, 25.

10 Vgl. Durkheim, Emile: Über die Teilung der sozialen Arbeit. Frankfurt am Main 1977, $324 \mathrm{ff}$.

11 Vgl. Halbwachs, Maurice: Das kollektive Gedächtnis. Frankfurt am Main 1991.

12 Vgl. zu Erinnerungsorten u. a. Nora, Pierre (Hg.): Les lieux de mémoire. Bd. 1: La République. Paris 1984; Bd. 2.1-2.3: La nation. Paris 1986; Bd. 3.1-3.3: Les France. Paris 1992; Zu Symbolpolitik u. a. Tacke, Charlotte: Denkmal im sozialen Raum: Nationale Symbole in Deutschland und Frankreich im 19. Jahrhundert. Göttingen 1995; Zu Gefallenenkult u. a. Mosse, George: Gefallen für das Vaterland: nationales Heldentum und namenloses Sterben. Stuttgart 1993; Zu kommemorativen Praktiken u. a. Hobsbawn, Eric (Hg.): The invention of tradition. Cambridge 1993. 
Begrifflich wurde Halbwachs' ’kollektives Gedächtnis` weiter ausdifferenziert. Jan Assmann führte die Unterscheidung zwischen kulturellem und kommunikativem Gedächtnis ein..$^{13}$ Aleida Assmann präzisierte das Konzept des kommunikativen Gedächtnisses mit ihrem Begriff des sozialen Gedächtnisses, für das als »Kurzzeitgedächtnis` der Gesellschaft ${ }^{14}{ }^{14}$ Altagskommunikation und ein generationell bedingt begrenzter Zeithorizont prägend sind. Das langfristige, symbolisch kommunizierte und institutionell gestützte kulturelle Gedächtnis differenzierte Aleida Assmann in ein 'Speichergedächtnis` und ein $>$ Funktionsgedächtnis ${ }^{15}$ Das Speichergedächtnis stellt dabei ein von Bibliotheken, Museen und Archiven getragenes Gerüst dar, das materiellen Überresten einer Kultur eine umfassende Existenzverlängerung ermöglicht. Das Funktionsgedächtnis aktualisiert auf Grundlage dieses Gerüstes, deutet und perspektiviert für eine bestimmte Zukunft. Eng verbunden mit dem >Funktionsgedächtnis` ist der Begriff des 'politischen Gedächtnisses`:

"Wo Geschichte im Dienst von Identitätsbildung steht, wo sie von den Bürgern angeeignet und von den Politikern beschworen wird, kann man von einem 'politischen Gedächtnis« oder `nationalen Gedächtnis« sprechen. « $^{16}$

Aleida Assmann beschreibt das politische Gedächtnis in Abgrenzung zum vielfältigen sozialen Gedächtnis als »einheitlichere Konstruktion, die in politischen Institutionen verankert ist und son oben wirkt. $\ll^{17}$

Um der Frage nachzugehen, wie sich die Begriffe von Gedächtnis und Erinnerung zur `Geschichte`verhalten, ist zunächst ein Blick auf den ursprünglich aus der Geschichtsdidaktik stammenden Begriff des Geschichtsbewusstseins sinnvoll. Er beschreibt die Verarbeitung von Zeiterfahrung zur Orientierung und Selbstverortung. ${ }^{18}$ Personen oder Gruppen fundieren ihr Selbstverständnis in der Gegenwart, indem sie sich in ein Verhältnis zur Vergangenheit setzen und sich auf diese Weise orientieren. ${ }^{19}$ In seiner gesellschaftlichen Dimension wird dieser Prozess von Jörn Rüsen als `Geschichtskultur beschrieben und in eine kognitive, eine ästhetische und eine politische Dimension aufgegliedert.

13 Vgl. Assmann, Jan: Das kulturelle Gedächtnis: Schrift, Erinnerung und politische Identität in frühen Hochkulturen. München 1992.

14 Assmann, Aleida: Der lange Schatten der Vergangenheit. Erinnerungskultur und Geschichtspolitik. Bonn 2007, 28.

15 Vgl. ebd., $54 \mathrm{ff}$.

16 Ebd., 37.

17 Ebd., 37.

18 Vgl. Rüsen, Jörn: Geschichtskultur. In: Geschichte in Wissenschaft und Unterricht 46 (1995), $513 \mathrm{ff}$.

19 Vgl. Wolfrum, Edgar: Erinnerungskultur und Geschichtspolitik als Forschungsfelder. In: Scheunemann, Jan (Hg.): Reformation und Bauernkrieg. Erinnerungskultur und Geschichtspolitik im geteilten Deutschland. Leipzig 2010, 16. 
Geschichtskultur umfasst die Artikulation von Geschichtsbewusstsein in einer Gesellschaft und damit beispielsweise auch die Erinnerungsarbeit. Eine klare Trennung von `Geschichte` und `Gedächtnis` erscheint vor diesem Hintergrund nicht sinnvoll.

Der Begriff `Erinnerungskultur \hat den Begriff `Geschichtskultur` zunehmend verdrängt, obwohl der erstere weniger spezifisch ist und als Oberbegriff mehr oder weniger alle Formen von bewusster Erinnerung an Ereignisse, Strukturen und Persönlichkeiten, sowohl in politischer als auch in ästhetischer oder kognitiver Perspektive, vereinigt. ${ }^{20}$ Die Frage danach, wie und welche Elemente der Vergangenheit ihre öffentliche Position in der Gegenwart bekommen, lässt sich als Neuaushandlung oder Neuformation von Erinnerungskultur beschreiben. Edgar Wolfrum stellte im Bereich der Erinnerungskultur-Forschung bereits 1999 eine Schieflage zugunsten der historiografiegeschichtlichen und der ästhetischen Dimension sowie eine Fixierung auf Instrumentalisierung von Geschichte fest. Damit einhergehend beklagte er eine »zumindest tendenzielle Blindheit für das Politische ${ }^{21}{ }^{21}$

Der Fokus in dieser Arbeit richtet sich auf die politische Konstruktionsund Konstrukteursebene, auf die Frage, wie politische Akteure Erinnerungskultur schaffen und formen:

»Um Erinnerung zu werden, muss vergangene Geschichte rezipiert und interpretiert werden. $\mathrm{Zu}$ jeder öffentlichen Deutung von Vergangenheit gehören benennbare Interessen von aktiv Handelnden. ${ }^{22}$

Die Arbeit setzt sich daher nicht die Erforschung des kollektives Gedächtnisses oder der Erinnerungskultur im postsowjetischen Russland zum Ziel. Das Erkenntnisinteresse gilt vielmehr dem staatlichen Handeln, das sich darauf richtet, individuelle und kollektive Formen des Gedächtnisses, das Geschichtsbewusstsein sowie die Erinnerungskultur zu beeinflussen.

\subsubsection{Geschichts- und Erinnerungspolitik}

Die Arbeit am politischen Gedächtnis und an der Erinnerungskultur wird in dieser Arbeit mit dem Begriff der Geschichtspolitik analysiert. Geschichtspolitik ist der gebräuchlichste und auch offenste Begriff, um den Umgang der

20 Vgl. Cornelißen, Christoph: Was heißt Erinnerungskultur? Begriff - Methoden - Perspektiven. In: Geschichte in Wissenschaft und Unterricht 54 (2003), 548-563.

21 Wolfrum, Edgar: Geschichtspolitik in der Bundesrepublik Deutschland. Der Weg zur bundesrepublikanischen Erinnerung 1948-1990. Darmstadt 1999, 25.

22 Kohlstruck, Michael: Erinnerungspolitik. Kollektive Identität, Neue Ordnung, Diskurshegemonie. In: Schwelling, Birgit (Hg.): Politikwissenschaft als Kulturwissenschaft. Wiesbaden 2004, 176. 
Politik mit Geschichte zu bezeichnen. Ursprünglich wurde der Begriff im Zusammenhang mit dem deutschen Historikerstreit 1986-1987 gebraucht, ${ }^{23}$ um konservativen Geschichtsrevisionismus zu kritisieren. Geschichtspolitik, so der Vorwurf, sei der Versuch, ein entlastendes Traditions- und Geschichtsbewusstsein jenseits der nationalsozialistischen Geschichte schaffen $\mathrm{zu}$ wollen, um der bundesrepublikanischen Politik neue machtpolitische Handlungsoptionen $\mathrm{zu}$ ermöglichen. ${ }^{24}$ Diese Zuschreibung als national-konservative Indienstnahme der Geschichte oder als das »anrüchige Geschäft von Intellektuellen und Wissenschaftlern $\ll^{25}$ wurde in der Folge sukzessive revidiert. Michael Wolffsohn bezeichnete Geschichtspolitik als pragmatisch bestimmte staatliche Interessenpolitik, die geschichtliche Erfahrung ihrem Handeln voraussetzt oder sich in ihrem Handeln auf sie bezieht, und begründete damit eine deutlich analytisch geprägte Perspektive. ${ }^{26}$

Ausformuliert findet sich diese Perspektive bei Edgar Wolfrum:

»Politische Eliten versuchten Traditionen zu schöpfen, Erinnerungen zu gestalten und Identitäten zu konstruieren. Sie bedienten sich dabei - in einem Wechselspiel mit Publizistik, Wissenschaft und öffentlicher Meinung - verschiedener Erinnerungsstrategien, umstrittener Inszenierungen, integrierender und desintegrierender Rituale und polarisierender Diskurse, kurz: sie betrieben Geschichtspolitik in der Demokratie und prägten damit gleichermaßen nachhaltig die politische wie auch die Geschichtskultur. ${ }^{27}$

Der normativ geprägte Ursprung des Begriffes muss jedoch weiterhin mitgedacht werden. Der politische Bezug auf Geschichte bewegt sich immer zwischen zwei Polen. Auf der einen Seite stellt der Rückgriff auf Geschichte ein konstitutives Element von Politik dar. Auf einer grundlegenden Ebene betrachtet, soll politisches Handeln in der Gegenwart für die Zukunft explizit Differenz oder Kontinuität zur Vergangenheit herstellen und auch in der Begründung von Politik sind temporale Vergleiche grundlegend angelegt: In der Argumentation für etwas Neues schwingt mindestens implizit der Verweis auf das Bisherige mit. Vor allem in Phasen der beschleunigter Veränderung, deren

23 Vgl. Augstein, Rudolf (Hg.): Historikerstreit. Die Dokumentation der Kontroverse um die Einzigartigkeit der nationalsozialistischen Judenvernichtung. 8. Auflage. München 1991.

24 Vgl. Donat, Helmut: Vorbemerkung: Die Indienstnahme der Geschichte. In: Donat, Helmut/Wieland, Lothar (Hg.): Auschwitz erst möglich gemacht? Bremen 1991, $12 \mathrm{f}$.

25 Kohlstruck, Michael: Erinnerungspolitik. Kollektive Identität, Neue Ordnung, Diskurshegemonie. In: Schwelling, Birgit (Hg.): Politikwissenschaft als Kulturwissenschaft. Wiesbaden 2004, 179.

26 Vgl. Wolffsohn, Michael: Ewige Schuld? 40 Jahre Deutsch-Jüdisch-Israelische Beziehungen. München 1988, 21.

27 Wolfrum, Edgar: Geschichtspolitik in der Bundesrepublik Deutschland. Der Weg zur bundesrepublikanischen Erinnerung 1948-1990. Darmstadt 1999, 2. 
Kulminationspunkte sich als $>$ critical junctures ${ }^{28}$ beschreiben lassen, kommt dem Rückbezug auf die Vergangenheit eine besondere Wirkmächtigkeit zu. Für soziale Verbände sind diese sinnstiftenden Rückbindungen jedoch nicht nur in Bezug auf den Gründungsakt elementar, sie sind auch für die Gegenwart der politischen Ordnung ein entscheidendes Instrument der Stabilisierung. ${ }^{29}$

Auf der anderen Seite steht die politisch-ideologische oder tagespolitische Indienstnahme der Geschichte. Beide Seiten lassen sich jedoch nicht trennen: So wie jeder konstituierende, stabilisierende Bezug auf Geschichte tagespolitisch-ideologische Komponenten enthält, wirkt umgekehrt auch jede Indienstnahme auf einer konstitutiven Ebene.

Auch der Blick aufden politischen Kontext ermöglicht keineklare Trennung. Die Indienstnahme der Geschichte ist keineswegs ausschließlich autoritären Regimen vorbehalten. So instrumentalisieren auch in pluralistischen Gesellschaften Akteure die Geschichte. Nur ist hier die Chance höher, dass sich diese Instrumentalisierungen einem argumentativen Austausch und multiperspektivischen Betrachtungen im Sinne eines sidealen Diskurses ${ }^{30}$ stellen müssen.

Einen Denkanstoß, sich dieser Problematik zu stellen, ohne auf normative Zuschreibungen zurückzugreifen, beschreibt Jürgen Kocka in seinen Angemessenheitskriterien historischer Argumente: ${ }^{31}$ Er argumentiert, dass es in der historiografischen Praxis selten darum gehe, etwas als objektiv oder als parteilich einzustufen. Viel bedeutender sei ein graduistisches Modell, in dem es um höhere oder niedrigere Plausibilität, um brauchbare oder weniger brauchbare bzw. um zu treffende oder weniger zutreffende Argumentationen ginge. Daher führt er die Denkfigur eines Spielraumes ein, in dem eine Vielzahl legitimer, »objektiver« und mehr oder weniger angemessener Argumentationen über ein und denselben historischen Gegenstand möglich sind. ${ }^{32}$

Der wesentlich neuere Ansatz des Erinnerungsmanagements versucht dem Problem der Vieldeutigkeit und normativen Aufladung durch Reduktion zu begegnen. Durch einen expliziten Verzicht auf den Anspruch, ssubstanzielles Fragen z. B. nach Identitäten zu beantworten, und einem klaren Fokus auf Pro-

28 Capoccia, Giovanni/Kelemen, R. Daniel: The Study of Critical Junctures: Theory, Narrative, and Counterfactuals in Historical Institutionalism. In: World Politics, 59/3 (2007), 348.

29 Vorländer, Hans: Gründung und Geltung. Die Konstitution der Ordnung und die Legitimität der Konstitution. In: Melville, Gert/Vorländer, Hans (Hg.): Geltungsgeschichten. Über die Stabilisierung und Legitimierung institutioneller Ordnungen. Köln 2002, 245 ff.

30 Vgl. Habermas, Jürgen: Vorstudien und Ergänzungen zur Theorie des kommunikativen Handelns. Frankfurt am Main 1989, 177 ff.

31 Kocka, Jürgen: Angemessenheitskriterien historischer Argumente. In: Koselleck, Reinhart/Mommsen, Wolfgang / Rüsen, Jörn (Hg.): Objektivität und Parteilichkeit in der Geschichtswissenschaft. München 1977, 469-475.

32 Vgl. ebd. 
zesse und Verfahren soll ein pragmatischer Zugang zu Fragen von Geschichte und Politik ermöglicht werden. ${ }^{33}$

In dieser Arbeit sollen jedoch explizit beide Seiten des Geschichtsbezugs berücksichtigt werden, es sollen gleichermaßen tagespolitische wie konstitutive Aspekte aufgezeigt werden. Das führt zu einer weiteren Dualität, die eng mit dieser Problematik verbunden ist: Birgit Schwelling weist überzeugend auf die Bedeutung der Unterscheidung zwischen »instrumentellem« und »symbolisch-expressivem« Handeln für die Betrachtung von Geschichtspolitik hin. ${ }^{34}$ Die Unterscheidung stammt aus den Untersuchungen zu politischen Verfahren in der frühen Neuzeit von Barbara Stollberg-Rilinger, die darauf hinweist, dass instrumentelles Handeln einen bestimmten Zweck verfolgt, während symbolisches Handeln sich auf Sinnstiftung richtet. Als entscheidend stellt Stollberg-Rilinger jedoch heraus, dass die begriffliche Unterscheidung zwischen instrumentellem und symbolischem Handeln keine Klassifikation unterschiedlicher Handlungen darstellt:

"Soziale Handlungen, von den Tischmanieren bis zum Gesetzgebungsakt, weisen vielmehr in der Regel beide Dimensionen auf, die symbolische und die instrumentelle, und es ist eine Frage der Perspektive, welche Dimension man wahrnimmt. ${ }^{35}$

Für die Betrachtung von Geschichtspolitik bedeutet dieser Ansatz, sowohl die symbolische, die sinnstiftende Dimension zu betrachten als auch die Dimension der »materiellen Entscheidungen (Verwaltungshandeln und Gesetzgebung) ${ }^{36}$, der zweckorientierten Handlungen. Schwelling schlägt dazu als Ausgangspunkt einer solchen Betrachtung politische Akteure vor, »die deutend auf Vergangenheit Bezug nehmen und diese Deutungen wiederum handelnd in den politischen Prozess einbringen. ${ }^{37}$

33 Vgl. Landkammer, Jochen/Zimmerli, Walther: Erinnerungsmanagement und politische Systemwechsel. Kleine Versuche zur Erklärung eines großen Problems. In: Landkammer, Jochen/Noetzel, Thomas (Hg.): Erinnerungsmanagement. Systemtransformation und Vergangenheitspolitik im internationalen Vergleich. München 2006, $268 \mathrm{f}$.

34 Vgl. Schwelling, Birgit: Politische Erinnerung. Eine akteurs- und handlungsbezogene Perspektive auf den Zusammenhang von Gedächtnis, Erinnerung und Politik. In: Heinrich, Horst-Alfred/Kohlstruck, Michael (Hg.): Geschichtspolitik und sozialwissenschaftliche Theorie. Stuttgart 2008, $103 \mathrm{f}$. Zur Unterscheidung expressiver und instrumenteller Variablen vgl. Luhmann, Niklas: Legitimation durch Verfahren. Frankfurt a. M. 1983, $223 \mathrm{ff}$.

35 Stollberg-Rilinger, Barbara: Symbolische Kommunikation in der Vormoderne. Begriffe Theorien - Forschungsperspektiven. In: Zeitschrift für historische Forschung 31/4 (2001), 498, 489-529.

36 Leggewie, Claus/Meyer, Erik: `Ein Ort, an den man gerne geht،. Das Holocaust-Mahnmal und die deutsche Geschichtspolitik nach 1989. München 2005, 13.

37 Schwelling, Birgit: Politische Erinnerung. Eine akteurs- und handlungsbezogene Perspektive auf den Zusammenhang von Gedächtnis, Erinnerung und Politik. In: Heinrich, Horst-Alfred/Kohlstruck, Michael (Hg.): Geschichtspolitik und sozialwissenschaftliche Theorie. Stuttgart 2008, 111. 
In vielen Bereichen der Arbeit wird der Begriff der Geschichtspolitik mit dem spezifischeren Ansatz der Erinnerungspolitik ergänzt. Während Geschichtspolitik nach Wolfrum maßgeblich auch konstitutive Funktionen wie Traditionsbildung berücksichtigt, weist Michael Kohlstruck dem Ansatz der Erinnerungspolitik eine engere Perspektive auf »das strategische Operieren mit Geschichtsdeutungen zur Legitimierung politischer Projekte ${ }^{38} \mathrm{zu}$, auf Ziele und Funktionen von Geschichtsdeutungen.

Kohlstruck fragt danach, wer im Kontext gegenwärtigen politischen Handelns bestimmte Deutungen in Umlauf gebracht hat und wie sie weiterverbreitet und transformiert werden. Kohlstruck benennt fünf Elemente von Erinnerungspolitik: ${ }^{39}$

1. Esgibtbestimmte politische Akteure, die mitanderen Akteuren interagieren.

2. Diese politischen Akteure versuchen, mit Hilfe von Erinnerungsstrategien Legitimation für politische Projekte einzuwerben.

3. Dies geschieht, indem bestimmte historische Ereignisse, Handlungen oder Personen ausgewählt werden.

4. Die Auswahl wird im Sinne des politischen Vorhabens interpretiert.

5. Um öffentlich wirksam zu werden, wird diese Deutung dann sprachlich oder in anderer Weise symbolisch kommuniziert.

Das Ziel dieser erinnerungspolitischen Strategie ist die Einwerbung von Legitimität. Legitimität ist in diesem Zusammenhang als empirischer, nicht normativer Begriff zu verstehen. ${ }^{40}$ Kielmansegg bezeichnet Legitimität als eine Qualität von sozialen Systemen - und damit auch politischen Systemen - die ihnen aus der Überzeugung der Rechtmäßigkeit zuwächst. ${ }^{41}$ Was Kielmansegg hier als spezifische Geltungserfahrung einführt, bezeichnete Max Weber, der als erster Vertreter der Sozialwissenschaften gilt, der den Begriff außerhalb eines normativen Kontextes verwendete, ${ }^{42}$ als den Umstand, daß neben den anderen Motiven die Ordnung mindestens einem Teil der Handelnden auch als vorbildlich oder verbindlich und als gelten sollend vorschwebt. ${ }^{43}$

38 Kohlstruck, Michael: Erinnerungspolitik. Kollektive Identität, Neue Ordnung, Diskurshegemonie. In: Schwelling, Birgit (Hg.): Politikwissenschaft als Kulturwissenschaft. Wiesbaden 2004, 176.

39 Vgl. ebd.,181.

40 Vgl. Weber, Max: Wirtschaft und Gesellschaft. Grundriss der verstehenden Soziologie. 5. rev. Ausgabe. Tübingen 1995, 16; Kielmansegg, Peter: Legitimität als analytische Kategorie. In: Zeitschrift für Politikwissenschaft 12/3 (1971), 368.

41 Vgl. Kielmansegg, Peter: Legitimität als analytische Kategorie. In: Zeitschrift für Politikwissenschaft 12/3 (1971), 368.

42 Kopp, Manfred/Müller, Hans-Peter: Herrschaft und Legitimität in modernen Industriegesellschaften. München 1980, 12.

43 Weber, Max: Wirtschaft und Gesellschaft. Grundriss der verstehenden Soziologie. 5. rev. Ausgabe. Tübingen 1995, 16. 
Der Begriff Erinnerungspolitik von Michael Kohlstruck soll in dieser Arbeit als spezifischerer Teilbereich von Geschichtspolitik betrachtet werden, der den Blick auf sehr spezielle Strategien richtet, die an Narrativen arbeiten und diese Deutungen versuchen zu popularisieren und sie in den politischen Prozess einzubringen.

Dieser spezifischere Fokus kann besonders in der Analyse von politischen Reden oder in der Analyse von Geschichtsinszenierungen in Shows und Paraden den Blick für das strategische Operieren an und mit Narrativen und die jeweiligen politischen Funktionen und Ziele schärfen. Gerade in der russländischen Forschung ist diese »instrumentelle« Perspektive vorherrschend. ${ }^{44}$

Legitimation spielt bei den Rückgriffen auf Geschichte eine zentrale Rolle: Die Funktion von Geschichtspolitik richtet sich auf „Orientierung, Legitimation, Selbstgewissheit « ${ }^{45}$. Harald Schmid beschreibt die primären Funktionen von Geschichtspolitik als Schaffung einer Tradition, Prägung von kollektiver Identität und Generierung politisch-historischer Legitimität. ${ }^{46}$

Noch direkter nach den legitimatorischen Wirkrichtungen fragt der Ansatz der Erinnerungspolitik. Mit Hilfe des Konzepts der diffusen politischen Unterstützung $^{47}$ aus der funktionalen politischen Systemanalyse von David Easton lassen sich die Richtungen näher bestimmen: Die legitimierende Funktion des Geschichtsbezuges richtet sich auf die politischen Herrschaftsträger (rauthorities $\varsigma)^{48}$, die politische Ordnung (২regime $)^{49}$ und die politische Gemeinschaft ('political community $)^{50}$. Besonders dem letzten Punkt wurde als kollektive Identität eine große Aufmerksamkeit zuteil.

Nach Rüsen sind die verschiedenen Orientierungsformen geschichtlicher Erinnerung Teil der Formierung von Identität. ${ }^{51}$ Der Begriff der Identität ist einer der umstrittensten in der kulturwissenschaftlichen Diskussion und

44 Vgl. z. B. Malinova, Ol'ga: Aktual'noe prošloe. Simvoličeskaja politika vlastvujuščej èlity i dilemmy rossijskoj identičnosti. Moskau 2015, 22 ff.; Miller, Alexei: Introduction. Historical Politics: Eastern European Convolutions in 21st Century. In: Miller, Alexei/Lipman, Maria (Hg.): The convolutions of historical politics. Budapest 2012, 11 f.; Miller, Aleksej: Rossija: vlast' i istorija. In: Pro et Contra 13/3-4 (2009), 6-23.

45 Jeismann, Karl-Ernst: `Identität` statt `Emanzipation`? Zum Geschichtsbewußtsein in der Bundesrepublik. In: Aus Politik und Zeitgeschichte 20-21 (1986), 4.

46 Schmid, Harald: Konstruktion, Bedeutung, Macht. Zum kulturwissenschaftlichen Profil einer Analyse von Geschichtspolitik. In: Heinrich, Horst-Alfred; Kohlstruck, Michael (Hg.): Geschichtspolitik und sozialwissenschaftliche Theorie. Stuttgart 2008, 78.

47 Vgl. Easton, David: A Systems Analysis of Political Life. New York 1967, 273 und Easton, David: A Re-Assesment of the Concept of Political Support. In: British Journal of Political Science 5/4 (1975).

48 Vgl. Easton, David: A Systems Analysis of Political Life. New York 1967, $212 \mathrm{ff}$.

49 Vgl. ebd., $190 \mathrm{ff}$.

50 Vgl. ebd., $171 \mathrm{ff}$.

51 Vgl. Rüsen, Jörn: Kultur macht Sinn. Orientierung zwischen Gestern und Morgen. Köln 2006, 82 . 
wurde bereits umfänglicher Kritik unterzogen. ${ }^{52}$ Rüsen argumentiert, dass der komplexe Begriff mit seiner Eigenschaft, Kohärenz und Homogenisierung einzufordern bzw. zu erzwingen und kulturelle Vielfalt auszublenden dennoch benötigt wird, gerade »um die Gewaltsamkeit von Identitätszuschreibungenund formierungen verstehen zu können «. ${ }^{53}$ In diesem Sinne und unter Berücksichtigung, dass kollektive Identität nicht als absolute Gleichheit, sondern als Ähnlichkeit in »ausgewählten und spezifizierten, explizierten Aspekten " ${ }^{54}$ zu begreifen ist, wird im Folgenden der Begriff verwendet.

Eine weitere Funktion von Geschichtspolitik richtet sich auf die Durchsetzung von Diskurspositionen und Deutungsmustern. ${ }^{55}$ Geschichtsbezogener »Kampf um Diskurshegemonie $«^{56}$ und das Durchsetzen von geschichtlichen Deutungsmustern sind zum einen Teil von geschichts- und erinnerungspolitischer Praxis - zum anderen schaffen sie dabei immer auch die Grundlagen für neue geschichtspolitische Rückgriffe.

\subsubsection{Weitere Begriffe: Narrativ und Event}

Der Bereich, den Kohlstruck unter Auswahl und Deutung bzw. Interpretation von historischen Ereignissen oder Persönlichkeiten subsumiert, steht in enger Verbindung zur Frage nach der narrativen Konstruktion von Wirklichkeitserfahrung. ${ }^{57}$ Unter Narrativ soll hier eine Erzähleinheit von Geschichte verstanden werden. Der Vorzug dieses Begriffs liegt darin, dass er die Perspektivität und das Erzählmuster von Geschichte in sich mittransportiert und dadurch verdeutlicht.

Dabei können Narrative unterschiedlich umfangreich gestaltet sein und zudem hierarchisch gestaffelt: Krijn Thijs plädiert für eine `narrative Hierarchie‘,

52 Vgl. z.B. Niethammer, Lutz: Kollektive Identität. Heimliche Quellen einer unheimlichen Konjunktur. Hamburg 2000,625; Straub, Jürgen: Identität. In: Jaeger, Friedrich/Liebisch, Burkhard (Hg.): Handbuch der Kulturwissenschaften. Band 1. Stuttgart 2004, 298.

53 Vgl. Rüsen, Jörn: Kultur macht Sinn. Orientierung zwischen Gestern und Morgen. Köln 2006, 82.

54 Straub, Jürgen: Identität. In: Jaeger, Friedrich/Liebisch, Burkhard (Hg.): Handbuch der Kulturwissenschaften. Band 1. Stuttgart 2004, 298.

55 Vgl. Kaschuba, Wolfgang: Geschichtspolitik und Identitätspolitik. In: Binder, Beate/Niedermüller, Peter/Kaschuba, Wolfgang (Hg.): Inszenierungen des Nationalen. Geschichte, Kultur und die Politik der Identitäten am Ende des 20. Jahrhunderts. Köln 2001, 28.

56 Kohlstruck, Michael: Erinnerungspolitik. Kollektive Identität, Neue Ordnung, Diskurshegemonie. In: Schwelling, Birgit (Hg.): Politikwissenschaft als Kulturwissenschaft. Wiesbaden 2004, 185.

57 Vgl. Kliems, Alfrun/Winkler, Martina: Einleitung. Sinnstiftung durch Narration. In: Kliems, Alfrun/Winkler, Martina (Hg.): Sinnstiftung durch Narration in Ost-MittelEuropa. Berlin 2005, 7; Koselleck, Reinhart: Geschichte. In: Brunner, Otto/Conze, Werner/Koselleck, Reinhart (Hg.): Geschichtliche Grundbegriffe. Bd. 2. Stuttgart 1975, 593 ff. 
in der `master narratives` als schematische Mustererzählungen intertextuellen Einfluss auf kleinere Erzählungen entfalten und damit strukturierend, rahmend und rechtfertigend auf konkrete Geschichten wirken. Kleinere, konkretere Erzählungen reproduzieren führende Erzählmuster und legitimieren sie oder widersprechen ihnen und delegitimieren sie. ${ }^{58}$

Narrative entfalten ihre Struktur dadurch, dass sie zeitlich aufeinander und kausal auseinander folgen. ${ }^{59}$ Als kleinste Einheit des Narrativs wird das Motiv bezeichnet. $^{60}$

Da `historische Ereignisse in aller Regel nicht ohne narrative Struktur vorliegen, müssen Geschichtspolitik und Erinnerungspolitik auf unterschiedlich weit ausgedeutete bzw. entfaltete Narrative zurückgreifen. Interpretation und Deutung meinen in dieser Perspektive Arbeit am Narrativ.

Die vor allem im Ansatz der Erinnerungspolitik präsente Handlungs- und Akteursperspektive sollte nicht darüber hinwegtäuschen, dass in der Arbeit an Narrativen kein Deutungsmonopol besteht. Zunächst wird auf bereits vorbestimmte und perspektivierte Narrative zurückgegriffen oder an sie angeschlossen. Bei der Arbeit am Narrativ spielt zudem der Faktor der pathdependency $^{61}$ eine Rolle; er verweist auf Aspekte wie Plausibilität und Anschlussfähigkeit. Zudem können Narrative ihren Deutern entgleiten oder von anderen Akteuren aufgegriffen und weitergedeutet werden: Die Geschichtspolitik der Russländischen Föderation bietet hierfür viele Beispiele. ${ }^{62}$

Sowohl Edgar Wolfrum als auch Kohlstruck thematisieren die symbolischexpressive Seite der Aktualisierung von Geschichte. Schon Eric Hobsbawn verwies in sInvented Traditions rituellen Praktiken insbesondere bei der Formulierung von Kontinuität. ${ }^{63}$

In den rituellen Komponenten von Feiern wird ein bestimmtes Narrativ durch die stetige und gleich bleibende Wiederholung aktualisiert und bekräftigt. ${ }^{64}$ Rüdiger Voigt verweist besonders auf die emotional-expressive Seite:

58 Thijs, Krijn: Vom `master narrativ`zur >Meistererzählung`? Überlegungen zu einem Konzept der >narrativen Hierarchie`. In: Kliems, Alfrun/Winkler Martina (Hg.): Sinnstiftung durch Narration in Ost-Mittel-Europa. Berlin 2005.

59 Vgl. Martinez, Matias/Scheffel, Michael: Einführung in die Erzähltheorie. München 2007, $109 \mathrm{f}$.

60 Vgl. ebd., $109 \mathrm{f}$.

61 Olick, Jeffrey: Genre memories and memory genres. In: American Sociological Review 64 (1999), 381.

62 Im Bereich der Feiertage beispielsweise der Tag der Vaterlandsverteidiger unter El'cin oder unter Putin der Tag der Einheit des Volkes in den ersten Jahren. Vgl. Kapitel: Erinnerungspolitik in Präsidentenreden.

63 Vgl. Hobsbawm, Eric (Hg.): The Invention of Tradition. Cambridge 1983, $1 \mathrm{f}$.

64 Vgl. Voigt, Rüdiger: Mythen, Rituale und Symbole in der Politik. In: Voigt, Rüdiger (Hg.): Symbole der Politik - Politik der Symbole. Opladen 1989, 12. 
»Rituale vermitteln Sinn nicht über das verstandesmäßige Denken, also nicht über den Kopf, sondern über den Körper oder - wenn man so will - über das Herz. Sie entlasten damit den einzelnen von dem Druck, ständig in neuen, noch unbekannten Situationen `vernünftige` Entscheidungen treffen zu müssen, deren Folgen er nicht absehen kann. ${ }^{65}$

Die entlastende Funktion des Rituals beschreibt auch Murray Edelmann in seiner Arbeit über >Politik als Ritualk: Das Ritual erzeuge Konformismus und zugleich Befriedigung und Freude über diesen. ${ }^{66}$

Diese Akzentuierung der emotionalen Wirkebene von Ritualen, z. B. im Rahmen von Gedenkfeiern, verweist auf allgemeine Tendenzen der Geschichtspräsentation: Die Inszenierung und Eventisierung. Ohne diese neueren Begriffe zu gebrauchen, erklärte Jörn Rüsen diese Tendenzen schon 1988 als Mythologisierung und als ı̈̈sthetische Autonomie der historischen Sinnstiftung « und deutete sie als Irrationalisierung, Entpolitisierung und Enthistorisierung von Geschichte. ${ }^{67}$ Mit Ästhetik, Bildern und Imaginationen beginne die Geschichte »die Herzen auf Kosten des Verstandes zu erwärmen. ${ }^{68}$ Die Diskussion um ästhetische Präsentationsformen der Geschichte hat sich in den folgenden Jahren deutlich versachlicht: Die Potenziale, wie beispielsweise Anschaulichkeit und sinnliche Affektion, wurden zunehmend herausgestellt, ohne jedoch die problematischen Aspekte auszublenden. ${ }^{69}$

Inzwischen befasst sich ein weites wissenschaftliches Spektrum mit ästhetischen Präsentationsformen und performativen Geschichtspraktiken von Reenactment bis hin zu Computersimulationen und Computerspielen. ${ }^{70}$ Dieser raffective turn ${ }^{71}$ fordert historiografische Zugänge wie Objektivität oder Dis$\tan z$ heraus und lenkt den Blick auf die physische Verkörperung, intersubjektive emotionale Erfahrung und das "großartige Erlebnis« als Ausgangspunkt von Identitätsbildung. ${ }^{72}$ Die Inszenierung von Geschichte und Veranstaltun-

65 Ebd., 12.

66 Vgl. Edelman, Murray: Politik als Ritual. Die symbolische Funktion staatlicher Institutionen und politischen Handelns. Frankfurt a. M. 1976, 14.

67 Vgl. Rüsen, Jörn: Für eine Didaktik historischer Museen. In: Rüsen, Jörn/Ernst, Wolfgang/Grütter, Heinrich Theodor (Hg.): Geschichte sehen. Beiträge zur Ästhetik historischer Museen. Pfaffenweiler 1988, $18 \mathrm{f}$.

68 Rüsen, Jörn: Vernunftpotenziale der Geschichtskultur. In: Rüsen, Jörn/Lämmert, Eberhard/Glotz, Peter (Hg.): Die Zukunft der Aufklärung. Frankfurt a. M. 1988, 106.

69 Vgl. Korff, Gottfried: Bildwelt der Ausstellung - Die Darstellung von Geschichte im Museum. In: Borsdorf, Ulrich/Grütter, Heinrich Theodor (Hg.): Orte der Erinnerung. Denkmal, Gedenkstätte, Museum. Frankfurt a. M. 1999.

70 Vgl. z. B. Vowinckel, Annette: Past Futures: From Re-enactment to the Simulation of History in Computer Games. In: Historical Social Research 34/2 (2009), 322-332.

71 Vgl. McCalman, Iain/Pickering, Paul A. (Hg.): Historical reenactment: From realism to the affective turn. Basingstoke 2010.

72 Vgl. Mikula, Maja: Historical re-enactment: narrativity, affect and the sublime. In: Rethinking History 19/4 (2015), 598. 
gen mit Event-Charakter stellen eine gesamteuropäische Entwicklung der vergangenen Jahre dar. ${ }^{73}$

\subsubsection{Methode}

Um dem vielschichtigen Thema gerecht zu werden, werden verschiedene methodische Ansätze berücksichtigt. Ein empirisch-analytisches Vorgehen ist notwendig, um administratives Handeln nachzuzeichnen. Politische Praxis vollzieht sich nicht nur auf einer kommunikativen oder symbolischen Ebene. Gesetze, Erlasse und staatliche Programme sind Regeln und Anleitungen für administratives Handeln. Sie formieren mit hoher Reichweite u. a. auch symbolische Formen von Geschichtspolitik.

Die Interpretationsarbeit muss >textbezogen $`$ und $>$ feldbezogen erfolgen $^{74}$ Auf der textbezogenen Ebene müssen die Textwelt, als innerer Bedeutungszusammenhang des Textes, sowie die intertextuellen Bezüge, wie beispielsweise semantische Traditionen und Deutungstraditionen, betrachtet werden. ${ }^{75}$

Auf der feldbezogenen Ebene muss berücksichtigt werden, aus welcher Position und mit welchem Ziel Analysegegenstände entstanden sind bzw. lanciert wurden - hier spielt der institutionelle Rahmen wie auch das gewählte Medium eine wichtige Rolle. ${ }^{76}$

Über texthermeneutische Verfahren hinaus werden diskursanalytische Elemente berücksichtigt, um die symbolische Seite von Geschichtspolitik auszuleuchten: Durch ein von der Linguistik >emanzipiertes` Diskursmodell lassen sich nicht nur Texte, sondern auch Praktiken des Redens und des Handelns in einen Bedeutungszusammenhang bringen, der auch steuernde kulturelle Regeln und Ordnungen berücksichtigt. ${ }^{77}$ Diskurs soll in Anlehnung an Foucault in einem breiteren kulturellen Sinn als eine »spezifische öffentliche Organisa-

73 Jaworski, Rudolf: Jubiläen und Gedenktage im östlichen Europa. Versuch einer einordnenden Betrachtung. In: Jaworski, Rudolf/Kusber, Jan (Hg.): Erinnern mit Hindernissen. Osteuropäische Gedenktage und Jubiläen im 20. und zu Beginn des 21. Jahrhunderts. Münster 2011, 11-28, hier 27.

74 >Text meint hier jede manifest gewordene Zeichenstruktur, unabhängig davon, ob sie sprachlich, multimedial, oder auch in anderen Formen gestaltet wurde. Vgl. Dörner, Andreas: Politischer Mythos und symbolische Politik. Sinnstiftung durch symbolische Formen. Opladen 1995, 14.

75 Vgl. Dörner, Andreas: Politischer Mythos und symbolische Politik. Sinnstiftung durch symbolische Formen. Opladen 1995, $14 \mathrm{f}$.

76 Vgl. ebd., $15 \mathrm{f}$.

77 Vgl. Kaschuba, Wolfgang: Geschichtspolitik und Identitätspolitik. In: Binder, Beate/Niedermüller, Peter/Kaschuba, Wolfgang (Hg.): Inszenierungen des Nationalen. Geschichte, Kultur und die Politik der Identitäten am Ende des 20. Jahrhunderts. Köln 2001, 24. 
tions- und Thematisierungsform kollektiven Wissens $\aleph^{78}$ betrachtet werden, »die Wahrnehmungs- Kommunikations- und Handlungslogiken mit einschließt. ${ }^{79}$ Wolfgang Kaschuba plädiert für ein pragmatisches Drei-Ebenen-Modell, um die Vorteile des diskursanalytischen Zugangs nutzbar zu machen: ${ }^{80}$ Auf der unteren Ebene sollen dabei Figurationen des kollektiven Gedächtnisses, auf der mittleren Ebene Strategien des Diskurses und seine Repräsentationsformen und schließlich auf der oberen dritten Ebene die Funktionsweisen und Regeln, der Diskursraum und die Diskursregeln in den Blick genommen werden.

\subsection{Struktur der Arbeit}

Die Arbeit gliedert sich in drei empirische Hauptteile und ein Zusatzkapitel. Der erste Teil nimmt die Patriotischen Programme zur Erziehung der Bürger als organisatorische Klammer von Geschichtspolitik in den Blick. Analysen von Geschichtspolitik sind häufig als Fallstudien konzipiert. Sie setzen an konkreten Ereignissen oder Prozessen an, ordnen die konkrete Analyse in einen größeren Kontext ein und treffen so Aussagen über geschichtspolitische Ausrichtungen und Schwerpunkte. Da die Programme zur Patriotischen Erziehung der Bürger als Ausgangspunkt verschiedene Bereiche von Geschichtspolitik bündeln und strukturieren, soll in diesem Teil der Arbeit in gegengesetzter Richtung vorgegangen werden. Von der Analyse dieser Grundstruktur ausgehend und unter Berücksichtigung der darin enthaltenen inhaltlichen Schwerpunktsetzungen und Budgetzuweisungen werden maßgebliche Tendenzen herausgearbeitet und dann im Kontext der Patriotischen Programme dargestellt und analysiert.

Dieser Zugang ermöglicht es beispielsweise, staatliche Reformen und Kooperationen mit nicht-staatlichen Trägern besser einzuordnen oder vereinzelte Phänomene und Elemente, beispielsweise aus camouflierten Kampagnen, in ihrer Bedeutung einzuschätzen.

Die in den Programmen angelegte Geschichtspolitik ist durch zwei verbundene Aspekte gekennzeichnet: Die einzelnen Programme laufen über mehrere Jahre und stellen dadurch in ihren Ausrichtungen ein auf Dauer angelegtes Grundgerüst dar. Entsprechend richtet sich die hier angelegte geschichtspolitische Praxis weniger auf den tagespolitischen Vorteil als auf langfristige Konsolidierung - auf die Stärkung mehrheitlich geteilter Einstellungen und die Legitimierung der Ordnung.

78 Ebd., 24.

79 Ebd., 24.

80 Vgl. ebd., 39. 
Neben den inhaltlichen Aspekten fragt dieser Teil auch nach den Organisationsstrukturen einer breit angelegten und koordinierten Geschichtspolitik, die sich aus Einzelfallanalysen in der Regel nicht erschließen. Auf diese Weise werden die inhaltliche, bzw. die symbolisch-sinnstiftende Ebene mit der Ebene der materiellen Entscheidungen verbunden.

Der zweite Teil der Arbeit beschäftigt sich mit dem Zusammenspiel von Geschichts- und Bildungspolitik. Die Bildungspolitik mit einem Fokus auf Schulbücher des Faches Geschichte nimmt einen der zentralen Bereiche in den Blick, in dem staatliche Politik langfristig geschichtliche Perspektiven und Ausrichtungen implementiert. Betrachtet wird die Entwicklung von staatlichen Vorgaben in diesem Bereich beispielsweise in Form von Bildungsstandards und Zulassungsverfahren für Schulbücher genauso wie deren Niederschlag in Gestalt der Schulbücher, die durch das Bildungsministerium für den Geschichtsunterricht empfohlen werden. Hier werden auch die in den Schulbüchern präsentierten Narrative im Quervergleich und im Kontext bestehender Vorgaben betrachtet.

Aufgrund der umfassenden staatlichen Beschränkungen des Geschichtsunterrichts in der Sowjetunion - etwa in Form des Einheitsbuches - wird gerade das Thema Schulbücher bis heute immer wieder intensiv diskutiert. Daher werden auch die gesellschaftlich-politischen Auseinandersetzungen nachgezeichnet, aber auch die Entwicklung des Schulbuchmarktes.

Einen Erkenntnisgewinn bezüglich der staatlichen Geschichtspolitik verspricht das Thema zudem, da in der Bildungspolitik - anders als beispielsweise bei politischen Reden - nicht ausschließlich vereinzelte Narrative herausgegriffen und bearbeitet werden können: Aufgrund der Daten- und Chronologie-orientierten Schulbuch- und Unterrichtstradition in der Russländischen Föderation müssen staatliche Eingriffe zumindest in Grundzügen ein fassbares konsistentes geschichtliches Koordinatensystem bereitstellen und somit auf einer gefestigten verbindlichen Interpretation beruhen. Der Lehrmethoden-Komplex von 2013/2014 wird in dieser Perspektive analysiert.

Der dritte Hauptteil beschäftigt sich mit Geschichtsbezügen in Präsidentenreden. Sie erlauben einen Blick auf die unmittelbare Arbeit an der Geschichte in der Öffentlichkeit und damit verbunden auf die tagespolitischen Aktualisierungen der Bedeutung von Geschichte. Mit dem Ansatz der Erinnerungspolitik kann in diesem Bereich untersucht werden, wie an verschiedenen Narrativen und auch an der Bedeutung dieser Narrative für die Gegenwart gearbeitet wird. Vor allem anhand von regelmäßigen Redeformaten kann diese >Arbeit< analysiert werden. Diachron betrachtet zeigt sich, wie die Narrative verändert oder umgedeutet werden und wie die Bedeutung, die der Geschichte für Gegenwart und Zukunft zugeschrieben wird, angepasst oder verändert wird.

Kennzeichnend für das Format der Präsidentenreden ist, dass der Rückgriff auf die Geschichte häufig in ein direktes - auch verbalisiertes - Verhältnis zu 
einem angenommenen Legitimationsdefizit gesetzt wird. Zum einen werden in Reden zu Feier- und Gedenktagen die wichtigen Linien der Staatsräson aus der Vergangenheit in die Zukunft verlängert, zum anderen wird beispielsweise die eigene Position mit den heroischsten Momenten der Geschichtsschreibung parallelisiert.

Staatliche Geschichtspolitik formt, implementiert und popularisiert Narrative. Reglementierende staatliche Einflussnahmen im Bereich der Geschichte bewegen sich in einem Spannungsfeld zwischen dem »Schutz« der Geschichte z. B. um wichtige Rechtsgüter wie die Menschenwürde zu schützen - und dem Schutz von Narrativen der staatlichen Geschichtspolitik. Im letzten Kapitel sollen einige Instrumente dargestellt werden, die sich auf den Schutz von Narrativen richten. Dazu zählen Maßnahmen, die durch das Verbindlich-machen eine Diskurshegemonie befördern sollen, Maßnahmen, die alternative Deutungen delegitimieren sollen, sowie Maßnahmen, die alternative Deutungen zurückdrängen sollen und sich auch gegen deren Träger richten.

\subsection{Eingrenzung}

In dieser Arbeit soll beschrieben werden, wie und zu welchem Zweck der Staat als geschichtspolitischer Akteur agiert. Dazu zählt auch die Frage, welche Geschichte eingesetzt wird und wie diese geformt wird.

Geschichtspolitik im allgemeinen Sinne ist keine staatliche Veranstaltung. Gesellschaftliche, politische und wirtschaftliche Akteure sind in diesem Feld aktiv. Der Fokus dieser Arbeit liegt auf staatlichen Akteuren und auf der von ihnen orchestrierten Kooperation mit nicht-staatlichen Akteuren. Eine Erforschung der russländischen Erinnerungskultur oder der kollektiven Erinnerung ist nicht intendiert. Es geht um die Erforschung staatlicher Politik, die sich darauf richtet, auf kollektive Erinnerung Einfluss zu nehmen. Am Beispiel von Präsidentenreden mit Geschichtsbezug heißt das: Die Analyse fragt nicht danach, wie die Thematisierung von Geschichte in den Reden die russländische Erinnerungskultur formt - sie fragt nach den präsentierten Narrativen, danach wie sie verändert werden und welche Bedeutung ihnen für die Gegenwart zugeschrieben wird. Am Beispiel der Patriotischen Programme und ihrer Outputs heißt das, dass Implementationsmechanismen, Inhalte und deren symbolische Ausgestaltung betrachtet werden - nicht jedoch gesellschaftliche Reaktionsprozesse oder politisch induzierte Veränderungen des Geschichtsbildes

Die Arbeit soll dagegen herausarbeiten, welche Geschichte in welcher Tradition erzählt wird, mit Hilfe welcher Instrumente deren Implementation versucht wird und worauf die Verbindung mit der Gegenwart abzielt. Die Arbeit fragt danach, wie und zu welchem Zweck staatliche Geschichtspolitik betrieben wird. 
Zeitlich liegt der primäre Untersuchungszeitraum auf der Zeit von der ersten Präsidentschaft Vladimir Putins bis zum Ende des Jahres 2015. Diese Periodisierung gründet sich auf der retrospektiven Betrachtung, die es erlaubt, inhaltliche und strukturelle Abgrenzungen zur vorangegangenen Geschichtspolitik vorzunehmen. Zur Einordnung aktueller Politik und um nicht nur Innovationen, sondern auch Traditionen in den Blick nehmen zu können, wird auch weiter ausgegriffen. Der zeitgeschichtliche Untersuchungszeitraum bis in das Jahr 2015 ist den jüngsten Veränderungen russländischer Geschichtspolitik ab dem Jahr 2012 geschuldet, die auf diese Weise abgebildet werden können.

\subsection{Forschungsstand}

Die russländische Geschichtspolitik wurde in den letzten Jahren in verschiedenen Perspektiven thematisiert. Fragen nach geschichtlich begründeter Identität, ${ }^{81}$ aber vor allem zum Verhältnis der Politik zur Geschichte ${ }^{82}$ fanden immer wieder Berücksichtigung - so z. B. in einem Themenheft von Pro et Contra 2009. ${ }^{83}$ Einen besonderen Schwerpunkt bilden in diesem Bereich Forschungen zur kriegsbezogenen Geschichtspolitik. ${ }^{84}$

81 Vgl. z. B. Langenohl, Andreas: Erinnerung und Modernisierung. Die Rekonstruktion politischer Kollektivität am Beispiel des neuen Russland. Göttingen 2000; Scherrer, Jutta: Ideologie, Identität und Erinnerung. Eine neue Russische Idee für Rußland? In: Osteuropa. Zeitschrift für Gegenwartsfragen des Ostens 54/8 (2004), 27-42; Zorn, Andrej: In search of a New Identity. Visions of Past and Present in Post-Communist Russia. In: Strath, Bo (Hg.): Myth and Memory in the Construction of Community. Brüssel 2000, 321-330; Simon, Gerhard: Auf der Suche nach der `Idee für Rußland. In: Osteuropa. Zeitschrift für Gegenwartsfragen des Ostens 47/12 (1997), 1169-1190; Tismaneanu, Vladimir: Fantasies of Salvation. Democracy, Nationalism and Myth in Post-Communist Europe. Princeton 1998.

82 Vgl. z. B. Miller, Alexei: The turn of Russian Historical Politics, from Perestroika to 2011. In: Miller, Alexei / Lipman, Maria (Hg.): The convolutions of historical politics. Budapest 2012, 253-278; Miller, Aleksej: Rossija: vlast' i istorija. In: Pro et Contra 13/3-4 (2009), 6-23; Miller, Alexei: Geschichtspolitik in Russland. In: Russland-Analysen Nr. 196 vom 12.02.2010, 2-5. Gjerde, Kristian Lundby: The use of history in Russia 2000-2011: the Kremlin and the search for consensus. In: East European Politics 31/2 (2015), 149-169; Koposov, Nikolaj: Pamyat' Strogogo Rezhima. Istoriya i politika Rossii. Moskva 2011; Fein, Elke: Geschichtspolitik in Russland. Chancen und Schwierigkeiten einer demokratischen Aufarbeitung der sowjetischen Vergangenheit am Beispiel der Tätigkeit der Gesellschaft MEMORIAL. Hamburg 2000; Malinova, Ol'ga: Aktual'noe prošloe. Simvoličeskaja politika vlastvujuščej èlity i dilemmy rossijskoj identičnosti. Moskau 2015.

83 Pro et contra 13/3-4 (2009).

84 Vgl. z. B. Danilova, Nataliya: The Politics of War Commemoration in the UK and Russia. London 2015; Aust, Martin: Polen und Russland im Streit um die Ukraine. Konkur- 
Die Patriotischen Programme der russländischen Regierung wurden bisher nicht auf ihre geschichtspolitische Ausrichtung hin untersucht, das gleiche gilt für die mit den Programmen verbundenen Kooperationen und Web-Strategien. ${ }^{85}$ In der russländischen Forschung liegen die Schwerpunkte vor allem auf soziologischen Aspekten und der Bedeutung der Programme für die Etablierung von patriotischen Einstellungen allgemein. ${ }^{86}$

$\mathrm{Zu}$ einzelnen Aspekten von Gedenk- und Feiertage liegen bereits Arbeiten vor, ${ }^{87}$ wie auch zur Reform der Staatssymbolik in den 2000er Jahren. ${ }^{88}$ Besondere Beachtung kommt bei der Betrachtung der Feiertage den Inszenierungen

rierende Erinnerungen an die Kriege des 17. Jahrhunderts in den Jahren 1934 bis 2006. Wiesbaden 2009; Lutz-Auras, Ludmila: >Auf Stalin, Sieg und Vaterland!.. Politisierung der kollektiven Erinnerung an den Zweiten Weltkrieg in Russland. Wiesbaden 2013; Wood, Elizabeth: Performing Memory: Vladimir Putin and the Celebration of World War II. in Russia. The Soviet and Post-Soviet Review 38 (2011), 172-200.

85 Anatolij Rapoport fokussiert seine Untersuchungen zu den Programmen auf den Aspekt der rcivic education : Rapoport, Anatoli: Similar Rhetoric, Different Goals: Contemporary Tendencies Patriotic Education in Russia and Ukraine. In: World Studies in Education 10/1 (2009), 27-40; Rapoport, Anatoli: In search of identity: Competing models in Russia's civic education. In: Grumet, Madeleine/ Yates, Lyn (Hg.): World Yearbook of Education 2011. Curriculum in Today's World: Configuring Knowledge, Identities, Work and Politics, 199-213. London 2011; Rapoport, Anatoli: Patriotic education in Russia: Stylistic move or the sign of substantive counter-reform? The Educational Forum 73/2 (2009), 141-153.

86 Vgl. Abramov, Aleksandr: Patriotičeskaja ideologija v Rossii: ètapy èvoljucii. In: Molodežnaja politika, vospitatel'naja i patriotičeskaja rabota: praktika XXI veka. Materialy Vserossijskoj naučno-praktičeskoj konferencii. RGUTiS, Moskau 2014, 6-14; Ešev, Marat: Patriotizm v sovetskoj i postsovetskoj Rossii. In: Vlast' 5 (2014), 85-89; Gavriljuk, Vera/Malenkov, Vjačeslav: Graždanstvennost', patriotizm i vospitanie molodeži. In: Sociologičeskie issledovanija 4 (2007), 44-50; Golunov, Sergej: Patriotičeskoe vospitanie v Rossii: za i protiv. In: Voprosy obrazovanija. 3 (2012), 258-273; Sanina, Anna: Patriotizm i patriotičeskoe vospitanie v sovremennoj Rossii. In: Sociologičeskie issledovanija 5 (2016); Sanina, Anna/Migunova, Dar'ja/Zuev, Daniil: Patriotičeskoe vospitanie kak ob"ekt gosudarstvennoj politiki. Doklad. XVIII Aprel'skaja meždunarodnaja naučnaja konferencija po problemam razvitija èkonomiki i obščestva. Online: https://eventsfiles-bpm.hse.ru/files/_reports/86241926-EEB6-4267-8A20-00C8A314FDE7/Sanina Migunova_Zuev.pdf.

87 Vgl. z. B. Bordjugov, Gennadij: Oktjabr'. Stalin. Pobeda. Kul't jubileev v prostranstve pamjati. Moskau 2010; de Keghel, Isabelle: Verordneter Abschied von der revolutionären Tradition. Der `Tag der nationalen Einheit` in der Russländischen Föderation. In: Karl, Lars/Polianski, Igor J. (Hg.): Geschichtspolitik und Erinnerungskultur im neuen Russland. Göttingen 2009; Jaworski, Rudolf: Jubiläen und Gedenktage im östlichen Europa. Versuch einer einordnenden Betrachtung. In: Jaworski, Rudolf/Kusber, Jan (Hg.): Erinnern mit Hindernissen. Osteuropäische Gedenktage und Jubiläen im 20. und zu Beginn des 21. Jahrhunderts. Münster 2011, 11-28.

88 Vgl. de Keghel, Isabelle: Die Staatssymbolik des neuen Russland. Traditionen - Integrationsstrategien - Identitätsdiskurse. Münster 2008. 
und Feierpraxen $\mathrm{zu}^{89}$ die Zeitschrift Neprikosnovennyj Zapas widmete dem Thema 2015 zwei Ausgaben. ${ }^{90}$

Auch im Bereich von Bildungspolitik und Schulbüchern kann auf umfangreiche Forschungen zurückgegriffen werden. ${ }^{91}$ Gerade die Schulbücher wurden in den vergangenen Jahren aus verschiedenen Perspektiven in den Blick genommen, ${ }^{92}$ bereits 1995 widmete die Zeitschrift Internationale Schulbuchforschung den Schulbüchern und der Bildungspolitik der Transformationszeit eine ganze Ausgabe mit vielen bis heute wichtigen Beiträgen, ${ }^{93}$ das gleiche

89 Vgl. z. B. Makhotina, Ekaterina: Auf der Suche nach der verlorenen Heimat. Das gesellschaftliche Erinnern an das 20. Jahrhundert im heutigen Russland. In: Zedler, Jörg (Hg.): ,Was die Welt im Innersten zusammenhält‘. Gesellschaftlich-staatliche Kohäsionskräfte im 19. und 20. Jahrhundert. München 2014, 77-104; Rolf, Malte: Das sowjetische Massenfest. Hamburg 2006; Oushakine, Serguei: Remembering in Public: On the Affective Management of History. In: Ab Imperio 1 (2013), 269-302; Oushakine, Serguei Alex: Emotional Blueprints: War Songs as an Affective Medium. In: Steinberg, Mark/Sobol, Valeria (Hg.): Interpreting Emotions in Russia and Eastern Europe. DeKalb 2011, 248-276; Danilova, Nataliya: The Politics of War Commemoration in the UK and Russia. London 2015; Andreev, Dmitrij: Znaki Putina. jubilej Pobedy kak prostranstvo simvoličeskich akcij vlasti. In: Bordjugov, Gennadij (Hg.): Pobeda-70: rekonstrukcija jubileja. Moskau 2015.

90 Vgl. Neprikosnovennyj Zapas 100/2 (2015) und Neprikosnovennyj Zapas 101/3 (2015).

91 Zu Bildungspolitik, Schulbüchern und Historiographie in der späten Sowjetunion und frühen Russländischen Föderation vgl. z. B. Davies, Robert: Soviet History in the Yeltsin Era. London 1997; Davies, Robert: Soviet History in the Gorbachev Revolution. Bloomington 1989; de Keghel, Isabelle: Die Rekonstruktion der vorsowjetischen Geschichte. Hamburg 2006; Geyer, Dietrich: Perestrojka in der sowjetischen Geschichtswissenschaft. In: Geyer, Dietrich (Hg.): Die Umwertung der sowjetischen Geschichte. Göttingen 1991, 9-31.

92 Vgl. z. B. Ševyrev, Aleksandr: Das Bild Rußlands in heutigen russischen Geschichtslehrbüchern. In: Internationale Schulbuchforschung 17/4 (1995), 397-424; Tjulaeva, Tamara: Die Reform der historischen und sozialkundlichen Bildung an russischen Schulen. In: Internationale Schulbuchforschung 17/4 (1995), 387-395; Golubev, Aleksandr: Das Bild der sowjetischen Vergangenheit in den rußländischen Schulbüchern der letzten Jahre. In: de Keghel, Isabelle/Maier, Robert(Hg.): Auf den Kehrichthaufen der Geschichte? Der Umgang mit der sozialistischen Vergangenheit. Hannover 1999, 103-113; Scheliha, Wolfram von: Analyse. Staatliche Geschichtsschreibung im Post-Imperium. Putins Einheitslehrbuch für den Geschichtsunterricht. In: Russland-Analysen Nr. 271 vom 14.02.2014, 3. Online: http://www.laender-analysen.de/russland/pdf/RusslandAnalysen271.pdf; Shnirelman, Victor: Stigmatized by History or by Historians? The peoples of Russia in School History Textbooks. In: History and Memory 21/2 (2009), 110-149; Shlapentokh, Dmitry: History and Interethnic Conflicts in Putin's Russia. Journal of Educational Media, Memory and Society 1/1 (2009), 165-179; Zur Entwicklung der sowjetischen Schulbücher bis Mitte der 1950er Jahre siehe auch: Brandenberger, David: National Bolshevism. Stalinist Mass Culture and the Formation of Modern Russian National Identity, 1931-1956. Cambridge 2002.

93 Internationale Schulbuchforschung 17/4 (1995). 
gilt für die Schwerpunktausgabe des Jahres 1999. ${ }^{94}$ Viele der Beiträge zum Thema Schulbücher haben einen Fokus auf die Darstellung von autoritärer Herrschaft und Stalinismus sowie die Auswirkung dieser Darstellungen auf die heutige Zeit. ${ }^{95}$ Eine Ausnahme stellt die Studie von Ekaterina Levintova und Jim Butterfield zur Darstellung der 1990er Jahre in den zugelassenen Schulbüchern dar. ${ }^{96}$

Deutlich weniger erforscht als die Schulbuchlandschaft ist die zugrunde liegendeBildungspolitikmitihren BildungsstandardsundZulassungsverfahren ${ }^{97}$

Die Reden der russländischen Präsidenten werden regelmäßig journalistisch-publizistisch begleitet. Eine gezielte übergreifende wissenschaftliche Analyse der präsentierten Narrative liegt bisher nicht vor. Einige Analysen befassen sich mit Aspekten der Linguistik, der Intonation und der ImageKonstruktion in einzelnen Redeformaten. ${ }^{98} \mathrm{Zu}$ den Reden vor der Föderalversammlung erscheinen regelmäßig politische Analysen von Hans-Henning

94 de Keghel, Isabelle (Hg.): Auf den Kehrichthaufen der Geschichte? der Umgang mit der sozialistischen Vergangenheit. Hannover 1999.

95 Vgl. z. B. Mironov, Boris: The Fruits of a Bourgeois Education. In: Kritika: Explorations in Russian and Eurasian History. 10/4 (2009), 847-860; Solonari, Vladimir: Normalizing Russia, Legitimizing Putin. In: Kritika: Explorations in Russian and Eurasian History. 10/4 (2009), 835-846; Zubkova, Elena: The Filippov Syndrom. In: Kritika: Explorations in Russian and Eurasian History. 10/4 (2009), 861-868; Čapkovskij, Filipp: Učebnik istorii i ideologičeskij deficit. In: Pro et Contra. 15/1-2 (2011), 117-133; Brandenberger, David: A New Short Course? A. V. Filippov and the Russian State's Search for a $>$ Usable Past‘. In: Kritika. Explorations in Russian and Eurasian History. 10/4 (2009), 825-833; Jakunin, Vladimir (Hg.): Škol’nyj učebnik istorii i gosudarstvennaja politika. Moskau 2009 und das Themenheft Kritika: Explorations in Russian and Eurasian History, 10/4 (2009).

96 Vgl. Levintova, Ekaterina/Butterfield, Jim: Kak formiruetsja istorija i otnošenie k nej: škol'nye učebniki o novejšej rossijskoj istorii. Vestnik obščestvennogo mnenija 101/3 (2009), 103-115.

97 Vgl. z. B. Dneprov, Ėduard: Novejšaja političeskaja istorija rossijskogo obrazovanija. Moskva 2011; Gorjuchin, Jurij: Dopuščeno - ne značit rekomendovano. Na odnogo pjatiklassnika prichoditsja 8 učebnikov po fizike. In: Učitel'skaja gazeta. Nr. 40 vom 25. September 2001, 10; Kaspržak, Anatolij/Loginova, Ol'ga/Polivanova, Katerina: Standart obrazovanija: istorija razrabotki i itogi. Voprosy obrazovanija 3 (2004), 24-43; Dneprov, Ėduard: Obrazovatel'nyj standart - instrument obnovlenija soderžanija obščego obrazovanija. In: Voprosy Obrazovanija. 3 (2004), 77-117.

98 Vgl. Gavrilova, Marina: Nekotorye čerty rečevogo portreta prezidenta rossii D. A. Medvedeva. Vestnik TvGU. Serija »Filologija « 1 (2011), 4-10; Gavrilova, Marina: Nekotorye čerty rečevogo portreta pervogo prezidenta Rossii B. N. El'cina. In: Političeskaja lingvistika 42/4 (2012), 17-22; Gavrilova, Marina: Diskursivnyj portret V. V. Putina. In: Diskurs-Pi 10/3 (2013), 114-115; Il'ičeva, Valerija: Inauguracionnaja reč kak instrument formirovanija političeskogo imidža v kontekste russkoj ritoričeskoj tradicii. Moskau 2015; Alyševa, Julija: Rečevoj portret V.V. Putina. In: Vestn Volgogradskij gosudarstvennyj universitet. 16/2 (2012), 171-174. 
Schröder. ${ }^{99}$ Die geschichtlichen Bezüge und die geschichtlich-rhetorischen Anleihen sind kaum systematisch untersucht. ${ }^{100}$

\subsection{Quellen}

Entsprechend der unterschiedlichen thematischen Schwerpunkte kommen in der Arbeit eine Vielzahl verschiedener Quellen zum Einsatz. Dazu zählen transkribierte Präsidentenreden und Protokolle beispielsweise aus Kommissionssitzungen genauso wie Gesetzestexte, Erlasse, staatliche Programme (i.e. Regierungsprogramme) und die dazugehörigen nachgeordneten Rechtsquellen, wie beispielsweise Bildungsstandards oder Bildungskonzeptionen. Die Protokolle werden entsprechend ihrer primären Publikationsart aus dem OnlineArchiv zitiert. Die Rechtsquellen werden mit Gattung, Datum, Nummer sowie Titel zitiert und sind so in jeder Sammlung zu Rechtsquellen auffindbar.

Für die Analyse von Geschichtsinszenierungen, wie Paraden und Shows, werden Fernsehmitschnitte herangezogen. Sie stellen für die Analyse der erinnerungspolitischen Intentionen die geeignete Quelle dar, da die Inszenierungen nicht primär auf die Perspektive des Zuschauers vor Ort ausgerichtet sind, sondern für die Filmproduktion fürs Fernsehen - sich also nicht an den Tribünengast, sondern den Fernsehzuschauer richten.

Weitere Medien stellen Videos dar, die zur Verbreitung auf Video-SharingPlattformen hochgeladen wurden.

Einen weiteren wichtigen Quellenbestand stellen Schulbücher dar. Der Fokus liegt dabei primär auf Publikationen, die den staatlichen Begutachtungs-, Zulassungs- oder auch Empfehlungsprozess in den 2000er und 2010er Jahren durchlaufen haben.

99 Vgl. z.B. Schröder, Hans-Henning: Vorwärts Russland! Die Botschaft des Präsidenten an die Nationalversammlung. In: Russland-Analysen Nr. 249 vom 14.12.2012, 2-5; Schröder, Hans-Henning: Auf dem Boden der Tatsachen. Putins Rede zur Lage der Nation im Dezember 2013. In: Russland-Analysen. Nr. 269 vom 20.12.2013, 2-6; Schröder, Hans-Henning: Politik in Zeiten nationaler Verzückung. Putins Botschaft zur Lage der Nation im Jahre 2014.. In: Russland-Analysen Nr. 288 vom 19.12.2014, 7-9; Schröder, Hans-Henning: Der Terror, die Türkei und die alltäglichen Probleme ... Die >Botschaft an die Föderalversammlung`zeigt, dass Putin ein politisches Konzept fehlt. In: Russland-Analysen. Nr. 307 vom 18.12.2015.

100 Vgl. z. B. Selunskaja, Nadežda: Sakral'nye mesta, investicii v pamjat' i srednevekovyj diskurs. Novacii istoričeskogo jazyka Vladimira Putina 2014 goda: vzgljad istorika-medievista. In: Gefter vom 29.12.2014. Online: http://gefter.ru/archive/13947; Sereda, Viktoria: Osobennosti reprezentacii national'no-istoričeskich identičnostej v oficial'nom diskurse prezidentov Ukrainy i Rossii. Sociologija: teorija, metody, marketing 3 (2006), 191-212. 
Zur Rekonstruktion von Ereignissen und zur Kontextualisierung, zur Absicherung von Daten und zur Rekonstruktion von Diskussionen usw. wird auf Zeitungsarchive zurückgegriffen - wo immer möglich, auf gedruckte Publikationen.

Für die Wiedergabe russischsprachiger Begriffe und Eigennamen wird in der Arbeit das wissenschaftliche Transliterationssystem verwendet. Die Übersetzungen aus dem Russischen in dieser Arbeit wurden vom Autor erstellt. Dabei wurde eine möglichst textnahe Übersetzung präferiert - manchmal zu Lasten der Lesbarkeit. Auf Präzisierungen ungenauer Originalpassagen wurde im Deutschen weitgehend verzichtet. 


\section{Patriotismus und Erinnerungspolitik}

\subsection{Die Programme zur Patriotischen Erziehung}

Identitätspolitik stand seit der Gründung der Russländischen Föderation, wie auch in anderen postsowjetischen Staaten, ${ }^{1}$ immer wieder auf der politischen Agenda. Während der 1990er Jahre ging es vor allem um die Etablierung von Staatssymbolen des neuen Staates und die Suche nach einer neuen Russischen Ideer. Während der Präsidentschaften Vladimir Putins wurde diese Politik fortgesetzt. Die Staatssymbolik wurde reformiert und die Bestrebungen, die Staatlichkeit durch eine verbindende Idee zu konsolidieren, wurden verstärkt. Einen organisatorischen Rahmen fanden diese Bestrebungen in dem ersten Programm zur Patriotischen Erziehung der Bürger der Russländischen Föderation von $2001 .^{2}$

Die sichtbaren Reformen der russländischen Staatssymbolik im Jahr 2001 wurden als eine Wende in der Geschichts- und Erinnerungspolitik interpretiert: Sie galten als Zeichen für eine Rehabilitierung sowjetischer Symbole und damit als wichtiger Schritt in der Ausbildung einer »russisch-sowjetischen Mischidentität. $^{3}$

Im Nachhinein betrachtet lassen sich diese Reformen jedoch eher als eine Fortsetzung der Politik Boris El'cins interpretieren. Bereits ab 1995 begann die Reintegration der sowjetischen Periode als positiver Bezugspunkt in die russländische Geschichtspolitik. Ein anschauliches Beispiel dafür war das Gesetz über die Tage des militärischen Ruhmes vom März 1995. ${ }^{4}$ Es bezieht explizit auch die sowjetische Zeit in das Ruhmesgedenken mit ein. Obwohl sich die die Bezugspunkte der 15 Feiertage über gut 700 Jahre verteilen, sind sechs dieser Tage der sowjetischen Periode zuzuordnen. Der erinnerungspolitische

1 Vgl. Rapoport, Anatoli: Similar Rhetoric, Different Goals: Contemporary Tendencies Patriotic Education in Russia and Ukraine. In: World Studies in Education 10/1 (2009), $27 \mathrm{ff}$.

2 Postanovlenie Pravitel'stva Rossijskoj Federacii ot 16 fevralja 2001 g. N 122: Koncepcija patriotičeskogo vospitanija graždan Rossijskoj Federacii. In: Rossijskaja gazeta, Nr. 49 vom 12.03.2001. Künftig zitiert als: Programm 2001.

3 de Keghel, Isabelle: Die Staatssymbolik des neuen Russland. Traditionen - Integrationsstrategien - Identitätsdiskurse. Münster 2008, 239.

4 Federal'nyj zakon ot 13.03.1995 N 32-FZ Zakon o dnjax voinskoj slavy Rossii. Heute: Zakon o dnjax voinskoj slavy i pamjatnyx datach Rossii. 
Kompromiss betont zwar die militärische Konnotation der Tage. Die Verbindung aus militärischen Ruhmestagen und sowjetischer Geschichte nimmt jedoch die forcierte Erinnerungspolitik Vladimir Putins in den 2000er Jahren vorweg.

Es gibt viele weitere Beispiele aus den Jahren 1995 bis 1999 für diese Tendenz, ${ }^{5}$ sodass die Erklärung, es handele sich um taktische Manöver, um beispielsweise die KPRF in Wahlkämpfen zu schwächen, indem ihr der militärische Ruhm als Legitimationsressource streitig gemacht wird, zu kurz greift.

In diesem Kontext sind die Programme zur Patriotischen Erziehung der Bürger zu sehen: Sie stellen keine genuin neue Politik dar, sondern greifen Vorhandenes auf, reformieren und konzentrieren es. In der Tonlage und der Herangehensweise lassen sich in den Programmen viele Parallelen zu Rechtsakten der 1990er Jahre wie dem `Gesetz über die Tage des militärischen Ruhmes` oder dem >Gesetz über die Verewigung des Andenkens an den Sieg im Großen Vaterländischen Krieg ${ }^{6}{ }^{6}$ feststellen.

In diesem Kapitel werden zunächst die drei Programme zur Patriotischen Erziehung der Bürger beschrieben und anschließend an drei Beispielkomplexen deren Implementierung und Ausrichtung in der Praxis dargestellt. Diese Beispiele spiegeln die primären Schwerpunktsetzungen der drei Programme in ihrer Umsetzung. Der erste Bereich beschreibt die Reformen der Feiertage in den 2000er Jahren unter besonderer Berücksichtigung der Novemberfeiertage. Als Beispiel der erinnerungspolitischen Inszenierung dient hier die Veteranenparade am 7. November. Der zweite Bereich beschreibt an zwei Beispielen die Öffnung der Patriotischen Erziehung für nichtstaatliche Akteure und der dritte Komplex beschreibt Strategien der Patriotischen Erziehung, die sich webbasiert an jüngere Adressaten richten.

5 So z.B. die 9. Mai Paraden, der Gedenkkomplex Siegespark/ Poklonnaya Gora, die Einführung des Siegesbanners (Ukaz prezidenta Rossijskoj Federacii ot 15 aprelja 1996 goda N 561 »O Znameni Pobedy«) und Gesetze: Federal'nyj zakon ot 19.05.1995 N 80-FZ uvekovečenii Pobedy sovetskogo naroda v Velikoj Otečestvennoj vojne 1941-1945 godov« etc.

6 Federal'nyj zakon ot 19.05.1995 N 80-FZ »Ob uvekovečenii pobedy sovetskogo naroda v Velikoj Otečestvennoj vojne 1941-1945 godov«. 


\subsubsection{Die Programme zur Patriotischen Erziehung}

Das erste Programm zur Patriotischen Erziehung der Bürger aus dem Jahr $2001^{7}$ wurde inzwischen dreimal, $2006^{8}, 2011^{9}$ und $2016^{10}$, neu aufgelegt. Das aktuelle Programm läuft bis 2020. Der Etat wurde dabei kontinuierlich erhöht, von 177,95 Millionen Rubel 2001 über 497,8 Millionen Rubel 2006 und 777,2 Millionen 2011 bis hin zu 1,66 Milliarden Rubel für das Programm 2016. ${ }^{11}$

Der Aufbau der Programmtexte wurde durch das erste Programm 2001 eingeführt und hat sich seitdem kaum verändert. Schon die Einleitung des ersten Programms macht deutlich, dass die Programme in ihrer Ausrichtung und Konzeption primär der Geschichts- und Erinnerungspolitik zuzuordnen sind: Für die erfolgreiche Umsetzung sollen die »Erfahrungen und Erfolge der Vergangenheit ${ }^{12}$ herangezogen werden:

»Die heroischen Ereignisse der vaterländischen Geschichte, die hervorragenden Errungenschaften des Landes in Politik, Wirtschaft, Wissenschaft, Kultur und Sport haben noch die Qualitäten der moralischen Ideale bewahrt. Dies schafft die realen Grundlagen zur Ausarbeitung der Veranstaltungen und Maßnahmen des Programms $[\ldots] . \ll^{13}$

Die Vergangenheit wird so zur direkten Legitimationsbasis für die Ziele des Programms.

Auch die Ziele werden in kurzer Form zu Beginn formuliert: Das Programm soll die Bürger zum Patriotismus erziehen, um »die gesellschaftliche Stabilität, das Wiedererstarken der nationalen Wirtschaft sowie die Verteidigungsfähigkeit des Landes zu fördern. ${ }^{14}$

7 Programm 2001.

8 Postanovlenie Pravitel'stva RF ot 11 ijulja 2005 g. N $422 » O$ gosudarstvennoj programme »Patriotičeskoe vospitanie graždan Rossijskoj Federacii na 2006-2010 gody« (s izmenenijami ot 13 nojabrja 2006 g.): »Sobranie zakonodatel'stva RF«, 18.07.2005, N 29, 3064. Künftig zitiert als: Programm 2006.

9 Postanovlenie Pravitel'stva RF ot 5 oktjabrja 2010 g. N 795 »O gosudarstvennoj programme »Patriotičeskoe vospitanie graždan Rossijskoj Federacii na 2011-2015 gody« (s izmenenijami i dopolnenijami): »Sobranie zakonodatel'stva RF«, 11.10.2010, N 41 (2 č.), 5250. Künftig zitiert als: Programm 2011.

10 Postanovlenie Pravitel'stva RF ot 30 dekabrja 2015 g. N 1493 »O gosudarstvennoj programme »Patriotičeskoe vospitanie graždan Rossijskoj Federacii na 2016-2020 gody. Online: http://static.government.ru/media/files/8qqYUwwzHUxzVkH1jsKAErrx 2dE4q0ws.pdf. Künftig zitiert als: Programm 2016.

11 Das laufende Programm 2016-2020 wird aufgrund der Aktualität im Rahmen dieser Arbeit nicht näher analysiert.

12 Vgl.: Programm 2001. I. Einleitung.

13 Ebd. II. Problemstellung.

14 Programm 2001. I. Einleitung. 
In der Begründung des Programms wird zunächst die Erziehung als gezielte Politik von staatlichen Organen und Organisationen definiert, die sich darauf richte, bei der Bevölkerung patriotische Einstellungen, ein Bewusstsein für die Legitimität des Vaterlandes sowie die Bereitschaft zur Erfüllung von bürgerliche Pflichten zu fördern. ${ }^{15}$ Patriotische Erziehung soll sich auf die »Entwicklung von Persönlichkeiten richten, die als Bürger und Patrioten ihrer Heimat fähig sind, in Friedens- und in Kriegszeiten ihre Bürgerpflichten zu erfüllen. $\aleph^{16}$

Als zugrunde liegende Problemlage wird festgestellt, dass die ökonomische Desintegration, die soziale Ausdifferenzierung sowie der allgemeine Werteverfall einen negativen Einfluss auf die Gesellschaft ausgeübt hätten. Zudem werde durch den Verlust von traditionellem russländischem Patriotismus Nationalismus befördert und die snationale Frage verschärft. In diesem Problemaufriss zeigt sich bereits, dass das Programm ein ideelles Gegengewicht zu den 1990er Jahren etablieren soll. Ohne die ersten Jahre der Russländischen Föderation explizit zu nennen, konstruiert der Programmtext über mit ihnen assoziierte Wörter wie Desintegration oder Ausdifferenzierung die 1990er Jahre als Negativ der anzustrebenden Zukunft.

Darüber hinaus schließt der Programmtext an ideengeschichtliche Diskurse der 1990er Jahre um die Suche nach einer 'neuen Russischen Idee ${ }^{17}$ an. Ähnlich wie im Zusammenhang des Diskurses zwischen Slawophilen und Westlern im 19. Jahrhundert, werden bestimmte Tendenzen wie z. B. Selbstsucht und Egoismus als westlich und als >unrussisch <efiniert und sogenannten traditionellen russischen Werten wie z. B. Gemeinsinn gegenüber gestellt. Diesem Muster entspricht auch der Programmtext:

»Im Bewusstsein der Bevölkerung zeigen sich vermehrt Gleichgültigkeit, Selbstsucht, Individualismus, Zynismus, aggressive und respektlose Einstellungen zu staatlichen und sozialen Institutionen. ${ }^{18}$

Der aus den Heldentaten der Vergangenheit gespeiste Patriotismus soll diesen Entwicklungen entgegenwirken. Auch aus den Zielen des Programms, lässt sich seine Funktion, bestimmte Entwicklungen der 1990er Jahre zu revidieren, herauslesen: Durch patriotische Einstellungen in der Bevölkerung soll die Gesellschaft konsolidiert, die öffentliche und wirtschaftliche Stabilität verbessert

15 Ebd. II. Problemstellung.

16 Ebd. II. Problemstellung.

17 Vgl. Scherrer, Jutta: Ideologie, Identität und Erinnerung. Eine neue Russische Idee für Rußland? In: Osteuropa. Zeitschrift für Gegenwartsfragen des Ostens 54/8 (2004), 27-42; Simon, Gerhard: Auf der Suche nach der `Idee für Rußland ‘. In: Osteuropa. Zeitschrift für Gegenwartsfragen des Ostens 47/12 (1997), 1169-1190.

18 Programm 2001. II. Problemstellung. 
sowie die Freundschaft der Völker der Russländischen Föderation gefestigt werden. ${ }^{19}$ Bei den Aufgaben des Programms wird zudem auf einen weiteren Aspekt der Russische Idee Bezug genommen: Russlands Rolle in der Welt:

»Durch [...] Bewusstsein für die historischen Werte und die Rolle Russlands für das Schicksal der Welt soll der Stolz auf das eigene Land gefördert werden. ${ }^{20}$

Zusammengefasst lässt sich feststellen, dass in der Anlage des Programms bereits zwei auffällige erinnerungspolitische Ansätze sichtbar werden: Zum einen die Diagnose des Ausgangspunktes als krisenhaft. Hier verweist der Programmtext deutlich auf das geläufige Narrativ der 1990er Jahre als Zeit des Werteniedergangs und der wirtschaftlichen wie auch sozialen Desintegration. Ein Teilaspekt dieser Bestimmung ist auch die Charakterisierung dieser Entwicklungen als >unrussisch . Damit verbunden ist auch der zweite direkt erkennbare Ansatz im Programmtext: Es ist der Rückgriff auf ’historische russische Werte ${ }^{21}$, um die diagnostizierten Problemlagen zu bearbeiten. Dem Werteverfall, der sich u.a. im Individualismus und Egoismus zeige, und der Desintegration soll mit ralten Werten begegnet werden - wie z. B. Gemeinsinn -, die in den Diskursen der vergangenen Jahrhunderte immer wieder als >russisch definiert wurden.

Daraus ergeben sich im Programmtext, ohne bereits auf konkrete historische Ereignisse oder Legitimationsobjekte zu verweisen, zwei erinnerungspolitische Relationen: Auf der einen Seite soll positiv an die >Heldentaten der Geschichte und Fortschritte in Politik und Wissenschaft in allen Zeiten angeknüpft werden. Ob diese positiven Bezugspunkte der Geschichte beispielsweise in der frühen Sowjetunion oder dem späten Zarenreich liegen, spielt in dieser Perspektive keine besondere Rolle. Ausschlaggebend ist vielmehr die Funktion, Ruhm und Größe für die Gegenwart zu vermitteln und nutzbar zu machen.

Auf der anderen Seite wird mit Abgrenzung zur Geschichte gearbeitet: Die jüngste Geschichte der Russländischen Föderation in den 1990er Jahren soll als Kontrapunkt eingesetzt werden: Soziale, politische und wirtschaftliche Desintegrationserscheinungen werden als negativer Bezugspunkt konstruiert. ${ }^{22}$

Diese Kombination aus positivem Bezug und Abgrenzung lässt sich als die Inszenierung eines Übergangs und damit als ein Konstitutionsritual interpretieren: Die Macht definiert sich als neu und grundlegend andersartig in Bezug auf die jüngste Geschichte. Kontinuitäten sollen auf diese Weise aus

19 Vgl. ebd. III. Ziele und Aufgaben.

20 Ebd. III. Ziele und Aufgaben.

21 Ebd. III. Ziele und Aufgaben.

22 In den Folgeprogrammen ab 2006 werden bereits Errungenschaften der Gegenwart in Abgleich zum Negativ der 1990er Jahre gebracht. 
dem Fokus gerückt werden. Stattdessen inszeniert sich die `neue Macht aber als in der Tradition zur wahren Geschichte stehend, in der sich die eigentlichen Ideale des Landes zeigen.

Während die Einleitung Zielsetzungen des Programms und die erinnerungspolitische Ausrichtung anreißt, wird im folgenden Abschnitt über die »Ursachen der Problemlage der Patriotischen Erziehung der Bürger und die Notwendigkeit ihrer Lösung durch die Maßnahmen des Programms « ${ }^{23}$ ausführlich der Ursprung der angenommenen Patriotismusdefizite und ihrer Folgen für Staat und Gesellschaft diskutiert.

Der Programmtext beschreibt als Problemanalyse, dass ökonomische Desintegration und soziale Ausdifferenzierung in den vorangegangenen Jahren einen negativen Einfluss auf Werte und Einstellungen der Bevölkerung ausgeübt hätten. Ein Verlust an »traditionellem russischen Patriotismus« zugunsten eines schädlichen Nationalismus habe die nationale Frage verschärft. ${ }^{24}$

In der folgenden Beschreibung der Auswirkungen dieser Entwicklungen Selbstsucht, Individualismus etc. - werden wiederum Anspielungen auf die Diskurse zur Russischen Idee deutlich, zudem wird festgestellt, dass das Prestige des Militär- und Staatsdienstes verloren gehe. ${ }^{25}$ Damit wird auf eine der zentralen Ausrichtungen der Patriotischen Erziehung verwiesen: die Stärkung der Wehrbereitschaft und die Verbesserung der Attraktivität des Staatsdienstes allgemein und des Wehrdienstes im Besonderen.

Aus dieser Problemanalyse leitet das Programm eine "offensichtliche Dringlichkeit einer einheitlichen Politik aller staatlichen Ebenen $\aleph^{26}$ ab: Dieser Teil des Programms endet mit der Feststellung, dass die Patriotische Erziehung für eine Konsolidierung in allen Bereichen sorge und damit auch im Sinne der staatlichen Sicherheit sei. ${ }^{27}$

Der dritte Abschnitt des Programms benennt Ziele und Aufgaben des Programms: Auch in dieser Wiederholung der inhaltliche Ziele werden die erinnerungspolitischen und wehrpolitischen Aspekte betont:

"Notwendig zum Erreichen der Ziele [...] sind die Ausbildung eines patriotischen Bewusstseins der Bürger, auf Basis historischer Werte, für die Rolle Russlands in Bezug auf das Schicksal der Welt, der Erhalt und die Entwicklung des Stolzes auf das Land sowie die Erziehung von Bürgerpatrioten, die bereit sind die staatlichen Interessen des Landes zu verteidigen. ${ }^{28}$

23 Programm 2001.

24 Vgl. ebd. Teil II.

25 Vgl. ebd. Teil II.

26 Ebd. Teil II.

27 Vgl. ebd. Teil II.

28 Ebd. Teil III. 
Auch hier ist wieder der Bezug zur Russischen Idee deutlich: Die Annahme einer besonderen Rolle Russlands für das Schicksal der Welt war in Verbindung mit dem Topos >Moskau als drittes Rom`immer ein zentraler Aspekt der Diskussion.

Auf der praktischen und organisatorischen Ebene sollen zunächst Ausarbeitungen zur methodischen Umsetzung der Patriotischen Erziehung erstellt und die notwendigen rechtlichen Grundlagen geschaffen werden. ${ }^{29}$ Beides wird sowohl für die föderale Ebene ${ }^{30}$ als auch für die Ebene der Föderationssubjekte festgeschrieben: Die Föderationssubjekte werden verpflichtet eigene Ausarbeitungen und Unterprogramme zur Patriotischen Erziehung zu erstellen. Die Umsetzung des Programms wird an dieser Stelle zunächst in zwei Phasen gegliedert: In der ersten Phase bis 2002 sollen die methodischen, normativen und rechtlichen Grundlagen für alle staatlichen Ebenen ausgearbeitet werden; in der zweiten Phase 2002 bis 2006 sollen die in der >Anlage 1< des Programms festgehaltenen Maßnahmen abgearbeitet werden. ${ }^{31}$

Im vierten Teil des Programms werden Bereiche beschrieben, in denen die im Programm enthaltenen Maßnahmen eingeteilt werden. Diese Bereiche von Programmmaßnahmen sind:

Erstens: »Die Schaffung der normativ-rechtlichen Basis der Patriotischen Erziehung. ${ }^{32}$ Dieser Bereich fasst die Rechtsakte zusammen, welche die Grundlagen für die Patriotische Erziehung darstellen. Dazu zählen Gesetzesreformen wie beispielsweise die Überarbeitung des Gesetzes über die Tage des militärischen Ruhmes, aber auch kleinteilige Veränderungen wie die Aufwertung bestimmter Museen und damit ihre bessere Finanzierung sowie die Ausarbeitung von Rechtsgrundlagen für regelmäßige patriotische Wettbewerbe und Militärsportspiele. Auch die Ausarbeitung der Wechselbeziehungen zwischen den beteiligten Akteuren bzw. Institutionen und ihrem rechtlichen Status ist hier verortet.

Der zweite Bereich beschäftigt sich mit der »Perfektionierung der Tätigkeit der staatlichen Institutionen auf dem Gebiet der Patriotischen Erziehung « ${ }^{33}$ beispielsweise durch die Initialisierung eines Gesetzes zur Patriotischen Erziehung. Weiterhin sollen zur Realisierung des Programms die Kompetenzen der `Kommission für soziale Fragen von Militärangehörigen, von Bürgern, die aus dem Wehrdienst entlassen wurden, und Angehörigen der Organe für innere

29 Vgl. ebd. Teil III.

30 Die sföderale Ebene` bezeichnet die gesamtstaatliche Ebene der Russländischen Föderation. Die Ebene der Föderationssubjekte bezieht sich auf die Untergliederungen der Föderation wie z. B. Regionen (Kraj), Gebiete (Oblast'), Republiken oder Städte mit Subjektstatus.

31 Vgl. Programm 2001. Teil III.

32 Ebd. Teil IV.

33 Ebd. Teil IV. 
Angelegenheiten sowie deren Familien ${ }^{34}$ auf föderaler Ebene ausgeweitet und auf regionaler Ebene Koordinationsräte und Zentren der Patriotischen Erziehung eingerichtet werden. Durch Schulungen und Kaderausbildungen auf regionalem und föderalem Niveau soll zusätzlich ein einheitliches Herangehen gewährleistet werden. Dazu sollen Konferenzen, Seminare und landesweite Kongresse der Patriotischen Erziehung sowie ein enger Austausch zwischen den Leitern der Koordinationsräte und Patriotischen Zentren organisiert werden.

Der dritte Maßnahmenbereich trägt die Überschrift »Maßnahmensystem staatlicher Institutionen zur Vervollständigung des Prozesses der Patriotischen Erziehung. ${ }^{35}$ Hier werden Maßnahmen zusammengeführt, die sich primär auf die Verbesserung des Ansehens der Streitkräfte und des Staatsdienstes richten. Dazu werden Ausstellungen, Sportspiele, Veranstaltungen von Suchdiensten und Gedenkveranstaltungen beispielsweise im Rahmen der 'Erinnerungswacht ${ }^{36}$ geplant. Die Veranstaltungen werden als militär-patriotisch, militär-historisch, militär-technisch oder militär-kulturell konzipiert.

Der vierte Bereich "Staatliche Einflussnahme auf die Propaganda des Patriotismus in den Massenmedien ${ }^{37}$ wird besonders ausführlich dargestellt. In diesem Bereich werden Maßnahmen gebündelt, mit denen Massenmedien unterstützt werden sollen, die an der Patriotischen Erziehung teilnehmen. Diese nicht weiter beschriebenen Massenmedien sollen durch Programminhalte, Zyklen und konkrete Empfehlungen zu einer stärkeren Gewichtung patriotischer Inhalte und zu einer >objektiven` Darstellung der Geschichte sowie der gegenwärtigen Ereignisse gebracht werden. Dazu zählt laut Programmtext auch, »der Verzerrung von Fakten und Verfälschungen der Geschichte des Vaterlandes aktiv entgegenzuwirken. ${ }^{38}$ In Presse, Radio und Fernsehen sollen Formate etabliert werden, in denen Politiker und Prominente, Vertreter von Wissenschaft, Kunst und Kultur sowie Veteranen und Militärvertreter Probleme der Patriotischen Erziehung erörtern.

Durch die Produktion von Kinofilmen, Videos und gedruckten Publikationen soll ein Bewusstsein für die »Besonderheiten der russländischen Entwicklung, die Geschichte und Kultur der Völker Russlands und ihrer gegen-

34 Russisch: Komissija po social'nym voprosam voennoslužaščich, graždan, uvolennych s voennoj služby, so služby v organach Vnutrenich Del, i členov ich semej. Künftig: `Kommission für soziale Fragen der Militärangehörigen`.

35 Programm 2001: Teil IV.

36 Die Erinnerungswacht (Vacht Pamjati) entstand Ende der 1980er auf Initiative des sowjetischen Verteidigungsministeriums und ist mit den Such-Organisationen verbunden.

37 Programm 2001: Teil IV.

38 Ebd. Teil IV. Das Programm zur patriotischen Erziehung der Bürger 2001 nimmt in diesem Punkt bereits die Aufgabenstellung der Kommission gegen die Verfälschung der Geschichte des Vaterlandes zum Nachteil der Russländischen Föderation vorweg, die 2009 durch Präsident Dmitrij Medvedev eingesetzt wurde. 
seitigen Bereicherung ${ }^{39}{ }^{39}$ geschaffen werden. Durch die Mobilisierung der Kulturelite sollen positive Vorbilder bzw. Heldenfiguren geschaffen werden, die sich an unterschiedliche Altersgruppen und soziale Schichten der Gesellschaft richten.

Auch in diesen Programmbereich werden Maßnahmen gegen die »Verfälschung « der Geschichte integriert. Durch Veranstaltungen, Serien von Büchern mit patriotischer Ausrichtung, Förderung von Erinnerungsliteratur, aber auch die Herausgabe von Archivdokumenten soll ein >objektives` Bild der vaterländischen Geschichte befördert werden. ${ }^{40}$

Im folgenden Abschnitt werden Vorgaben für Schulbücher formuliert, die im Rahmen des Programms umgesetzt bzw. in die entsprechenden Richtlinien aufgenommen werden sollen:

»Es sollen Schulbücher herausgegeben werden, die die Bedeutung der im Lande durchgeführten sozialen, wirtschaftlichen, und kulturellen Umgestaltungen sowie die Rolle des Staates und von Persönlichkeiten für das Schicksal des russischen Volkes würdigen. ${ }^{41}$

Beendet wird dieser Teil über die staatliche Einflussnahme auf Massenmedien durch die Maßgabe, die kreativen Potenziale von Filmemachern, Journalisten und Schriftstellern für die Patriotische Erziehung nutzbar zu machen bzw. im Sinne der Überschrift Einfluss auf ihr Schaffen zu nehmen, indem jährliche Wettbewerbe ausgerichtet und Preise vergeben werden sollen.

Der fünfte Bereich fasst unter dem Titel »Konsolidierung und Koordinierung der Tätigkeit gesellschaftlicher Akteure und Organisationen im Interesse der Patriotischen Erziehung « ${ }^{42}$ Unterstützungsmaßnahmen und die Verbesserung von Rahmenbedingungen für öffentliche Vereinigungen und Organisationen zusammen, die sich in der Patriotischen Erziehung engagieren. Veteranen- und Jugendverbände, aber auch kreative oder kulturelle Organisationen sollen aktiviert sowie ihre Tätigkeiten konsolidiert und koordiniert werden, um Gedenkveranstaltungen im traditionellen Sinne durchzuführen, wie zu Ehren der Tage des militärischen Ruhmes, aber auch um neue Formen der Schaffung eines kollektiven patriotischen Bewusstseins zu entwickeln.

Der sechste und damit letzte Maßnahmenbereich fasst Programmaktivitäten zusammen, die sich mit der »Schaffung der wissenschaftlich-theoretischen und methodischen Grundlagen der Patriotischen Erziehung “ ${ }^{43}$ beschäftigen. Diese Maßnahmen sollen zum einen das intellektuelle Potenzial der Wissenschaftler für die Patriotische Erziehung aktivieren, zum anderen

39 Ebd. Teil IV.

40 Vgl. ebd. Teil IV.

41 Ebd. Teil IV.

42 Programm 2001: Teil IV.

43 Ebd. Teil IV. 
sollen ein theoretischer Unterbau für das Programm geschaffen, Methodik ausgearbeitet und auftretende Probleme behandelt werden. Durch methodische Handreichungen, pädagogische Empfehlungen und wissenschaftliche Begründungen soll der Zugriff der Patriotischen Erziehung auf die nachwachsenden Generationen und das Heranwachsen von Bürgerpatrioten sichergestellt werden.

Nach dieser ausführlichen Kategorisierung von sechs Maßnahmenbereichen in Teil vier beschreibt der fünfte Teil des Programms zur Patriotischen Erziehung der Bürger »Mechanismen zur Umsetzung des Programms. $\aleph^{44} \mathrm{Als}$ ausführender Hauptakteur in der internen Koordination des Programms, in Fragen der Abstimmung und Präzisierung von Maßnahmen mit der Regierung der Russländischen Föderation und in der Finanzkontrolle wird die `Kommission für soziale Fragen von Militärangehörigen eingesetzt. Kontaktorgan der Kommission in der Regierung ist dabei das `Russländische staatliche militärhistorisch-kulturelle Zentrum bei der Regierung der Russländischen Föderation..$^{45}$ Als primäre ausführende Organe des Programms werden das Bildungsministerium, das Kulturministerium, das Verteidigungsministerium und das militärhistorisch-kulturelle Zentrum bei der Regierung genannt. Sie sind für die konkrete Ausarbeitung der Veranstaltungen, deren Ausschreibung und Finanzierung zuständig. Die exekutiven Organe der Föderation arbeiten Grundlagen der Patriotischen Erziehung aus und gewährleisten ihre Einhaltung, während die Exekutivorgane der Föderationssubjekte Unterprogramme ausarbeiten und für deren Umsetzung und Finanzierung aus eigenen Mitteln verantwortlich sind.

Teil sechs des Programms regelt die Finanzversorgung des Programms zur Patriotischen Erziehung. Die Zuweisung der Mittel an die ausführenden Akteure wird in einer gesonderten Anlage ${ }^{46}$ ausgewiesen.

Der letzte Textteil des Programms entwickelt unter dem Titel Evaluation und Effektivität des Programms $«^{47}$ einen Katalog mit den erwarteten Resultaten der Durchführung. Auf einer "sozial-ideologischen" Ebene sollen durch das Programm die ideologische Gegnerschaft bekämpft, moralische Einheit erreicht und für eine Wiedergeburt der wahren geistigen Werte des russischen Volkes gesorgt werden. Ausdrücklich wird auch auf die angestrebte Konsolidierung der Einheit des Landes und der innerrussländischen Völkerfreundschaft verwiesen. Auf der ökonomischen Ebene werden eine allgemeine Konsolidierung der wirtschaftlichen Verhältnisse und dadurch ein Abbau ideologischer Spannungen angestrebt. Auf der militärischen Ebene wird eine

44 Ebd. Teil V.

45 Russisch: Rossijskij gosudarstvennyj voennyj istoriko-kul'turnyj centr pri Pravitel'stve Rossijskoj Federacii.

46 Vgl. Programm 2001. Anlage Nr. 2.

47 Ebd. Teil VII. 
verbesserte Motivation der jungen Menschen angestrebt, Dienst in der Armee zu leisten, aber auch allgemein soll die Bereitschaft zur Verteidigung des Vaterlandes bei den Bürgern gestärkt werden.

Endergebnis des Programms zur patriotischen Erziehung der Bürger sollen der wirtschaftliche, geistige und kulturelle Aufstieg, die Festigung des Staates und seiner Verteidigungsbereitschaft sowie soziale und wirtschaftliche Stabilität sein. Die Spiritualität der Menschen, ihre bürgerliche Einstellung und ein ausgeprägtes patriotisches Bewusstsein der Russen werden als wichtiger Schritt zur Lösung der anstehenden Aufgaben und als bestimmend für die Zukunft Russlands bezeichnet. ${ }^{48}$

Das zweite Programm zur Patriotischen Erziehung der Bürger von 2006 behält die Gliederung bei, wurde aber inhaltlich teilweise ergänzt und teilweise umgeschrieben. So wird in der Einleitung zusätzlich auf die »Prinzipien eines funktionierenden demokratischen Staates und der Zivilgesellschaft ${ }^{49}$ und im weiteren Verlauf auf die »Unterstützung Russlands in seiner Entwicklung als freier demokratischer Staat ${ }^{50}$ als Ziel der Patriotischen Erziehung verwiesen.

Die Problemanalyse wurde ebenfalls überarbeitet: Es werden nun auf der einen Seite erste Erfolge des ersten Programms im Bereich der Einflussnahme auf die Massenmedien herausgestellt: So habe sich die Tonart, in der insbesondere über den multiethnischen Charakter der Russländischen Föderation berichtet werde, verändert.

»Es wächst das Verständnis dafür, dass die Multinationalität unseres Landes, die Vielfältigkeit der nationalen Kulturen und ihre gegenseitige Durchdringung zum materiellen und geistigen Fortschritt der Gesellschaft beitragen. ${ }^{51}$

Auf der anderen Seite werden jedoch auch bestehende Problem konstatiert: Neben Problemen in der Kaderausbildung für die Patriotische Erziehung wird darauf hingewiesen, dass das erste Programm nicht in allen Föderationssubjekten zufriedenstellend umgesetzt wurde und beispielsweise in einigen Regionen noch keine Koordinationsräte und Zentren eingerichtet wurden. ${ }^{52}$

Einige der Veränderungen und Ergänzungen sind von besonderem Interesse, weil sie sich aus aktuell gewordenen politischen Kontexten erklären lassen. Die erste dieser Ergänzungen fordert die verstärkte Ausrichtung des Programms auf die »Ausbildung des patriotischen Bewusstseins als der wichtigsten Grundlagen der geistig-moralischen Einheit der Gesellschaft. ${ }^{53}$ Sie lässt sich als ein Konzept zur Bearbeitungen sezessionistischer Tendenzen

48 Vgl. ebd. Teil VII.

49 Programm 2006. Teil I.

50 Ebd. Teil III.

51 Ebd. Teil II.

52 Vgl. ebd. Teil II.

53 Programm 2006. Teil I. 
lesen. Die Entstehungsphase dieses Programms fällt in eine Phase, in der sich deutlich eine Einhegung des Krieges in Tschetschenien zeigt. Der direkte militärische Konfliktaustrag spielt dadurch eine weit weniger wichtige Rolle als Strategien, die sich darauf richten, den Terroristen und feindlichen Kampfgruppen den Rückhalt zu entziehen. Die patriotische Wertschätzung für die Einheit soll dabei nicht nur in Regionen mit sezessionistischen Tendenzen und Bewegungen wie dem Nordkaukasus gestärkt werden. Ein Schwerpunkt scheint sich darauf zu richten, bei der Majorität beispielsweise in Zentralrussland einen positiven Bezug zur Einheit in Multiethnizität zu stärken. Auch das bereits erwähnte Rekurrieren auf Freiheit, Demokratie, Rechtsstaat und Bürgergesellschaft ist diesen Intentionen zuzurechnen.

Eine weitere Ergänzung lässt sich ebenfalls aus dem zeitlichen Entstehungskontext der Neuauflage des Programms erklären. 2006 wird die Bedeutung und Rolle von zivilgesellschaftlichen Akteuren in der Patriotischen Erziehung der Bürger stärker gewichtet und präzisiert:

"Das Programm stützt sich auf die Prinzipien eines funktionierenden demokratischen Staates und die Zivilgesellschaft und ist für Akteure des Staates, der Zivilgesellschaft und Wissenschaft auf Grundlage von Eigeninitiative zugänglich." ${ }^{54}$

Auch im weiteren Verlauf des Programmtextes wird der Aspekt der nichtstaatlichen Akteure in der Patriotischen Erziehung deutlich akzentuiert: Gesellschaftliche Akteure wie Organisationen, Verbände, Gewerkschaften und Bürgerinitiativen sollten mehr Bedeutung bekommen.

Ursächlich für diese Entwicklung dürften vor allem drei Betrachtungen sein: Erstens wird durch diese Öffnung eine bessere gesellschaftliche Verankerung und damit eine größere Breitenwirkung der Maßnahmen ermöglicht. Zweitens können über diese zusätzlichen Akteure zusätzliche finanzielle Mittel für die Patriotische Erziehung akquiriert werden. Der dritte Grund für diese Ergänzung dürfte in den Bestrebungen der russländischen Führung liegen, eine Antwort auf das >orange Szenario zu finden. Die sogenannte »orange Revolution" von Kiew 2004, aber auch ähnliche Vorgänge in Georgien 2003 und Kirgisistan 2005 haben in verschiedenen Politikbereichen der Russländischen Föderation zur Implementierung von Gegenstrategien geführt. Die Integration möglichst vieler gesellschaftlicher Akteure in die patriotische Bildungsarbeit kann als Teil dieser konsolidierenden Strategie gewertet werden.

Bei den Maßnahmenbereichen kommt es ebenfalls zu größeren Veränderungen: Die Maßnahmen zur Schaffung einer methodisch-normativen Basis entfallen; hier scheint das erste Programm erfolgreich gewesen zu sein. Dafür wird ein neuer Bereich eingerichtet: »Die Nutzung der Staatssymbolik in der 
Patriotischen Erziehung. ${ }^{55}$ In diesem neuen Bereich werden Maßnahmen gebündelt, die die Sichtbarkeit der Russländischen Staatssymbolik, die nicht zuletzt durch das erste Programm in einigen Bereichen reformiert wurde, zu verbessern und ihren Einsatz in der Patriotischen Erziehung zu regeln. ${ }^{56}$

Die zweite Neuauflage des Programms für die Jahre 2011-2015 behält ebenfalls grob den Aufbau der ersten Programme bei, ist aber inhaltlich deutlich gestrafft und verzichtet auf die Aufschlüsselung von Maßnahmenbereichen. ${ }^{57}$ Ausführlich bleibt lediglich die Einleitung, in der die wichtigsten beiden Aspekte des Programms dargestellt werden: Die Methoden der Patriotischen Erziehung sollen modernisiert und an aktuelle Erfordernisse angepasst werden. Damit im Zusammenhang steht der zweite Aspekt: Die Möglichkeiten neuer Medien und insbesondere Internetformate sollen stärker in der Patriotischen Erziehung eingesetzt werden. ${ }^{58}$ In den zu erwartenden Resultaten des Programms wird besonders die Jugend als Zielgruppe hervorgehoben. ${ }^{59}$ Dementsprechend wird der Maßnahmenkatalog im Verhältnis zu den Vorgängerprogrammen weiter ausgebaut.

Darüber hinaus wird eine Zusammenfassung der Ergebnisse der Vorgängerprogramme vorgenommen: Der Aufbau der Patriotischen Erziehung als System wird unter Hinweis auf die flächendeckend arbeitenden Koordinationsräte als weitgehend abgeschlossen bezeichnet, als maßgebliche Instanzen werden staatliche Organe, Organe der kommunalen Selbstverwaltung und gesellschaftliche Organisationen benannt. ${ }^{60}$

\subsubsection{Budgets und Struktur}

Eine deutliche Veränderung erfuhr bei jeder Neuauflage die Ressourcenversorgung des jeweiligen Programms sowie die Verteilung der Mittel auf die ausführenden Akteure. Das Budget des ersten Programms 2001-2005 betrug 177,95 Millionen Rubel. Davon wurden 130,78 Millionen Rubel aus dem föderalen Haushalt, 32,67 Millionen Rubel aus den regionalen Haushalten und 14,5 Millionen Rubel aus Quellen außerhalb des Budgets veranschlagt. ${ }^{61}$ Die Anlage Nr. 2 des Programms macht deutlich, dass die Zuweisungen ganz

55 Ebd. Teil IV.

56 Zu Maßnahmen zur Popularisierung und zum Schutz der Staatsymbole vgl. de Keghel, Isabelle: Die Staatssymbolik des neuen Russland. Traditionen - Integrationsstrategien Identitätsdiskurse. Münster 2008, $151 \mathrm{ff}$.

57 Vgl. Programm 2011.

58 Vgl. ebd. Teil I.

59 Vgl. ebd. Teil V.

60 Vgl. ebd. Teil I.

61 Programm 2001: Teil VI. 
überwiegend an das Bildungsministerium, das Kulturministerium und das Ministerium für Presse und Massenmedien gehen. ${ }^{62}$

In den folgenden Programmen wird das Budget kontinuierlich erweitert. Für das Programm 2006-2010 werden bereits insgesamt 497,8 Millionen Rubel veranschlagt. Davon 378,05 Millionen Rubel aus dem föderalen Haushalt und 119,75 Millionen Rubel aus Quellen außerhalb des Budgets, beispielsweise durch Spenden, Patenschaften und aus den Budgets der beteiligten nichtstaatlichen Akteure. Die Föderationssubjekte werden nicht mehr herangezogen, da sie inzwischen eigene Unterprogramme selbst finanzieren. Auffällig ist, dass sich der Anteil des Föderationshaushaltes ungefähr verdreifacht und der fremdfinanzierte Teil sogar ungefähr verachtfacht hat.

Bei den Zuweisungen an die ausführenden Akteure hat sich einiges verändert: Die größten Verschiebungen innerhalb des Budgets sind dem veränderten Zuschnitt von Ministerien und damit einhergehend der zunehmenden Einrichtung von Regierungsagenturen bei der Regierung, wie der Kulturagentur (Roskul'tura) oder der Agentur für Presse und Kommunikation (Rospečat'), geschuldet. Beide genannten Agenturen bekommen erhebliche Mittel aus dem Programm. Dies gilt ebenfalls für die staatliche Medienholding (VGTRK), die zunehmend seit 2002 zu den bestimmenden Akteuren im Bereich Fernsehen wurde und damit maßgeblich für die vom Programm intendierte staatliche Einflussnahme auf die Massenmedien ist. Eine weitere auffällige Veränderung ist die Verdreifachung der Zuweisung an das Verteidigungsministerium und zusätzlich die neue Zuweisung an das Militärzentrum über 22,95 Millionen Rubel. Beides kommt der Ausweitung der `militär-patriotischen` Komponente des Programms zugute. Sie ist, zusammen mit der umfangreichen Integration nichtstaatlicher Akteure und deren Budgets, die deutlichste Modifikation des Programms 2006-2010.

Für das Programm 2011-2015 erhöht sich das Gesamtbudget auf 777,02 Millionen Rubel. Davon kommen 596,75 Millionen Rubel aus dem föderalen Haushalt und 180,45 Millionen Rubel aus sonstigen Quellen außerhalb des Budgets. Neben der erneut deutlichen Vergrößerung des Budgets für das Programm 2011-2015 sind es vor allem wieder die Zuweisungen an Agenturen, die auffällig sind. Die zum ersten Mal berücksichtigte Russische Agentur für Jugendangelegenheiten (Rosmolodëž) wird direkt mit 65,67 Millionen Rubel ausgestattet. Eine weitere Akzentuierung stellt die Zuweisung an die Agentur für Presse und Kommunikation (Rospečat') dar. Die Zuweisung steigt von 17,5 Millionen Rubel auf 138,5 Millionen Rubel, während beispielweise die staatliche Medienholding WGTRK keine Rolle mehr spielt. Die Bündelung

62 Bildungsministerium: 35 Prozent; Kulturministerium: 24 Prozent; Ministerium für Presse und Massenmedien: 18 Prozent. Vgl. ebd. Anlage Nr. 2. 
von Mitteln und Aufgaben bei der Agentur für Presse und Kommunikation, aber auch die Integration der Agentur für Jugendangelegenheiten in die Patriotische Erziehung verweisen auf eine Neuausrichtung des Programms: Die Agentur für Jugendangelegenheiten koordiniert zum einen die staatliche Jugendpolitik und zum anderen die gesellschaftlichen Akteure und Organisationen in diesem Bereich. Nicht zuletzt durch regen personellen Austausch bestehen engste Verflechtungen zwischen der Agentur und den politischen Jugendorganisationen in Russland. Die Agentur verfügt über erhebliche finanzielle Mittel und kann sich jederzeit an den Personalressourcen und der Kampagnenfähigkeit der Organisationen bedienen. Die Agentur für Presse und Kommunikation ist in verschiedensten Bereichen tätig, von der Registrierung von elektronischen Medien bis hin zur Kontrolle von Rundfunk- und Fernsehfrequenzen. Für die besondere Berücksichtigung im Programm 2011 dürfte ein weiterer Bereich entscheidend sein: Die Agentur zählt zu ihren Hauptaufgaben auch die Unterstützung sozial bedeutsamen Erzeugnissen der Massenmedien sowie die Schaffung und Verstetigung von Webseiten, die eine soziale oder bildende Bedeutung haben. ${ }^{63}$

Beide Kompetenzen zusammengenommen, die Verflechtung mit Jugendorganisationen und deren Kampagnenfähigkeit sowie die langjährige Erfahrung in Herausgeberschaft sowie Schaffung und Verstetigung von OnlineInhalten, lassen die Agenturen - in den Augen der Programmmacher - zu einem erfolgversprechenden Werkzeug für die Ausrichtung der zweiten Neuauflage der Patriotischen Erziehung werden: Die Möglichkeiten von OnlineFormaten sollen verstärkt und gezielt benutzt werden, um auch kommende Generationen für die Inhalte der Patriotischen Erziehung zu gewinnen.

In den Jahren seit 2001 hat sich eine Programmstruktur über mehrere Ebenen herausgebildet. Auf der föderalen Ebene der Russländischen Föderation existieren die bereits beschriebenen drei Programme zur Patriotischen Erziehung von 2001, 2006, 2011 und 2016. Zudem existiert eine offizielle und 2003 veröffentlichte Grundkonzeption der russischen Regierung zur Patriotischen Erziehung. ${ }^{64}$ Auf Grundlage der Programme von 2001 und 2006 wurden die Föderationssubjekte verpflichtet eigene Programme aufzulegen und aus ihren Haushalten zu finanzieren. Dadurch entstand eine weitere Programmebene

63 Vgl. Webseite der Agentur Rospečat': Allgemeine Informationen. 08.12.2010. In: http:// fapmc.ru/rospechat/rospechat/about/information.html.

64 Vgl. Die Konzeption wurde im Rahmen einer Sitzung der `Kommission für soziale Fragen von Militärangehörigen` angenommen. Vgl. Koncepcija patriotičeskogo vospitanija graždan Rossijskoj Federacii (odobrena na zasedanii Pravitel'stvennoj komissii po social'nym voprosam voennoslužaščich, graždan, uvolennych s voennoj služby, i členov ich semej. Protokol N 2(12)-P4 ot 21 maja 2003 g. In: Vedomosti ugolovno-ispolnitel'noj sistemy. Nr. 1/2004. Künftig zitiert: Konzeption 2003. 
mit einer Vielzahl von Unterprogrammen der Föderationssubjekte. ${ }^{65}$ Die Programme auf der Ebene der Föderationssubjekte sind häufig in andere regionale Unterprogramme, z. B. zur Förderung der Jugend oder der Zivilgesellschaft integriert, oder stehen mit regionalen militär-patriotischen Programmen in Verbindung. ${ }^{66}$ Darüber hinaus verpflichtet die föderale Ebene die Ebene der Föderationssubjekte bis hinunter zu den Organen der kommunalen Selbstverwaltung zur Kooperation mit Akteuren der Patriotischen Erziehung auf allen Ebenen.

Einige Föderationssubjekte wie zum Beispiel das Gebiet Wolgograd haben für bestimmte Verwendungen noch weitere Unterprogramme eingerichtet. So sind für das Gebiet Wolgograd das »Föderale Programm zur Patriotische Erziehung der Bürger der Russländischen Föderation «, das regionale Unterprogramm zur »Patriotischen Erziehung der Bürger des Wolgograder Gebiets ${ }^{67}$ sowie dessen Unterprogramme "Stalingrader Charakter ${ }^{68}{ }^{8}$ und $»$ Entwicklung der heimatkundlichen Bewegung ${ }^{69}$ relevant.

Die Programmtexte orientieren sich in Struktur und Inhalt durchgängig deutlich an den föderalen Programmen und Konzeptionen. Dagegen sind die auf allen Ebenen des Programms umfangreichen Maßnahmenkataloge sehr unterschiedlich und tragen auch regionalen Erfordernissen Rechnung.

Die Patriotische Erziehung der Bürger der Russländischen Föderation basiert nicht nur auf dem eigentlichen Programmtext. Sie ist darüber hinaus in einer Vielzahl von föderalen Gesetzen ${ }^{70}$ Präsidialerlassen ${ }^{71}$ und Beschlüssen der Russländischen Regierung ${ }^{72}$ verankert.

65 Zur Regionalstruktur der Patriotischen Programme vgl. Sanina, Anna/Migunova, Dar'ja/Zuev, Daniil: Patriotičeskoe vospitanie kak ob"ekt gosudarstvennoj politiki. Doklad. XVIII Aprel'skaja meždunarodnaja naučnaja konferencija po problemam razvitija èkonomiki i obščestva. Online: https://events-files-bpm.hse.ru/files/_reports/86241926EEB6-4267-8A20-00C8A314FDE7/Sanina_Migunova_Zuev.pdf.

66 Vgl.ebd.

67 Vgl. Postanovlenie Administracii Volgogradskoj oblasti ot 28 nojabrja 2011 g. N 756-p »Ob utverždenii dolgosročnoj oblastnoj celevoj programmy »Patriotičeskoe vospitanie graždan« na 2012-2015 gody«.

68 Ebd.

69 Ebd.

70 Vgl. Föderale Gesetze zur patriotischen Erziehung nach der Auflistung aus dem Konzept 2003 (S. 7): Federal'nye zakony Rossijskoj Federacii: »Ob obrazovanii«, »O vysšem i poslevuzovskom obrazovanii«, »O voinskoj objazannosti i voennoj službe«, »O veteranach, »O dnjach voinskoj slavy (pobednych dnjach) Rossii«, »Ob uvekovečenii Pobedy sovetskogo naroda v Velikoj Otečestvennoj vojne 1941-1945 godov«.

71 Vgl. Präsidialerlasse zur patriotischen Erziehung nach der Auflistung aus dem Konzept 2003 (S. 7): Ukaz Prezidenta Rossijskoj Federacii ot 10 janvarja 2000 g. N 24 »O koncepcii nacional'noj bezopasnosti Rossijskoj Federacii«.

72 Vgl. Beschlüsse der russländischen Regierung zur patriotischen Erziehung nach der Auflistung aus dem Konzept 2003 (S. 7): Postanovlenija Pravitel'stva Rossijskoj Federacii ot 31 dekabrja 1999 g. N 1441 »Ob utverždenii Položenija o podgotovke graždan Rossijskoj 
Beispiele hierfür sind das »Gesetz über die Bildung ${ }^{73}$, das »Gesetz über den Wehrdienst und den Dienst in der Armee « ${ }^{74}$ oder auch das »Gesetz über Veteranen. ${ }^{75}$ Auch in den beiden Strategien der Nationalen Sicherheit des Präsidenten der Russländischen Föderation von $2000^{76}$ und $2009^{77}$ wird $\mathrm{Pa}$ triotismus als Aufgabe im nationalen Interesse berücksichtigt. Die bis 2020 gültige Sicherheitsstrategie von 2009 verweist bereits direkt auf die Patriotische Erziehung als notwendige Aufgabe zur Gewährleistung der staatlichen Sicherheit. $^{78}$

Die Ausführungsbestimmungen des Programms selbst zielten zusätzlich von Anfang an auch darauf, bestehende Rechtgrundlagen zu verändern und neue Rechtsakte zu initiieren. Der erste vollzogene Schritt in diesem Bereich war die Aufwertung einer Reihe von Museen durch ihre Aufnahme in die Liste der staatlichen Museen. Betroffen war eine Reihe kleinerer Museen der verschiedenen Waffengattungen der Streitkräfte und des Innenministeriums. In den Programmen von 2001 und 2006 wurde darüber hinaus eine Vielzahl an Reformen im Feiertagskalender initiiert. Zentral waren dabei Änderungen am »Gesetz über die Tage des militärischen Ruhmes und die Gedenktage «. ${ }^{79}$ Initiiert durch das Programm wurde daneben auch das »Gesetz über die Verewigung des Andenkens der Opfer bei der Verteidigung des Vaterlandes« reformiert. ${ }^{80}$ In den Programmen von 2006 und 2011 werden zudem Änderungen am »Gesetz über die kommunale Selbstverwaltung ${ }^{81}{ }^{81}$ projektiert. Durch diese Modifikationen sollten die Steuerungspotenziale sowie das Ineinandergreifen verschiedener Ebenen der Patriotischen Erziehung verbessert werden.

Federacii k voennoj službe«, Postanovlenija Pravitel'stva Rossijskoj Federacii ot 16 fevralja 2001 g. N $122 » O$ gosudarstvennoj programme »Patriotičeskoe vospitanie graždan Rossijskoj Federacii na 2001-2005 gody«.

73 Federal'nyj zakon Rossijskoj Federacii »Ob obrazovanii«: z. B. Artikel 3, Absatz 3.

74 Federal'nyj zakon Rossijskoj Federacii »O voinskoj objazannosti i voennoj službe«: z.B. Artikel 11.

75 Federal'nyj zakon Rossijskoj Federacii »O veteranach«: hier wurden 2004 Bestandteile des Programms integriert, ohne direkt auf das Programm Bezug zu nehmen: Kapitel 1, Paragraph 8.

76 Ukaz Prezidenta RF ot 10 janvarja 2000 g. N 24 » Koncepcii nacional'noj bezopasnosti Rossijskoj Federacii«.

77 Ukaz Prezidenta Rossijskoj Federacii ot 12 maja 2009 g. N $537 » O$ Strategii nacional'noj bezopasnosti Rossijskoj Federacii do 2020 goda«.

78 Ebd. vgl. Teil IV.7 Kultur.

79 Federal'nyj zakon RF ot 13 marta 1995 g. N 32-FZ »O dnjach voinskoj slavy i pamjatnych datach Rossii«.

80 Federal'nyj zakon RF ot 14.01.1993 N 4292-1 »Ob uvekovečenii pamjati pogibšich pri zaščite Otečestva«.

81 Federal'nyj zakon Rossijskoj Federacii ot 6 oktjabrja 2003 g. N 131-FZ »Ob obščich principach organizacii mestnogo samoupravlenija v Rossijskoj Federacii«. 
Ein Vorhaben, das bereits in allen drei Programmen projektiert wurde, stellt das föderale Gesetz über die Patriotische Erziehung dar. Das Gesetz zirkuliert bereits seit Jahren in Entwurfsform, wurde jedoch bisher noch nicht verabschiedet. Ein Grund dafür dürfte sein, dass es keine substanziellen Änderungen enthält und deshalb vor allem eine symbolische Aufwertung darstellen würde.

\subsubsection{Patriotismus-Begriff und Identität}

Auf der begrifflichen Ebene sind in den Texten zur Patriotischen Erziehung zwei Konstanten augenfällig: Zum einen die erwartbar häufige Verwendung des Begriffs Patriotismus und zum anderen das Nichtvorhandensein von Begriffen wie Identität, russische Identität oder Russische Idee. Das ist insofern bemerkenswert, weil insbesondere in den 1990er Jahren, aber auch bis in die Gegenwart, die Diskurse um russische Identität, russländische Identität und Patriotismus eng verbunden waren. ${ }^{82}$ Die Programme verzichten dagegen weitgehend auf kulturologische Grundierungen und Herleitungen.

Obwohl die Wörter >patriotisch und >Patriotismus in den Programmen zur Patriotischen Erziehung der Bürger in erstaunlich hoher Frequenz benutzt werden, ${ }^{83}$ bleibt der dahinter stehende Patriotismus-Begriff auffallend unscharf. In den drei bisher aufgelegten Programmen von 2001, 2006 und 2011 wird er kaum definiert. Lediglich im ersten Programm 2001 findet eine kurze Abgrenzung zum Begriff Nationalismus statt. Nationalismus wird als kontraproduktiv für das Zusammenleben in einem multiethnischen Staat eingestuft, wogegen dem Patriotismus in diesem Zusammenhang ohne nähere Erklärung das Potenzial zur Konsolidierung von Staat und Gesellschaft zugeschrieben wird. Diese Unterscheidung ist eine Konstante auch in wissenschaftlichen Texten zum Patriotismus, ${ }^{84}$ auch wenn sie sich sowohl konzeptionell ${ }^{85}$ als auch empirisch ${ }^{86}$ zunehmend als problematisch erweist.

82 Vgl. Simon, Gerhard: Auf der Suche nach der `Idee für Rußland،. In: Osteuropa. Zeitschrift für Gegenwartsfragen des Ostens 47/12 (1997), 1169-1190; Scherrer, Jutta: Ideologie, Identität und Erinnerung. Eine neue Russische Idee für Rußland? In: Osteuropa. Zeitschrift für Gegenwartsfragen des Ostens 54/8 (2004), 27-42.

83 Die Begriffe sind pro Textseite im Programm 2000-2005 durchschnittlich mehr als zehn Mal vertreten.

84 Vgl. Bizeul, Yves: Nationalismus, Patriotismus und Loyalität zur offenen Republik. In: Aus Politik und Zeitgeschichte 1-2 (2007), $30 \mathrm{ff}$.

85 Vgl. Koselleck, Reinhart: Begriffsgeschichten. Frankfurt a. M. 2006, 238.

86 Vgl. Becker, Julia/ Wagner, Ulrich/Christ, Oliver: Nationalismus und Patriotismus als Ursache von Fremdenfeindlichkeit. In: Heitmeyer, Wilhelm (Hg.): Deutsche Zustände. Folge 5. Frankfurt a. M. 2007, 131-149. 
Wesentlich aufschlussreicher ist für die Bestimmung des zugrunde liegenden Begriffs ein Konzept der Regierung zur Patriotischen Erziehung aus dem Jahr 2003, ${ }^{87}$ das im Rahmen des ersten Programms erarbeitet wurde und die offizielle Position zu den behandelten Fragen wiedergibt.

In der Einführung wird lediglich die Funktion von Patriotismus in der Patriotischen Erziehung "als Impuls zur geistigen Gesundung des Volkes « ${ }^{88}$ und zur Entstehung einer Bürgergesellschaft angerissen. Weitere Ausführungen fehlen an dieser Stelle, sodass zunächst offenbleibt, auf welches `Krankheitsbild sich die Gesundung beziehen soll.

Im folgenden Abschnitt über das Verhältnis von Patriotismus und Patriotischer Erziehung wird genauer bestimmt, was im Rahmen des Programms zur Patriotischen Erziehung der Bürger unter Patriotismus zu verstehen ist.

»Patriotismus - das ist die Liebe zur Heimat, die Ergebenheit gegenüber dem Vaterland und das Streben, seinen Interessen und seinem Schutz bis zur Selbstaufopferung zu dienen. $\ll^{89}$

Auf der Ebene des Individuums wird angenommen, dass Patriotismus eine "stabile Charaktereigenschaft eines Menschen darstellt, die sich in seiner Weltsicht, seinen moralischen Idealen und Verhaltensnormen widerspiegelt. ${ }^{90}$ Auf einer übergreifenden Ebene wird Patriotismus als ein Teil des öffentlichen Bewusstseins beschrieben, der in "kollektiven Stimmungen und Einstellungen in Bezug auf Volk, Lebensweise, Geschichte, Kultur, den Staat und das grundlegende Wertesystem $"{ }^{91}$ zum Ausdruck kommt.

Abgesehen von diesen nicht weiter erläuterten Ausführungen und der Definition als `Liebe zur Heimat<, wird Patriotismus in diesem Konzept nahezu ausschließlich in seiner Bedeutung für Staat und Gesellschaft oder in seiner Bedeutung für das Verhältnis zwischen dem Bürger auf der einen und Staat und Gesellschaft auf der anderen Seite beschrieben. Die Bedeutung für den Staat wird primär als ein mobilisierender Aspekt beschrieben:

»Patriotismus ist eine moralische Grundlage der Lebensfähigkeit eines Staates und repräsentiert eine wichtige Ressource der inneren Mobilisierung zur Entwicklung der Gesellschaft, der aktiven bürgergesellschaftlichen Position einer Person und ihrer Bereitschaft, selbstlos dem Vaterland zu dienen. ${ }^{92}$

Patriotismus wird in dieser Sichtweise als ein bei den Bürgern vorhandener oder zu stimulierender Ansatzpunkt betrachtet, der eine Aktivierung der

87 Konzeption 2003.

88 Ebd., 2.

89 Ebd., 2.

90 Ebd., 3.

91 Ebd., 3.

92 Ebd., 3. 
Bürger für staatliche Interessen ermöglicht. Als eine weitere Funktion wird er als konsolidierende Grundlage von Nation und Staatlichkeit beschrieben. ${ }^{93}$

Besonders ausführlich geht das Konzept auf die Bedeutung des Patriotismus für das Verhältnis zwischen Bürger und Staat ein. In diesem Zusammenhang wird mehrfach auf die »Bereitschaft zum Dienst am Vaterland $\aleph^{94}$ hingewiesen, die maßgeblich aus dem Patriotismus gespeist werde, und darüber hinaus auf weitere staatliche Interessen, deren Wahrung von patriotischen Gefühlen begünstigt werde:

»Patriotismus - das ist eine besondere Ausrichtung der Selbstverwirklichung und des sozialen Verhaltens der Bürger, deren Kriterien die Liebe und der Dienst am Vaterland, die Sicherstellung der staatlichen Integrität und der Souveränität Russlands, die Sicherheit des Staates, seine nach haltige Entwicklung, Pflicht und die Verantwortung, die Annahme der Priorität von öffentlichen und staatlichen Ansätzen über individuelle Interessen sind [...].. ${ }^{95}$

Die gerade zitierte Annahme einer Priorität von öffentlichen Ansätzen gegenüber Individualinteressen wird noch an weiteren Stellen ausgeführt und wird so zu einem Kernstück der Bestimmung des Patriotismus im Verhältnis zwischen Bürger und Staat: Staatliche und gesellschaftliche Priorität sollen nicht als Einschränkung, sondern als Stimulus von individueller Freiheit und als Voraussetzung der Bürgergesellschaft betrachtet werden. ${ }^{96}$

Damit greift das Konzeptpapier auf eine etablierte Deutung des Patriotismus-Begriffs zurück, die sich als >republikanisch definieren lässt. ${ }^{97}$ Patriotismus lässt sich hiernach in der bürgerlich aufgeklärten Tradition als ein sozialpolitisches Verhalten interpretieren, das das Allgemeinwohl über Individualinteressen stellt und sich auf das Vaterland oder als Teil des modernen Nationalbewusstseins auf die Nation bezieht. ${ }^{98}$

Darüber hinaus bleibt das Konzept insgesamt in seiner Charakterisierung von Patriotismus auffallend diffus. Der Schwerpunkt liegt deutlich auf der Bestimmung des Verhältnisses zwischen Individuum und Staat. Patriotismus wird hier als Hilfsmittel beschrieben, welches es dem Individuum ermögliche, die Priorität des Staates gegenüber seinen Interessen nicht nur zu tolerieren, sondern auch als notwendig und sinnvoll zu akzeptieren.

93 Vgl. ebd., 3.

94 Ebd., 3.

95 Ebd., 3.

96 Vgl. ebd., 3.

97 Vgl. Bizeul, Yves: Nationalismus, Patriotismus und Loyalität zur offenen Republik. In: Aus Politik und Zeitgeschichte 1-2 (2007), 35.

98 Vgl. Dann, Otto: Nation und Nationalismus in Deutschland. 1770-1990. 2. Aufl. München 1994, 16. 
Neben diesen Ausführungen fallen in diesem Teil des Konzepts besonders zwei Bereiche auf, die auf sehr traditionsreiche Diskurse verweisen: Zum einen wird in einem Abschnitt, in dem es um eine Abgrenzung des PatriotismusBegriff geht, darauf hingewiesen, dass Patriotismus und Kosmopolitismus unvereinbar seien:

»Der Patriotismus ist unzertrennlich mit dem Internationalismus verbunden - Nationalismus, Separatismus und Kosmopolitismus sind ihm fremd. ${ }^{99}$

Diese Gegenüberstellung, insbesondere von Internationalismus und Kosmopolitismus, knüpft an Diskurse aus verschiedenen Epochen der sowjetischen Geschichte an. So ist die zitierte Gegenüberstellung von >gutem` Patriotismus und Internationalismus auf der einen sowie Kosmopolitismus auf der anderen Seite Teil des Eintrags über Internationalismus in der >Großen Sowjetischen Enzyklopädie`: »Internationalismus stimmt mit dem sozialistischen Patriotismus überein. Er ist das Gegenteil des Kosmopolitismus. ${ }^{100}$ Auch die antisemitischen Kampagnen unter Stalin wurden offiziell unter dem Begriff »Kampf gegen das Kosmopolitentum« bzw. »den wurzellosen Kosmopolitismus« geführt. ${ }^{101}$

In einem Konzept der Regierung der Russländischen Föderation des Jahres 2003 wirkt die nicht weiter erläuterte Reaktivierung dieses ideologisch stark aufgeladenen und historisch vieldeutigen Diskurses merkwürdig deplatziert und anachronistisch.

Eine Erklärung für diese Reaktivierung des Begriffes Kosmopolitismus könnte in einem Aspekt seiner Bedeutung liegen: In sowjetischer Lesart negiert der Kosmopolitismus als reaktionär-bourgeoise Ideologie die staatliche und nationale Souveränität. ${ }^{102}$ Der Staat als souveräner und vor Einmischung in innere Angelegenheiten geschützter Akteur in den internationalen Beziehungen ist eines der konstanten Ziele russländischer Außenpolitik. Das Bekenntnis zum Internationalismus und die Absage an den Kosmopolitismus ließen sich in dieser Perspektive als Entscheidung gegen Ordnungssysteme und Beziehungsstrukturen jenseits von nationalstaatlicher Souveränität und Organisation interpretieren.

Dagegen zieht sich die Verbindung von Patriotismus und Internationalismus, ganz in sowjetpatriotischer Tradition, durch viele Texte der Patriotischen

99 Konzeption 2003, 3.

100 Kaltachčjan, Suren Tigranovič: Internacionalizm. In: Bol’šaja sovetskaja ènciklopedija (BSĖ). 3. Auflage. Moskau 1969-1978.

101 Vgl. Grüner, Frank: Patrioten und Kosmopoliten: Juden im Sowjetstaat 1941-1953. Köln 2008, 510.

102 Vgl. Modržinskaja, Elena Dmitrievna: Kosmopolitizm. Bol’šaja sovetskaja ènciklopedija (BSĖ ). In: Große Sowjetische Enzyklopädie. 3. Auflage. Moskau 1969-1978. 
Erziehung. ${ }^{103}$ Sie wird lediglich modifiziert: Der Patriotismus soll sich auf den Gesamtstaat richten, während ein nach innen gerichteter, sinnerer Internationalismus` das Zusammenleben unterschiedlicher kultureller und geschichtlicher Prägung regeln soll.

Der zweite Bereich, der diskursgeschichtlich deutlich über das Konzept hinausweist, definiert Patriotismus als eine Eigenschaft des >nationalen Charakters.く Dem russländischen Patriotismus werden anschließend besondere Eigenschaften zugewiesen, die ihn vom Patriotismus anderer Länder unterscheiden würden:

»Der Patriotismus ist einer der positivsten Züge des russländischen nationalen Charakters. Ihm sind einige Besonderheiten zu eigen: Diese sind vor allem die humanistische Ausrichtung der russländischen patriotischen Idee, die Glaubensfreiheit; der Kollektivgeist [Sobornost'] und der Gesetzesgehorsam; der Gemeinsinn [Obščnost'] als eine dauerhafte Neigung, das Bedürfnis der Russen nach dem kollektiven Leben sowie die besondere Liebe zur Natur. ${ }^{104}$

Einige dieser `Charaktereigenschaften` haben ihren Ursprung in aktuellen Kampagnen und sozialen Initiativen. Begriffe wie Sobornost' oder Obščnost' verweisen jedoch unmissverständlich auf Diskurse zur »russischen Idee« auch wenn der Text den Begriff vermeidet und stattdessen von der russländisch-patriotischen Idee spricht. Die Russische Idee funktioniert in diesem Zusammenhang weniger inhaltlich, sondern mehr als ein unspezifischer Verweis. Lediglich ein Strang dieses komplexen Themas, der Diskurs über die Besonderheit, die kulturelle Einzigartigkeit, wird isoliert zitiert. Hier geht es nicht um die Kontroversen zwischen Nikolaj Gogol' und Vissarion Belinskij oder Aleksandr Solženicyn und Andrej Sacharov. ${ }^{105}$ Auch Ansätze, dass die Russische Idee das Bemühen darstelle, die europäischen Widersprüche in sich zu versöhnen, wie sie Fëdor Dostoevskij 1880 in seiner Puškin-Rede erklärte ${ }^{106}$ sind hier nicht gemeint. Die >Russische Idee` in der Konzeption zur Patriotischen Erziehung der Bürger hat lediglich die Funktion, Differenz nach außen zu konstruieren. Wie schon in den Diskursen Ende der 1980er und bis zur Mitte der 1990er Jahre, geht es im Zusammenhang mit der Russischen Idee weniger um eine intensive Beschäftigung mit konkreten Positionen: Im Zentrum steht eine Identitätsbildung, deren Kern vor allem mythisch strukturiert

103 Zur Koexistenz von Sowjetpatriotismus und proletarischem Internationalismus in der sowjetischen Theorie vgl. Oberländer, Erwin: Sowjetpatriotismus und Geschichte. Dokumentation. Köln 1967, 25 ff.

104 Konzeption 2003, 3.

105 Vgl. Scherrer, Jutta: Ideologie, Identität und Erinnerung. Eine neue Russische Idee für Rußland? In: Osteuropa. Zeitschrift für Gegenwartsfragen des Ostens 54/8 (2004), 31.

106 Ivantsov, Dmitrij: Ideengeschichtliche Entwicklungslinien der `Russischen Ideer. In: Russland - Deutschland - Europa. Ost-West-Wissenschaftsforum. Münster 2004, 33 ff. 
ist und die »Sicherheit und Geborgenheit in einem absoluten, harmonischen, ewigen und universalen Ganzen verbürgt. « ${ }^{107}$

Vieles an der Verwendung des Patriotismus-Begriffs in der Patriotischen Erziehung hat einen diffusen und inkonsistenten Charakter. Schlüssiger wird das Bild erst, wenn man Patriotismus primär als eine Konzeption des Verhältnisses zwischen Staat und Individuum betrachtet. Patriotismus, als auszubildende Charaktereigenschaft, befähigt den Bürger, die Legitimität - das Gelten-Sollen - der staatlichen Ordnung zu erkennen.

Bringt man die unbestimmte Verwendung des Patriotismus-Begriffs mit dem Fehlen des Begriffes der Identität zusammen, erschließt sich eine weitere Perspektive auf die Funktion des Begriffs: Der diffuse Patriotismus lässt sich als ein Substitut für Identität betrachten. Ein Identitätsbegriff muss seine Beschaffenheit zumindest grob umreißen, damit das adressierte Individuum eine Selbstzuschreibung zu dieser kollektiven Identität vornehmen kann. Patriotismus schafft in seiner Diffusion den Kunstgriff, sich in seiner positiven Bezugnahme nicht festlegen zu müssen. Entscheidend ist die affirmative Haltung des Einzelnen dem Staat gegenüber. Ob die Grundlage dieses Patriotismus das Verständnis und die Achtung gegenüber der über 1000-jährigen russländischen Geschichte allgemein ist, der Stolz auf den Sieg im Großen Vaterländischen Krieg, auf die technischen oder sportlichen Erfolge der Sowjetunion oder der Glanz des russischen Imperiums, ist dabei zweitrangig. In dieser Lesart stellt Patriotismus eine weite Klammer dar, um verschiedenste Zuschreibungen zusammenzuführen, zu bündeln und in ihrer affirmativ-legitimatorischen Wirkung auf den Staat und die Macht auszurichten.

So wie der militärische Ruhm in allen Zeiten eine übergreifende Klammer darstellt, mit der Brüche und innere Konflikte überblendet werden können, so stellt der Patriotismus in dieser Lesart ein Instrument dar, das das Konfliktpotenzial von nationaler Identität in einem multi-ethnischen und multikonfessionellen Staat umgehen soll.

\subsection{Neugestaltung der Feiertage}

Staatliche Feste gehören zu den wichtigsten Eckpunkten der symbolischen Ordnung eines Staates: An ihnen lässt sich ablesen, welche Werte und Normen kommuniziert werden sollen. ${ }^{108}$ Bei den Festen, die sich auf die Vergangenheit

107 Sieber, Bettina: `Russische Idee` und Identität. >Philosophisches Erbe` und Selbstthematisierung der Russen in der öffentlichen Diskussion 1985-1995. Bochum 1998, 382.

108 Vgl. de Keghel, Isabelle: Verordneter Abschied von der revolutionären Tradition. Der `Tag der nationalen Einheit in der Russländischen Föderation. In: Karl, Lars / Polianski, Igor J. (Hg.): Geschichtspolitik und Erinnerungskultur im neuen Russland. Göttingen 2009, 119. 
beziehen, wird von staatlicher Seite aus Jahr für Jahr aktualisiert, woran erinnert werden soll und warum. Das `Woran ergibt sich in der Regel aus dem Namen und dem Datum. Das 'Warum`, d.h. welche Bedeutung das Fest oder der Gedenktag für die Gegenwart haben, wird durch begleitende Erläuterungen und die performative Ausgestaltung kommuniziert. Andersherum lässt sich an der Rezeption der Feste ablesen, inwieweit individuelle und kollektive, staatlich propagierte Erinnerungswerte konvergieren. ${ }^{109}$

Der Festkalender der Russländischen Föderation umfasst heute rund 120 Einträge. ${ }^{110}$ Die Bekanntheit und auch die Popularität der verschiedenen Feste unterscheiden sich jedoch deutlich. Auch weist nur ein Teil der Feste ${ }^{111}$ einen direkten historischen Bezug auf. Bei den meisten handelt es sich um Feste verschiedener Berufsgruppen. Darunter gibt es neuere wie z. B. den Tag des Russischen Unternehmers ${ }^{112}$ oder den Tag des Programmierers, ${ }^{113}$ aber auch ältere wie den Tag des Fischers ${ }^{114}$ oder den Tag des Kinos ${ }^{115}$.

Bei einigen Festen ist der erinnerungspolitische Vergangenheitsbezug nicht eindeutig. So kann beispielsweise der Frauentag heute sowohl als entpolitisiert betrachtet werden als auch als Tag, dem durch seine frühere Bedeutung in der Sowjetunion auch heute noch erinnerungspolitisches Potenzial innewohnt. Der Tag der Kosmonauten ${ }^{116}$ hingegen gehört der Form nach eigentlich zu

109 Vgl. Knoll, Joachim: `Heil dir im Siegerkranz« Nationale Feier- und Gedenktage als Formen kollektiver Identifikation. In: Zeitschrift für Religions- und Geistesgeschichte. 57/2 (2005), $151 \mathrm{ff}$.

110 Bogatyrenko, Zacharij: Kalendar' prazdničnych dnej, professional'nych prazdnikov, dnej voinskoj slavy i pamjatnych dat (dnej), otmečaemych na federal'nom urovne v Rossijskoj Federacii v 2012 godu. In : Rossiskaja Gazeta. 30.12.2011, Online: http://www. rg.ru/2011/12/30/prazdniki-site.html.

111 Je nach Definition weisen ungefähr 35 der knapp 120 Feste und damit rund 30 Prozent einen direkten historischen Bezug auf.

112 Am 26. Mai. Eingeführt durch: Ukaz Prezidenta RF ot 18.10.2007 N $1381 »$ O Dne rossijskogo predprinimatel'stva«.

113 Am 12. September. Eingeführt durch: Ukaz Prezidenta RF ot 11.09.2009 N $1034 » O$ dne programmista «.

114 Am 8. Juli. Eingeführt durch: Ukaz Prezidiuma Verchovnogo Soveta SSSR ot 01.10.1980 N 3018-Ch »O prazdničnych i pamjatnych dnjach« (v red. Ukaza Prezidiuma Verchovnogo Soveta SSSR ot 01.11.1988 N 9724-XI »O vnesenii izmenenij v zakonodatel'stvo SSSR o prazdničnych i pamjatnych dnjach «).

115 Am 28.August. Eingeführt durch: Ukaz Prezidiuma Verchovnogo Soveta SSSR ot 01.10.1980 N 3018-Ch »O prazdničnych i pamjatnych dnjach (v red. Ukaza Prezidiuma Verchovnogo Soveta SSSR ot 01.11.1988 N 9724-XI »O vnesenii izmenenij v zakonodatel'stvo SSSR o prazdničnych i pamjatnych dnjach«).

116 Am 12. April. Eingeführt durch: Federal'nyj zakon ot 13.03.1995 N 32-FZ »O dnjach voinskoj slavy i pamjatnych datach Rossii« (v red. Federal'nogo zakona ot 21.07.2005 N $98-\mathrm{FZ} » \mathrm{O}$ vnesenii izmenenij v Federal'nyj zakon »O dnjach voinskoj slavy (pobednych dnjach) Rossii $)$. 
den Festen der Berufsgruppen, sticht aber zum einen durch seine prominente rechtliche Verankerung als Tag des Gedenkens ${ }^{117}$ sowie zum anderen durch seine aufwendige und geschichtsbezogene Ausgestaltung hervor und lässt sich deshalb klar als erinnerungspolitisches Fest bestimmen.

Die Festtage der Russländischen Föderation sind in sehr unterschiedlichen Rechtsquellen niedergelegt, wie z.B. in Dekreten des Präsidenten, Dekreten des Präsidiums des Obersten Sowjets oder in föderalen Gesetzen. Als die wichtigsten Rechtsquellen sind zu nennen: Das Arbeitsgesetz Paragraph 112, ${ }^{118}$ in dem die arbeitsfreien Tage festgelegt sind, das Dekret über die Einrichtung von Berufsfeiertagen in den Streitkräften der Russländischen Föderation vom 31. Mai $2006^{119}$ sowie das $>$ Gesetz über die Tage des militärischen Ruhmes und Gedenktage Russlands ${ }^{120}$ Sowohl die Veränderungen am Gesetz über die Tage des militärischen Ruhmes als auch das Dekret über die militärischen Berufsfeiertage lassen sich direkt dem Programm zur Patriotischen Erziehung der Bürger zuordnen. Sie sind Gegenstand der in den ersten beiden Programmen festgeschriebenen Strategie zur >Schaffung einer normativ rechtlichen Basis ${ }^{121}$

Allerdings ist das Dekret über die militärischen Berufsfeiertage in erinnerungspolitischer Perspektive wenig ergiebig, da es nur mittelbar auf die Vergangenheit verweist: Es ist Teil der Strategie des Programms, das Ansehen der Streitkräfte zu steigern und so die Identifikation der Bürger mit dem Staat sowie die allgemeine Verteidigungsbereitschaft zu verbessern. Außer dem Hinweis in der Präambel des Dekrets, die abstrakt eine Wiedergeburt von vaterländischen militärischen Traditionen fordert, finden sich keine Bezüge auf Vergangenes. Das Dekret ist also primär gegenwartsbezogen. Es führt lediglich bestehende militärische Berufsfeiertage, wie z. B. den Tag des Panzerfahrers ${ }^{122}$, der erstmals 1946 begangen wurde und seit 1980 am 9. September begangen wird, oder den Tag der Raketentruppen und der Artillerie am 19. November $^{123}$, in einer einheitlichen Rechtsgrundlage zusammen und erweitert die

117 Federal'nyj zakon ot 13 marta 1995 g. N 32-FZ »O dnjach voinskoj slavy i pamjatnych datach Rossii«

118 Stat'ja 112 Trudovogo kodeksa RF (v red. Federal'nogo zakona ot 29.12.2004 N 201-FZ »O vnesenii izmenenij v stat'ju 112 Trudovogo kodeksa Rossijskoj Federacii«.

119 Ukaz Prezidenta RF ot 31.05.2006 N 549 »Ob ustanovlenii professional'nych prazdnikov i pamjatnych dnej v Vooružennych Silach Rossijskoj Federacii«.

120 Federal'nyj zakon ot 13 marta $1995 \mathrm{~g}$. N 32-FZ O dnjach voinskoj slavy i pamjatnych datach Rossii

121 Vgl. Programm 2001: Teil IV.1.

122 Ukaz Prezidenta RF ot 31.05.2006 N 549 »Ob ustanovlenii professional'nych prazdnikov i pamjatnych dnej v Vooružennych Silach Rossijskoj Federacii«.

123 Den' Raketnych vojsk i artillerii. Ukaz Prezidenta RF ot 31.05.2006 N 549 »Ob ustanovlenii professional'nych prazdnikov i pamjatnych dnej v Vooružennych Silach Rossijskoj 
Liste erheblich durch weitere Festtage wie z.B. den Tag des Spezialisten der elektronischen Kampfführung. ${ }^{124}$ Durch zusätzliche Dekrete wurden zudem weitere Festtage eingerichtet, die nicht den Streitkräften zuzuordnen, aber dennoch Teil des Programms zur Patriotischen Erziehung sind, wie der Tag des Mitarbeiters des Strafvollzuges. ${ }^{125}$

\subsubsection{Tage des militärischen Ruhmes}

Im Hinblick auf Geschichtspolitik ist das 1995 von Boris El'cin unterzeichnete Gesetz über die Tage des militärischen Ruhmes ergiebiger. ${ }^{126}$ Dieses Gesetz belebt eine alte Tradition wieder: Bis zur Oktoberrevolution 1917 wurden im Russischen Reich die sogenannten Siegestage (Viktorial'nye dni) ${ }^{127}$ gefeiert, als Erinnerung an die Siege, Schlachten und Friedensschlüsse. Seit Pëtr I. wurden an einer ganzen Reihe von Jahrestagen in den Kirchen Dankesgebete abgehalten. 1862 wurde diese Praxis wieder reduziert. Einige Tage wie z.B. die Schlacht von Poltawa 1709 oder Borodino 1812 blieben erhalten. Die Tage waren teilweise in Gebetsbüchern und darüber hinaus in verschiedenen Kirchenkalendern abgedruckt. Das Gesetz über die Tage des militärischen Ruhmes greift die wichtigsten dieser Tage wieder auf.

Die Präambel des Gesetzes ist zunächst ein Hinweis auf die Kontinuität in der postsowjetischen, russländischen Erinnerungspolitik: Schon die ursprüngliche von Boris El'cin 1995 unterschriebene Fassung gibt in ihren Formulierungen den Stil des späteren Programms zur Patriotischen Erziehung der Bürger vor. Die Betonung von militärischer Größe und soldatischem Heldentum ist bereits in diesen Texten deutlich ausgeprägt und nicht etwa ein erst in den 2000er Jahren neu etabliertes Narrativ:

»In allen Jahrhunderten waren das Heldentum und der Mut der Kämpfer Russlands sowie die Macht und der Ruhm der russischen Waffen untrennbarer Bestandteil der Größe des russländischen Staates. [...] Die Tage des Ruhmes Russlands sind Tage

Federacii ». Bei diesem Tag besteht Verwechslungsgefahr mit dem Tag der Strategischen Raketentruppen am 17. Dezember.

124 Ukaz Prezidenta RF ot 31.05.2006 N 549 »Ob ustanovlenii professional'nych prazdnikov i pamjatnych dnej v Vooružennych Silach Rossijskoj Federacii«.

125 Am 12. März. Eingeführt durch: Ukaz Prezidenta RF ot 16.11.2010 N 1433 »O Dne rabotnika ugolovno-ispolnitel'noj sistemy«.

126 Federal'nyj zakon ot 13 marta 1995 g. N 32-FZ »O dnjach voinskoj slavy i pamjatnych datach Rossii«.

127 Lukaševič, A.: Viktorial'nye dni. Eintrag in: Kirill I. (Hg.): Orthodoxe Enzyklopädie. Online: http://www.pravenc.ru/text/158568.html. Die in der Enzyklopädie erwähnten Ereignisse sind u. a. die Schlacht von Poltawa 1709, die Einnahme von Narva, die Schlachten von Gangut und Çeşme sowie verschiedene Friedensschlüsse. 
der ruhmreichen Siege, welche eine entscheidende Rolle in der Geschichte Russlands gespielt haben und in denen sich die russländischen Truppen den Respekt und die Achtung der Zeitgenossen sowie dankbares Andenken der Nachkommen erworben haben." 128

Im Anschluss an die Präambel legt das Gesetz in der Fassung von 1995 im ersten Artikel 15 Tage des militärischen Ruhmes fest. ${ }^{129}$ Beginnend bei Aleksandr Nevskijs Sieg in der Schlacht auf dem Peipussee 1242, Dmitrij Donskojs Sieg in der Schlacht auf dem Kulikowo Pole 1380 und der Befreiung Moskaus durch das Volksheer unter Minin und Požarskij 1612 werden die bekanntesten Daten der Kriegsgeschichte bedient. Der Große Nordische Krieg wird mit zwei Daten berücksichtigt, dem Sieg in der Schlacht bei Poltawa 1709 sowie dem Sieg in der Seeschlacht bei Kap Gangut 1714. Für den russisch-österreichischen Türkenkrieg (1787-1792) stehen mit der Einnahme der Festung Ismail und dem Sieg der Flotte bei Kap Tendra (jeweils 1790) wiederum ein Sieg der Landstreitkräfte und ein Sieg der Seestreitkräfte. Für den Vaterländischen Krieg steht die Schlacht von Borodino (1812), für den Krimkrieg der Sieg der Flotte bei Sinop (1853) und in Bezug auf den Ersten Weltkrieg wird der 23. Februar als der Tag des Sieges über die kaiserlichen Truppen Deutschlands festgeschrieben (1918).

128 Federal'nyj zakon ot 13.03.1995 N 32-FZ Zakon »O dnjax voinskoj slavy Rossii«.

129 18. April - Tag des Sieges der russischen Truppen des Fürsten Aleksandr Nevskijs über die deutschen Ritter in der Schlacht auf dem Peipussee (Eisschlacht 1242); 21. September - Tag des Sieges der russischen Regimenter unter der Führung des Großfürsten Dmitrij Donskoj über die mongolisch-tatarischen Truppen in der Schlacht von Kulikovo (1380); 7. November - Tag der Befreiung Moskaus durch die Kräfte des Volksheeres unter Kuz’ma Minin und Dmitrij Požarskij von den polnischen Besatzern (1612); 10. Juli - Tag des Sieges der russischen Armee unter dem Kommando Peters I. über die Schweden in der Schlacht von Poltawa (1709); 9. August - Tag des ersten Sieges der russischen Flotte in der Geschichte unter dem Kommando Peters I. über die Schweden beim Kap Gangut (1714); 24. Dezember - Tag der Einnahme der türkischen Festung Ismail durch die russischen Truppen unter dem Kommando von A. W. Suvorov (1790); 11. September - Tag des Sieges der russischen Flotte unter dem Kommando von F. F. Ušakov über die türkische Flotte bei Kap Tendra (1790). Der Feiertag für die Schlacht am 8. und 9. September 1790 wurde möglicherweise wegen des Datums der Schlacht von Borodino auf den 11. September gelegt; 8. September - Tag der Schlacht von Borodino zwischen der russischen Armee unter dem Kommando M.I. Kutuzovs und der französischen Armee (1812); 1. Dezember - Tag des Sieges der russischen Flotte unter dem Kommando P. S. Nachimovs über die türkische Flotte bei Sinop (1853); 23. Februar - Tag des Sieges der Roten Armee über die kaiserlichen Truppen Deutschlands (1918) - Tag der Verteidiger des Vaterlandes; 5. Dezember - Beginn der Gegenoffensive der sowjetischen Truppen gegen die faschistischen Truppen in der Schlacht bei Moskau (1941); 2. Februar - Tag der Zerschlagung der faschistischen Truppen durch die sowjetischen Truppen in der Schlacht von Stalingrad (1943); 23. August - Tag der Zerschlagung der faschistischen Truppen durch die sowjetischen Truppen in der Schlacht bei Kursk (1943).

27. Januar - Tag der Aufhebung der Blockade der Stadt Leningrad (1944); 9. Mai - Tag des Sieges des sowjetischen Volkes im Großen Vaterländischen Krieg 1941-1945 (1945). 
Die fünf übrigen Tage des militärischen Ruhmes beziehen sich alle auf den Großen Vaterländischen Krieg. Sie sind den Schlachten um Moskau (1941), Stalingrad (1943) und Kursk (1943) sowie dem Ende der Blockade von Leningrad (1944) und dem Tag des Sieges, dem 9. Mai 1945 gewidmet.

Neben der Parallelität der Berücksichtigung von Siegen der See- und Landstreitkräfte in zwei Kriegen fällt besonders die deutliche Gewichtung des Großen Vaterländischen Krieges mit einem Drittel der Gedenktage auf. Daran lässt sich bereits deutlich die gezielte Reintegration des Großen Vaterländischen Krieges in die russländische Geschichtspolitik unter Boris El'cin in der Mitte der 1990er Jahre ablesen, die mit der Eröffnung des Parks des Sieges in Moskau ebenfalls im Jahr 1995 ein augenfälliges Beispiel erfuhr.

Der Entstehungskontext des Gesetzes zeigt, dass es sich hier nicht um eine Konzession des Präsidenten an seine politischen Gegner handelte: Das Gesetz wurde ursprünglich vom Komitee für Geopolitik unter dem Vorsitzenden Viktor Ustinov (LDPR) in die Duma eingebracht und in erster Lesung angenommen. El'cin fügte anschließend vor der Wiedervorlage die entscheidende Veränderungen ein: Der Ursprüngliche Entwurf hatte in Bezug auf den Großen Vaterländischen Krieg lediglich den Tag des Sieges berücksichtigt. El'cin fügte als weitere Tage des militärischen Ruhmes die Schlachten von Moskau, Stalingrad und Kursk sowie die Aufhebung der Blockade von Leningrad ein. ${ }^{130}$ Durch diese Ergänzungen wies das Gesetz dann deutlich über die militärischen Ruhmestraditionen des Russländischen Imperiums hinaus. Eine Marginalisierung der erinnerungspolitischen Bezüge auf die Zeit der Sowjetunion, wie sie noch in der Frühphase der Identitätsfindung der Russländischen Föderation unter Boris El'cin intendiert war, ${ }^{131}$ lässt sich in der ersten Fassung des Gesetzes über die Tage des militärischen Ruhmes vom 13. März 1995 bereits nicht mehr feststellen.

Einen wichtigen Grund für die Etablierung dieses auf militärische Traditionen rekurrierenden Gedenkkalenders dürfte der Tschetschenienkrieg darstellen, der ein Vierteljahr vor Inkrafttreten des Gesetzes im Dezember 1994 begann. In dieser Lesart stellt das Gesetz den Versuch dar, legitimatorische Ressourcen für den Krieg zu mobilisieren, indem »Respekt und Achtung der Zeitgenossen« für die Streitkräfte gefördert werden. Die wiederkehrende parallele Berücksichtigung von Land- und Seeschlachten ließe sich in dieser Perspektive als Strategie deuten, die Anschlussfähigkeit der Tage für die Feierpraxis der Waffengattungen zu konkretisieren und zu verbessern.

130 Vgl. Cechmistrenko, Sergej: Slavu bol’ševikov razdelili Minin i Požarskij. In: Kommersant«. Nr. 25 vom 11.02.1995. Online: http://www.kommersant.ru/doc/101901.

131 de Keghel, Isabelle: Die Staatssymbolik des neuen Russland. Traditionen - Integrationsstrategien - Identitätsdiskurse. Münster 2008, 27 ff. 
Im zweiten Artikel werden $» F o r m e n$ der Verewigung des Andenkens an die Kämpfer Russlands « ${ }^{132}$ beschrieben. Dazu gehören zum einen der Erhalt oder die Einrichtung von Museen, Denkmälern und historischen Bauten, die mit den Feiertagen verbunden sind. Zum anderen sollen zur Verstetigung des Andenkens aber auch Ausstellungen durchgeführt sowie Materialien zu den Tagen in den Massenmedien publiziert werden. ${ }^{133}$ Anschließend wird festgeschrieben, dass die Regierung Pläne und Programme zur Verwirklichung entwickelt.

Insgesamt liest sich die erste Fassung des Gesetzes von 1995 wie eine Vorlage für das sechs Jahre später initialisierte Programm zur Patriotischen Erziehung der Bürger. Dies gilt für den sprachlichen Stil, die erinnerungspolitischen Intentionen, aber auch für die festgelegten Ausführungsbestimmungen. Der entscheidende Unterschied liegt jedoch im geringeren Umfang, der beschränkten Reichweite und der Art und Höhe der finanziellen Ausstattung.

Schon der Änderungsverlauf des »Gesetzes über die Tage des militärischen Ruhmes« gibt einen Hinweis darauf, dass dieses Gesetz eine zentrale Rolle in der Erinnerungspolitik der Präsidentschaften Vladimir Putins einnimmt: Während das Gesetz zwischen den Jahren 1995 und 2004 unverändert blieb, wurden in den folgenden acht Jahren dreizehn Änderungen und Ergänzungen vorgenommen, die ausnahmslos den im Programm formulierten Zielen entsprechen.

Die Überarbeitung des Gesetzes war als einer der zentralen Punkte im Bereich der $>$ Schaffung einer normativ rechtlichen Basis ${ }^{134}$ in der ersten Auflage des Programms zur Patriotischen Erziehung der Bürger 2001 festgeschrieben. In den Programmen von 2001 und 2006 wurden im Bereich slegislative Grundlagen und Rechtsakte zur patriotischen Erziehung ${ }^{135}$ ebenfalls entsprechende Gesetzesinitiativen festgeschrieben. Das Programm von 2011 bezog sich nochmals auf die Tage des militärischen Ruhmes. Jedoch wurden hier nur noch Förderprogramme festgeschrieben, um diese Tage durch Maßnahmen wie Filmproduktionen bekannter zu machen.

132 Federal'nyj zakon ot 13 marta $1995 \mathrm{~g}$. N 32-FZ »O dnjach voinskoj slavy i pamjatnych datach Rossii«.

133 Vgl. ebd.

134 Vgl. Programm 2001. Teil IV.1.

135 Programm 2001. Teil IV.1 und Anlage; Programm 2006. Anlage II.1; Programm 2011. Anlage II. 27. 


\subsubsection{Reform der Novemberfeiertage}

Die erste Überarbeitung des Gesetzes über die "Tage des militärischen Ruhmes (Siegestage) « ${ }^{136} \mathrm{im}$ Jahr 2004 richtete sich primär auf die Neuordnung der Novemberfeiertage: ${ }^{137}$ Der 7. November - Datum der »Großen Sozialistischen Oktoberrevolution " - wurde neu strukturiert und am 4. November der Tag der Einheit des Volkes als arbeitsfreier Tag eingeführt. Beide Daten haben eine lange Festtradition und sind eng mit den Umbrüchen in der jüngeren russischen Geschichte verbunden.

Seit dem Jahr 1918 wurde am 7. November der Tag der Sozialistischen Oktoberrevolution gefeiert. ${ }^{138}$ Dieser Tag entwickelte sich zu einem der wichtigsten Festtage, der mit Demonstrationen und Militärparaden gefeiert wurde. ${ }^{139}$ Eine zusätzliche Bedeutung bekam der Tag im ersten Jahr des Großen Vaterländischen Krieges. Obwohl die deutschen Streitkräfte bereits nah an Moskau herangerückt waren und die Gefahr von Luftangriffen bestand, wurde am 7. November 1941 die Parade auf dem Roten Platz in Moskau abgehalten und von Iosif Stalin abgenommen. Die Durchführung der Parade unter diesen Umständen wurde in der Sowjetunion genauso wie bei den Verbündeten als Demonstration des Widerstandswillens wahrgenommen. Unabhängig von der Frage, ob diese Parade tatsächlich eine entscheidende Rolle für die Motivation und die Kampfmoral der Roten Armee gespielt hat und damit entscheidend für die Schlacht um Moskau war, lässt sie sich als weltweit wahrgenommener Propagandaerfolg bezeichnen. Bis heute wird das Narrativ der Parade, als Manifestation des Widerstandswillens, in allen Schulbüchern berücksichtigt. ${ }^{140}$

Im letzten Absatz der Rede Stalins zu diesem Anlass wird bereits das Motiv des epochenübergreifenden militärischen Ruhms formuliert, wie es auch in der Erinnerungspolitik der Russländischen Föderation prägend ist:

136 Federal'nyj zakon ot 13 marta 1995 g. N 32-FZ »O dnjach voinskoj slavy i pamjatnych datach Rossii«.

137 Einen zusätzlichen Nebenaspekt stellt die Erweiterung der Finanzierungsbasis durch diese Novelle dar: In der ersten Fassung des Gesetzes waren primär föderale Mittel vorgesehen. Die neue Fassung erweitert die Finanzierung der Tage des militärischen Ruhmes zusätzlich auf die Budgets der Föderationssubjekte sowie der Kommunen.

138 Den' Velikoj Oktjabr'skoj socialističeskoj revoljucii. Tag der großen sozialistischen Oktoberrevolution. 25. Oktober nach dem Julianischen Kalender.

139 Der Tag setzte sich dabei auch gegen das Gedenken an die Februarrevolution durch - das in den ersten Jahren nach 1917 ebenfalls Gewicht hatte.

140 Vgl. z. B. Volobuev, Oleg: Istorija Rossii. Načalo XX - načalo XI v. 10 kl. Učebnik. Drofa, Moskau 2016, 159; Gorinov, Michail: Istorija Rossii. 10 kl. Učebnik. Čast'2. Prosveščenie, Moskau 2016, 117. 
"Möge euch in diesem Krieg das mutige Vorbild unserer großen Vorfahren inspirieren - Aleksandr Nevskij, Dmitrij Donskoj, Kuz’ma Minin, Dmitrij Požarskij, Aleksandr Suvorov, Michail Kutuzov! Möge euch das unbesiegbare Banner des großen Lenins den Weg erleuchten! ${ }^{141}$

Die Parade zum 24. Jahrestag der Oktoberrevolution wurde so selbst zu einem Erinnerungsdatum. Als in den 1960er Jahren das Narrativ des Sieges im Großen Vaterländischen Krieges zunehmend ins Zentrum erinnerungspolitischer Legitimation rückte, konnte der 7. November als eine Art »doppelter Gründungsmythos ${ }^{142}$ aufgebaut werden: Über das Gedenken an die Oktoberrevolution als zentrales Gründungsmotiv hinaus wurde der Tag als Ausgangspunkt für den Sieg über das nationalsozialistische Deutschland gefeiert. Nicht zuletzt diese Zusammenführung der beiden wichtigsten erinnerungspolitischen Referenzpunkte sorgte dafür, dass der Tag der Oktoberrevolution bis zum Ende der Sowjetunion seine herausragende Bedeutung im Festkalender behielt. ${ }^{143}$

Die Spätphase der Sowjetunion und die ersten Jahren der Russländischen Föderation waren von einer kritischen Diskussion über die kommunistische Vergangenheit geprägt, jedoch ohne dass daraus eine neue klare Geschichtspolitik entstanden wäre. Das öffentliche Gedenken an die Oktoberrevolution wurde allerdings sukzessive reduziert. Schon 1991 fand die Parade nicht mehr statt und 1992 wurde der 8. November wieder zu einem Arbeitstag ${ }^{144}$.

Der 4. November ${ }^{145}$ wurde bereits seit 1649, eingeführt durch Zar Aleksej I., als Tag der Ikone der Gottesmutter von Kazan gefeiert. ${ }^{146}$ Dieser orthodoxe Feiertag erinnerte an das Ende der "polnischen Invasion ${ }^{147}$ im Jahre 1612. Dabei soll die Ikone der Gottesmutter von Kazan bei der Eroberung Moskaus von den Streitkräften des Fürsten Dmitrij Požarskij mitgeführt worden sein. ${ }^{148}$ Nach der Revolution 1917 wurden diese orthodoxen Traditionen im-

141 Stalin, Iosif: Reč’ Predsedatelja Gosudarstvennogo Komiteta Oborony i Narodnogo Komissara Oborony tov. I. V. Stalina na Krasnoj ploščadi v den' XXIV godovščiny Velikoj Oktjabr'skoj Socialističeskoj Revoljucii. In: Pravda Nr. 310(8718) vom 8. November 1941, 1.

142 Rolf, Malte: Das sowjetische Massenfest. Hamburg 2006, 326.

143 Jedoch gewannen ab den 1970er Jahren das Neujahr und der Tag des Sieges an Bedeutung, während sich an den beiden Feiertage am 7. und 8 . November neben den offiziellen Feierlichkeiten vor allem private Freizeitgestaltung und Rituale wie eine Morgentafel im Familienkreis, bei der die Fernsehübertragung der Parade geschaut wurde, etablierten.

144 Der 7. November blieb als arbeitsfreier Tag erhalten, jedoch ohne aufwendige offizielle Inszenierungen.

145 Nach Julianischem Kalender der 22. Oktober.

146 Vgl. Bulgakov, Sergej: Nastol’naja kniga dlja svjaščenno-cerkovno-služitelej. Kiev 1913, 421.

147 Ebd., 419.

148 Vgl. ebd., 421. 
mer weiter eingeschränkt. Erst seit dem Ende der Sowjetunion gewinnt der Tag wieder an Bedeutung. Der erste Versuch der Russländischen Föderation einer Neukonzeption des Festkalenders ist das Gesetz über die Feiertage des militärischen Ruhmes in seiner ersten Fassung von 1995. ${ }^{149}$ Mit diesem Gesetz entfiel der Tag der Oktoberrevolution. Stattdessen wurde der vorrevolutionäre 4. November unter dem Titel »Tag der Befreiung Moskaus durch die Kräfte des Volksheeres unter der Führung von Kuz'ma Minin und Dmitrij Požarskij von den polnischen Invasoren (1612)« um drei Tage auf den 7. November verschoben neu eingeführt. Boris El'cin versuchte durch diesen Rückgriff auf vorrevolutionäre Traditionen neue Legitimationsbezüge $\mathrm{zu}$ erschließen, die sich nicht auf die Zeit der Sowjetunion bezogen.

Neben der Schaffung von legitimatorischen Grundlagen für den neuen Staat war auch immer die innenpolitische Auseinandersetzung mit den wieder erstarkenden Kommunisten ein bedeutender Faktor in El'cins Erinnerungspolitik. Durch die Neuregelungen, wie hier z. B. im Bereich der Feiertage, sollte den Kommunisten ein erinnerungspolitisches Legitimationsreservoir genommen werden, um ihren nach wie vor großen Rückhalt in Teilen der Bevölkerung zurückzudrängen.

Die faktische Abschaffung des Revolutionstages durch seine Umwidmung zum `Tag der Befreiung Moskaus` wurde in der Öffentlichkeit kaum beachtet, da sie keine besonderen Folgen hatte und der Tag arbeitsfrei blieb. Zudem erfolgte bereits 1996 die Umbenennung des 7. Novembers in den Tag der >Eintracht und Versöhnung` per Präsidentendekret ${ }^{150}$. In dem Dekret nimmt Boris El'cin noch einmal Bezug auf den Tag der Oktoberrevolution:

»Die Oktoberrevolution des Jahres 1917 hatte tiefgreifenden Einfluss auf das Schicksal unseres Landes. Um zukünftig Konfrontationen zu vermeiden und zwecks der Einigkeit und Konsolidierung der russländischen Gesellschaft, erkläre ich den 7. November zum Tag der Eintracht und Versöhnung. «" ${ }^{151}$

Auch diese Veränderung erregte keine besondere Aufmerksamkeit. ${ }^{152}$ Weder die Umbenennung noch die von Boris El'cin akzentuierten Deutungsangebote

149 Federal'nyj zakon ot 13.03.1995 N 32-FZ O dnjach voinskoj slavy (pobednych dnjach) Rossii. Heute: Federal'nyj zakon ot 13.03.1995 N 32-FZ O dnjach voinskoj slavy i pamjatnych datach Rossii.

150 Den' soglasija i primirenija. Eingeführt durch: Ukaz Prezidenta RF ot 7 nojabrja 1996 g. N 1537 »O dne soglasija i primirenija«. Bisher scheint sich keine einheitliche Übersetzung durchgesetzt zu haben. Vgl. de Keghel, Isabelle: Verordneter Abschied von der revolutionären Tradition. Der `Tag der nationalen Einheit‘ in der Russländischen Föderation. In: Karl, Lars / Polianski, Igor J. (Hg.): Geschichtspolitik und Erinnerungskultur im neuen Russland. Göttingen 2009, 120.

151 Ukaz Prezidenta RF ot 7 nojabrja 1996 g. N 1537 »O dne soglasija i primirenija«.

152 Da die Duma den Erlass nicht bestätigte, blieb zudem der ursprüngliche Name des Feiertages im Föderalen Gesetz unverändert. 
hinsichtlich einer besseren sozialen Kohäsion setzten sich in der Bevölkerung durch. ${ }^{153}$

In den Fokus der Öffentlichkeit rückt der 7. November erst wieder durch die erste Reform des Gesetzes über die militärischen Feiertage unter Vladimir Putin im Jahr 2004. ${ }^{154}$ In dieser Gesetzesnovelle sind sowohl der alte Tag der Befreiung Moskaus als auch der Tag der Oktoberrevolution von besonderer Bedeutung: Per Gesetz wird der 7. November als der Tag der Befreiung Moskaus, welcher durch das Dekret El'cins zum Tag der `Eintracht und Versöhnung` erklärt worden war, abgeschafft. Stattdessen wird am 4. November der arbeitsfreie `Tag der Einheit des Volkes` eingeführt, der sich auf die gleichen Grundlagen, die Befreiung Moskaus im Jahr 1612, bezieht. Durch den neuen Namen wird nun jedoch weniger der äußere Aspekt, die Vertreibung der Polen, und mehr der Gedanke der sich in diesem Sieg zeigenden inneren 'Einheit des Volkes betont. Mit einigen weiteren Umbenennungen ist der neue Name beispielhaft für eine zwischenzeitliche Tendenz der russländischen Erinnerungspolitik, auf die Nennung von Gegnern zugunsten von nach innen gerichteten, integrierenden Formulierungen zu verzichten.

Die 2005 öfter geäußerte These, dass der Kreml durch die Neugestaltung einen anti-polnischen Feiertag eingeführt hätte, ${ }^{155}$ übergeht den Ursprung des Tages unter El'cin und die Umbenennung im Zuge der Verschiebung. Gleichwohl verliert der Tag seine Bemäntelungsfunktion für den Revolutionstag und bekommt dadurch und durch seine Rückverlegung auf das bis zur Revolution 1917 geltende Datum ein größeres Gewicht.

Am 7. November wird ein neuer, nicht arbeitsfreier Tag eingeführt: Der "Tag der Parade auf dem Roten Platz anlässlich des 24. Jahrestages der Oktoberrevolution 1941 «. ${ }^{156}$ Dieser Tag repräsentiert, wie beschrieben, einen Bedeutungsaspekt des sowjetischen 7. Novembers. Ein Jahr später wird in der nächsten Novelle des Gesetzes am 7. November zusätzlich der Gedenktag der Oktoberrevolution eingeführt und damit der andere Bedeutungsaspekt

153 Vgl. de Keghel, Isabelle: Verordneter Abschied von der revolutionären Tradition. Der \Tag der nationalen Einheit in der Russländischen Föderation. In: Karl, Lars/Polianski, Igor J. (Hg.): Geschichtspolitik und Erinnerungskultur im neuen Russland. Göttingen 2009, 120.

154 Zur Gesetzesnovelle 2004 vgl.: Federal'nyj zakon ot 13.03.1995 N 32-FZ »O dnjach voinskoj slavy (pobednych Dnjach) Rossii« v red. Federal'nych zakonov ot 22.08.2004 N 122-FZ.

155 Veser, Reinhard: Rußland feiert die Befreiung von Polen. In: Frankfurter Allgemeine Zeitung, Nr. 258 vom 05.11.2005, 6.

156 Die Vollständige Bezeichnung lautet: Tag der Durchführung der Militärparade auf dem Roten Platz der Stadt Moskau im Andenken an den 24. Jahrestag der Großen Sozialistischen Oktoberrevolution. Den' provedenija voennogo parada na Krasnoj ploščadi v gorode Moskve v oznamenovanie dvadcat' četvertoj godovščiny Velikoj Oktjabr'skoj socialističeskoj revoljucii (1941 god). 
reintegriert. Dadurch existiert erstmals seit 1995 wieder ein Gedenken an die Revolution. Allerdings spiegelt sich in der Rechtsgrundlage die Gewichtung der doppelten Bedeutung: Vorrangig ist der Tag des militärischen Ruhmes mit seinem Andenken an die Parade des Jahres 1941. Der >einfache` Gedenktag für die Oktoberrevolution teilt sich einen Rang mit dem `Tag der Studentenschaft oder dem >Tag der Christianisierung der Rus.

Da sich der neue 7. November als Tag der Einheit und Versöhnung im Bewusstsein der Bevölkerung nie gegen das aus Zeiten der Sowjetunion fortbestehende Andenken an die Oktoberrevolution durchsetzen konnte, ${ }^{157}$ stellte diese Neuordnung 2004/2005 einen erneuten Versuch dar, die legitimatorischen Gewichte vom Tag der Oktoberrevolution hin zu einem neuen Bezugspunkt, dem Tag der Einheit des Volkes, zu verschieben. Dies kommt auch darin zum Ausdruck, dass der für die Wahrnehmung eines Feiertages wichtige Status eines arbeitsfreien Tages ebenfalls auf den 4 . November verschoben wurde.

Insgesamt zeigt sich in der Umgestaltung des 7. Novembers aber auch ein neues Austarieren der erinnerungspolitischen Gewichte in Bezug auf die sowjetische Zeit. Zum einen kehrt das Andenken an die Oktoberrevolution zurück in den Festtagskalender. Zum anderen wird dieses Andenken als Legitimationsressource für das postsowjetische Russland anschlussfähig gemacht, indem der ideologische, sozialistische Charakter dieses Tages zurückgedrängt wird: Durch den Bezug auf die Parade von 1941 wird das Andenken an die Oktoberrevolution in das Gedenken an den Großen Vaterländischen Krieg integriert, dadurch entpolitisiert und somit nutzbar für das Erinnern in der Russländischen Föderation.

Den erheblichen Bemühungen und dem im Vergleich zu den 1990er Jahren elaborierten Ansatz zum Trotz zeigen Umfragen, dass sich diese Umkodierung oder Neuausrichtung der Novemberfeiertage nur sehr langsam durchsetzt. ${ }^{158}$ Das Grundproblem des Gegensatzes zwischen gesellschaftlicher Feierpraxis und von oben annoncierten Feiertagen bleibt bestehen. ${ }^{159}$

Wie diese Strategie der Neukodierung des Revolutionstages in der Festtagspraxis ab 2004 umgesetzt und popularisiert wird, zeigen die jährlichen erinnerungspolitischen Inszenierungen am 7. November auf dem Roten Platz.

157 Vgl. Cavel'e, Oleg: 16\% rossijan otprazdnujut Den' narodnogo edinstva 4 oktjabrja. Levada-Zentrum, 31.10.2012. Online: http://www.levada.ru/2012/10/31/16-rossiyanotprazdnuyut-den-narodnogo-edinstva-4-oktyabrya.

158 Cavel'e, Oleg: $16 \%$ rossijan otprazdnujut Den' narodnogo edinstva 4 oktjabrja. Levada-Zentrum, 31.10.2012. Online: http://www.levada.ru/2012/10/31/16-rossiyanotprazdnuyut-den-narodnogo-edinstva-4-oktyabrya.

159 Sacharov, Andrej: PPrazdniki ne naznačajutsja sverchu«. In: Ivestija, 23.11.2004. Online: http://izvestia.ru/news/296849. 


\subsubsection{Einführung der Gedenktage}

Die zweite Novelle des `Gesetzes über die Tage des militärischen Ruhmes` fand bereits einige Monate später im Juli 2005 statt. Kern der Novelle war eine Erweiterung des Gesetzes um Gedenktage, die keinen direkten Bezug zu militärischen Siegen aufweisen. Dazu wurde der Titel des `Gesetzes über die Tage des militärischen Ruhmes um den Zusatz und Gedenktage Russlands` ergänzt sowie die Präambel durch die Erläuterung erweitert, dass "neben den militärischen Siegen auch weitere Ereignisse existieren, die es verdient haben, im Volksgedächtnis verewigt zu werden. " $^{160}$

Diese ‘weiteren Ereignisse - z. B. der Tag der russländischen Studenten, Tag der Oktoberrevolution des Jahres 1917 oder der Tag der Verfassung der Russländischen Föderation - wurden im Rahmen der Novelle unter dem Artikel »1.1 Gedenktage Russlands « festgeschrieben. ${ }^{161}$

Diese Gedenktage decken in unterschiedlicher Hinsicht ein breites Spektrum ab. Bei dem Tag der Studenten am 25. Januar handelt es sich um die offizielle Sanktionierung eines Tages, der schon vor der Revolution begangen wurde, während der Zeit der Sowjetunion keine größere offizielle Bedeutung besaß und sich seit den 1990er Jahren sukzessive neu etabliert hatte. Die Aufnahme des Tages in das Gesetz ist eines der augenscheinlichen Beispiele dafür, wie der festgeschriebene Gedenkkanon auf Bereiche erweitert wird, die primär gesellschaftliche Bedeutung haben. Obwohl der Tag - auch vom gebräuchlichen Namen Tatjana-Tag her ${ }^{162}$ - ein traditioneller Tag der orthodoxen Kirche ist ${ }^{163}$ wird er heute ganz im Wortlaut des Gesetzes an den Universitäten unter großer Resonanz der Studierenden als Tag der Studenten sehr weltlich gefeiert. Hier wurde eine bestehende gesellschaftliche Festtradition durch die Aufnahme in das Gesetz von offizieller Seite integriert.

Der `Tag der Solidarität im Kampf gegen den Terrorismus« stellt eine Neuschöpfung dar und ist direkt mit dem terroristischen Überfall am 3. September 2004 auf die Schule Nr. 1 im nordossetischen Beslan ein Jahr zuvor verbunden. Auch an diesem Tag lässt sich eine Erweiterung der Perspektive darstellen: Hier wurde kein heroischer, positiv besetzter Bezugspunkt gewählt, sondern es wird an Ereignisse erinnert, die über Nordossetien hinaus in der ganzen

160 Federal'nyj zakon ot 13.03.1995 N 32-FZ; Redakcija N 3; in der dritten Fassung vom 21.07.2005.

161 Tag der russländischen Studenten; Tag der Kosmonauten; Tag der Solidarität im Kampf gegen den Terrorismus; Tag der Oktoberrevolution des Jahres 1917; Tag der Verfassung der Russländischen Föderation. Vgl. Federal'nyj zakon ot 13.03.1995 N 32-FZ in der dritten Fassung vom 21.07.2005.

162 Russisch: Tat'janin den'.

163 Vgl. Bulgakov, Sergej: Nastol’naja kniga dlja svjaščenno-cerkovno-služitelej. Kiev 1913, 35 . 
Russländischen Föderation als traumatisch in verschiedener Hinsicht in Erinnerung geblieben sind. Zum einen bleibt Beslan als gezielter Angriff gegen Kinder an ihrem ersten Schultag in Erinnerung, der hunderte Menschen der Kleinstadt das Leben kostete. Zum anderen bleibt auch die Hilflosigkeit der Sicherheitskräfte in Erinnerung, die nicht in der Lage waren, die Katastrophe zu verhindern. Hier wird der Gedenkkalender, über ein heroischen Heldengedenken und Erinnern von Schlachten und Siegen hinaus, auf eine sehr fragile Ebene der jüngsten Vergangenheit der Russländischen Föderation erweitert. Der 3. September hat das legitimatorische Potenzial, jedes beliebige Mittel im Kampf gegen den Terrorismus zu rechtfertigen. Die direkte Verbindung mit Beslan macht den Tag aber auch doppeldeutig: Auch die Ohnmacht des starken Staates ist in ihm angelegt, sodass der Tag vor allem ein Tag der Trauer ist.

Die Tradition, den Tag der Verfassung zu feiern, geht auf die Sowjetunion zurück. Bis 1977 wurde am 5. Dezember die Verfassung des Jahres 1936 gefeiert, danach am 7. Oktober die bis zum Ende der Sowjetunion gültige Fassung. Der Tag der Verfassung wird durch die Aufnahme in das Gesetz und den enthaltenen Kontext der übrigen Feiertage an sich aufgewertet. Durch die parallele Änderung des Arbeitskodexes ${ }^{164}$, die den arbeitsfreien Status aufhob, wurde der Tag, zumindest was die Feierpraxis betrifft, erheblich abgewertet. Allerdings hatte der Feiertag, trotz seines arbeitsfreien Status, in der Russländischen Föderation nie eine besondere Dynamik entwickelt.

Erinnerungspolitisch interessant ist besonders die Festschreibung des Jahrestages der Oktoberrevolution 1917 als Gedenktag: Hierdurch wird an den 7. November doppelt und dabei hierarchisch erinnert: Zum einen als Gedenktag der Oktoberrevolution ${ }^{165}$ und zum anderen als Tag des militärischen Ruhmes ${ }^{166}$ unter Bezugnahme auf den $>$ Tag des Andenkens an die Militärparade auf dem Roten Platz anlässlich des 24. Jahrestages der Oktoberrevolution 1941. Die primäre Bedeutung wird somit weiterhin dem 7. November 1941 zugeschrieben. Obwohl der Jahrestag der Oktoberrevolution wieder offiziell berücksichtigt wird, ist diese Neustrukturierung als ein Versuch zu interpretieren, langfristig eine Umkodierung des 7. Novembers vorzunehmen. Zum einen wird der Tag an sich geschwächt, indem der arbeitsfreie Tag entfällt. Zum anderen wird das Deutungsangebot als Tag des militärischen Ruhmes vor allem durch die Ressourcenausstattung der Patriotischen Erziehung forciert: Nicht mehr der politische Tag der Oktoberrevolution wird begangen, sondern langfristig soll sich an seiner Stelle das Gedenken an die Parade des Jahres 1941 etablieren.

164 Trudovoj Kodeks Rossijskoj Federacii. Stat'ja 112. Nerabočie prazdničnye dni. Redakcija N 5; Arbeitsgesetz in der 5. Fassung vom 15.03.2005.

165 Federal'nyj zakon ot 13.03.1995 N 32-FZ. Nach Kapitel 1.1: »Gedenktage«.

166 Ebd. Nach Kapitel 1: »Tage des militärischen Ruhmes«. 
Dieser Ansatz ist für viele Bereiche der russländischen Erinnerungspolitik exemplarisch: Die positiven Identifikationspotenziale der Sowjetunion werden nutzbar gemacht, jedoch werden politische Komponenten in der Regel zugunsten von heroischen, militärischen Komponenten marginalisiert.

Insgesamt wurde durch diese Novelle der Gedenkkanon deutlich erweitert: Nicht mehr nur gewonnene Schlachten und Kriege werden erinnert, sondern auch zivilen Gedenktraditionen wird an prominenter Stelle Raum gegeben. Spätestens dadurch wird das Gesetz zu einem der zentralen Orte, an dem das offizielle Gedenken festgeschrieben und Bedeutung für Traditionen und historische Daten generiert wird. Mit der Einführung der Dualität von Tagen des militärischen Ruhmes in Artikel 1 und den Gedenktagen in Unterartikel 1.1 wird aber auch, indem der hervorgehobene Status der Ruhmestage beibehalten wird, bewusst oder unbewusst eine Trennung des Gedenkens aufrecht erhalten. ${ }^{167}$ Die Tage des militärischen Ruhmes und die Gedenktage stehen in Titel, Text und Präambel nebeneinander. Diese Gleichwertigkeit lässt darauf schließen, dass die Reformen tatsächlich den Versuch darstellen, die Gedenktraditionen zu erweitern und dabei um eine ızivile` Ebene zu ergänzen.

Die Aufnahme in das Gesetz stellt damit für die Gedenktage eine klare Hervorhebung als bedeutend dar. Ähnliche Bedeutung genießen nur die Feiertage, die nach dem Arbeitskodex arbeitsfreien Status genießen. ${ }^{168}$ In der Hierarchisierung niedriger anzusiedeln sind die Gedenk- und Feiertage, die nur durch einen einzelnen Präsidentenerlass sanktioniert sind und keinen Eingang in die föderale Gesetzgebung finden, wie beispielsweise die Ehrentage verschiedener Berufsgruppen oder Waffengattungen. ${ }^{169}$

Auf der Grundlage dieser Novelle des Gesetzes aus dem Jahr 2005 wurde der Gedenkkanon in den vergangenen Jahren sukzessive erweitert oder teilweise modifiziert. Als erste Modifikation wurde der `Tag des Sieges der Roten Armee über die Kaiserlichen Truppen Deutschlands (1918) - Tag der Verteidiger des Vaterlands`zum $\gg$ Tag des Verteidigers des Vaterlandes. ${ }^{170}$ Ähnlich wie bei dem >Tag der Befreiung Moskaus durch die Kräfte des Volksheeres unter der Führung von Kuz'ma Minin und Dmitrij Požarskij von den polnischen Invasoren (1612)' der zum `Tag der Einheit des Volkes« wurde, wird auch hier

167 Die Aufnahme in das Gesetz bleibt aber eine klare Gewichtung als bedeutend. Ähnliche Bedeutung entsteht für die Feiertage, die nach dem Arbeitskodex Artikel 112 arbeitsfreien Status genießen. In der Hierarchisierung niedriger anzusiedeln sind die Gedenkund Feiertage die nur durch einen einzelnen Präsidentenerlass sanktioniert sind und keinen Eingang in die föderale Gesetzgebung finden. Z.B. der Tag des Unternehmertums am 26. Mai. Eingeführt durch: Ukaz Prezidenta RF ot 18.10.2007 N 1381 » Dne rossijskogo predprinimatel'stva«.

168 Vgl. Trudovoj Kodeks Rossijskoj Federacii. Stat'ja 112.

169 Vgl. z. B. `Tag des Unternehmertums: Ukaz Prezidenta RF ot 18.10.2007 N $1381 »$ O Dne rossijskogo predprinimatel'stva«.

170 Federal'nyj zakon ot 13.03.1995 N 32-FZ. Änderung vom 15.04.2006. Redakcija N 4. 
der historische Bezug, der erinnerungspolitisch aggressiv nach außen gewendet gedeutet werden kann, gestrichen und durch eine positive Identifikation ersetzt: Anstelle des 'Sieges über` wird nun die Leistung der Soldaten für die Verteidigung des Vaterlandes explizit gewürdigt. Das Gewicht wird so vom Prinzip der Identifikation durch Exklusion bzw. Differenz hin zu einer Identifikation durch Inklusion verschoben. Ob sich ein Gedenken aggressiv nach außen richtet oder seine primäre Wirkung durch Werteintegration nach innen entfaltet, beispielsweise durch die Aktualisierung von Einigkeit, zeigt sich jedoch vor allem in der performativen Ausgestaltung und weniger in Gesetzestexten. Grundsätzlich ist aber in dieser Form der verbalen Abrüstung< die Möglichkeit enthalten, das Gedenken neu auszurichten und langfristig transnational oder international anschlussfähiger zu gestalten.

\subsubsection{Neue Gedenktage seit 2007}

In der Folge wurde in regelmäßigen Abständen eine ganze Reihe von Gedenktagen ergänzt. Dazu zählen: der Tag der Helden des Vaterlandes ${ }^{171}$, der Tag der Erinnerung und Trauer - Beginn des Großen Vaterländischen Krieges $1941^{172}$, der Tag der Partisanen und der Angehörigen des Untergrundes ${ }^{173}$, der Tag der Christianisierung der Rus ${ }^{174}$, der Tag des Endes des Zweiten Weltkrieges ${ }^{175}$, der Tag der Russländischen Bürger, die ihren Dienst außerhalb des Vaterlandes versehen ${ }^{176}$, der Tag der Teilnehmer an der Liquidierung der Folgen der radioaktiven Unfälle und Katastrophen und Andenken an die Opfer dieser Unfälle und Katastrophen ${ }^{177}$, der Tag des russländischen Parlamentarismus ${ }^{178}$ sowie der Tag der russländischen Kämpfer, die im Ersten Weltkrieg umgekommen sind ${ }^{179}$.

Neben diesen Ergänzungen von Gedenktagen nach Artikel 1.1 wurden die Tage des militärischen Ruhmes nur um ein Datum ergänzt: Im Juli 2012 wurde der 'Tag des Sieges der russischen Flotte über die türkische Flotte in der Seeschlacht von Češme (1770)< eingeführt. ${ }^{180}$

171 Ebd. Änderung vom 28.02.2007. Redakcija N 5.

172 Ebd. Änderung vom 24.10.2007. Redakcija N 6.

173 Ebd. Änderung vom 10.04.2009. Redakcija N 7.

174 Ebd. Änderung vom 31.05.2010. Redakcija N 8.

175 Ebd. Änderung vom 23.07.2010. Redakcija N 9.

176 Ebd. Änderung vom 29.11.2010. Redakcija N 10.

177 Ebd. Änderung vom 01.04.2012. Redakcija N 11.

178 Ebd. Änderung vom 27.06.2012. Redakcija N 12.

179 Ebd. Änderung vom 30.12.2012. Redakcija N 14.

180 Ebd. Änderung vom 10.07.2012. Redakcija N 13. 
Diese Ergänzungen von Gedenktagen ziehen sich über einen Zeitraum von ungefähr fünf Jahren. Insgesamt betrachtet ergeben diesen Neuerungen ein vielschichtiges Bild, sowohl in der erinnerungspolitischen Ausrichtung als auch in ihrem historischen Bezug. Die historischen Bezugspunkte decken zu gleichen Teilen die sowjetische und die vorsowjetische Geschichte ab, wobei in beiden Bereichen bemerkenswerte Daten berücksichtigt werden.

Der `Tag der Helden des Vaterlandes` geht auf den von Ekaterina II. im Jahr 1769 gestifteten Orden des Heiligen Georgs zurück. Bis zur Oktoberrevolution 1917 wurden in Erinnerung an die Stiftung des Ordens am 7. Dezember ${ }^{181}$ die Träger des Ordens geehrt. In der Russländischen Föderation wurde der Orden 1992 wieder eingeführt, jedoch erst im Jahr 2008, nach der Einführung des Tages der Helden des Vaterlandes 2007, zum ersten Mal wieder verliehen. Ebenfalls in Verbindung mit dem Orden und dem Gedenktag steht das GeorgsBändchen ${ }^{182}$. Das zum ursprünglichen Orden gehörende schwarz-orange Band hat als Auszeichnung für militärische Tapferkeit über die Oktoberrevolution hinaus auch eine Tradition in der Sowjetunion. Seit einer begleitenden Kampagne der Nachrichtenagentur RIA Novosti, der Regierung Moskaus und der Organisation "Studentengemeinschaft ${ }^{183}$ zu den aufwendigen Feiern zum 60. Tag des Sieges 2005 ist das schwarz-orange Band als Georgs-Bändchen ein weit verbreitetes Symbol für die Verehrung der Veteranen des Großen Vaterländischen Krieges. Die Aktion Georgs-Bändchen wird sowohl auf föderaler Ebene als auch auf der Ebene der Föderationssubjekte aus Mitteln des Programms zur Patriotischen Erziehung der Bürger finanziert. ${ }^{184}$

Der Tag der Christianisierung der Rus', der sich auf Ereignisse des Jahres 988 bezieht, wurde auf Initiative der Synode der Russisch-Orthodoxen Kirche eingeführt. Da es sich um einen föderalen Gedenktag handelt, steht seine Einführung in einem gewissen Gegensatz zu der nicht zuletzt in weiten Teilen des Programms zur Patriotischen Erziehung der Bürger üblichen Betonung von

181 Nach altem Stil: 26. November.

182 Zum Georgs-Bändchen (Georgievskaja lenta) vgl. Makhotina, Ekaterina: Auf der Suche nach der verlorenen Heimat. Das gesellschaftliche Erinnern an das 20. Jahrhundert im heutigen Russland. In: Zedler, Jörg (Hg.): >Was die Welt im Innersten zusammenhält‘. Gesellschaftlich-staatliche Kohäsionskräfte im 19. und 20. Jahrhundert. München 2014, 77-104; Oushakine, Serguei: Remembering in Public: On the Affective Management of History. In: Ab Imperio 1 (2013), 269-302.

183 Russisch: ROOSPM »Studenčeskaja obščina« (Regional'naja obščestvennaja organizacija social'noj podderžki molodëži Studenčeskaja obščina).

184 Vgl. Postanovlenie Pravitel'stva Moskvy ot 29.03.2011 N 88-PP »O plane meroprijatij po patriotičeskomu vospitaniju naselenija goroda Moskvy na 2011 god « oder Postanovlenie Pravitel'stva RF ot 05.10.2010 N 795 (red. ot 07.10.2013) »O gosudarstvennoj programme »Patriotičeskoe vospitanie graždan Rossijskoj Federacii na 2011-2015 gody«: Anlage 1 (Nr. 25). 
Multiethnizität und Multikonfessionalität der Russländischen Föderation. ${ }^{185}$ Seine Verankerung über den Kirchenkalender ${ }^{186}$ hinaus im staatlichen Festtagskalender stellt eine Neuerung dar.

Ebenfalls eine Neueinführung stellt der `Tag des Parlamentarismus` dar. Auch hier wurde mit dem 27. April ein vorsowjetischer Bezugspunkt gewählt, der sich auf die Gründung der ersten Duma im Jahr 1906 bezieht. Die Presseerklärung zur Unterzeichnung der neuen Gesetzesversion durch Vladimir Putin erklärt die erste Duma von 1906 zur ersten demokratischen Institution in der Geschichte des Vaterlandes und damit zur Grundlage des heutigen russländischen Parlamentarismus. ${ }^{187}$

Einen weiteren Gedenktag mit vorsowjetischem Bezugspunkt stellt der Ende 2012 eingeführte `Tag der russländischen Kämpfer, die im Ersten Weltkrieg umgekommen sind ‘ dar. Er ist der erste Gedenktag, der an den ersten Weltkrieg erinnert. Anders als in den meisten anderen teilnehmenden Staaten, die am 11. November, dem Tag des Waffenstillstandes zwischen Entente und Deutschem Reich, erinnern, wird in Russland am 1. August, dem Tag der deutschen Kriegserklärung an das Russische Reich, erinnert.

Die Daten, die sich auf die Zeit der Sowjetunion beziehen, lassen sich in zwei Gruppen unterteilen: Zum einen gibt es die Tage die das gängige Narrativ des siegreichen Großen Vaterländischen Kriegs stützen: Der `Tag der Erinnerung und Trauer` wurde ursprünglich 1996 per Erlass durch Boris El'cin eingeführt. ${ }^{188}$ Durch die Aufnahme in das Gesetz über die Tage des Ruhmes wird er zusätzlich in der föderalen Gesetzgebung festgeschrieben. Der `Tag des Endes des Zweiten Weltkrieges`am 2. September, eingeführt 2010, ist ebenfalls keine Neuschöpfung: Im Jahr 1945 wurde am 2. September der 3. September per Erlass des Obersten Sowjets zum arbeitsfreien `Tag des Sieges über Japan` erklärt. ${ }^{189}$ Bereits 1947 wurde der 3. September durch einen weiteren Erlass ${ }^{190}$

185 Das vom Russländischen Ministerium für Kultur ausgearbeitete Gesetzesprojekt wurde dementsprechend in seiner Einführung kommunikativ begleitet: So bekundeten der Vorsitzende des Rates der Muftis Russlands sowie der Vertreter der buddhistischen Gemeinschaft ihre Unterstützung für dieses Gesetzesprojekt der Staatsduma. RIA-Novosti vom 21.05.2010. Online: http://ria.ru/religion/20100521/236961888.html.

186 Vgl. Bulgakov, Sergej: Nastol'naja kniga dlja svjaščenno-cerkovno-služitelej. Kiev 1913, 266.

187 Vgl. Presseerklärung vom 27. Juni 2012: Ustanovlena novaja pamjatnaja data - Den' rossijskogo parlamentarizma. Online: http://kremlin.ru/news/15779.

188 Ukaz Prezidenta RF ot 08 ijunja 1996 goda N 857 »O Dne pamjati i skorbi« (RG 96-109).

189 Ukaz Prezidiuma VS SSSR ot 02.09 .1945 ob ob" javlenii 3 sentjabrja prazdnikom pobedy nad Japoniej. Data sozdanija: 2 sentjabrja 1945 goda. In: Mandel'štam Ju. I.(Hg.): Sbornik zakonov SSSR i ukazov Prezidiuma Verchovnogo Soveta SSSR. 1938 g.- ijul' 1956. Moskau 1956, 216.

190 Ukaz Prezidiuma VS SSSR ot 07.05.1947 ob izmenenii Ukaza Prezidiuma Verchovnogo Soveta SSSR ot 2 sentjabrja 1945g Data sozdanija: 7 maja 1947 goda. In: Mandel'štam Ju. I. (Hg.): Sbornik zakonov SSSR i ukazov Prezidiuma Verchovnogo Soveta SSSR. 1938 g.- ijul' 1956. Moskau 1956, 376. 
wieder zum Arbeitstag und tauchte in offiziellen Gedenkkalendern selten auf. Schon 1997 wurde nach Eingabe des Gebietes Sachalin, wo dem Gedenken an die Kapitulation Japans eine wichtige Rolle zukommt, die Wiedereinführung des `Tag des Sieges über das militaristische Japan` am 3. September im Gesetz über die Tage des militärischen Ruhmes zwar von der Duma gebilligt, jedoch von Boris El'cin nicht unterschrieben. Auch die weiteren Versuche, den Tag des Sieges über Japan` wiederzubeleben, 2000, 2002 und 2003 auf Initiative Sachalins, blieben erfolglos. Die offiziellen Begründungen richteten sich in der Regel auf Mehrkosten für das föderale Budget. Spätestens mit der besseren Finanzausstattung von erinnerungspolitischen Projekten in den 2000er Jahren wurde aus Sachalin die ablehnende Haltung Moskaus zunehmend als falsche Rücksichtnahme gegenüber Japan in der Kurilen-Frage thematisiert. Diese ablehnende Haltung Moskaus bzw. die Rücksichtnahme gegenüber Japan änderte sich erst 2010, nachdem sich der Streit mit Japan nach einem Besuch des russischen Präsidenten Dmitrij Medvedevs auf den Kurilen deutlich verschärft hatte, mit der Einführung des iTages des Endes des Zweiten Weltkrieges . Entgegen der diplomatisch aufheizten Situation des Jahres 2010 lässt sich der erinnerungspolitische Niederschlag im Gesetz über die Tage des militärischen Ruhmes als moderat beschreiben: Entgegen den Eingaben aus Sachalin und der sowjetischen Tradition wurde der Gedenktag nicht auf den 3., sondern auf den 2. September gelegt und zusätzlich wurde das Konfliktpotenzial durch den Verzicht auf die alte Bezeichnung `Tag des Sieges über das militaristische Japan` verringert. Auch wenn beispielsweise in den USA nicht des Tages der Unterzeichnung der Kapitulation, sondern des 15. August als Ende des Zweiten. Weltkrieges gedacht wird, so lässt sich der russländische Feiertag zum Kriegsende, zumindest abseits von Sachalin, ohne die direkte Benennung des Kriegsgegners Japan begehen.

Eine tatsächliche Neuerung stellt der `Tag der Partisanen und der Angehörigen des Untergrundes dar, der 2010 auf Initiative der Duma des Gebietes Brjansk eingeführt wurde. Sein Datum, der 29. Juni, bezieht sich auf den Erlass zur Bildung von Partisanengruppen von $1941 .^{191}$

Neben diesen Tagen, welche sich in das gängige Narrativ vom Großen Vaterländischen Krieg einfügen, wurden noch zwei weitere Feiertage mit einem Bezugspunkt in der Zeit der Sowjetunion eingeführt. Beide beziehen sich auf die 1980er Jahre und entsprechen weniger einem heroischen Narrativ.

Ende 2010 wurde der $>$ Tag der Russländischen Bürger, die ihren Dienst außerhalb des Vaterlandes versehen eingeführt. Obwohl die Bezeichnung

191 Direktiva Sovnarkoma SSSR i CK VKP(b) partijnym i sovetskim organizacijam prifrontovych oblastej o mobilizacii vsech sil i sredstv na razgrom fašistskich zachvatčikov. In: Bogoljubova, K. M./Smirtjukova, M. S. (Hg.): Rešenija partii i pravitel'stva po chozjajstvennym voprosam. Bd. 3. Moskau 1968, 38-39. 
sehr offen gehalten ist, macht das Datum, der 15. Februar, klar, dass es sich in erster Linie um einen Gedenktag für den Afghanistankrieg handelt. Am 15. Februar 1989 verließen offiziell die letzten sowjetischen Truppen Afghanistan, indem sie bei Termiz den Amudarja überquerten. Weit verbreitet ist auch die Bezeichnung ,Tag der Soldaten-Internationalisten (Vojny-internacionalisty).< Durch diese inoffizielle Bezeichnung in sowjetischer Begrifflichkeit wird das Gedenken über die sowjetischen Soldaten des Afghanistankrieges hinaus besonders auf die Internationalisten erweitert, die in verschiedensten bewaffneten Konflikten beispielsweise in Korea, Vietnam oder afrikanischen Ländern aktiv waren. Die offizielle, sehr offen gehaltene Bezeichnung schließt darüber hinaus implizit auch jüngere Konflikte wie beispielsweise den Krieg um Südossetien 2008 mit ein.

Der zweite Gedenktag, der sich auf die 1980er Jahre bezieht, ist der `Tag der Teilnehmer an der Liquidierung der Folgen der radioaktiven Unfälle und Katastrophen und Andenken an die Opfer dieser Unfälle und Katastrophen. Bereits in den letzten Jahren der Sowjetunion wurden in vielen Städten der Sowjetunion kleinere Denkmäler für die `Liquidatoren der Nuklearkatastrophe von Tschernobyl errichtet. Mit dem Jahrestag der Katastrophe am 26. April wird neben dem Abzug aus Afghanistan ein weiterer negativ konnotierter Bezugspunkt in das Gesetz über die Tage des militärischen Ruhmes integriert.

Hier zeigt sich, neben der Integration zivilen Gedenkens, eine weitere Erweiterung: Auch Ereignisse, die sich nicht ohne Weiteres in einen heroischen Gedenkzusammenhang bringen lassen finden Eingang in den Feiertagskalender des Gesetzes. Die beiden genannten Tage sind in ihrer Anlage und ihrem Bezugspunkt dem `Tag der Solidarität im Kampf gegen den Terrorismus ähnlich.

\subsection{Die Veteranenparaden am 7. November}

Die Wiederbelebung der großen Paraden auf dem Roten Platz nach dem Ende der Sowjetunion geht auf Boris El'cins Versuche ab Mitte der 1990er Jahre zurück, eine Staatssymbolik und damit auch einen Feiertagskalender mit einer breiten Kohäsionswirkung zu schaffen. Ein zentraler Aspekt war dabei das Wiedererschließen des Großen Vaterländischen Krieges als Identifikationsressource. Die ersten Schritte dazu waren 1995 das Gesetz über die Tage des militärischen Ruhmes ${ }^{192}$ und die Inszenierung der Militärparade zum Tag des Sieges am 9. Mai. 
Ein weiterer Schritt, der später im Rahmen des Programms zur Patriotischen Erziehung fortgeführt wurde, bestand in der Einführung des sfeierlichen Marsches der Veteranen` am Tag der `Eintracht und Versöhnung auf dem Roten Platz 1997. Dabei handelte es sich zunächst um eine kleine Veranstaltung, während der einige hundert Veteranen, die bereits an der Parade zum Tag der Oktoberrevolution am 7. November 1941 teilgenommen hatten, über den Roten Platz marschierten. Seit 1998 nahmen zusätzlich Abordnungen von Moskauer Jugendorganisationen teil. Allerdings standen diese Märsche im Schatten der wesentlich größeren Demonstrationen, die z. B. durch die KPRF traditionell anlässlich der Oktoberrevolution an diesem Tag organisiert wurden. Der Zugang zur Parade war streng kontrolliert, um Demonstrationen auf dem Roten Platz zu verhindern.

\subsubsection{Neugestaltung der Parade}

Im Rahmen des Programms zur Patriotischen Erziehung der Bürger und im Zusammenhang mit der Novelle des Gesetzes über die militärischen Feiertage wurde die Parade erstmalig im Jahr 2004 aufwendiger gestaltet. ${ }^{193}$ Die Veteranen der Parade von 1941 saßen nun überwiegend auf der Tribüne, während neben den Jugendorganisationen nun Militärorchester und Angehörige der Streitkräfte in historischen Uniformen paradierten.

Der Ablauf und die einzelnen Elemente der Parade wurden von Jahr zu Jahr aufwendiger gestaltet und zudem sukzessive Inszenierungen eingefügt. Dazu zählten zum einen Spielszenen wie z. B. ein Sturmlauf von Soldaten in historischen Uniformen unter dem Ruf »Für die Heimat, für den Sieg! « über den Roten Platz, aber auch von pathetischer Musik untermalte gesprochene Passagen über den Ablauf der 'Schlacht um Moskau und die Vorbildhaftigkeit der Kriegsgeneration.

Seit der Parade 2009 lässt sich ein relativ festes Grundgerüst an Programmpunkten beobachten. ${ }^{194}$ Nach einer Eingangsmoderation und einer kurzen Rede des Bürgermeisters der Stadt wird zunächst die Hymne der Russländischen Föderation gespielt und nach einer Übergangsmoderation die Hymne

193 Allerdings tritt die Gesetzesnovelle, die aus dem 7. November den `Tag der Durchführung der militärischen Parade auf dem Roten Platz in Moskau im Gedenken an den 24. Jahrestag der großen sozialistischen Oktoberrevolution (1941)< macht, erst einige Wochen nach der Parade am 29.12.2004 in Kraft. Federal'nyj zakon ot 29.12.2004 N $200-\mathrm{FZ} » \mathrm{O}$ vnesenii izmenenij v stat' ju 1 Federal'nogo zakona »O dnjach voinskoj slavy (pobednych dnjach) Rossii«.

194 Vgl. Fernsehübertragung. Kanal TV Centr: Prjamaja transljacija. Moskva, Krasnaja ploščad'. Parad Pervoj Pobedy. 07.11.2009, 10.00 Uhr. Online: http://www.tvc.ru. 
der Stadt Moskau ${ }^{195}$ gesungen. Auffällig ist die regionale Akzentuierung: Während die Staatshymne ohne Text und in einer Kurzversion gespielt wird, wird die Hymne der Stadt Moskau in voller Länge von allen Anwesenden gesungen. Darauf folgen eine Inszenierung mit Begleitmusik, Text und Soldaten in historischen Kostümen sowie ein Schwur der jungen Generation, das Andenken zu bewahren und die Heimat zu verteidigen, und anschließend die eigentliche Parade.

Die Parade wird durch eine Marschkapelle und einige Korps in historischen Uniformen eröffnet, die die Feldzeichen der Parade von 1941 tragen. Dann marschieren gut 30 Abordnungen verschiedener Einrichtungen über den Platz. Zuerst marschieren die Formationen mit militärischen Paradeuniformen, wie z. B. die Schüler der Kadettenschule Nr. 8, >Moskauer Kadettenkorps der Justiz,${ }^{196}$ und das Kadettenkorps des Katastrophenschutzministeriums, ${ }^{197}$ dann marschieren die Abordnungen ohne militärische Uniformen ${ }^{198}$ wie z. B. die Jugendbewegungen der Stadt Moskau, ${ }^{199}$ die nach den Verwaltungsbezirken gegliedert sind. ${ }^{200}$ Angeführt werden viele der einzelnen Abordnungen von Enkeln oder Großenkeln von Veteranen der Schlacht um Moskau. Abgeschlossen wird diese Parade durch die Ehrenformationen von Land-, Luftund Seestreitkräften.

Auf die Parade folgt als Abschluss der Veranstaltung eine weitere Inszenierung mit Begleitmusik, Text und Soldaten in historischen Kostümen.

Dieses Grundgerüst der Gesamtveranstaltung wird Jahr für Jahr geringfügig ergänzt oder variiert. Es enthält Elemente der Aktualisierung und der Kontinuierung.

Eines der auffälligsten Elemente der Aktualisierung der Veranstaltungen bis ins Jahr 2010 war die Inszenierung am Ende: ${ }^{201}$ Als Abschluss stürmten einige hundert Soldaten in historischen Uniformen und mit erhobenen Waf-

195 »Moja Moskva» (»Mein Moskau«) aus dem Jahr 1941 ist seit 1995 die offizielle Hymne der Stadt Moskau. Musik: Isaak Ossipovič Dunajevskij; Text: Sergej Agranjan und Mark Lisyanskij.

196 Moskovskij kadetskij korpus justicii. Online: http://mkku.ru.

197 Kadetskij korpus MČS. Online: http://kadetmchs.narod.ru.

198 Die Formationen ohne militärische Paradeuniform sind jeweils einheitlich gekleidet, die Blöcke sind nach Farben der Oberbekleidung zu unterscheiden. Einheitlich sind schwarze Hosen, weiße Handschuhe, weiße Schals und weiße Mützen mit dem Wappen Moskaus.

199 Diese Jugendbewegungen, zu denen z. B. die >Pioniere oder die $>$ Patrioten zählen, sind nicht mit den politischen Jugendorganisationen wie `Junge Garde oder $\gg$ Unsrige $\prec$ zu verwechseln. Die politischen Organisationen nehmen - zumindest offiziell - nicht teil.

200 Detskoe Dviženie Moskvy. Online: http://www.tema-ddm.ru/district. Zuletzt aufgerufen: 23.07.2015.

201 Vgl. Fernsehübertragung. Kanal TV Centr: Prjamaja transljacija. Moskva, Krasnaja ploščad'. Parad Pervoj Pobedy. 07.11.2010, 10.00 Uhr. Online: http://www.tvc.ru. 
fen, gefolgt von einer Kavallerieeinheit, unter dem Ruf »Für die Heimat - für den Sieg!« über den Roten Platz. In den Jahren 2009 und 2010 wurde diese Inszenierung eines Sturmangriffs zusätzlich von zwei restaurierten Panzern des Typs T-34 angeführt. Im Jahr 2011 wurde der martialische Sturmangriff durch eine Kolonne von historischen Militärfahrzeugen ersetzt, die ohne besondere Inszenierung, aber begleitet von Kommentaren der Sprecher, die die besondere Bedeutung der Technik für den Sieg herausstellet, bis vor die Tribüne fuhr und dort bis zum Abschluss der Veranstaltung stehen blieb. ${ }^{202}$

Sowohl die alte als auch die neue Variante sind klare Elemente der Aktualisierung eines bestimmten Narrativs, d. h. einer bestimmten Vergangenheit. Die Inszenierung ermöglicht es jedoch, durch das Zusammenspiel von verschiedensten Elementen wie Schauspiel, Film, Musik, Rede und Requisiten die >Vergangenheit zum Leben zu erwecken und eine unmittelbare und nicht zuletzt emotionale Identifikation des Betrachters mit dem Dargebotenen zu ermöglichen. ${ }^{203}$ Dabei geht es primär darum, bei den Adressaten eine emotionale Ebene zu bedienen, die der Politikwissenschaftler David Easton als »the miranda and credenda of power ${ }^{204}$ bezeichnete.

\subsubsection{Emotionale Aktualisierung}

Die Parade des Jahres $2011^{205}$ bietet ein weiteres Beispiel für diese emotional inszenierte Form der Aktualisierung: Zunächst wird durch einen Sprecher die Bedeutung der Parade des 7. Novembers 1941 für die Schlacht um Moskau dargestellt. Auf der Großbildleinwand werden dazu Aufnahmen von der Parade 1941 gezeigt. $^{206}$ Dann wird als Eröffnung der Spielszenen das Lied $»$ Heiliger Krieg ${ }^{207}$ eingespielt, das bereits in den ersten Kriegstagen 1941 ur-

202 Vgl. Fernsehübertragung. Kanal TV Centr: Prjamaja transljacija. Moskva, Krasnaja ploščad’. Parad Pervoj Pobedy. 07.11.2011, 10.00 Uhr. Online: http://www.tvc.ru.

203 Oushakine analysiert die Parade in dieser Hinsicht als Beispiel für den Wandel der Kriegserinnerung in Russland. Vgl. Oushakine, Serguei: Remembering in Public: On the Affective Management of History. In: Ab Imperio 1 (2013), 269-302.

204 Easton, David: A Re-Assesment of the Concept of Political Support. In: British Journal of Political Science. 5/4 (1975), 446. Eastons Bezeichnung >Miranda and Credenda of Power ist an Charles E. Merriam angelehnt. Vgl. Merriam, Charles E.: Political Power. New York 1934.

205 Vgl. Fernsehübertragung. Kanal TV Centr: Prjamaja transljacija. Moskva, Krasnaja ploščad'. Parad Pervoj Pobedy. 07.11.2011, 10.00 Uhr. Online: http://www.tvc.ru.

206 Die Aufnahmen stammen aus dem Film»XXIV-yj Oktjabr, Reč’ I. V. Stalina(L. Varlamov, 1941)«; 1943 erhielten die Aufnahmen als Teil des Films »Moscow strikes back (1942)« den Oscar als bester ausländischer Dokumentarfilm. Für die Präsentation des Jahres 2011 wurden alle Einstellungen entfernt, die Stalin zeigen.

207 »Svjaščennajavojna«(1941). Text: VasilijLebedev-Kumač.Musik:Aleksandr Aleksandrov. 
aufgeführt sowie während des Krieges regelmäßig im sowjetischen Rundfunk wiederholt wurde und bis heute zu den bekanntesten und eindrücklichsten Liedern aus dieser Zeit gehört. ${ }^{208}$ Dazu werden auf der Großleinwand die Originalaufnahmen des Jahres 1941 auf eine digital konstruierte Perspektive übergeblendet, auf denen die Parade auf den Betrachter zumarschiert. In dem Moment, in dem die Marschkolonnen der Filmaufnahme das untere Ende der Leinwand erreichen, öffnet sich diese und Soldaten in historischen Uniformen marschieren in identischen Marschformationen durch die Leinwand auf den Roten Platz. Die Vergangenheit in Form der Originalaufnahmen wird auf diese Weise symbolisch, als Marschritual, aber auch praktisch in die Gegenwart verlängert.

Diese Szene stellt verdichtet dar, was Rüdiger Voigt über das öffentliche Ritual als >Aufhebung der Zeit ${ }^{209}$ im Allgemeinen geschrieben hat:

"Durch das Ritual wird die Vergangenheit - im wahrsten Sinne des Wortes - wieder lebendig. Rituale bewirken oft ein Gefühl des Dazugehörens und geben durch Sinnvermittlung dem Individuum wie der Gruppe einen emotionalen Halt. ${ }^{210}$

Zunächst wird die Meistererzählung der Parade 1941 als der moralische Ausgangspunkt des Sieges in der Schlacht um Moskau narrativ entfaltet. Dann wird dieses Narrativ durch eine rituelle Inszenierung aus Film, Musik, Schauspiel und Requisite aktualisiert bzw. llebendig gemacht und somit emotionalisiert. Dem Betrachter wird durch diese emotionale Überführung in die Gegenwart eine Anbindung an die präsentierten Identifikationsangebote auf einer vor allem emotionalen Ebene ermöglicht.

\subsubsection{Kontinuierung: Der Schwur der Jugend}

Neben diesen Elementen der Aktualisierung enthalten die Paraden zum 7. November auch Elemente der Kontinuierung, die in unterschiedlicher Form die Gegenwart an Narrative der Vergangenheit rückbinden. Eines dieser Elemente ist der Schwur der jungen Generation, der als fester Bestandteil des Ablaufs seit 2009, ähnlich wie der martialische Sturmlauf, über die Jahre zivilere Formen angenommen hat. Dabei würdigt ein Sprecher die Heldentaten der Kriegsgeneration und schwört das Andenken zu bewahren und die Heimat genauso

208 Zur emotionalen Bedeutung von Kriegsliedern vgl. Oushakine, Serguei Alex: Emotional Blueprints: War Songs as an Affective Medium. In: Steinberg, Mark/Sobol, Valeria (Hg.): Interpreting Emotions in Russia and Eastern Europe. DeKalb 2011, 248-276.

209 Vgl. Voigt, Rüdiger: Mythen, Rituale und Symbole in der Politik. In: Pribersky, Andreas/Unfried, Berthold (Hg.): Symbole und Rituale des Politischen. Frankfurt a.M. $1999,66$.

210 Ebd., 66. 
wie die Alten zu verteidigen. Anschließend wiederholen alle anwesenden Abordnungen der Jugendverbände drei Mal: »Wir schwören!« Im Jahr 2009 war dieses Element noch in eine der Inszenierungen mit historischen Uniformen eingebunden. ${ }^{211}$ Am Ende der Spielszene trat ein Soldat mit einem Feldzeichen der Parade von 1941 vor die auf dem Platz stehenden Jugendabteilungen und nahm ihnen den Schwur ab. Im darauf folgenden Jahr wurde am Ende der Spielszene das Feldzeichen von einem Soldaten in historischer Uniform an einen zivilen Vertreter der Jugendorganisationen übergeben, der anschließend den Schwur abnahm.

Im Jahr 2011 zum großen 70. Jubiläum der Parade und auch im Jahr $2012^{212}$ wurde das Element des Schwurs vollständig von der vorangegangenen Inszenierung abgetrennt. Im Jahr 2011 traten zwei und im Jahr 2012 drei Vertreter der Jugendorganisationen in zivilen Uniformen ${ }^{213}$ vor die Tribüne und nahmen den Schwur ab. Doch auch ohne die Anbindung an den inszenierten Abschnitt und auch ohne die militärischen Uniformen, bleibt der Schwur in Form und Inhalt auffällig pathetisch:

»Wir gedenken jener großen Heldentat unserer Großväter und Urgroßväter, die in der Schlacht um Moskau gekämpft haben und auch gestorben sind. Sie verteidigten unsere Stadt gegen den Feind, sie verteidigten unser Recht, auf heimischem Boden zu leben. Dank euch! - den Verteidigern Moskaus, für die Rettung unserer Stadt, für unser Leben, für unsere Zukunft. Wir, die Enkel und Urenkel des großen Sieges, werden so leben, dass ihr auf uns stolz seid. Wir werden unser Russland und unser Moskau mit ganzem Herzen lieben und verteidigen. Wir schwören! ${ }^{214}$

Hier wiederholt sich auf einer anderen gestalterischen Ebene das Element aus dem Jahr 2010, als ein Soldat in historischer Uniform das alte Feldzeichen an den Vertreter der Jugend weitergab. Das militärische Ritual der Übergabe der Feldzeichen als Symbol der Kontinuierung, der Pflicht, die Heimat zu verteidigen, wurde ab 2011 auf eine neue, eine zivile Ebene transponiert. Ohne militärische Anleihen wird die Verantwortung für das Erbe durch die Jugend nicht mehr >empfangen`, sondern in Zivil aktiv übernommen.

211 Vgl. Fernsehübertragung. Kanal TV Centr: Prjamaja transljacija. Moskva, Krasnaja ploščad’. Parad Pervoj Pobedy. 07.11.2009, 10.00 Uhr. Online: http://www.tvc.ru.

212 Vgl. Fernsehübertragung. Kanal TV Centr: Prjamaja transljacija. Moskva, Krasnaja ploščad'. Toržestvennyj marš v čest' Pervoj Pobedy. 07.11.2012, 10.00 Uhr. Online: http:// www.tvc.ru.

213 Wie auch die Formationen ohne militärische Paradeuniform sind auch die Sprecher des Schwurs einheitlich, aber zivil gekleidet und damit klar von den Korps der Kadettenanstalten zu unterscheiden.

214 Fernsehübertragung. Kanal TV Centr: Prjamaja transljacija. Moskva, Krasnaja ploščad’. Parad Pervoj Pobedy. 07.11.2011, 10.00 Uhr. Online: http://www.tvc.ru. 
In diesem Schwur-Ritual wird eine Art erinnerungspolitischer Generationenvertrag beschworen: Die jüngeren Generationen geloben das Andenken an das Vermächtnis und die Heldentaten der Älteren zu bewahren und stellen sich in deren Tradition. Aus dieser Identifikation mit Heroismus und Patriotismus der Kriegsgeneration leitet sich die Legitimität gegenwärtigen Handelns der heutigen Generation ab.

Ein Vorbild für dieses Element bildet die Abschlussveranstaltung des Allunionstreffens in Moskau 1966. ${ }^{215}$ Auch hier legten die Teilnehmer auf dem Roten Platz einen feierlichen 'Schwur der Jugend ab. Auch hier ging es um die Rückbindung der Gegenwart an die Vergangenheit, um »den Versuch, dem Generationenproblem mit revolutionär-patriotischen Massenveranstaltungen beizukommen. ${ }^{216}$

In den Formulierungen gibt es - abgesehen vom mehrfach wiederholten Ruf »Wir schwören« - kaum Überschneidungen mit der Reinszenierung der späten 2000er Jahre. Lediglich der Grundgedanke, die Taten der früheren Generationen zu erinnern und sich ihrer würdig zu erweisen, gleicht sich:

»Bei der Heiligkeit der Massengräber, bei den grauen Haaren unserer Mütter, bei der Freude des Sieges schwören wir, uns der unsterblichen Väter würdig zu erweisen und bei der geringsten Besorgnis unter den Bannern des ewigen Ruhms in den Kampf zu gehen und zu siegen! "17 $^{217}$

Insgesamt betrachtet finden sich jedoch in der heutigen Inszenierung der $\mathrm{Pa}$ raden vereinzelt Anleihen beim Schwur von 1966, wie: „Von hier, vom Roten Platz, zogen unsere Väter in den tödlichen Kampf « ${ }^{218}$ oder, wenn von den »heiligen Mauern des Kreml ${ }^{219}$ die Rede ist. Der Schwur von 1966 war jedoch in jeder Zeile durchzogen von sowjetisch-sozialistischer Rhetorik:

"Hier, auf dem Roten Platz, an den heiligen Mauern des Kreml, schwören wir, die Enkel derer, die das Winterpalais stürmten, die Kinder der Zerstörer des Reichstags, im Namen unserer Generation aus tiefstem Herzen auf die Richtigkeit der Sache Lenins, der Partei und der Sache des Oktobers. ${ }^{220}$

Wie am Beispiel des Schwurs der jungen Generation deutlich wird, sind in den heutigen Inszenierungen zum 7. November die Anleihen beim Sowjet-

215 Eine Wiederholung des Schwurs der Jugend fand am 9. Mai $1975 \mathrm{im}$ Rahmen der »Feierlichen Manifestation der Jugend auf dem Roten Platz« anlässlich des Siegestages statt. Vgl. Izvestija Nr. 109(17952) vom 10.05.1975, $1 \mathrm{f}$.

216 Oberländer, Erwin: Sowjetpatriotismus und Geschichte. Dokumentation. Köln 1967, 36.

217 Kljatva molodeži. Prinjata na Krasnoj ploščadi 11 sentjabrja 1966 goda. In: Pravda, Nr. 255 (17572) vom 12.09.1966, 1.

218 Ebd., 1.

219 Ebd., 1.

220 Ebd., 1. 
patriotismus $^{221}$ augenfällig. Von den offensichtlichsten Elementen der sowjetisch-sozialistischen Sprache entkleidet, bleibt vom Sowjetpatriotismus der heutige Patriotismus - als naher Verwandter - übrig.

Das oben beschriebene Motiv der Übergabe der Feldzeichen kehrte im Jahr 2012 zurück. Dabei ging es allerdings nicht darum, den patriotisch-heroischen Generationenvertrag zwischen der Kriegsgeneration und der `Jugend des 21. Jahrhunderts « zu besiegeln, sondern um eine Erweiterung des erinnerungspolitischen Bezugsrahmens der Parade über das Jahr 1941 hinaus bis zum Vaterländischen Krieg gegen Napoleon 1812.

\subsubsection{Verbindung der Zeiten: Von 1612 bis 2012}

Im Jahr 2012 jährten sich zum 200. Mal Napoleons Russlandfeldzug und die Schlacht von Borodino. In den Programmen zur Patriotischen Erziehung nimmt dieses Jubiläum eine wichtige Position ein und ist Anlass für eine Vielzahl von Maßnahmen, von Konferenzen über Publikationen bis hin zu Jubiläumsfeiern. Auch in die Parade zum 7. November 2012 wurde 1812 an verschiedenen Stellen als gänzlich neuer Bezugspunkt integriert.

Die erinnerungspolitische Verbindung von 1812 und 1941 ist dabei nichts Neues. Schon in der ersten Reaktion der sowjetischen Führung auf den Angriff des Deutschen Reiches auf die Sowjetunion am 22. Juni 1941 verwies Vjačeslav Molotov in seiner Radioansprache als Volkskommissar für auswärtige Angelegenheiten auf den `Vaterländischen Krieg` von 1812:

"Nicht zum ersten Mal hat unser Volk mit dem Angriff eines überheblichen Feindes zu tun. Seinerzeit hat unser Volk auf den Russlandfeldzug Napoleons mit dem Vaterländischen Krieg geantwortet und es kam zu Napoleons Niederlage und er erlebte den Zusammenbruch. Dasselbe wird der überhebliche Hitler erleben, der erneut einen Feldzug gegen Russland erklärt hat. Die Rote Armee und das gesamte Volk werden wieder einen siegreichen Vaterländischen Krieg für die Heimat, für die Ehre und für die Freiheit führen. ${ }^{222}$

Auch wenn durch die gängige Bezeichnung `Großer Vaterländischer Krieg` der Bezug auf 1812 implizit immer mitklingt, so spielte der tatsächliche Vaterländische Krieg bei der Inszenierung der Paraden zum 7. November nie eine explizite Rolle. Bis zum Ende der Sowjetunion dienten die Paraden primär der Erinnerung an die Revolution. Das Gedenken an den Krieg und speziell an

221 Oberländer, Erwin: Sowjetpatriotismus und Geschichte. Dokumentation. Köln 1967.

222 Alle großen sowjetischen Zeitungen. Vgl. z. B.: Pravda Montag 23.06.1941 Nr. 172 (8580), 1. 
die Parade von 1941 als doppelten Gründungsmythos der Sowjetunion spielte keine sichtbare Rolle, sodass auch Bezüge auf 1812 nicht vorkamen.

Nach der Wiederbelebung der Parade in der Russländischen Föderation 1997 spielten solche Bezüge bis 2012 ebenfalls keine Rolle. Eine wahrscheinliche Ursache dafür ist vermutlich in der Akteurskonstellation zu sehen: Zwar war jetzt nicht mehr die Revolution von 1917, sondern die Parade zu ihrem Andenken des Jahres 1941 das zentrale Motiv und gerade die erinnerungspolitischen Ansätze Boris El'cins, auf vorsowjetische Traditionen zurückzugreifen, hätten für eine Anknüpfung der Parade an 1812 gesprochen. Jedoch war die Parade 1997 noch primär eine Veranstaltung der Veteranen und der Veteranenverbände, die ganz überwiegend diese Anknüpfungen an vorsowjetische Traditionen als Angriff auf die geschichtliche Legitimität der Sowjetunion bzw. ihre Lebensleistung werteten und daher eher ablehnten. ${ }^{223}$

Im Jahr 2012 wurden durch Bezüge auf die Ereignisse der Jahre 1612 und 1812 die beiden wahrscheinlich wichtigsten erinnerungspolitischen Bezugspunkte der Russländischen Föderation neben dem Großen Vaterländischen Krieg auch in die Parade zum 7. November integriert. Damit setzte sich der Trend fort, aus der ehemaligen Veteranenveranstaltung eine Leistungsschau für die aktuelle Erinnerungspolitik der Russländischen Föderation zu formen.

In seiner Eröffnungsrede thematisierte der Bürgermeister der Stadt Moskau, Sergej Sobjanin, zunächst das Jahr 1612 als das Jahr des Endes der `Zeit der Wirren ${ }^{224}$ :

»Nicht nur einmal entschied sich an den Mauern der Hauptstadt das Schicksal Russlands. In diesen Tagen jährt sich zum 400. Mal das Ende der Smuta. 1612 schlossen sich die Russen zusammen, um ihr Heimatland zu retten. Alte Kränkungen wurden vergessen, alte Konflikte beendet und persönliche Streitigkeiten beigelegt. Das Volksheer unter der Führung Kuz’ma Minins und des Fürsten Dmitrij Požarskij vertrieb die fremden Invasoren aus Moskau. Es begann der Aufbau eines starken und blühenden Russlands. ${ }^{225}$

Hier präsentiert Sobjanin das inzwischen etablierte Narrativ zum Ende der Smuta, das auch grundlegend für den `Tag der Einheit des Volkes` am 4. November ist: Die Einigkeit des Volkes nach innen, unter Aufgabe von individuellen Partikularinteressen, ist der Ausgangspunkt für die Verteidigung der

223 de Keghel, Isabelle: Die Staatssymbolik des neuen Russland. Traditionen - Integrationsstrategien - Identitätsdiskurse. Münster 2008, $70 \mathrm{f}$.

224 Die `Zeit der Wirren` (auch `Smuta`, 'Smutnoe vremja`) bezeichnet die Jahre von 1598 bis 1613.

225 Fernsehübertragung. Kanal TV Centr: Prjamaja transljacija. Moskva, Krasnaja ploščad'. Toržestvennyj marš v čest’ Pervoj Pobedy. 07.11.2012, 10.00 Uhr. Online: http://www. tvc.ru. 
russländischen Interessen nach außen und das Fundament für eine prosperierende und souveräne, weil starke Russländische Föderation.

Interessanterweise kehrt die Inszenierung auf diese Weise zu der ursprünglich von Boris El'cin für den 7. November erdachten Widmung zurück.

Die Ereignisse des Vaterländischen Krieges des Jahres 1812 thematisiert Sergej Sobjanin anschließend bereits in einem impliziten Deutungszusammenhang mit dem Großen Vaterländischen Krieg 1941:

»Im Vaterländischen Krieg 1812 fiel Moskau eine große und tragische Rolle zu. Auf dem Schlachtfeld von Borodino und im Feuer von Moskau gingen die Eroberungspläne Napoleons endgültig zugrunde. Indem sie ihr Heimatland befreite, brachte die russische Armee, zusammen mit ihren Verbündeten, den Völkern Europas Frieden und Freiheit. ${ }^{226}$

Diese Deutung der russischen Armee als Befreier Europas und als Garant für Frieden und Freiheit ermöglicht eine direkte erinnerungspolitische Parallelisierung von 1812 und 1941, indem sie einen gemeinsamen Nenner der Ereignisse postuliert und so eine Anschlussfähigkeit herausstellt. Die Ereignisse lassen sich so nebeneinander stellen und auf die Gegenwart beziehen.

"Die Heldentaten des Volksheeres unter Minin und Požarskij, der Helden des Vaterländischen Krieges von 1812, und der Verteidiger Moskaus 1941 bleiben in der Geschichte Russlands für immer Vorbilder für gegenwärtigen Patriotismus, Mut und Heldentum. Sie begeisterten viele Generationen von Mitbürgern ihrem Vaterland zu dienen. Heute erinnern uns diese Heldentaten an die zeitlose Bedeutung von nationaler Einheit, Eintracht und Glauben an die eigene Stärke. ${ }^{227}$

Nachdem Sobjanin hier herausgestellt hat, welche Bedeutung die Vergangenheit für die Gegenwart hat, bezieht er abschließend noch einmal in gegensätzlicher Richtung die Gegenwart auf die Vergangenheit.

"Unsere Pflicht, die Pflicht der jungen Generation ist es, sich des Ruhmes der heldenhaften Großväter und Väter würdig zu erweisen. ${ }^{228}$

Durch diesen doppelten Bezug, der von einem Schuldverhältnis der Gegenwart gegenüber der Vergangenheit ausgeht, welches in der Zukunft eingelöst werde muss, wird es möglich, die Vergangenheit über die Gegenwart hinaus in die Zukunft zu verlängern.

Dieser Rückbezug auf die Vergangenheit als ein Schuldverhältnis für die Zukunft erinnert an Ernest Renans Bild von der Nation als "große Solidargemeinschaft, getragen vom Gefühl der Opfer, die man gebracht hat, und der 
Opfer, die man noch bringen will. $^{229}$ Anlässlich der Paraden zum 7. November in Moskau wird diese Solidargemeinschaft jedes Jahr als ein heroischpatriotischer Generationenvertrag zelebriert.

Das erinnerungspolitische Motiv von Sergej Sobjanins Rede - die Beschreibung und Deutung eines Ausschnitts der Vergangenheit und seine Interpretation entsprechend aktueller Legitimationsanforderungen - wird im Anschluss noch einmal mit den Mitteln der Inszenierung wiederholt.

Zunächst beschreibt ein Sprecher, begleitet durch Musik und Filmausschnitte, die Schlacht um Moskau und die Bedeutung der Parade am 7. November 1941 für ihren Ausgang:

"Als der Feind vor den Mauern der Stadt stand, wurde auf dem Roten Platz die Militärparade durchgeführt. Sie war der Ursprung des ersten Sieges im Großen Vaterländischen Krieg. . $^{230}$

Anschließend wird die Verbindung zur Schlacht von Borodino 1812 hergestellt:

"1941 wurde Borodino wieder zum Schlachtfeld im Kampf um Moskau. Als Vorbild dienten den Verteidigern des Vaterlands der Mut und die Tapferkeit der Helden von 1812. Vor 200 Jahren kam Napoleon bei der Eroberung Europas zum Kämpfen auch nach Russland. Dieser Krieg wurde ein Volkskrieg, er wurde zum Vaterländischen Krieg. Die Heldentaten und der Sieg der Verteidiger des Vaterlandes sind für immer in den heroischen Chroniken des russländischen Ruhmes eingeschrieben. ${ }^{231}$

An dieser Stelle marschieren Soldaten in historischen Uniformen des Jahres 1812 auf den Platz. Angeführt werden diese Marschformationen von Darstellern auf Pferden in speziellen Kostümen, die Kommandeure wie Michail Kutuzov, Pëtr Bagration oder Nikolaj Raevskij darstellen und einzeln durch den Sprecher vorgestellt werden.

Nach dem Kommando »Vorwärts! - für Mutter Russland! $^{232}$ treten die Marschformationen zurück und werden durch Soldaten in historischen Uniformen von 1941 ersetzt, die auf den Platz stürmen, während der Sprecher die Bedeutung der Verteidigung Moskaus als der letzten Verteidigungslinie herausstellt.

Mit Ton und begleitet von dramatischer Musik zeigt die Großbildleinwand in diesem Moment einen Ausschnitt aus der Spielfilmreihe `Kampf um

229 Renan, Ernest: Was ist eine Nation? Rede am 11. März 1882 an der Sorbonne. Hamburg 1996, 35.

230 Fernsehübertragung. Kanal TV Centr: Prjamaja transljacija. Moskva, Krasnaja ploščad'. Toržestvennyj marš v čest' Pervoj Pobedy. 07.11.2012, 10.00 Uhr. Online: http://www. tvc.ru.

231 Ebd.

232 Ebd. 
Moskau ${ }^{233}$ von 1985, in dem Viktor Polosuchin, der Kommandant des Frontabschnitts Borodino 1941, die Feldzeichen der russischen Armee von 1812 an die Soldaten der Roten Armee ausgeben lässt, um ihnen die Bedeutung der Schlacht zu vermitteln und ihre Kampfmoral zu stärken.

Nach der Filmeinspielung wird der Ausschnitt in der Realität nachvollzogen: Die Soldaten in den Uniformen von 1812 überreichen in einer feierlichen Zeremonie die Feldzeichen einzelner Regimenter der Schlacht von Borodino an die Darsteller einzelner Regimenter der Schlacht von $1941 .^{234}$

Das Schlusswort dieser Sequenz wird von einem Darsteller in einer Winteruniform von 1941 gesprochen, während die Musik auf die Schlussfanfaren von Pëtr Čajkovskijs `Ouvertüre $1812{ }^{235}$ überblendet:

„Kämpfer, Soldaten! Mit unserem Mut werden wir uns derer würdig erweisen, die die Heimat in allen Jahrhunderten verteidigt haben. Wir werden um jede Handbreit Heimatboden kämpfen. Bis zum letzten Tropfen Blut! « ${ }^{236}$

Nach dieser symbolischen Kontinuierung von 1812 und 1941 gehen die Darsteller in historischen Uniformen ab und vor der Tribüne erscheinen drei Vertreter der heutigen Jugendorganisationen ohne militärische Uniformen, um den Schwur der Jugend abzunehmen. Neben der Kleidung wird dieser weitere generationelle Brückenschlag auch verbal akzentuiert, indem die Selbstbezeichnung $>$ Jugend des 21 . Jahrhunderts` eingeführt wird:

"Wir, die Jugend des 21. Jahrhunderts, sind unseren Vorfahren, unseren Großvätern und Urgroßvätern, den Verteidigern der Heimat in allen Zeiten dankbar. ${ }^{237}$

Anschließend folgt der Schwur, mit einem zum Vorjahr leicht veränderten Text, mit dem sich die Vertreter der Jugendorganisationen in eine historische Linie zu den Veteranen der Parade des Jahres 1941 stellen:

»Wir sind stolz auf euch, wir erinnern eure Heldentaten im Namen des Heimatlandes, im Namen Russlands! Wir werden unser Land lieben, bewahren und verteidigen. Wir werden jene Zukunft schaffen, von der ihr geträumt habt und für die ihr an den Mauern unserer unbesiegten Hauptstadt gekämpft habt! Wir schwören! ${ }^{238}$

233 Mosfil'm 1985: Bitva za moskvu - Tajfun. Mosfilm Studios 1985. Kampf um Moskau Taifun (1/2).

234 So wird beispielsweise das Feldzeichen des Sibirischen Infanterieregiments an die 20. Panzerbrigade übergeben.

235 Čajkovskij, Pëtr: Ouvertüre 1812, Op. 49. Uraufführung 1882.

236 Fernsehübertragung. Kanal TV Centr: Prjamaja transljacija. Moskva, Krasnaja ploščad'. Toržestvennyj marš v čest’ Pervoj Pobedy. 07.11.2012, 10.00 Uhr. Online: http://www. tvc.ru.

237 Ebd.

238 Ebd. 
Schon die Schwurrituale der vorangegangenen Jahre waren prägnante Beispiele für Kontinuierung, für das direkte Aufeinander-Beziehen von Vergangenheit und Gegenwart. Die Gegenwart bekennt sich zu einer bestimmten Deutung der Vergangenheit und versucht auf diese Weise, von den gleichen Legitimitätsvorstellungen zu profitieren. Die Inszenierung des Jahres 2012 lässt sich als eine Erweiterung des erinnerungspolitischen Bezugsfeldes im Sinne eines doppelten erinnerungspolitischen Brückenschlages verstehen. Nicht nur der Jahreszahl 2012, sondern auch den Leitlinien der russländischen Erinnerungspolitik folgend, wird der heroisch-patriotische Generationenvertrag um einen weiteren Brückenschlag in die Vergangenheit zum Vaterländischen Krieg von 1812 erweitert.

Die Kriegsgeneration von 1941 wird in die Tradition von 1812 gestellt und so mit den Legitimitätsvorstellungen des Vaterländischen Krieges verbunden. Die heutige `Generation des 21. Jahrhunderts $`$ wird in eine Tradition mit 1941 gestellt und wird so mit den Legitimitätsvorstellungen des Großen Vaterländischen Krieges verbunden.

Die Darstellung der heutigen Generation und der auf sie bezogenen Legitimitätsquellen ist von besonderem Interesse, da die Jugend in der Parade nicht nur für die jungen Menschen im heutigen Russland und ihr Verhältnis zur Vergangenheit steht. Die Jugend steht in der Inszenierung der Parade nicht zuletzt auch als Sinnbild für die Russländische Föderation und die mit ihr verknüpften Legitimitätsvorstellungen.

Die verschiedenen Generationen werden in der Parade nicht abgelöst von ihrem staatlich-politischen Kontext präsentiert: In den Choreographien der Darsteller der Parade von 1941 werden ausgiebig rote Fahnen verwendet und nicht nur auf historischen Feldzeichen sind Hammer und Sichel deutlich sichtbar.

Auch wenn die heutige Staatsymbolik der Russländischen Föderation auf den ersten Blick nicht besonders dominant erscheint, so wird sie doch durch die Abordnungen der Jugendorganisationen in die Parade integriert. Neben dem Stadtwappen Moskaus an den einheitlich weißen Mützen sind die dominanten Farben der zivilen Uniformen Weiß, Blau und Rot. Auf diese Weise bilden die Blöcke nebeneinander immer wieder in unterschiedlichen Variationen die russländische Trikolore. Zusätzlich tritt bei expliziten Jugendelementen wie dem Schwur, der Show-Einlage und dem Verteilen der Blumensträuße am Ende der Parade ein Block von ca. 300 Jugendlichen in den Vordergrund, der keiner der Jugendorganisationen zuzuordnen ist und der als ganzes die Trikolore abbildet, indem jeweils hundert Jugendliche in einer Farbe gekleidet sind.

Auf diese Weise wird die `Jugend ‘, ohne z. B. in jeder Abordnung eine Fahne mitzuführen, permanent mit der heutigen Staatssymbolik assoziiert und ist dadurch in Verbindung mit dem Schwurritual als Selbstrepräsentation des 
heutigen Staates innerhalb der Parade zu interpretieren. ${ }^{239}$ In Anbetracht der repräsentativen Rolle der Jugend innerhalb der Parade, ist es ein interessanter Aspekt, dass die Rolle der jugendlichen `Zivilisten innerhalb der Parade immer weiter zulasten der jugendlichen Uniformträger ausgebaut worden ist.

\subsubsection{Zivile Gegenwart?}

Die Vergangenheit wird im Rahmen der Parade durchgängig militärisch uniformiert dargestellt. Im Paradeteil der Jugendorganisationen marschieren sowohl Abordnungen in typischen Kadetten-Uniformen als auch in den zivilen Uniformen, die im Stil an die Kleidung der russländischen Olympiamannschaft angelehnt sind. Der Schwur der Jugend wurde seit 2009 sukzessive soweit szivilisiert،, dass in der aktuellen Inszenierung militärische Uniformen keine Rolle mehr spielen. Dass diese Akzentverschiebung eine gezielte Maßnahme darstellt, lässt sich z. B. an der Bildregie für die maßgebliche Fernsehübertragung feststellen: Während des Schwurs 2012 sind, abgesehen von der Marschkapelle im Hintergrund, keine Uniformen zu sehen. Und auch während im Anschluss die Abordnungen aller Jugendorganisationen die Hymne Moskaus mit allen Strophen singen, werden mit Ausnahme weniger Sekunden ausschließlich die zivilen Abordnungen gefilmt. Die militärisch Uniformierten werden durch die Paradenregie in dieser Sequenz am Rand des Roten Platzes neben dem Historischen Museum quasi unsichtbar gemacht.

In die gleiche Richtung weist auch ab dem Jahr 2011 die Neuinszenierung des Endes der Parade: Als letztes Element, nach der Präsentation der Kolonne historischer Militärfahrzeuge, folgt eine choreographierte Gesangseinlage. Im Jahr 2011 wurde das Kinderlied `Danke Großvater für den Sieg` aufgeführt, ${ }^{240}$ dessen Musik und Text von den Leitern des Moskauer Kinder-Musiktheaters >Domisol'kar stammt. ${ }^{241}$ Am Ende der Parade des Jahres 2012 wurde das Kinderlied `Urgroßvater`von Aleksandr Ermolov und Michail Zagot aufgeführt. ${ }^{242}$

Die Lieder sind in Text, Arrangement und Instrumentierung als Kinderlieder zu erkennen: Die eingängigen Rhythmen und Reime sowie die ein-

239 Auch der Bürgermeister Sergei Sobjanin definiert sich gegenüber der Generation der Veteranen als Teilder Jugend. Vgl. Fernsehübertragung. Kanal TV Centr: Prjamaja transljacija. Moskva, Krasnaja ploščad'. Toržestvennyj marš v čest' Pervoj Pobedy. 07.11.2012, 10.00 Uhr. Online: http://www.tvc.ru.

240 Vgl. Fernsehübertragung. Kanal TV Centr: Prjamaja transljacija. Moskva, Krasnaja ploščad’. Parad Pervoj Pobedy. 07.11.2011, 10.00 Uhr. Online: http://www.tvc.ru.

241 Titel: ১Spasibo dedu za Pobedur. Text: Ivan Žiganov, Musik: Ol'ga Judachina (KinderMusiktheater Domisol'ka).

242 Titel: >Pradeduška.< Text: Michail Aleksandrovič Zagot. Musik: Aleksandr Vladimirovič Ermolov. Aleksandr Ermolov tritt häufiger im Zusammenhang mit patriotischen LiederWettbewerben in Erscheinung. 
prägsamen Melodien erhöhen den Wiedererkennungswert und erleichtern das Mitsingen. Die einfach gehaltenen Texte lassen sich erinnerungspolitisch interpretieren: Im Lied `Urgroßvater` von Zagot und Ermolov wird zunächst die Bedeutung der Urgroßväter für das Geschichtsbild der Kinder und die Tradierung herausgestellt.

»Ich bin erst seit kurzem auf der Welt/Und Geschichte kenne ich aus Büchern / Aber dafür über den großen Krieg/Höre ich lebendige Geschichten/Es gibt einen guten Menschen/Der mir immer die Wahrheit sagt/Im Herzen bleiben Spuren/Es bleibt mit mir mein Urgroßvater. ${ }^{243}$

Anschließend wird im Refrain und in der mittleren Strophe die vorbildhafte Rolle der Urgroßväter thematisiert:

"Urgroßvater, Urgroßvater, er hat den ganzen Krieg mitgemacht/Von der Wolga bis ganz nach Berlin / Urgroßvater, Urgroßvater, er verteidigte das Land / Er schützte seine Frau und seinen Sohn. [...] $\aleph^{244}$

Und daraufhin wird die Bedeutung dieser Vorbildhaftigkeit für die heutige Jugend erklärt:

"Ich bin sehr stolz auf meinen Urgroßvater / Er ist mir Vorbild und Hilfe im Leben / Aber die Traurigkeit in seinem Herzen verfliegt nicht - / Sein Weg war schwer / Alles liegt noch vor mir, und ich muss meinen eigenen Weg wählen/Aber ich will meinen Weg gehen / Wie mein Urgroßvater durchs Leben gegangen ist. ${ }^{245}$

Erinnerungspolitisch interpretiert spiegelt das Lied einen Teilaspekt der russländischen Erinnerungspolitik wider, wie er im Programm zur Patriotischen Erziehung der Bürger angelegt ist. Der Sieg im Großen Vaterländischen Krieg ist konstitutiv für eine positive Identifikation mit der Geschichte, diese `Leistung « wird primär den Soldaten d.h. den Veteranen zugeschrieben, die heute die Großväter und Urgroßväter sind. Dieser Generation werden Attribute wie Mut, Einsatzbereitschaft für das Gemeinwohl sowie das Eintreten für das Richtige und Gute zugeschrieben, die heute wieder vorbildhaft für die junge Generation sein sollen. Die Großväter und Urgroßväter sollen der Jugend durch ihre aus dem Krieg resultierende moralische Autorität Orientierung im Leben bieten und Vorbild sein.

Das angeführte Lied aus der Parade des Jahres 2012 setzt diesen Ansatz um: Zunächst wird die positive Beziehung zwischen den Großvätern bzw. Urgroßvätern und der Jugend beschrieben und die bedeutende Rolle der Alten als

243 Fernsehübertragung. Kanal TV Centr: Prjamaja transljacija. Moskva, Krasnaja ploščad'. Toržestvennyj marš v čest’ Pervoj Pobedy. 07.11.2012, 10.00 Uhr. Online: http://www. tvc.ru.

244 Ebd.

245 Ebd. 
Vermittler eines authentischen, positiven und lebendigen Geschichtsbilds herausgestellt. Dann werden die Leistungen und die positiven Eigenschaften der älteren Generation gewürdigt. Als Abschluss wird die Funktion der Großväter und Urgroßväter für das Leben der Jüngeren erklärt: Sie sollen als moralische Autorität und Vorbild dienen und durch ihre Lebenserfahrung praktische Orientierung und Hilfe bieten. Die Befähigung zu dieser Rolle, die positiven Eigenschaften werden ausschließlich mit ihrer Rolle im Krieg erklärt: Die Vorbildhaftigkeit wurde im Großen Vaterländischen Krieg erworben und oder unter Beweis gestellt.

Während im Jahr 2011 das Lied lediglich durch den Auftritt eines Blocks von ungefähr 300 Jugendlichen begleitet wurde, ${ }^{246}$ die als Ganzes die Fahne der Russländischen Föderation darstellten, so wurde im Jahr 2012 zusätzlich zu diesem Block eine Tanzchoreographie von gut 20 Kindern zwischen den historischen Militärfahrzeugen ergänzt.

Die choreographierte Interpretation von Kinderliedern stellt im Rahmen dieser ursprünglich militärischen Veteranenparade das ungewöhnlichste Element dar und ist für die Paradentraditionen nicht typisch. Diese Art der Aufführung ist ein Format, das primär im Rahmen von patriotischen Festivals oder Wettbewerben, wie sie beispielsweise an vielen Schulen der Russländischen Föderation stattfinden, zu verorten ist.

Spätestens mit diesem Element verliert die Parade ihren militärischen Charakter zugunsten der nicht militärisch uniformierten Jugend. Sicherlich nicht zufällig erinnert die Kleidung der Akteure dieses letzten Programmpunktes mit dem Schriftzug »Ich erinnere mich, ich bin stolz (Ja pomnju i goržus')« an die Kleidung der Aktivisten der Jungen Garde, der Parteijugend von Edinaja Rossija.

\subsubsection{Leistungsschau der Erinnerungspolitik}

Dieser letzte Programmpunkt der Paraden der Jahre 2011 und 2012 lässt sich als charakteristisch für die Entwicklung der Parade insgesamt über die letzten Jahre betrachten. Aus der Veteraneninitiative der 1990er Jahre ist sukzessive eine für die Fernsehübertragung durchorchestrierte Showveranstaltung geworden. Die Veteranen, Teilnehmer der ursprünglichen Parade von 1941, spielen nicht zuletzt altersbedingt keine bedeutende Rolle mehr. Stattdessen ist aus der Erinnerung der Veteranen an die eigene Geschichte eine Veranstaltung der Patriotischen Erziehung geworden.

246 Auf den weißen, blauen oder roten Jacken ist die Losung \Ja pomnju i goržus« (১Ich erinnere mich, ich bin stolz`) der Aktion `Georgievskaja lentočka`(Georgsbändchen) aufgedruckt. 
Die beschriebene Verschiebung weg von den militärischen Uniformen hin zu sportlichen Ziviluniformen, wie sie auch von den Russländischen Olympiateilnehmern getragen werden, ist nicht in erster Linie als ein Hinweis darauf zu verstehen, dass zeitgemäßer Patriotismus ohne Uniformen und Militarismus auskommt. Das Programm zur Patriotischen Erziehung der Bürger als Kontext der Parade mit seinen expliziten Zielen, das Ansehen des Militärs, aber auch anderer uniformierter Dienste zu verbessern, legt einen anderen Schluss nahe: Das zivilere Erscheinungsbild soll zeitgemäß wirken und ist als Hinwendung an das junge Großstadtpublikum zu interpretieren. In Moskau sind Jugendliche in Kadettenuniformen auf den Straßen weit weniger präsent als in den Städten der Regionen - auch wenn viele militärisch ausgerichtete Schulen in der Stadt existieren. Die zivile Gestaltung der Parade in allen Bereichen, die sich primär auf die `Generation des 21. Jahrhunderts` beziehen, soll das Erinnern an die Heldentaten der Vergangenheit und die Verteidigung der Stadt im Sinne des >Programms zur Patriotischen Erziehung der Bürger für die urbane Jugend anschlussfähig präsentieren und zwischen den Generationen vermittelnde Identifikationsangebote bereitstellen.

Dafür müssen deutliche kognitive Dissonanzen in Kauf genommen werden, die sich mitunter auch in den Gesichtern der Älteren auf der Tribüne widerspiegeln: Die Distanz zwischen den Kampfuniformen des Jahres 1941 und dem sportiven Chic der Politaktivisten des Jahres 2012 erscheint übergroß. Auch das Nebeneinander der alten martialischen Klänge von Kampfliedern der Sowjetunion wie »Heiliger Krieg (Svjaščennaja vojna) und den heutigen Popmusik-Arrangements des russländischen Kinderfernsehens wirkt irritierend.

Die Inszenierung des letzten Programmpunktes verdeutlicht die Entwicklung der Parade als Ganzes: Genauso wie bei der abschließenden Gesangseinlage mit Tanzchoreographie der militärische Fuhrpark aus Lastwagen und Panzern nur noch einer Kulisse wie in einem Freilichtmuseum gleicht, so hat sich die Veranstaltung zum Gedenken an die Parade zum 24. Jahrestag der Großen Sozialistischen Oktoberrevolution 1941 im Laufe der Jahre zu einer Kulisse für die Patriotische Erziehung der Bürger und damit für die russländische Erinnerungspolitik entwickelt. Nicht mehr das Gedenken steht im Vordergrund, wie noch bei den ersten Paraden Ende der 1990er Jahre, sondern die Präsentation dessen, was der Gegenstand des Gedenkens für die heutigen Generationen bedeuten soll. Damit reiht sich die Inszenierung in ihrem EventCharakter auch in eine gesamteuropäische Entwicklung ein. ${ }^{247}$

247 Jaworski, Rudolf: Jubiläen und Gedenktage im östlichen Europa. Versuch einer einordnenden Betrachtung. In: Jaworski, Rudolf/Kusber, Jan (Hg.): Erinnern mit Hindernissen. Osteuropäische Gedenktage und Jubiläen im 20. und zu Beginn des 21. Jahrhunderts. Münster 2011, 27. 
Die Entwicklung der Paradeninszenierung insgesamt, in der Ausgestaltung von narrativen Elementen genauso wie in Showeinlagen und Ritualen, erscheint als eine taktisch geführte Bearbeitung der Kontingenz der russländischen Geschichte. Die einzelnen Narrative, auf die Bezug genommen wird oder die entfaltet werden, wie beispielsweise Borodino, die Smuta oder die Schlacht um Moskau, sind bekannt und erinnerungspolitisch in dieser Form weitgehend etabliert. Allerdings erscheinen sie in ihrem Zusammenspiel, durch die Integration in einen gemeinsamen Gesamtkontext genauso wie vor dem Hintergrund der Geschichte der Parade, die sich von einem einfachen Marsch einiger Veteranen zu einer Großinszenierung gewandelt hat und ihren Gedenkcharakter zugunsten einer gegenwartsbezogenen erinnerungspolitischen Staatsoper verloren hat, sehr konstruiert. Die Geschichte Russlands wurde in den vergangenen Jahren im Rahmen der Paraden zum Gedenken an die Parade anlässlich des 24. Jahrestages der Großen Sozialistischen Oktoberrevolution als eine stringente und teleologische Grundlage erzählt. Die politischen und gesellschaftlichen Verwerfungen der verhandelten Epochen werden wie auch jegliche Kontingenz ignoriert; der Fokus wird auf gemeinsame Werte und Interessen des Volkes gerichtet. Als zentrale Legitimationsobjekte lassen sich in diesem Zusammenhang, in Übereinstimmung mit den formulierten Zielen des Programms zur Patriotischen Erziehung der Bürger, Gemeinsinn und Opferbereitschaft für die Gemeinschaft sowie Wehrhaftigkeit nach außen feststellen.

Die Paraden der letzten Jahre wiederholen somit eine Fokussierung, wie sie bereits 1941 von Stalin vorgenommen wurde: Angesichts des Überfalls des Deutschen Reiches auf die Sowjetunion erklärte Stalin den Krieg in Anlehnung an den sogenannten Vaterländischen Krieg von 1812 zum Großen Vaterländischen Krieg. Diese Parallelisierung folgte den gleichen Mechanismen. Durch eine sehr spezifische Fokussierung, d. h. immer auch Ausblendung von Ungewolltem, werden gesamtgesellschaftliche Kohäsionschancen und Legitimationsressourcen bereitgestellt. Obwohl diese Großinszenierungen in ihrer Eklektik konstruiert wirken, gibt es doch neben dem gerade angeführten Beispiel von 1941 eine Vielzahl von weiteren Beispielen für die Wirkmächtigkeit dieser Strategie der Wirklichkeitsreduktion auf Dichotomien und den Rückgriff auf Mechanismen der Inklusion und Exklusion.

\subsection{Neue Akteure - Kooperationen der Patriotischen Erziehung}

Durch das zweite Programm im Jahr 2006 wurde die Patriotische Erziehung der Bürger für verschiedenste Akteure geöffnet. Die Öffnung und Förderung für nicht-staatliche Akteure erlaubte es, die Maßnahmen deutlich stärker aus- 
zubauen, als es der für sich schon erhebliche Mittelzuwachs erlaubt hätte. Für beide Seiten der Kooperationen entstehen durch das Engagement als praktischer Mehrwert Ansprechpartner und Kontakte, die auch anderweitig genutzt werden können.

\subsubsection{Prosveščenie - Karte der Erinnerungen}

Das Engagement des Verlags Prosveščenie in der Patriotischen Erziehung der Bürger der Russländischen Föderation kann in seiner Konstellation als beispielhaft für diese Kooperationsformen des zweiten Programms gelten.

Der Verlag Prosveščenie druckte die sowjetischen Schulbücher und viele andere Lehrbücher. Nach den Liberalisierungen auf dem Schulbuchmarkt in den 1990er Jahren behauptete er - trotz massiver finanzieller Probleme - seine führende Position. Auch unter den harten Konkurrenzbedingungen auf dem russländischen Schulbuchmarkt blieb der Verlag im Staatsbesitz der auflagenstärkste im Bereich Schulbücher. Nicht nur in Bezug auf die Eigentümerschaft, auch darüber hinaus kann der Verlag als sstaatsnah bezeichnet werden - und profitierte von dieser Stellung. Es ist davon auszugehen, dass der Verlag bei der Ausarbeitung der Schulbücher für das neue Fach `Russland und die Welt«, das durch die neuen Bildungsstandards 2012 eingeführt wurde, mindestens einen gewissen Vorsprung bei der Ausarbeitung hatte: Der Generaldirektor des Verlags war maßgeblich an der Ausarbeitung beteiligt. ${ }^{248}$ Konkurrenzverlage erklärten dagegen, das gesamte Fach sei nur in die Standards integriert worden, weil Prosveščenie bereit ein Buch zu dem Thema herausgebracht habe, das aber nicht nachgefragt worden sei. ${ }^{249}$ Das vor allem inhaltlich kritisierte Handbuch für Lehrer von Filippov $2007^{250}$ und die entsprechenden Bücher für den Unterricht ${ }^{251}$ entstanden nach Angaben der Autoren auf die Initiative von Kreml und Bildungsministerium hin ${ }^{252}$ - der Verlag war auch hier Prosveščenie. 2011/2012 wurde der Verlag privatisiert - ohne jedoch seine guten Kontakt in die Politik zu verlieren. ${ }^{253}$

248 Vgl. Bojarskij, Aleksej: Učebnik čistoj pribyli. In: Kommersant« Den'gi. Nr.39 vom 03.10.2011, 46. Online: http://www.kommersant.ru/doc/1773074.

249 Vgl. ebd.

250 Filippov, Aleksandr: Novejšaja istorija Rossii 1945-2006 gg. Kniga dlja učitelja. Prosveščenie. Moskau 2007.

251 Danilov, Aleksandr: Istorija Rossii, 1945-2008, 11 klass. Prosveščenie. Moskau 2009 und Danilov, Aleksandr: Istorija Rossii, 1900-1945, 11 klass. Prosveščenie. Moskau 2012.

252 Vgl. Kačurovskaja, Anna: Istoričeskij pripadok. In: Kommersant« Vlast'. Nr. 27 vom 16.07.2007, 14. Online: http://www.kommersant.ru/doc/782464.

253 Vgl. Kapitel: Schulbücher, Bildungspolitik - Geschichtspolitik. 
Anfang des Jahres 2015, im Vorfeld der groß angelegten Feierlichkeiten zum 70. Jahrestag des Sieges im Großen Vaterländischen Krieg, startete Prosveščenie die Aktion "Karte der Erinnerung « ${ }^{254}$ als allrussisches LongMob-Projekt. ${ }^{255}$ Im Ankündigungstext heißt es:

»Die Denkmäler des Großen Vaterländischen Krieges - die monumentalen und bescheidenen, Massengräber und einzelne Gräber, Obelisken, Gedenkstätten, Gedenktafeln... Sie sind die Reflexion der heroischen Heldentat unseres Volkes im vergangenen Krieg! Und es ist sehr wichtig - wo sie sich auch befinden mögen - dass man von ihnen in jedem beliebigen Winkel unseres riesigen Landes weiß. ${ }^{256}$

Im Rahmen von Projektarbeit sollen Schulen, Schulklassen oder Projektgruppen materielle Zeugnisse der Kriegserinnerung fotografieren, beschreiben und die Ergebnisse an den Verlag schicken. Der Verlag stellt eine Website zur Verfügung, in die - auf Basis des Yandex-Kartendienstes - die Ergebnisse der Projekte eingepflegt werden. Staatlicher Kooperationspartner der privatwirtschaftlichen Initiative ist das Bildungsministerium.

Ziel ist es, dass die Teilnehmer über Kriegsereignissen und Kriegshelden gewidmete Denkmale ihrer «kleinen Heimat ‘ Bescheid wissen und ihre Dokumentation mit allen anderen teilen. Das Motto der Aktion lautet: »Erinnerung und Dankbarkeit.«

Das Projekt korrespondiert in jeder Hinsicht mit den Zielen der Programme zur Patriotischen Erziehung. Auf der inhaltlichen Ebene ist es darauf gerichtet, die Achtung vor der ruhmreichen Geschichte zu fördern: In diesem Fall dadurch, dass sich die junge Generation mit den materiellen Zeugnissen der Kriegserinnerung beschäftigt und dadurch mit Ereignissen des militärischen Ruhmes und den Heldentaten der Kriegsgeneration. Die Zusammenführung der Dokumentationen auch zu kleinen Denkmalen an einem zentralen Ort in Form einer Weltkarte bettet das örtliche Denkmal und den örtlichen Gedenkstein in einen weltweiten Erinnerungskontext ein und vermittelt so Bedeutung und Universalität des militärischen Ruhmes. Auf der organisatorischen Ebene entspricht das Projekt dem Ziel, Akteure der Patriotischen Erziehung zu vernetzen, in diesem Fall die staatliche Ebene unmittelbar mit dem Verlag und mittelbar mit den gesellschaftlichen Akteuren, den Lehrern und Schulklassen sowie weiteren Gruppen, die sich beteiligen.

Für die Schulen soll das Projekt einen Rahmen für Projektarbeit im Bereich Regionalgeschichte bieten - die umfassende Vernetzung soll motivierend

254 Karta pamjati. Voinam Velikoj Otečestvennoj vojny posvjaščaetsja. Online: http:// memory-map.prosv.ru.

255 Der Begriff Long-Mob soll als Gegenentwurf zur kurzfristigen Organisationsform des Flash-Mobs verstanden werden. Vgl. Ankündigung des Verlages Prosveščenie. Online: http://www.prosv.ru/about.aspx?ob_no=222\&d_no=17139.

256 Ebd. 
wirken und die Relevanz des eigenen Beitrags verdeutlichen. Die Beiträger bekommen Ehrenurkunden des Organisationskomitees der Projektpartner zugesandt. Das Bildungsministerium kann in der Kooperation mit geringem Aufwand, im Sinne der Programme, die gesellschaftliche Aktivität im Bereich der Patriotischen Erziehung ausweiten. Für den Verlag bestehen Vorteile in verschiedener Hinsicht. Die Kooperation mit dem Bildungsministerium, aber auch mit den Schulen und Lehrern fasst die für das Schulbuchgeschäft wichtigsten Akteure in einem Projekt zusammen. In beide Richtungen kann sich der Verlag als patriotischer und gesellschaftlich engagierter Akteur präsentieren. Dieses Image nützt dem Verlag sowohl bei seinen Kontakten ins Ministerium, beispielsweise im Rahmen von Zulassungsverfahren von Schulbüchern, als auch bei den Kontakten in die Schulen, in Bezug auf die Buchbestellungen. Darüber hinaus generiert das Projekt für den Verlag in großem Umfang direkte Kontaktdaten von Lehrern der Fächer Geschichte und Gesellschaftskunde.

Das Projekt verlief sehr erfolgreich. Die Karte wies nach wenigen Monaten einige tausend Einträge auf - Ende des Jahres 2015 waren es bereits fast 10.000. Die Texte sind von unterschiedlicher Qualität und Länge. Einige enthalten nur Ort und Namen des Denkmals, andere referieren ausführlich Entstehungskontext und historischen Bezugspunkt. Manche Einträge enthalten auch Zeitzeugenberichte, Gedichte oder Beschreibungen der sozialen Praxen an den jeweiligen Orten. Bei den Fotos ist auffällig, dass sich die Beiträger häufig zusammen mit dem Denkmal fotografiert haben. ${ }^{257}$ Zusätzlich sind manchmal Fotos von sozialen Praxen ergänzt wie Wachen durch Militärschulen ${ }^{258}$ oder Paraden sowie Blumen- und Kranzniederlegungen an Festtagen. ${ }^{259}$ Manche Fotos von sozialen Praxen sind auch direkt im Rahmen der Projektarbeit entstanden - so z. B. Treffen mit Veteranen und Zeitzeugen an den entsprechenden Orten oder die Pflege des Areals. ${ }^{260}$

Den Höhepunkt des Projektes bildete eine Festveranstaltung am 22. Juni 2015, dem Tag des Gedenkens und der Trauer, im Museum des Großen Vaterländischen Krieges im Siegespark in Moskau. ${ }^{261}$ Eingebettet in die anderen Veranstaltungen des Gedenktages und gerahmt durch Konzerte und Treffen

257 Zur sozialen Praxis der Fotografie an sowjetischen Kriegsdenkmalen vgl. Makhotina, Ekaterina: Der »Tag des Sieges« als ein erinnerungskulturelles Konfliktfeld: Der 9. Mai in Vilnius« (in russischer Übersetzung). In: Gabovič, Michail (Hg.): >Pamjatnik i prazdnik«. NLO, Moskau 2016. unveröff. Manuskript.

258 Vgl. Karta pamjati (Prosveščenie): ,Voin - osvoboditel’. Online: http://memory-map. prosv.ru/?item $=2257$.

259 Vgl. Karta pamjati (Prosveščenie): Monument Večnaja slava aviatoram, pavšim v bojach za Rodinu. Online: http://memory-map.prosv.ru/?item=9635.

260 Vgl. Karta pamjati(Prosveščenie): Pamjatnik biljar-ozërcam, ne vernuvšimsja s vojny. Online: http://memory-map.prosv.ru/?item=5025.

261 Vgl. IA Regnum: Na Poklonnoj gore pojavilas' karta pamjatnikov Velikoj Otečestvennoj vojny. 22. Juni 2015. Online: http://regnum.ru/news/cultura/1935869.html. 
mit Veteranen wurde das Projekt `Karte der Erinnerung`vorgestellt. Einen Höhepunkt des Programms bildete daneben die symbolische Übergabe der "Stafette der Generationen « durch die Kriegsgeneration. ${ }^{262}$

Das Projekt `Karte der Erinnerung` des Verlags Prosveščenie kann als beispielhaft dafür gelten, wie durch die Öffnung der Patriotischen Erziehung durch das zweite Programm 2006 verschiedene Akteure kooperieren und verschiedene Interessen miteinander verbunden werden. Zudem repräsentiert es in seiner Anlage als interaktives Web-Projekt, das sich auf die Beteiligung von Schülern stützt, die Neuausrichtungen, die besonders durch das dritte Programm 2011 vorgenommen wurden.

\subsubsection{Bike-Shows und Patriotische Erziehung}

Die Bike-Show »Stalingrad $2013 \ll^{263}$ stellt die bisherig auffälligste Kooperation zwischen staatlichen und nicht-staatlichen Akteuren in der Patriotischen Erziehung dar. Das Festival, an dem nach Medienberichten am 23. und 24. August 2013 bis zu 250.000 Menschen teilnahmen, wurde auf der einen Seite unter der Leitung von Aleksander Zaldostanov und seinem Motorradclub `Nachtwölfe ${ }^{264}$ organisiert. Auf der anderen Seite wurde die Veranstaltung umfangreich durch staatliche Akteure wie den Gouverneur oder die Regierung des Wolgograder Gebiets unterstützt. Diese Veranstaltung lässt sich so als eine der Maßnahmen beschreiben, die erstmals in der zweiten Auflage des Programms 2006 im Bereich der Verzahnung von staatlichen und gesellschaftlichen Initiativen gefordert wird. ${ }^{265}$ In diesem Programmabschnitt wird hervorgehoben, dass, nachdem bereits umfangreich von staatlicher Seite Strukturen geschaffen wurden, nun auch verstärkt gesellschaftliche Akteure in die Patriotische Bildungsarbeit integriert werden sollten.

Die Entstehungsgeschichte dieser Veranstaltung ist eng mit der Person Aleksandr Zaldostanov verbunden, der gute Beziehungen zu Vladimir Putin unterhält. Vladimir Putin nahm 2010 auf einem Trike an der Seite von Zaldostanov an einer Ausfahrt der $`$ Nachtwölfe auf der Krim teil. Der Motorradklub veranstaltete bereits seit 2009 ein Motorrad-Festival in Sewastopol. Neben genre-typischen Elementen wie Live-Auftritten berühmter Rockbands und Motorrad-Stunt-Shows wurden in das Festival zunehmend patriotische Inszenierungen russländischer Geschichte integriert.

262 Vgl. Veranstaltungsprogramm Bol'šaja Moskva: Den' pamjati i skorbi. 22.06.2015. Online: http://b-m.info/novosti/den_pamyati_i_skorbi.

263 Fernsehübertragung. Kanal Rossija 2: Stalingrad. Bajk-Šou. 23.08.2013, 23.30 Uhr. Online: http://2.russia.tv/brand/show/brand_id/46444.

264 Russisch: ,Nočnye Volki<

265 Vgl. Programm 2006. 
Die patriotischen Inszenierungen der Bike-Show $2012^{266}$ rückten den Veranstaltungsort Sewastopol in den Fokus. Dies wurde zum einen durch Symboliken des Bühnenbildes erreicht. Das Andreaskreuz als Flagge der Russländischen Marine, die einen ihrer größten Stützpunkte hier unterhält, sowie die Stadtfahne von Sewastopol waren wiederkehrende Elemente. Zudem wurde das Bühnenbild durch eine Nachbildung der Adlersäule, eines der bekanntesten Denkmäler der Stadt, dominiert. Zum anderen spielte der historische und gegenwärtige Ort Sewastopol eine bedeutende Rolle in den Inszenierungen. Aber auch Symboliken, die mit der Sowjetunion verbunden sind, wurden vielfach eingesetzt: Dazu zählten die rote Fahne und das Wappen der Sowjetunion genauso wie rote Banner mit Losungen aus der Zeit des Großen Vaterländischen Krieges.

In der Inszenierung des Jahres 2012 wurde das Bühnenbild zunächst von der Nachbildung einer übergroßen Zarenglocke dominiert, aus der sich dann nach und nach eine Weltkugel mit übergroßer und leuchtend rot gezeichneter Sowjetunion absenkt. Die Sowjetunion wird so symbolisch aus dem Zarenreich geboren. um dann Feuer zu fangen und anschließend symbolisch auseinandergerissen zu werden. Dazu intoniert der Sänger Igor' Demakin ${ }^{267}$ die Zeilen:

»Noch wird das Herz von der Lüge umhüllt,

Noch ist die Morgenröte der Rettung nicht gekommen;

Wenn du dich umschaust, dann wirst du verstehen,

Es ist Zeit, die Glocken zu schlagen;

Um mich herum liegen die Scherben meiner Heimat, Es ist Zeit, die Glocken zu schlagen; «268

Sewastopol wird zum Symbol für die Katastrophe des Zerfalls der Sowjetunion. Kaum verdeckt steht bereits hier die Wahrnehmung des Verlustes der "russischen " Stadt aus der Perspektive Russlands im Hintergrund. In einem weiteren Teil der Inszenierung wird dieses Element noch ausgebaut. Auf einer Großleinwand wird Vladislav Malenkos Gedichtverfilmung 'Sevastopol gezeigt. ${ }^{269}$ Das Gedicht geht zunächst auf Moskau ein:

266 Video der Produktionsfirma FeoShow auf YouTube. Kanal FeoShow: Bajk šou - 2012 Sevastopol'. Kul'minacija. Veröffentlicht am 29.07.2012. Online: https://www.youtube. com/watch?v=Um_DMJDNWzk.

267 Igor' Demakin war als Sänger und Komponist bereits an vorangegangenen Produktionen beteiligt, wie z. B. der Bike-Show Noworossijsk 2011.

268 Diese Zeilen stammen aus dem Gedicht `Kolokola (Glocken)` von Nikolaj Dobronravov. Die letzten beiden Zeilen wurden jedoch dem Original angefügt.

269 Vgl. Malenko, Vlad: Sevastopol'. 19.07.2013. Online: http://vladmalenko.ru/video und https://www.youtube.com/watch?v=HiDImHX23Mg. Der gezeigte Kurzfilm ist eine leicht gekürzte Fassung des Originals von Vladislav Malenko. Der Film ist eine Kollage 
»Moskau!

Du bist keine Heldenstadt mehr;

Diese Finanz-Hämorrhoide -

Unvereinbar mit den Traumata des Krieges. ${ }^{270}$

Anschließend wird in 14 Strophen Sewastopol als Heldenstadt beschrieben, die die wahren russischen Werte bewahrt habe:

»Sewastopol!

Wir bereiten auf dem ewigen Feuer noch keine Pommes für McDonalds zu. [...]

Sewastopol!

Hier ist jede Nacht der 22. Juni und jeder Tag der 9. Mai.« ${ }^{271}$

Das Motiv, dass Russland die kulturelle Kraft zur eigenen Wiederauferstehung nicht aus dem `verwestlichten Z Zentrum, sondern aus der Weite der ursprünglich gebliebenen Peripherie schöpfen müsse, hat seine Wurzeln im 19. Jahrhundert. Seit dem Zerfall der Sowjetunion und den Krisenphänomenen der 1990er Jahre wird dieses Motiv jedoch wieder verstärkt aktualisiert.

So ist es kaum verwunderlich, dass als Finale der Inszenierung der BikeShow 2012 in Sewastopol Igor' Demakin zusammen mit dem Chor der Schwarzmeerflotte immer wieder »Lebe auf, Vaterland/Lebe auf, Vaterland in heiliger Gestalt « intoniert. ${ }^{272}$ Begleitet wurde dieser Part durch die Einfahrt eines schwarzen Tanklastzuges mit der Aufschrift »Mad Max«, auf dessen Tank fünf Biker in Leder-Kleidung und Club-Kutte stehen und die Fahne der Romanovs schwenken. ${ }^{273}$

Die religiöse Konnotation, wie sie sich in der vielfach wiederholten Zeile "Lebe auf, Vaterland in heiliger Gestalt», aber auch in anderen Elementen der

aus vielen bekannten Filmausschnitten, überwiegend aus der Zeit des Großen Vaterländischen Krieges. Darüber spricht Malenko sein Gedicht `Sewastopol. Die musikalische Untermalung stammt von dem Cellisten Borislav Strulev.

270 Ebd.

271 Ebd.

272 Das Lied „Vozrodis' otečestvo (Lebe auf, Vaterland)« wurde von Demakin selbst komponiert, der Text stammt von Nikolaj Zinov'ev.

273 Dieses Arrangement von Auferstehungslyrik, Motorradrockern, Filmtruck und Zaristenfahnen ist aller Wahrscheinlichkeit nach nicht selbstironisch gemeint. Es ist eher als Hinweis darauf zu verstehen, dass der Rahmen, aus dem Symbolik integriert wird, sehr weit gefasst ist. Der Hinweis auf die »Mad Max« Filme (Regisseur: George Miller, 1979-1985) kann unterschiedliche Gründe haben. Inhaltlich beschreiben die Filme eine archaische Welt nach dem Ende der Zivilisation, in der sich in verschiedenen Formen die Frage nach Rückbesinnung auf ursprüngliche Lebensformen stellt. Praktisch gesehen, gehören gestalterische Elemente aus dem Bereichen >Postapokalypse` oder `EndzeitFiction $\prec$ zu den Selbstinszenierungen des Motorrad-Clubs `Nachtwölfe`. So ist das Areal des `Hauptquartiers`, das Bike-Center Moskau, überwiegend Filmkulissen, wie der des Filmes »Mad Max - Jenseits der Donnerkuppel (1985)< nachempfunden. 
Inszenierung zeigt, ist keineswegs zufällig. Unter der Führung von Aleksandr Zaldostanov inszenieren sich die Biker der >Nachtwölfe`seit ungefähr 2009 zunehmend als staatstragend und eben auch kirchennah. $\mathrm{Zu}$ dieser Strategie zählen vor allem medienwirksame Auftritte bei Kreuzprozessionen, Engagement bei kirchlichen Bauvorhaben oder auch Ausfahrten zu Ehren des orthodoxen Patriarchen, auf denen Losungen wie »Glaube, Kirche, Heimat» präsentiert werden. Im Jahr 2009 organisierten Mitglieder der >Nachtwölfe Wachen, um eine Kirche in Moskau, die sie durch islamistische Terroristen bedroht sahen, zu schützen. Ebenfalls 2009 empfing Patriarch Kirill Aleksandr Zaldostanov zu einem persönlichen Gespräch.

Im März 2013 wurde Zaldostanov für sein Engagement von Vladimir Putin der Ehrenorden der Russländischen Föderation verliehen. In dem Ukaz zur Verleihung wird festgehalten, dass er »für die Arbeit in der Patriotischen Erziehung der Jugend, für die Teilnahme an der Sucharbeit und die Verewigung des Andenkens an die Verteidiger des Vaterlandes ${ }^{274}$ ausgezeichnet wird.

\subsubsection{Bike-Show "Stalingrad 2013«}

Vor diesem Hintergrund der bestehenden guten Kontakte zwischen der Leitung des Motorradklubs >Nachtwölfe` und einflussreichen Gruppen in Gesellschaft und Politik, aber auch der voran gegangenen Veranstaltungen in Sewastopol ist die Bike-Show `Stalingrad 2013 « zu betrachten.

Die Bike-Show wurde von Beginn an als fremdfinanzierte Maßnahme der Patriotischen Bildung betrachtet. Das Programm von 2006 und auch das folgende legten einen Akzent darauf, nichtstaatliche Akteure für Maßnahmen im Sinne des Programms zu gewinnen und damit auch patriotische Bildung außerhalb des öffentlichen Haushaltes zu realisieren. Aus diesem Grund wurde die Bike-Show Stalingrad, zumindest direkt, weder aus dem »Programm zur Patriotischen Erziehung der Bürger 2012-2015 « ${ }^{275}$ für das Gebiet Wolgograd noch aus dem speziellen Unterprogramm »Stalingrader Charakter ${ }^{276}$ finanziert. Der Vize-Regierungschef des Wolgograder Gebietes Vasilij Galuškin betonte in einem Interview: »Wir haben viele öffentliche Organisationen und

274 Ukaz Prezidenta RF ot 12 marta 2013 g. N 190 »O nagraždenii gosudarstvennymi nagradami Rossijskoj Federacii«.

275 Postanovlenie Administracii Volgogradskoj oblasti ot 28 nojabrja 2011 g. N 756-p »Ob utverždenii dolgosročnoj oblastnoj celevoj programmy »Patriotičeskoe vospitanie graždan« na 2012-2015 gody«.

276 Podprogramma »Stalingradskij charakter«. Vgl. Postanovlenie Administracii Volgogradskoj oblasti ot 28 nojabrja 2011 g. N 756-p »Ob utverždenii dolgosročnoj oblastnoj celevoj programmy »Patriotičeskoe vospitanie graždan« na 2012-2015 gody«. 
Freiwillige versammelt. Alles was, wir machen, machen wir ohne eine einzige Kopeke aus dem öffentlichen Haushalt. ${ }^{277}$

Jedoch wurde von Beginn an die sogenannten radministrative Ressource aktiviert. Nach einem ersten Treffen zwischen dem Gouverneur des Gebiets Wolgograd, Sergej Boženov, und Aleksandr Zaldostanov im März 2012 wurde von Seiten der Regierung ein Organisationskomitee unter der Leitung des stellvertretenden Regierungschefs eingerichtet. ${ }^{278}$ Zudem bekundete Gouverneur Sergej Boženov öffentlich seine Unterstützung für das Projekt.

Diese Unterstützung durch die Regierung und die Administration wirkte sich primär in den Bereichen »Freiwilligendienste«, Sicherheit und Sponsoring vorteilhaft für die Show aus:

Im Bereich der Freiwilligen wurden die Helfer der Motorradclubs, die maßgeblich an den Bühnenarbeiten beteiligt waren, in verschiedensten Einsatzgebieten durch Freiwillige der >administrativen Ressource« unterstützt. Dazu wurden, wie bereits oben erwähnt, öffentliche Organisationen mobilisiert oder öffentliche Initiativen zur Unterstützung eingebunden. Dies hatte beispielsweise zur Folge, dass das Festivalgelände mehrfach im Rahmen der Initiative »Saubere Stadt ${ }^{279}$ von Mitarbeitern der Wolgograder Steuerbehörde oder den Mitgliedern des Komitees für die Unterstützung der Friedensgerichte aufgeräumt und gereinigt wurde. ${ }^{280}$ Abordnungen der Wolgograder Kosakenvereinigung waren eingesetzt, um das illegale Abladen von Hausmüll oder Bauschutt auf dem Gelände zu verhindern. ${ }^{281}$

Noch deutlicher zeigte sich das Engagement der Administration im Bereich Sicherheit: Zusätzlich zu ungefähr 2800 Polizisten sowie 150 OMON-Kräften, die speziell für die Sicherheit der Veranstaltung eingesetzt waren, wurden durch das Wolgograder Innenministerium weitere Kräfte mobilisiert: Die Polizeieinheiten wurden durch 500 Soldaten ergänzt, die beim Innenministerium entweder gerade ihren Wehrdienst ableisteten oder an der Akademie studierten. ${ }^{282}$ In diesem massiven Einsatz von regulären und improvisierten Sicherheitskräften zeigt sich deutlich die finanziell entlastende Bedeutung, die

277 Fernsehübertragung. Pervyj Volgogradskij Kanal: Volgograd gotovitsja k provedeniju grandioznogo Meždunarodnogo bajk-šou. 3. Juli 2013. Online: http://1vtv.tv/news/ obshchestvo/6358.

278 Oficial'nyj portal Gubernatora i Administracii Volgogradskoj oblasti: Sergej Boženov podderžal ideju provedenija v regione masštabnogo bajk-šou. 30.03.2012. Online: http:// www.volganet.ru/news/news/2012/03/news_00785.html.

279 Akcija: »Volgograd - Čistyj gorod «

280 Oficial'nyj portal Gubernatora i Administracii Volgogradskoj oblasti: Novosti. Online: http://ams.volganet.ru/news/news/2013/07/news_00233.html.

281 Oficial'nyj portal Gubernatora i Administracii Volgogradskoj oblasti: Novosti. Online: http://kdnk.volganet.ru/export/sites/kdk/folder_10/folder_03/kv2_2003.pdf.

282 Oficial'nyj portal Gubernatora i Administracii Volgogradskoj oblasti: Novosti. Online: http://www.volganet.ru/news/news/news_02647.html. 
die Aktivierung des administrativen Einflusses für die finanzielle Durchführbarkeit der Veranstaltung hatte.

Diese finanziellen Vorteile zeigten sich auch in der Akquise von Sponsoren. Über für Großveranstaltungen und Festivals übliche Sponsoren wie beispielsweise Getränkehersteller hinaus engagierten sich im Rahmen der Bike-Show Stalingrad 2013 auch große Unternehmen aus der Gas- und Ölindustrie, Energieversorger und Metallindustrie. ${ }^{283}$ Auch die großen Traditionsfirmen der Wolgograder Rüstungsindustrie `ZKB Titan` und `Barrikady` beteiligten sich. ${ }^{284}$

Diese besondere Zusammensetzung der Sponsoren, die auf den Einfluss der Administration zurückzuführen war, oder der Einsatz beispielsweise von Studenten als Sicherheitskräfte, sind Beispiele dafür, wie nichtstaatliche Initiativen in der Patriotischen Bildung formal ohne Mittel aus öffentlichen Budgets realisiert werden, praktisch aber die Aktivierung der administrativen Ressource der maßgebliche Faktor für die finanzielle Durchführbarkeit wird. Durch Sponsoring, Bereitstellung von Freiwilligen und durch Vermittlung von Kontakten konnte die Bike-Show Stalingrad auf Eintrittsgelder verzichten und neben den 250.000 Besuchern vor Ort auch ein breites Fernsehpublikum mit Patriotischer Erziehung erreichen.

Ein weiterer Vorteil, der aus der klaren Positionierung des Gouverneurs und der Administration sowie aus der Einbindung vieler gesellschaftlicher Organisationen über das Organisationskomitee resultierte, bestand darin, dass es verhältnismäßig wenig Kritik an der Veranstaltung gab. Ohne eine Einbeziehung der großen Verbände hätte schon das Vorhaben, eine Show-Veranstaltung mit Musik an dem Gedenktag für die Opfer des deutschen Bombenangriffs vom 23. August 1942 durchführen zu wollen, massiven Widerspruch beispielsweise aus den Veteranen- und Angehörigenverbänden provozieren können.

Trotzdem: Die Veranstaltung an diesem besonderen Tag wurde in den Medien, insbesondere aus dem kommunistischen Spektrum, teilweise als Trivialisierung der Geschichte und als gegen den Trauercharakter des Tages gerichtet kommentiert. ${ }^{285}$ Von den Befürwortern wurde in der Regel argumentiert, die Show sei eine Möglichkeit, vor allem bei der jungen Generation ein Bewusstsein für die Geschichte der Stadt zu bewahren oder sogar ein Bewusstsein überhaupt zu schaffen.

283 Oficial'nyj portal Gubernatora i Administracii Volgogradskoj oblasti: Novosti. Online: http://www.volganet.ru/news/news/news_02555.html.

284 Oficial'nyj portal Gubernatora i Administracii Volgogradskoj oblasti: Novosti. Online: http://www.volganet.ru/news/news/news_02555.html.

285 Vgl. z.B. Pavlova, Tat'jana: Bajk-Šou-Patriotizm. Ili Pominki po-volgogradski. In: Sovetskaja Rossija. 25.Juli 2013. Online: http://www.sovross.ru/modules.php?name= News\&file $=$ article\&sid $=594331$. 
Allerdings stellte die Bike-Show selbst nur den Höhepunkt einer Gesamtinszenierung dar: Der gesamte Komplex wurde eingeleitet durch eine Sternfahrt, in der Motorrad-Kolonnen aus mehreren Richtungen nach Wolgograd fuhren. Neben Sewastopol und Moskau waren auch Minsk, das nenzische Narjan-Mar an der Barentssee sowie Miass im Ural Ausgangspunkte der Kolonnen. Die Kolonne aus Miass stellte sogar im Motto der Fahrt den Bezug zum historischen Ansatz der Veranstaltung her: »Aus dem Hinterland an die Front«. Den auffälligsten Teil dieser Sternfahrt stellte jedoch die Gruppe aus Sewastopol dar. Ihre Ankunft war in die landesweite Fernsehübertragung integriert.

Um die eigentliche Show war eine ganze Reihe von Programmpunkten gelegt. Dazu zählten ein Besuch des Denkmals »Vereinigung der Fronten« im 70 Kilometer von Wolgograd entfernten Pjatimorsk am Wolga-Don-Kanal, ein Besuch des Museums der Wolgograder Traktorenfabrik, ein Besuch der Kirche am Mamaev Kurgan mit anschließender Kranzniederlegung in der Halle des Ruhmes oder der gemeinsame Besuch des Panoramamuseums "Schlacht von Stalingrad."

Der erste große Programmpunkt am Tag der Bike-Show bestand in einer gemeinsamen Ausfahrt der Teilnehmer der Kolonnen durch die Innenstadt von Wolgograd, entlang der großen Gedenkstädten wie dem Gedenkkomplex am Mamaev Kurgan mit der die Stadt überragenden Mutter-Heimat-Statue. Neben vielen Vereinsfahnen der `Nachtwölfe ‘ wurden dabei auch Fahnen der jeweiligen Herkunftsorte und Wolgograds, aber auch viele historische Fahnen mitgeführt: Besonders häufig zu sehen waren die Fahne der Sowjetunion sowie die Fahnen der Roten Armee und das Andreaskreuz, weniger häufig die Fahne der Marine der Sowjetunion, die Fahne der russischen SFSR und die schwarz-gold-weiße Trikolore mit dem Wappen der Romanovs. Eröffnet wurde diese Formation durch einige historische Militär-Geländewagen und Motorräder und eine martialisch im Stile der Mad-Max-Filme umgebaute schwarze Zugmaschine, von der Lieder des Großen Vaterländischen Krieges gespielt wurden. Auf diese Zugmaschine folgte ein Gespann aus einem >GAZ21 Wolga $<$ mit einem brennenden $>$ Ewigen Feuer ${ }^{286}$ als Anhänger. Diese Form eines >mobilen ewigen Feuers ist ungewöhnlich. ${ }^{287}$ Auch wenn sich die Ver-

286 Zur Entwicklung des Symbols des ewigen Feuers vgl. Makhotina, Ekaterina: Symbole der Macht, Orte der Trauer. Die Entwicklung der rituellen und symbolischen Ausgestaltung von Ehrenmalen des Zweiten Weltkriegs in Russland. In: Heinemann, Monika/Maischein, Hannah (Hg.): Medien zwischen Fiction-Making und Realitätsanspruch. Konstruktionen historischer Erinnerungen. München 2011, $289 \mathrm{ff}$.

287 Am 23. Februar 2010 wurde im Rahmen einer umfangreichen Zeremonie das zeitweise in den Siegespark in Moskau ausgelagerte Ewige Feuer vom Grab des unbekannten Soldaten zurück an die Kremlmauer verlegt. In diesem ungleich feierlicheren und offiziellen Rahmen wurde für den Transfer ebenfalls ein mobiles ewiges Feuer installiert - in 
wendung und die Bedeutung dieses Symbols in den letzten Jahren verändert haben, ${ }^{288}$ so stellt es in Russland immer noch ein Symbol mit einer sakralen Aura dar. Die Praxis, den Fünfstern mit der Flamme im Zentrum auf einem Anhänger hinter einem Oldtimer herzuziehen, dürfte im Sinne einer Profanierung nicht durchgängig auf ein positives Echo stoßen.

Ziel dieser Ausfahrt war der nächste Programmpunkt vor dem Bahnhof Wolgograds: Die Wiedereröffnung des Brunnens "Kinderreigen«. Das Bild des Brunnens wurde 1942 in vielen Zeitungen weltweit zum Symbolfoto für den Angriff Deutschlands auf Stalingrad. Am 23. August 1942 zerstörte die deutsche Luftwaffe Stalingrad und tötete zehntausende Zivilisten. Der TASS Foto-Korrespondent Ėmmanuil Evžerichin fotografierte die Figurengruppe an diesem Tag vor der brennenden Ruine des Stalingrader Bahnhofs. ${ }^{289}$ Auch spätere Bilder zeigen immer wieder den Brunnen mit den sechs Kindern die um ein Krokodil tanzen, vor dem Hintergrund des zerstörten Stalingrads. Im Zuge des Wiederaufbaus der Stadt nach dem Krieg wurde die Figurengruppe entfernt.

Im Rahmen der Gesamtinszenierung der Bike-Show stiftete der Motorradklub `Nachtwölfe ‘ der Stadt Wolgograd den Wiederaufbau des Ensembles in einer vergrößerten Variante. An der Einweihungszeremonie nahmen neben zahlreichen Veteranen und Aleksandr Zaldostanov auch Präsident Vladimir Putin teil. Die gemeinsamen Bilder von Präsident, Zaldostanov und Veteranen wurden in fast allen russischen Fernsehnachrichten des Tages gezeigt.

Auf der seitlich angebrachten Gedenktafel stellen sich die Biker der `Nachtwölfe in eine Reihe mit den Soldaten der Schlacht um Stalingrad: „Von den Motorradfahrern der Nachtwölfe (Russland) - den Nachfolgern des 8. Stalingrader Motorradregiments."

Die Hauptveranstaltung am Abend gliederte sich in drei Teile: ${ }^{290}$ Zunächst traten bis Mitternacht die russischen Bands »13. Sozvezdie«, "Dekabr" «, "Arija«, »Ljubė« sowie der Sänger Aleksandr Maršal auf. Um Mitternacht begann der Showteil mit verschiedenen Inszenierungen und zwischen ein Uhr und

diesem Fall auf einem Schützenpanzer. Auf dieselbe Weise wurde am 30. April 2010 das ewige Feuer im Siegespark nach einem Transfer vom Grab des unbekannten Soldaten entzündet. Vgl. Večnyj ogon' vnov' zažžën na Mogile Neizvestnogo soldata u Kremlëvskoj steny. Moskau, 23.02.2010. Online: http://kremlin.ru/events/president/news/6948.

288 Vgl. Makhotina, Ekaterina: Symbole der Macht, Orte der Trauer. Die Entwicklung der rituellen und symbolischen Ausgestaltung von Ehrenmalen des Zweiten Weltkriegs in Russland. In: Heinemann, Monika/ Maischein, Hannah (Hg.): Medien zwischen FictionMaking und Realitätsanspruch. Konstruktionen historischer Erinnerungen. München 2011, $294 \mathrm{f}$.

289 Evzerichin, Ėmmanuil Noevič: Fontan »Detskij chorovod « na vokzal'noj ploščadi Stalingrada posle naleta fašistskoj aviacii 23 avgusta 1942 goda. TASS, Volgograd August 1942.

290 Vgl. Fernsehübertragung. Kanal Rossija 2: Stalingrad. Bajk-Šou. 23.08.2013, 23.30 Uhr. Online: http://2.russia.tv/brand/show/brand_id/46444. 
vier Uhr morgens traten die deutsche Band »UDO« und die finnische Gruppe »The Rasmus« auf.

Während die internationalen Bands des Nachtprogramms keinen nennenswerten Bezug zur Veranstaltung aufwiesen, sind einige der russischen Bands des Abendprogramms schon öfter im Rahmen von patriotischen Veranstaltungen aufgetreten. Besonders herauszuheben ist dabei die Gruppe »Ljube் Ihr Sänger Nikolaj Rastorguev ist seit 2010 Abgeordneter der Partei `Einiges Russland in der Staatsduma. Die Auftritte der Band bei patriotischen Veranstaltungen werden regelmäßig an wichtigen Feiertagen im Fernsehen ausgestrahlt. Viele berühmte Lieder der Gruppe lassen sich als patriotische Soldatenlieder beschreiben. ${ }^{291}$ Genau wie der Anführer der `Nachtwölfe`, Zaldostanov, wurde auch der Sänger Rastorguev von Vladimir Putin mit dem Ehrenorden der Russländischen Föderation ausgezeichnet. ${ }^{292}$

Aber auch Aleksandr Maršal tritt häufig bei patriotischen Veranstaltungen und Festivals auf. Während der Bike-Show 2013 trug er das Lied »Auf der namenlose Anhöhe« aus dem sowjetischen Film »Stille« von 1963 vor. ${ }^{293}$ Das Lied ist seit den 1960er Jahren ein populäres Lied über den Krieg, in dem, in Anlehnung an tatsächliche Ereignisse, der vergebliche Kampf um eine Siedlung auf einer Anhöhe beschrieben wird.

Der Höhepunkt der abendlichen Inszenierung bestand anschließend aus einem Wechsel zwischen Reenactment, anderen Show-Elementen und Textpassagen, die überwiegend von Aleksandr Zaldostanov persönlich vorgetragen werden. Zunächst rezitiert er eine Überarbeitung des Textes »Heiliges Stalingrad $\ll^{294}$ von Aleksandr Prochanov: ${ }^{295}$

»Stalingrad - das ist ein heiliger Ort der Menschheit genau wie Jerusalem, Mekka, Bethlehem. Stalingrad - das ist eine brennende Ikone, verborgen unter dem blank geputzten gegenwärtigen Pseudonym. Die Völker der Welt fühlten die heilige Macht und die Schönheit des Namens Stalingrad und benannten nach Stalingrad Plätze und Straßen ihrer Hauptstädte. Bei Stalingrad wurde ein mystischer Sieg errungen, als 1943 über der mit vergossenem Blut geheiligten Erde eine unüberwindbare Wand des Lichts errichtet wurde, vor der die Kräfte des Dunklen zurückwichen. ${ }^{296}$

291 Das Album »Rebjata našego polka» fasst viele dieser Lieder zusammen. Veröffentlichungstermin war der 23.02.2004, der Tag der Verteidiger des Vaterlandes.

292 Ukaz Prezidenta RF ot 21.02.2012 N 223 »O nagraždenii ordenom Početa Rastorgueva N.V.«

293 Lied »Na bezymjannoj vysote« aus dem Film »Tišina« Mosfilm-Studio 1963.

294 Prochanov, Aleksandr: Svjatoj Stalingrad. In: Gazeta Zavtra. Nr. 53 (997) vom 26.12.2012. Online: http://www.zavtra.ru/content/view/svyatoj-stalingrad-2012-12-26-000000.

295 Prochanov ist Publizist und Chefredakteur der Zeitschrift `Zavtra<.

296 Fernsehübertragung. Kanal Rossija 2: Stalingrad. Bajk-Šou. 23.08.2013, 23.30 Uhr. Online: http://2.russia.tv/brand/show/brand_id/46444. 
Dann folgt eine Reenactment-Show, in der die Schlacht von Stalingrad dargestellt wird. Daran sind dutzende Darsteller in Uniformen der Wehrmacht und der Roten Armee mit Lastwagen, Motorrädern, Jeeps, Panzern und einem deutschen Bomber beteiligt. Die aufwendige Show endet mit dem Hissen der Roten Fahne und dem Entzünden eines roten Feuers am höchsten Punkt der Bühne.

Nach dieser Einlage rezitiert erneut Zaldostanov:

"Die Mystiker erkennen in diesem Kampf nicht nur eine kolossale und blutige Schlacht, sondern auch die Wiederkunft Jesu Christi. Gekleidet in die Uniform des sowjetischen Soldaten, blutverschmiert und von Kugeln durchsiebt, überquerte Christus die Wolga - die Armee des Paulus einäschernd und den gefallenen roten Helden die Augen schließend. Hier an der Nahtstelle der Fronten am Bauernhof Baburkins, in der Nacht vor Weihnachten, fiel der Vater des Autors dieser Zeilen als Teil eines Strafbataillons. Und in der Weihnachtsnacht lag er unter den glühenden Sternen der Steppe, das Gesicht nach oben, und in seinen Augen blitzten die gefrierenden Tränen. ${ }^{297}$

Beide Passagen sind zusammengefügt aus Fragmenten ursprünglichen Textes »Heiliges Stalingrad «. Dafür wurden, ohne besondere Rücksicht auf das Original, einige besonders prägnante Formulierungen nebeneinander gestellt. Die zentrale Forderung nach einer Rückbenennung der Stadt Wolgograd - »der Stadt an der Wolga ihren heiligen Namen Stalingrad zurückzugeben $\aleph^{298}$ wird ausgeklammert und bleibt nur als Anspielung erhalten. Auch die ätzende Gegenwartskritik Prochanovs wird ausgeblendet. Im Original heißt es:

»Erst heute, nach dem Ende der Sowjetunion, wo Schwachsinn und Deformation herrschen, kommt die grandiose Sinfonie dieses Denkmals zum Vorschein. ${ }^{299}$

Prochanov ist in Russland wegen seiner politischen Positionen, die sich am ehesten als sowjetnostalgischer Nationalismus beschreiben ließen, umstritten. Mit seinem politischen Engagement oder auch durch seine Artikel und Romane steht er in deutlicher Opposition zu Präsidenten und Regierungen der letzten zwanzig Jahre. Gleiches gilt für die von ihm herausgegebene und seit Anfang der 1990er Jahre maßgeblich von ihm geprägten Wochenzeitung. Die Zeitung ist primär als oppositionell gegenüber den postsowjetischen Machthabern einzuordnen. ${ }^{300}$ Dies gilt nicht nur für die Präsidentschaften Dmitrij

297 Ebd.

298 Prochanov, Aleksandr: Svjatoj Stalingrad. In: Gazeta Zavtra. Nr. 53 (997) vom 26.12.2012. Online: http://www.zavtra.ru/content/view/svyatoj-stalingrad-2012-12-26-000000.

299 Ebd.

300 Zunächst war Prochanov Chefredakteur der Zeitung `Den« - die sich in der Verfassungskrise 1993 auf die Seite des Parlamentes stellte und in der Folge durch die El'cinAdministration verboten wurde. Ab November 1993 erschien die Zeitung unter dem neuen Namen `Zavtrar. 
Medvedevs und Vladimir Putins, sondern insbesondere auch für die Boris El'cins.

Dass Prochanovs Texten im Rahmen der Veranstaltung Raum gegeben wird, lässt sich unter drei Aspekten erklären: Zum einen war die patriotische Bike-Show kein direktes staatliches Projekt der Patriotischen Erziehung, sondern durch gesellschaftliche Akteure realisiert. Diese Akteurskonstellation scheint klaren Einfluss auf die inhaltliche Gestaltung gehabt zu haben und führte zu anderen Inhalten als bei rein staatlichen Projekten. Zum anderen wurden die Texte verändert: Erst die Auslassungen und Umstellungen machen den Einsatz seines Textes im Rahmen dieser staatstragenden Veranstaltung möglich. Drittens hat sich die politische Schnittmenge zwischen dem von Prochanov repräsentierten Spektrum und der Kreml-Politik durch die spatriotische Neuausrichtung Putins ab 2012 und durch dessen Ukraine-Politik 2014 deutlich erhöht.

Abgesehen davon, dass sich die verwendeten Texte Prochanovs vom politischen Mainstream abheben und in ihrem Stil und Inhalt über den üblichen Rahmen der Patriotischen Erziehung hinausgehen, sind sie doch für viele Rezipienten anschlussfähig. Die gängige heroische Thematisierung des Großen Vaterländischen Krieges wird durch mystische und christliche Elemente ergänzt. Beides sind Elemente, die in der russischen Gesellschaft in den letzten Jahren mehr und mehr Anklang finden. Zusammen mit der bildhaften und kraftvollen Sprache Prochanovs werden diese Rezitationen so zu einem eindrücklichen Teil einer Inszenierung, in der sich Narrative von sowjetischer Macht und Christentum verbinden.

Neben Elementen wie diesen, die Geschichtsnarrative entwickeln, indem sie bestimmte Bedeutungen kommunizieren, standen im Wechsel immer wieder Elemente, die diese Narrative an die Gegenwart anbinden: So präsentierte nach diesem Textteil und einem kurzen Auftritt des Schwarzmeerflotten-Chores im nächsten Programmteil die Band »Das 13. Sternzeichen ${ }^{301}$ ihr Lied »Živoj« (»Lebendig«). In diesem Lied wird die russische Geschichte vom Verlust der Stadt Rjasan über Borodino und den Großen Vaterländischen Krieg bis zum Afghanistankrieg als eine Geschichte des militärischen Ruhmes dargestellt.

Die Beschreibung der Kontinuität des Kampfes und des Ruhmes aus der Vergangenheit bis in die Gegenwart zeigt sich auch in der begleitenden Inszenierung: Während auf der Bühne die Band spielt, wechseln sich vor der Bühne Darbietungen von uniformierten Reitern und anderen Darstellern in historischen Uniformen ab. Das Spektrum reicht von Rüstungen des 13. Jahrhunderts bis zu NKWD-Uniformen der 1940er Jahre. Der Bezug zur Gegen-

301 Russ.:»13 Sozvezdie«. Die Band tritt seit einigen Jahren auch unter dem Titel»Sozvezdue» (lateinisch und kyrillisch gemischt) auf. 
wart wird mit dem Höhepunkt und Abschluss dieses Elementes hergestellt: Die Bühne wird von einem Schützenpanzers der russischen Armee abgefahren, auf dessen Panzerung ein Fallschirmjäger mit Sturmgewehr steht. Hier wird die Vergangenheit bis in die Gegenwart fortgeschrieben: Von der Reiterei des 13. bis zu den Fallschirmjägern des 21. Jahrhunderts.

Auch der Aspekt des Verlustes des Imperiums wird wieder, wie schon im Vorjahr in Sewastopol, betont: In einem von Zaldostanov vorgetragenen Text werden Stalingrad und Sewastopol nebeneinander gestellt.

»Es gibt zwei glühende Punkte auf dem russischen Weg.

Und zwischen ihnen die schändliche Grenze zweier Länder.

Stalingrad - das ist das Sewastopol an der Wolga;

Und der Malachov- gleicht dem Mamaev-Kurgan.

Der Wind der Wahrheit hat die Mauern zwischen ihnen eingerissen,

Und gegen die Feinde erhebt sich ein neues Heer.

Sei gegrüßt Bruder, ruft Sewastopol Stalingrad,

Uns ruft die Mutter-Heimat. [...] $\aleph^{302}$

Die Bezeichnung der russisch-ukrainischen Grenze als Grenze der Schande und damit implizit auch die Bezeichnung der ukrainischen Unabhängigkeit als Schande - ist in dieser Deutlichkeit nur im Rahmen der speziellen Akteurskonstellation dieser Veranstaltung möglich. Im Rahmen der rein staatlichen Patriotischen Erziehung lassen sich solche Äußerungen nicht feststellen. ${ }^{303}$ In ihnen zeigen sich, wie auch in den Texten Prochanovs, sowjet-nostalgische Tendenzen und damit verbunden imperiale Ansprüche: Nicht nur der Verlust des Weltmachtstatus' wird beklagt, auch die Wiederherstellung des Imperiums durch das Einreißen der "schändlichen« Grenzen wird gefordert. Anfang 2014 beteiligten sich die >Nachtwölfer sowohl durch physische Gewalt als auch durch die Bereitstellung von Netzwerken sowie Kooperationen mit russländischen Sicherheitsorganen auf der Krim an der Teil-Umsetzung dieser Forderung.

Den augenfälligsten Hinweis darauf, dass Projekte der Patriotischen Erziehung von nicht-staatlichen Akteuren in ihrem Themenspektrum und in ihrer inhaltlichen Ausrichtung wesentlich weiter gefasst sind als staatliche oder quasi-staatliche, bietet der letzte rezitierte Text der Bike-Show vor der abschließenden Musikeinlage. Eingeleitet wird dieser Teil durch die Aufführung eines Fragments aus dem Titelsong des Albums 'Stalingrad` der deutschen Heavy-Metal-Band >Accept $«$ : Das Fragment besteht aus einer Rockversion der

302 Fernsehübertragung. Kanal Rossija 2: Stalingrad. Bajk-Šou. 23.08.2013, 23.30 Uhr. Online: http://2.russia.tv/brand/show/brand_id/46444.

303 Auch nach den Ereignissen Anfang des Jahres 2014 lassen sich in dieser Deutlichkeit keine vergleichbaren Aussagen in der rein staatlichen Patriotischen Erziehung feststellen. 
Hymne der Sowjetunion, bei der eine E-Gitarre in ausgeprägtem Legato die Melodie-Stimme spielt. Nach einer Strophe geht dieses Zwischenspiel wieder in den brachial instrumentierten Refrain des Accept-Liedes über, der in dem von Riffs unterbrochenen pathetisch intonierten und mehrfach wiederholten Ruf >Stalingrad! , besteht. Bei der Bike-Show wird dieses Arrangement, sowohl die Hymne als auch der Stalingrad-Refrain, zusätzlich vom Chor der Schwarzmeerflotte intoniert und dadurch in seinem Pathos noch weiter gesteigert.

Die Rezitation beginnt direkt im Anschluss mit einer Stimme aus dem Off, die mit georgischem Akzent an die Stimme Iosif Stalins erinnern soll:

»Viele Angelegenheiten unserer Partei und unseres Volkes werden, vor allem im Ausland, aber auch in unserem Land, verdreht und bespuckt werden. Man wird sich für unsere Erfolge und Errungenschaften grausam an uns rächen. Und auch mein Name wird verleumdet werden. Man wird mir eine Menge Gräueltaten zuschreiben. Und doch .... ${ }^{304}$

An dieser Stelle wird die Rezitation live durch Aleksandr Zaldostanov fortgesetzt:

»... Und doch, wie sich die Dinge auch entwickeln mögen, die Zeit wird fortschreiten, und der Blick der neuen Generationen wird sich auf das Werk und die Siege unseres Vaterlandes richten. Jahr für Jahr werden neue Generationen kommen. Sie werden die Banner ihrer Väter und Großväter wieder erheben [...]. Sie werden ihre Zukunft auf unserer Vergangenheit errichten. Iosif Stalin, 1939. ${ }^{305}$

Ob es sich, wie von Zaldostanov abschließend kenntlich gemacht, tatsächlich um ein Zitat von Stalin handelt, ist fraglich. Dieser Text wurde seit 1998 als Teil eines Gespräches zwischen Stalin und der Diplomatin Aleksandra Kollontaj mehrfach veröffentlicht, seine Authentizität wird jedoch in der Regel angezweifelt. $^{306}$

Die Frage der Authentizität ist jedoch in diesem Zusammenhang von nachrangiger Bedeutung. Das Bemerkenswerte ist, dass hier Aussagen, die von den Veranstaltern der Show Stalin zugeschrieben werden, in der Patriotischen Erziehung eingesetzt werden. Dieser Umstand muss als ein besonderes Phänomen der nicht-staatlichen Patriotischen Erziehung betrachtet werden. In den Projekten, die direkt aus den Programmen finanziert und dementsprechend staatlich orchestriert werden, wird Iosif Stalin nicht berücksichtigt. Ein direk-

304 Fernsehübertragung Kanal Rossija 2: Stalingrad. Bajk-Šou. 23.08.2013, 23.30 Uhr. Online: http://2.russia.tv/brand/show/brand_id/46444.

305 Ebd.

306 Vgl. Dialog. 1998. Nr. 8, 92-94; Dialog. 2004. Nr. 3, 20-33; Stalin I. V.: Sočinenija. Bd. 18. Tver' 2006, 606-611. Das `Original ist nicht zugänglich, inhaltlich gibt es verschiedene Hinweise auf eine nachträgliche Komposition, zeitlich gibt es einen Widerspruch zu dem veröffentlichten Tagebuch von Aleksandra Kollontaj. 
tes Stalinzitat, um ein Anliegen zu unterstützen, wäre in diesem Zusammenhang sehr untypisch. Selbst im Rahmen des durch die Patriotische Erziehung aufwendig inszenierten Gedenkens an die Revolutionsparade am 7. November 1941 auf dem Roten Platz in Moskau, die persönlich von Stalin abgenommen wurde, findet er selbst nicht statt.

Ein weiterer Aspekt der Verwendung erinnert wiederum an die Praxis, die sich bereits im Umgang mit den Texten Prochanovs zeigte: Die Texte werden zumindest teilweise in ihrer Radikalität beschnitten. Die umstrittene Druckversion des Stalin-Zitats ist deutlich antisemitisch: Hier wird die Rache für die Erfolge der Sowjetunion einem zur Weltherrschaft strebenden Zionismus zugeschrieben. ${ }^{307}$ Dieser Aspekt, der sich auch in anderen Teilen der Druckversion zeigt, wurde aus dem von Zaldostanov vorgetragenen Text vollständig entfernt.

Trotzdem gehen die Texte bei Prochanov inhaltlich oder wie im Falle des Stalin-Zitats durch seine zugeschriebene Urheberschaft deutlich über den Kanon der staatlichen Patriotischen Erziehung hinaus.

Inhaltlich schließt das umstrittene Stalin-Zitat jedoch an den Mainstream der Patriotischen Erziehung an. Das Zitat verweist auf die traditionsreiche Diskussion über die >Fälschung der Geschichte zum Nachteil der Interessen Russlands ${ }^{308}$ : Der Angriff auf das Selbstbild als Sieger und Befreier im Großen Vaterländischen Krieg wird nicht nur als verleumderisch und ehrverletzend gegenüber der Veteranengeneration gesehen, sondern auch als Gefahr für die Interessen der Russländischen Föderation. Die `Sicherung der eigenen Geschichte als Legitimationsressource ist deshalb auch Bestandteil der Patriotischen Erziehung.

Begleitet von einem großen Feuerwerk über der Bühne tritt als musikalischer Abschluss der Bike-Show `Stalingrad 2013 «, wie im Vorjahr bei der Show in Sewastopol, Igor' Demakin unterstützt durch den Chor der Schwarzmeerflotte, auf und intoniert in breiter Orchestrierung die bereits bekannten Zeilen:

"Lebe auf, Vaterland / Lebe auf, Vaterland in heiliger Gestalt « ${ }^{309}$

gefolgt von der Strophe:

»Noch gibt es Talente

Noch nicht alle Wurzeln sind zerschlagen

Geist Russlands, lebe wieder auf!

Man hat dich noch nicht ganz eingeäschert. «"10

307 Stalin I. V.: Sočinenija. Bd. 18. Tver' 2006, 610.

308 Vgl. Kapitel: Verewigung und Schutz der Narrative.

309 „Vozrodis' otečestvo (Lebe auf, Vaterland)«, Komponist Igor’ Demakin, Text Nikolaj Zinov'ev.

310 Fernsehübertragung. Kanal Rossija 2: Stalingrad. Bajk-Šou. 23.08.2013, 23.30 Uhr. Online: http://2.russia.tv/brand/show/brand_id/46444. 
Im Vergleich zum Vorjahr wurde lediglich die letzte und vielfach wiederholte Zeile verändert. Die Show in Wolgograd 2013 endet mit den Worten:

»Es wird die Zeit der neuen Rus anbrechen.«" ${ }^{311}$

Der Begriff der >neuen Rus` ist aus dem völkischen russischen Spektrum entliehen. Es handelt sich um ein Schlagwort, unter dem sich radikale russische Nationalisten und Anhänger völkischer Slawenbewegungen beispielsweise in sozialen Netzwerken wie VKontakte und in Jugendbewegungen organisieren.

An der Veranstaltung Bike-Show Stalingrad 2013 ist vieles bemerkenswert: Als erstes fällt die Akteurskonstellation auf. Ein Motorradclub mit besten Kontakten zum russländischen Präsidenten organisierte mit massiver Unterstützung des Gebietes Wolgograd ein Festival für 250.000 Besucher. Obwohl die Show nicht direkt aus dem staatlichen Programm zur Patriotischen Erziehung finanziert wurde, lassen sich indirekt eine Reihe von finanziellen Verbindungen feststellen: Viele der Komitees und Organisationen, die finanzielle Mittel aus dem Wolgograder Programm erhalten, waren aktiv an der Vorbereitung und Durchführung der Show beteiligt. Darüber hinaus wurde die sogenannte administrative Ressource des Gebietes in großem Umfang aktiviert, um das Festival durchführbar zu machen. Die Show entspricht dem Ziel des Programms, die Patriotische Erziehung für nichtstaatliche Akteure zu öffnen.

In diesem Fall lässt sich durch die ausführenden Akteure Aleksandr Zaldostanov und den Motorrad-Club >Nachtwölfe ‘ ein klarer Einfluss auf die Inhalte festmachen. Bei der Auswahl der Inhalte, wie beispielsweise der Texte Prochanovs, zeigen sich bestimmte Sympathien der Veranstalter für politische Richtungen, die deutlich von der Kreml-Linie abweichen. Teilweise bleibt es bei Andeutungen, da Inhalte abgemildert werden. Über Schlagwörter oder Andeutungen ist die Herkunft und Position dieser Beiträge jedoch nachvollziehbar. Es ist offensichtlich, dass bei den Organisatoren der Bike-Shows >imperiale und auch russisch-nationale Positionen mehr Anklang finden, als es die Staatsräson des Kremls zulässt. Diese Abweichung zeigt sich am deutlichsten in dem Rückgriff auf Stalin, der in der staatlichen Patriotischen Erziehung fast vollständig ausgeklammert wird.

Auch an der Sprache wird deutlich: Man ist hier sprachlich dichter am radikalen Chic von Autoren wie Sachar Prilepin, Eduard Limonov, Aleksandr Prochanov und anderen als an der staatstragenden Patriotischen Erziehung. Vielfach stimmt die Inszenierung mit den Worten und der Analyse der genannten Autoren überein. Lediglich die Gegnerschaft zum Kreml wird nicht übernommen. Die lyrische Sprache und der radikale Chic der Verweise haben aber möglicherweise auch eine Funktion: Die Inhalte werden noch deutlich heroischer und martialischer inszeniert als im Rahmen der staatlichen Ver- 
anstaltungen. Zudem kommen sie nahezu ohne Bezüge auf den heutigen Staat und damit auf wenig geliebte Staatsvertreter und Parteien aus. Dieser Ansatz dürfte bei vielen Adressaten die Identifikation mit den Inhalten erleichtern. Die Tonart der Bike-Show, die Nationalismus, Chauvinismus und Großmachtstreben kaum camoufliert, besitzt eine hohe Anschlussfähigkeit, die der staatlichen Patriotischen Erziehung aus Gründen der Staatsräson häufig fehlt: Aus gutem Grund betonen die staatlichen Inszenierungen in der Regel den multiethnischen und multikonfessionellen Charakter der Russländischen Föderation. In diesem Sinne kann die Bike-Show als Versuch gelesen werden, die Patriotische Erziehung auch für ein sowjetnostalgisch-nationales Spektrum anschlussfähig zu machen, welches sich eigentlich in Opposition zum putinschen Russland definiert.

Wiederkehrende Motive der Inszenierung sind die Darstellung von Schwäche und Degeneration durch `Verwestlichung und Modernität sowie die Entwicklung eines Szenarios, das die russische Kultur, in einer völkisch-kulturellen Konnotation, von der Auslöschung bedroht sieht.

Worauf die Inszenierung insgesamt abzielt, wird in der letzten Kameraeinstellung der Fernsehübertragung deutlich: Bevor die Kamera in eine letzte Totale der Bühne wechselt, werden noch einmal die großen Symbole der Show nebeneinander und in langsamen Bildern abgebildet. Was vorher größtenteils durch die Fixierung auf das Show-Programm und schnelle Schnitte verdeckt wurde, wird am Ende der Übertragung noch einmal deutlich gezeigt: Das Bühnenbild besteht aus einer Fülle politisch-historischen Reminiszenzen: Auf der einen Seite der Bühne steht eine Nachbildung der Adlersäule aus Sewastopol, in Erinnerung an den Krimkrieg, auf der anderen eine Nachbildung der Wolgograder 'Mutter Heimat, in Erinnerung an die Schlacht von Stalingrad. Wie schon im Jahr zuvor in Sewastopol gibt es Nachbildungen der Zarenglocke in Originalgröße, als Sinnbild für die Macht der Zaren. Das auffälligste Element am Fuße der Bühne ist ein übergroßes, dem Publikum zugeneigtes 'Ewiges Feuer, das nach Bedarf eine bis zu drei Meter hohe Flamme erzeugt. Das zentrale Element, das über der Bühne die gesamte Szenerie beherrscht, ist ein ungefähr fünf mal fünf Meter großes Wappen, welches in sich noch einmal dieses Konglomerat vereinigt: Es ist das Staatswappen der Sowjetunion, ein Ährenkranz mit Banderole, ${ }^{312}$ der oben einen roten Fünfstern rahmt. Der Unterschied ist jedoch: Über der aufgehenden Sonne im Innern des Wappens schwebt nicht die Weltkugel mit Hammer und Sichel, sondern der Doppelköpfige Adler des Zarenreichs.

Insgesamt versucht die Show mit dieser erinnerungspolitischen Travestie, die Brüche und Widersprüche der russländischen Geschichte aufzulösen. In

312 Der auf der Banderole des Originalwappens in verschiedenen Sprachen aufgebrachte Text `Proletarier aller Länder, vereinigt Euch!` fehlt. 
der Idee von Größe und Macht werden Zarenreich und Sowjetunion miteinander versöhnt. Sogar Orthodoxie und Rote Armee finden so zueinander. Auf diese Weise wird unabhängig vom unbeliebten heutigen Beamtenstaat der 'wahre russische Geist konstruiert, wie er sich genauso in Glanz und Macht des Zarenreiches wie auch in der weltpolitischen Bedeutung der Sowjetunion manifestierte. Die Kraft zur Restauration soll aus der Vergangenheit geschöpft werden und aus der Peripherie, in der sich die urtümlichen russischen Eigenschaften noch erhalten haben. In diesem Verständnis wird Russland, unabhängig von Wahlen, Recht oder Verfassung und besonders abgelöst vom ungeliebten politischen Betrieb, zu einer Entität an sich mit traditionaler auf 'Heiligkeit‘ beruhender Legitimität im Sinne Max Webers.

\subsection{Ausrichtung auf das Web - Helden der Timelines}

$\mathrm{Ab}$ der ersten Neuauflage des Programms und noch verstärkt mit dem Programm 2011 wurde versucht durch neue erinnerungspolitische Formate die Patriotische Erziehung auch auf Bevölkerungsschichten zu erweitern, die über Printmedien oder Fernsehen und Radio kaum zu erreichen waren. Diese Neuausrichtung spiegelt sich auch in den Mittelzuweisungen des Programms, die neben den sklassischen Akteuren wie den Ministerien auch zunehmend an die föderalen Agenturen gehen. Diesen Agenturen, wie beispielsweise die Agentur für Jugendangelegenheiten (Rosmolodëž̌ $)^{313}$ oder die Agentur für Presse und Massenmedien (Rospečat') ${ }^{314}$, bündeln konkrete Kompetenzen in neuen Strukturen, Rosmolodëž im Bereich Jugendpolitik sowie Jugendorganisationen und Rospečat' im Bereich Web und Internet.

Für die Patriotische Erziehung dieses neuen Typs werden von den Akteuren offenbar kurze Videos als ein vielversprechendes Mittel angesehen. Dies scheint in der einfachen Erschließbarkeit und den vielfältigen Möglichkeiten ihrer Audiovisualität begründet. Bild, Text, Musik und Sprache können genauso nach Belieben arrangiert werden wie Fiktion und Realität. Die Chance, über Emotionalisierung oder auch Ästhetik einen Zugang für Inhalte beim Rezipienten zu erzeugen, scheint vergleichsweise hoch zu sein. Zudem sind viele Gattungen im Web auf die Popularisierung und Verbreitung von Videos zugeschnitten. Video-Sharing-Plattformen wie YouTube sind dabei häufig nur noch eine Infrastruktur zur Bereitstellung. Websites, Social Media und Blogs binden diese Plattform-Inhalte ein und verbreiten die Verweise auf sie. Inhalte mit Bezug zu diesen Videos, Kommentare und Diskussionen verlagern sich

313 Federal'noe agentstvo po delam molodëži (Rosmolodëž’).

314 Federal'noe agentstvo po pečati i massovym kommunikacijam (Rospečat', FAPMK). 
auf diese Weise vielfach vom eigentlichen Bereitstellungsort des Videos in eine Vielzahl von anderen Gattungen.

Der Erfolg solcher Videos beruht darauf, dass sie von möglichst vielen Nutzern in verschiedenen Web-Formaten verlinkt, geteilt, geliked und kommentiert werden. Dadurch verteilt und popularisiert der einzelne Nutzer das Video unter den mit seinem Profil verbundenen Profilen, bzw. Freunden oder Followers und wird so zum Multiplikator. Für diesen sepidemischen breitungsweg hat sich die Bezeichnung >viral etabliert. Dabei wird gerade bei kommerziellen oder politischen Viral-Kampagne häufig darauf verzichtet, die Herkunft - als Produkt von Social Advertising - kenntlich zu machen.

Viral-Videos der Patriotischen Erziehung werden auf unterschiedliche Weise bereitgestellt. Zum einen sind sie das Produkt von Wettbewerben, die aus den verschiedenen Programmen initiiert werden. Sie werden anschließend von den ausrichtenden Institutionen oder auch von den Produzenten selbst verbreitet. Zum anderen werden Inhalte auch als direkte Auftragsarbeiten an Produktionsfirmen vergeben. In diesem Fall wird die Verbreitung als ViralVideo häufig ebenfalls durch diese spezialisierten Firmen initialisiert. Sowohl Wettbewerbe als auch Auftragsarbeiten werden daneben auch von nicht-staatlichen Partnern der Patriotischen Erziehung wie Firmen oder NGOs durchgeführt bzw. vergeben.

\subsubsection{Wir erinnern uns!}

Ein Beispiel für einen Wettbewerb als Entstehungszusammenhang bietet das Video »Wir erinnern uns «. ${ }^{315}$ Dieses Video geht auf das Patriotische Jugendprogramm der Stadt Stawropol zurück und wurde aus dem städtischen Budget finanziert. Anlässlich des 70. Jahrestages der Befreiung Stawropols wurde im Rahmen der Förderlinie >Maßnahmen, die sich auf die Verewigung des Andenkens an den Großen Vaterländischen Krieg richten für das beste Video oder Plakat zum Motto »Der Sieg in den Augen der Zeitzeugen« ausgeschrieben.

Das in diesem Zusammenhang entstandene Video wurde Anfang Mai 2013 zunächst mehrfach auf YouTube und später auf weitere Video-Plattformen hochgeladen. In dem Video blicken zwei Rotarmisten des Großen Vaterländischen Krieges in die Ferne und äußern sich bewundernd über die Schönheit dessen, was sie sehen. Ein dritter kommt hinzu und erzählt vom Abschuss eines Messerschmidt-Flugzeugs und der Vernichtung seiner Einheit, um anschließend ebenfalls die Schönheit zu bewundern. Gemeinsam werfen sie die

315 YouTube Kanal Igor' Juškov: My pomnim. Hochgeladen am 04.05.2013. Online: http:// www.youtube.com/watch?v=uf1BINIaLRc. 
Frage auf, ob man sich serinnere . Einer der Soldaten stellt fest "Sie erinnern sich bestimmt! «. Anschließend schwenkt die Kamera in die Blickrichtung der Soldaten und zeigt sie sitzend auf einer bewaldeten Anhöhe über einer heutigen russischen Stadt. Begleitet werden diese Szenen zunächst von Dmitrij Šostakovičs folkloristischem Walzer Nr. 2 und später von Friedrich Händels pathetischer Sarabande. Als Abschluss und während das Schlussfermate der Sarabande erklingt, zeigt das Video in lodernder Schrift den Satz »Wir erinnern uns."

Das Video will einen emotionalen Brückenschlag zwischen den in der Programmbeschreibung vorgesehenen Augenzeugen und den heutigen Generationen, evozieren. Durch den Dialog wird die Verpflichtung der heutigen Generationen sich an das Leid und das Heldentum des Krieges zu erinnern, plastisch. Tatsächlich erfuhr das Video eine große Verbreitung und Popularität innerhalb der Blogosphäre und der Social Media Sites. Bis heute wird das Video an Gedenktagen wie dem Tag des Sieges oder dem Tag der Erinnerung und Trauer das Ziel von Posts, Reposts und Kommentaren. Der häufigste Kommentar der Betrachter ist: "Wir erinnern uns!« Damit treten die Kommentatoren in einen symbolischen Dialog mit der Geschichte ein, dessen Motivation Selbstvergewisserung in der Gegenwart ist.

\subsubsection{Nationale Helden auf YouTube}

Ein Beispiel für eine Auftragsarbeit in diesem Bereich ist der $\$ NationalHeroChannel ${ }^{316}$, ein Kanal der Video-Sharing Plattform YouTube, in dem zwischen Ende 2010 und Ende 2011 zwölf Kurzfilme hochgeladen wurden, in denen Identifikationsfiguren der russischen Geschichte präsentiert werden. Auftraggeber dieser Kampagne war die Abteilung für Jugend- und Familienpolitik der Stadt Moskau, realisiert wurde dieses Projekt durch die auf Social Advertising spezialisierte Moskauer Firma $>$ Chorošaja Žizn'si17. Es stellt ein Teilprojekt der Förderlinie >Patriotische Erziehung` der Abteilung für Öffentlichkeitsarbeit der Stadt Moskau aus dem August des Jahr 2010 dar. Diese Förderlinie soll patriotische Einstellungen in unterschiedlichen Bereichen fördern.

Die Videos sind als Viral-Videos konzipiert, d.h. sie sollen sich über verschiedene Gattungen des Webs wie Blogs, Social Media oder auch Communities ausbreiten. Sie variieren in ihrer Aufmachung und in ihren geschichtlichen

316 YouTube Kanal: NationalHeroChannel. Seit 16.12.2010. Online: http://www.youtube. com/user/NationalHeroChannel.

317 Die Firma präsentierte sich bis Juli 2013 auf der Seite хорошаяжизнь.pф (chorošajažizn' rf). 
Bezugspunkten. Dabei bilden sie sowohl inhaltlich als auch in technisch-kommunikativer Hinsicht einige Tendenzen der Patriotischen Erziehung und damit der russländischen Erinnerungspolitik der späten 2000er Jahre ab.

Die Publikation der Videos erfolgte in zwei Kampagnen: Die erste Gruppe von Videos wurde zwischen Dezember 2010 und Februar 2011 hochgeladen $^{318}$ - die Gruppe folgte September bis Dezember 2011. ${ }^{319}$

Das erste Video der ersten Kampagne mit dem Titel "Echte Superhelden" war gleichzeitig das aufwendigste und auch erfolgreichste Video, gemessen an seinen Aufrufen. Es besteht aus Straßeninterviews im Wechsel mit animierten Grafiken. Zunächst fragt ein Interviewer Passanten, was für sie Superhelden seien. Neben teilweise ironisch vorgetragenen Antworten wie "mein Ehemann" oder »der Präsident« antworten die meisten mit »Superman«. Dann wechselt das Video auf animierte Grafiken in einen Graphic-Novel-Stil. Zunächst werden einige Charakteristika des Protagonisten »Clark Kent» aus der Comic-Serie 'Superman ${ }^{320}$ referiert: Als Superkräfte werden ihm Fliegen und Eis-Atem zugeschrieben, als Hauptfeind wird Lex Luthor vorgestellt. Als Nächstes wird ebenfalls im gleichen Stil ein anderer Held vorgestellt: Ivan Kožedub. Als Superkräfte werden Fliegen, Super-Wille und Super-Tapferkeit vorgestellt. Als Hauptfeind: Faschisten. Dann wird das Comic-Portrait in ein Foto übergeblendet und der `echteく Kožedub vorgestellt:

"Kožedub, Ivan Nikitovič (1920-1991). Fliegerass des Großen Vaterländischen Krieges. Dreifacher Held der Sowjetunion. Er führte 320 Feindflüge durch; schoss 62 Flugzeuge des Gegners ab..$^{321}$

318 Vgl. YouTube: Nastojaščie Supergeroi - Real Superheroes (Hochgeladen am 17.12.2010). Online: https://www.youtube.com/watch?v=ZmkCqs0O-wg; Samaja bol'šaja pobeda (Hochgeladen am 11.01.2011). Online: https://www.youtube.com/watch?v=z1 BKVTlus_U; Sraženie (Hochgeladen am 20.01.2011). Online: https://www.youtube.com/ watch?v=KyCicNDsWZk; Flotovodec (Hochgeladen 25.01.2011). Online: https://www. youtube.com/watch? v=vy8lNSkwN7g; Viktorina (Hochgeladen am 27.01.2011). Online: https://www.youtube.com/watch?v=a7Mh0ewjrNg.

319 Vgl. YouTube: Vozvraščenie (Hochgeladen am 21.09.2011). Online: https://www.youtube.com/watch?v=Opf1PvCK20k; Nastojaščij geroj: Rokossovskij (Hochgeladen am 09.12.2011). Online: https://www.youtube.com/watch?v=W3rKrqdPNdg; Nastojaščij geroj: Konev (Hochgeladen am 09.12.2011). Online: https://www.youtube.com/watch?v= Phq9nIWSTxI; Nastojaščij geroj: Nachimov (Hochgeladen am 09.12.2011). Online: https://www.youtube.com/watch?v=k7Fad20xH10; Nastojaščij geroj: Nevskij (Hochgeladen am 09.12.2011). Online: https://www.youtube.com/watch?v=lZ-bIl2zPDs; Nastojaščij geroj: Donskoj (Hochgeladen am 09.12.2011). Online: https://www.youtube. com/watch?v=PDa00NoJlNo; Nastojaščij geroj: Bagration (Hochgeladen am 09.12.2011). Online: https://www.youtube.com/watch? $v=\_M 2 Z m S y \_o f A$.

320 Z.B. Siegel, Jerry/Shuster, Joe: Action Comics featuring Superman. DC Comics, New York 1938.

321 YouTube: Nastojaščie Supergeroi - Real Superheroes. Hochgeladen am 17.12.2010. Online: https://www.youtube.com/watch?v=ZmkCqs0O-wg. 
Danach wird der Bildschirm schwarz und eine Einblendung fragt: "Gibt es noch weitere Superhelden?" Anschließend beginnt wieder eine InterviewSequenz wie zu Anfang. Diesmal stellt sich auf die Frage nach Superhelden »Batman« als häufigste Antwort heraus. Wie im ersten Teil des Videos wird nun der Held vorgestellt:

»Bruce Wayne, entschied das Verbrechen zu bekämpfen - mit seinen Superkräften: er konstruierte das Batmobil und beherrschte viele Kampfstile.»

Entsprechend der ersten Sequenz wechselt nun das Video wieder auf die Vorstellung eines rechten`Superhelden:

"Marija Oktjabr'skaja, entschied gegen die Faschisten zu kämpfen - mit ihren Superkräften: mit eigenem Geld baute sie einen T-34 Panzer. Perfekt beherrschte sie das Maschinengewehr."

Dann wird das Comic-Portrait wieder in ein Foto übergeblendet und die echte Heldin vorgestellt:

»Oktjabr'skaja, Marija Vasilevna (1902-1944). In den Jahren des Großen Vaterländischen Krieges baute sie von eigenen Ersparnissen einen Panzer T-34 `Kampfgefährtin und wurde dessen Fahrer und Mechaniker.»

Das Video endet mit der Einblendung:

»In Russland gibt es viele Helden, die tatsächlich die Welt gerettet haben. Erinnere dich daran!»

Das Video führt zwei wichtige Aspekte der ersten Kampagne zusammen: Zum einen verweist es auf ein geringes Bewusstsein für die ruhmreiche eigene Geschichte. Es inkriminiert, dass Bewusstsein für fiktive, US-amerikanische Superhelden vorhanden sei, wogegen die echten, die eigenen Helden vergessen würden.

Das Vergessen der eigenen Geschichte wird noch in zwei weiteren Videos der ersten Kampagne thematisiert: Das Video »Viktorina « ${ }^{322}$ stellt ein TV-Quiz dar, in dem die Moderatorin den Anrufern die Frage stellt, wer der Erfinder der »Čiževskij-Lampe ${ }^{323}$ sei. Während im Laufe des Videos verschiedene Anrufer an der Frage scheitern und damit ihr mangelndes geschichtliches Wissen offenbaren, erläutert die Moderatorin anhand von Einblendungen immer mehr Details zur Biografie und zum wissenschaftlichen Werk der Person unter besonderer Hervorhebung seiner Herkunft aus einer Generalsfamilie.

322 YouTube: Viktorina. Hochgeladen am 27.01.2011. Online: https://www.youtube.com/ watch? $\mathrm{v}=\mathrm{a} 7 \mathrm{Mh} 0$ ewjrNg.

323 Lampa Čiževskogo. 
Der letzte Anrufer beantwortet dann unter Hinweis auf die Hilfe seiner Großmutter die Frage richtig: Die Čiževskij-Lampe wurde von Aleksandr Leonidovič Čiževskij erfunden. Abschließend werden alle Details noch einmal in einer animierten Grafik zusammengeführt. Diese Details beschränken sich jedoch auf den Werdegang und verschiedene Erfindungen des Biophysikers. Ausgespart wird dagegen die Denunziation Čiževskijs als »Feind unter der Maske des Wissenschaftlers « ${ }^{324}$, der konterrevolutionäre Theorien verbreite, sowie Repressionen und Zwangsarbeit.

Im Video $»$ Schlacht $\star^{325}$ werden zunächst die Ausmaße der Schlacht von Borodino im Stile eines Blockbuster-Trailers referiert: »Eine der größten Schlachten der Menschheitsgeschichte - zwei Großmächte - zwei große Heerführer 260.000 Menschen - 100.000 Gefallene: Die Schlacht von Borodino.« Dann wird die Frage gestellt: »Aber was wissen die Menschen heute über die Schlacht von Borodino? « und das Video blendet auf Passanten-Interviews über. Um das geringe Wissen der Passanten darzustellen, werden ihnen fehlerhafte Fragen gestellt wie beispielsweise: "War es richtig von Suvorov, nach der Schlacht nach Moskau zurückzuweichen?« oder »Beeinflusste die Teilnahme Puškins den Kampfgeist der Soldaten?" Als Abschluss des Videos werden in einem animierten Comic-Stil die Fragen richtig gestellt - Suvorov war 12 Jahre vor der Schlacht gestorben und Puškin erst 13 Jahre alt - und dem Zuschauer die Frage gestellt »Und was erinnerst du?

Die beiden übrigen Videos der ersten Kampagne sind - entgegen ihrem militärischen Sujet - deutlicher dem Bereich des Social Advertising zuzuordnen. Das Video »Der größte Sieg « ${ }^{326}$ beschreibt im Stil eines Comics, der auf einem Handy-Display angezeigt wird, das Leben eines kleinen Jungen mit schwacher Physis, dessen Vater sich gegen eine Militärkarriere stellt:

»Doch ungeachtet aller Rückschläge verfolgte er seine Ziele. Sein Name: Aleksandr Vasil'evič Suvorov (1729-1800) - Großer russischer Feldherr, der in seiner militärischen Karriere keine einzige Niederlage hinnehmen musste. ${ }^{327}$

Als Abschluss des Videos wird das Handy-Display aus dem Fokus der Kamera genommen und so der Blick auf die nächtliche Skyline von Moskva-Citi freigegeben. Vor diesem Hintergrund wird die Schrift eingeblendet: »Alles beginnt mit einem Sieg über sich selbst. Alles beginnt jetzt. «28 $^{328}$

324 Vrag pod maskoj učenogo. Pravda Nr. 354(6600) vom 25. Dezember 1935, 4.

325 YouTube: Sraženie. Hochgeladen am 20.01.2011. Online: https://www.youtube.com/ watch? $\mathrm{v}=\mathrm{KyCicNDsWZk}$.

326 YouTube: Samaja bol'šaja pobeda. Hochgeladen am 11.01.2011. Online: https://www. youtube.com/watch?v=z1BKVTlus_U.

327 Ebd.

328 Ebd. 
Im Video »Flottenkommandeur « ${ }^{329}$ erklärt ein junger Mann, der als Unternehmer vorgestellt wird, wie er sich mit seiner kleinen Firma gegen größere Konkurrenten durchsetzen kann. Sein Vorbild seien die Seekriegstaktiken von Fëdor Fëdorovič Ušakov - Auflösung des Linienkampfes, Schnelligkeit, Aufmerksamkeit, ständige Kampfbereitschaft und Reservegeschwader. Sein abschließender Kommentar lautet:

»Ich persönlich denke, er war ein großer Mensch. Sein Leben ist ein Vorbild, nach dem jeder Mensch trachten muss, unabhängig davon, womit er sich beschäftigt.." ${ }^{330}$

Alle fünf Videos dieser ersten Kampagne haben gemeinsam, dass sie heroische Geschichtsnarrative vermitteln. Während jedoch bei den zuerst vorgestellten Videos mangelhaftes geschichtliches Wissen und Unkenntnis der heldenhaften Geschichte bemängelt werden, so stehen bei den beiden zuletzt beschriebenen Videos Themen von Social Advertising im Vordergrund: Typische Motivationssätze wie `Glaub an dich!‘, ১Gehe deinen Weg! ’ oder `Nutze deine Chancen! werden in der geschichtlichen Kulisse der Patriotischen Erziehung aufgeführt.

Dieser Ansatz wurde auch in der zweiten Kampagne ab September 2011 fortgeführt. Genre-typisch wurde zunächst ein Teaser-Video veröffentlicht, in dem »die Rückkehr der Helden« angekündigt wird, dem dann weitere sieben Videos zu jeweils einem »echten Helden« folgten.

Die Helden dieser Kampagne sind Konstantin Konstantinovič Rokossovskij, Ivan Stepanovič Konev, Pavel Stepanovič Nachimov, Aleksandr Jaroslavič Nevskij, Dmitrij Ivanovič Donskoj und Pëtr Ivanovič Bagration. Stil und Narrativ der Videos gleichen jeweils dem Suvorov-Video der ersten Kampagne. Zunächst wird in jedem Video der Werdegang eines jungen Mannes beschrieben, der allen Widrigkeiten zum Trotz seinen Weg geht, an sich glaubt und niemals aufgibt. Dann werden der jeweilige Held und seine militärischen Leistungen benannt. Darauf folgt ein dem Protagonisten zugeschriebenes Zitat. Am Ende jedes Videos steht die Aufforderung »Kenne deine Helden!«

Exemplarisch ist das Video zu Rokossovskij:

»Er träumte davon oldat zu werden - doch er musste arbeiten statt zu lernen. Dessen ungeachtet bewahrte er seinen Traum und indem er sich drei Jahre älter machte kam er an die Front.«

Anschließend wird seine Auszeichnung mit dem Georgskreuz, seine Rolle als furchtloser Motivator bei der Verteidigung Moskaus und die Gefangennahme von General Paulus in Stalingrad erzählt. Dann erst wird sein Name

329 YouTube: Flotovodec. Hochgeladen am 25.01.2011. Online: https://www.youtube.com/ watch? $\mathrm{v}=\mathrm{vy} 8 \mathrm{lNSkwN7g}$.

330 Ebd. 
genannt: »Konstantin Konstantinovič Rokossovskij (1896-1968). Marshall und zweifacher Held der Sowjetunion." Das ihm zugeschriebene Zitat lautet abschließend: »Wenn man sterben muss, dann mit reinem Gewissen. « $^{331}$

An dem Video zeigen sich einige Aspekte, die auch für die anderen Videos der Kampagne typisch sind. Der Werdegang der Helden und ihre Heldentaten werden sehr selektiv dargestellt. So gibt es keinen Hinweis auf Rokossovskijs polnische Herkunft oder seine spätere Rolle als polnischer Verteidigungsminister. Stattdessen wird er in einer Einstellung als junger Mann mit der antipolnischen Novelle Taras Bul'ba ${ }^{332}$ von Nikolaj Gogol' abgebildet. Auch die Verhöre durch den NKVD und seine Degradierung werden nicht erwähnt, obwohl das genannte heroische Zitat sich nicht auf den Kampf bezieht, sondern höchstwahrscheinlich auf die Verhörsituationen als NKVD-Häftling. ${ }^{333}$ Einen weiteren exemplarischen Aspekt stellt die teilweise Dekontextualisierung dar: Es wird nicht benannt, in welche Zeit und zu welchem Krieg die Ereignisse gehören oder gegen wen gekämpft wird.

In den Videos der Kampagne werden fast ausschließlich Schlachten mit Namen, Ort und Jahreszahl genannt, aber keine Kriege. Es wird nicht benannt, ob für das Großfürstentum Moskau, das Russische Imperium oder die Sowjetunion gekämpft wurde. Auch gegen wen gekämpft, wurde bleibt vage: Es sind Feinde, Gegner, Mächte, Faschisten oder einzelne Personen. ${ }^{334}$ Lediglich im Video über Aleksandr Nevskij werden die Schweden als Gegner benannt. ${ }^{335}$

Nicht zuletzt da jedes Video der Kampagne im Zusammenhang mit mindestens einem der Tage des militärischen Ruhmes steht, wirken diese Dekontextualisierungen untypisch für militärische Heldennarrative. Eine Erklärung hierfür ist der Hintergrund als Social Advertising Kampagne. Neben Geschichtsnarrativen und militärischem Heldentum liegt ein besonderer Schwerpunkt auf der Betonung von positiven Einstellungen und Charaktereigenschaften der Helden, die auch abgelöst vom militärischen Kontext vorbildhaft für die heutige Jugend sein sollen. Die Vermittlung von Traditionen des militärischen Ruhmes im Sinne der Patriotischen Erziehung verschmilzt in der Kampagne mit den positiven Motivationsbotschaften des Social Adver-

331 YouTube: Nastojaščij geroj: Rokossovskij. Hochgeladen am 09.12.2011. Online: https:// www.youtube.com/watch?v=W3rKrqdPNdg.

332 Zur anti-polnischen Ausrichtung von russischen Schriftstellern nach 1830/1831 vgl. Harle, Vilho: The Enemy with a thousand faces: The tradition of the other in western political thought and history. Westport 2000, 131.

333 Bei Belov wird das Zitat wie folgt angegeben: »Keine falschen Geständnisse ablegen, weder sich selbst noch andere bezichtigen. Wenn man sterben muss, dann mit reinem Gewissen.« Vgl. Belov, Michail: Maršaly pobedy: pobediteli germanskich fel'dmaršalov. Moskau 1995, 115.

334 Genannt werden Mamai, Napoleon und Paulus.

335 Vgl. YouTube: Nastojaščij geroj: Nevskij. Hochgeladen am 09.12.2011. Online: https:// www.youtube.com/watch?v=1Z-bIl2zPDs. 
tisings. Die Nichtbenennung des Gegners entspricht zudem einer zeitweiligen Tendenz der Patriotischen Erziehung in den 2000er Jahren: Bei den Reformen der Feiertage wurde teilweise die Benennung des Gegners gestrichen und durch eine positive, integrierende Bezeichnung ersetzt. So wurde beispielsweise aus dem »Tag des Sieges über die Kaiserlich deutschen Truppen « der »Tag des Verteidigers des Vaterlandes. ${ }^{336}$

\subsection{Zusammenfassung: Patriotismus und Erinnerungspolitik}

Mit den staatlichen Programmen zur Patriotischen Erziehung der Bürger wurde in den letzten Jahren ein komplexes System geschaffen, das zu einem erheblichen Anteil durch erinnerungspolitische Ansätze gesamtgesellschaftliche Kohäsionskräfte generieren soll. Der Patriotismus, als `Liebe zur Heimat‘ und Bereitschaft, sich für den Staat zu engagieren, soll aus Geschichtsbewusstsein sowie dem Stolz auf die eigene Geschichte generiert werden. Dieser $\mathrm{Zu}$ griff erklärt die zentrale Rolle militärischer Traditionen und insbesondere die prominente Stellung des Großen Vaterländischen Krieges innerhalb des Programms.

Insgesamt stehen die Programme zur Patriotischen Erziehung sowohl im Aufbau als auch im Inhalt durchaus in der Tradition der Identitäts- und Geschichtspolitik der Präsidentschaften Boris El'cins.

Der projektierte Patriotismus soll vor allem zwei Funktionen erfüllen: Zum einen soll er Legitimität generieren und dadurch den Staat konsolidieren. Zum anderen sollen die Bürger durch den Patriotismus für die Interessen des Staates aktivierbar gemacht werden. Der Bürger wird als Ressource sowohl für den Wehrdienst und den regulären Dienst in den staatlichen Organen gebraucht als auch für bürgergesellschaftliches Engagement im Sinne des Staates als subsidiäres Entlastungsprogramm.

Für dieses Ziel betreibt das Programm erheblichen Aufwand: Verschiedenste Akteure werden genauso vernetzt wie die verschiedenen staatlichen Ebenen bis hinunter zu den Organen der kommunalen Selbstverwaltung. Inhaltlich zielt das Programm auf eine breite Einflussnahme auf Kultur, Bildung und nicht zuletzt die Massenmedien und das Internet.

An der Verteilung der Mittel des Programms auf verschiedene Akteure lassen sich Veränderungen in seiner groben Ausrichtung ausmachen. In seiner Anfangsphase lässt sich das Programm in seiner Aufstellung als typisch für den Bereich Geschichtspolitik bezeichnen: Primäre Empfänger sind Kultur-

336 Auch wurde der »Tag der Vertreibung der polnischen Besatzer aus Moskau« der »Tag der nationalen Einheit.« Vgl. Kapitel: Neugestaltung der Feiertage. 
und Bildungsministerium als Großinstitutionen. Mit den Neuauflagen hat das Programm hier deutliche Veränderungen erfahren: Die Mittel werden gezielter eingesetzt und neben den Großinstitutionen kommen neue Akteure wie staatliche Medienholdings und staatliche Agenturen hinzu. Gerade die in den letzten Jahren in Russland gebildeten Agenturen mit ihren differenzierten Tätigkeitsfeldern wie die Jugendagentur oder die Agentur für Presse gehören heute zu den primären Nutznießern des Programms auf der föderalen Ebene.

Die Maßnahmen des Programms haben häufig vor allem Initiativcharakter. Sie haben die Funktion, beispielsweise Themen oder Kampagnen anzustoßen oder zu administrieren. Gleiches gilt auch für die genannten vom Programm bedachten Akteure. Die tatsächliche Vollfinanzierung oder auch praktische Umsetzung erfolgt dann häufig durch Projektpartner oder andere staatliche oder nicht-staatliche Akteure.

In einer ersten Phase waren Veränderungen im Feiertagskalender die sichtbarsten Umsetzungen der Programme. Die Entwicklung des Gesetzes über die Tage des militärischen Ruhmes zeigt zunächst in ihrem Ausgangspunkt, dass eine heroisierende Erinnerungspolitik, die staatliche Macht und militärische Erfolge in den Mittelpunkt stellt, keine Entwicklung der 2000er, sondern ein Element der Präsidentschaft Boris El'cins darstellt. Diese Politik, die militärische Traditionen betont und sich dabei genauso aus der Zeit der Sowjetunion als auch der früheren Phasen der russischen Geschichte bedient, wurde dann unter Vladimir Putin fortgesetzt, ausgeweitet und finanziell deutlich besser ausgestattet. Zudem wurden in vielen Bereich Rechtsakte vereinheitlicht bzw. in aktuellen Gesetzestexten zusammengeführt.

Später wurde das Gesetz explizit über militärische Traditionen hinaus auf Gedenktage ohne militärischen Bezug erweitert. Das Gedenken an die Schlacht von Borodino steht jetzt neben dem Tag der Verfassung der Russländischen Föderation und neben der Schlacht von Stalingrad wird des ersten demokratisch gewählten Parlamentes gedacht. Zudem werden in diesen Novellen auch Gedenkbezüge integriert, die sich nicht ohne Weiteres in ein heroisches Gedenken einfügen.

Auch in einem anderen Zusammenhang wird das militärische Pathos der Urfassung des Gesetzes aufgeweicht: In einer Reihe von Fällen werden Gedenktage in ihrem Wortlaut sabgerüstet indem auf die Nennung des Feindes zugunsten einer identitätsstiftenden, nach innen integrierenden Bezeichnung verzichtet wird.

Insgesamt ist es möglich, diese Neugewichtung, welche die erinnerungspolitischen Gewichte von den militärischen Ruhmestagen hin zu weniger heroischem Gedenken und zu >zivilen Bezugspunkten verschiebt, als eine Erweiterung der erinnerungspolitischen Agenda im Bereich des Festtagskalenders zu beschreiben. 
Ob diese Neuausrichtung Bestand hat, ist jedoch fraglich. Ab dem Jahr 2013 lassen sich erste Anzeichen für einen Rollback der verbalen Abrüstung feststellen: So wurde am 2. November 2013 das Gesetz über die Tage des militärischen Ruhmes erneut geändert. Der Tag des militärischen Ruhmes anlässlich der "Aufhebung der Blockade von Leningrad « am 27. Januar wurde, augenscheinlich im Zusammenhang mit den Feierlichkeiten zum 70. Jahrestag im Jahr 2014, umbenannt. Die neue Bezeichnung ist: »Tag der vollständigen Befreiung der Stadt Leningrad durch die sowjetischen Truppen von der Blockade der deutsch-faschistischen Truppen.« Neben der »Rolle der sowjetischen Truppen « wird hier aber auch wieder der ehemalige Gegner aktualisiert. ${ }^{337}$ Diese Änderung des Gesetzes läuft also den zuvor attestierten Tendenzen zuwider.

Ein eindrückliches Beispiel dafür, wie die neuen Feiertage umgesetzt werden, sind die Inszenierungen, die jährlich am ehemaligen Revolutionstag in Moskau stattfinden. Hier wird ein patriotisch-heroischer Generationenvertrag beschworen, der das Gedenken an den Großen Vaterländischen Krieg in den jüngeren Generationen verankern soll. In den Inszenierungen der Paraden reiht sich die Jugend symbolisch in die Tradition der Verteidiger des Vaterlandes ein. Sie geloben das Andenken an die Heldentaten zu bewahren und bekennen sich selbst zu Einsatzbereitschaft für die Gemeinschaft und Patriotismus. Im Gegenzug können sie teilhaben an der moralischen Autorität und Legitimität der Kriegsgeneration.

Wie sich im Wandel der Inszenierung der vergangenen Jahre zeigt, spielen dabei die wirklichen Interessen oder Ansichten der Älteren keine entscheidende Rolle. Ihre eigene Vergangenheit, an die die Veteranen ursprünglich erinnern wollten, wird in den Paradeninszenierungen der letzten Jahre zunehmend zur Kulisse einer Erinnerungs- und damit Identitätspolitik der Gegenwart.

Mit der ersten Neuauflage des Patriotismus Programms fand eine neue Schwerpunktsetzung statt: Die Öffnung der Patriotischen Erziehung für nicht-staatliche Akteure führte zu vielfältigen Kooperationen mit sehr unterschiedlichen Motivationen. Die Beispiele - die Aktion `Karte der Erinnerung und die Bike-Show der Nachtwölfe - zeigen, wie sich die Patriotische Erziehung durch die Integration nicht-staatlicher Akteure verändert. Dabei entspricht die `Karte der Erinnerung inhaltlich vollständig der Ausrichtung der staatlichen Programme. Das Beispiel der Bike-Shows zeigt dagegen, wie die Nachtwölfe in ihrer Kooperation eigenständige inhaltliche Akzente setzen.

337 In der Presseerklärung des Kremls hieß es dazu: „Die Umbenennung des Tages ermöglicht es, die Rolle der sowjetischen Truppen bei der Liquidierung der Blockade vollständiger darzustellen und damit das bisherige Bedeutungsdefizit der Bezeichnung zu beheben.« Presseerklärung des Präsidenten der Russländischen Föderation vom 2. November 2013: Vneseno izmenenie v zakon o dnjach voinskoj slavy i pamjatnych datach Rossii. Online: http://www.kremlin.ru/acts/19536. 
Elemente wie der orthodoxe Stalinismus aus der Feder Aleksandr Prochanovs stehen außerhalb des Rahmens der gängigen russländischen Erinnerungspolitik. In der patriotischen Kooperation wird diesen Inhalten jedoch eine breite mediale Bühne bereitet.

Neben der inhaltlichen Arbeit werden durch die Programme Netzwerke geschaffen, in denen unterschiedliche Akteure auf unterschiedlichen Ebenen profitieren, aber auch Kontakte aufbauen. Die organisatorischen Kontakte der Nachtwölfe aus dieser Kooperation dürften auch im Februar 2014 auf der Krim eine wichtige Rolle gespielt haben. In enger Abstimmung mit dem russländischen Militär und Sicherheitsdiensten waren die Nachtwölfe an der Ausschaltung Kiew-treuer Kräfte beteiligt. Durch ihre patriotischen Projekte, wie u. a. die Bike-Shows, verfügten die Biker sowohl über administrative und gesellschaftliche Kontakte in Russland als auch auf der Krim. Russische Sicherheitskräfte konnten auf diese Kontakte genauso zurückgreifen wie auf die Biker selbst, um `Bürgerwehren zu organisieren und die Macht auf der Krim zu übernehmen.

Der dritte große Schwerpunkt der Programme richtet sich auf ein jüngeres Publikum. Budgetverschiebungen und Kompetenzbündelung bei speziellen Agenturen zeugen von diesen Ansätzen. Die Patriotische Erziehung versucht z. B. mit Projekten wie dem NationalHeroChannel - die heroischen Vorbilder für die Gegenwart durch die Nutzung von Viralstrategien in die Time Lines und news-updates eines Publikums zu bringen, das über das Fernsehen kaum noch erreicht wird.

Die deutliche Dekontextualisierung der geschichtlichen Inhalte, wie sie sich in Videos der National-Hero-Serie zeigt, ist nicht als Relativismus oder Beliebigkeit des geschichtlichen Bezugs zu verstehen. Sie ermöglicht als Strategie vielmehr eine bruchlose Darstellung über Jahrhunderte und Umbrüche hinweg. Nicht wer für wen und gegen wen gekämpft hat, steht im Fokus, sondern das vorbildhafte Handeln und Engagement in allen Zeiten. Zusammen mit den Social Advertising Elementen stellt diese Strategie den Versuch dar, die `ruhmreiche russländische Geschichte` für die Jugend der Gegenwart der Russländischen Föderation sinnhaft zu perspektivieren, ohne durch Exklusion von Epochen die Kohäsionswirkung einzuschränken.

Die Betrachtung der Patriotischen Programme macht deutlich, dass ihre Bedeutung über die geschichtspolitische Förderung eines heroischen, vorbildhaften Geschichtsbildes hinausgeht. Die Programme fördern, organisieren und finanzieren die vertikale und horizontale Vernetzung staatlicher Akteure genauso wie die enge Verzahnung von Staat und gesellschaftlichen sowie wirtschaftlichen Akteuren. Die Programme schaffen auf diese Weise vielfältig nutzbare Kontroll- und Mobilisierungspotenziale auf einer Vertikalen vom Weißen Haus bis hinunter zum patriotischen Nachbarschaftskomitee eines Wohnblocks. 


\section{Schulbücher, Bildungspolitik - Geschichtspolitik}

\subsection{Geschichte und Perestrojka}

Schulbücher und inhaltliche Vorgaben von Bildungspolitik sind Themen, die in der Russländischen Föderation schon immer intensiv und kontrovers diskutiert wurden. Ein Grund hierfür könnte in der Erfahrung der Menschen mit dem staatliche Deutungsmonopol über Geschichte zu Zeiten der Sowjetunion liegen. Was über Geschichte gewusst werden und wie Geschichte gedeutet werden sollte, war nicht Ergebnis eines Aushandlungsprozesses, sondern folgte staatlichen Vorgaben. Das Ende des sowjetischen Systems ging einher mit der sukzessiven Aufgabe dieses Deutungsmonopols und parallel dazu mit der Erosion des Geschichtsbildes durch gesellschaftliche Prozesse. Bildungspolitik und ihre inhaltlichen Vorgaben - und durch Zulassungsverfahren können auch Schulbücher hierzu gezählt werden - bewegten sich in diesem sensiblen schulischen Bildungsbereich, in dem auch der post-sowjetische Staat zumindest potenziell auf Geschichtsdeutungen einwirken kann.

Für den Geschichtsunterricht in der Sowjetunion galt: ein Fach ein Buch. Daher gab es ein Buch für sowjetische Geschichte und ein Buch für allgemeine Geschichte pro Klassenstufe. ${ }^{1}$

Das Einheitsbuch für sowjetische Geschichte für die oberen Klassen ${ }^{2}$ hatte eine klare Struktur: Die Kapitel waren streng chronologisch angeordnet. Ihre Untergliederungen behandelten verschiedene Aspekte des Zeitabschnitts, wie z. B. ökonomische oder politische Entwicklungen. Formal bestanden die Kapitel aus einem durchgehenden Fließtext, der am Ende durch einige Quellenauszüge ergänzt wurde. Den Abschluss des Kapitels bildete ein Absatz mit einigen Fragen und Aufgaben zu dem vorangegangenen Kapitel. Im Gegensatz zu den Büchern für die unteren Klassen wurde auf Bilder und Grafiken weitgehend verzichtet.

Das sowjetische Einheitsgeschichtsbuch, das einen synchronisierten $4 \mathrm{Ge}-$ schichtsunterricht in der gesamten Sowjetunion ermöglichen sollte, geriet im

1 Vgl. de Keghel, Isabelle: Die Rekonstruktion der vorsowjetischen Geschichte. Hamburg 2006, $72 \mathrm{ff}$.

2 Vgl. z.B. Rybakov, Boris: Istorija SSSR. Moskau 1985. 
Laufe der Perestroika zunehmend in die Kritik. ${ }^{3}$ Durch die Enttabuisierung von Themen und die neue Offenheit, mit der öffentlich, aber auch privat die Geschichte der Sowjetunion verhandelt wurde, verbreiteten sich vielfach neue Geschichtsdeutungen, die das traditionelle sowjetische Geschichtsbild in Frage stellten. Durch die Lockerung der Zensur und die Liberalisierung der Diskussion kam Geschichtswissen hinzu, das nicht nur neu war, sondern auch häufig in direktem Widerspruch zum Lehrbuchwissen stand. Das vereinheitlichte Geschichtsbild war, als in sich geschlossenes System, nur unter den Bedingungen eines Deutungs- und Informationsmonopols möglich. In dem Moment, als dieses Monopol wegfiel und Widersprüche zu Tage traten, wurde dementsprechend das gesamte Geschichtsbild desavouiert.

Als Konsequenz der konfligierenden Geschichtsdeutungen wurden im Mai 1988 zunächst die Geschichtsprüfungen an Schulen ausgesetzt - bzw. durch ein ızwangloses Gespräch ersetzt - und kurz darauf sogar explizit das Abweichen von der Lehrbuchmeinung in Prüfungen erlaubt. ${ }^{4}$ Zudem fand 1988 eine Neuausschreibung für das Schulbuch zur Geschichte Russlands und der Sowjetunion im 20. Jahrhundert statt. ${ }^{5}$

1990 brachte der sowjetische Schulbuchverlag Prosveščenie eine letzte überarbeitete Version der $>$ Geschichte der UDSSR ${ }^{6}{ }^{6}$ für die 11 . Klasse heraus. Obwohl das Buch noch ganz der marxistisch-leninistischen Geschichtsdeutung verpflichtet war, formulierten die Autoren das Ziel, auf der Grundlage von neuen historischen Fakten und Meinungen - wie z.B. dem erstmals in einem sowjetischen Schulbuch thematisierten geheimen Zusatzprotokoll zum deutsch-sowjetischen Nichtangriffsvertrag von 1939 - »mutig den Weg zu einer demokratischen und menschlichen Gesellschaft zu beschreiten. ${ }^{7}$

\subsection{Pluralität und Stagnation in den 1990er Jahren}

Wie die Reformversuche des sowjetischen Systems allgemein, so wurden auch die Reformversuche des sowjetischen Geschichtsbildes - in Form des letzten Schulbuches - von den Ereignissen überrollt und konnten keine Wirkung entfalten. Im Bereich des Geschichtsunterrichtes und der Schulbücher begann

3 Vgl. Davies, Robert: Soviet History in the Yeltsin Era. London 1997, $119 \mathrm{ff}$. oder Husband, William: Secondary School History Texts in the USSR: Revising the Soviet Past, 19851989. In: The Russian Review 50/4 (1991), 458-480.

4 Vgl. de Keghel, Isabelle: Die Rekonstruktion der vorsowjetischen Geschichte. Hamburg 2006, 73.

5 Vgl. Davies, Robert: Soviet History in the Gorbachev Revolution. Bloomington 1989, 184.

6 Ostrovskji, Valerii: Istoriya SSSR. Moskau 1990.

7 Ebd., 4. 
daher eine Phase des erzwungenen Experimentierens, in der verschiedene Strategien zum Einsatz kamen: Zum einen bildeten Lehrer Material-Pools aus gesammelten Zeitungs- und Zeitschriftenartikeln. Diese Sammlungen aus Artikeln, Karten und Fotos wurden in vielen Schulen aufgrund der schlechten Finanzausstattung noch über viele Jahre weiter genutzt. Zum anderen wurde aber auch versucht, bestehendes - und als ideologisch unbelastet geltendes - Wissen zu transferieren. Dies geschah sowohl durch die Neuauflage vorrevolutionärer Lehrbücher als auch durch die Übersetzung ausländischer Lehrbücher. Dieser Transfer stellte jedoch keine befriedigende Lösung dar: Die vorrevolutionäre Literatur war didaktisch und inhaltlich veraltet. Die ausländischen Werke - hier fand vor allem die Geschichte der Sowjetunion von Nicolas Werth Verbreitung ${ }^{8}$ - waren nicht für Schüler geschrieben.

Neben der Improvisation und dem Wissenstransfer setzte sich zunehmend die Neufassung der russländischen Geschichte für den Unterricht durch: Im Frühjahr 1992 kam das erste russländische Geschichtsschulbuch auf den Markt: »Istorija Otečestva 1900-1940«, »Die Geschichte des Vaterlands. 1900-1940 «. ${ }^{9}$ Das Buch beschrieb unter Rückgriff auf einen zivilisationsorientierten Ansatz eine Geschichte der Annäherung Russlands an Westeuropa. ${ }^{10}$ Im gleichen Jahr kam auch die "Geschichte des Vaterlandes 1939-1991 ${ }^{11}$ von Valerij Ostrovskij heraus. ${ }^{12}$ Beide Publikationen hatten wegen der Monopolstellung des Verlags Prosveščenie eine Millionen-Auflage und wurden aufgrund der schlechten wirtschaftlichen Bedingungen über Jahre eingesetzt.

Ab 1994 brachte eine zunehmende Zahl an Verlagen eine Vielzahl von Schulbüchern auf den Markt. ${ }^{13}$ Die Bücher unterschieden sich deutlich sowohl in ihrer didaktischen Konzeption als auch in ihrer politischen Grundhaltung und in den enthaltenen Geschichtsdeutungen.

Während einige Publikationen die Struktur des Einheitsbuches weiter verwendeten, erprobten andere Publikationen neue Strukturen. Der Fließtext wurde zunehmend durch Fragen, Quellen oder Grafiken aufgebrochen. Insgesamt blieb in den 1990er Jahren die Gestaltung jedoch auf einem einfachen Niveau. Wohl auch aus Kostengründen wurde weitgehend auf Bildelemente oder sogar Farbdruck verzichtet.

8 Vert, Nikolja: Istorija Sovetskogo gosudarstva. 1900-1991. Progress, Moskau 1992.

9 Žarova, Ljudmila/Mišina, Irina: Istorija Otečestva, 1900-1940. Prosveščenie, Moskau 1992.

10 Vgl. Ševyrev, Aleksandr: Das Bild Rußlands in heutigen russischen Geschichtslehrbüchern. In: Internationale Schulbuchforschung 17/4 (1995), $413 \mathrm{ff}$.

11 Ostrovskij, Valerij: Istorija Otečestvo. 1939-1991. Moskau 1992.

12 Eine Besprechung findet sich in: Ševyrev, Aleksandr: Das Bild Rußlands in heutigen russischen Geschichtslehrbüchern. In: Internationale Schulbuchforschung 17/4 (1995), $418 \mathrm{ff}$.

13 Vgl. z. B. Doluckij, Igor': Otečestvennaja istorija. XX vek. Čast' I. Moskva 1994; Danilov, Aleksandr: Istorija Rossii. XX vek. Moskva 1995; Ostrovskij, Valerij: Istorija Rossii. XX vek. Moskva 1994. 
Parallel zu der Entwicklung eines vielfältigen Angebots auf dem Schulbuchmarkt gab es auch erste legislative Weichenstellungen im Bildungsbereich: Im "Gesetz über die Bildung ${ }^{14}{ }^{14}$ wurde bereits 1992 die Erziehung zum Patriotismus, zur $»$ Liebe zur Heimat ${ }^{15}$ als grundlegendes Prinzip festgeschrieben und durch die erste Novelle des Gesetzes 1996 erweitert. ${ }^{16}$ Dem Schulunterricht in den Fächern Geschichte und Sozialkunde wurde durch das russländische Bildungsministerium eine wichtige Rolle bei der Transformation und der Konsolidierung der Gesellschaft zugeschrieben: Sie seien beinahe die einzigen stabilen Mechanismen, um »in das politische, wirtschaftliche, nationale, rechtliche und konfessionelle Chaos Elemente der gegenseitigen Verständigung und der Zusammengehörigkeit einzubringen. ${ }^{17}$

Von Bedeutung für den Schulunterricht und die Regulierung von Schulbüchern war darüber hinaus die Festlegung im Gesetz von 1992, dass staatliche Bildungsstandards mit föderalen und national-regionalen Elementen durch den Obersten Rat der Russländischen Föderation eingeführt werden sollten. ${ }^{18}$ Die neue Verfassung 1993 machte diese Pläne obsolet: In Artikel 43 der Verfassung wurde festgelegt föderale Standards zu erlassen - am 24. Dezember 1993 dekretierte El'cin die Kompetenz dazu an die Russländische Regierung. ${ }^{19}$ Anfang 1994 wurden dann Vorgaben zur Erstellung föderaler Bildungsstandards festgelegt. ${ }^{20}$ Die tatsächliche Ausarbeitung zog sich dann jedoch über Jahre, sodass sich die Entwicklung auf dem Schulbuchmarkt abgekoppelt davon vollzog. Viele Entscheidungen - beispielsweise darüber, wie der Stoff auf die Schuljahre verteilt wird oder ob allgemeine und russländische Geschichte integriert oder getrennt unterrichtet werden - durften bzw. mussten daher durch die Kollegien getroffen werden. ${ }^{21}$

Für Schulbücher gab es ab 1994 eine Liste raktuell gültiger Literatur und ab dem Schuljahr 1995/1996 wurden Lehrbücher durch die Aufnahme in das sogenannte sföderale Paket empfohlen und in ihrer Verbreitung gefördert. ${ }^{22}$

14 Zakon RF ot 10.07.1992 N 3266-1»Ob obrazovanii«. 1. Fassung.

15 Ebd. 1. Fassung, Artikel 2.

16 In der ersten Überarbeitung nach der Verabschiedung der neuen Verfassung wurde später noch die »Liebe zur Umwelt» und die »Liebe zur Familie« ergänzt. Vgl. ebd. 2. Fassung, Artikel 2.

17 Tjulaeva, Tamara: Die Reform der historischen und sozialkundlichen Bildung an russischen Schulen. In: Internationale Schulbuchforschung 17/4 (1995), 393.

18 Zakon RF ot 10.07.1992 N 3266-1 »Ob obrazovanii«. 1. Fassung, Artikel 2.

19 Ukaz Prezidenta RF ot 24.12.1993 N 2288 » merach po privedeniju zakonodatel'stva Rossijskoj Federacii v sootvetstvie s Konstituciej Rossijskoj Federacii«.

20 Postanovlenie Pravitel'stva Rossijskoj Federaciiot 28 fevralja 1994 g. N 174.

21 Vgl. Tjulaeva, Tamara: Die Reform der historischen und sozialkundlichen Bildung an russischen Schulen. In: Internationale Schulbuchforschung 17/4 (1995), 392.

22 Vgl. de Keghel, Isabelle: Die Rekonstruktion der vorsowjetischen Geschichte. Hamburg 2006, $75 \mathrm{f}$. 
Über die Aufnahme von Büchern in das Paket entschied ein Gremium des Bildungsministeriums - das Paket war dadurch in gewisser Hinsicht Ersatz und Vorläufer von föderalen Bildungsstandards. ${ }^{23}$ Das föderale Paket für das Schuljahr 1996/1997 umfasste beispielweise vierzehn Titel für das Fach Geschichte, wobei neun Titel für den Unterricht der 10. und 11. Klasse und lediglich fünf Titel für die Klassen 4-9 enthalten waren. ${ }^{24}$

Bei aller Entwicklung im Bereich der Schulbücher in den 1990er Jahren bleibt ihr tatsächlicher Einfluss auf den Geschichtsunterricht umstritten: ${ }^{25}$ Aus Kostengründen wurden vielfach die sowjetischen Bücher über Jahre weiterverwendet. ${ }^{26}$ Die Auflagen der neuen Bücher waren deutlich niedriger als der anzunehmende Bedarf. ${ }^{27}$ Zudem waren Schulbuchentwicklung und Bildungspolitik selten aufeinander abgestimmt - die ersten russländischen Schulbücher waren erschienen, bevor die ersten Lehrpläne feststanden ${ }^{28}$ und die Schulbuchautoren waren weiterhin mit einem fluiden Prozess der Geschichtsumdeutung konfrontiert:

»Da aber das historische Umdenken bezüglich der Standpunkte, Ereignisse und Persönlichkeiten andauert und zunehmend einen totalen Charakter annimmt, wird jedes neue Lehrwerk schon im Manuskriptzustand veraltet sein. ${ }^{29}$

Die ersten föderalen Bildungsstandards wurden erst 1998 erlassen $^{30}$ - wenn auch nur als provisorische Übergangslösung; ein Jahr später wurden noch Standards für die Abschlussklassen ergänzt. ${ }^{31}$ Die Standards enthalten eine konservative russische Geschichtsperspektive: Es gibt den »Kampf der Rus

23 Vgl. Gorjuchin, Jurij: Dopuščeno - ne značit rekomendovano. Na odnogo pjatiklassnika prichoditsja 8 učebnikov po fizike. In: Učitel'skaja gazeta Nr. 40 vom 25.09.2001, 10.

24 Vgl. Federal'nyj komplekt učebnikov dlja obščeobrazovatel'nych učreždenij Rossijskoj Federacii na 1996/97 učebnyj god. (Priloženie 1 k prikazu Ministerstva obrazovanija Rossijskoj Federacii ot 1 nojabrja 1995 g.N 564). In: Učitel'skaja gazeta Nr. 52 vom 26.12.1995.

25 Vgl. de Keghel, Isabelle: Die Rekonstruktion der vorsowjetischen Geschichte. Hamburg 2006, $76 \mathrm{f}$.

26 Vgl. ebd., 77.

27 Davies, Robert: Soviet History in the Yeltsin Era. London 1997, 126.

28 Vgl. de Keghel, Isabelle: Die Rekonstruktion der vorsowjetischen Geschichte. Hamburg 2006, 76 .

29 Tjulaeva, Tamara: Die Reform der historischen und sozialkundlichen Bildung an russischen Schulen. In: Internationale Schulbuchforschung 17/4 (1995), 392.

30 Prikaz Minobrazovanija RF ot 19.05 .1998 N 1236 »Ob utverždenii Vremennych trebovanij k objazatel'nomu minimumu soderžanija osnovnogo obščego obrazovanija« für die unteren Klassen 5-9; Prikaz Minobrazovanija RF ot 19.05.1998 N 1235 »Ob utverždenii Objazatel'nogo minimuma soderžanija« für die Klassen 1 bis 4 .

31 Prikaz Minobrazovanija RF ot 30.06.1999 N 56 »Ob utverždenii Objazatel'nogo minimuma soderžanija srednego (polnogo) obščego obrazovanija« Für die Klassen 10 bis 11. 
gegen die Aggressionen aus dem Westen $\aleph^{32}$ - die russischen Erden werden »vereint «. Die Zeit der Wirren endet mit dem »Befreiungskampf gegen die polnischen und schwedischen Interventen ${ }^{33}{ }^{33}$ die "russische Kriegskunst « wird gewürdigt. Für das 20. Jahrhundert werden die Verbrechen des Stalinismus berücksichtigt, wobei Industrialisierung und Kollektivierung lediglich im Kontext einer »beschleunigten Modernisierung « vorkommen und Hungertod und der GULag ${ }^{34}$ als Faktoren nicht thematisiert werden. Die Sowjetunion wird durchgängig als totalitäres System charakterisiert.

Die verschiedenen Regulierungen hatten jedoch keinen negativen Einfluss auf die weiter zunehmende Pluralität am Schulbuchmarkt. Die staatlichen Initiativen bildeten vielmehr im Kleinen bestehende Irritationen in der russländischen Geschichtspolitik ab: Zentrifugale Tendenzen der Regionen sollten durch konsolidierende russländische Identitätspolitik aufgefangen werden, die häufig - wie im Falle der Standards - primär russo-zentrisch orientiert war. Dieses Anknüpfen an die vorrevolutionären russisch-imperialen Geschichtsbilder war der inneren politischen Auseinandersetzung mit den sowjetisch-konservativen Kräften geschuldet: Es erlaubte das Ausgrenzen positiver Bezugnahmen auf die Sowjetunion - und bot konservativ-sowjetischen Kräften über den Umweg des Sowjetpatriotismus, der diese Geschichtsbilder teilweise übernommen hatte, ${ }^{35}$ Anknüpfungspunkte.

Die 1990er Jahre erscheinen insgesamt als eine Phase, in der der Bildungspolitik kein hoher Stellenwert zukam, in der Reformen blockiert wurden und der Staat sich aus der Finanzierung zurückzog. ${ }^{36}$ Der russische Bildungsminister von 1990-1992, Ėduard Dneprov, der federführend bei der Ausarbeitung des Bildungsgesetzes von 1992 war, fasste die 1990er Jahre in einer Kapitelüberschrift als »Blockierte Transition. Achtjährige Stagnation ${ }^{37}$ zusammen.

32 Prikaz Minobrazovanija RF ot 19.05.1998 N $1236 »$ Ob utverždenii Vremennych trebovanij k objazatel'nomu minimumu soderžanija osnovnogo obščego obrazovanija."

33 Ebd.

34 GULag steht für Hauptverwaltung der Besserungsarbeitslager und -kolonien.

35 Vgl. Oberländer, Erwin: Sowjetpatriotismus und Geschichte. Dokumentation. Köln 1967, 45.

36 Vgl. Dneprov, Ėduard: Novejšaja političeskaja istorija rossijskogo obrazovanija. Marios, Moskva 2011, $133 \mathrm{f}$.

37 Ebd., 122. 


\subsection{Bildungspolitik und Schulbücher in den 2000er Jahren}

Im Zuge der ersten Präsidentschaft Vladimir Putins wurde bald deutlich, dass sowohl der Geschichtspolitik als auch der Bildungspolitik ein höherer Stellenwert zugemessen wurde als während der 1990er Jahre. In Kombination zeigte sich diese Tendenz in einer Sitzung der Regierung im August 2001, als Ministerpräsident Michail Kas'janov die Inhalte von offiziell zugelassenen Schulbüchern für den Geschichtsunterricht thematisierte. Kas'janov warf den Autoren der Werke zur neuesten russländischen Geschichte mangelnde Unterstützung der demokratischen Gesellschaft vor. Er zitierte dazu die Darstellung des Jahres 1999 aus einem Schulbuch:

„Die Gesellschaft überschreitet noch nicht die Grenze, die den gesellschaftlich-politischen Konflikt vom Bürgerkrieg trennt. (38 $^{38}$

Auch eine Passage über die Eliten-Kontinuität in politischen Schlüsselpositionen im post-sowjetischen Russland und die Angewohnheit der Eliten, kompromittierendes Material über Konkurrenten zu sammeln, fand unter den Ministern keine Zustimmung. ${ }^{39}$

Als Konsequenz forderte Kas'janov, die Zahl der Lehrbücher zu begrenzen und dafür zu sorgen, dass dort »die Prinzipien des demokratischen Lebens formuliert werden, wie sie von der Mehrheit der Bevölkerung verbreitet werden. $\aleph^{40}$ Diese Sitzung macht deutlich, dass man gewillt war, politischen Einfluss bis in die Schulbücher hinein durchzusetzen. ${ }^{41}$

Auch Vladimir Putin machte diesen Gestaltungsanspruch deutlich, als er sich im November 2003 bei einem Treffen mit Historikern zu der Funktion von Geschichte in Schulbüchern äußerte:

„Die Schulbücher der Gegenwart [...] dürfen nicht zum Ort für einen neuen politischen und ideologischen Kampf werden. In den Schulbüchern sollten historische Fakten angeführt werden, sie sollen bei den jungen Menschen das Gefühl des Stolzes für die Geschichte des Vaterlands, für ihre Heimat erzeugen. $\aleph^{42}$

38 Netreba, Petr: Pravitel'stvo zaselo za učebniki.Bol'šoj pedsovet strany prodolžaetsja. In: Kommersant«. Nr. 157 vom 31.08.2001, 2. Online: http://www.kommersant.ru/doc/ 280972.

39 Vgl. ebd, 2.

40 Ebd., 2.

41 Dieser Anspruch, Einfluss auf die Ausgestaltung von Geschichtsschulbüchern zunehmen, war bereits einige Monate zuvor in Abschnitt IV des ersten Programm zur Patriotischen Erziehung formuliert worden. Vgl. Kapitel: Die Programme zur Patriotischen Erziehung.

42 Putin, Vladimir: Vstupitel'noe slovo na vstreče s učenymi-istorikami. 27 nojabrja 2003 goda, 19:07. Moskva, Rossijskaja gosudarstvennaja biblioteka. Online: http://www.kremlin.ru/events/president/transcripts/22227 
In der folgenden Diskussion machte Putin deutlich, dass er eine sehr pragmatische Vorstellung von Geschichtsschreibung und der konstruierenden Arbeit von Historikern favorisiert:

"Damals [zu Zeiten der Perestrojka] betonten die Historiker das Negative, weil sie vor der Aufgabe standen, das System zu zerstören, und heute haben wir eine andere, schöpferische Aufgabe ${ }^{43}$

Geschichte und Geschichtsunterricht werden hier als Teile der Patriotischen Erziehung betrachtet und dadurch mittelbar als Instrumente der Konsolidierung des Staates.

Der höhere Stellenwert von Bildungspolitik allgemein ließ sich ab dem Jahr 2000 auch an den zunehmden Novellen des Bildungsgesetzes ablesen: War das Gesetz zwischen 1992 und 2000 lediglich zweimal verändert worden, so wurde es in den 2000er Jahren permanent mehrmals pro Jahr angepasst. ${ }^{44}$

\subsubsection{Regulierungen der 2000er Jahre}

Neben den vielen Anpassungen des Bildungsgesetzes war die Verabschiedung von föderalen Bildungsstandards eines der zentralen politischen Anliegen, um das Provisorium der 1990er Jahre abzulösen. Die Bildungsstandards der ersten Generation ${ }^{45}$ wurden im Jahr 2004 als föderale Komponente erlassen. ${ }^{46}$ Neben der föderalen Komponente gibt es zusätzlich Bildungsstandards auf der Ebene der Föderationssubjekte und der Bildungseinrichtungen. ${ }^{47}$

Die föderale Komponente legt allgemeine Bildungsziele, fachspezifische Bildungsziele sowie einen inhaltlichen Mindeststandard für die Anfangsstufe, die Hauptstufe sowie die mittlere Bildungsstufe fest.

43 Ot redakcii: Delo istorikov. In: Vedomosti Nr. 1019 vom 28.11.2003. Online: http://www. vedomosti.ru/newspaper/articles/2003/11/28/ot-redakcii-delo-istorikov

$44 \mathrm{Ab}$ dem Jahr 2000 bis zum Inkrafttreten des neuen Bildungsgesetzes im Jahr 2012 fanden ca. 67 Novellen Eingang in den Gesetzestext von 1992.

45 Der Begriff erklärt sich aus der Überarbeitung bis zum Jahr 2012, deren Ergebnis die sogenannte zweite Generation darstellt. Dneprov bezeichnet die erste Generation als Übergangsstandards, um kenntlich zu machen, dass durch sie u.a. verspätet die Transition von der unitär-totalitären zur bürgerlichen Gesellschaft vollzogen wurde. Vgl. Dneprov, Ėduard: Novejšaja političeskaja istorija rossijskogo obrazovanija. Marios, Moskva 2011, $337 \mathrm{f}$.

46 Prikaz Minobrazovanija RF ot 05.03.2004 N 1089 »Ob utverždenii federal'nogo komponenta gosudarstvennych obrazovatel'nych standartov načal'nogo obščego, osnovnogo obščego i srednego (polnogo) obščego obrazovanija.«

47 Allgemein zur Entstehung des Standards und zu seiner bildungspolitischen Bedeutung vgl. Kaspržak, Anatolij/Loginova, Ol'ga/Polivanova, Katerina: Standart obrazovanija: istorija razrabotki i itogi. Voprosy obrazovanija 3 (2004), 24-43. 
Aus erinnerungspolitischer Perspektive sind besonders die fachspezifischen Teile interessant. Hier wird deutlich, wie die Patriotische Erziehung in der Schulbildung verankert wurde: Die Standards legen bei einer ganzen Reihe von Fächern wie Russische Sprache, Literatur und Geografie Patriotismus oder die Ausbildung zur Heimatliebe als Lernziel fest. ${ }^{48}$ Besonders prominent ist diese Ausrichtung im Bildungsstandard für das Fach Geschichte der Klassen 5-9 angelegt: Hier steht unter den Lernzielen »die Erziehung zum Patriotismus, zur Liebe zur Heimat und zur Achtung gegenüber unserer Geschichte und den Traditionen unserer Heimat ${ }^{49}$ an erster Stelle. Danach folgt die Erziehung zu »Menschen- und Freiheitsrechten, den demokratischen Prinzipien des öffentlichen Lebens. ${ }^{50}$ Darüber hinaus wird dem Geschichtsunterricht eine besondere Funktion bei der Erziehung zur Toleranz und zur Wertschätzung der polykulturellen, polyethnischen und multikonfessionellen Gesellschaft zugeschrieben. ${ }^{51}$ Neben diesen übergreifenden Zielen enthält der Standard auch fachspezifischere Lernziele wie Geschichtsbewusstsein oder Quellenkritik.

In den inhaltlichen Teilen wird in Form von Stichworten und vereinzelt auch ganzen Sätzen das im Unterricht zu behandelnde Minimum abgesteckt. Dieser Teil ist sehr deutlich an den provisorischen Standard aus dem Jahr 1998 angelehnt. ${ }^{52}$ Auch hier wird eine relativ konservative russische Geschichtsperspektive präsentiert, die lediglich in einigen Punkten das nationale Narrativ der 1990er ein wenig zurücknimmt bzw. pluralisiert. So wird beispielsweise im Standard von 2004 nicht nur die Ausbreitung des Christentums, sondern auch die Ausbreitung des Islam und des Judentums deutlicher berücksichtigt - weiterhin verwendet wird der Begriff des »Jochs der Goldenen Horde", das abgeworfen wird. Aus dem »Kampf gegen Aggressionen aus dem Westen « wurde der "Kampf gegen äußere Aggressionen«, die »Zeit der Wirren" wird als »Kampf gegen äußere Expansion« beschrieben. Die Darstellung der Verbrechen des Stalinismus bleibt etwas unscharf, die Verwendung des Begriffs Totalitarismus fällt differenzierter aus als in der 1998er Version.

48 Vgl. Prikaz Minobrazovanija RF ot 05.03.2004 N 1089 »Ob utverždenii federal'nogo komponenta gosudarstvennych obrazovatel'nych standartov načal'nogo obščego, osnovnogo obščego i srednego (polnogo) obščego obrazovanija.«

49 Ebd.

50 Ebd.

51 Vgl. ebd.

52 Vgl. Prikaz Minobrazovanija RF ot 19.05 .1998 N 1236 »Ob utverždenii Vremennych trebovanij k objazatel'nomu minimumu soderžanija osnovnogo obščego obrazovanija für die Hauptstufe 5-9; Prikaz Minobrazovanija RF ot 19.05.1998 N 1235 »Ob utverždenii Objazatel'nogo minimuma soderžanija« für die Klassen 1 bis 4. Prikaz Minobrazovanija RF ot 30.06.1999 N 56 »Ob utverždenii Objazatel'nogo minimuma soderžanija srednego (polnogo) obščego obrazovanija« Für die Klassen 10 bis 11. 
Die Auflistung der Geschichte in diesem Teil des Standards geschieht, ohne explizite Wertungen und Deutungen vorzunehmen. Implizit sind jedoch durchaus Wertungen enthalten, die beispielsweise im Zusammenhang mit der russo-zentrischen Perspektive stehen. So ist für das 13. Jahrhundert der Kampf gegen äußere Aggressionen aufgeführt - durch das Wort Aggression wird negativ gewertet. In derselben Zeile wird die als reigene` wahrgenommene Ausbreitung des russischen Herrschaftsbereichs neutral als »Expansion nach Westen« beschrieben.

Insgesamt überwiegt jedoch sehr deutlich die neutrale Indizierung von Ereignissen ohne klare Deutungen, Wertungen oder auffällige Gewichtungen. Das gilt allerdings nicht für den Bereich des Standards, der neu hinzugekommen ist: die Zeit nach den Präsidentschaftswahlen des Jahres 2000. Hier wird von dem neutralen Schema abgewichen und die Ereignisgeschichte mit Deutung versehen. Die Vorgabe für Unterricht und Schulbücher für diese Zeit im Standard für die Abschlussklassen lautet:

»Präsidentenwahlen im Jahr 2000. Kurs auf die Stärkung der Staatlichkeit, den wirtschaftlichen Aufschwung, soziale und politische Stabilität, Stärkung der nationalen Sicherheit und das Erlangen eines würdigen Platzes Russlands in der Weltgemeinschaft. ${ }^{53}$

Damit geben die Bildungsstandards in diesem Bereich eine für den damals amtierenden Präsidenten vorteilhafte Geschichtsdeutung wieder, in der die 2000er Jahre als eine uneingeschränkte Erfolgsgeschichte russischer Staatlichkeit und präsidentieller Führung dargestellt werden.

Auch in den Standards der zweiten Generation ab 2009 bleiben diese Deutungen erhalten. Die Überarbeitungen konzentrieren sich auf die neu eingeführten Fächer 'Religiöse Kulturen` und 'Weltliche Ethikı, auf Verkehrserziehung, die Einführung von Futsal und Mini-Basketball sowie die Darstellung von Berufsfeldern, die mit den jeweiligen Unterrichtsfächern in Verbindung stehen und so den Praxiswert hervorheben sollen. Zudem wird entsprechend der vielen Auszeichnungen und Ehrungen der vorangegangenen Jahre Aleksandr Solženicyns >Der Archipel Gulag`zusätzlich zu `Ein Tag im Leben des Iwan Denissowitsch` und `Matrjonas Hof`auf die Liste der Pflichtlektüre für das Fach Literatur gesetzt. ${ }^{54}$

53 Prikaz Minobrazovanija RF ot 05.03.2004 N 1089 »Ob utverždenii federal'nogo komponenta gosudarstvennych obrazovatel'nych standartov načal'nogo obščego, osnovnogo obščego i srednego (polnogo) obščego obrazovanija«.

54 Vgl. Prikaz Minobrnauki RF ot 31.08.2009 n 320 »O vnesenii izmenenij v federal'nyj komponent gosudarstvennych obrazovatel'nych standartov načal'nogo obščego, osnovnogo obščego i srednego (polnogo) obščego obrazovanija, utverždennyj Prikazom Ministerstva obrazovanija Rossijskoj Federacii ot 5 marta 2004 g. n 1089 »Ob utverždenii federal'nogo komponenta gosudarstvennych obrazovatel'nych standartov načal'nogo obščego, osnovnogo obščego i srednego (polnogo) obščego obrazovanija«. 
Für das Fach Geschichte wird durch die Novelle des Bildungsstandards im Jahr $2011^{55}$ die Fälschung der Geschichte zum Unterrichtsinhalt für die Klassen 10 und 11 gemacht. Für das Basisniveau der 10. und 11. Klassen wird direkt im Anschluss an die zitierte Passage über die 2000er Jahre - »die Falsifikation der neuesten Geschichte als Gefahr für die nationale Sicherheit des Landes $~^{56}{ }^{6}$ thematisiert. Für die Schüler der Profilniveaus der obersten Klassen ist darüber hinaus die Beschäftigung mit Gegenmaßnahmen obligatorisch. Der Standard für diese Stufe ergänzt "methodische Zugänge zur Abwehr der Versuche der Falsifizierung der Schlüsselereignisse der vaterländischen Geschichte. ${ }^{57}$

Die Integration dieses Themas in den Geschichtsunterricht der obersten Klassen ist im Zusammenhang mit dem erinnerungspolitischen Projekt der 'Kommission beim Präsidenten gegen die Fälschung der Geschichte zum Nachteil Russlands im Jahr 2009 zu sehen. Während diese Kommission bereits im Jahr 2012 wieder aufgelöst wurde, ${ }^{58}$ ist die daraus resultierende Thematisierung weiterhin Teil des Bildungsstandards und strahlt dadurch auch auf den Unterricht und die Schulbücher des Faches Geschichte aus.

In Bezug auf die Schulbücher für den Geschichtsunterricht besteht eine bedeutende Regulierung in dem vom Bildungsministerium herausgegebenen Verzeichnis der zugelassenen und empfohlenen Lehrbücher. Schon Ende der 1990er Jahre war das sogenannte Föderale Paket zunehmend erweitert worden. Mitte der 1990er Jahre war das Paket noch sehr übersichtlich: Es enthielt die Schulbücher, an deren Anschaffung das föderale Budget beteiligt werden konnte - und war somit ein budgetrelevantes Auswahlkriterium. Ende der 1990er Jahre hatte es sich zu einem staatlichen Schulbuch-Verzeichnis mit rund 1400 zugelassenen Titeln entwickelt, von denen nur ungefähr fünf Prozent das Siegel »Empfohlen durch das Bildungsministerium « trugen. $^{59} \mathrm{Zu}$ ständig für das Verzeichnis war seit 1999 der Föderale Expertenrat des Bil-

55 Vgl. Prikaz Ministerstva obrazovanija i nauki RF ot 10 nojabrja 2011 g. N $2643 » O$ vnesenii izmenenij v Federal'nyj komponent gosudarstvennych obrazovatel'nych standartov načal'nogo obščego, osnovnogo obščego i srednego (polnogo) obščego obrazovanija, utverždennyj prikazom Ministerstva obrazovanija Rossijskoj Federacii ot 5 marta 2004 g. N 1089 «.

56 Prikaz Minobrnauki RF ot 24.01.2012 N $39 » O$ vnesenii izmenenij v federal'nyj komponent gosudarstvennych obrazovatel'nych standartov načal'nogo obščego, osnovnogo obščego i srednego (polnogo) obščego obrazovanija, utverždennyj Prikazom Ministerstva obrazovanija Rossijskoj Federacii ot 5 marta 2004 g. N 1089«.

57 Ebd.

58 Vgl. Kapitel: Verewigung und Schutz der Narrative.

59 Vgl. Gorjuchin, Jurij: Dopuščeno - ne značit rekomendovano. Na odnogo pjatiklassnika prichoditsja 8 učebnikov po fizike. In: Učitel'skaja gazeta Nr. 40 vom 25. September 2001, 10. 
dungsministeriums $s^{60}$ - die Finanzierung ging vollständig in die Kompetenz der Föderationssubjekte über. ${ }^{61}$ Das Verfahren zur Aufnahme in das Verzeichnis wurde regelmäßig verändert - grundsätzlich beruhte die Aufnahme jedoch auf einer wissenschaftlichen und einer pädagogischen Expertise. Über die Jahre verkehrte sich das Verhältnis von zugelassener und empfohlener Literatur: ${ }^{62}$ Das Verzeichnis für das Schuljahr 2011/2012 weist rund 1400 Bücher mit Empfehlung und nur noch 400 Bücher auf, die lediglich die Zulassung besitzen. ${ }^{63}$ Jedoch erst das neue Bildungsgesetz von 2012 schrieb explizit fest, dass die Schulen auf zugelassene oder empfohlene Lehrbücher aus der Liste zurückgreifen müssen. Zudem wurden die Regeln für die Aufnahme in das Verzeichnis erweitert: Die Schulbücher müssen als vollständige Linien herausgegeben werden, die den Bereich einer Stufe (z. B. Klassen 5-9) abdecken, sie müssen mit zusätzlichen methodischen Lehrerausgaben sowie mit elektronischen Ressourcen ergänzt werden. Bei einigen Büchern müssen zusätzlich zur wissenschaftlichen und pädagogischen auch ethnokulturelle und regionale Expertisen eingeholt werden. ${ }^{64}$

Der Umfang der Liste schwankte über die Jahre: Zwischen 2005 und 2010 waren etwa 1000 Schulbücher verzeichnet. Ab der Liste für das Schuljahr 2010/2011 nahm die Zahl dann Jahr für Jahr zu, bis zu einem Höchststand im Jahr 2013/2014 mit 2591 empfohlenen Büchern. Im Folgejahr sank die Zahl aufgrund der neuen Kriterien wieder auf ungefähr 1400 Titel. ${ }^{65}$

60 Bis 1999 Föderaler Expertenrat für allgemeine und berufliche Bildung: Prikaz Minobrazovanija RF ot 12.11 .1999 N 865 O pereimenovanii gosudarstvennogo učreždenija »Federal'nyj èkspertnyj sovet po obščemu obrazovaniju « Minobrazovanija Rossii.

61 Durch das neue Bildungsgesetz von 2012 ging die Finanzierung von Schulbüchern in die Kompetenz der Bildungseinrichtungen über. Vgl. Federal'nyj zakon ot 29.12.2012 N 273-FZ Ob obrazovanii v Rossijskoj Federacii«.

62 Der Empfehlungsstatus ist eine aus dem Zulassungsverfahren der 1990er übrig gebliebene Erweiterung der Zulassung, die den Zulassungsstatus beinhaltet.

63 Vgl. Prikaz Ministerstva obrazovanija i nauki Rossijskoj Federacii (Minobrnauki Rossii) ot 24 dekabrja 2010 g. N 2080 g. Moskva »Ob utverždenii federal'nych perečnej učebnikov, rekomendovannych (dopuščennych) k ispol'zovaniju v obrazovatel'nom processe v obrazovatel'nych učreždenijach, realizujuščich obrazovatel'nye programmy obščego obrazovanija i imejuščich gosudarstvennuju akkreditaciju, na 2011/2012 učebnyj god «.

64 Vgl. Press-služba Minobrnauki Rossii: V Minobrnauki Rossii formirujut federal'nyj perečen' učebnikov soglasno novomu porjadku. 05.03.2014. Online: http://минобрнауки. рф/новости/3995.

65 Das Verzeichnis für das Schuljahr 2015/2016 kommt trotz der hektischen Änderungen im Fach Geschichte - verbunden mit einer nachträglichen Korrektur - wieder auf einen ähnlichen Wert. Für eine Auswertung des Verhältnisses von zugelassenen und empfohlenen Schulbüchern für den Geschichtsunterricht der 9. und 11. Klasse vgl. Čapkovskij, Filipp: Učebnik istorii i ideologičeskij deficit. In: Pro et Contra. 15/1-2 (2011), 123. 
Die Zahlen machen deutlich, dass das Verzeichnis zwar ein regulierendes Instrument darstellt, dass es aber in der Regel nicht eingesetzt wird, um bestimmte Inhalte auszuschließen. Die deutliche Kürzung des Verzeichnisses für das Schuljahr 2014/2015 lässt sich nicht als inhaltlich-politisch charakterisieren: Betroffen waren alle Unterrichtsfächer. Allerdings waren die Verlage unterschiedlich stark betroffen - am wenigsten die Publikationen des Verlages Prosveščenie. Der Verlag war Ende 2011 unter der Regie des Premierministers Putin privatisiert worden. Nach einer undurchsichtigen Transformationsphase, in der der ehemals sowjetische Verlag in ein zypriotisches Offshore-Unternehmen verwandelt wurde, stieg Ende 2013 Arkadij Rotenberg, der als enger Vertrauter Vladimir Putins gilt, als Vorstandsvorsitzender bei Prosveščenie ein. ${ }^{66}$ Laut Kommersant dürfte die Kürzung des Schulbuchverzeichnisses für das Schuljahr 2014/2015 zu Gunsten des Verlages den ursprünglichen Marktanteil von 35 Prozent noch einmal deutlich erhöhen. ${ }^{67}$

Das Beispiel macht deutlich, dass manches, was als Einflussnahme auf die Inhalte von Geschichtsbüchern interpretiert wurde, eher dem Kampf um Anteile auf dem lukrativen und verhältnismäßig stabilen Schulbuchmarkt geschuldet ist. Dieser Kampf wurde bis weit in die 2000er Jahre hinein auch vereinzelt gewaltsam durch Attentate auf leitende Angestellte von Schulbuchverlagen oder Beamte, die mit Schulbuchbestellungen betraut waren, ausgetragen. ${ }^{68}$

\subsubsection{Einflussnahmen in den 2000er Jahren}

Auch wenn staatliche Einflusspotenziale auf den Inhalt von Schulbüchern wie das föderale Verzeichnis - nicht genutzt wurden, so gab es in den 2000er Jahren immer wieder direkte Eingriffe auf unterschiedlichen Ebenen. Zwei dieser Eingriffe können als beispielhaft gelten: Die Förderung des Buches $>\mathrm{Ge}-$ schichte Russlands` von Aleksandr Filippov und die öffentliche Verurteilung des Buches `Vaterländische Geschichte`von Igor’ Doluckij.

66 Vgl. Belavin, Pavel: Arkadij Rotenberg vzjalsja za učebniki. Predprinimatel' vchodit v biznes izdatel'stv. »Prosveščenie« i »Olma Media Grupp«. In: Kommersant«. Nr. 200 vom 31.10.2013, 1. Online: http://kommersant.ru/doc/2332416.

67 Vgl. Jakoreva, Anastasija: Skandaly, intrigi, učebniki. Komu vygodny novye pravila ocenki škol'noj literatury. »Kommersant« Den'gi«. Nr. 13 vom 07.04.2014, 27. Online: http://www.kommersant.ru/doc/2437844.

68 Vgl. Varyvdin, Maksim: Pokušenie na činovnicu. Prestupniki deljat škol'nye den'gi. In: Kommersant«. Nr. 78 vom 28.05.1997, 7. Online: http://www.kommersant.ru/doc/178375 und Lebedev, Sergej: Rynok učebnikov ostaetsja kriminal'noj sferoj. In: Pervoe sentjabrja. Učitel'skaja gazeta. Nr. 79 (1246), 11.11.2003, 1. Online: http://ps.1september.ru/article. php?ID=200307903. 
Die oben zitierten Passagen aus dem Treffen Vladimir Putins mit Historikern im Jahr $2003^{69}$ hatten implizit einen direkten Bezugspunkt. Am selben Tag war bekannt geworden, dass dem Schulbuch »Vaterländische Geschichte des 20. Jahrhundert ${ }^{70}{ }^{0}$ von Igor' Doluckij das Siegel `empfohlen durch das Bildungsministerium ‘ entzogen werden sollte. Das Ministerium hatte den föderalen Expertenrat beauftragt das Buch einer erneuten Prüfung zu unterziehen, so das Mitglied des Rates Aleksandr Čubar'jan. ${ }^{71}$ Die Passage, die durch das Ministerium primär inkriminiert wurde, steht tatsächlich im Widerspruch zu Putins Forderungen, dass Schulbücher die Schüler zum Stolz auf das eigene Land erziehen sollen und nicht der Ort für »ideologische « Auseinandersetzungen seien. Auch der Forderung, die Gegenwart im Sinne einer "schöpferischen Aufgabe ${ }^{72}$ in ein positives Licht zu rücken, entspricht die Passage über die erste Phase der Präsidentschaft Putins nicht:

»Die Reform des Föderationsrats (der Lehrer erklärt deren Kern), das Recht des Präsidenten, Gouverneure abzusetzen, das neue Parteiengesetz, waren für den Publizisten Ju. G. Burtin der Anlass zu behaupten, dass in Russland ein Staatstreich stattgefunden hat und als Folge >ein Regime der persönlichen Macht Putins, eine autoritäre Diktatur entstanden ist.< Der Führer von `Jabloko< Javlinskij meinte, dass bereits 2001 in Russland `ein Polizeistaat geschaffen wurde $\ll^{73}$

In der folgenden Aufgabe sollen die Schüler versuchen diese Perspektive entweder zu bestätigen oder zu widerlegen.

Dieser Eingriff in die Inhalte macht den Anspruch der Politik deutlich, bis auf die Ebene der Schulbücher zu intervenieren, wie ihn Kas'janov bereits im Jahr 2001 formuliert hatte. Er macht aber auch deutlich, dass bis dahin der Expertenrat - der das Buch bis zur Intervention des Ministers nicht beanstandet hatte - keine politische Aufsicht im Sinne des Kremls ausgeübt hatte.

Der öffentliche Entzug der Empfehlung - sekundiert von Vladimir Putins parallelem Auftritt mit Historikern - blieb bisher der einzige Eingriff in dieser Form und lässt sich daher vor allem als öffentliches Exempel interpretieren. Um wirtschaftlichen Schaden vom Verlag abzuwenden, dürften Lektoren als Folge im Zweifel eine Passage eher glätten.

69 Putin, Vladimir: Vstupitel'noe slovo na vstreče s učenymi-istorikami. 27. November 2003, Moskau. Online: http://www.kremlin.ru/events/president/transcripts/22227.

70 Doluckij, Igor': Otečestvennaja Istorija XX. Vek. Moskva 2003.

71 Newsru: Minobrazovanija zapretit učebnik »Otečestvennaja istorija XX veka« za kritiku Putina. 27. November 2003. Online: http://www.newsru.com/russia/27Nov2003/uchebnik. html.

72 Ot redakcii: Delo istorikov. In: Vedomosti. Nr. 1019 vom 28.11.2003. Online: http://www. vedomosti.ru/newspaper/articles/2003/11/28/ot-redakcii-delo-istorikov.

73 Doluckij, Igor': Otečestvennaja Istorija XX. Vek. Moskva 2003, 254. 
Der andere beispielhafte Fall erschien ähnlich orchestriert wie im Falle Doluckijs. Diesmal äußerte sich Vladimir Putin im Zuge der Allrussischen Konferenz der Lehrer der Geistes- und Gesellschaftswissenschaftlichen Fächer zum Thema Geschichtsschulbücher. Die Konferenz war - über den Auftritt des Präsidenten hinaus - prominent besetzt: Sowohl Bildungsminister Andrej Fursenko als auch der erste Stellvertreter des Leiters der Kremladministration, Vladislav Surkov, nahmen teil. ${ }^{74}$ Putin monierte, dass die Schulbücher die neueste Geschichte nicht umfassend und objektiv darstellen würden. ${ }^{75}$ Die meisten Bücher würden kaum über die 1990er hinausgehen - und dort, wo die 2000er Jahre enthalten seien, würden sie, "vorsichtig gesagt, abstrakt und sehr widersprüchlich dargestellt. ${ }^{76}$ Zur Darstellung des Großen Vaterländischen Krieges erklärte Putin, dass unterschiedliche Standpunkte und Perspektiven berücksichtigt werden müssten - das eigene Volk dürfe jedoch nicht beleidigt werden. ${ }^{77}$

In einem Nebensatz wies er darauf hin, dass bereits für das folgende Schuljahr verbesserte Lehrbücher sowohl für Lehrer als auch für Schüler erscheinen würden..$^{78}$ Damit bezog sich Putin implizit auf die Präsentation eines neuen Lehrbuches ebenfalls im Rahmen der Konferenz - »Neueste Geschichte Russlands 1945-2006 - Ausgabe für Lehrer «"

Den Grund für diese äußerst prominente Rahmung der Präsentation eines Geschichtsbuches für Lehrer erklärte der Autor Aleksandr Filippov im Interview mit der Zeitung Kommersant: Der Auftrag zur Ausarbeitung sei direkt von der Präsidialadministration und dem Bildungsministerium gekommen, wo man besorgt gewesen sei, dass in den existierenden Schulbüchern die neueste Geschichte der Russländischen Föderation beinahe fehle, und, wenn sie enthalten sei, lediglich wie ein Nachwort zur Geschichte der UdSSR wirke. $^{80}$

Anders als im Fall Doluckij - wo ein Autor und ein etabliertes Schulbuch öffentlichkeitswirksam beschädigt wurden - wurde im Fall Filippovs eine Lehrbuchserie durch koordiniertes Auftreten von Bildungsminister, Präsidialadministration und Präsident öffentlichkeitwirksam gefördert.

74 Vgl. Kačurovskaja, Anna: Istoričeskij pripadok. In: Kommersant« Vlast’. Nr.27 vom 16.07.2007, 14. Online: http://www.kommersant.ru/doc/782464.

75 Vgl. Putin, Vladimir: Stenografičeskij otčet o vstreče s delegatami Vserossijskoj konferencii prepodavatelej gumanitarnych i obščestvennych nauk. 21. Juni 2007, Novo-Ogarevo. Online: http://kremlin.ru/events/president/transcripts/24359.

76 Ebd.

77 Vgl. ebd.

78 Vgl. ebd.

79 Filippov, Aleksandr: Novejšaja istorija Rossii 1945-2006 gg. Kniga dlja učitelja. Prosveščenie, Moskva 2007.

80 Vgl. Kačurovskaja, Anna: Istoričeskij pripadok. In: Kommersant« Vlast'. Nr. 27 vom 16.07.2007, 14. Online: http://www.kommersant.ru/doc/782464. 
Dies führte in der öffentlichen Diskussion zu der Befürchtung, dass dem Lehrbuch mit Hilfe der administrativen Ressource zu einer marktbeherrschenden Stellung verholfen werden sollte - und so ein Einheitsschulbuch durch die Hintertür eingeführt werde. ${ }^{81}$ Inhaltlich wurden diese Befürchtungen - neben einer allgemein herrschaftsaffirmativen Herangehensweise - vor allem durch das Kapitel zur jüngsten Geschichte ab dem Jahr 2000 begründet. Es wurde von Pavel Danilin geschrieben, zum damaligen Zeitpunkt Mitglied des Politrates der Jungen Garde von Edinaja Rossija, Publizist und Polittechnologe. Es trug den Titel »Souveräne Demokratie $«^{82}$ und bezog sich damit direkt auf die von Vladislav Surkov im Vorjahr präsentierte Konzeption. ${ }^{83}$

Das Schulbuch zu der vorgestellten Lehrerausgabe >Geschichte Russlands 1945-2007 ${ }^{84}$ wurde Ende 2007 in das föderale Verzeichnis aufgenommen und startete mit kleinen Testauflagen. Erst die spätere dritte Ausgabe von $2009^{85}$ erreichte mit der ungewöhnlich hohen Auflage von 250.000 Exemplaren eine große Verbreitung. ${ }^{86}$ Der tatsächliche Einfluss auf den Unterricht ist schwer zu bestimmen. Zunächst fehlte trotz Rekordauflage noch die erste Hälfte des 20. Jahrhunderts. Der zweite Teil $>$ Geschichte Russlands $1900-1945{ }^{8{ }^{87}}$ kam erst deutlich später auf den Markt - die Auflage der zweiten Ausgabe betrug nur noch 12.000 Exemplare. Eine dominierende Stellung konnte das Werk nicht entwickeln. Die Art und Weise, wie es am Markt etabliert wurde, stellte jedoch einen der wenigen offenen staatlichen Eingriffe in den 2000er Jahren dar.

\subsubsection{Die Schulbuchgeneration Ende der 2000er Jahre}

Bei aller Vielfalt hatten die Schulbücher für das Fach Geschichte Ende der 1990er und Anfang der 2000er Jahre vor allem in didaktischer, aber auch inhaltlicher Hinsicht keinen guten Ruf. ${ }^{88}$ Viele der Bücher waren sprachlich

81 Vgl. Brandenberger, David: A New Short Course? A. V. Filippov and the Russian State's Search for a `Usable Past . In: Kritika. Explorations in Russian and Eurasian History. 10/4 (2009), $827 \mathrm{f}$.

82 Vgl. Filippov, Aleksandr: Novejšaja istorija Rossii 1945-2006 gg. Kniga dlja učitelja. Prosveščenie, Moskva 2007, 420.

83 Vgl. Surkov, Vladislav: Nacionalizacija buduščego. Paragrafy pro suverennuju demokratiju. In: Ėkspert. Nr. 43 (537) 20. November 2006. Online: http://expert.ru/expert/2006/43/ nacionalizaciya_buduschego.

84 Danilov, Aleksandr: Istorija Rossii, 1945-2007, 11 klass. Prosveščenie, Moskva 2008.

85 Danilov, Aleksandr: Istorija Rossii, 1945-2008, 11 klass. Prosveščenie, Moskva 2009.

86 Laut Aleksej Miller wurde das Buch an zwei verschieden Standorten gedruckt: einmal in einer Auflage von 100.000, einmal in einer Auflage von 150.000 Büchern. Vgl. Miller, Aleksej: Rossija: vlast' i istorija. In: Pro et Contra, 13/3-4 (2009), 14.

87 Danilov, Aleksandr: Istorija Rossii, 1900-1945, 11 klass. Prosveščenie, Moskva 2012.

88 Vgl. Golubev, Aleksandr: Das Bild der sowjetischen Vergangenheit in den rußländischen Schulbüchern der letzten Jahre. In: de Keghel, Isabelle/Maier, Robert(Hg.): Auf den Keh- 
nicht auf die Altersgruppen abgestimmt oder enthielten essayistische oder stark deutende Formulierungen, die für Schüler schwer einzuordnen sind. So schrieb beispielsweise Igor' Doluckij im Lehrbuch für die 10. und 11. Klasse über die Präsidentschaftswahlen 1996:

»Der Sieg El'cins [...] wendete jedoch die Tragödie des Landes kaum ab. Der folgende Infarkt brachte den Präsidenten fast um. Aber sein Wille zur Macht erwies sich als stärker als der Tod." ${ }^{89}$

Anfang der 2000er Jahre wurde die Gestaltung der Schulbücher zunehmend aufwendiger. Bis 2003 stellten alle Verlage ihre Publikationen von SchwarzWeiß auf Mehrfarb- oder Buntdruck um und statteten sie mit Bildern, Fotos, Grafiken und Karten aus. Der noch in den 1990er Jahren dominierende Autorentext wurde in den aktuelleren Ausgaben durch Zusatzinformationen, Rechercheaufgaben und Fragen an den Gegenstand aufgebrochen und breit mit Quellen abgestützt. Das Layout dieser Schulbuchgeneration ist übersichtlicher und die einzelnen Elemente, wie Autorentext, Zusatzinformationen, Portraits oder auch Kommentare, sind klar voneinander zu unterscheiden. Lediglich im Bereich der Querverweise innerhalb des Buches, der Verweise auf externe Zusatzinformationen und der Integration von Vertiefungsangeboten zeigen einige der Bücher deutliche Defizite.

Die russländischen Schulbücher der 2000er Jahre entsprechen somit weitgehend den konsensualen Mindestanforderungen an Schulbücher, ${ }^{90}$ wie sie beispielsweise in der deutschen Schulbuchforschung formuliert werden. ${ }^{91}$ Dabei wird jedoch an der grundsätzlichen Konzeption festgehalten: Der Autorentext nimmt weiterhin breiten Raum ein und einer umfassenden Ereignisgeschichte wird der Vorrang vor exemplarischem Lernen eingeräumt.

Um einen groben Überblick über die Ausrichtung der Schulbücher für den Geschichtsunterricht zu geben, werden im Folgenden einige inhaltliche Aspekte der Schulbuch-Generation der 2000er Jahre dargestellt. Als Vergleichsgruppe werden die acht Schulbücher für russländische Geschichte in den 11. Klassen aus der Empfehlungsliste des Bildungsministeriums für das

richthaufen der Geschichte? Der Umgang mit der sozialistischen Vergangenheit. Hannover 1999, 112.

89 Doluckij, Igor’: Otečestvennaja Istorija XX. Vek. Moskva 2003, 249.

90 Auch wenn einige konsensuale Mindestanforderungen für die Bereich Gestaltung und Inhalt formuliert werden: Grundsätzlich existieren aufgrund von unterschiedlichen Akteursperspektiven und Prioritäten didaktischer Schulen keine allgemein anerkannten Qualitätskriterien zur Bewertung von Schulbüchern. Vgl. Maier, Robert: Was ist ein gutes Schulbuch? In: Eckert Beiträge 2009/3.

91 Vgl. Rüsen, Jörn: Das ideale Schulbuch. Überlegungen zum Leitmedium des Geschichtsunterrichts. In: Internationale Schulbuchforschung. Zeitschrift des Georg-Eckert-Instituts 14/3 (1992), $242 \mathrm{ff} ;$ Maier, Robert: Was ist ein gutes Schulbuch? In: Eckert Beiträge 2009/3. Online: http://d-nb.info/1001808479/34, 1 
Schuljahr 2011/2012 herangezogen, ${ }^{92}$ da hier zum einen die Bildungsstandards der ersten Generation vollständig implementiert sein sollten und zum anderen die an den Schulen eingesetzte Literatur weitgehend vollständig abgebildet wird. ${ }^{33}$

Die Darstellung der Geschichte in den verschiedenen Schulbüchern orientiert sich grob an den Vorgaben aus den 1998er und 2004er Standards. Allerdingsist die föderale Komponente zu knapp formuliert, um ausihrbeispielweise eine klare Vorgabe der Periodisierung abzuleiten. Daher ist das augenfälligste Merkmal der Schulbücher, dass sie alle über unterschiedliche Periodisierungen, Schwerpunktsetzungen und Kapitelstrukturen verfügen. Selbst die Kapitel zum Zweiten Weltkrieg bzw. zum Großen Vaterländischen Krieg unterscheiden sich deutlich in ihrem Zuschnitt: Während drei der Bücher ${ }^{94}$ den Großen Vaterländischen Krieg 1941-1945 in einem Kapitel behandeln und dadurch die Jahre 1939-1941 auslagern, umfassen die Kapitel bei vier der Bücher ${ }^{95}$ den Zeitraum des Zweiten Weltkriegs von 1939-1941 und trennen somit die Vorgeschichte des Großen Vaterländischen Krieges nicht ab.

Diese Unterschiede treffen auch auf andere Themenbereiche zu, die sich als Schlüsselmomente für die russländische Historiografie bezeichnen lassen. So werden in den Büchern der Fall der Monarchie, die Politik der provisorischen

92 Vgl. Volobuev, Oleg/Kulešov, Sergej: Istorija Rossii XX - načalo XXI veka. Mnemozina, Moskva 2008; Zagladin, Nikita: Istorija Rossii XX - načalo XXI veka. Russkoe slovo, Moskva 2011. Levandovskij, Andrej: Istorija Rossii XX - načalo XXI veka. Prosveščenie, Moskau 2011. Danilov, Aleksandr: Istorija Rossii 1900-1945, Prosveščenie, Moskau 2012. Filippov, Aleksandr: Istorija Rossii 1945-2008, Prosveščenie, Moskau 2009. Izmozik, Vladlen/Rudnik, Sergej: Istorija Rossii. Ventana-Graf, Moskau 2011. Šestakov, Vladimir: Istorija Rossii XX - načalo XXI veka. Prosveščenie, Moskau 2011. Kiselev, Aleksandr: Istorija Rossii XX - načalo XXI veka. Drofa, Moskau 2012. Die Bücher Istorija Rossii 1900-1945 und Istorija Rosii 1945-2008 bauen aufeinander auf.

93 Nicht berücksichtigt werden die Schulbücher für die Bereiche `Allgemeine Geschichte` (Vseobščaja istorija) und $>$ Russland und die Welt` (Rossija i mir). Zudem werden alte, nicht mehr im Verzeichnis aufgeführte Lehrbücher häufig bis zu ihrem Verschleiß weiterverwendet.

94 Volobuev, Oleg/Kulešov, Sergej: Istorija Rossii XX - načalo XXI veka. Mnemozina, Moskva 2008; Zagladin, Nikita: Istorija Rossii XX - načalo XXI veka. Russkoe slovo, Moskva 2011; Levandovskij, Andrej: Istorija Rossii XX - načalo XXI veka. Prosveščenie, Moskau 2011.

95 Izmozik, Vladlen/Rudnik, Sergej: Istorija Rossii. Ventana-Graf, Moskau 2011; Šestakov, Vladimir: Istorija Rossii XX - načalo XXI veka. Prosveščenie, Moskau 2011; Kiselev, Aleksandr: Istorija Rossii XX - načalo XXI veka. Drofa, Moskau 2012; Danilov, Aleksandr: Istorija Rossii 1900-1945, Prosveščenie, Moskau 2012.

Wobei Kiselev und Danilov anders als die beiden anderen den Ausdruck `Zweiter Weltkrieg ‘ in der Kapitelüberschrift vermeiden. Kiselev titelt `Die Sowjetunion am Vortag und in den Jahren des Großen Vaterländischen Kriegs`vgl. Kiselev, Aleksandr: Istorija Rossii XX - načalo XXI veka. Drofa, Moskau 2012, 124. Danilov titelt `Der Große Vaterländische Krieg 1941-1945 - beginnt jedoch das Kapitel mit dem 1. September 1939 vgl. Danilov, Aleksandr: Istorija Rossii 1900-1945, Prosveščenie, Moskau 2012, 324. 
Regierung oder die Machtübernahme der Bolschewiki auf unterschiedliche Weise dargestellt und eingeordnet. Schon die Bezeichnungen für die Ereignisse im Oktober 1917 reichen von »Bewaffneter Oktoberaufstand. >Prolog des Bürgerkriegs « ${ }^{96}$ über "Bewaffneter bolschewistischer Aufstand in Petrograd und Moskau ${ }^{97}$ und $»$ Die Bolschewiki ergreifen die Macht ${ }^{98}$ bis hin zu »Oktoberumsturz $1917 \ll .{ }^{99}$ Nicht nur die Ereignisse selbst, sondern auch deren Einordnung nimmt breiten Raum ein. Danilov widmet der »Diskussion um den Charakter der Oktoberereignisse « in der Historiografie ein ganzes Kapitel - nicht ohne seinen eigenen Beitrag zu dieser Diskussion herauszustellen. ${ }^{100}$

Auch die Politik Stalins und die mit ihr verbundenen Verbrechen und dunklen Seiten der Geschichte stellen einen solchen Schlüsselmoment dar. Grundsätzlich stellen die Schulbücher im Vergleich zu vielen Publikationen der 1990er Jahren die historischen Ereignisse deutlicher und offener dar. Die Millionen Opfer der Kollektivierung in der Ukrainischen Sowjetrepublik und anderen Republiken der Sowjetunion, der Zusammenhang von Modernisierung und GULag, Staatsterror und Massenrepression sowie das geheime $\mathrm{Zu}$ satzprotokoll zum deutsch-sowjetischen Nichtangriffsvertrag werden durchgängig thematisiert. Die Massenerschießungen von polnischen Gefangenen u. a. bei Katyn 1940 fehlen lediglich bei Zagladin und Volobuev. ${ }^{101}$

Die Unterschiede zwischen den verschiedenen Büchern bestehen dementsprechend vor allem darin, wie ausführlich und in welchem Kontext diese Themen dargestellt werden.

In einem Teil der Bücher werden die Repressionen und die Errichtung der stalinistischen Herrschaft in eigenen Kapiteln behandelt: ${ }^{102}$ So enthält beispielweise Zagladins Schulbuch die Kapitel »Stalin und der politische Terror

96 Izmozik, Vladlen/Rudnik, Sergej: Istorija Rossii. Ventana-Graf, Moskau 2011, 113.

97 Volobuev, Oleg/Kulešov, Sergej: Istorija Rossii XX - načalo XXI veka. Mnemozina, Moskva 2008, 90.

98 Levandovskij, Andrej: Istorija Rossii XX - načalo XXI veka. Prosveščenie, Moskau 2011. 84.

99 Šestakov, Vladimir: Istorija Rossii XX - načalo XXI veka. Prosveščenie, Moskau 2011, 65.

100 Danilov, Aleksandr: Istorija Rossii 1900-1945, Prosveščenie, Moskau 2012, 148 ff. Das Kapitel »Russland im Strudel der Revolution und des Bürgerkriegs« wurde von Danilov und Ljudmila Kosulina geschrieben, 107-171.

101 Zagladin widmet dem deutsch-sowjetischen Nichtangriffsvertrag zwar ein Unterkapitel, das als Quelle einen längeren Auszug aus dem geheimen Zusatzprotokoll enthält, in der Beschreibung der Folgen bleibt der Text jedoch dann kursorisch und übergeht das Schicksal der gefangenen polnischen Offiziere und Sicherheitsbeamten. Vgl. Zagladin, Nikita: Istorija Rossii XX - načalo XXI veka. Russkoe slovo, Moskva 2011, $183 \mathrm{ff}$.

102 Vgl. z. B. Šestakov, Vladimir: Istorija Rossii XX - načalo XXI veka. Prosveščenie, Moskau 2011, 195 ff. oder Zagladin, Nikita: Istorija Rossii XX - načalo XXI veka. Russkoe slovo, Moskva 2011, $162 \mathrm{ff}$. 
in der UdSSR « ${ }^{103}$ und »Repressionen $1936-1938$ «, ${ }^{104}$ in denen ausführlich die ideologische Verschärfung, Schauprozesse, Repressionen, der Unterhalt von Konzentrationslagern, die Errichtung des GULag-Systems und die Massenerschießungen behandelt werden. Der Vorteil dieser Herangehensweise liegt vor allem in der guten Sichtbarkeit und dem großen Raum, den die Darstellung so einnehmen kann. Der

Nachteil besteht darin, dass beispielsweise die Errichtung des GULag-Systems zwar mit der Modernisierung und Industrialisierung verbunden wird, aber eben im Kapitel zu den Repressionen und nicht im Kapitel zur Modernisierung und zur Entwicklung der Sowjetunion abgehandelt wird.

Andere Bücher vermeiden diese Abtrennung, indem sie die Errichtung des GULag-Systems in Kapiteln zur Modernisierung thematisieren und Zwangsarbeit so als integralen Bestandteil der Entwicklung der Sowjetunion vermitteln. So sind Repressionen und der GULag bei Kiselev in das Kapitel zum $»$ Kurs auf die forcierte Industrialisierung « integriert. ${ }^{105}$ Verbrechen und Fortschritt werden auf diese Weise nicht getrennt. Bei dieser Herangehensweise besteht der Nachteil vor allem darin, dass der Errichtung des GULags hier weniger Raum gegeben wird, oder dass das Thema eventuell schlecht eingebunden ist. ${ }^{106}$

Ein Beispiel dafür, wie der Kontext der Thematisierung auch genutzt werden kann, um Verbrechen zu relativieren, bietet die Passage zu den Massenerschießungen an polnischen Gefangenen bei Danilov. Im Unterkapitel ${ }^{107}$ heißt es zunächst lakonisch:

»Entsprechend der Entscheidung des Politbüros des ZK VKP(b) vom 5. März 1940 wurden 21.857 Offiziere und eine Reihe anderer Gefangener (Polizeidienstleistende, Sonderdienste u. a.) erschossen."

Anschließend spekuliert der Autor plastisch und weniger lakonisch über die Gründe für diese Entscheidung:

„Es ist möglich, dass diese Entscheidung mit der Bestrafung der >Weißpolen für die bestialische Vernichtung gefangener Rotarmisten während und nach dem SowjetischPolnischen Kriegs 1920 verbunden war $[\ldots] .{ }^{108}$

103 Zagladin, Nikita: Istorija Rossii XX - načalo XXI veka. Russkoe slovo, Moskva 2011, $162 \mathrm{ff}$.

104 Ebd., $164 \mathrm{ff}$.

105 Vgl. Kiselev, Aleksandr: Istorija Rossii XX - načalo XXI veka. Drofa, Moskau 2012, 98.

106 Dass die Errichtung des GULag, die Toten beim Bau des Weißmeer-Kanals und der Schachty-Prozess bei Izmozik im Kapitel `Die stalinsche Modernisierung des Landes und ihre Besonderheiten`im Unterkapitel `Arbeitsheroismus des Volkes` angesiedelt sind, ist mehr als unglücklich. Izmozik, Vladlen / Rudnik, Sergej: Istorija Rossii. VentanaGraf, Moskau 2011, $165 \mathrm{f}$.

107 Verfasst von Michail Gorinov.

108 Danilov, Aleksandr: Istorija Rossii 1900-1945, Prosveščenie, Moskau 2012, 325. 
Hier besteht das Problem nicht - wie bei den vorangegangenen Beispielen - in einer methodologischen Abwägung, sondern darin, dass das vom Politbüro angeordnete Verbrechen durch den spekulativen Kontext relativiert werden soll.

In der Darstellung des Großen Vaterländischen Krieges bestehen zwar wie beschrieben - deutliche Unterschiede in der Anlage des Themas, dennoch sind die Bücher durchgängig einem militärisch-heroischen Narrativ verpflichtet: ${ }^{109}$

"Der hitlersche Plan des Blitzkriegs zerschellte an der heroischen Gegenwehr der Roten Armee und des gesamten sowjetischen Volkes. ${ }^{110}$

Dabei gibt es wiederkehrende Elemente, die fast durchgängig in allen Büchern enthalten sind und ausführlich dargestellt werden. Dazu zählen im Bereich der Kriegsereignisse die Niederlagen der ersten Monate 1941, die Schlacht um Moskau, die Blockade Leningrads, die Schlacht von Stalingrad, die Schlacht am Kursker Bogen, die Befreiung der Länder Europas und die Niederlage Deutschlands. ${ }^{111}$ Weitere Themen sind die Mobilisierung und das sowjetische Hinterland, Okkupations-Regime, Partisanenbewegung, Anti-Hitler Koalition und Staat, Ideologie und Kultur während des Krieges.

Einige der Bücher, wie Zagladin, Izmozik und Volobuev, diskutieren zudem die Präventivkriegsthese, nach der Deutschland lediglich einem sowjetischen Überfall zuvorgekommen sei, und einige Bücher, wie z.B. Danilov, thematisieren ausführlich die »Zusammenarbeit mit dem Feind $\aleph^{112}$ in verschiedenen Bereichen.

Die Gruppierung dieser Elemente variiert. In den meisten Büchern wird der Kriegsverlauf als Rahmen benutzt, der von Themen wie »Faschistische Okkupation ${ }^{113}$ oder $»$ Die Russisch Orthodoxe Kirche in den Kriegsjahren $\aleph^{114}$ unterbrochen wird. Die Mehrzahl der Bücher legen dem Kriegskapitel zudem

109 Dies stellt eine Kontinuität seit den ersten post-sowjetischen Schulbüchern und darüber hinaus dar. Auch das Schulbuch von Igor' Doluckij aus den 1990er Jahren, das in der Diskussion um russländische Schulbücher im In- und Ausland in der Regel als eines der liberalsten und progressivsten apostrophiert wird, stellt hier keine Ausnahme dar. Vgl. Doluckij, Igor': Otečestvennaja Istorija XX. Vek. Čast' 2. Mnemozina, Moskva 2003, $17-60$

110 Izmozik, Vladlen/Rudnik, Sergej: Istorija Rossii. Ventana-Graf, Moskau 2011, 201.

111 In einigen Büchern wird auch der Krieg mit Japan hervorgehoben vgl. Volobuev, Oleg/Kulešov, Sergej: Istorija Rossii XX - načalo XXI veka. Mnemozina, Moskva 2008, 211 und Danilov, Aleksandr: Istorija Rossii 1900-1945, Prosveščenie, Moskau 2012, $367 \mathrm{ff}$.

112 Danilov, Aleksandr: Istorija Rossii 1900-1945, Prosveščenie, Moskau 2012. $391 \mathrm{ff}$.

113 Izmozik, Vladlen/Rudnik, Sergej: Istorija Rossii. Ventana-Graf, Moskau 2011, 219.

114 Zagladin, Nikita: Istorija Rossii XX - načalo XXI veka. Russkoe slovo, Moskva 2011, 217. 
eine Struktur von $»$ katastrophaler Anfang ${ }^{115}{ }^{115}$, entscheidende Schlachten ${ }^{116}$ und »von Sieg zu Sieg « ${ }^{117}$ zugrunde.

Fast alle dieser Elemente waren, zumindest in ähnlicher Form, schon in den Schulbüchern der Sowjetunion enthalten. Keine Berücksichtigung mehr finden lediglich Elemente wie die besondere Rolle der Parteikader beim Kampf an der Front, ${ }^{118}$ die Verteidigung der Revolution oder die Unbesiegbarkeit der Partei oder des sozialistischen Systems, die bis in die spätern 1980er Jahre prägend waren. ${ }^{119}$

Ein Beispiel dafür, wie sich sowjetische Narrative in den Schulbüchern gehalten haben, ist die Thematisierung der sogenannten Panfilovcy in der Schlacht um Moskau, der Soldaten der 316. Schützenbrigade von General Ivan Panfilov. Obwohl eine sowjetische Untersuchungskommission bereits 1948 festgestellt hatte, dass die Ereignisse, wie sie in der Armeezeitung Krasnaja Zvezda am 22. Januar 1942 vermeldet wurden, nicht stattgefunden hatten, ${ }^{120}$ stand in den sowjetischen Schulbüchern:

"An diesem Tag, an der Ausfahrt Dubosekovo, nahmen 28 Kämpfer unterschiedlicher Nationalität - Russen, Ukrainer, Kasachen, Kirgisen - den Kampf gegen 50 deutsche Panzer auf. Der Politruk der Kompanie, V. G. Kločkov, spornte die Kämpfer mit den unsterblichen Worten $>$ Russland ist groß, aber wir können nirgendwohin zurückweichen - hinter uns liegt Moskau zu Heldentaten an. Vier Stunden dauerte der Kampf. Die Helden löschten 18 Panzer und viele Hitleristen aus. ${ }^{121}$

In vielen Büchern für das Schuljahr 2011/2012 ist dieser Mythos immer noch präsent - wenn auch nicht vollständig. Bei Zagladin, Izmozik und Šestakov wird die Heldentat der 28 Panilovcy beschrieben, bei Levandovskij werden sogar die legendären Worte des Politruks zitiert. Kiselev, Volobuev und das vielfach als patriotisch-selektiv beschriebene Buch von Danilov ${ }^{122}$ erwähnen das Thema nicht.

115 Volobuev, Oleg/Kulešov, Sergej: Istorija Rossii XX - načalo XXI veka. Mnemozina, Moskva 2008,185.

116 Šestakov, Vladimir: Istorija Rossii XX - načalo XXI veka. Prosveščenie, Moskau 2011, 230.

117 Volobuev, Oleg/Kulešov, Sergej: Istorija Rossii XX - načalo XXI veka. Mnemozina, Moskva 2008, 206.

118 Vgl. Ostrovskij, Valerij: Istorija SSSR. Učebnik dlja 11 klassa. Moskau 1990, 97.

119 Vgl. Valev, Vasilij: Istorija SSSR 1938-1978. Učebnik dlja 10 klassa. Prosveščenie, Moskau 1980, 121.

120 Vgl.Chamraev,Viktor:»Razoblačeniefal'sifikatoraiizgotovlennojimfal'šivkineizbežno«. In:Kommersant«. Nr. 69 vom 20.04.2015, 4. Online: http://kommersant.ru/Doc/2712788.

121 Valev, Vasilij: Istorija SSSR 1938-1978. Učebnik dlja 10 klassa. Prosveščenie, Moskau 1980, 53.

122 Vgl. Brandenberger, David: A New Short Course? A. V. Filippov and the Russian State's Search for a `Usable Past.. In: Kritika. Explorations in Russian and Eurasian History. 10/4 (2009), 825-833. 
Der Holocaust spielt dagegen in den Büchern keine bedeutende Rolle. Er findet in der Regel im Kapitel zum deutschen Besatzungsregime und zu den nationalsozialistischen Verbrechen während des Großen Vaterländischen Kriegs Erwähnung. Entsprechend der föderalen Komponente der Bildungsstandards ist die Vernichtung des Judentums dem Bereich rallgemeine Geschichter zugeordnet und findet in den Schulbüchern zur allgemeinen Geschichte breiteren Raum.

Auch die Zeit nach dem Krieg wird in den einzelnen Büchern unterschiedlich erzählt und auch periodisiert - lediglich die Geschichte der Russländischen Föderation bekommt durchgängig ein eigenes Kapitel. Der Teil dieser Kapitel, der sich auf die 2000er Jahre bezieht, ist von besonderem Interesse, da es hier klarere Vorgaben durch die Bildungsstandards gibt, die zudem Deutungen der Geschichte enthalten.

Ein Bereich, in dem sich die Bandbreite der Schulbuchgeneration von 2011/2012 zeigt, ist die Umsetzung der Vorgaben der Bildungsstandards von 2004 bezüglich der Zeit ab den Wahlen im Jahr 2000. Anders als in ihren sonstigen, eher kursorischen Auflistungen, ist die Passage zu den 2000er Jahren einer der wenigen Bereiche der föderalen Komponente der Bildungsstandards für den Geschichtsunterricht, in dem eine Wertung von Geschichte festgeschrieben wird: Die Zeit der putinschen Präsidentschaften soll als Stärkung der Staatlichkeit, der nationalen Sicherheit und des Einflusses Russlands in der Welt, als wirtschaftlicher Aufschwung und Phase der sozialen und politischen Stabilität beschrieben werden. ${ }^{123}$

Der Bildungsstandard gibt auf diese Weise eine Geschichtsinterpretation vor, die die jüngste Geschichte als eine Leistungsschau der Kremlpolitik darstellt und dadurch den Machtanspruch und den Kurs des Präsidenten legitimiert. Das öffentliche Vorgehen gegen das Buch ,Vaterländische Geschichte im 20. Jahrhundert von Doluckij hatte bereits vor der Verabschiedung der föderalen Komponente deutlich gemacht, dass man im Kreml und im Bildungsministerium bereit war, Einflusspotenziale bezüglich der jüngsten Geschichte zu nutzen.

Diesen klaren Vorgaben zum Trotz fallen die entsprechenden Kapitel in den verschiedenen Schulbüchern auf der Empfehlungsliste des Bildungsministeriums durchaus unterschiedlich aus. Auf der einen Seite ist sicherlich das Schulbuch »Geschichte Russlands 1945-2008 « ${ }^{124}$ von Danilov, Utkin und Filippov zu nennen. Hier wird der Anspruch, die Vorgaben des Bildungsministeriums nicht nur umzusetzen, sondern auch bis ins Detail wohlwollend

123 Prikaz Minobrazovanija RF ot 05.03.2004 N 1089 »Ob utverždenii federal'nogo komponenta gosudarstvennych obrazovatel'nych standartov načal'nogo obščego, osnovnogo obščego i srednego (polnogo) obščego obrazovanija«.

124 Danilov, Aleksandr: Istorija Rossii 1900-1945, Prosveščenie, Moskau 2012. 
zu kommentieren, durch die Entscheidung der Herausgeber unterstrichen, das Kapitel über die jüngste Geschichte von einem Polittechnologen des Kremls und Funktionär der Jungen Garde von Einiges Russland - Pavel Danilin schreiben zu lassen. ${ }^{125}$

Jeder der in der föderalen Komponente festgeschriebenen Aspekte bekommt bei Danilov unter dem Titel »Der neue Kurs Russlands $\aleph^{126}$ ein eigenes Unterkapitel: „Der Kurs des Präsidenten V. V. Putin auf die Konsolidierung der Gesellschaft ${ }^{127}$, Innenpolitik am Anfang des 21. Jahrhunderts - Wiederherstellung des Staates $\aleph^{128}$, Kurs auf die souveräne Demokratie ${ }^{129}$ und $» W i e d e r-$ herstellung der Stellung Russlands in der internationalen Politik. ${ }^{130}$ Dementsprechend werden die 2000er Jahre als eine sehr glatte Erfolgsgeschichte ohne bemerkenswerte Irritationen dargestellt. Die Entwicklung wird primär als eine Abfolge präsidentieller Entscheidungen und Reformen präsentiert - für die Quellenarbeit werden fast ausschließlich Präsidentenreden vor der Föderalversammlung oder Präsidenteninterviews vorgeschlagen. ${ }^{131}$ Diese Schwerpunktsetzungen sind nicht verwunderlich - nach Angaben von Aleksandr Filippov geht das gesamte Projekt auf eine Initiative von Kreml und Bildungsministerium zurück. ${ }^{132}$ Auch bei Levandovskij und Šestakov wird - teilweise ebenfalls unter Rückgriff auf die Schlagwörter der Polittechnologen - eine sehr glatte Entscheidungs- und Reformgeschichte des Kremls erzählt. So schreibt Šestakov über die wirtschaftliche Entwicklung Anfang des 20. Jahrhunderts:

»Insgesamt wurde die Periode der ersten Präsidentschaft Putins für Russland zur erfolgreichsten Entwicklungsperiode der letzten 100 Jahre. ${ }^{133}$

Auch wenn Šestakov den Schülern im folgenden Kapitel die Aufgabe erteilt, diese »Erklärung des Autors des Schulbuchs $^{134} \mathrm{zu}$ überprüfen, spiegelt der Superlativ die geringe Distanz des Textes zur Politik der 2000er Jahre wider.

125 Als Autor der letzten Kapitel wird Pavel Danilin in Zusammenarbeit mit Filippov genannt. Lediglich das letzte Unterkapitel `Die russische Gesellschaft in der Epoche des Wandels (1992-2008) « wird Irina Semenenko zugeordnet.

126 Danilov, Aleksandr: Istorija Rossii 1900-1945, Prosveščenie, Moskau 2012, 306.

127 Ebd., 306.

128 Ebd., 312.

129 Ebd., 319. Der Titel des Kapitels bedient sich ohne Anführungsstriche bei der Konzeption Vladislav Surkovs vgl. Surkov, Vladislav: Nacionalizacija buduščego. Paragrafy pro suverennuju demokratiju. In: Ėkspert. Nr. 43 (537) vom 20.11.2006. Online: http://expert.ru/ expert/2006/43/nacionalizaciya_buduschego.

130 Danilov, Aleksandr: Istorija Rossii 1900-1945, Prosveščenie, Moskau 2012, 331.

131 Vgl. ebd., 312, $330 \mathrm{f}$ und $345 \mathrm{f}$.

132 Vgl. Kačurovskaja, Anna: Istoričeskij pripadok. In: Kommersant« Vlast'. Nr. 27 vom 16.07.2007, 14. Online: http://www.kommersant.ru/doc/782464.

133 Šestakov, Vladimir: Istorija Rossii XX - načalo XXI veka. Prosveščenie, Moskau 2011, 379.

134 Ebd., 380. 
Die anderen empfohlenen Bücher für die Oberstufe geben ein differenzierteres Bild ab: Bei Zagladin werden die Vorgaben - beispielsweise in Bezug auf die Stabilisierung des Landes - zwar formal erfüllt, aber auch kritisch ergänzt. ${ }^{135}$ So werden die Weltmarktpreise für Rohstoffe als Hauptgrund für die wirtschaftliche Entwicklung und die soziale Stabilisierung angeführt. ${ }^{136}$ Ähnlich verfährt Izmozik: in seinem Kapitel »Russland am Beginn des 21. Jahrhunderts: Probleme und Perspektiven der Entwicklung « ${ }^{137}$ beklagt er, dass zwar immer mehr Menschen die wirtschaftliche Abhängigkeit vom Staat hinter sich lassen und ein Bewusstsein für Marktprinzipien und Eigentum entwickeln, aber gleichzeitig die russische Wirtschaft und der Staatshaushalt weiterhin in starker Abhängigkeit zu den Weltmarktpreisen für Öl und Gas stehen. ${ }^{138}$ Kiselev verweist ebenfalls auf die Rolle der "Öl-Dollar ${ }^{139}$ bei der Lösung wichtiger Haushaltsprobleme und ordnet das Wirtschaftswachstum, im Verhältnis zur Wirtschaftskraft von 1989, als lediglich »restauratives Wachstum« ein.

Auch sonst wird - unter formaler Erfüllung der Vorgaben - eine weitaus weniger glatte Geschichte erzählt. So schließt Volobuev ${ }^{140}$ das Kapitel zur Konsolidierung der staatlichen Macht mit einem Plädoyer für mehr Rechtsstaatlichkeit und politische Freiheiten, die Beachtung der Menschenrechte und für den Kampf gegen Korruption und Bürokratie. ${ }^{141}$ Im Rahmen der Beschreibung der politischen Stabilität werden neben Einiges Russland, KPRF, LDPR und Gerechtes Russland auch die kleinen liberalen Parteien Union der rechten Kräfte und Jabloko beschrieben. ${ }^{142}$ Zudem sind Auszüge aus den Parteiprogrammen der kleinen Parteien als Materialien abgedruckt. ${ }^{143}$ Auch Kiselevs Kapitel zu den 2000er Jahren berücksichtigt durchaus kritische Aspekte. Der Abschnitt zu den politischen Parteien thematisiert die Gefahr, dass sich Edinaja Rossija analog zur KPSS zu einer neuen Einheitspartei für Karrieristen entwickeln könnte, ${ }^{144}$ sowie die Schwächung der Opposition durch verschiedene Maßnahmen, wie die Anhebung der Sperrklausel für die Dumawahlen. Insgesamt charakterisiert Kiselev das Parteiensystem als schwach und referiert als Gründe:

135 Zagladin, Nikita: Istorija Rossii XX - načalo XXI veka. Russkoe slovo, Moskva 2011, 366.

136 Vgl. ebd., 366.

137 Izmozik, Vladlen/Rudnik, Sergej: Istoriya Rossii. Ventana-Graf, Moskva 2011, $337 \mathrm{ff}$.

138 Vgl. ebd.,341 f.

139 Kiselev, Aleksandr: Istorija Rossii XX - načalo XXI veka. Drofa, Moskau 2012, 303.

140 Volobuev, Oleg/Kulešov, Sergej: Istorija Rossii. XX - načalo XXI veka. Mnemozina, Moskva 2008.

141 Vgl. ebd., $299 \mathrm{f}$.

142 Vgl. ebd., 298.

143 Vgl. ebd. Parteiprogramme auch als Quellen: $320 \mathrm{f}$.

144 Kiselev, Aleksandr: Istorija Rossii XX - načalo XXI veka. Drofa, Moskau 2012, 299. 
»Das Fehlen einer Bürgergesellschaft in Russland, wo in den meisten Bereichen des öffentlichen Lebens weiterhin staatliche Strukturen die führende Rolle spielen, die amorphen ökonomischen Interessen der Mehrheit der Bevölkerung, die Übermacht von Monopolen, die mangelnde Entwicklung von kleinem und mittlerem Business u.a. « ${ }^{145}$

An diesen Beispielen wird deutlich, dass die Bildungsstandards des Ministeriums von 2004 für die Darstellung der 2000er Jahre zwar entsprechend der parteipolitischen Agenda und Geschichtsinterpretation von Kreml und Einiges Russland formuliert wurden, aber in der Praxis der Zulassung und Empfehlung von Schulbüchern lediglich formal angewendet werden. Passagen, die der offensichtlichen parteipolitischen Intention der Standards durch eine breitere Kontextualisierung zuwider laufen und die keine glatte Erfolgsgeschichte präsentieren, verhindern nicht die Zulassung oder Empfehlung der entsprechenden Schulbücher. ${ }^{146}$

Insgesamt geben sich die Schulbücher des Faches Geschichte Ende der 2000er Jahre ein sehr vielfältiges Bild ab. Sie unterscheiden sich in ihren didaktischen Ansätzen genauso wie in ihren Periodisierungen und politischen Grundausrichtungen. Manche sind auf dem aktuellen Forschungsstand, andere hinken hinterher, manche betonen Politikgeschichte, andere Kultur- oder Wirtschaftsgeschichte.

Diese Vielfalt ist eine Folge des in den 1990er Jahren entstandenen und weiter bestehenden Schulbuchmarktes, auf dem eine Reihe von Verlagen mit unterschiedlichen Produkten und eine Reihe etablierter Historiker als Autoren konkurriert.

Daraus lässt sich der Schluss ziehen, dass zwar staatlicher Einfluss auf die Inhalte von Schulbüchern besteht, z.B. durch die Vorgaben der Bildungsstandards, dieser aber nicht konsequent umgesetzt wird. Die Eingriffe sind eher punktuell, werden aber, wie die Fälle Doluckij und Danilov/Filippov zeigen, öffentlichkeitswirksam inszeniert und können so normierend wirken. Dennoch lässt sich kein systematischer staatlicher Zugriff auf die Inhalte der Geschichtsbücher feststellen. Ein solcher Zugriff müsste sich zum einen vereinheitlichend auf die Inhalte auswirken und zum anderen, in letzter Konsequenz, in Richtung der Wiedereinführung des Einheitsschulbuches gehen.

145 Ebd., 300.

146 Alle angeführten Publikationen sind aus der Liste der empfohlenen Schulbücher des Schuljahres 2011/2012. Vgl. Prikaz Ministerstva obrazovanija i nauki Rossijskoj Federacii (Minobrnauki Rossii) ot 24 dekabrja 2010 g. N 2080 g. Moskva »Ob utverždenii federal'nych perečnej učebnikov, rekomendovannych (dopuščennych) $k$ ispol'zovaniju v obrazovatel'nom processe v obrazovatel'nych učreždenijach, realizujuščich obrazovatel'nye programmy obščego obrazovanija i imejuščich gosudarstvennuju akkreditaciju, na 2011/2012 učebnyj god «. 


\subsection{Der 2013er Standard - Geschichte mit offizieller Bewertung?}

Im Frühjahr 2013 kam erneut Bewegung in die regelmäßig aufflammende Debatte um die Geschichte in Schulbüchern allgemein und die Erstellung eines Einheitsgeschichtsbuches für den Unterricht im Besonderen.

Im Zuge einer Sitzung des Rates für zwischennationale Beziehungen im Toleranzzentrum und Jüdischen Museum in Moskau brachte Vladimir Putin vereinheitlichte Schulbücher ins Gespräch. Der Kontext waren Bildungsmaßnahmen zur Verbesserung des gegenseitigen kulturellen Verständnisses und Respekts zwischen Menschen unterschiedlicher ethnischer Zugehörigkeit innerhalb der Russländischen Föderation. Putin regte an, über »einheitliche Schulbücher ${ }^{147}$ nachzudenken, die »im Rahmen einer einheitlichen Konzeption, im Rahmen einer einheitlichen Logik der ununterbrochenen russischen Geschichte, der Wechselbeziehungen aller ihrer Etappen, des Respekts vor allen Seiten unserer Vergangenheit« aufgebaut sein sollten. Diese Schulbücher sollten darüber hinaus an konkreten Beispielen zeigen, »dass sich das Schicksal Russlands auf der Einigkeit verschiedener Völker, Traditionen und Kulturen gründet. ${ }^{148}$ Besonders häufig zitiert wurde Vladimir Putins Zusatz, dass die Bücher ohne »innere Gegensätze und doppeldeutige Interpretationen $\aleph^{149}$ geschrieben sein sollten.

Etwas zurückhaltender positionierte sich der Bildungs- und Wissenschaftsminister Andrej Livanov im Anschluss zur Frage vereinheitlichter Schulbücher: Man habe zwar derzeit mehr als tausend zugelassene Schulbücher, diese seien jedoch alle in einem bewährten Verfahren geprüft worden: ${ }^{150}$

"Wir brauchen sicherlich nicht eine so riesige Menge an Schulbüchern, obwohl wir natürlich finden, dass der Lehrer eine Auswahl haben muss. ${ }^{151}$

In der Einschätzung der konsolidierenden und legitimierenden Funktion der Schulbücher teilt Livanov die Position Putins und überflügelt ihn sogar: Die erziehende Funktion von Schulbüchern bestehe darin, den Kindern Werte zu vermitteln und ihnen ein einheitliches historisches, kulturelles und mora-

147 Putin, Vladimir: Stenografičeskij otčët o zasedanii Soveta po mežnacional'nym otnošenijam. 19 fevralja 2013 goda, Moskva. Online:http://kremlin.ru/events/president/news/ 17536.

148 Ebd.

149 Ebd.

150 Vgl. Livanov, Dmitrij: Stenografičeskij otčët o zasedanii Soveta po mežnacional'nym otnošenijam. 19 fevralja 2013 goda, Moskva. Online: http://kremlin.ru/events/president/ news/17536.

151 Ebd. 
lisches Gepäck mitzugeben, das sie ihr ganzes Leben begleiten werde und welches eine wichtige Rolle in der Ausbildung einer russländischen Identität, der Liebe zur Heimat und des Stolzes auf deren Geschichte spielen werde. ${ }^{152}$

In der Zeitung Kommersant kommentierte Andrej Kolesnikov: "Das heißt, dass sie jetzt wieder anfangen die Geschichte umzuschreiben.« ${ }^{153}$ Tatsächlich setzte parallel zu den ersten Schritten zur Umsetzung der Empfehlung Putins Kritik ein. Als der Duma-Sprecher und Vorsitzende der Russischen Historischen Gesellschaft Sergej Naryškin einige Tage nach der Veranstaltung die ersten Ergebnisse einer Konsultation mit der Historischen Gesellschaft präsentierte, hatten sich bereits viele ablehnende Stimmen öffentlich zu Wort gemeldet. Das ehemalige Mitglied der `Kommission gegen die Fälschung der Geschichte zum Nachteile Russlands`, Nikolaj Svanidze, erklärte:

»Man kann auch auf Geschichte stolz sein, wenn sie tragisch, gewunden und uneindeutig ist. Eine eindeutige Geschichte - das ist der Kratkij Kurs VKP(B). ${ }^{154}$

Der Widerspruch kam insbesondere aus nicht-russischen Regionen wie Inguschetien, Baschkirien oder Tatarstan, wo bemängelt wurde, dass sich die unterschiedlichen historischen Erfahrungen der verschiedenen Völker und Regionen nicht in einem zentralen Schulbuch widerspiegeln könnten. Der Vize-Präsident der Akademie der Wissenschaften Tatarstans, Rafail' Chakimov, verwies unter Hinweis auf den bundesdeutschen Schulbuch-Föderalismus darauf, dass man zwar auf gesamtstaatlicher Ebene Schlüsselfragen regulieren könne, in den Föderationssubjekten jedoch vielfältige Schulbücher existieren müssten. ${ }^{155}$

Einige Monate später, im Juni 2013, stellte Minister Livanov die Fortschritte des Projektes vor. Allerdings machte er sofort deutlich, dass man von der Ausarbeitung eines Einheitsschulbuches für das Fach Geschichte Abstand genommen habe und stattdessen einen 'historisch-kulturellen Standard ausgearbeitet habe. ${ }^{156}$ Solche Standards für Schulbücher, die u.a. offizielle Ein-

152 Vgl. ebd.

153 Kolesnikov, Andrej: Russkim jazykom otkazano. Vladimir Putin ob"javil biblioteku Šneersona nevyezdnoj. In: Kommersant«. Nr. 31 vom 20.02.2013, 1. Online: http://kommersant.ru/doc/2130909

154 Svanidse bezieht sich hier auf den von Stalin in Auftrag gegebenen und 1938 erstmals in einer Serie in der Pravda erschienen Kurzen Lehrgang der Geschichte der KPDSU(B) Kratkij kurs istorii VKP(b). Ivanov, Maksim/Muradov, Musa/Antonov, Kirill/Baširov, Bulat/Pavlova, Natal'ja: Rossiju izmerjat obščim učebnikom. Sergej Naryškin zanjalsja sozdaniem edinogo kursa otečestvennoj istorii. In: Kommersant«. Nr. 36 vom 28.02.2013, 3. Online: http://kommersant.ru/doc/2137507.

155 Vgl. ebd., 3.

156 Vgl. Černych, Aleksandr: Vladimir Medinskij postavil točku v istorii. Razrabotan edinyj standart prošlogo Rossii. In: Kommersant«. Nr. 103 vom 18.06.2013, 5. Online: http:// kommersant.ru/doc/2213690. 
schätzungen von Schlüsselaspekten der russländischen Geschichte beinhalten, hatte Vladimir Putin im Rahmen der Fernsehsendung >Prjamaja Linija $<$ - >Direkte Leitung ${ }^{157}$ ins Gespräch gebracht. ${ }^{158}$ Livanov erklärte, dass der Standard veröffentlicht, über den Sommer diskutiert und dann zur Grundlage für die Ausschreibung eines neuen Schulbuchs werden soll. ${ }^{159}$

Die Diskussion, die sich bereits bei der Vorstellung des Projektes angekündigt hatte, setzte sich in den folgenden Wochen - vor allem nach der tatsächlichen Veröffentlichung der Standards - fort. Zentral waren dabei weiterhin grundlegende Überlegungen über den Sinn und die Risiken einer vereinheitlichten Geschichte genauso wie die Frage abweichender, nicht-russischer Geschichtsperspektiven. Vor allem in Tatarstan wurde Kritik laut, sodass sich Naryškin im Rahmen der Eröffnung der Kazaner Filiale der Russländischen Historischen Gesellschaft persönlich der Kritik an den Standards stellen musste. Insbesondere in der Bezeichnung und Bewertung der "Goldenen Horde«, des "tatarisch-mongolischen Jochs«, der Schlacht auf dem Kulikover Pole und des Falls der Stadt Kazan bestanden erhebliche Differenzen. ${ }^{160}$ Rafail' Chakimov erklärte dazu: »Die Moskauer Sicht auf die vaterländische Geschichte ist allen klar. Aber die Sicht aus Kazan stimmt damit nicht ganz überein. ${ }^{161}$

Was die Berücksichtigung nicht-russischer Geschichtsperspektiven bei der Ausarbeitung vereinheitlichter Geschichtskonzeptionen angeht, zeigen sich hier Parallelen zu dem Prozess der Ausarbeitung neuer ssowjetpatriotischer Schulbücher in den 1930er Jahren. ${ }^{162}$ Auch damals wurde argumentiert, dass das erste Lehrbuch Šestakovs `Geschichte der UdSSR von 1934 - entgegen der Vorgaben Stalins, Ždanovs und Kirovs, eine echte Geschichte der UdSSR und nicht eine russische Geschichte zu schreiben - kein Interesse an der Geschichte der nichtrussischen Völker zeige. ${ }^{163}$

157 Die jährlich stattfindende Sendung `Direkte Leitung mit Valdimir Putin`(»Prjamaja linija s Vladimirom Putinym«), in der der Präsident Zuschauerfragen beantwortet, wurde am 25.04.2013 von den Fernsehkanälen `Erster Kanal`, ’Russland 1^und `Russland 24 sowie vielen Radiosendern live übertragen.

158 Vgl. Putin, Vladimir: Prjamaja linija s Vladimirom Putinym. 25. April 2013, Moskva. http://kremlin.ru/events/president/news/17976.

159 Vgl. Ot redakcii/Otdel politiki: Učebnikovye manevry. Sergej Naryškin priechal v Kazan' pogovorit' pro istoriju. In: Kommersant«. Nr. 124 vom 17.07.2013, 1. Online: http:// kommersant.ru/doc/2235283.

160 Vgl. ebd., 1.

161 Ebd., 1.

162 Zur Entwicklung der sowjetischen Schulbücher bis Mitte der 1950er Jahre siehe auch: Brandenberger, David: National Bolshevism. Stalinist Mass Culture and the Formation of Modern Russian National Identity, 1931-1956. Cambridge 2002, $251 \mathrm{ff}$.

163 Vgl. Oberländer, Erwin: Sowjetpatriotismus und Geschichte. Dokumentation. Köln 1967, $45 \mathrm{f}$. 
Darüber hinaus konnte die Kritik an dem Juli 2013 veröffentlichten Text jetzt zusätzlich am Text und den enthaltenen Begriffen und Deutungen ansetzen. Dass in der Frage der Ausarbeitung einheitlicher Standards und gegebenenfalls neuer Geschichtsbücher vielfältige Interessen - auch persönlicher Art aufeinander trafen, zeigte sich auch daran, dass die Standards im Juli in der Izvestia in handwerklicher Hinsicht angegriffen wurden: Sie seien mit Fehlern und Plagiaten durchsetzt und von Seiten für Schulreferate abgeschrieben. ${ }^{164}$

\subsection{Der Lehrmethodenkomplex Geschichte}

In der Betrachtung der Standards muss zunächst zwischen der Diskussionsversion des Projektes vom Juli $2013^{165}$, der überarbeiteten Fassung vom Oktober $2013^{166}$ und der finalen Version ${ }^{167}$ unterschieden werden. Die Oktoberversion ist im Vergleich zum ersten Entwurf ungefähr doppelt so lang und weist auf ihren rund 80 Seiten hunderte Streichungen, Ergänzungen und Verschiebungen auf. Die finale Version - publiziert nicht auf der Seite des Ministeriums, sondern auf der Seite der Russländischen Historischen Gesellschaft - entspricht der Oktoberversion. Lediglich einige Korrekturen wurden eingefügt sowie einige kleinere Veränderungen vorgenommen.

Die finale Version besteht aus einem Anfangsteil, dem eigentlichen historisch-kulturellen Standard und abschließend aus einer Liste mit »schwie-

164 Vgl. Kutnij, Anželika/Coj, Julija: Koncepciju učebnika istorii »spisali«s sajtov s gotovymi referatami. Ėksperty Gosdumy raskritikovali podgotovlennyj Rossijskim istoričeskim obščestvom dokument. 11. Juli2013. Online:http://izvestia.ru/news/553446\#ixzz3s2gmi63n.

165 Rabočaja gruppa po podgotovke koncepcii novogo učebno-metodičeskogo kompleksa po otečestvennoj istorii: Istoriko-kul'turnyj-standart (Geschichtlich-Kultureller Standard). Auf der Seite des Bildungs- und Wissenschaftsministeriums in der Version vom 01.07.2013: http:/минобрнауки.рф/документы/3483/файл/2325/13.07.01-Проект_ Историко-культурного_стандарта.pdf. Künftig zitiert als: Konzept LehrmethodenKomplex - Erster Entwurf.

166 Rabočaja gruppa po podgotovke koncepcii novogo učebno-metodičeskogo kompleksa po otečestvennoj istorii: Koncepcija novogo učebno-metodičeskogo kompleksa po otečestvennoj istorii (Konzeption des neuen Lehrmethoden-Komplex für vaterländische Geschichte). Auf der Seite des Bildungs- und Wissenschaftsministeriums in der Version vom 21.10.2013: http:/минобрнауки.рф/документы/3721/файл/2506/13.10.21-Проект_ Концепции_уМК.pdf. Künftig zitiert als: Konzept Lehrmethoden-Komplex - Zweiter Entwurf.

167 Rabočaja gruppa po podgotovke koncepcii novogo učebno-metodičeskogo kompleksa po otečestvennoj istorii: Koncepcija novogo učebno-metodičeskogo kompleksa po otečestvennoj istorii (Konzeption des neuen Lehrmethoden-Komplex für vaterländische Geschichte). Auf der Seite der Russischen Historischen Gesellschaft in der endgültigen Version: http://rushistory.org/images/documents/konsepsiyafinal.pdf. Künftig zitiert als: Konzept Lehrmethoden-Komplex. 
rigen Fragen« der Geschichte Russlands. Alle drei Teile sind auf verschiedene Weise in geschichtspolitischer Hinsicht interessant.

\subsubsection{Konzeptionelle Grundlagen}

Der Anfangsteil ist gegliedert in zehn Bereiche, die größtenteils die Ziele des Komplexes und teilweise auch die Instrumente zum Erreichen dieser Ziele erläutern. So soll der Komplex grundsätzlich den »Status Russlands als demokratischen, föderativen Rechtsstaat mit republikanischer Regierungsform, in dem der Mensch, seine Rechte und Freiheiten den höchsten Wert darstellen «, ${ }^{168}$ stärken.

Betont wird u.a. auch die Absicht, die bürgergesellschaftliche Identität der Heranwachsenden zu stärken. Dazu sollen, wo immer es möglich erscheint, historische Anknüpfungspunkte - z.B. Gemeinden, Gilden, Wissenschaftsgesellschaften, gesellschaftliche Organisationen, politische Parteien, Korporativen usw. - in die Lehrbücher integriert werden. ${ }^{169}$

An mehreren Stellen enthält der Anfangsteil Passagen, in denen es um den multiethnischen und multikonfessionellen Charakter der Russländischen Föderation und die daraus resultierenden Konsequenzen geht. Auf der einen Seite wird in diesem Zusammenhang immer wieder Toleranz und Wertschätzung für andere Kulturen, Religionen und Ethnien als Bildungsziel formuliert, ${ }^{170}$ zum anderen wird als Konsequenz daraus auf die Notwendigkeit des pluralistischen und vielschichtigen Zugangs zur Geschichte hingewiesen:

»Der Unterricht der vaterländischen Geschichte muss die Geschichte des Russländischen Staates und der ihn besiedelnden Völker mit der Geschichte der Regionen und der Lokalgeschichte verbinden. ${ }^{171}$

Die Russländische Geschichte wird als Geschichte aller Territorien, Länder und Völker definiert, »die unseren Staat in der entsprechenden historischen Epoche bildeten. ${ }^{172}$

Der in diesem Zugang angelegten "partiellen `Entrussifizierung ১ des historischen Narrativs ${ }^{173}$ - also dem Aufbrechen einer russischen Zentralper-

168 Konzept Lehrmethoden-Komplex, 4.

169 Vgl. ebd., 9.

170 Vgl. z. B. ebd., 6.

171 Ebd., 6.

172 Ebd., 3.

173 Scheliha, Wolfram von: Analyse. Staatliche Geschichtsschreibung im Post-Imperium. Putins Einheitslehrbuch für den Geschichtsunterricht. In: Russland-Analysen Nr. 271 vom 14.02.2014, 3. Online: http://www.laender-analysen.de/russland/pdf/RusslandAna lysen271.pdf 
spektive in der Geschichte - werden jedoch ebenfalls im Anfangsteil klare Grenzen gesetzt. Im Bereich der allgemeinen Empfehlungen zur Ausarbeitung der neuen Materialien heißt es zwar noch einmal, dass auf Grund des multinationalen und multikonfessionellen Charakters Russlands das Lehrmaterial auf die Geschichte der verschiedenen Völker ausgedehnt werden müsse, um die Wechselwirkungen der Kulturen und Religionen, die Festigung der wirtschaftlichen, sozialen und politischen Beziehungen zwischen den Völkern zu akzentuieren. ${ }^{174}$ Es sei aber nötig zu betonen, dass der Beitritt und die $\mathrm{Zu}$ gehörigkeit zu Russland eine positive Bedeutung für alle Völker des Landes gehabt habe: ${ }^{175}$ Dazu werden der Schutz vor äußeren Feinden, die Beendigung von inneren Wirren und Unruhen, wirtschaftliche Entwicklung sowie die Verbreitung von Aufklärung, Bildung und Gesundheitswesen gezählt. ${ }^{176}$

Die Frage, wie die Ausdehnung des Herrschaftsbereichs zu deuten sei, wandelte sich in verschiedenen Phasen der sowjetischen Geschichte deutlich. Erwin Oberländer bezeichnete diese Frage sogar als einen eindrucksvollen "Gradmesser dafür, wie stark die Identifikation von Sowjetpatriotismus und großrussischem Nationalismus zu den unterschiedlichen Zeiten ausgeprägt war. ${ }^{177}$ Während das von Michail Pokrovskij geprägte Geschichtsbild bis weit in die 1930er Jahre hinein die "annexionistisch-kolonisatorische Rolle des russischen Zarismus zusammen mit der Bourgeoisie und Gutsbesitzern (Zarismus - das Völkergefängnis) « ${ }^{178}$ betonte, änderte sich diese Betrachtung spätestens ab 1937 deutlich. Zunächst wurde ab 1937 die Bezeichnung vom ,geringsten Übel gebraucht, dann wurden im Zuge der `Ždanovščina‘ Erweiterungen des Machtbereichs als >Wohltat` oder `Fortschritt bezeichnet und nach Stalins Tod etablierte sich der Sprachgebrauch von Russland als dem älteren Bruder, »der den betroffenen Völkern zu beiderseitigem Vorteil den Weg in eine bessere Zukunft wies und weist. «" 179

Die Formel, die in der Konzeption verbindlich gemacht wird, kann somit als eine Synthese aus dem Ansatz des `geringsten Übels` der Vorkriegszeit - als Schutz vor Annexion durch andere Kräfte sowie Stabilität - und dem poststalinistischen sälterer Bruder-Ansatz mit seiner Betonung von beidseitigen Vorteilen gesehen werden. Der als Periode dazwischen liegende offene Chauvinismus der `Ždanovščina wird dabei ausgespart.

174 Vgl. Konzept Lehrmethoden-Komplex, 9.

175 Vgl. Ebd., 9.

176 Vgl. Ebd., 9.

177 Oberländer, Erwin: Sowjetpatriotismus und Geschichte. Dokumentation. Köln 1967, 47.

178 Stalin, Iosif/Ždanov, Andrej/Kirov, Sergej: Zamečanija po povodu konspekta učebnika po »Istorija SSSRv (Bemerkungen anlässlich des Entwurfs des Schulbuches zur Geschichte der UdSSR). In: Pravda vom 27.01.1936 Nr. 26 (6632), 2.

179 Oberländer, Erwin: Sowjetpatriotismus und Geschichte. Dokumentation. Köln 1967, 47. 
Aleksandr Čubar'jan - wissenschaftlicher Leiter der Abteilung für allgemeine Geschichte der Akademie der Wissenschaften, Co-Vorsitzender der Russländischen Historischen Gesellschaft und wissenschaftlicher Leiter der Arbeitsgruppe der Konzeption - erklärte im Kommersant, dass die regionale Problematik und dabei insbesondere die Frage der Beitritte bzw. Vereinigungen der Territorien und der "Eintritt der Völker in den Bestand Russlands « ${ }^{180}$ das umstrittenste Thema bei der Ausarbeitung dargestellt habe. Man habe daher bei der Darstellung der entsprechenden Epochen versucht auch die Folgen zu berücksichtigen: ${ }^{181}$

Als Folgen benannte er Druck aus dem Zentrum des Imperiums genauso wie Zusammenarbeit mit den nationalen Eliten, Zugang zu fortschrittlichen Technologien und zur Weltkultur sowie die Ausbildung von nationalem Selbstbewusstsein. ${ }^{182}$

Gleichzeitig machte Čubar'jan auch deutlich, dass er wenig von grundsätzlich anderen Definitionen hält, die beispielweise - wie in vielen ehemaligen Sowjetrepubliken üblich - die Erweiterung des russländischen Herrschaftsraumes als Kolonialismus interpretieren. ${ }^{183}$

Im ersten Entwurf des Standards wurde im Abschnitt zum Russländischen Imperium im 19. und 20. Jahrhundert noch eine ausbalancierte Darstellung der Konfessions- und Nationalitätenpolitik gefordert: Sowohl das Stereotyp von der Peripherie als ausgebeuteter Kolonie als auch das Stereotyp von der vollkommenen Harmonie der Interessen von Zentrum und Peripherie sei zu vermeiden. ${ }^{184}$ In der Endfassung ist diese Forderung nicht mehr enthalten.

Zwischen 1994 und 2003 gab es auch ein russländisches Schulbuch, das die These von der imperialen Peripherie als Kolonie präsentierte: Igor' Doluckijs ,Vaterländische Geschichte` widmete diesem Thema unter der Überschrift >Das Russländische Kolonialimperium ‘ ein ganzes Kapitel. ${ }^{185}$ Es verlor - wenn auch nicht in erster Linie aufgrund seines dissidenten Inhalts in diesem Bereich - im Jahr 2003 das Siegel `empfohlen durch das Bildungsministerium der Russländischen Föderation $\prec{ }^{186}$ Für die neuen Schulbücher werden durch

180 Chamraev, Viktor/Čerkasov, Gleb: >Važno tol'ko ne politizirovat' istoriju, i togda mesto v nej najdetsja vsemu.く Akademik Aleksandr Čubar'jan o proekte istoriko-kul'turnogo standarta.In:Kommersant«. Nr. 200vom 31.10.2013,4. Online: http://www.kommersant. $\mathrm{ru} / \mathrm{doc} / 2332034$.

181 Vgl. ebd., 4.

182 Vgl. ebd., 4.

183 Vgl. ebd., 4.

184 Vgl. Konzept Lehrmethoden-Komplex - Erster Entwurf, 18.

185 Vgl. Doluckij, Igor': Otečestvennaja istorija. XX vek. Čast' 1. Mnemozina 1994, 47-51. Überarbeitete Auflage von 2003: Doluckij, Igor': Otečestvennaja istorija. XX vek. Čast' 1. Mnemozina 2003, 41-44.

186 Vgl. Kačurovskaja, Anna/Taratuta, Julija: Vladimiru Putinu napisali plochuju rol'. V škol'nom učebnike. In: Kommersant«. Nr. 218 vom 28.11.2003, 7. Online: http://www. kommersant.ru/doc/431806. 
die Konzeption alternative Interpretationen in diesem Bereich praktisch ausgeschlossen. $^{187}$

Eine zentrale Rolle kommt im Anfangsteil der Beförderung des russländischen Patriotismus zu, dessen Erwähnung als eines der wichtigsten Anliegen der Konzeption sich durch fast alle Abschnitte zieht. Dem erzieherischen Potenzial der historischen Bildung wird eine "Schlüsselrolle in der Ausbildung der russländischen bürgerlichen Identität und des Patriotismus « ${ }^{188} \mathrm{zu}-$ geschrieben. Dabei werden besonders ein methodologischer und ein inhaltlicher Zugang hervorgehoben:

Methodologisch fordert das Konzept unter der Überschrift »Mensch und Geschichte« einen shistorisch-anthropologischen Zugang für die Aufbereitung von Geschichte. Dadurch sollen Interesse und Achtung für die eigene Geschichte sowie eine emotionale Wahrnehmung der Vergangenheit erzeugt werden. $^{189}$

„Die Größe der Siege und die Schwere der Niederlagen werden durch das Leben und die Schicksale der Menschen, einschließlich der Väter und der Großväter der Schüler, durch die Geschichte ihres Geschlechtes und ihrer Familie eindringlich dargestellt. « ${ }^{190}$

Deshalb sei es besonders wichtig, dass sich in den Lehrbüchern die Anwesenheit des Menschen - sowohl der herausragenden als auch der einfachen - in den konkreten Ereignissen widergespiegelt. Auf diese Weise könne bei den jungen Menschen das Gefühl der Teilhaberschaft an der Geschichte erzeugt werden. $^{191}$

»Die Geschichte soll wie eine hinreißende Erzählung über die Vergangenheit, über die Menschen und ihre Charaktere, über das alltägliche Leben erscheinen. ${ }^{192}$

Als inhaltlichen Zugang, um die junge Generation zum Stolz auf das eigene Land zu erziehen, fordert die Konzeption eine Betonung des Massenheroismus in den Befreiungskriegen von 1812 und 1941-1945, da sich hier »die Heldentaten des Volkes als Beispiel des staatsbürgerlichen Bewusstseins und der Selbstaufopferung im Namen des Vaterlandes ${ }^{193}$ offenbarten.

Aber auch über das Militärische hinaus fordert die Konzeption, Massenheroismus darzustellen. Die großen Anstrengungen des Volkes bei der »An-

187 Allerdings lassen sich einige Bereiche der in der Konzeption enthaltenen Liste mit sschwierigen Fragen der Geschichte Russlands auch als Spielräume zu diesem Thema interpretieren.

188 Konzept Lehrmethoden-Komplex, 5.

189 Vgl. ebd., 7.

190 Ebd., 7.

191 Vgl. ebd., 7.

192 Ebd., 7.

193 Ebd., 8f. 
eignung der riesigen Räume Eurasiens und deren rauer Natur « ${ }^{194}$ sowie die »Bildung der russländischen Gesellschaft auf einer komplizierten multinationalen und polykonfessionellen Basis « ${ }^{195}$ sollen ebenfalls als vorbildhafter Massenheroismus dargestellt werden.

In diesem Abschnitt, der Patriotismus als Grundlage der Darstellung von Geschichte bestimmt, sind noch einige grundsätzliche Aussagen enthalten, die Aufschluss über die Intentionen und Ausrichtungen des konzeptionierten Geschichtsbildes geben. Der Ansatz, eine affirmative, positive Geschichte zu erzählen, wird offen benannt, aber auch begrenzt:

»Im Schulkurs soll das Pathos der Erschaffung, die positive Einstellung in der Wahrnehmung der einheimischen Geschichte vorwiegen. Nichtsdestoweniger soll bei den Schülern nicht der Eindruck entstehen, dass die Geschichte Russlands eine Reihe der triumphalen Aufmärsche, Erfolge und Siege ist. « ${ }^{196}$

Explizit sollen auch die »tragischen Epochen« der Geschichte unterrichtet werden, um ein vollständiges Bild zu ermöglichen. Als diese Perioden werden konkret die Zeit der Wirren, die Revolution, der Bürgerkrieg und die politischen Repressionen benannt. Sie sollen jedoch erinnerungspolitisch ins Positive gewendet unterrichtet werden, indem betont wird, dass »das russische Volk und andere Völker des Landes die Kraft fanden, gemeinsam diese zu ihren Lasten auf sie einstürzenden schweren Herausforderungen zu überwinden. " ${ }^{197}$

Der prekäre Charakter dieses Formelkompromisses - die Seiten der Geschichte, die einer positiven Wahrnehmung entgegenstehen, zu erzählen, sie jedoch als Element der Genese der multiethnischen Gemeinschaft positiv zu deuten - wird an dem Anspruch der Konzeption deutlich, eine russländische und keine russische Geschichte zu erzählen: Die Erinnerungsgemeinschaften unter Stalin repressierter Ethnien werden beispielsweise die verlustreiche Deportation und Verbannung eher nicht als eine Herausforderung erinnern, die sie und die Titularnation gemeinsam überwunden hätten. ${ }^{198}$

Insgesamt macht diese sowohl inhaltlich als auch konzeptionell angelegte Schwerpunktsetzung deutlich, dass eines der zentralen Anliegen der Konzeption in der Ausweitung der geschichtlich unterfütterten staatlichen Patriotischen Erziehung auf die neuen Schul-Geschichtsbücher besteht. Allerdings wurde die endgültige Version der Konzeption von Kritikern wie Chakimov

194 Ebd., 9.

195 Ebd., 9.

196 Ebd., 9.

197 Ebd., 9.

198 Zur Darstellung der repressierten Völker in der russländischen Geschichtsschreibung siehe: Ro'i, Yaakov: The Transformation of Historiography on the >Punished Peoples`. In: History and Memory 21/2 (2009), 150-176. 
als deutlich abgemildert und pluralistischer ${ }^{199}$ im Vergleich zur Juli-Vorlage bezeichnet. Ein Beispiel für diese Abmilderung ist eine Empfehlung aus den konzeptionellen Grundlagen der Juli-Vorlage:

"Die Geschichte der Religionen, in erster Linie des orthodoxen Christentums, soll systematisch dargestellt werden und das gesamte Schulbuch durchziehen. ${ }^{200}$

Die gesamte Empfehlung wurde in der Überarbeitung der Konzeption ersatzlos gestrichen.

\subsubsection{Der »historisch-kulturelle Standard»}

In der medialen Diskussion standen jedoch weniger diese Grundlegungen und Empfehlungen im Mittelpunkt als der eigentliche sogenannte »historischkulturelle Standard", in dem konkret Geschichte dargestellt wird. Dies lag vor allem daran, dass der historisch-kulturelle Standard laut Ankündigung und Einleitung "grundsätzliche Einschätzungen von Schlüsselereignissen der Vergangenheit ${ }^{201}$ umfassen und somit ein offizielles Geschichtsbild definieren soll.

Wie beim Eingangsteil der Konzeption ist auch im inhaltlich-geschichtlichen Teil kaum etwas von der ersten Vorlage vom Juli 2013 erhalten geblieben. Lediglich im ersten Bereich der Geschichtsepochen bis zum 16. Jahrhundert ist der Text in seiner inneren Struktur - wenn auch mit vielen Veränderungen - übernommen worden. Die Epochen vom 16. bis zum 21. Jahrhundert wurden grundsätzlich überarbeitet - weder größere zusammenhängende Teile des Textes noch die Periodisierungen wurden beibehalten. Der Standard in der endgültigen Fassung besteht aus neun Abschnitten: ${ }^{202}$

1. Von der Alten Rus zum Russländischen Staat

2. Russland im 16. und 17. Jahrhundert: Vom Großfürstentum zum Zarismus

3. Russland Ende des 17. bis zum 18. Jahrhundert: Vom Zarismus zum Imperium

4. Das Russländische Imperium im 19. bis Anfang des 20. Jahrhunderts

5. Russland in den Jahren der »Großen Erschütterungen«. 1914-1921

6. Die Sowjetunion in den 1920-1930er Jahren

7. Der Große Vaterländische Krieg. 1941-1945

199 Vgl. Chamraev, Viktor/Samochina, Sof' ja: Kulikovskuju bitvu vyveli na rossijskij rynok. Vtoroj variant istoriko-kul'turnogo standarta vynosjat na obsuždenie. In: Kommersant«. Nr. 174 vom 25.09.2013, 2. Online: http://kommersant.ru/doc/2304366.

200 Konzept Lehrmethoden-Komplex - Erster Entwurf, 3.

201 Ebd., 2.

202 Ebd., 14-79. 
8. Höhepunkt und Krise des Sowjetischen Systems. 1945-1991

9. Russländische Föderation 1991-2012

Jeder der Abschnitte beginnt mit einem historischen Abriss über den jeweiligen Zeitraum, der - je nach Abschnitt variierend - eine grobe Einordnung bis hin zur Hervorhebung bestimmter Ereignisse oder Aspekte bietet. Danach wird der Zeitraum noch einmal in Unterbereiche aufgegliedert und detaillierter dargestellt. Diese Untergliederungen sind überwiegend zeitlich definiert, teilweise behandeln sie aber auch einen übergreifenden inhaltlichen Aspekt des Zeitraums, wie beispielsweise die kulturelle Entwicklung. Im Gegensatz zum einleitenden historischen Abriss sind diese Unterbereiche jedoch sehr kursorisch, enthalten selten Deutungen und bestehen passagenweise lediglich aus Stichworten. Diese Teile des Standards haben große Ähnlichkeit mit den inhaltlich-geschichtlichen Teilen der föderalen Komponente der allgemeinen staatlichen Bildungsstandards von 2004, die zuletzt 2012 überarbeitet wurden. $^{203}$ Jeder der neun Abschnitte endet mit einer Sammlung wichtiger Begriffe und Fachausdrücke, einer Auflistung wichtiger Persönlichkeiten, einer chronologischen Ereignisliste und einer Übersicht über die wichtigsten Quellen des jeweiligen Zeitraums. Alle Abschnitte unterscheiden sich in ihrer Gliederung und inhaltlichen Detailtiefe.

\subsubsection{Neue Perspektiven?}

Gerade im ersten Abschnitt ,Von der alten Rus zum Russländischen Staat‘ wurden bei der Überarbeitung viele Einzelkorrekturen eingearbeitet, die das Verhältnis von russischem Zentrum und nicht-russischer Peripherie betreffen. In diesen Änderungen spiegelt sich die Kritik aus den nicht-russischen Republiken, dass die vorbereitenden Standards, die russländische Geschichte aus einer Moskauer Zentralperspektive beschreiben würden. Vor allem die Anmerkungen von Rafail' Chakimov von der Akademie der Wissenschaften Tatarstan wurden - wenn auch bereits größtenteils vor der Veröffentlichung der ersten Version - berücksichtigt. Im Zentrum standen hier vor allem Begriffe wie z. B. »das tatarisch-mongolische Joch«. In der Juli-Fassung der Konzeption wurde dieser Begriff - den Čubar'jan im Nachhinein als belletristisch bezeichnete ${ }^{204}$ - durch den etwas kryptisch klingenden Ausdruck »System der

203 Vgl. Prikaz Minobrazovanija Rossii ot 05.03.2004 N 1089 (red. ot 31.01.2012)»Ob utverždenii federal'nogo komponenta gosudarstvennych obrazovatel'nych standartov načal'nogo obščego, osnovnogo obščego i srednego (polnogo) obščego obrazovanija«.

204 Vgl. Chamraev, Viktor/Čerkasov, Gleb: ,Važno tol'ko ne politizirovat' istoriju, i togda mesto v nej najdetsja vsemu. A Akademik Aleksandr Čubar'jan o proekte istoriko-kul'turnogo standarta. In: Kommersant«. Nr. 200 31.10.2013, 4. Online: http://www.kommer sant.ru/doc/2332034. 
Abhängigkeit der russischen Länder von den Chanen der Horde « ${ }^{205}$ ersetzt. In der endgültigen Fassung wurde in Klammern erklärend angefügt: »das sogenannte Joch der Horde. ${ }^{206}$ Aber auch Wörter wie z. B. Heidentum wurden durch den neutraleren Ausdruck »traditioneller Glauben« ersetzt. ${ }^{207}$ Ein weiteres Beispiel, das Chakimov anführt, um den veränderten Charakter der Moskauer Zentralperspektive im Standard darzustellen, ist die auf Kazaner Einfluss hin aufgenommene Erwähnung von Parteien und Fraktionen der nicht-russischen Nationalitäten in der zweiten imperialen Duma. ${ }^{208}$

Nicht durchsetzen konnte sich die Kazaner Position laut Chakimov bei der Erwähnung der nicht-russischen Soldaten und Regimenter 1812/1813 oder auch bei einer differenzierteren Darstellung der Interessenkonstellation um die Schlacht auf dem Kulikovo Pole. ${ }^{209}$

Insgesamt kann man - gerade in diesem Bereich des Standards, der sich mit den Grundlegungen des multiethnischen Staates befasst - tatsächlich von einer Reihe von Kompromissen sprechen, die teilweise auch über die begriffliche Ebene hinausgehen. Im sensiblen legitimatorischen Kernbereich des Narrativs - der Legitimität der staatlichen Integrität und Ausdehnung - sind keine wirklichen Kompromisse erkennbar. Hier wird das zentralrussische Narrativ in seiner konventionellen Form erhalten. ${ }^{210}$

\subsubsection{Die Zeit der Wirren}

Auch in der Darstellung der 'Zeit der Wirren < - einem Narrativ, das in den letzten zehn Jahren durch die Etablierung des Tags der Einheit des Volkes in den Fokus aktueller Erinnerungspolitik gerückt wurde - bleibt der Standard dicht an der staatstragenden Version. Jedoch wird die Periode nicht als Kampf gegen fremde Besatzer, sondern als Bürgerkrieg charakterisiert, der allerdings auch durch äußere Einmischung ausgelöst wurde. ${ }^{211}$ Die Kernbotschaften des Smuta-Narrativs, die auch in den Reden Vladimir Putins anlässlich des Tages der Einheit des Volkes vor allem seit 2012 enthalten sind, ${ }^{212}$ wurden auch im

205 Konzept Lehrmethoden-Komplex - Erster Entwurf, 7.

206 Konzept Lehrmethoden-Komplex, 17.

207 Vgl. Chamraev, Viktor/Samochina, Sof' ja: Kulikovskuju bitvu vyveli na rossijskij rynok. Vtoroj variant istoriko-kul'turnogo standarta vynosjat na obsuždenie. In: Kommersant«. Nr. 174 vom 25.09.2013, 2. Online: http://kommersant.ru/doc/2304366.

208 Vgl. ebd., 2.

209 Vgl. ebd., 2.

210 Zur Darstellung der verschiedenen russländischen Ethnien in den Schulbüchern siehe: Shnirelman, Victor: Stigmatized by History or by Historians? The peoples of Russia in School History Textbooks. In: History and Memory 21/2 (2009), 110-149.

211 Vgl. Konzept Lehrmethoden-Komplex, 21.

212 Vgl. z.B. Putin, Vladimir: Priëm po slučaju Dnja narodnogo edinstva. 4 nojabrja 2012 goda, Moskva. Online: http://news.kremlin.ru/transcripts/16752. 
Standard berücksichtigt: zum einen die existenzielle Gefahrensituation des "vollständigen Verlustes der nationalen Unabhängigkeit ${ }^{213}$ und zum anderen die zukunftsweisende Konsolidierung der Gesellschaft als letzte Rettung, um die staatliche Unabhängigkeit zu bewahren:

"Nur die Konsolidierung der Gesellschaft, die ihren markantesten Ausdruck im Wirken der Volkswehr und des `Rates aller Länder fand, angeführt durch den Fürsten D. M. Požarskij und K. Minin, erlaubte es die Unabhängigkeit des Staates zu bewahren « ${ }^{214}$

Diese Konsolidierung der Gesellschaft wird dann im Standard folgend als Grundlage für die Schaffung neuer politischer Institutionen, die Stärkung der Zentralmacht, die Ausdehnung des staatlichen Territoriums und auch für das Aufblühen der Ständeversammlungen interpretiert. ${ }^{215}$ An solchen Übergängen zeigt sich beispielhaft das im Anfangsteil der Konzeption geforderte >Pathos der Erschaffung $<$ - die affirmative Geschichtsperspektive.

\subsubsection{Modernisierung und Imperium}

Auch im Kapitel `Russland Ende des 17. bis zum 18. Jahrhundert: Vom Zarismus zum Imperium ${ }^{216}$ zeigt sich dieser auf den $>$ Pathos der Erschaffung ausgerichtete Zugang zur Geschichte. Die Epoche wird als Zeit der Modernisierung von Wissenschaft, Kultur, Wirtschaft und Verwaltung beschrieben als Russlands Aufschwung zur imperialen Weltmacht mit einer »starken, zeitgemäßen Armee und Flotte für die Gewährleistung der nationalen Sicherheit und die Lösung der wichtigsten außenpolitischen Aufgaben. « $^{217}$

Unterbrochen wird diese Progression lediglich durch eine kurze Phase, in der die »Verschärfung des Kampfes aristokratischer Gruppen um die Macht das politische System destabilisierte und zu einer Reihe von sogenannten Palastrevolten führte. ${ }^{218}$ Vor diesem Hintergrund wird dann die Herrschaft Elizaveta Petrovnas als Rückkehr zur Stabilität und zur endgültigen Etablierung Russlands als »führende Kraft im System der internationalen Beziehungen ${ }^{219}$ interpretiert - der imperiale Hof wird dabei als »einer der prächtigsten in Europa $\aleph^{220}$ beschrieben.

Abgeschlossen wird diese Fortschrittsgeschichte mit einem geschichtsphilosophisch-deterministisch anmutenden Resümee:

213 Konzept Lehrmethoden-Komplex, 21.

214 Ebd., 21.

215 Vgl. ebd., 21.

216 Ebd., 27-34.

217 Ebd., 27.

218 Ebd., 27.

219 Ebd., 27.

220 Ebd., 27. 
"Eine Serie von militärischen Siegen und grossen außenpolitischen Erfolgen führt zur wesentlichen Erweiterung des russischen Gebietes, Russland hat die historische Aufgabe gelöst, fast das ganze Erbe der Kiewer Rus zu vereinigen und Zugang zum Schwarzen Meer zu bekommen. «21 $^{221}$

Auch das Kapitel zum >Russländischen Imperium im 19. bis Anfang des 20. Jahrhunderts ${ }^{222}$ ist in ähnlicher Weise als Modernisierungsgeschichte angelegt. Im Eingangsteil wird die Epoche primär als Zeit beschrieben, in der Grundlagen für das moderne Russland gelegt wurden. Die Entstehung der Industriegesellschaft, der Demokratie, des Rechtsstaates und der Bürgergesellschaft werden in diesem Zusammenhang genannt. Als spezifisch russländische Entwicklung wird angeführt, dass dieser Modernisierung zum Trotz der konservative Charakter des politischen Regimes - die Autokratie-Bestand gehabt habe. ${ }^{223}$ Die daraus im Vergleich zum Westen resultierenden unvollständigen und verschleppten Systemreformen werden als Ursache für das Entstehen von gesellschaftlichen Spannungen gedeutet, die schließlich zum Ende der Monarchie führten. ${ }^{224}$

Daneben wird nicht zuletzt auch Russlands Rolle in der europäischen Politik in der Folge des Sieges im Vaterländischen Krieg betont. Bemerkenswert ist, dass der Vaterländische Krieg, entgegen der Empfehlung im Anfangsteil der Konzeption, als Narrativ nicht weiter entfaltet wird. In einem lakonischen Satz wird lediglich seine Bedeutung bestimmt:

»Der Vaterländische Krieg 1812 - das wichtigste Ereignis der Russländischen und der Weltgeschichte im 19. Jahrhundert. ${ }^{225}$

Die weitere Deutung, Ausgestaltung oder auch Kontextualisierung wird nicht festgelegt - auch nicht durch die angefügte Personenliste oder die Liste wichtiger Ereignisse.

\subsubsection{Die großen Erschütterungen}

Bei den Beratungen über den Standard stand jedoch insgesamt das 20. Jahrhundert im Zentrum, und dabei besonders die Deutungen zu 1917 und zur Herrschaft Stalins. Im Falle des Jahres 1917 bestand das primäre Problem darin, dass weiterhin sehr unterschiedliche Interpretationen dazu existieren, wie die einzelnen Phasen vom Februar bis zum Oktober und darüber hinaus zu deuten sind, oder auch welche die korrekten Begriffe sind.

221 Ebd., 28.

222 Ebd., 35-45.

223 Vgl. ebd., 35.

224 Vgl. ebd., 36.

225 Ebd., 38. 
»Und so haben wir auf die Verwendung der Begriffe `Februarrevolution` und `Sozialistische Oktoberrevolution` verzichtet. Weil der eine diese Ereignisse als Revolution der andere als Umsturz betrachtet. ${ }^{226}$

Letztendlich verständigte man sich darauf - innerhalb des Kapitels `Russland in den Jahren der Großen Erschütterungen. 1914-1921 - von der »Großen Russländischen Revolution ${ }^{227}$ zu sprechen und damit sowohl die `Februarrevolution` als auch die >Oktoberrevolution` und die Ereignisse dazwischen $\mathrm{zu}$ bezeichnen. Im Standard selbst werden die grundlegenden Etappen der Großen Russländische Revolution wie folgt beschrieben: Die Ereignisse im Februar und März werden als »Aufstand in Petrograd und Fall der Monarchie«, als »Ende des Russländischen Imperiums« bezeichnet, Frühjahr und Sommer als "schwankende Balance ${ }^{228}$. Zum 25. Oktober - oder dem 7. November nach dem neuen Stil - heißt es: »Sturz der provisorischen Regierung und Übernahme der Macht durch die Bolschewiki (〉Oktoberrevolution $).{ }^{229}$ Čubar' jan bezeichnete diesen Konsens als eine gute Idee in Analogie zur >Großen Französischen Revolution ${ }^{230}$

Die gewählte Periodisierung des Abschnitts zu den "großen Erschütterungen« von 1914 bis 1921 und damit die Zusammenfassung von Erstem Weltkrieg, Revolution und Bürgerkrieg ermöglicht eine Interpretation im Sinne des >Pathos der Erschaffung`: Die Periode fasst Krieg, menschliches Leid und geschichtliche Kontingenz zusammen und deutet sie in einem gesamteuropäischen Kontext:

»Als Folge des Weltkrieges und der Revolutionen hatte sich die geopolitische Karte Europas grundlegend verändert. Fast gleichzeitig zerfielen vier Imperien. [...] Die Zivilisation befand sich im Zustand einer bislang ungesehenen globalen Krise, begleitet vom Massensterben der Soldaten und der Zivilisten[...]. ${ }^{231}$

Bemerkenswerterweise wird an dieser Stelle der Bürgerkrieg nicht in einem internationalen Kontext interpretiert, sondern als "gesamt-nationale Katastrophe«, deren Ursache in der »tiefen Spaltung der russländischen Gesellschaft»

226 Chamraev, Viktor/Čerkasov, Gleb: >Važno tol'ko ne politizirovat' istoriju, i togda mesto v nej najdetsja vsemu.` Akademik Aleksandr Čubar'jan o proekte istoriko-kul'turnogo standarta.In:Kommersant«. Nr. 200vom 31.10.2013,4. Online: http://www.kommersant. $\mathrm{ru} / \mathrm{doc} / 2332034$.

227 Konzept Lehrmethoden-Komplex, 47.

228 Ebd., 47.

229 Ebd., 47.

230 Vgl. Chamraev, Viktor/Čerkasov, Gleb: ,Važno tol'ko ne politizirovat' istoriju, i togda mesto v nej najdetsja vsemu. Akademik Aleksandr Čubar'jan o proekte istorikokul'turnogo standarta. In: Kommersant«. Nr. 200 vom 31.10.2013, 4. Online: http://www. kommersant.ru/doc/2332034.

231 Konzept Lehrmethoden-Komplex, 46. 
begründet sei. ${ }^{232}$ Das militärische Eingreifen von außen in den Krieg wird lediglich durch den Stichpunkt »Militärische Intervention« erwähnt, jedoch nicht ausgeführt oder gedeutet. Aleksandr Čubar'jan erklärte dazu: »Wir haben uns dazu entschieden, das alles als inner-russländisches Phänomen zu betrachten. ${ }^{233}$

Um den übergreifenden Schreckenscharakter der Periode zu illustrieren, war in der überarbeiteten Oktober-Version des Standards noch der Hinweis darauf enthalten, dass im Ersten Weltkrieg und im Bürgerkrieg zusammen vier Millionen Soldaten und durch Krieg, Hunger und Epidemien noch einmal ein Vielfaches an Zivilbevölkerung umgekommen seien. ${ }^{234}$ Diese Passage wurde in der endgültigen, von der Russländischen Historischen Gesellschaft veröffentlichten Fassung jedoch gestrichen. ${ }^{235}$

Am Ende des Einleitungsteils zu dieser Epoche von Krieg und Revolution, von globaler Krise und inner-russländischer Spaltung wird das Ergebnis zusammengefasst:

"Auf der Tagesordnung stand als Hauptfrage - die Frage nach der Existenz des russländischen Staates. ${ }^{236}$

\subsubsection{Sowjetunion und Stalinismus}

Vor diesem düsteren Hintergrund kann im folgenden Kapitel `Die Sowjetunion in den 1920-1930er Jahren nächst eine Fortschrittsgeschichte geschrieben werden:

»Jedoch hat das Land nicht nur die Kräfte für die Wiederherstellung der Wirtschaft unter den Bedingungen der von den Bolschewiki im Frühling 1921 erklärten Neuen Ökonomischen Politik (nèp) gefunden, sondern auch für einen rasanten wirtschaftlichen Sprung in den Jahren der ersten Fünfjahrespläne gefunden. $^{237}$

232 Zur Darstellung des Bürgerkriegs in sowjetischen und postsowjetischen Schulbüchern vgl. de Keghel, Isabelle: Die Rekonstruktion der vorsowjetischen Geschichte. Identitätsdiskurse im neuen Russland. Hamburg 2006, 265 ff. und $339 \mathrm{ff}$.

233 Chamraev, Viktor/Čerkasov, Gleb: ,Važno tol'ko ne politizirovat' istoriju, i togda mesto v nej najdetsja vsemu.< Akademik Aleksandr Čubar'jan o proekte istoriko-kul'turnogo standarta.In:Kommersant«. Nr. 200vom 31.10.2013,4. Online: http://www.kommersant. $\mathrm{ru} / \mathrm{doc} / 2332034$.

234 Vgl. Konzept Lehrmethoden-Komplex - Zweiter Entwurf, 46.

235 In der Praxis ermöglicht die Entfernung solcher Details den Autoren auf der einen Seite, einer detaillierten Beschreibung auszuweichen, zum anderen hebt sie jedoch auch die Bindung an vorgegebene Opferzahlen auf und gibt den Autoren mehr Freiheit.

236 Konzept Lehrmethoden-Komplex, 46.

237 Ebd., 51. 
Tatsächlich wird in diesem Kapitel ein Schwerpunkt auf die Erfolge von Modernisierung und Industrialisierung gelegt. Sie werden in einem Vorgriff sogar als Grundlagen des Sieges von 1945 und der Nachkriegserrungenschaften in den Bereichen Weltraum- und Atomtechnik interpretiert. ${ }^{238}$ Gebremst wird das Pathos von Fortschritt und Erschaffung lediglich durch Einschübe zum $»$ Preis« dieser Entwicklung.

Die Einordnung von Themen wie Industrialisierung und GULag, Kollektivierung und Repression, dem Großen Vaterländischen Krieg und dem Preis des Sieges steht regelmäßig im Zentrum gesellschaftlicher, medialer und politischer Debatten in der Russländischen Föderation. So ist es folgerichtig, dass diese Themen auch im Zuge der Ausarbeitung des Standards zu vielfältigen Diskussionen geführt haben. ${ }^{239}$

Obwohl beispielsweise ein Konsens darüber bestand, dass die stalinistischen Verbrechen kein `spontanes Phänomen`, sondern grundsätzlich in der Herrschaftslogik angelegt waren, ${ }^{240}$ beziehen sich allein fünf der zwanzig in der Konzeption dokumentierten sschwierigen Fragen` auf diese Epoche der Geschichte.

Grundsätzlich wird eine Geschichte der nachholenden Modernisierung in verschiedenen Bereichen beschrieben - jedoch mit einem »widersprüchlichen Charakter. ${ }^{241}$ So werden >Errungenschaften` vor- und ihre Bedeutung herausgestellt. Gleichzeitig wird aber auch auf die andere Seite - »die Einschränkung sowjetischer Demokratie, die Verstärkung der ideologischen Zensur, die Suche nach Volksfeinden und die politischen Massenrepressionen ${ }^{242}$ - hingewiesen:

»Neben den industriellen Giganten der ersten Fünfjahrespläne entstanden die Lagertürme des GULags, wo die Häftlinge zur Zwangsarbeit eingesetzt wurden. « ${ }^{243}$

Die "gewaltsame Kollektivierung« wird als »Tragödie für das Land « beschrieben, die von »brutalen Repressionen in Bezug auf die wohlhabenden Bauern

238 Ebd., 52.

239 Vgl. Chamraev, Viktor: 2000-m godam podberut istoričeskij standart. V ocenke revoljucij i repressij u istorikov somnenij ne ostalos'. In: Kommersant«. Nr. 161 vom 06.09.2013, 4. Online: http://kommersant.ru/doc/2272303 und Chamraev, Viktor/Čerkasov, Gleb: ,Važno tol'ko ne politizirovat' istoriju, i togda mesto v nej najdetsja vsemu.< Akademik Aleksandr Čubar'jan o proekte istoriko-kul'turnogo standarta. In: Kommersant«. Nr. 200 vom 31.10.2013, 4. Online: http://www.kommersant.ru/doc/2332034.

240 Vgl. Chamraev, Viktor: 2000-m godam podberut istoričeskij standart. V ocenke revoljucij i repressij u istorikov somnenij ne ostalos'. In: Kommersant«. Nr. 161 vom 06.09.2013, 4. Online: http://kommersant.ru/doc/2272303.

241 Konzept Lehrmethoden-Komplex, 52.

242 Ebd., 52.

243 Ebd., 52. 
begleitet wurde. ${ }^{244}$ In der Beschreibung der Millionen von Hungertoten als Folge dieser Politik bleibt die Konzeption beispielsweise in Bezug auf ihre intentionale Komponente äußerst vage:

"Die Kollektivierung und die Zwangsrequirierungen der Nahrungsmittel führten 1932/33 zu Hunger und Epidemien. ${ }^{245}$

Zusätzlich wurde im Vergleich zur Oktober-Version aus der endgültigen Version der Zusatz gestrichen, dass diese Politik nach unterschiedlichen Einschätzungen zwischen drei und sechs Millionen Menschenleben gefordert habe. ${ }^{246}$ Auch in den folgenden Unterkapiteln ist lediglich von der »Kollektivierung und ihren tragischen Folgen« oder dem »Hunger in der UdSSR 1932-1933 als Folge der Kollektivierung « die Rede, nicht aber davon, inwieweit der Hungertod Teil einer intentionalen Strategie zur Durchsetzung der Kollektivierung war. In der ersten Version des Standards war noch die Empfehlung enthalten, nicht nur den Hunger 1932-1933, sondern auch seine aktuellen Interpretationen zu berücksichtigen. ${ }^{247}$

In der Beschreibung von Repressionen und GULag wird der Standard deutlicher. Die Rolle von Parteiorganen und Sicherheitsorganen bei der »Unterstützung der Diktatur « wird genauso berücksichtigt wie verschiedene Aspekte der "massenhaften politischen Repressionen« wie die "Nationalen Operationen" oder auch die Resultate der Repressionen auf der Ebene der Regionen und nationalen Republiken. ${ }^{248}$ Für den Bereich GULag wird festgeschrieben, die sozial-politischen und nationalen Charakteristika sowie die Rolle der Zwangsarbeit bei der Verwirklichung der Industrialisierung und bei der Aneignung der entlegenen Territorien zu berücksichtigen. ${ }^{249}$

Insgesamt erscheint der Standard in der Beschreibung dieses Zeitabschnitts jedoch beliebig. Während beispielsweise die Herausgabe des Kratkij Kurs VKP(b) - der selbst im Zuge der Ausarbeitung des Standards immer wieder als warnendes Beispiel thematisiert wurde ${ }^{250}$ - im Kontext der Verstärkung von ideologischer Kontrolle thematisiert und damit praktisch obligatorisch für die Schulbücher gemacht wird, ${ }^{251}$ trifft dies auf das geheime Zusatzprotokoll zum Deutsch-Sowjetischen Nichtangriffsvertrag nicht zu: Während das Pro-

244 Ebd., 51.

245 Ebd., 51.

246 Vgl. Konzept Lehrmethoden-Komplex - Zweiter Entwurf, 51.

247 Vgl. Konzept Lehrmethoden-Komplex - Erster Entwurf, 28.

248 Vgl. Konzept Lehrmethoden-Komplex, 53.

249 Ebd., 53.

250 Vgl. Putin, Vladimir: Vstreča s avtorami koncepcii novogo učebnika istorii. Vladimir Putin vstretilsja s razrabotčikami koncepcii novogo učebno-metodičeskogo kompleksa po otečestvennoj istorii. 16 janvarja 2014 goda, Moskva. Online: http://www.kremlin.ru/ events/president/news/20071.

251 Konzept Lehrmethoden-Komplex, 53. 
tokoll in der Juli-Version noch Erwähnung fand, ${ }^{252}$ ist dieser Hinweis aus den späteren Versionen entfernt worden. Dass eine Darstellung der Ereignisse im August und September 1939 in den Schulbüchern ohne Erwähnung des Protokolls fragmentarisch und unverbunden ausfallen könnte, macht schon die entsprechende Passage im Standard deutlich:

»Vertragsschluss über den Nichtangriff zwischen der UdSSR und Deutschland 1939. Inklusion Lettlands, Litauens und Estlands, Bessarabiens, der Nord-Bukovina, der Westukraine und West-Weißrusslands in den Bestand der UdSSR. ${ }^{253}$

Die Passage macht darüber hinaus deutlich, dass der Standard an den grundsätzlichen Narrativen und Periodisierungen nicht rüttelt. Auch wenn keine Deutung vorgegeben wird, wird der Einmarsch der Sowjetunion u. a. in Polen nicht im Kontext des Zweiten Weltkrieges erzählt, sondern ist Teil der Außenpolitik der 1930er Jahre. Dies trifft auch auf die "Tragödie von Katyn« und den »Winterkrieg« mit Finnland « zu, die dem Kapitel zur Außenpolitik in den 1920er und 1930er Jahren als Stichpunkte angehängt sind. ${ }^{254}$

\subsubsection{Der Große Vaterländische Krieg}

Das einleitende Kapitel zum Großen Vaterländischen Krieg fokussiert auf die entscheidende Rolle der Sowjetunion beim Sieg über Deutschland und den hohen Preis, den die Menschen dafür zahlen mussten. Der Krieg wird als "Volkskrieg, vaterländischer Krieg und heiliger Krieg um das Überleben und die Bewahrung der Staatlichkeit ${ }^{255}$ eingeführt. Nicht nur in der Betonung der existenziellen Gefahr für die Staatlichkeit, sondern auch in einem weiteren Punkt bestehen in den Deutungen des einführenden Kapitels Parallelen zum Smuta-Narrativ. Auch für den Großen Vaterländischen Krieg wird die Bedeutung als gesellschaftskonsolidierende Kraft in den Fokus gerückt. Dabei wird explizit darauf verwiesen, dass gerade der verbrecherische Charakter des deutschen Krieges für viele mobilisierend gewirkt habe, die eigentlich zu den Leidtragenden der Sowjetherrschaft gehörten:

"Das Verhalten der `Befreier vom Bolschewismus , die Brutalitäten und das kriminelle Verhalten in den besetzten Gebieten, der unmenschliche Umgang mit den Kriegsgefangenen, wurde abermals zum Grund, warum sich viele, die an der Sowjetmacht während der Revolution, Kollektivierung und der Massenrepressionen gelitten hatten, der Verteidigung der Heimat anschlossen. ${ }^{256}$

252 Konzept Lehrmethoden-Komplex - Erster Entwurf, 29.

253 Konzept Lehrmethoden-Komplex, 55.

254 Vgl. ebd., 55.

255 Ebd., 57.

256 Ebd., 57. 
Betont wird darüber hinaus neben Patriotismus und der Einheit von Front und Hinterland auch die Rolle des Zusammenhalts der Völker der Sowjetunion: Einen der wichtigsten Faktoren für den Sieg stellte demzufolge »die Erfolglosigkeit der Versuche der Nazisten, einen Keil zwischen die Völker der UdSSR zu treiben ${ }^{257}$, dar.

Der verbrecherische Charakter des »rassistischen Vernichtungskrieges gegen die Sowjetunion ${ }^{258}$ stellt einen weiteren Schwerpunkt der Ausführungen dar. Der Holocaust findet lediglich im Unterkapitel über die erste Phase des Krieges Erwähnung - als Stichpunkt in einer Aufzählung deutscher Massenverbrechen gegen sowjetische Bürger im Rahmen des Okkupationsregimes. ${ }^{259}$ Traditionell ist die Geschichte der Judenverfolgung und des Holocaust nicht bei der Behandlung der russländischen, sondern in der allgemeinen Geschichte angesiedelt. ${ }^{260}$

Der Standard gibt für den Krieg eine chronologische Dreigliederung vor: ${ }^{261}$ In einer ersten Phase - von Juni 1941 bis November 1942 - sei die Aufgabe der Sowjetunion gewesen, den Blitzkrieg der Deutschen zu verhindern und alle Kräfte zu mobilisieren. In einer zweiten Phase - von Herbst 1942 bis Ende 1943 - sei durch das Zerschlagen der deutschen Streitkräfte in großen Schlachten und die Übernahme der Initiative der Wendepunkt des Krieges erreicht worden. In der dritten Zeitphase - 1944 bis Mai 1945 - seien die Kräfte der Wehrmacht endgültig zerschlagen und das gesamte Gebiet der Sowjetunion durch die Rote Armee befreit worden. Dabei wird zum einen auf die Bedeutung der Eröffnung der zweiten Front in Europa durch die Alliierten hingewiesen und zum anderen wird das Schicksal der befreiten Länder Osteuropas thematisiert:

»Die Befreiung der von den Hitleristen okkupierten Länder Zentral- und Osteuropas durch die sowjetischen Streitkräfte befreite deren Völker vom Nazismus und förderte gleichzeitig ihre darauffolgende Inklusion in den Einflussbereich der UdSSR. « ${ }^{262}$

Insgesamt wird der Große Vaterländische Krieg - im Gegensatz zum Vaterländischen Krieg von 1812 - mit einer Vielzahl von Deutungen präsentiert. Viele davon, wie beispielsweise die Deutung als konsolidierendes Element oder die Betonung der Multiethnizität, sind für die heutige Politik von großer Bedeutung. Diese Deutungen sind jedoch keine Innovationen, sondern haben lange Traditionen in den sowjetischen und russländischen Kriegsnarrativen.

257 Ebd., 57.

258 Ebd., 57.

259 Vgl. ebd., 59.

260 Vgl. z.B.: Volobuev, Oleg/Ponomarev, Michail/Rogožkin, Vasilij: Istorija. Vseobščaja istorija. 11 klass. Bazovyj i uglublënnyj urovni. Drofa, Moskva 2014, 71 und $84 \mathrm{f}$.

261 Vgl. Konzept Lehrmethoden-Komplex, $57 \mathrm{f}$.

262 Vgl. ebd., 58. 


\subsubsection{Stalin}

Für die Deutung Iosif Stalins macht der Standard keine direkten Vorgaben. Allerdings taucht sein Name sehr selten und nur einmal - als oberster Befehlshaber zu Beginn des Krieges - auf, ohne dass er im Kontext von negativ besetzten Begriffen stehen würde: So wird er als Person im Zusammenhang mit der Liquidierung der Parteiopposition und der Errichtung des Personenkultes genannt. Im Zusammenhang mit der skizzierten Fortschrittsgeschichte taucht sein Name nicht auf - der Vorwurf, ihn zu rehabilitieren, ihn als effektiven Manager zu präsentieren - eine der häufigsten Debatten im Schulbuchbereich ${ }^{263}$ verfängt hier nicht. Allerdings werden auch die Repressionen, der GULag oder auch die Kollektivierung nicht direkt mit seinem Namen verbunden.

In dem Kapitel ^Höhepunkt und Krise des sowjetischen Systems (1945-1991) wird er noch einmal im Zusammenhang mit den Repressionen des sogenannten Spätstalinismus erwähnt - so werden die »Leningrader Affäre«, der »Kampf mit dem Kosmopolitismus«, die »Ärzteverschwörung«, der »Lyssenkoismus « und die Verfolgung des Jüdischen Antifaschistischen Komitees thematisiert. ${ }^{264}$ In der Folge werden wiederholt die Entstalinisierung, Tendenzen der Restalinisierung und die zweite Entstalinisierung in den 1980er Jahren berücksichtigt.

Insgesamt lässt sich eine gewisse Zurückhaltung in der Erwähnung Iosif Stalins konstatieren: ${ }^{265}$ Stalingrad und die Schlacht von Stalingrad werden im Standard beispielsweise wesentlich häufiger genannt - genauso wie viele auf ihn folgende Staatschefs der Sowjetunion und Russlands. ${ }^{266}$ Diese Zurückhaltung in der Erwähnung im Bereich der Schulbildung hat eine Tradition seit der Brežnev-Zeit - schon damals tauchte Stalins Name in den Lehrplänen nur einmal in einer Aufzählung auf. ${ }^{267}$ Für die sowjetischen Schulbücher stellte Arkadij Tsfasman dagegen eine zunehmende Tendenz der Erwähnung ab dem Ende der 1960er Jahre fest. ${ }^{268}$

263 Zu der Debatte vgl. u. a. Mironov, Boris: The Fruits of a Bourgeois Education. In: Kritika: Explorations in Russian and Eurasian History. 10/4 (2009), 847-860; Solonari, Vladimir: Normalizing Russia, Legitimizing Putin. In: Kritika: Explorations in Russian and Eurasian History. 10/4 (2009), 835-846. Zubkova, Elena: The Filippov Syndrom. In: Kritika: Explorations in Russian and Eurasian History. 10/4 (2009), 861-868.

264 Vgl. Konzept Lehrmethoden-Komplex, 66.

265 Das gilt zumindest in Relation zu seiner Präsenz in öffentlichen Debatten, aber auch in Relation zu der Bedeutung, die weiten Teilen seiner Amtszeit allgemein im Standard zugemessen wird.

266 Seltener Erwähnung finden im Standard Brežnev, Andropov, Černenko und Medvedev.

267 Vgl. Davies, Robert: Perestroika und Geschichte. Die Wende in der sowjetischen Historiographie. München 1991, $217 \mathrm{f}$.

268 Vgl. Tsfasman, Arkadij: Die Darstellung der Rolle Stalins in sowjetischen Schulbüchern zur Geschichte der UdSSR (Mitte der 1930er bis Mitte der 1980er-Jahre des 20. Jahrhun- 


\subsubsection{Tauwetter, Stagnation und Perestroika}

Das Kapitel `Höhepunkt und Krise des sowjetischen Systems (1945-1991) ‘ ${ }^{269}$ ist anhand der Amtszeiten der Staatschefs strukturiert: Die Zeit des »Spätstalinismus« wird als Phase globaler Weichenstellungen in den Bereichen Geopolitik, Technologie, Wirtschaft und Soziales gedeutet. Aufgrund »des Konservatismus der politischen Institutionen ${ }^{270}$ habe die Sowjetunion in der $»$ für Jahrzehnte vorentscheidenden Phase keine adäquaten Antworten auf diese globalen Prozesse finden können. ${ }^{271}$

Das »Tauwetter « der Amtszeit Nikita Chruščëvs wird als nachholende Phase charakterisiert, in der gesellschaftliche Erwartungen der Nachkriegsjahre im Bereich der Sozialpolitik und der politischen Liberalisierung, angegangen wurden. Brežnevs Regierungszeit wird zum einen als die stabilste Zeit des Landes im 20. Jahrhundert bezeichnet - die konservative Politik des entwickelten Sozialismus und die mit ihr einhergehende "Stagnation" wird jedoch auch als Ursache einer Systemkrise gedeutet, die durch die Politik der Perestrojka beantwortet wurde und die zum Zerfall der Sowjetunion geführt habe. ${ }^{272}$

Das Kapitel zählt gerade in den Bereichen Wirtschafts- und Sozialgeschichte sowie gesellschaftliche Veränderungen insgesamt zu den differenziertesten des Standards. So werden beispielweise die inneren und äußeren Verflechtungen des sentwickelten Sozialismus` genauso herausgearbeitet wie gegensätzliche Entwicklungen in der Nationalitätenpolitik oder die Entstehung der Dissidentenbewegung mit Bürgerrechtsaktionen, Petitionen und den folgenden Prozessen. Sergej Žuravlev - Stellvertretender Leiter der Russländischen Historischen Gesellschaft - begründete die Schwerpunktsetzung im Bereich Wirtschaftsgeschichte damit, dass sonst weder der Verlauf der Perestrojka noch der Zerfall der UdSSR noch die Widersprüche der Reformen El'cins erklärbar seien. ${ }^{273}$

Die Politik der Perestrojka und die Reformen Gorbačëvs als Antwort auf die »verspäteten Reformen« und die »Unfähigkeit der politischen Eliten « ${ }^{274}$,

derts). In: Bulletin 1- Systemumbrüche und historisches Gedächtnis in der deutschen und russischen Geschichte. Gemeinsame Kommission für die Erforschung der jüngeren deutsch-russischen Geschichte. Online-Publikation2014.http://www.deutsch-russischegeschichtskommission.de/fileadmin/user_upload/Dateien/Bulletin_1_deutsch.pdf, $47 \mathrm{ff}$.

269 Konzept Lehrmethoden-Komplex, 63-73.

270 Ebd., 63.

271 Vgl. ebd., 63.

272 Vgl. ebd., 63.

273 Vgl. Chamraev, Viktor: 2000-m godam podberut istoričeskij standart. V ocenke revoljucij i repressij u istorikov somnenij ne ostalos'. In: Kommersant«. Nr. 161 vom 06.09.2013, 4. Online: http://kommersant.ru/doc/2272303.

274 Konzept Lehrmethoden-Komplex, 65. 
sich den Herausforderungen der Zeit zu stellen, werden ausführlich dargestellt und als positiv, aber verspätet gedeutet. Es ergibt sich das Narrativ von einer Eigendynamik der politischen Prozesse, in der Gorbačëv, als Getriebener zwischen konservativer Nomenklatur und demokratischer Opposition, versucht Steuerungspotenziale zu bewahren.

Die beschriebene Schwerpunktsetzung in dieser Epoche geht mit einer deutlich knapperen Darstellung der Außenpolitik einher - die selten über Aspekte der Blockkonfrontation hinausgeht. Die »Ereignisse in Ungarn 1956 « ${ }^{275}$ oder »Prager Frühling - Einmarsch der Streitkräfte der Staaten des Warschauer Paktes in die Tschechoslowakei auf Initiative der UdSSR « ${ }^{276}$ - sind nur in Form von Stichpunkten enthalten. Gleiches gilt für den Afghanistankrieg: Über die Daten des Einmarsches und des Abzuges hinaus wird lediglich im Bereich zu Pluralität und Glasnost' angeregt, das gesellschaftliche Verhältnis zum Krieg zu erörtern. ${ }^{277}$

Durch die streckenweise sehr differenzierte Darstellung entzieht sich dieses Kapitel einer dichotomischen Deutung von Krisen, Spannungen und Instabilität auf der einen und dem Pathos der Erschaffung und Progression auf der anderen Seite. Auf einer subtileren Ebene scheint lediglich - ähnlich wie in der Beschreibung der letzten Jahrzehnte des Russländischen Imperiums - Kritik an politischem Konservatismus und mangelndem Reformvermögen- und willen als Deutung der Epoche durch.

\subsubsection{Die Russländische Föderation}

Nach der ersten Konzeption des Standards hätte die Geschichte der Russländischen Föderation lediglich bis zum Jahr 2000 berücksichtigt werden sollen. Unter dem Hinweis, dass Geschichtsunterricht nicht nur ein wissenschaftliches, sondern auch ein »erzieherisches Fach" sei und die Schüler auch die Zeit seit ihrer Geburt wiederfinden sollen, wurde der Zeitraum der Darstellung bis zur Präsidentenwahl 2012 erweitert. ${ }^{278}$

In der Einführung wird eine Periodisierung vorgenommen, die dem entspricht, was auch in offiziellen Reden präsentiert wird, die regelmäßig einen erinnerungspolitischen Fokus auf die Geschichte der Russländischen Föderation legen, wie z. B. Reden am Tag der Verfassung oder dem Tag Russlands. ${ }^{279}$

275 Ebd., 67.

276 Ebd., 72.

277 Vgl. ebd., 69.

278 Vgl. Chamraev, Viktor: 2000-m godam podberut istoričeskij standart. V ocenke revoljucij i repressij u istorikov somnenij ne ostalos'. In: Kommersant«. Nr. 161 vom 06.09.2013, 4. Online: http://kommersant.ru/doc/2272303.

279 Vgl. Kapitel: Erinnerungspolitik in Präsidentenreden. 
Die erste Periode von 1991 bis 1993 wird als spostsowjetische und in vielerlei Hinsicht als Übergangsperiode bezeichnet. Die ökonomischen Reformen werden in diesem Zusammenhang als notwendig für den Übergang zur Marktwirtschaft, aber auch als Auslöser für das Entstehen von inneren Spannungen und das Absinken des allgemeinen Lebensstandards eingeführt. »Der wachsende Gegensatz zwischen präsidentieller und parlamentarischer Macht (in der Gestalt des obersten Rats der RSFSR)« wird als Paralysierung der Macht und die sogenannte Verfassungskrise als drohender Zerfall des Landes gedeutet. »Russland befand sich an der Schwelle zum Bürgerkrieg. "280 $^{28}$

Die Verfassungskrise selbst wird im Standard lediglich genannt, aber weder ausgeführt noch gedeutet - sie wirkt wie ausgespart.

Die folgende neue Verfassung wird nicht speziell gedeutet. Inhaltlich wird zur Verfassung ergänzt, dass sie dem Präsidenten weitreichende Befugnisse einräumt, die letzten Reste des sowjetischen Systems beseitigte und bis heute Gültigkeit hat. ${ }^{281}$

Als zweite Periode wird die Zeit zwischen 1993 und 2000 beschrieben: Sie sei gekennzeichnet durch »die Korrektur des Reformkurses und Versuche der ökonomischen Stabilisierung. . $^{282}$ Auch in der kurzen Beschreibung dieser Epoche gibt es kaum Festlegungen. Lediglich die Situation, in der Vladimir Putin die Amtsgeschäfte von El'cin übernahm, wird als zugespitzte Krisensituation gedeutet.

Vor diesem Hintergrund kann dann die dritte Periode von 2000-2012 als Zeit eingeführt werden, in der Putin eine Stabilisierung des Landes erreicht, »Maßnahmen zur Stärkung der Vertikale der Macht trifft« und in der »die günstige Konjunktur zum Wirtschaftswachstum beiträgt, das bis zur Weltfinanzkrise 2008 anhält. ( $^{283}$ Unter Medvedev seien dann Maßnahmen zur Überwindung der Krise getroffen worden. Der Standard endet mit der Wiederwahl Putins 2012.

Dieses letzte Kapitel des Standards enthält deutlich weniger Deutungen von Geschichte als die vorangegangenen. Žuravlev äußerte nach der Publikation der ersten Version, dass man sich bis zur endgültigen Version unter den Historikern noch auf einheitliche Deutungen einigen werde. ${ }^{284}$ Nach den Beratungen erklärte Čubar' jan auf die Frage, wie der Zerfall der Sowjetunion oder der Aufbau eines zentralistischen Staates im Standard gedeutet werden:

280 Konzept Lehrmethoden-Komplex, 74.

281 Vgl. ebd., 74.

282 Ebd., 74.

283 Ebd., 74.

284 Vgl. Chamraev, Viktor: 2000-m godam podberut istoričeskij standart. V ocenke revoljucij i repressij u istorikov somnenij ne ostalos'. In: Kommersant«. Nr. 161 vom 06.09.2013, 4. Online: http://kommersant.ru/doc/2272303. 
»Eine Bewertung oder eingehende Analyse dieser Ereignisse haben wir im Standard noch zurückgestellt. Sie sind uns noch zu nahe. ${ }^{285}$

Der letzte Teil sei deswegen »maximal faktenbezogen« angelegt.

Tatsächlich lässt sich feststellen, dass der Standard gerade in der Beschreibung des Aufschwungs in den 2000er Jahren differenzierter ausfällt als die föderale Komponente der Bildungsstandards von 2004 bzw. 2012. Die These, dass der russländische Wirtschaftsaufschwung weniger mit inneren Reformen als mit externen Faktoren zu tun hat, wird zu einer offiziell sanktionierten Deutungsvariante und bricht die glatte Progressionsperspektive der föderalen Komponente. In diesem Bereich scheint die Fachdiskussion in Einzelfällen zu einer Pluralisierung der Perspektive und allgemein zu einem Verzicht auf Deutungen geführt zu haben. Auffällig sind zudem die Leerstellen in sensiblen Bereichen: Nicht nur die Verfassungskrise ist ein Bereich, der auffällig unterbelichtet und ungedeutet bleibt, auch die Tschetschenienkriege werden nur in Stichworten erwähnt - als »militärisch-politische Krise in Tschetschenien «. ${ }^{286}$

\subsubsection{Die »schwierigen Fragen der russländischen Geschichte»}

Den Abschluss der Konzeption bildet eine Liste der Fragen, bei denen man sich nicht auf eine einheitliche Betrachtungsweise einigen konnte. ${ }^{287}$ Für diese Fragen wird empfohlen, zusätzliche Handreichungen für Lehrer zu ent-

285 Chamraev, Viktor/Čerkasov, Gleb: >Važno tol'ko ne politizirovat' istoriju, i togda mesto v nej najdetsja vsemu.く Akademik Aleksandr Čubar'jan o proekte istoriko-kul'turnogo standarta.In:Kommersant«. Nr. 200vom 31.10.2013,4. Online: http://www.kommersant. $\mathrm{ru} / \mathrm{doc} / 2332034$.

286 Vgl. z. B. Konzept Lehrmethoden-Komplex, 74.

287 1. Bildung des altrussischen Staates und die Rolle der Feinde in diesem Prozess; 2. Die Existenz der altrussischen Völkerschaft und die Wahrnehmung des Erbes der Altertümlichen Rus als allgemeines Fundament der Geschichte Russlands, der Ukraine und Weißrusslands; 3. Die historische Wahl [Entscheidung] Aleksandr Nevskis; 4. Die Rolle Iwans IV. Grosnys in der russischen Geschichte: Reformen und ihr Preis; 5. Die Versuche der Beschränkung der Macht des Staatsoberhauptes in der Periode der Wirren und in der Epoche der Palastrevolutionen, mögliche Gründe der Misserfolge dieser Versuche; 6. Der Beitritt der Ukraine zu Russland (der Grund und die Folgen); 7. Grundlegende Besonderheiten der sozialen und politischen Ordnung Russlands (Leibeigenschaft, Autokratie) im Vergleich mit den Staaten Westeuropas; 8. Gründe, Besonderheiten, Folgen und der Preis der Petrinischen Reformen; 9. Gründe, Folgen und Einschätzung des Falls der Monarchie in Russland, der Machterlangung der Bolschewiki und ihres Sieges im Bürgerkrieg; 10. Gründe der Rücknahme der NEP, Einschätzung der Ergebnisse der Industrialisierung, der Kollektivierung und der Umgestaltungen in der Sphäre der 
wickeln und herauszubringen, die die verschiedenen Betrachtungsweisen abbilden. »Auf diese Weise wird ein einheitlicher Wissenschafts- und Bildungsraum geschaffen und die Rolle des Schulbuches 'Geschichter als Navigator gestärkt. ${ }^{288}$ Gleichzeitig ist die Liste laut Žuravlev so zu verstehen, dass in den entsprechenden Themenbereichen, in denen zu Ereignissen und Prozessen kein Konsens besteht, die Schulbücher variabel gestaltet werden können. ${ }^{289}$

Im Gespräch mit Vladimir Putin erklärte Naryškin, dass es erstmals gelungen sei, die Fragen der russländischen Geschichte herauszuarbeiten, zu denen kein Konsens bezüglich von Wahrnehmung und Deutung sowie Fakten und Ereignissen bestehe. Diese Fragen seien das größte Hindernis für die Ausarbeitung eines beding $\mathrm{t}^{290}$ einheitlichen Schulbuches. ${ }^{291}$

Auch Putin kommentierte die Fragen: Sie hätten teilweise einen 1000 jährigen Charakter, aber bei einigen seien eher Streitigkeiten zwischen Historikern das Problem. ${ }^{292}$

In einem längeren, emotionalen Monolog führte Putin aus, dass unterschiedliche Perspektiven auf die Geschichte im Prinzip nicht problematisch, die Beschäftigung mit ihnen sogar sinnvoll sei. Es gehe vielmehr darum zu verhindern, dass beispielsweise in Bezug auf den Zweiten Weltkrieg »Unsinn « und »ideologischer Müll» in den Schulbüchern stehen könne, der für jedes beliebige Land oder Volk sei, als würde man ihm ins Gesicht spucken. Die Ge-

Kultur; 11. Der Charakter der Nationalitätenpolitik der Bolschewiki und ihre Einschätzung; 12. Gründe, Folgen und Einschätzung der Errichtung der Einparteiendiktatur und der Alleinherrschaft I. Stalins; Gründe der Repressionen. 13. Einschätzung der Außenpolitik der UdSSR vor Beginn und zu Anfang des Zweiten Weltkriegs; 14. Der Preis des Sieges der UdSSR im Großen Vaterländischen Krieg; 15. Einschätzung der UdSSR unter den Bedingungen »des Kalten Krieges«; 16. Gründe, Folgen und Einschätzung der Reformen N. Chruščëvs; 17. Einschätzung der Periode der Regierung L.Brežnevs und der Rolle der Dissidentenbewegung; 18. Gründe, Folgen und Einschätzung der »Perestroika" und des Zerfalles der UdSSR; 19. Einschätzung der Gründe, des Charakters und der Folgen der Wirtschaftsreformen Anfang der 1990 (»Schocktherapie«, Methoden der Privatisierung); Gründe und Folgen der Siege B. El'cins in den politischen Kämpfen der 1990er; 20. Gründe, Folgen und Einschätzung der Stabilisierung der Wirtschaft und des politischen Systems Russlands in den 2000ern.

288 Konzept Lehrmethoden-Komplex, 80.

289 Vgl. Chamraev, Viktor: 2000-m godam podberut istoričeskij standart. V ocenke revoljucij i repressij u istorikov somnenij ne ostalos'. In: Kommersant«. Nr. 161 vom 06.09.2013, 4. Online: http://kommersant.ru/doc/2272303.

290 Naryškin wiederholte mehrfach, dass es sich eben nur um ein ১bedingt einheitliches Buch handeln werde.

291 Vgl. Putin, Vladimir: Vstreča s avtorami koncepcii novogo učebnika istorii. Vladimir Putin vstretilsja s razrabotčikami koncepcii novogo učebno-metodičeskogo kompleksa po otečestvennoj istorii. 16 janvarja 2014 goda, Moskva. Online: http://www.kremlin.ru/ events/president/news/20071.

292 Vgl. ebd. 
schichtsdeutung, die als Auslöser für diese Philippika betrachtet werden kann, erläutert und kommentiert er wie folgt: ${ }^{293}$

»Sie sprechen davon, dass infolge des Zweiten Weltkriegs Osteuropa in die Finsternis der Besatzung des Stalinregimes eingetaucht ist. Teilweise muss man anerkennen, dass dort die sowjetische Ideologie arbeitete und negativen Einfluss auf die Entwicklung dieser Staaten hatte. Aber wir sprechen über die Folgen: und was wären die Folgen, wenn der Faschismus gesiegt hätte? Es würde einige dieser Völker überhaupt nicht mehr geben, sie wären einfach vernichtet worden, das ist alles. ${ }^{294}$

Als Lösung dieses Problems verweist Putin auf die Notwendigkeit der internationalen Zusammenarbeit von Historikern, um gemeinsam zu möglichst objektiven Bewertungen zu gelangen.

Der eigentliche Fragenkatalog ist so umfassend formuliert, dass er den Schulbuchautoren, im Gegensatz zur ursprünglichen Intention der Konzeption, in fast allen kontroversen Bereichen freie Hand für voneinander abweichende Darstellungen der Geschichte lässt. Besonders deutlich wird das an den Fragen zur Zeit des Stalinismus. ${ }^{295}$ Aber auch für die jüngste russländische Geschichte ist keine einheitliche Deutung verbindlich: Wie beschrieben, wurde in der föderalen Komponente der Bildungsstandards von 2004 beispielweise noch die Darstellung der 2000er Jahre als eine mit wichtigen Persönlichkeiten verbundene Geschichte der Stabilisierung und des Aufschwungs festgeschrieben. Im Fragenkatalog werden nun die Gründe für die Entwicklung offiziell zur Diskussion gestellt. ${ }^{296}$

293 Wolfram von Scheliha interpretiert die Passage in dem Sinne, dass eine kritische Darstellung der Expansion des sowjetischen Machtbereichs durch Putin als sins Gesicht spucken inkriminiert würde. Da Putin jedoch die Doppeldeutigkeit der Integration in den sowjetischen Machtbereich im Folgesatz selbst thematisiert, erscheint es schlüssiger, dass er sich auf ethnische Nationaldiskurse beispielsweise im Baltikum bezieht, die, im Rahmen der These von der doppelten Okkupation, die ssowjetische Okkupation als schlimmer als die deutsche Okkupation beschreiben und dabei die Perspektive der eigenen Bevölkerungsteile ausblenden, die durch Deutschland größtenteils vernichtet wurden. Schlüssig wiederum ist Schelihas Hinweis, dass der sowjetische Sieg und die sowjetische Machtpolitik in der Folge getrennt betrachtet werden können.

294 Putin,Vladimir:Vstreča savtoramikoncepciinovogo učebnikaistorii. Vladimir Putinvstretilsja s razrabotčikami koncepcii novogo učebno-metodičeskogo kompleksa po otečestvennoj istorii. 16 janvarja 2014 goda, Moskva. Online: http://www.kremlin.ru/events/ president/news/20071.

295 Vgl. z. B. die Fragen Nummer 10 bis 15, die angefangen mit Industrialisierung und Kollektivierung bis hin zum >Preis des Sieges im Krieg` die Darstellung der gesamten Epoche für abweichende Darstellungen öffnen. Konzept Lehrmethoden-Komplex, 80.

296 Siehe oben Frage Nr. 20. Konzept Lehrmethoden-Komplex, 80. 


\subsubsection{Resümee zum Lehrmethodenkomplex}

Nimmt man die im Vorfeld geäußerten Befürchtungen, das Vorhaben sei ein neuer Kratkij Kurs VKP(b) oder der erneute Beginn, Geschichte umzuschreiben zum Maßstab, ist die letztendliche Konzeption inklusive Standard wenig spektakulär. In weiten Teilen erscheint das Ergebnis eine erweiterte Variante der föderalen Komponente der Bildungsstandards von $2004 \mathrm{zu}$ sein. Dieser Katalog von zu berücksichtigenden Ereignissen wurde neu periodisiert und in jedem Abschnitt durch einen Essay ergänzt, der ein gewisses Maß an Deutung und Einordnung enthält. Diese Deutungen und Einordnungen erscheinen aber weniger als ein neuer Entwurf russländischer Geschichte, sondern mehr als eine Synthese - teilweise basierend auf dem kleinsten gemeinsamen Nenner - aus bestehenden Schulbuchtexten.

Das lässt sich aus dem Entstehungskontext erklären. Am Beginn der Ausarbeitungen stand Vladimir Putins Forderung nach einem Schulbuch, das innere Widersprüche und Doppeldeutigkeiten vermeidet - kurz: eine eindeutigere Geschichte präsentiert. Aber schon in dem im Anschluss daran gewählten Verfahren war strukturell angelegt, dass man dieses Ziel kaum erreichen würde. Die gewählte Kooperation aus Bildungsministerium, Russischer Historischer Gesellschaft und Akademie der Wissenschaften ist auch für das allgemeine Zulassungs- und Empfehlungsverfahren für Schulbücher maßgeblich. Sie bildet in großem Umfang die Breite des wissenschaftlichen Spektrums in Russland ab. Zusätzlich sind die einflussreichen Haupt-Herausgeber der bisherigen Geschichtsschulbücher, als Historiker und Autoren, einflussreiche Akteure in den beteiligten Institutionen. Diese Autoren vertreten genauso ihre geschichtswissenschaftlichen Positionen wie auch mittelbar die Interessen der mit ihnen verbundenen großen Schulbuchverlage. Auch die Durchführung einer öffentlichen Diskussionsphase war absehbar kein geeignetes Instrument, um die Diversität von Geschichtsbetrachtungen zu reduzieren. Einiges spricht dafür, dass hier eine Kooperation von mittelbaren und unmittelbaren Akteuren des Schulbuchmarktes einer ihren wissenschaftlichen und kommerziellen Interessen zuwiderlaufenden Vereinheitlichung von Geschichtsperspektiven entgegengewirkt hat.

Inhaltlich hat das Verfahren in manchen Bereichen gar zu einer Pluralisierung und zu einem Aufbrechen einer ausschließlich russo-zentrischen Geschichtsperspektive geführt. Wie beschrieben gilt dies aber auch nur partiell: Die Bereiche, die die Staatsräson tangieren - z. B. im Bereich der territorialen Integrität - blieben unangetastet.

Im öffentlichen und fachöffentlichen Aushandlungsprozess wurden auch viele Bereiche der ersten Variante der Konzeption ıweichgespültt: Das trifft sowohl auf Bereiche zu, die einem ethnisch-russischen Chauvinismus das Wort geredet hätten, als auch auf Passagen, die die dunklen Seiten der Geschichte - 
die sich nicht in das Pathos der Erschaffung einfügen wollen - zu sehr ausleuchten.

Der Intention, die Deutung der Geschichte für Geschichtsschulbücher zu vereinheitlichen, kann das Konzept also nur in sehr geringem Umfang gerecht werden. Der Versuch, eine staatliche Perspektive auf die Geschichte und einheitliche Deutungen zu etablieren, scheiterte vor allem daran, dass primär in den ausführenden Institutionen - der Russländischen Historischen Gesellschaft und der Russländischen Akademie der Wissenschaften - kein Konsens in diesen Fragen besteht.

Nur in einigen Bereichen finden sich in der Konzeption klar identifizierbare Geschichtsinterpretationen wieder, die in den letzten Jahren über die allgemeine Erinnerungspolitik - zum Beispiel in Präsidentenreden - etabliert wurden. Das Smuta-Narrativ ist hier, zumindest partiell, ein Beispiel. In Bezug auf die Beschreibung der Situation als existenzielle Gefahr für das Fortbestehen des Landes entspricht der Standard dem Präsidenten-Narrativ. Mit der Darstellung der Smuta als >inner-russische Angelegenheit‘, als Bürgerkrieg, setzt sich der Standard jedoch vom Narrativ der äußeren Bedrohung ab.

Seine eigentliche Wirkung werden das Konzept und auch der Standard jedoch nicht über die Festschreibung bestimmter Deutungen von Geschichte entfalten. Dafür wurde schlicht zu wenig an Deutungen verbindlich gemacht und der angehängte Katalog von sschwierigen Fragen ‘ eröffnet selbst in Bezug auf die bestehenden Deutungen des Standards weite Interpretationsspielräume.

Die Wirkung wird vielmehr von drei Bereichen ausgehen, die auf einer von konkreten Ereignissen abgekoppelten Ebene funktionieren: Erstens die Festlegung von methodischen Zugängen wie z. B. der sozial-anthropologischen Perspektive. Zweitens die Empfehlung, eine mitreißende Geschichte und, wo möglich, eine Fortschrittsgeschichte zu präsentieren. Und drittens die in ihrer Bedeutung kaum zu unterschätzende Periodisierung. Die ersten beiden Bereiche sind geeignet, die Distanz der Lernenden zur Geschichte zu verringern und sie emotional zu binden. Die Periodisierung kann Perspektiven präformieren, Geschichte einordnen und kann - wenn nötig - ganze Perioden in erinnerungspolitische Quarantäne auslagern, um das >Pathos der Erschaffung` nicht zu behindern.

Alle drei Bereiche zusammen lassen sich als Maßnahme deuten, um dem erzieherischen Aspekt des Geschichtsunterrichts Geltung zu verschaffen Geschichtsunterricht als Erziehung zum Patriotismus. 


\subsection{Die Schulbücher für das Schuljahr 2015/2016}

Im Januar 2014 traf sich Vladimir Putin mit den Autoren des Lehrmethoden Komplex. Sergej Naryškin lobte ausführlich die Konzeption und die Art und Weise ihrer Entstehung und erklärte, dass es gelungen sei, die Spekulationen zu zerstreuen, man habe im stillen Kämmerlein irgendeine neue Version des Kratkij Kurs VKP(b) geschrieben. ${ }^{297}$

Putin präzisierte seine Aussagen vom Treffen im Vorjahre mit dem Hinweis, dass mit einer einheitlichen Herangehensweise an die Lehre von Geschichte nicht eine staatlich-offiziöse und ideologisierte Gesinnungsgleichheit gemeint sei. Es gehe vielmehr um eine einheitliche Logik für den Geschichtsunterricht, um das Verständnis der Untrennbarkeit und der Wechselbeziehungen aller Etappen der staatlichen Entwicklung und darum, dass auch die dramatischsten und mehrdeutigsten Ereignisse untrennbarer Bestandteil der Vergangenheit seien. ${ }^{298}$

»Bei allen unterschiedlichen Bewertungen und Meinungen sollten wir unserer Vergangenheit mit Achtung begegnen, weil sie das Leben unseres Volkes, das Leben unserer Vorfahren ist und die vaterländische Geschichte die Grundlage unserer nationalen Identität, unseres kulturhistorischen Codes ist. ॥ $^{299}$

In der Folge des Treffens und auf der Grundlage der Konzeption sollten für das Schuljahr 2015/2016 neue Schulbuch-Linien erstellt werden. Die Bücher sollten bis zum April 2015 geschrieben werden, um dann den vorgeschriebenen Begutachtungs- und Zulassungsprozess zu durchlaufen. ${ }^{300}$

Von den acht Linien, die von fünf Verlagen vorgelegt wurden, wurden lediglich zwei vollständige Linien zugelassen - jeweils eine von Prosveščenie und eine von Drofa. Neben diesen Linien der beiden größten Schulbuchverlage wurde noch eine dritte Linie des Verlags Russkoe Slovo für die Anfangsstufe und die Hauptstufe zugelassen, die Bücher für die Abschlussklassen wurden aufgrund von zu vielen Beanstandungen vorläufig nicht zugelassen. Die Beanstandungen reichten, laut Andreij Petrov, dem zuständigen Sekretär der Russländischen Historischen Gesellschaft, von falschen historischen Daten

297 Vgl. Putin, Vladimir: Vstreča s avtorami koncepcii novogo učebnika istorii. 16 janvarja 2014 goda, Moskva. Online: http://www.kremlin.ru/events/president/news/20071.

298 Vgl. ebd.

299 Ebd.

300 Vgl. Chamraev, Viktor/Belavin, Pavel: Učenym razrešili pisat' novye učebniki istorii. Oni projdut mnogostupenčatuju fil’traciju. In: Kommersant«. Nr. 84 vom 20.05.2014, 3. Online: http://kommersant.ru/doc/2474758. 
bis hin $\mathrm{zu} »$ nicht richtig dargelegten Schlussfolgerungen. ${ }^{301}$ Ebenfalls nicht zugelassen wurden jeweils eine Buchreihe von Drofa, Vlados, Ventana-Graf sowie zwei Linien von Prosveščenie. ${ }^{302}$

Nach der Aufnahme der neuen Schulbuchreihen wurden die übrigen Bücher aus den Vorjahren aus dem föderalen Verzeichnis ausgeschlossen. ${ }^{303} \mathrm{Sie}$ können aber - so die stellvertretende Bildungsministerin Natal'ja Tret'jak bis zu ihrem Verschleiß weiter eingesetzt werden. ${ }^{304}$

Eines der neuen Zulassungskriterien für Schulbücher schreibt vor, geschlossene Buchreihen für die jeweilige Stufe herauszubringen. Dementsprechend haben Prosveščenie und Drofa jeweils Linien von der sechsten bis zur zehnten Klasse herausgebracht. Bei Drofa besteht die Linie jeweils aus einem Buch pro Schuljahr ${ }^{305}$, während die Buchreihe von Prosveščenie von der sechsten bis zur neunten Klasse aus zwei Bänden pro Schuljahr besteht ${ }^{306}$ und für das zehnte Schuljahr aus drei Bänden. ${ }^{307}$ Ebenfalls entsprechend der neuen Regelung verfügen beide Linien über digitale Versionen. Die Version von Drofa ist beispielsweise in einer Html-Version verfügbar, in der die Texte und Bilder des

301 Ebd., 3.

302 Vgl. Chamraev, Viktor: Edinych učebnikov budet poka tri. Ministerstvo obrazovanija zakončilo otbor novych učebnikov po istorii Rossii. Kommersant«. Nr. 84 vom 18.05.2015, 5. Online: http://kommersant.ru/doc/2728740.

303 Vgl. Prikaz Minobrnauki Rossii ot 08.06 .2015 N $576 » O$ vnesenii izmenenij v federal'nyj perečen' učebnikov, rekomenduemych $\mathrm{k}$ ispol'zovaniju pri realizacii imejuščich gosudarstvennuju akkreditaciju obrazovatel'nych programm načal'nogo obščego, osnovnogo obščego, srednego obščego obrazovanija, utverždennyj prikazom Ministerstva obrazovanija i nauki Rossijskoj Federacii ot 31 marta 2014 g. N 253«.

304 Vgl. Chamraev, Viktor: Edinych učebnikov budet poka tri. Ministerstvo obrazovanija zakončilo otbor novych učebnikov po istorii Rossii. Kommersant«. Nr. 84 vom 18.05.2015, 5. Online: http://kommersant.ru/doc/2728740.

305 Vgl. Volobuev, Oleg: Istorija Rossii. Načalo XX - načalo XI v. 10 kl. Učebnik. Drofa, Moskau 2016; Ljašenko, Leonid: Istorija Rossii. XIX - nacălo XX v. 9 kl. Učebnik. Drofa, Moskau 2016; Andreev, Igor': Istorija Rossii. Konec XVII-XVIII v. 8 kl. Učebnik. Drofa, Moskau 2016; Andreev, Igor': Istorija Rossii. XV - konec XVII v. 7 kl. Učebnik. Drofa, Moskau 2016; Andreev, Igor': Istorija Rossii s drevnejšich vremën XVI v. 6 kl. Učebnik. Drofa, Moskau 2016.

306 Vgl. Arsent'ev, Nikolaj: Istorija Rossii. 9 kl. Učebnik. Čast' 1. Prosveščenie, Moskau 2016; Arsent'ev, Nikolaj: Istorija Rossii. 9 kl. Učebnik. Čast' 2. Prosveščenie, Moskau 2016; Arsent'ev, Nikolaj: Istorija Rossii. 8 kl. Učebnik. Čast' 1. Prosveščenie, Moskau 2016; Arsent'ev, Nikolaj: Istorija Rossii. 8 kl. Učebnik. Čast' 2. Prosveščenie, Moskau 2016; Arsent'ev, Nikolaj: Istorija Rossii. 7 kl. Učebnik. Čast' 1. Prosveščenie, Moskau 2016; Arsent'ev, Nikolaj: Istorija Rossii. 7 kl. Učebnik. Čast' 2. Prosveščenie, Moskau 2016; Arsent'ev, Nikolaj: Istorija Rossii. 6 kl. Učebnik. Čast' 1. Prosveščenie, Moskau 2016; Arsent'ev, Nikolaj: Istorija Rossii. 6 kl. Učebnik. Čast' 2. Prosveščenie, Moskau 2016;

307 Gorinov, Michail: Istorija Rossii. 10 kl. Učebnik. Čast' 1. Prosveščenie, Moskau 2016; Gorinov, Michail: Istorija Rossii. 10 kl. Učebnik. Čast' 2. Prosveščenie, Moskau 2016; Gorinov, Michail: Istorija Rossii. 10 kl. Učebnik. Čast' 3. Prosveščenie, Moskau 2016; 
Buches durch Filmausschnitte, Video-Präsentationen, Podcasts und Quiz zu den einzelnen Kapiteln ergänzt werden. ${ }^{308}$

In der Buchversion knüpfen die beiden Serien in ihrer Gestaltung an die fortschrittlicheren Publikationen der Vorgängergeneration an. Der Autorentext dominiert weiterhin - er ist aber durch eine Vielzahl verschiedener Elemente, wie Fragen an den Text, Karten, Datenmaterial, Bilder und Quellen, aufgebrochen. In der Prosveščenie-Linie sind Quellen besonders umfangreich berücksichtigt und immer wieder werden verschiedene Historikermeinungen nebeneinander gestellt. Dies geschieht u.a. in den Bereichen, die sich mit den sschwierigen Fragen der russländischen Geschichte` aus der geschichts-methodischen Konzeption beschäftigen.

In ihrer Struktur orientieren sich die beiden Linien bis zur neunten Klasse ungefähr an den Vorgaben. Die Bücher für die zehnten Klassen übernehmen dann die Periodisierungen des geschichtsmethodischen Standards. Volobuev übernimmt teilweise den ersten Satz eines Bereichs aus dem Standard wortgleich als ÜberschriftfürdasbetreffendeKapitel. ${ }^{309}$ AbweichendvomStandardwerden an einigen Stellen Themenkomplexe zusätzlich in Unterkapitel gegliedert. ${ }^{310}$

Michail Gorinov treibt in seinem Buch für die 10. Klasse die strikte Orientierung am Lehrmethoden-Komplex auf die Spitze: Sein Einleitungstext für die drei Bücher des 20. Jahrhunderts ist ein Kompilat aus den Essays zu den jeweiligen Zeitabschnitten des historisch-kulturellen Standards, die hintereinander kopiert und an einigen Stellen gekürzt oder leicht verändert wurden. ${ }^{311}$

Auch inhaltlich orientieren sich die beiden Linien in verschiedenen Bereichen an Vorgaben der Konzeption. Dies gilt sowohl für die Vorgaben aus der Konzeption, wie und unter welchen Schwerpunktsetzungen Geschichte dargestellt werden soll, als auch für inhaltliche Vorgaben aus dem geschichtskulturellen Standard selbst.

308 So sind beispielsweise in der digitalen Version des Buches für die 7. Klasse von Igor'Andreev für Kapitel 2, Paragraf 16 >Beendigung der Smuta - neue Dynastie ‘ drei Elemente hinterlegt: Eine Videopräsentation, in der vor dem Hintergrund einer Karte Grenzverläufe, Truppenbewegungen, Orte, Quellen und Bilder präsentiert werden. Ein dreizehnminütiger Filmausschnitt aus dem sowjetischen Film `Minin i Požarskij< von 1939 (Mosfil'm). Ein Quiz, das beispielsweise das Datum des Tages der nationalen Einheit im heutigen Russland abfragt.

309 Vgl. z. B. Vgl. Volobuev, Oleg: Istorija Rossii. Načalo XX - načalo XI v. 10 kl. Učebnik. Drofa, Moskau 2016, 15 und 50.

310 Während beispielsweise im Standard ein Abschnitt zur `Außenpolitik der Sowjetunion in den 1920er und 1930er Jahren vorgegeben wird und es im folgenden Kapitel mit Juni 1941 weiter geht, teilt Volobuev den Bereich Außenpolitik in >1919 - August 1939 und ,September 1939 - Juni 1941«. Vgl. Volobuev, Oleg: Istorija Rossii. Načalo XX - načalo XI v. $10 \mathrm{kl}$. Učebnik. Drofa, Moskau 2016, 133 und 141.

311 Vgl. Gorinov, Michail: Istorija Rossii. 10 kl. Učebnik. Čast' 1. Prosveščenie, Moskau 2016, 5-8 und Konzept Lehrmethoden-Komplex. Z. B. 46, 51, 57 usw. 


\subsubsection{Die Zeit der Wirren}

An der Darstellung der Zeit der Wirren in den entsprechenden Büchern der beiden Linien lässt sich diese Ausrichtung an den Vorgaben beispielhaft darstellen. Vor allem bei Igor' Andreev (Drofa) ${ }^{312}$ wird die im Konzept geforderte Erziehung zu Patriotismus und staatsbürgerlichem Bewusstsein durch Beispiele militärischer Heldentaten ${ }^{313}$ hervorgehoben. Die übergreifende Frage zu Beginn des Kapitels lautet:

»Wer rettete das Land vor dem Untergang - die Autokraten oder das Volk, erzogen zum orthodoxen Glauben und zur Liebe zur Heimat? $\ll^{314}$

In der Frage kommt zudem die Einordnung der Situation als existenzgefährdend zum Ausdruck, wie sie im Standard vorgegeben ist.

Noch deutlicher wird die Verbindung von Patriotismus, als Liebe zur Heimat, und militärischem Ruhm in der Beschreibung des Sieges der Aufständischen über die Truppen Jan Chodkiewiczs. Seinen Truppen wird als Motivation vor allem der Zugriff auf die Schätze der Zaren zugeschrieben, während die Aufständischen von anderen Gefühlen angeleitet seien:

"Der Liebe zur Heimat, dem Streben, den orthodoxen Glauben zu verteidigen, die Unabhängigkeit des Landes zu verteidigen..$^{315}$

Wie im Standard vorgesehen, wird die Smuta als »innere Angelegenheit ${ }^{316}$ und nicht als Abwehrkampf gegen ausländische Besatzer dargestellt. Das entsprechende Kapitel wird bei Andreev durch die Frage eingeleitet:

„Was war die Smuta - Bürgerkrieg oder der Kampf des Adels um die Macht? «17

Bei Arsent'ev (Prosveščenie) ${ }^{318}$ wird die Smuta und vor allem die Rolle der Bauern und Kaufleute bei ihrer Beendigung ähnlich dargestellt ${ }^{319}$ - wenn auch insgesamt mit weniger Emphase in Bezug auf die Liebe zur Heimat. Stattdessen wird jedoch in der Zusammenfassung des Kapitels auf die Einführung des Tags der nationalen Einheit im Jahr 2005 und seine Verbindung zum Unter-

312 Andreev, Igor': Istorija Rossii. XV - konec XVII v. 7 kl. Učebnik. Drofa, Moskau 2016.

313 Vgl. Konzept Lehrmethoden-Komplex, 7.

314 Andreev, Igor': Istorija Rossii. XV - konec XVII v. 7 kl. Učebnik. Drofa, Moskau 2016, 84.

315 Ebd., 104.

316 Chamraev, Viktor/Čerkasov, Gleb: ,Važno tol'ko ne politizirovat' istoriju, i togda mesto v nej najdetsja vsemu.< Akademik Aleksandr Čubar'jan o proekte istoriko-kul'turnogo standarta.In:Kommersant«.Nr. 200vom 31.10.2013,4. Online: http://www.kommersant. $\mathrm{ru} / \mathrm{doc} / 2332034$.

317 Andreev, Igor': Istorija Rossii. XV - konec XVII v. 7 kl. Učebnik. Drofa, Moskau 2016, 101.

318 Arsent'ev, Nikolaj: Istorija Rossii. 7 kl. Učebnik. Čast' 2. Prosveščenie, Moskau 2016.

319 Vgl. ebd., 27. 
richtstoff hingewiesen. ${ }^{320}$ Um der Erwähnung der Smuta in den $>$ schwierigen Fragen ‘ der Konzeption gerecht zu werden, lässt Arsent'ev sieben Historiker in Zitaten zu den Ursachen der Zeit der Wirren zu Wort kommen. ${ }^{321}$

\subsubsection{Reformen und multiethnisches Imperium}

An den Kapiteln zu den petrinischen Reformen wird das Bemühen beider Linien deutlich, der Forderung nach einer Progressionsgeschichte - dem Pathos der Erschaffung - nachzukommen, ohne eine zu glatte Geschichte, die nachteilige Entwicklungen übergeht, darzustellen. Andreev und Arsent'ev beschreiben die Reformen in den jeweiligen Kapiteln sehr positiv - als grundlegenden Meilenstein, als Kurs in Richtung der europäischen Aufklärung und als Grundlage des Aufstiegs Russlands zur europäischen Großmacht. ${ }^{322}$ Daneben werden aber auch sowohl der begrenzte Charakter als auch weitere problematische Aspekte der Reformen jeweils in eigenen Kapiteln behandelt. ${ }^{323}$

Diese Herangehensweise setzt sich fort: Andreev beschreibt Ekaterina II. als eine äußerst erfolgreiche Reformerin, geht aber auch auf zunehmende innergesellschaftliche Widersprüche ein, zwischen »Kapitalismus und Leibeigenschaft, Rechtlosigkeit und dem Gefühl persönlicher Würde der Bürger, Absolutismus und dem Streben nach Freiheit.« ${ }^{324}$

Beide Linien tun sich schwer, wie in der Konzeption angelegt, die russische Zentralperspektive aufzubrechen und die Geschichten verschiedener Ethnien tatsächlich zu integrieren. Gerade in den Büchern zum 18. Jahrhundert der Prosveščenie-Serie nimmt das Thema der Multiethnizität zwar breiten Raum ein - jedoch ganz überwiegend in den Bereichen zur Projektarbeit und zum Selbststudium. Neben einem Kapitel »Völker Russlands. Nationalitäten- und Religionspolitik unter Ekaterina II. " $^{325}$ werden in einem weiteren Kapitel Russen, Ukrainer, Weißrussen, Kalmyken, die Völker des Wolgagebiets, Kasachstans, des Kaukasus, Sibiriens und des Fernen Ostens in ihrer Entwicklung im 18. Jahrhundert skizziert. ${ }^{326}$

320 Ebd., 27.

321 Ebd., $20 \mathrm{f}$.

322 Vgl. Andreev, Igor': Istorija Rossii. Konec XVII-XVIII v. 8 kl. Učebnik. Drofa, Moskau 2016, 64 und Arsent'ev, Nikolaj: Istorija Rossii. 8 kl. Učebnik. Čast' 1. Prosveščenie, Moskau 2016, 79.

323 Vgl. ebd., 75. Auch zu dieser sschwierigen Frage der russländischen Geschichte kommen bei Arsent'ev wieder verschiedene Historiker zu Wort. Vgl., 81.

324 Andreev, Igor': Istorija Rossii. Konec XVII-XVIII v. 8 kl. Učebnik. Drofa, Moskau 2016, 209.

325 Arsent'ev, Nikolaj: Istorija Rossii. 8 kl. Učebnik. Čast' 2. Prosveščenie, Moskau 2016, 32.

326 Vgl. ebd., 101-104. 
Im Drofa-Buch zum 18. Jahrhundert von Andreev wird das Thema »Multinationales Imperium « ${ }^{327}$ im letzten Kapitel mit dem Titel »18. Jahrhundert glänzend und heroisch ${ }^{328}$ behandelt. Zu Beginn versucht Andreev die Entstehung und die Erweiterung des multinationalen Imperiums entsprechend den Vorgaben aus der Konzeption einzuordnen. Das Hinzufügen von Territorien zum Imperium, in denen nicht-russische Ethnien lebten, beschreibt er als mehrdeutig:

"Unter der Schaffung des Imperiums sind nicht nur freiwillige oder gewaltsame Beitritte von Völkern zu verstehen. Tatsächlich stand hinter jeder Inklusion eine konkrete Geschichte, in der nicht selten freiwillige Bestrebungen und gewaltsames Handeln vermischt waren. ॥ $^{329}$

Als Beispiele für Erweiterungen durch Eroberung führt er das Kazaner Chanat, die Linksufrige Ukraine und das Baltikum an, Georgien firmiert als Beispiel für ein Protektorat und die Teilungen Polens werden als Erweiterung in der Folge von internationalen Verträgen dargestellt. ${ }^{330}$ Als weitere Formen werden einvernehmliche und vertragliche sowie Eingliederungen »im Zuge wirtschaftlicher Kolonisation ${ }^{331}$ genannt.

Am Ende des Kapitels kommt Andreev auf die Besonderheiten des Imperiums zu sprechen. Seine These ist, dass die Besonderheit darin bestand, dass die Titularnation nicht die herrschende gewesen sei. Der Grad der Ausbeutung der Russen und ihre Verpflichtungen gegenüber dem Staat seien höher gewesen als die anderer Ethnien des Imperiums. ${ }^{332}$ Die Sicherung der nationalen Einheit und der Kampf mit politischem Separatismus in einem multiethnischen Staat wird in dem Kapitel als geschichtlich gesammelter Erfahrungsschatz implizit auch für die Gegenwart - beschrieben. ${ }^{333}$

\subsubsection{Eine Sowjetische Erfolgsgeschichte?}

Im zwanzigsten Jahrhundert orientieren sich beide Linien in ihrer Periodisierung sehr deutlich am historisch-kulturellen Standard. Die Linien beginnen dementsprechend mit der Zeit der großen Spannungen, die den Ersten Weltkrieg, die `Große Russländische Revolution` und den Bürgerkrieg umfasst. Da der Standard über die Periodisierung hinaus auch inhaltlich nahelegt, die Zeit

327 Andreev, Igor': Istorija Rossii. Konec XVII-XVIII v. 8 kl. Učebnik. Drofa, Moskau 2016, 196.

328 Ebd., 193.

329 Ebd., 196.

330 Vgl. ebd., 196.

331 Ebd., 196.

332 Vgl. ebd., 199.

333 Vgl. ebd., 198. 
nach diesen 'Spannungen vor allem als Entwicklungs- und Modernisierungsgeschichte zu beschreiben, ist die Frage nach der Darstellung der Industrialisierung und der Kollektivierung in den Büchern zum 20. Jahrhundert von besonderer Bedeutung.

Volobuev leistet sich im Bereich von Industrialisierung und Kollektivierung deutliche Schwächen. Die Industrialisierung wird als eine gegenüber dem Westen aufholende Fortschrittsgeschichte beschrieben. Die Entstehung neuer Industrien und Fabriken nimmt großen Raum ein, dagegen fällt die Thematisierung von Zwangsarbeit sehr kurz aus. Volobuev verweist zwar auf die Beschlüsse, die Arbeitskraft von Häftlingen auszubeuten, ${ }^{334}$ und darauf, dass massenhafte Zwangsarbeit im Zuge der Industrialisierung zu einer normalen Erscheinung in der UdSSR wurde. ${ }^{335}$ Der Zusammenhang zwischen Industrialisierung und Zwangsarbeit bleibt jedoch unterbelichtet - bei der Beschreibung des Lagersystems ist der Begriff GULag nicht enthalten.

Ähnliche Probleme ergeben sich beim Thema der Kollektivierung. Das Thema wird über weite Strecken als Modernisierungs- und Reformgeschichte dargestellt. Der Widerstand gegen die Kollektivierung und die Repressionen gegen die Bevölkerung werden nur am Rande behandelt. Erst der letzte Absatz des Abschnitts geht auf die Hungertoten als Folge der Kollektivierung ein und deutet die Schuldfrage als eine Form von unterlassener Hilfeleistung:

»Der Schlag, den die Landwirtschaft durch die Kollektivierung erlitten hatte, erlaubte es nicht, die Folgen der Missernten 1932 und 1933 zu überwinden. In den südlichen Gebieten der UdSSR begann ein schrecklicher Hunger. [...] Die Regierung gewährte den Hungernden keinerlei Hilfe. ${ }^{336}$

Die Zahl der Hungertoten für die Ukraine, den Nordkaukasus, das Wolgagebiet und Kasachstan gibt der Autor mit ungefähr 2,7 bis 4,5 Millionen an. ${ }^{337}$

In den anschließenden Fragen und Aufgaben zum Kapitel sollen sich die Schüler zusätzlich mit der Frage nach den Ursachen der Hungersnot, mit der Frage, wie der Hunger in der Ukraine genannt wird, und der Frage, ob der Hunger mit der nationalen Zugehörigkeit der betroffenen Bevölkerung in $\mathrm{Zu}$ sammenhang stand, auseinandersetzen. Auch wenn hier abschließend interessante Fragen an das Kapitel gestellt werden, bleiben diejenigen Aspekte der Kollektivierung unterbelichtet, die sich nicht in eine positive Modernisierungsgeschichte einfügen - nicht zuletzt, weil das Kapitel beispielsweise die genannten Fragen weder beantwortet noch behandelt.

334 Vgl. Volobuev, Oleg: Istorija Rossii. Načalo XX - načalo XI v. 10 kl. Učebnik. Drofa, Moskau 2016, 99.

335 Vgl. ebd., 109.

336 Ebd., 106.

337 Vgl. ebd., 106. 
Deutlich ausführlicher und differenzierter werden diese Themen bei Gorinov dargestellt. Im Kapitel »Die große Wende - Industrialisierung" wird zunächst im Kontext der stalinschen Industrialisierung die Schaffung des Systems der Zwangsarbeit beschrieben ${ }^{338}$ und dann später in einem weiteren Kapitel über »Preis und Kosten der Industrialisierung « weiter ausgeführt. ${ }^{339}$ Hier wird die Bedeutung der Zwangsarbeit in vielen Bereichen der Modernisierung und Industrialisierung wesentlich deutlicher als bei Volobuev.

Auch die Darstellung der Kollektivierung und ihrer Folgen fällt bei Gorinov differenzierter aus. Der Hunger und seine Ursachen werden in einem eigenen Unterkapitel behandelt.

"Zu einem bedeutenden Teil wurde der Hunger durch die Macht provoziert. [...] Ungeachtet der Dimension des Hungers, wurden 18 Millionen Zentner Korn ausgeführt, um für die Industrialisierung benötigte Devisen zu bekommen. Am Hunger starben bis zu sieben Millionen Menschen in verschiedenen Teilen der UdSSR.. ${ }^{340}$

Auch der rechtliche Status der Kolchos-Bauern wird thematisiert und mit der Leibeigenschaft in Verbindung gebracht. ${ }^{341}$ Das Prinzip einer glatten, erfolgreichen Modernisierungsgeschichte wird zudem aufgebrochen, indem der deutliche Bevölkerungsrückgang zwischen 1926 und 1937 dargestellt wird ${ }^{342}$ und Quellen zur Hungersnot ${ }^{343}$ und zur Entkulakisierung ${ }^{344}$ abgedruckt werden. Sowohl Gorinov als auch Volobuev stellen politischen Terror und Massenrepressionen in einem eigenen Kapitel dar. ${ }^{345}$

\subsubsection{Der Große Vaterländische Krieg}

Der Große Vaterländische Krieg wird in beiden Linien entlang des in den Schulbüchern nicht nur der Vorgängergeneration etablierten militärisch-heroischen Narrativs dargestellt. Bei Volobuev trägt das Kapitel den Namen »Großer. Va-

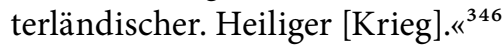

338 Vgl. Gorinov, Michail: Istorija Rossii. 10 kl. Učebnik. Čast' 1. Prosveščenie, Moskau 2016, 127.

339 Vgl. ebd., 129.

340 Ebd., 138.

341 Vgl. ebd., 140.

342 Vgl. ebd., 138.

343 Vgl. ebd., 138.

344 Vgl. ebd., 141.

345 Vgl. ebd., 144 ff. und Volobuev, Oleg: Istorija Rossii. Načalo XX - načalo XI v. 10 kl. Učebnik. Drofa, Moskau 2016, $113 \mathrm{ff}$.

346 Volobuev, Oleg: Istorija Rossii. Načalo XX - načalo XI v. 10 kl. Učebnik. Drofa, Moskau 2016, 152. 
Obwohl der historisch-kulturelle Standard in seiner finalen Version die Berücksichtigung des geheimen Zusatzprotokolls des deutsch-sowjetischen Nichtangriffsvertrages nicht mehr vorgibt, findet es sowohl bei Gorinov als auch bei Volobuev ausführliche Erwähnung und wird in Auszügen abgedruckt. ${ }^{347}$ In der Darstellung wird darauf verwiesen, dass der Nichtangriffsvertrag zwar der Sowjetunion Zeit verschaffte habe, aber auch allgemein "als 'grünes Licht`für die hitlersche Aggression gegen Polen ${ }^{348}$ verstanden worden sei und günstige Bedingungen für die deutschen Kriegspläne geschaffen habe. Volobuev erweitert die Perspektive über den Horizont des sowjetischen Narrativs hinaus. So beschreibt er, dass der "Befreiungsfeldzug " ${ }^{349}$ der Roten Armee von Polen als erneute Polnische Teilung betrachtet wurde, die Liquidierung Polens als Staat bedeutete und für die »neue Bevölkerung« wiederholte Wellen der Repressionen und Deportationen nach sich zog. ${ }^{350}$

Während das Schicksal der polnischen Offiziere in sowjetischer Gefangenschaft bei Gorinov lediglich in zwei Sätzen behandelt wird, ${ }^{351}$ geht Volobuev ausführlicher auf die Massenerschießungen u. a. in Katyn ein. Er thematisiert zudem die Verschleierung der Schuld durch die Sowjetunion, den ersten Wandel während der Perestrojka und schließt den Abschnitt mit dem Hinweis auf die Erklärung der Staatsduma über die Anerkennung der Massenerschießungen als Verbrechen des stalinistischen Regimes im Jahr 2010. ${ }^{352}$

In der Darstellung des Krieges wie auch der Sowjetunion nach dem Krieg gibt es fast keine auffälligen Veränderungen zur Vorgängergeneration. Lediglich in der Beschreibung der Geschichte ab Mitte der 1960er Jahre fällt auf, dass sowohl Volobuev als auch Gorinov - entsprechend der Vorgabe aus dem Standard - die Dissidentenbewegung breit thematisieren. ${ }^{353}$

347 Vgl. Gorinov, Michail: Istorija Rossii. 10 kl. Učebnik. Čast' 1. Prosveščenie, Moskau 2016, 172, 174 und Volobuev, Oleg: Istorija Rossii. Načalo XX - načalo XI v. 10 kl. Učebnik. Drofa, Moskau 2016, $138 \mathrm{ff}$., 140.

348 Gorinov, Michail: Istorija Rossii. 10 kl. Učebnik. Čast' 1. Prosveščenie, Moskau 2016, 139.

349 Der Ausdruck wird im Schulbuch als Quellenbegriff kenntlich gemacht. Volobuev, Oleg: Istorija Rossii. Načalo XX - načalo XI v. 10 kl. Učebnik. Drofa, Moskau 2016, 142.

350 Vgl. Volobuev, Oleg: Istorija Rossii. Načalo XX - načalo XI v. 10 kl. Učebnik. Drofa, Moskau 2016, $142 \mathrm{f}$.

351 Vgl. Gorinov, Michail: Istorija Rossii. 10 kl. Učebnik. Čast’ 2. Prosveščenie, Moskau 2016, 4.

352 Vgl. Volobuev, Oleg: Istorija Rossii. Načalo XX - načalo XI v. 10 kl. Učebnik. Drofa, Moskau 2016, $144 \mathrm{f}$.

353 Ebd., 167 ff. und Gorinov, Michail: Istorija Rossii. 10 kl. Učebnik. Čast’ 2. Prosveščenie, Moskau 2016, $265 \mathrm{ff}$. 


\subsubsection{Neueste Geschichte in den Büchern 2015/2016}

Aufgrund der verschiedenen Vorgaben und staatlichen Eingriffe mit Bezug auf die 2000er Jahre ist die Darstellung dieser Epoche in den neuen Büchern von besonderem Interesse. In beiden Büchern ist die Darstellung der politischen und wirtschaftlichen Entwicklung der 2000er Jahre sehr knapp gehalten und verzichtet weitgehend auf patriotisches Pathos. Im Vergleich zur Vorgängergeneration sind beide eher als unkritisch einzustufen, auch wenn sie in Tonlage und Inhalt bei weitem nicht den Affirmationsgrad von Filippovs > Geschichte Russlands $1945-2008{ }^{354}$ erreichen.

Die politische, gesellschaftliche und wirtschaftliche Entwicklung wird als Konsolidierung bzw. Stärkung dargestellt, die auf politische Reformen der Putin-Administration zurückgeführt wird. ${ }^{355}$ Auf externe Faktoren wird vor allem im Zusammenhang mit Krisen verwiesen. Viele Themen wie die Rohstoffabhängigkeit der Wirtschaft, das Wohlstandsgefälle oder der staatliche Zugriff auf Medien werden angerissen, aber nicht kritisch eingeordnet. Volobuev berücksichtigt kritische Aspekte - z.B. der Wirtschaftspolitik - häufig nicht im Text, sondern in Fragen zum Kapitel. ${ }^{356}$ Sein Text gibt jedoch keine Antworten auf die Fragen. Nur in Bezug auf die "schweren politischen und wirtschaftlichen Schwierigkeiten « ${ }^{357}$ durch die westlichen Sanktionen 2014 verweist Volobuev darauf, dass diese keinen Einfluss auf das hohe Rating Vladimir Putins hatten, obwohl dieser 2002 demokratische Entwicklung, Rechtsstaat und Verbesserung des Lebensstandards der Bevölkerung zu seinen Prioritäten erklärt habe. ${ }^{358}$

Besonders fällt ins Auge, dass beide Bücher über den im Standard vorgeschriebenen Zeitraum - bis zu den Präsidentschaftswahlen 2012 - hinausgehen. So endet Gorinov mit einem kurzen Abschnitt über die »Wiedervereinigung der Krim mit Russland $\aleph^{359}$ und der entsprechenden Passage aus Vladimir Putins außerplanmäßiger Rede vor der Föderalversammlung am 18. März 2014. Als Ursache der Ereignisse führt er aus, dass in Kiew Anfang 2014 Nationalisten an die Macht gekommen seien, die die Abschaffung des Gesetzes über die Stellung der russischen Sprache vorgeschlagen hätten, was dem Autor zufolge ein faktisches Verbot des Gebrauchs der Sprache bedeutet

354 Filippov, Aleksandr: Istorija Rossii 1945-2008, Prosveščenie, Moskau 2009.

355 Vgl. Volobuev, Oleg: Istorija Rossii. Načalo XX - načalo XI v. 10 kl. Učebnik. Drofa, Moskau 2016, 318 ff. und Gorinov, Michail: Istorija Rossii. 10 kl. Učebnik. Čast’ 3. Prosveščenie, Moskau 2016, $76 \mathrm{ff}$.

356 Vgl. z. B. Volobuev, Oleg: Istorija Rossii. Načalo XX - načalo XI v. 10 kl. Učebnik. Drofa, Moskau 2016, 329.

357 Ebd., 325.

358 Ebd., $325 \mathrm{f}$.

359 Gorinov, Michail: Istorija Rossii. 10 kl. Učebnik. Čast’ 3. Prosveščenie, Moskau 2016, 104. 
habe. Als Reaktion habe sich im Süden und Südosten der Ukraine die russischsprachige Bevölkerung für ihre Rechte eingesetzt und in einem Referendum habe sich die Bevölkerung der Krim und Sewastopols für den Beitritt zu Russland entschieden, dem entsprochen worden sei. ${ }^{360}$

Bei Volobuev wird die Vorgeschichte wesentlich differenzierter dargestellt.

»Korruption und autoritäre Allüren des Präsidenten Janukovič, der Unwillen sich mit örtlichen Eliten vor dem Hintergrund des niedrigen Lebensstandards der Bevölkerung zu einigen, führte in der Ukraine zu einer Entfremdung der Macht von der Gesellschaft und der Gesellschaft von der Macht. Die Macht begann Fehler zu machen, darunter insbesondere die Aufhebung der Verfassung von 2004 und die Verurteilung von Ju. Timošenko. ${ }^{361}$

Auch die Beschreibung des Maidans ist - vor dem Hintergrund der Berichterstattung der meisten russländischen Medien - fast wohlwollend geschrieben. Der Maidan wird als Massenprotest gegen Janukovič charakterisiert, der von der Opposition angeführt wurde. ${ }^{362}$

Die Beschreibung der "Aufnahme der Krim in den Bestand der Russländischen Föderation ${ }^{363}$ entspricht den Darstellungen der Russländischen Führung. Allerdings wird zudem die Erklärung der westlichen Staaten über die »Annexion der Krim ${ }^{364}$ vorgestellt. Die offizielle russländische wie auch die "westliche« Sichtweise werden als Aufgabe zur Diskussion gestellt:

"Wie bewerten Sie die Wiedervereinigung der Krim mit Russland? Bringen Sie mindesten drei Argumente für und gegen jede der beiden Positionen.. ${ }^{365}$

\subsubsection{Resümee: Die aktuellen Schulbücher}

Bei der Betrachtung der beiden vollständigen Schulbuchlinien, die nach den Vorgaben der historisch-kulturellen Konzeption verfasst wurden, fällt vor allem für das 20. Jahrhundert die klare Orientierung an der Periodisierung ins Auge. Andere Aspekte des Konzepts, wie die militärisch-patriotische Ausrichtung, mussten nicht gesondert implementiert werden - sie waren bereits in der Vorgängergeneration fast durchgängig enthalten und durch die föderale Komponente der Bildungsstandards vorgegeben.

360 Vgl. ebd., 104.

361 Volobuev, Oleg: Istorija Rossii. Načalo XX - načalo XI v. 10 kl. Učebnik. Drofa, Moskau $2016,341$.

362 Vgl. ebd., 341.

363 Ebd., 342.

364 Ebd., 342.

365 Ebd., 343. 
Ergänzungen lassen sich in der Berücksichtigung der Multiethnizität der Russländischen Föderation feststellen. Jedoch sind diese Ansätze häufig kaum integriert und konzeptionell wenig überzeugend. Ein Grund hierfür ist in der Konzeption selbst angelegt: Die geschichtlichen Perspektiven unterschiedlicher Ethnien sollen zwar einfließen, die Grundpfeiler der moskau-zentrischen Perspektive, gerade in der Ausweitung des Staates, aber unberührt bleiben. Deutlich ist, dass Aspekte, die im Standard hervorgehoben werden - wie etwa die Dissidentenbewegung - auch in den Büchern breiter berücksichtigt sind.

Insgesamt lässt sich aber weder ein deutlicher Umbau der etablierten Narrative noch eine neue perspektivische Festlegung in den aktuellen Schulbüchern feststellen. Dafür fehlen schon in der geschichts-kulturellen Konzeption klare Vorgaben. Besonders in der Prosveščenie-Linie werden die sschwierigen Fragen aus der Konzeption immer wieder kenntlich gemacht, indem verschiedene Historikermeinungen nebeneinander gestellt werden.

Auch im Vergleich der beiden Linien miteinander wird klar, dass es durchaus gravierende Unterschiede in der Darstellung und Deutung der Geschichte gibt. Die beiden Linien sind weit davon entfernt, ein getarntes Einheitsbuch zu sein, das von zwei Verlagen herausgegeben wird.

Dennoch hat sich in den Büchern durch Orientierung an den Vorgaben die Darstellung von Geschichte vereinheitlicht. Der wichtigste Grund für die Verringerung der Pluralität liegt jedoch im rigiden Zulassungsverfahren begründet: In der Vorgängergeneration bestand zumindest formal eine breite Auswahl an Lehrbüchern. Für die zehnte Klasse hat sich diese Auswahl auf zwei Bücher reduziert. Nicht zuletzt die affirmative Darstellung des 21. Jahrhunderts in diesen beiden Büchern macht den Verlust an unterschiedlichen Perspektiven in der neuen Schulbuchgeneration deutlich.

Die Wiederherstellung eines breiteren Spektrums von verschiedenen Büchern durch die Zulassung weiterer Linien, aber auch inhaltlich in der Darstellung von Geschichte ist formal entsprechend der Rechtsakte und inhaltlichen Vorgaben möglich. Die Zulassungsverzeichnisse der kommenden Jahre werden zeigen, ob dies politisch gewollt ist.

Die vollständige Übernahme des großen Schulbuchverlags Ventana-Graf durch die verkaufsstärkste Verlagsgruppe Russlands, Ěksmo-Ast, Ende 2015, deutet darauf hin, dass dem Schulbuchmarkt zumindest in kommerzieller Hinsicht eine Zukunft gegeben wird. ${ }^{366}$ diroval »Ventanu-Graf«. In: Kommersant«. Nr. 204 vom 06.11.2015, 12. Online: http:// kommersant.ru/doc/2847419. 


\subsection{Zusammenfassung: Bildungspolitik und Schulbücher}

In den 1990er hatte sich der Staat weit aus der Bildungspolitik zurückgezogen. Viele Anpassungen an die neue Verfassungsrealität wurden nicht vorgenommen oder umgesetzt. Für den Bereich der Schulbücher hatte das Vor- und Nachteile: Auf der einen Seite konnten sich die Schulbücher für den Geschichtsunterricht sehr frei entwickeln und so auch das breite und widersprüchliche Spektrum von Geschichtsbetrachtungen in der Gesellschaft abbilden. Auf der anderen Seite waren die Lehrbücher fast durchgängig schlecht auf die Erfordernisse des Unterrichts und die Bedürfnisse der Schüler abgestimmt.

In den 2000er Jahren kam der Bildungspolitik ein höherer Stellenwert zu: die Stagnation der Bildungspolitik ging direkt in eine Phase permanenter Reformen über. Die politische Führung machte zudem ihren Gestaltungsanspruch bis in die Inhalte des Geschichtsunterrichts hinein deutlich. Im Zusammenspiel mit der geschichtlich grundierten Patriotischen Erziehung sollte auch der Geschichtsunterricht seinen Beitrag leisten, um bei den »jungen Menschen das Gefühl des Stolzes für die Geschichte des Vaterlands, für seine Heimat [zu] erzeugen. ${ }^{367}$ Dieser Zugriff auf die Geschichte wurde durch die föderale Komponente der Bildungsstandards im Jahr 2004 institutionalisiert.

Schon 2003 war einem Schulbuch, das die Gegenwart in ein sehr kritisches Licht gerückt hatte, exemplarisch und öffentlich die staatliche Empfehlung entzogen worden. Die Bildungsstandards von 2004 machten die positive Darstellung der 2000er Jahre dann zur offiziellen Vorgabe. In der Praxis führten diese Eingriffe jedoch nicht zu einer durchgängigen Vereinheitlichung der Geschichtsdeutungen in den Schulbüchern.

Zehn Jahre nach Putins Worten zur erschaffend-schöpferischen und patriotischen Funktion von Schulbüchern, forderte er 2013 - wieder öffentlichkeitswirksam - einheitliche Schulbücher ohne innere Widersprüche und doppeldeutige Interpretationen. Die folgende Ausarbeitung eines Lehrmethoden-Komplex erfüllte diese Forderung nicht. Die beteiligten Akteure hatten kein Interesse, ein eindeutiges offizielles Geschichtsbild über 1000 Jahre festzuschreiben. Inhaltlich stellt die Konzeption weniger ein neues russländisches Geschichtsbild als eine Dokumentation des kleinsten gemeinsamen Nenners der etablierten Geschichtswissenschaft unter besonderer Erwähnung nichtkonsensualer Bereiche dar. Ihre Wirkung wird die Konzeption daher weniger durch offizielle Deutungen als durch methodische und strukturelle Vorgaben entfalten.

367 Putin, Vladimir: Vstupitel'noe slovo na vstreče s učenymi-istorikami. 27 nojabrja 2003 goda, Moskva. Online: http://www.kremlin.ru/events/president/transcripts/22227 
Durch das neue Zulassungsverfahren, das auf der Konzeption basiert, hat sich die Auswahl an Büchern für das Schuljahr 2015/2016 drastisch reduziert. Auch wenn sich die beiden zugelassenen vollständigen Linien voneinander unterscheiden und kein getarntes Einheitsschulbuch darstellen, so ist das Spektrum von unterschiedlichen Lehrbüchern einem »entweder-oder" gewichen. Ob diese Verengung auf Dauer politisch gewollt ist oder nicht, werden die kommenden Zulassungslisten zeigen.

Noch während das Bildungsministerium Mitte Mai 2015 die neuen Schulbuchlinien vorstellte, kam aus den Reihen von Edinaja Rossija bereits der nächste Vorstoß in Richtung eines Einheitsbuches. ${ }^{368}$ Hier zeigen sich Interessenkonflikte innerhalb des Regierungslagers in Bezug auf einheitliche Schulbücher. In der Bevölkerung zeichnet sich Levada-Umfragen zufolge seit einigen Jahren eine zunehmende Zustimmung zu Einheitsbüchern in einigen Fächern $a b{ }^{369}$ Forderungen, zu einem einheitlichen verbindlichen Schulgeschichtsbuch zurückzukehren und ein eindeutiges offizielles Geschichtsbild durchzusetzen, werden daher auch in Zukunft die Agenda bestimmen.

368 Afanas'eva, Anna/Chamraev, Viktor: Odin predmet - odin učebnik. Deputaty vnov' pravjat zakon »Ob obrazovanii«. Kommersant«. Nr. 81 vom 13.05.2015, 4. Online: http:// kommersant.ru/doc/2725058.

369 Elkina, Marija: EGĖ okončatel'no razočaroval rossijan. Izvestija, 3. Juni 2015. Online: http://izvestia.ru/news/587305. 



\section{Erinnerungspolitik in Präsidentenreden}

\subsection{Formen der Erinnerungspolitik in öffentlichen Reden}

Erinnerungspolitische Passagen in Reden offizieller Repräsentanten und ganz besonders in Präsidentenreden sind durch ihre hohe Reichweite in verschiedener Hinsicht von besonderem Interesse für die umfassende Analyse von Erinnerungspolitik. ${ }^{1}$ Sie stellen das direkteste Instrument dar, um Narrative in einer bestimmten Weise zu präsentieren, zu popularisieren und mit einer spezifischen Bedeutung für die Gegenwart zu funktionalisieren. Bei Boris El'cin kam dem Geschichtsbezug in Reden noch eine nachgeordnete Bedeutung zu. Vladimir Putin dagegen erklärte die Geschichte von Beginn an zu einem Bezugspunkt für seine Politik. Bereits in seiner Inaugurationsrede im Jahr 2000 wird diese Ausrichtung deutlich:

»Hier im Kreml, dem Zentrum unseres nationalen Gedächtnisses, in den Mauern des Kremls ereignete sich über Jahrhunderte die Geschichte unseres Landes, und wir dürfen keine Ivane sein, die ihre Herkunft nicht kennen. Wir dürfen nichts vergessen, wir müssen unsere Geschichte kennen; so wie sie ist, müssen wir Lehren aus ihr ziehen und uns immer an jene erinnern, die den russländischen Staat geschaffen haben, seine Würde verteidigt und ihn zu einem großen, mächtigen und kraftvollen Staat gemacht haben. Wir bewahren dieses Andenken und wir bewahren diese Verbindung der Zeiten - und das Beste aus unserer Geschichte geben wir an unsere Nachfahren weiter. « ${ }^{2}$

Dieser Auszug aus Putins Inaugurationsrede lässt sich als ein Grundsatzprogramm für die Ausrichtung der Erinnerungspolitik in seinen folgenden Präsidentschaften deuten. Von der Geschichtsvergessenheit als Schwäche über die Notwendigkeit, aus der gesamten Geschichte Lehren für die Gegenwart zu ziehen, bis hin zum Topos der Verbindung der Zeiten, dem Bekenntnis zu russländischer Kontinuität über alle Brüche hinweg, sind bereits die wichtigsten Eckpfeiler enthalten. ${ }^{3}$ Die Ausrichtung der Erinnerungspolitik auf

1 Vgl. Jaworski, Rudolf: Jubiläen und Gedenktage im östlichen Europa - Versuch einer einordnenden Betrachtung. In: Jaworski, Rudolf/Kusber, Jan (Hg.): Erinnern mit Hindernissen. Osteuropäische Gedenktage und Jubiläen im 20. und zu Beginn des 21. Jahrhunderts. Münster 2011, $17 \mathrm{f}$.

2 Putin, Vladimir: Vystuplenie na ceremonii vstuplenija v dolžnost' Prezidenta Rossii. 7 maja 2000 goda. Moskva. Online: http://kremlin.ru/events/president/transcripts/21399.

3 Insbesondere bei `Verbindung der Zeiten handelt es sich um Begriffe, die schon in der späten Sowjetunion und den ersten post- 
diejenigen, die das Land geschaffen, groß gemacht und verteidigt haben, trägt bereits grundlegend den Fokus auf den militärischen Ruhm in allen Zeiten als verbindendes Element in sich.

Diese beiden Elemente - militärischer Ruhm und die Verbindung der Zeiten - machen den Anknüpfungspunkt seiner Rede deutlich: Beide Elemente sind wichtige Teile der Rede Boris El'cins am 9. Mai 1996. ${ }^{4}$

Für die Reden der russländischen Präsidenten ist die Referentur zuständig, eine Abteilung der Präsidialadministration. Derzeit besteht die Referentur unter der Leitung von Dmitrij Kalimulin aus den zwei Oberreferenten Jaroslav Šabanov und Larisa Mišustina sowie aus den drei übrigen Referenten Natal'ja Melikova, Tat'jana Trubinova und Ekaterina Chutorskaja. Über die derzeitigen inneren Abläufe, die Entstehungsprozesse der Reden oder auch die jeweilige Urheberschaft gibt die Kreml-Administration keine Auskünfte. ${ }^{5}$ Aus Beiträgen ehemaliger Redenschreiber - sogenannter Spičrajtery - geht hervor, dass die Ausarbeitung der Reden häufig in Zusammenarbeit mit entsprechenden Fachreferaten der Ministerien und im Falle der Rede des Präsidenten vor der Föderalversammlung in einem engen Austauschprozess zwischen Referentur und der Regierung entsteht. ${ }^{6}$ Das Personal der Referentur weist ein hohes Maß an Kontinuität auf, die jedoch auch personenbezogen ist. ${ }^{7}$ Der derzeitige Leiter war schon seit 1997 als Berater der Referentur unter Boris El'cin tätig.

Für erinnerungspolitische Analysen sind in besonderem Maße Reden von Interesse, die Jahr für Jahr, d. h. in bestimmter Regelmäßigkeit zu bestimmten Anlässen gehalten werden. Sie bieten die Chance, die Ausrichtung staatlicher Erinnerungspolitik über einen längeren Zeitraum in ihren Kontinuitäten, aber vor allem auch in ihrem Wandel sichtbar zu machen. Zum einen können sich die Rückgriffe auf die Geschichte ändern: Je nach Redeformat kann sich der geschichtliche Bezugspunkt als Ganzes oder die Ausgestaltung des präsen-

sowjetischen Jahren im Geschichtsdiskurs präsent waren. Vgl. de Keghel, Isabelle: Die Rekonstruktion der vorsowjetischen Geschichte. Identitätsdiskurse im neuen Russland. Hamburg 2006, $137 \mathrm{f}$.

4 Fernsehübertragung. Telekanal ORT: Voennyj parad vojsk na Krasnoj ploščadi. 09.05.1996, $9.00 \mathrm{Uhr}$.

5 Einige Hinweise enthält eine Analyse der Novaja Gazeta, die sich auf anonyme Informanten stützt: Kolesnikov, Andrej: Spičrajtery prezidenta Vladimira Putina: »Začem nužny èti 6 let?«. Novaja Gazeta. Nr. 104 vom 14.09.2012, 2-3.

6 Vgl. Kolesnikov, Andrej: Spičrajtery: chroniki professii, sočinjavšej i izmenjavšej mir Spičrajtery: chronika professii, sočinjavšej i izmenjavšej mir. Moskau 2007, 252 ff.

7 Der derzeitige Leiter der Referentur war schon unter El'cin beratender Referent, während der ersten Präsidentschaft Putins einfacher Referent und während der zweiten Präsidentschaft Oberreferent. Er wechselte mit Putin zur Regierung und kehrte 2012 zurück in die Präsidialadministration. 
tierten Narrativs ändern. Zum anderen kann sich die Bedeutung verändern, die dem Narrativ für die Gegenwart zugeschrieben wird.

Eine ausschließlich nach erinnerungspolitischen Themen strukturierte Analyse von Reden läuft sowohl Gefahr, diese mehrschichtigen Dynamiken zu vernachlässigen, als auch das jeweilige Redeformat als Einflussfaktor zu gering zu gewichten. Einige Schwerpunkte werden jedoch im Anschluss an die Reden vorgestellt.

Die im Folgenden präsentierten Redeformate teilen sich einige Eigenschaften: Sie sind die zentralen Formate, in denen die Bedeutung der Geschichte für die Gegenwart formuliert wird, in denen an den geschichtlichen Narrativen gearbeitet wird und die über Jahre einen stabilen Charakter aufweisen.

Die Reden anlässlich der Paraden zum Tag des Sieges nehmen eine hervorgehobene Position ein: Ausgestattet mit einem definierten geschichtlichen Bezugspunkt, zählen sie zu den wichtigsten Anlässen an denen das Kriegsgedenken aktualisiert wird. Sie vereinen in sich die meisten Aspekte, die, auch über den Großen Vaterländischen Krieg hinaus, prägend sind für eine Erinnerungspolitik, die sich zu einem wichtigen Teil auf militärischen Ruhm gründet. Um die Kontinuitäten und Dynamiken des Formats, aber auch seine große Bedeutung in der Gegenwart zu erfassen, werden auch die Entwicklungen des Formats in den 1990er Jahren und in der Sowjetunion berücksichtigt. Über die Reden hinaus zeigen hier auch das diskursive Umfeld, die Festpraxis und die symbolische Ausgestaltung Faktoren auf, die bis in die Gegenwart hinein prägend für die Reden und Feierlichkeiten am 9. Mai sind.

Auch den Reden vor der Föderalversammlung kommt eine besondere erinnerungspolitische Bedeutung zu. In der Begründung von Regierungspolitik kommen regelmäßig auch Geschichtsbezüge zum Ausdruck. So waren die Reden vor der Föderalversammlung über Jahre ein Anlass, am Narrativ über die 1990er Jahre zu arbeiten, und auch einer der Orte, an denen die neue patriotische, an shistorischen Werten orientierte Ausrichtung ab dem Jahr 2012 deutlichen Niederschlag fand.

Weitere Reden, z. B. am Tag des Vaterlandsverteidigers, am Tag der Einheit des Volkes oder am Tag Russlands, können auf einer weniger öffentlichkeitswirksamen Ebene einen Blick auf die Arbeit an Narrativen und Bedeutungszuweisungen eröffnen. 


\subsection{Der 9. Mai in Präsidentenreden: Die Siegesparaden bis 1999}

Der Tag des Sieges ist im heutigen Russland einer der zentralen Feiertage und auch einer der Tage, an denen durchgängig auf eine spezifische Bedeutung der Geschichte für die Gegenwart verwiesen wird. Die Parade an diesem Tag und die Ansprache des Präsidenten nehmen einen großen Raum in der Berichterstattung vor, während und nach dem 9. Mai ein. Der Tag der Unterzeichnung der Kapitulation der deutschen Streitkräfte hatte jedoch im Laufe der Zeit ganz unterschiedliche Funktionalisierungen im russländischen wie auch im sowjetischen Gedenkkalender.

Im Jahr 1945 war die >Parade des Sieges` am 24. Juni auf dem Roten Platz in Moskau die zentrale und groß orchestrierte Feier des Sieges. Die Bezeichnung und auch die Ausgestaltung dieser Feier wurden später immer wieder in unterschiedlichen Variationen aufgegriffen. Zunächst wurde der Tag der deutschen Kapitulation in der Sowjetunion lediglich in den ersten beiden Nachkriegsjahren, 1946 und 1947, als arbeitsfreier Tag des Sieges gefeiert. ${ }^{8}$ Im Dezember 1947 wurde der 9. Mai wieder zum Arbeitstag erklärt, der zwar seinen Status als Tag des Sieges behielt, jedoch in der Folge erheblich an Bedeutung verlor. ${ }^{9}$ Auch insgesamt wurde die Erinnerung an den Krieg von offizieller Seite aus weitgehend ausgeblendet. ${ }^{10}$

Erst 1965 wurde der Tag wieder arbeitsfrei ${ }^{11}$ und im Kontext der sneuen Kriegserinnerung unter Leonid Brežnev ${ }^{12}$ aufwendig begangen. Die Parade am 9. Mai 1965 gab in ihren Abläufen weitgehend den Rahmen für die Chronologie der folgenden Paraden vor: Die einzelnen auf dem Platz wartenden Truppenteile wurden begrüßt, dann machte der Kommandeur der Parade Meldung beim Oberkommandierenden, anschließend folgte eine Rede des Verteidigungsministers, Rodion Malinovskij. Abschließend folgte die eigentliche Parade: Die auf dem Platz versammelten Soldaten marschierten an der Tribüne vorbei. Dann folgten verschiedene Militärfahrzeuge - Lastwagen, Truppentransporter, Panzer, Artillerie, Geschütze, Luftabwehr und Raketensysteme.

8 Ukaz Prezidiuma Verchovnogo Soveta SSSR ot 8 maja 1945 g. »Ob ob”javlenii 9 maja Prazdnikom Pobedy«.

9 Vedomosti Verchovnogo Soveta Sovetskich Socialističeskich Respublik. Nr. 45 (499) vom 26.12.1947. An Stelle des 9. Mai wurde der 1. Januar arbeitsfrei.

10 Vgl. Karl, Lars: `Der Tag des Sieges in der Sowjetunion: Inszenierung eines politischen Mythos. Magisterarbeit. Tübingen 1999, 19 ff.; Rolf, Malte: Das Sowjetische Massenfest. Hamburg 2006, 328.

11 Vedomosti Verchovnogo Soveta SSSR. Nr. 17 (1260) vom 28.04.1965.

12 Zur allgemeinen Beschaffenheit des Diskurses unter Brežnev vgl. Yurchak, Alexei: Everything was forever, until it was no more: the last Soviet generation. Princeton 2005. 
Das Vorbild der Rede Rodion Malinovskijs ist die Rede Georgij Žukovs bei der Siegesparade 1945. Auch wenn die äußeren Umstände der Rede im Rahmen der Parade ähnlich arrangiert waren, so unterscheiden sich die Reden inhaltlich deutlich. Žukov hielt 1945 primär eine Lobrede auf Stalin:

»Wir haben gesiegt, weil uns unser großer Führer, der geniale Feldherr und Marschall der Sowjetunion, zum Sieg führte - Stalin! ${ }^{13}$

Weitere Faktoren des Sieges, wie etwa die Stärke der Roten Armee, nahmen dagegen nur sehr geringen Raum ein. Zwar wurden zum Ende hin die Kämpfer, das 'große sowjetische Siegervolkı und die `Partei Lenins und Stalins` geehrt, die letzten Worte waren jedoch wieder Stalin, dem »weisen Führer und Feldherrn ${ }^{14}$, gewidmet.

Bemerkenswert an Malinovskijs Rede 1965 ist die Neuzuschreibung der »Urheber« des Sieges und die vollständige Ausblendung Stalins: An erster Stelle stehen nun Kämpfer, Kommandeure und Politarbeiter sowie die Überlegenheit der sowjetischen Militärkunst und Ideologie. ${ }^{15}$ Ein hoher Stellenwert wird nun aber auch dem Patriotismus und den Anstrengungen der Gemeinschaft im Hinterland zugeschrieben - den Arbeitern und Bauern, der Intelligenzija, den sowjetische Frauen und der Jugend. ${ }^{16}$ Die Rolle der Partei »als Seele und Organisatorin des Heldenhaften Kampfes ${ }^{17}$ hat einen ähnlichem Stellenwert wie zwanzig Jahre zuvor in der Rede Žukovs.

Das Narrativ von der "hohen sowjetischen Kriegskunst« und der Stärke, die aus der Gemeinschaft von Werktätigen, Bauern, Intelligenzija, Partisanen und Untergrund resultiert, prägte über Jahrzehnte die Kriegserinnerung, und gerades dieses Narrativ wurde während der Präsidentschaften Boris El'cins und seiner Nachfolger in verschiedenen Variationen aktualisiert.

Die Parade 1965 zum 20. Jahrestag des Sieges war zur damaligen Zeit weder die zentrale sowjetische Militärparade noch ein Anlass, der regelmäßig begangen wurde. Die nächste groß orchestrierte Parade am Tag des Sieges fand erst wieder 1985 statt. Die regelmäßigen Großparaden in dieser Zeit waren die Paraden zum Tag der Arbeit am 1. Mai und dem Tag der Großen Sozialistischen Oktoberrevolution am 7. November. Beide Feste sind in den Jahrzehnten nach dem Krieg jährliche Anlässe für große Militärparaden, bei denen sowohl die Ausstattung der Bodentruppen als auch die aktuelle Militärtechnik präsentiert werden.

Ab Ende der 1960er wurden die Feierlichkeiten zum 1. Mai umgestaltet bzw. der militärische Charakter wurde zugunsten eines sozialistischen und

13 Pravda. Nr. 151 (9922) vom 25.06.1945, 3.

14 Ebd., 3.

15 Vgl. Pravda. Nr. 130 (17082) vom 10.05.1965, 2.

16 Vgl. ebd., 2.

17 Ebd., 2. 
internationalistischen Festes zurückgedrängt. Das Motiv der Völkerfreundschaft wurde zunehmend betont.

Mit einer ähnlichen Tendenz wurden auch die Feierlichkeiten zum 30. Jahrestag des Sieges 1975 begangen. Es fand keine Militärparade statt, sondern eine »feierliche Kundgebung der Jugend Moskaus ${ }^{18}$. Lediglich eine kleine Ehrenformation marschierte - nach einer Kranzniederlegung am 1967 eingeweihten >Grab des unbekannten Soldaten` - über den Roten Platz. Im Fernsehen wurde eine Entschließung des Zentralkomitees der KPdSU, des Präsidiums des Obersten Sowjet der UdSSR sowie der Regierung der UdSSR verlesen, die als Konsequenz der ‘faschistischen Zeit die Bewahrung des Friedens zur obersten Maxime erklärte und eine weitere Stärkung der gleichen Rechte und der Souveränität der Staaten, den Gewaltverzicht in den internationalen Beziehungen sowie die Fokussierung aller Kräfte auf eine friedliche Welt forderte. ${ }^{19}$

Während der 1970er Jahre blieb der Tag der Oktoberrevolution der regelmäßige Anlass für eine Militärparade, bei der bis auf wenige Ausnahmen schwere Militärtechnik präsentiert wurde. Vor allem in der Zeit der Brežnevschen Stagnation hielt man an dem sowjetischen Gründungsmythos, der ১Oktoberrevolution` fest und ergänzte ihn mit einem weiteren Mythos: Es sollte auch an die Verteidigung der Revolution gegen die faschistischen Eroberer erinnert werden, symbolisiert durch die Revolutionsparade am 7. November 1941 während der Schlacht um Moskau. ${ }^{20}$

Zum 40. Jahrestag des Sieges 1985 wurde am 9. Mai wieder eine große Militärparade abgehalten. Sie folgte der Inszenierung von 1965 - wurde jedoch um ein Reenactment-Element erweitert: Die Parade der Militärtechnik wurde eröffnet durch eine Abordnung historischer Panzer und Militärfahrzeuge des Großen Vaterländischen Krieges. Die Rede hielt Verteidigungsminister Sergej Sokolov. Michail Gorbačëv, der erst wenige Wochen zuvor zum Generalsekretär der KPdSU gewählt worden war, stand schweigend neben seinem Verteidigungsminister und nahm die Parade, umringt von den Führungskräften von Partei und Militär, auf der Tribüne des Lenin-Mausoleums ab. Seine Festrede am Abend zuvor im Kremlpalast unter dem Titel »Unsterbliche Heldentat des sowjetischen Volkes « ${ }^{21}$ setzte noch keine neuen inhaltlichen Akzente.

Sokolov interpretiert den Sieg im Großen Vaterländischen Krieg als Beweis für die Einheit von Partei und Volk, die Überlegenheit der marxistischleninistischen Ideologie sowie »der Macht und Unzerstörbarkeit des Landes der Sowjets, seiner großen ökonomischen, sozialpolitischen und geistigen Fähigkeiten." ${ }^{22}$

18 Pravda. Nr. 130 (20734) vom 10.05.1975, 2.

19 Fernsehübertragung. Kanal Televidenie SSSR: Vremja. 9. Mai 1975, 21.00 Uhr.

20 Vgl. Rolf, Malte: Das Sowjetische Massenfest. Hamburg 2006, 326.

21 Pravda. Nr. 129 (24386) vom 09.05.1985, 1 ff.

22 Ebd., 1. 
Typisch für die Reden zum 9. Mai in dieser Zeit ist auch, dass keine direkten erinnerungspolitischen Elemente enthalten sind. Die Legitimation von Gegenwart und Zukunft muss nicht aus der Geschichte abgeleitet werden, sie ist notwendige Folge der Ideologie. Genauso wie auch die >Heldentaten des sowjetischen Volkes und seiner Streitkräfte in der Geschichte notwendig aus der marxistisch-leninistischen Ideologie folgen sollten - »organisiert und inspiriert $^{23}$ von der KPdSU, »der Organisatorin aller unserer Siege! $\aleph^{24}$

Zwischen diesen zeittypischen Elementen fällt aus heutiger Sicht lediglich eine Passage über die Bestrebungen der »bourgeoisen Propaganda « ${ }^{25}$, die Geschichte des Weltkrieges zu verfälschen und die Rolle der Sowjetunion herabzuwürdigen, auf. Hier wird erstmals im Rahmen der Parade am 9. Maider Topos formuliert, der in den 2000er Jahren durch die Programme der Patriotischen Erziehung der Bürger, in Präsidentenreden und durch die Einrichtung einer Kommission beim Präsidenten im Jahre 2009 zu einem wichtigen erinnerungspolitischen Faktor in der Russländischen Föderation aufgewertet wurde. ${ }^{26}$

\subsubsection{Die Parade als Rettung für das System? Das Jahr 1990}

Bereits 1990 fand die nächste Siegesparade am 9. Mai statt. Schon die Verringerung des zeitlichen Abstands von zwanzig auf fünf Jahre gibt einen Hinweis auf die außerordentliche politische Situation und die veränderte politische Funktion der Parade. Für Michail Gorbačëv waren zunehmende Kontrollverluste bezüglich seiner Reformen und Umgestaltungen absehbar. Dies traf besonders auf die Versuche zu, die Einheit der Sowjetunion zu bewahren.

Kurz vor dem Tag des Sieges, bei der Parade zum 1. Mai 1990 auf dem Roten Platz, waren Unmutsäußerungen der Demonstranten gegenüber der Führung der Sowjetunion und nationale Forderungen nach Autonomie insbesondere der baltischen Staaten - sogenannte »extremistische Losungen ${ }^{27}$ - nicht $\mathrm{zu}$ überhören gewesen. ${ }^{28}$ Die Demonstration am 1. Mai 1990, spiegelt in ihrem Verlauf die Konflikte des politischen Umbruchs wider. Der erste Teil der De-

23 Ebd., 2.

24 Ebd., 2.

25 Ebd., 2.

26 Die Warnung vor der Verfälschung der Geschichte des Krieges ist ein wiederkehrendes Thema im Rahmen der Paraden. So auch in der Rede des Verteidigungsministers Pavel Gračëv anlässlich der Parade am 9. Mai 1995.

27 Pravda. Nr. 122 (26205) vom 02.05.1990, 1.

28 Die sowjetischen Zeitungen verzichteten weitgehend auf eine direkte Wiedergabe der Losungen - im Gegensatz zum deutschen Spiegel. Das sowjetische Fernsehen übertrug einige Minuten des sinoffiziellen Teils - bis zum plötzlichen Abbruch der Live-Sendung. Vgl. Mickiewicz, Ellen: Changing Channels. Television and the Struggle for Power in Russia. London 1999, 6. 
monstration bestand aus Vertretern der Berufsverbände und Gewerkschaften. Anders als in den vorangegangenen Jahren wurden die Repräsentanten der Sowjetunion, die sich auf der Tribüne des Lenin-Mausoleums versammelt hatten, aus diesem konservativen Spektrum durch Losungen auf Transparenten und in Reden der Gewerkschafter massiv kritisiert. Im Zentrum der Kritik standen dabei die Reformversuche - "Wir wollen Perestrojka, doch nicht zu jedem Preis $\ll^{29}$ - und das mit diesen betraute Personal: »Jagt die Dilettanten aus dem Führungsapparat! « ${ }^{30}$

Der folgende zweite Teil der Demonstration griff die Politik Gorbačëvs aus einer anderen Richtung an, mit Losungen wie "Sozialismus - Nein Danke ${ }^{31}$ oder »Marxismus-Leninismus auf den Müllhaufen der Geschichte! ${ }^{32}$. Sowohl die Losungen des ersten Teils als auch diese Losungen des zweiten Teils stellten keine prinzipiellen, sondern eher taktische Probleme für Gorbačëv dar: Sollte er sich - wie der Spiegel schrieb - »mit dem nationalen Proletariat, das den Wandel fürchtet, oder mit der liberalen Bourgeoisie, die ihn begehrt $\star^{33}$ verbünden?

Wesentlich problematischer waren Forderungen und Losungen, die sich, vor dem Hintergrund der Unabhängigkeitserklärung Litauens und der sowjetischen Rohstoffblockade, mit der Legitimität und staatlichen Integrität der Sowjetunion beschäftigten - »Nieder mit dem Reich des roten Faschismus! ${ }^{34}$ und mit der sowjetischen Rolle in diesem Konflikt: »Russische Soldaten sind keine Gendarmen des Imperiums! $\aleph^{35}$. Vielfach forderten die Demonstranten »Freiheit für Litauen! « ${ }^{36}$ oder »Verhandlungen mit dem freien Litauen ${ }^{37}$.

Die Siegesparade am 9. Mai 1990 - acht Tage später - lässt sich vor diesem Hintergrund als ein Versuch interpretieren, in einer Situation von drohender staatlicher Desintegration den Sieg im Großen Vaterländischen Krieg als verbindendes Element der verschiedenen sowjetischen Nationalitäten zu inszenieren. Die Siegesparade folgte weitgehend dem Vorbild von 1985. Lediglich eine lebendige Reenactment-Version der Befreier-Statue aus dem Treptower Park in Berlin, die nach den Ehrenformationen über den Platz gefahren wurde, stellte ein neues Element dar. Die eigentliche erinnerungspolitische Aufladung, die Begründung gegenwärtiger Politik, fand im Rahmen der Rede des Verteidigungsministers Dmitrij Jazov statt - Michail Gorbačëv stand

29 \Wir haben sie vertrieben` In: Der Spiegel. 19/1990 vom 07.05.1990, 180.

30 Ebd., 180.

31 Ebd., 180.

32 Ebd., 180.

33 Vgl. ebd., 181.

34 Ebd., 180.

35 Ebd., 180.

36 Ebd., 180.

37 Ebd., 180. 
neben Jazov, ergriff jedoch wie bei der Parade fünf Jahre zuvor nicht persönlich das Wort.

Der erinnerungspolitische Rahmen der Rede Jazovs wurde durch Michail Gorbačëvs Vortrag am Vorabend bei der Festveranstaltung im Kremlpalast vorgegeben. Diese umfangreiche Rede unter dem Titel: »Lehren des Krieges und des Sieges $^{38}$ wurde begleitend am 9. Mai in der Pravda ${ }^{39}$, in der Moskauer Abendausgabe der Izvestija sowie als Broschüre veröffentlicht.

Gorbačëv präsentiert die Einigkeit des sowjetischen Volkes als den entscheidenden Faktor für den Sieg und als Rezept, um mit den Herausforderungen der Gegenwart umzugehen - das Andenken der im Krieg gefallenen Väter und Großväter dient als Verpflichtung, deren Ideale in Gegenwart und Zukunft zu verwirklichen. ${ }^{40}$

Diese Einheit des Volkes in Krisenzeiten nimmt auch in der Rede von Verteidigungsminister Jazov bei der Parade am 9. Mai 1990 eine entscheidende Stellung ein. ${ }^{41}$ Dabei wirbt die Rede deutlich um Unterstützung für die begonnene Politik der Perestrojka.

»Das neue politische Denken, das aus der Perestrojka geboren wurde, ist zum Schlüssel zur konstruktiven Lösung der heftigen Probleme der Gegenwart geworden. ${ }^{42}$

Das Motiv der Einigkeit in Jazovs Rede richtet sich daher nicht nur abstrakt auf die Notwendigkeit der Einigkeit von Volk, Armee und Partei. Es beschwört die Einigkeit als notwendig für die Durchführung der konkreten Reformen der Perestrojka. Besonders hervorgehoben wird die Unterstützung des Volkes und der Soldaten für Entscheidungen, »die auf die Konsolidierung der Einheit der UdSSR gerichtet sind. « $^{43}$

Den Streitkräften wird in diesem Zusammenhang die Funktion zugewiesen, friedliche Rahmenbedingungen für die »revolutionäre Erneuerung der sowjetischen Gesellschaft« im Zuge der Perestrojka zu gewährleisten. ${ }^{44}$

Diese Betonung der patriotischen Pflicht der Streitkräfte, die Reformen und die Einheit abzusichern, wirkt sicherlich nicht nur aus heutiger Perspektive wie eine Drohung - der Satz erscheint wie eine direkte Antwort auf das eine Woche zuvor gezeigte Transparent einiger Demonstranten: »Russische Soldaten sind keine Gendarmen des Imperiums! $\aleph^{45}$.

38 Izvestija. Nr. 130 (23033) vom 9. Mai 1990, $1 \mathrm{f}$.

39 Pravda. Nr. 129 (26212) vom 9. Mai 1990, $1 \mathrm{f}$.

40 Vgl. Izvestija. Nr. 130 (23033) vom 9. Mai 1990, 2.

41 Vgl. Pravda. Nr. 130 (26213) vom 10. Mai 1990, 1.

42 Ebd., 1.

43 Ebd., 1.

44 Vgl. ebd., 1.

45 ,Wir haben sie vertrieben` In: Der Spiegel. 19/1990 vom 07.05.1990, 180. 
Auch wenn die erinnerungspolitische Funktion der Rede Jazovsim Vergleich zu Gorbačëvs Ansprache abgeschwächt scheint, so ist die Intention weiterhin deutlich und begründet damit eine Tradition der Rede, die sich bis heute erhalten hat: Die Legitimation von aktueller Politik im Rahmen der Siegesparade. ${ }^{46}$

Die Rede anlässlich der Parade beschwört die Einheit der Sowjetunion als historisch erprobten Weg, um mit den Herausforderungen der Gegenwart umzugehen. Die politische Linie Gorbačëvs sollte als notwendige und richtige Reaktion auf diese Herausforderungen vermittelt werden. Argumentiert wird dabei mit den »Idealen der Kriegsgeneration « und dem Anliegen, die »Früchte des Sieges ${ }^{47}$ weiterhin zu bewahren.

Der Umstand, dass trotz der angespannten Lage und Gorbačëvs thematisch engagierten Vortrags "Lehren des Krieges und des Sieges«, wie schon 1965 und 1985 der Verteidigungsminister diese Rede hielt, könnte darin begründet liegen, dass durch den Marschall der Sowjetunion Dmitrij Jazov, die Autorität, Entschlossenheit und Einheit von Politik und Militär demonstriert werden sollte. Dass diese patriotische Einheit nicht weit trug, zeigte sich ein gutes Jahr später im August 1991, als Dmitrij Jazov zu den Anführern des Putsches gegen Gorbačëv zählte.

\subsubsection{Eine Pause. Die 1990er und die Entsowjetisierung}

Nach der Parade 1990, deren großes Arrangement den speziellen Umständen geschuldet war, wurde es Anfang der 1990er Jahre zunächst wieder ruhiger um den 9. Mai. Die Feiertraditionen wurden jedoch nicht abgeschafft, sondern fanden nur viel weniger Beachtung. Auch die Siegesparaden wurden nicht abgeschafft ${ }^{48}$ - wie schon zur Sowjetzeit erfolgten sie weiterhin nicht im jährlichen Takt. ${ }^{49}$

1991 fanden wie gewohnt die Kranzniederlegungen am Grab des unbekannten Soldaten statt und in den Parks gratulierten die jüngeren Generationen den Veteranen. In Teilen der Medien veränderte sich jedoch die Perspektive auf die Feierlichkeiten: Das Leid des Krieges rückte in den Fokus. So titelte

46 Schon die Rede Malinovskijs 1965 enthielt in geringem Umfang entsprechende Elemente. Ab 1990 sind durchgängig erinnerungspolitische Elemente enthalten. Vgl. Pravda. Nr. 130 (17082) vom 10.05.1965, 2.

47 Pravda. Nr. 130 (26213) vom 10. Mai 1990, 1.

48 Die Betrachtung, dass die Siegesparaden nach 1990 abgeschafft und 1995 wieder eingeführt wurden, ist fragwürdig, da sie retrospektiv aus den späten 1990er Jahren und den 2000er Jahren von der Tradition einer jährlichen Parade ausgeht, die so nie existierte. Tatsächlich unterbrochen wurde ab dem Jahr 1991 die Tradition der Militärparaden zum Tag der Oktoberrevolution auf dem Roten Platz.

49 Nach 1965, 1985 und 1990 fand die nächste Siegesparade im Jahr 1995 statt. 
die Izvestija am 9. Mai 1991 zwei Zeilen aus einem nachdenklichen Lied über das Kriegsende von Bulat Okudžava: »Wir sind alle des Krieges tolle Kinder: General wie einfacher Soldat. « ${ }^{50}$

Auch im folgenden Jahr 1992 fanden kleinere Feierlichkeiten an verschiedenen Orten in Moskau statt sowie ein feierlicher Marsch der Veteranen vom Weißrussischen Bahnhof zum Manege-Platz. Der erste Präsident der Russländischen Föderation, Boris El'cin, veröffentlichte am 8. Mai in der Izvestija ein kurzes Grußwort mit einem erinnerungspolitischen Kernsatz:

»Jetzt ist das Wichtigste, nicht vom Kurs der radikalen Umgestaltung zurückzuweichen. Wenn wir, wie in den Jahren des Krieges, aushalten, ertragen, uns nicht ängstigen und nicht die Seiten wechseln, wird der Sieg mit uns sein. ${ }^{51}$

El'cin knüpft damit - was den erinnerungspolitischen Rückgriff auf den Krieg angeht - an Gorbačëv an. Bei El'cin steht jedoch nicht die Geschlossenheit als Lehre aus dem Krieg im Zentrum, sondern das Kurshalten, um seine "radikalen Umgestaltung « zu legitimieren. In dem kurzen Text vermied El'cin konsequent jegliche Erwähnung der Sowjetunion, ihrer Ideologie oder ihrer Institutionen, wie der Roten Armee:

»Der Präsident erkennt an, dass Russland eine große Schuld gegenüber denjenigen hat, die den Sieg geholt haben. ${ }^{52}$

Die Pravda titelte lakonisch:

»Front und Hinterland kämpften für ein Land, das es nicht mehr gibt $^{53}$

1993 standen die Feierlichkeiten bereits im Zeichen der sich anbahnenden Verfassungskrise. Wenige Tage zuvor war es bei der 1. Mai-Demonstration zu massiven Ausschreitungen gekommen, sodass vielfach am 9. Mai eine Fortsetzung des `blutigen 1. Mai befürchtet wurde. Der Oberste Sowjet unter der Führung von Ruslan Chasbulatov mobilisierte mit einer Resolution für die Feierlichkeiten zum 9. Mai und versuchte die Ängste unter Hinweis auf die Versammlungsfreiheit und die staatliche Pflicht zum Schutz der Bürger bei Veranstaltungen zu zerstreuen. ${ }^{54}$

Obwohl der Marsch über die Tverskaja-Straße friedlich blieb und die oppositionellen Demonstranten sogar über den Roten Platz ziehen konnten, zeich-

50 Izvestija. Nr. 110 (23376) vom 09.05.1991,1. Die Zeilen stammen aus dem Lied »Beri šinel', pošli domoj« aus dem sowjetischen Film »Ot zari do zari«, Mosfilm 1975.

51 Izvestija. Nr. 108 (23682) vom 08.05.1992, 1.

52 Ebd., 1.

53 Pravda. Nr. 67 (26821) vom 13.05.1992, 1.

54 Vgl. Postanovlenie VS RF ot 06.05.1993 N 4930-1 »O prazdnovanii 48-j godovščiny Pobedy v Velikoj Otečestvennoj vojne«. 
neten sich die Fronten der Verfassungskrise bereits in der Feierpraxis ab: Boris El'cin und der Oberbürgermeister Moskaus, Jurij Lužkov, feierten die Eröffnung des Memorialkomplexes auf den Poklonnaja Gora - Aleksandr Ruckoj, Ruslan Chasbulatov und Valerij Zor'kin wurde der Zutritt zur Tribüne durch El'cins Sicherheitsdienst verweigert. Daher begingen sie den Tag des Sieges im Gorki-Park. Bereits einige Tage später beschloss der Oberste Sowjet eine Resolution zur Planung der Siegesfeiern für das Jahr $1995 .^{55}$

1994, im Jahr nach der blutigen Verfassungskrise, verstärkte sich die Politisierung der Feiern am 9. Mai weiter. Wie schon im Jahr zuvor trat Boris El'cin im Siegespark auf den Poklonnaja Gora auf. In seiner Rede stellte er die Einigkeit als die entscheidende Lehre aus dem Krieg dar und schloss damit erinnerungspolitisch an die Reden Gorbačëvs des Jahres 1990 an. Die Pravda bewertete weite Teile seiner Rede als Hurra-Patriotismus - so etwa seine Forderung an den Westen, mit Russland »na vy« zu sprechen - d.h. der Westen solle Russland `Siezen ${ }^{56}{ }^{56}$

Am Weißrussischen Bahnhof trafen sich erneut die oppositionellen Gruppierungen zu einem Marsch über die Tverskaja-Straße zur Lubjanka. Der Marsch wurde zeitweise von Aleksandr Ruckoj angeführt, der nach seiner Inhaftierung wegen seiner Führungsrolle beim Widerstand gegen El'cin im Vorjahr bereits durch die neue Duma wieder amnestiert worden war.

Bei der Kundgebung vor der Lubjanka warf der Vorsitzende der KPRF, Gennadij Zjuganov, der >Macht die Vereinnahmung der Siegesfeier und die Spaltung des Volkes vor - »Der große Sieg wurde gestohlen ${ }^{57}$ Zjuganov schloss seinen Vortrag in Anlehnung an die Rede Vjačeslav Molotovs vom 22. Juni 1941 mit den Worten »Unsere Sache ist gerecht, der Sieg wird unser sein! « ${ }^{58}$

Dass sich die bei dieser Versammlung anwesenden oppositionellen Gruppierungen in ihren historischen Bezugspunkten keineswegs so einig waren, wie Zjuganovs Rede vermuten lassen könnte, zeigten andere Losungen der Demonstranten wie beispielsweise »Für Glaube, Zar und Vaterland. ${ }^{59}$

\subsubsection{Die Wiederkehr: 1995}

Im Jahr 1995 begannen viele der Traditionen, die bis heute für die Paraden am Tag des Sieges prägend sind. Dazu zählen die Rede des Präsidenten sowie die jährliche Ausrichtung. Nach einer Übergangsphase, in der vor allem die

55 Vgl. Postanovlenie VS RF ot 13.05.1993 N 4963-1 »O podgotovke k prazdnovaniju 50letija Pobedy v Velikoj Otečestvennoj vojne 1941-1945 godov«.

56 Vgl. Pravda. Nr. 79 (27254) vom 11.05.1994, 1.

57 Ebd., 1.

58 Ebd., 1.

59 Ebd., 1. 
konservativen kommunistischen und nationalen Kräfte eine wichtige Rolle spielten, rückte der 9. Mai im Jahr 1995 in den Fokus erinnerungspolitischer Bestrebungen der El'cin-Administration.

Den 50. Jahrestag des Sieges nicht groß zu inszenieren, hätte mehr noch als in den Vorjahren den politischen Gegnern Mobilisierungspotentiale überlassen. ${ }^{60}$ Auch bot das Jubiläum die Möglichkeit, durch eine internationale Ausrichtung Russland als einen bedeutenden und respektierten Partner auf der internationalen Ebene zu präsentieren. Die militärische Eskalation des Tschetschenienkonfliktes seit Dezember 1994 bedingte und überschattete die Feierlichkeiten gleichermaßen.

1995 fand die Parade zweigeteilt statt: ein Teil auf dem Roten Platz, der andere auf dem Kutuzovskij-Prospekt am fertig gestellten Memorialkomplex Poklonnaja Gora. Auf dem Roten Platz fand unter den Augen von vielen internationalen Gästen und Staatschefs die sogenannte historische Parade statt. Historische Feldzeichen, wie beispielsweise das Banner des Sieges, und historische Uniformen dominierten diesen Teil der Parade. Die Veteranen des Krieges marschierten zum letzten Mal am 9. Mai in Formation. ${ }^{61}$ Nach der Meldung des Kommandanten der Parade hielt Boris El'cin eine Rede und ersetzte damit den Part der Verteidigungsminister in den Paraden 1965, 1985 und 1990..$^{2}$ Der Verteidigungsminister Pavel Gračëv hielt eine Rede im Rahmen der Parade am Memorialkomplex Poklonnaja Gora. Das Bild dieser im Verhältnis zum Roten Platz weitaus größere Parade war geprägt von aktuellen Uniformen und schwerer Militärtechnik der russländischen Armee. Als Grund für die Teilung der Parade wurde angegeben, dass die schwere Militärtechnik die Bauarbeiten am Einkaufszentrum »Ochotnyj Rjad« unter dem Manege-Platz gefährdet hätten.

El'cins Rede lässt sich als Versuch interpretieren, der Geschichte des Krieges und des Sieges angemessen zu gedenken, ohne jedoch positive Bezugspunkte zur Sowjetunion oder ihrer Ideologie zu schaffen. Er vermied konsequent Begriffe wie Sowjetunion, Rote Armee, sowjetisches Volk oder sowjetische Soldaten. Diese Vermeidungsstrategie wurde durch den Schriftzug auf dem

60 Der Oberste Sowjet unter Ruslan Chasbulatov hatte bereits im Mai 1993 in einer Resolution ein Planungskomitee eingerichtet. Vgl. Postanovlenie VS RF ot 13.05.1993 N 4963-1 »O podgotovke k prazdnovaniju 50-letija Pobedyv Velikoj Otečestvennoj vojne 1941-1945 godov«.

61 Auch im Rahmen der Veranstaltung der Opposition marschierten, wie in den Vorjahren, Veteranen auf der Tverskaja-Straße.

62 Erwähnenswert ist, dass neben El'cin und Gračëv auf der Tribüne des Lenin-Mausoleums der ehemalige Verteidigungsminister Sergej Sokolov in seiner sowjetischen MarschallUniform stand. Sokolov hatte bei der Siegesparade 1985 an dieser Stelle die Rede am 9. Mai gehalten. Michail Gorbačëv ersetzte ihn 1987 im Zuge der Rust-Affäre durch Dmitrij Jazov. 
Großtransparent am Historischen Museum illustriert:»Ruhm den Völkern der Länder, die den Faschismus besiegten!«

Diesen Auslassungen zum Trotz waren mit der Sowjetunion assoziierte Symbole in der Dekoration des Roten Platzes dennoch präsent. Am oberen Rand des genannten Transparents fand neben den Flaggen Frankreichs, Großbritanniens und der USA auch die rote Fahne der Sowjetunion Platz. Das zentrale Großtransparent über dem Haupteingang des Warenhauses GUM $^{63}$ bildete den sowjetischen `Orden des Sieges` ab und ein weiteres Großtransparent an der Fassade des GUM zeigte eine grafisch leicht veränderte Version des berühmten Kriegsplakats »Mutter Heimat ruft!« von Iraklij Toidze. Zusammen mit den historischen Uniformen und den Feldzeichen, Frontzeichen und Bannern der Roten Armee fällt die Abwesenheit der Begriffe in El'cins Rede noch deutlicher auf. ${ }^{64}$

Bei der Parade am Kutuzovskij-Prospekt an den Poklonnaja Gora hielt der Verteidigungsminister Pavel Gračëv die Rede. Diese Rede war gerade in Bezug auf heroische Narrative und militärischen Ruhm wesentlich deutlicher an die Reden bei den vorangegangenen Siegesparaden angelehnt: Dennoch vermied auch Gračëv über weite Strecken direkt ’kontaminierter Begriffe. Lediglich vereinzelt benutzte er Wendungen wie sunser sowjetisches Volkı oder ssowjetisch-russische Soldaten . Zum Abschluss seiner Rede benutzte er die armeetypische Anrede `Genossen .

Bei dem Teil der Siegesparade auf dem Kutuzovskij-Prospekt neben dem Siegespark war in der Gestaltung vor allem die Farbe Orange präsent. Dies lag zum einen daran, dass entlang des Prospekts rote und orange Fahnen gehisst waren, eine Kombination ohne Vorbild bei anderen Paraden, und zum anderen am dominanten Einsatz des orange-schwarzen Sankt-Georgs-Bands als Dekoration. Schon bei der Siegesparade 1985 war das Georgs-Band als Teil der Dekoration sichtbar, so etwa an einem Transparent an der Fassade des GUM und im unteren Bereich des großen Transparents an der Fassade des Historischen Museums. 1990 war es bereits ein Element auf allen Großtransparenten am Historischen Museum und am GUM. 1995 war es dann das dominierende Symbol bei dem smodernen ‘ Teil der Parade. Absperrungen, Straßenlaternen und sogar die beiden Tribünen waren mit dem orange-schwarz gestreiften Band geschmückt. Auffällig war zudem, dass als zentrales Symbol in der Mitte der Orchestertribüne der Orden des Großen Vaterländischen Krieges verwendet wurde, da er mit goldenem Hammer und Sichel im Zentrum auf

63 Torgovyj Dom GUM (Glavnyj Universal'nyj Magazin).

64 Zudem war am Vortag das Žukov-Denkmal auf dem Manege-Platz feierlich eröffnet worden. Vgl. Postanovlenie Pravitel'stva RF ot 14.04.1995 N $328 » O$ podgotovke toržestvennogo otkrytija 8-9 maja 1995 g. pamjatnika G. K. Žukovu na Manežnoj ploščadi, glavnogo monumenta i Central'nogo muzeja Velikoj Otečestvennoj vojny 1941-1945 godov na Poklonnoj gore v g. Moskve«. 
rotem Grund anders als der Orden des Sieges unverkennbar kommunistische Symbolik abbildet.

Insgesamt lässt sich daher für das Jahr 1995 eine sowjetisch-russische Mischidentität in der symbolischen Gestaltung der beiden Teile der Siegesparade feststellen. Sowjetische Symbolik und Bildsprache aus der Kriegszeit sind präsent und stehen neben den sneuen`Symbolen der Russländischen Föderation wie beispielsweise der russischen Trikolore. Beispielhaft hierfür kann auch das zentrale Monument im Siegespark stehen, das am 9. Mai 1995 eröffnet wurde ${ }^{65}$ Es vereint in sich sowohl Elemente der sowjetischen Formensprache als auch Staatssymbolik der Russländischen Föderation: den >Reiter, der mit der Lanze einen Drachen tötet ${ }^{66}$

Sowohl El'cin als auch Gračëv hielten erinnerungspolitisch geprägte Reden, die in ihrer Rhetorik an die Zweiteilung der Parade angepasst scheinen. Bei El'cin standen die Veteranen und das Leid des Krieges im Vordergrund. Das korrespondiert mit dem Auftritt der Veteranen in Marschformation und dem insgesamt historisch ausgerichteten Stil der Parade auf dem Roten Platz.

Einen besonderen Schwerpunkt legte El'cin auf die nationalsozialistischen Verbrechen:

»Der überlieferte Plan Hitlers war es, unser Volk zu versklaven und das Land zu vernichten, Moskau zu verbrennen und seine Bewohner in Konzentrationslager zu treiben. ${ }^{67}$

Die erinnerungspolitische Konsequenz geht über ein "Nie wieder! « hinaus: Nach innen beschwört El'cin die einigende Kraft des Krieges und die vereinigende Kraft der Erinnerung an den Krieg für die Gegenwart. ${ }^{68}$ Aber auch nach außen betont El'cin die vereinigende Kraft des Sieges hinsichtlich der Kooperation zwischen den Staaten, um »die kommende Generation vor dem Elend des Krieges zu bewahren. ${ }^{69}$

Entsprechend dem eher zeitgenössischen und martialischen Charakter der Parade auf dem Kutuzovskij-Prospekt ist auch die Rede Gračëvs durch mehr Gegenwartsbezug und martialisch-heroische Rhetorik gekennzeichnet. Im

65 Vgl. Postanovlenie Pravitel'stva RF ot 14.04.1995 N $328 » O$ podgotovke toržestvennogo otkrytija 8-9 maja 1995 g. pamjatnika G. K. Žukovu na Manežnoj ploščadi, glavnogo monumenta i Central'nogo muzeja Velikoj Otečestvennoj vojny 1941-1945 godov na Poklonnoj gore v g. Moskve«.

66 Zum Drachentöter in der russländischen Staatssymbolik und zur Rekontextualisierung dieses vorrevolutionären Symbols in diesem Zusammenhang vgl. de Keghel, Isabelle: Die Staatssymbolik des neuen Russland im Wandel. Vom antisowjetischen Impetus zur russländisch-sowjetischen Mischidentität. Bremen 2003, $15 \mathrm{f}$. und $23 \mathrm{ff}$.

67 Fernsehübertragung. 1-j kanal Ostankino: Moskva, Krasnaja Ploščad'. Parad v čest' 50-letija pobedy. 09.05.1995, 8.50 Uhr.

68 Vgl. ebd.

69 Ebd. 
Zentrum steht wie bei El'cin »die Vereinigung der gesamten russländischen Gesellschaft ${ }^{70}$ als erinnerungspolitische Lehre aus dem Krieg.

Deutlicher als bei El'cin wird vor allem, dass sich der Begriff der Einigkeit nicht nur auf eine abstrakte innere Geschlossenheit, sondern auch auf die Durchsetzung territorialer Integrität richtet. Gračëv warnt vor dem Entstehen regionaler Konflikte als Funken, an denen sich große Kriege entzünden könnten. ${ }^{71}$ Insgesamt ist die Rhetorik der Rede Gračëvs pathetischer als bei El'cin.

»Nur der Soldat ist in der Lage, die Heimaterde zu verteidigen, der im Geiste der Liebe zur Heimat erzogen wurde. Stolz auf die Heimat, im Geiste der Ehrerbietung für die Geschichte und die ruhmreichen Taten der Vorfahren, die für die Freiheit und Unabhängigkeit des Vaterlandes eingetreten sind - auch das ist eine Lehre unseres großen Sieges, an welchen für immer zu gedenken wir verpflichtet sind. ${ }^{72}$

Die hier präsentierte Verbindung von Verteidigungsbereitschaft, Liebe zur Heimat und Ehrerbietung für die Heldentaten der Geschichte nimmt den Patriotismus-Begriff der Programme zur Patriotischen Erziehung der 2000er Jahre vorweg und ist prägend für viele Präsidentenreden vor allem ab dem Jahr 2012.

Beide Reden ergänzen sich: El'cins Rede auf dem Roten Platz ist einem würdigen Andenken an die Opfer der Kriegsgeneration verpflichtet und demonstriert Friedens- und Kooperationswillen vor den versammelten Spitzen der internationalen Politik. Gračëvs Rede kommt ohne diese Funktion aus - sie ist primär nach innen gerichtet und beschwört in heroischer Rhetorik "Leiden und Einsatz für das Vaterland « sowie die nationale Einheit in Hinblick auf den nicht explizit genannten Krieg in Tschetschenien.

In der Betrachtung von Rhetorik und Gestaltung der Siegesparaden wird deutlich, dass im Jahr 1995 die El'cin-Administration vor allem zwei Ziele verfolgte: Durch die gestalterischen und rhetorischen Zugeständnisse sollte die Deutungshoheit im Bereich Kriegsgedenken von den konservativ-kommunistischen und nationalen Kräften zurückerobert werden. Der Ansatz dazu war ein Fokus auf die Soldaten bzw. Veteranen sowie auf einzelne Kriegsereignisse und die Verbrechen Deutschlands. Dafür wurde auch in Kauf genommen, dass entheroisierte und entmythisierte Zugänge zur Kriegserinnerung, wie sie sich im Zuge der Perestrojka entwickelt hatten, aufgegeben wurden. ${ }^{73}$ Das

70 Fernsehübertragung. 1-j kanal Ostankino: Voennyj parad, otkrytie Glavnogo monumenta i Central'nogo muzeja Velikoj Otečestvennoj vojny na Poklonnoj gore. 09.05.1995, $11.55 \mathrm{Uhr}$.

71 Vgl. ebd.

72 Ebd.

73 Zur Revision der sowjetischen Geschichte vgl. de Keghel, Isabelle: Die Rekonstruktion der vorsowjetischen Geschichte. Identitätsdiskurse im neuen Russland. Hamburg 2006, $121 \mathrm{ff}$. 
zweite Ziel bestand darin, durch die Rückgewinnung der Deutungshoheit das Kriegsgedenken als sinnstiftende und vereinigende Ressource im Angesicht des Krieges im Nordkaukasus nutzbar zu machen.

\subsubsection{Vom 9. Mai zum Wahltag: Zuspitzung 1996}

1996 fand die Parade zum ersten Mal im neuen, jährlichen Intervall auf dem Roten Platz statt, wenn auch in kleinerem Rahmen als im Vorjahr. Die Dekoration des Platzes stellte eine Kombination aus den Elementen der beiden Paraden des Vorjahrs dar: Zum einen war wieder das Georgs-Band präsent und zum anderen war ein großes Transparent mit dem Orden des Großen Vaterländischen Krieges an der Fassade des GUM angebracht. Ein neues Element stellte ein Großtransparent über dem Haupteingang des GUM dar: eine riesige Kopie eines Gemäldes von Sergej Prisekin, das im Zentrum Georgij Žukov und daneben Konstantin Rokossovskij bei der Siegesparade 1945 vor dem Hintergrund des Minin und Požarskij Denkmals und der Basilius-Kathedrale abbildet. ${ }^{74}$ Allerdings wurde das prominent wehende rote Banner mit den Portraits Stalins und Lenins am oberen Bildrand des Originals herausretuschiert. Der Ort über dem Haupteingang des GUM, den Žukov 1996 einnahm, ist in der Tradition der Paraden symbolträchtig: Bei den Paraden zur Oktoberrevolution und den Siegesparaden 1965 und 1985 war hier ein riesiges Portrait von Lenin angebracht. ${ }^{75}$

Rhetorisch knüpfte Boris El'cin an die pathetisch-heroische Vorjahresrede von Gračëv an. Allerdings gab er die in den Vorjahren geübte Zurückhaltung in Bezug auf >sowjetische` Terminologie auf: Schon in der Begrüßung verwendete er den Begriff »Genossen«, sprach von der »heldenhaften sowjetischen Armee « und gratulierte nicht nur den Helden des Krieges, sondern auch den Helden der Arbeit. Auch in anderen Bereichen, wie der Erwähnung aller Waffengattungen, der Partisanen, des Untergrunds sowie des Zusammenwirkens von Front und Hinterland, knüpfte seine Rede an sowjetische Traditionen an.

Erstmals stellte El'cin auch die Gegenwart in eine direkte, positiv konnotierte Tradition, in der die russländischen Streitkräfte das heldenhafte Erbe

74 Prisekin, Sergej Nikolaevič: Maršaly Sovetskogo Sojuza G. K. Žukov i K. K. Rokossovskij na Krasnoj ploščadi 24 ijunja 1945 goda. Cholst, maslo. Central'nyj muzej Vooružënnych Sil, Moskau 1989.

75 Bei den Paraden zur Oktoberrevolution am 7. November war selbst 1990 noch ein Leninportrait über dem Eingang angebracht. Zuvor war im Rahmen der Siegesparade an dieser Stelle bereits der Orden des Großen Vaterländischen Krieges zu sehen gewesen. Anlässlich der Paraden am 1. Mai waren über dem Eingang bis 1990 Marx, Engels und Lenin zu sehen. Bei der ersten Parade der russländischen Föderation 1995 war an dieser Stelle ein Großtransparent mit dem Orden des Sieges angebracht. 
der Väter und Großväter antreten. ${ }^{76}$ Explizit benennt er das Banner des Sieges als Symbol, das die geschichtlichen Brüche überwindet und die Kontinuität wieder herstellt:

»Und heute weht dieses heilige Symbol unseres Volkes wieder über dem Roten Platz, über Moskau, über ganz Russland. Das ganze Land wird heute Zeuge der lebendigen Verbindung der Zeiten. ${ }^{77}$

Der Rückgriff auf die Ruhmestraditionen, der bereits im März 1995 in dem Gesetz über die Tage des militärischen Ruhmes institutionalisiert wurde, wird in dieser Rede El'cins erstmals erinnerungspolitisch umgesetzt. Wie auch in dem Gesetz des Vorjahres angelegt, beschränkt sich der militärische Ruhm nicht auf den Großen Vaterländischen Krieg: Der Sieg ist lediglich Ausdruck und Konsequenz der ruhmreichen Militärtraditionen in allen Zeiten.

»In der Todesgefahr 1941 standen unsichtbar neben den Soldaten des Großen Vaterländischen Krieges unsere ruhmreichen Vorfahren Aleksandr Nevskij, Dmitrij Donskoj, Minin und Požarskij, Pëtr I., die Anführer Suvorov und Kutuzov. Die Rote Armee schöpfte den Willen zum Sieg aus der heroischen Vergangenheit des Vaterlandes. ${ }^{78}$

Neben diesem Element, das in den 2000er Jahren nicht zuletzt durch die Programme zur Patriotischen Erziehung der Bürger weiter ausgebaut wurde, führte El'cin in seiner Rede ein weiteres, bis heute prägendes Element ein: das Motiv der Erinnerungsgemeinschaft, die sich ihrer Vorfahren würdig erweisen muss:

»Das ewige Feuer der Erinnerung wird in unserem Herzen und an den Massengräbern der Helden brennen. Wir werden uns der Heldentaten unserer Väter würdig erweisen. ${ }^{79}$

Insgesamt setzt Boris El'cin im Rahmen der Parade 1996 das um, was er mit dem Gesetz über die Tage des militärischen Ruhmes vorbereitet und was sich in der symbolischen Gestaltung des aktuellen Teils der Siegesparade 1995 auf dem Kutuzovskij-Prospekt bereits abgezeichnet hatte: die Reintegration des Großen Vaterländischen Krieges und der sowjetischen Symbolik als Legitimationsressource in den symbolpolitischen Haushalt der Russländischen Föderation.

Neben dem immer noch andauernden Krieg in Tschetschenien dürften die Veränderung der Rhetorik und der grundsätzliche Richtungswechsel, sowjetische Identifikationspotenziale explizit zu nutzen, vor allem in den anstehenden

76 Vgl. Fernsehübertragung. Telekanal ORT. Voennyj parad vojsk na Krasnoj ploščadi. 09.05.1996, 9.00 Uhr.

77 Ebd.

78 Ebd.

79 Ebd. 
Präsidentschaftswahlen des Jahres 1996 begründet sein. So attestierte die Izvestija Boris El'cin unter dem Titel »Tag des Sieges. Boris El'cin auf dem Weg vom 9. Mai zum 18. Juni [Wahltag] $\ll^{80}$ die Fähigkeit, »den Feind mit den eigenen Waffen zu schlagen. ${ }^{81}$

Auch wenn sein Gegner Gennadij Zjuganov sich vor den Wahlen als Sozialdemokrat inszenierte, ${ }^{82}$ so stand er trotzdem weiterhin für ein konservativsowjetnostalgisches Elektorat. Ihm die Sowjetunion als positiven erinnerungspolitischen Bezugspunkt streitig zu machen, erschien daher erfolgversprechend.

Nach dieser Zuspitzung wurden die Feierlichkeiten im Jahr 1997 wieder zurückhaltender inszeniert. Auf das große Žukov-Transparent wurde genauso verzichtet wie auf das Transparent mit dem Orden des Großen Vaterländischen Krieges. Die Transparente waren überwiegend in Blau mit Blumenmotiven gestaltet. Die Stelle des Kriegsordens nahm wiederum der Orden des Sieges ohne prominente kommunistische Symbolik ein. Eine weitere Reduktion zeigte sich an der Tribüne: Erstmals wurde die Parade nicht von der Tribüne des LeninMausoleums abgenommen. Stattdessen hielt Boris El'cin seine Rede auf einem kleinen Podest vor dem Mausoleum, das mit der russländischen Trikolore und dem Doppelköpfigen Adler der Russländischen Föderation geschmückt war.

Auch die Rhetorik war in der Verwendung sowjetisch geprägter Begriffe deutlich zurückhaltender. In zwei Punkten knüpfte El'cin jedoch an die Rede des Vorjahres an: Zum einen wurde der Verweis auf die Traditionen des militärischen Ruhmes in Bezug auf die Sowjetunion beibehalten und zum anderen blieb der heroisch-pathetische Stil erhalten:

"Von den Ufern der Wolga, von den Mauern des heldenhaften Stalingrads, der mächtige Wille des heiligen Krieges jagte den Feind zurück. Und es gab auf der Welt keine Kräfte, die die Rote Armee hätten aufhalten können. ( $^{83}$

In den Jahren 1998 und 1999, dem letzten Jahr unter Boris El'cin blieb es bei dieser Form der zurückhaltenden Inszenierung bei gleichzeitiger pathetischer Rhetorik und Betonung der Traditionen des militärischen Ruhmes. 1998 ließ sich jedoch eine verstärkt national-patriotische Tonlage feststellen, die an die Rede 1994 erinnerte:

"Es gibt keine Kraft, die unseren Willen brechen kann. Es gibt keine Kraft, die Russland dazu bringen kann, sich zu unterwerfen. [...] Damals, 1945, ermöglichten die

80 Izvestija. Nr. 85 (24692) vom 12.05.1996, 1.

81 Ebd., 1.

82 Spiegel/Panorama: Bonn Besuch. Nackter Tisch. In: Der Spiegel. Nr. 20/1996 vom 13.05.1996, 18.

83 Ebd. 
geistige Kraft und die Einheit des Volkes den Sieg - ich glaube, dass diese heute das große Russland zurückbringen können. ${ }^{84}$

Im Rahmen der Parade 1999 wurde das Narrativ des militärischen Ruhmes in allen Zeiten auch in der Dekoration des Roten Platzes umgesetzt. Das zentrale Großtransparent über dem Haupteingang des GUM zeigte drei Kämpfer: im Zentrum einen Rotarmisten, der rechts von einem Soldaten des Vaterländischen Kriegs und links von einem Kämpfer der Zeit Dmitrij Donskojs flankiert wird. ${ }^{85}$

\subsubsection{Resümee: Die Siegesparaden bis 1999}

Insgesamt stellen sich die Jahre der El'cin-Präsidentschaften als bedeutend für die Entwicklung der heutigen russländischen Erinnerungspolitik dar. Gerade die Jahre bis 1996, in denen die reformorientierten Kräfte auf der Straße wie in der Politik von den nationalistischen und konservativ-kommunistischen Kräften massiv unter Druck gesetzt wurden, weisen viele Veränderungen und auch ein hohes Maß an Flexibilität im Umgang mit der Geschichte auf.

Nach einer Phase von 1992 bis 1994, in der gegenüber den Legitimationspotenzialen der Geschichte der Sowjetunion der Versuch eines >Containments betrieben wurde, folgte 1995 eine Aufweichung dieser Position. Symbolisch, aber auch zumindest in der Rede Gračëvs rhetorisch werden positive geschichtliche Verweise auf die Sowjetunion reintegriert. Die nüchterne, auf Entmythologisierung und Entheroisierung ausgerichtete Geschichtsbetrachtung, die sich im Zuge der Perestrojka herausgebildet hatte, wurde dabei 1995 aufgegeben, um die Kriegserinnerung für aktuelle Konflikte nutzbar zu machen.

Während El'cin sich vor den internationalen Gästen 1995 rhetorisch noch zurückgenommen und die Neuausrichtung Gračëv überlassen hatte, griff er dann im Vorfeld der anstehenden Präsidentschaftswahlen 1996 auch persönlich auf diese Legitimationspotenziale zu. In Symbolik und Rhetorik wurde die Sowjetunion in die russländische Erinnerungspolitik reintegriert. Mit der Kombination aus patriotischen Anleihen, dem Herausstellen einer schicksalhaften Erinnerungsgemeinschaft und dem Narrativ des militärischen Ruhmes in allen Zeiten prägte dieses Jahr Eckpunkte der russländischen Erinnerungspolitik, die bis heute Bestand haben und vor allem in den 2000er Jahren Eingang in die Programme zur Patriotischen Erziehung der Bürger fanden.

84 Fernsehübertragung. Telekanal ORT. Voennyj parad na Krasnoj ploščadi, posvjašennyj Dnju Pobedy. 09.05.1998, 9.50 Uhr.

85 Das Motiv ist an das Denkmal »Den Verteidigern der russischen Erde« angelehnt, das 1995 am Rande des Siegesparks in Moskau eröffnet wurde. 
Auch wenn in den folgenden Jahren die Betonung von sowjetgeschichtlichen Referenzpunkten in Teilen zurückgenommen wurde, blieben diese genannten Eckpunkte auch in den Jahren 1997 bis 1999 bestehen.

Die Zuspitzung des Jahres 1996 - geprägt von politischer Konkurrenz aus dem konservativ-kommunistischen und nationalen Lager im Vorfeld der Präsidentschaftswahlen und dem Krieg in Tschetschenien - lässt sich somit als ein bis heute nachwirkender Katalysator russländischer Erinnerungspolitik beschreiben.

\subsection{Reden und Paraden am 9. Mai von 2000 bis 2015}

Im Jahr 2000 fand die erste Parade am 9. Mai unter der Präsidentschaft Vladimir Putins statt, welcher bei der Parade des Vorjahres noch nicht einmal im Hintergrund in Erscheinung getreten war. Anders als 1996 hatte die Wahl am 26. März, also vor dem Siegestag, stattgefunden, sodass eine direkte Politisierung des Festes ausblieb.

In der Inszenierung und auch mit der Rede Vladimir Putins schließt diese Parade an die Traditionen der El'cin-Jahre an. ${ }^{86}$ Der Ton der Rede ist jedoch zurückhaltender als im Vorjahr: Typische Wendungen El'cins wie »der Ruhm der russischen Waffen« oder »Leben, die auf dem Altar des Sieges geopfert wurden « finden keine Verwendung.

Die seit 1996 durchgängig enthaltenen Motive der Siegestradition und des militärischen Ruhmes werden zwar beibehalten - sie werden in ihrer Bedeutung jedoch über das Militärische hinaus erweitert: Auch in Friedenszeiten habe man - beim Aufbau eines starken, blühenden Landes - von den Siegestraditionen profitiert. ${ }^{87}$

In seiner zivilen Interpretation dient der Sieg im Großen Vaterländischen Krieg auf diese Weise wieder als Sinnbild für die Fähigkeit, mit jeder Herausforderung erfolgreich umgehen zu können. Damit knüpfte Putin an die Worte Michail Gorbachevs aus seinem Vortrag zum 9. Mai 1990 an. $^{88}$

Der 9. Mai des Jahres 2001 fällt auch mit dem Ende der offenen militärischen Phase des zweiten Tschetschenienkrieges zusammen. In den ersten Monaten des Jahres waren die letzten größeren tschetschenischen und islatischen Ver-

86 Über dem Haupteingang des GUM war wie schon 1998 ein großes Transparent mit dem Orden des Sieges angebracht.

87 Vgl. Putin, Vladimir: Vystuplenie na parade, posvjaščennom 55-j godovščine Pobedy v Velikoj Otečestvennoj vojne. Rede Vladimir Putins am 9. Mai 2000 auf dem Roten Platz, Moskau. Online: http://kremlin.ru/transcripts/21421.

88 Siehe Kapitel: Der 9. Mai in Präsidentenreden: Die Siegesparaden bis 1999 und Izvestija. Nr. 130 (23033) vom 9. Mai 1990, 2. 
bände zerschlagen worden. In der Rede Putins finden diese Ereignisse einen impliziten Niederschlag: Der Sieg wird als Warnung an diejenigen präsentiert, »die Terror und Gewalt als ihre hauptsächlichen Waffen betrachten. ${ }^{89}$ Der Bezug zwischen dem Großen Vaterländischen Krieg - dem Kampf gegen den "Nazismus" - und dem »Kampf gegen den Terror" der wahhabitischen Kämpfer und der Tschetschenischen Separatisten ist als erinnerungspolitisches Element auf diese Weise bereits in der ersten Rede Putins zum Siegestag enthalten.

Die Reden der folgenden Jahre setzen in ihrer erinnerungspolitischen Ausrichtung den Ansatz des Jahres 2000 fort, wobei die Siegestraditionen bzw. die Traditionen des militärischen Ruhmes ab 2003 geringer gewichtet werden und 2004 und 2005 keine Erwähnung finden. Das Thema des Terrorismus nimmt dagegen sukzessive größeren Raum ein und wird auch thematisch ausgeweitet.

\subsubsection{Terroristische Bedrohung und internationale Kooperation}

Blieb der Verweis auf den Terrorismus als Bedrohung in den Jahren 2000 und 2001 noch unauffällig, so war er im Jahr 2002 ein zentraler Punkt der Rede.

"Die Kräfte des Bösen und der Gewalt erheben sich wieder und wieder auf der Erde. Sie tragen heute andere Namen, doch haben die alten Angewohnheiten. Sie verbreiten Tod und Zerstörung." ${ }^{90}$

Die Bezeichnung 'Kräfte des Bösen ‘ hat hier eine doppelte Bedeutung: Zum einen gehörte der Ausdruck `Kräfte des Bösen oder auch der `dunklen Kräfte` zum Begriffsbestand sowjetischer Festreden, Lieder und Gedichte, um den `Nazismus oder `Faschismus` zu beschreiben oder zu umschreiben. Die Übertragung des Begriffs des `Bösen ‘ auf die Bedrohungen der Gegenwart an gleich zwei Stellen in dieser Rede 2002 ist jedoch ein neuer Aspekt und erfolgte in Übereinstimmung mit dem von der US-Regierung geprägten Sprachgebrauchs in der Folgezeit der Anschläge des 11. Septembers 2001.91

Diesem Sprachgebrauch entsprechend, wird in dieser Rede auch der erinnerungspolitische Bogen vom gemeinsamen Kampf der Staaten in der Anti-Hitler-Koalition zum aktuellen Kampf der Staaten gegen den internationalen Terror etabliert: Wie in der Antihitlerkoalition müsse man sich auch heute gegen

89 Putin, Vladimir: Vystuplenie na parade, posvjaščennom 55-j godovščine Pobedyv Velikoj Otečestvennoj vojne. Rede Vladimir Putins am 9. Mai 2000 auf dem Roten Platz, Moskau. Online: http://kremlin.ru/transcripts/21421.

90 Putin, Vladimir: Vystuplenie na voennom parade v čest' 57-j godovščiny Pobedy v Velikoj Otečestvennoj vojne 9 maja 2002 goda. Moskva, Krasnaja ploščad'. Online: http://kremlin. $\mathrm{ru} /$ transcripts/21587.

91 Vgl. Klusmeyer, Douglas und Suhrke, Astri: Comprehending 'Evilk: Challenges for Law and Policy. In Ethics \& International Affairs 16/1 (2002), 27. 
die neue Bedrohung, den Terrorismus, zusammenschließen. ${ }^{92}$ Im Jahr 2003 wird dieser erinnerungspolitische Bereich noch weiter ausgebaut. Vladimir Putin macht die abwartende Haltung und die Tatenlosigkeit der internationalen Gemeinschaft für das Erstarken des Nazismus verantwortlich und fordert als erinnerungspolitische Konsequenz für die Gegenwart Geschlossenheit. ${ }^{93}$

Die Geschichte des Großen Vaterländischen Krieges dient erinnerungspolitisch nicht nur dazu, die Totalität der Bedrohung in der Gegenwart und die Notwendigkeit der sicherheitspolitischen Kooperation herauszustellen. Die vorbildliche Standhaftigkeit der Kriegsgeneration, der Väter und Großväter, wird - neben der physischen Stärkung der Streitkräfte - als die entscheidende geistige Ressource präsentiert, um den Bedrohungen der Gegenwart zu begegnen. ${ }^{94}$

Das Ziel dieser erinnerungspolitischen Analogiebildung ist die Legitimierung des eigenen Vorgehens gegen den tschetschenischen Separatismus und den eng damit verbundenen militanten Islamismus. Die Trennlinien zwischen Separatismus und Islamismus sowie zwischen bewaffnetem Kampf und Terrorismus waren gerade in den ersten Jahren des Konfliktes in den 2000er Jahren sehr unscharf, da es nach der Zerschlagung der letzten größeren geschlossenen Kampfverbände im Frühjahr 2000 kaum noch einheitliche Vorgehensweisen oder einen Konsens über die legitimen Strategien gab.

Der durchgehende Einsatz der Bezeichnung Terrorismus dient der grundsätzlichen Delegitimierung der Gegner. Die Bezeichnung internationaler Terrorismus verstärkt diese Wirkung, indem sie auf die nicht-russländische bzw. nicht-tschetschenische Herkunft vieler Kämpfer verweist. Zudem wird dadurch auf die internationale Vernetzung der Kämpfer, auf internationale Unterstützung und die Vernetzung mit anderen Konfliktregionen verwiesen.

Dieser erinnerungspolitische Komplex richtet sich zum einen nach innen: durch die geschichtlichen Verknüpfungen des Themas mit dem Großen Vaterländischen Krieges, aber auch durch die jährliche Einbettung in den festlichen Rahmen des Jahrestages wird um Zustimmung geworben.

Durch die Verknüpfung mit internationaler Sicherheitspolitik und dem Eintreten für internationale Kooperationen bekommt der Komplex jedoch eine weitere, außenpolitische Funktion. Die Formulierung gemeinsamer internationaler Sicherheitsinteressen im Rahmen der Feiern sowie die erinnerungspolitische Aufladung dieser Kooperation machen die Reden anlässlich

92 Vgl. Putin, Vladimir: Vystuplenie na voennom parade v čest' 57-j godovščiny Pobedy v Velikoj Otečestvennoj vojne 9 maja 2002 goda. Moskva, Krasnaja ploščad'. Online: http:// kremlin.ru/transcripts/21587.

93 Vgl. Putin, Vladimir: Vystuplenie na parade v čest' 58-j godovščiny Pobedy v Velikoj Otečestvennoj vojne. 9 maja 2003 goda. Moskva, Krasnaja ploščad'. Online: http://kremlin. $\mathrm{ru} /$ transcripts/21991.

94 Vgl. ebd. 
der Parade am 9. Mai zu einem Anlass, bei dem öffentlichkeitswirksam für eine konkrete Sicherheits- und Außenpolitik sowohl im Lande als auch bei potenziellen internationalen Partnern geworben wird. Diese Wendung nach außen stellt eine neue Qualität der Reden dar, die konsequent ab 2002 und bis 2006 betrieben wurde.

Dieser neue Aspekt ist vor allem im Zusammenhang mit den Anschlägen des 11. Septembers in den USA und dem in der Folge ausgerufenen "Krieg gegen den Terror" zu sehen: Die Interessenkongruenz mit den Staaten der NATO und die Vergleichbarkeit des Handelns in diesem Bereich der Sicherheitspolitik sollte betont werden und die eigene sinnerer Sicherheitspolitik durch diesen Vergleich legitimiert werden. In dieser Perspektive richten sich diese appellativen Teile der Reden auch gezielt an jenen Ausschnitt der internationalen Staatenwelt als strategischen Partner.

\subsubsection{Tagespolitische Ausrichtungen}

Im Jahr 2005, anlässlich des 60. Tages des Sieges, bei dem wie schon 1995 viele internationale Staats- und Regierungschefs anwesend waren, fiel zudem die Akzentuierung der internationalen Aspekte der Kriegserzählung auf. ${ }^{95} \mathrm{Zu}-$ nächst ging Vladimir Putin auf die Rolle der internationalen Verbündeten, der Alliierten genauso wie der europäischen Antifaschisten, ein:

"Wir haben den Sieg niemals in einen eigenen und einen fremden geteilt. Wir werden uns immer an die Hilfe der Verbündeten erinnern: der Vereinigten Staaten von Amerika, Großbritanniens, Frankreichs, anderer Staaten der Antihitlerkoalition, der deutschen und italienischen Antifaschisten. Heute zollen wir dem Mut aller Europäer, die dem Nazismus Widerstand leisteten, Anerkennung. ${ }^{96}$

Anschließend hob er die besonders hohen Verluste aller "Nationalitäten der Sowjetunion ${ }^{97}$ hervor und schrieb dem Tag eine gemeinsame sakrale Bedeutung zu:

»Alle Völker und alle Republiken der Sowjetunion haben unwiederbringliche Verluste erlitten[...]. Und deshalb ist der 9. Mai ein heiliges Datum für alle Länder der Gemeinschaft Unabhängiger Staaten. ${ }^{98}$

95 Zur Tendenz der internationalen Einbettung der Kriegserinnerung vgl. Langenol', Andreas: Oficial'nye vizity. Internacionalizacija pamjati o Vtoroj mirovoj vojne v Rossii i Germanii. In: Neprikosnovennyj zapas 40-41/2-3 (2005), 403-418.

96 Putin, Vladimir: Vystuplenie na Voennom parade v čest' 60-j godovščiny Pobedy v Velikoj Otečestvennoj vojne. 9 maja 2005 goda. Moskva, Krasnaja ploščad'. Online: http:// kremlin.ru/transcripts/22959.

97 Ebd.

98 Ebd. 
Aus dieser gemeinsamen Leidensgeschichte, in der er eine Erinnerungsgemeinschaft der ehemaligen Staaten der Sowjetunion begründet sieht, leitete er dann eine besondere, erinnerungspolitisch privilegierte Verbindung der GUS-Staaten ab: Das gemeinsame Leid, aber auch die gemeinsamen Ziele und Hoffnungen der Vergangenheit werden als Verpflichtung zu einer gemeinsame Zukunft interpretiert. ${ }^{99}$

Diese Betonung des gemeinsamen Erbes kann zunächst einmal als Würdigung der bis auf Michail Saakašvili vollständig anwesenden Staats- und Regierungschefs der GUS-Staaten gelten. Darüber hinaus zeigt sich jedoch auch in dieser erinnerungspolitischen Betonung ein tagespolitischer Bezug: In der Folge der sogenannten `Orangen Revolution` in der Ukraine 2004 mehrten sich 2005 die Anzeichen, dass Viktor Juščenko die GUAM zu einer echten GUS-Konkurrenz unter Ausschaltung des russländischen Einflusses ausbauen würde. ${ }^{100}$ Die Betonung der aus der Geschichte resultierenden Verpflichtung zu Freundschaft und Bruderschaft durch Putin weist in dieser Perspektive auch eine klare machtpolitische Komponente auf.

Auch die Rede anlässlich der Parade 2006 enthielt neben dem Werben für internationale Sicherheitskooperationen einen aktuellen erinnerungspolitischen Bezug, der sich jedoch, anders als im Vorjahr, primär auf die Innenpolitik richtete.

»Diejenigen, die wieder versuchen die gestürzten Fahnen des Nazismus zu hissen, die Rassenfeindschaft, Extremismus und Xenophobie säen, führen die Welt in die Sackgasse, zu sinnlosem Blutvergießen und Barbarei. ${ }^{101}$

Auch wenn diese Passage nicht explizit auf die Russländische Föderation verweist, ist ihr Bezugspunkt durch die Verwendung von Wörtern wie Rassenhass oder Xenophobie sehr deutlich. Vladimir Putin nimmt die Rede anlässlich der Parade 2006 zum Anlass, um den in den Jahren 2005 und 2006 zunehmend in den Fokus der Öffentlichkeit rückenden rassistischen Gewalttaten erinnerungspolitisch entgegenzutreten. Auch wenn die Russländische Politik in Bezug auf den gewalttätigen Rechtsradikalismus und Rassismus gerade im Jahr 2006 keine durchgehende Konsistenz aufweist, wie sich am Umgang mit den rassistischen Unruhen in Kondopoga im September 2006 zeigte ${ }^{102}$ macht die

99 Vgl. ebd.

100 Vgl. Šnajder, Ėberchard: Vnešnjaja politika Ukrainy pri Viktore Juščenko. In: Vestnik Analitiki 21/3 (2005) vom 01.09.2005, $107 \mathrm{ff}$.

101 Putin, Vladimir: Vystuplenie na voennom parade v čest' 61-j godovščiny Pobedy v Velikoj Otečestvennoj vojne. 9 maja 2006 goda. Moskva, Kreml'. Online: http://kremlin.ru/ transcripts/23576.

102 Shlapentokh, Dmitry: Kondopoga - Ethnic/Social Tension in Putin's Russia. European Review 18/2 (2010), $192 \mathrm{ff}$. 
prominente Erwähnung und erinnerungspolitische Verknüpfung des Themas im Rahmen der Parade deutlich, dass dem Thema bereits ein hoher Stellenwert eingeräumt wurde.

Auch die Rede im folgenden Jahr ist wieder von tagesaktueller Politik bestimmt. Wie schon im Jahr 2005 wird die enge Verbundenheit der GUS-Staaten als Folge der gemeinsamen Geschichte beschrieben. ${ }^{103}$ Davon ausgehend kommt Putin dann, wenn auch implizit, auf diejenigen zu sprechen, die aus dieser Erinnerungsgemeinschaft ausscheren.

»Diejenigen, die heute versuchen, diese unschätzbare Erfahrung herabzuwürdigen, die die Denkmäler der Kriegshelden besudeln, beleidigen das eigene Volk, säen Streit und neues Misstrauen zwischen Staaten und Menschen. " $^{104}$

Dieser Abschnitt ist klar im Kontext des Streites um den $>$ Bronzenen Soldaten in Tallinn zu sehen. Wenige Tage zuvor, am 27. April, war in Tallinn das >Denkmal der Befreier Tallinns` durch estnische Behörden abgebaut und später an anderer Stelle wieder aufgebaut worden. ${ }^{105}$ Die russländische Regierung hatte scharf gegen dieses Vorgehen protestiert, im Vorfeld kam es zu schweren Ausschreitungen zwischen Gegnern des Abbaus und der Polizei. Putin hatte die Pläne als "absolut kurzsichtige, ultranationalistische Politik, die weder die Probleme des Kampfes mit dem Nazismus noch die heutigen Realitäten berücksichtigt ${ }^{106}$, bezeichnet.

\subsubsection{Sicherheitspolitik und Konfrontation 2007}

In seiner vorerst letzten 9. Mai-Rede als Präsident rückt Putin im Jahr 2007 wieder die internationale Sicherheitspolitik in den Fokus. Maßgeblich für diesen Teil der Rede anlässlich der Parade ist die Rede Putins einige Monate zuvor bei der Münchner Sicherheitskonferenz. Bei dieser international vielbeachteten Rede hatte Putin bereits in sehr deutlichen Worten vor Versuchen eine monopolare Weltordnung zu errichten, gewarnt, da eine solche nachteilhaft für alle sei, nicht praktikabel, undemokratisch und der sittlich-moralischen

103 Vgl. Putin, Vladimir: Vystuplenie na voennom parade v čest' 62-j godovščiny Pobedy v Velikoj Otečestvennoj vojne 9 maja 2007 goda, 11:27 Moskva, Krasnaja ploščad'. Online: http://kremlin.ru/transcripts/24238.

104 Ebd.

105 Vgl. Münch, Felix: Diskriminierung durch Geschichte? Der Deutungsstreit um den >Bronzenen Soldaten $<$ im postsowjetischen Estland. Marburg 2008.

106 Putin, Vladimir: Stenografičeskij otčet o press-konferencii dlja rossijskich i inostrannych žurnalistov. 1 fevralja 2007 goda. Moskva, Kreml', Kruglyj zal. Online: http://kremlin. ru/events/president/transcripts/24026. 
Basis der heutigen Zivilisation widerspreche. ${ }^{107}$ Die Rede war allgemein als Warnung an die USA und die NATO aufgefasst worden. ${ }^{108}$

Bei der Parade 2007 greift Putin das Thema erneut auf, interpretiert es jedoch diesmal in einer erinnerungspolitisch aufgeladenen Variante. Er beschreibt als Gründe für Kriege Fehler in Friedenszeiten und eine »Ideologie der Konfrontation und des Extremismus « ${ }^{109}$. Heutige Grundlagen dieser Ideologie seien »dieselbe Verachtung gegenüber Menschenleben und dieselben Ansprüche auf einen weltweite Exzeptionalismus und ein weltweites Diktat « ${ }^{110}$ wie zu Zeiten des `Dritten Reiches`.

Der Vorwurf an die USA, eine monopolare Weltordnung zu ihren Gunsten durchsetzen zu wollen, ist der gleiche wie in der Rede in München. Anlässlich des Tages des Sieges wird dieser Vorwurf jedoch durch den Verweis auf das >Dritte Reich erinnerungspolitisch aufgeladen: Die Politik der USA wird implizit neben die des nationalsozialistischen Deutschlands gestellt und als Bedrohung des Weltfriedens interpretiert. Dieser bis dahin in den Reden Putins anlässlich der Parade präzedenzlosen Zuspitzung folgt wiederum, wie auch im Rahmen der Münchner Rede oder auch in den früheren Reden zum 9. Mai, der Appell für eine Stärkung internationaler Institutionen und Kooperation zur Lösung von Konflikten.

Die Zuspitzung in diesem Teil der Rede, das alarmierende Element, besteht darin, dass in der rhetorischen Figur der Part, der in vielen vorangegangen Jahren vom Terrorismus als dem Bösen und der »faschismusgleichen« Bedrohung eingenommen wurde, nun dem US-amerikanischen Vormachtstreben zugewiesen wird. Nicht mehr der internationale Terrorismus gefährdet in diesem Anwurf den Frieden in der Welt und erfordert verrechtlichte internationale Kooperation, sondern die Hegemonialpolitik der USA.

Schlaglichtartig nimmt Vladimir Putin in dieser Rede - in Bezug auf Konfrontation und Feindbildprojektion - ein wichtiges Element der rhetorischen Neuorientierung im Zuge seiner dritten Amtszeit ab 2012 vorweg.

107 Vgl. Putin, Vladimir: Vystuplenie i diskussija na Mjunchenskoj konferencii po voprosam politiki bezopasnosti. 10 fevralja 2007 goda 17:37, Mjunchen. Online: http://kremlin.ru/ events/president/transcripts/24034.

108 Vgl.Rolofs, Oliver: Ein Hauch von Kaltem Krieg. Putins Brandrede verschreckt die Münchner Sicherheitskonferenz 2007 und warnt die USA und NATO. Online: https://www. securityconference.de/ueber-uns/muenchner-momente/ein-hauch-von-kaltem-krieg/.

109 Vgl. Putin, Vladimir: Vystuplenie na voennom parade v čest' 62-j godovščiny Pobedy v Velikoj Otečestvennoj vojne. 9 maja 2007 goda. Moskva, Krasnaja ploščad'. Online: http://kremlin.ru/transcripts/24238.

110 Ebd. 


\subsubsection{Pragmatismus und militärische Stärke bei Dmitrij Medvedev}

Auch unter Dmitrij Medvedev setzt sich die skizzierte Entwicklung fort: In den Reden anlässlich der Paraden zum 9. Mai wird neben dem aktualisierenden Teil auch Tagespolitisches erinnerungspolitisch legitimiert bzw. zu delegitimiert, aber auch ganz allgemein Aktuelles im historisch aufgeladenen Kontext der Parade zu verhandelt. Vor allem die Reden der ersten beiden Jahre sind deutlich durch aktuelle politische Geschehnisse gekennzeichnet.

So stand anlässlich der Parade zum 9. Mai 2008 die Anerkennung der Unabhängigkeit des Kosovo von Serbien durch einen Teil der internationalen Gemeinschaft im Zentrum des erinnerungspolitischen Teils der Rede. Allerdings blieb Medvedev, im Gegensatz zu der deutlichen Rhetorik Putins im Vorjahr, eher zurückhaltend und formulierte zunächst etwas verklausuliert einen Exkurs zur Entstehung und notwendigen Vermeidung von Konflikten. ${ }^{111}$

Erst im darauf folgenden Abschnitt machte er deutlich, dass es um die Revision von Grenzen also die Anerkennung des Kosovo, ging. Die Regeln des Völkerrechts dürften nicht ignoriert werde, da sie die Früchte der Arbeit der internationalen Gemeinschaft seien, ohne die kein sicheres Leben oder eine gerechte Weltordnung möglich seien. ${ }^{112}$

Obwohl die russländische Politik insgesamt mit sehr scharfer Ablehnung der Kosovopolitik der USA und Teilen der EU-Staaten reagiert hatte, formulierte Medvedev in dieser Rede sehr zurückhaltend. Die Erwähnung der Einmischung in Angelegenheiten anderer Staaten und der versuchten Revision von Grenzen als Gefahren für die Friedensordnung erscheinen weniger als ein Angriff auf die USA und EU-Staaten als eine Einleitung für das bekannte Plädoyer für die Einhaltung des internationalen Rechts als Garanten von Frieden und Gerechtigkeit in der internationalen Welt. Es scheint der Versuch zu sein, die eigene Position deutlich zu vertreten, ohne die Gegner dieser Position zu brüskieren. Auch fehlen die zur damaligen Zeit verbreiteten Hinweise, durch die Anerkennung sei ein Präzedenzfall geschaffen worden, aus dem die Russländische Föderation eigene Konsequenzen ziehen würde. ${ }^{113}$ Noch als Präsident hatte Vladimir Putin Ende Februar 2008 die Anerkennung des Kosovo als sschrecklichen Präzedenzfall, der das gesamte System der inter-

111 Vgl. Medvedev, Dmitrij: Vystuplenie na Voennom parade v čest' 63-j godovščiny Pobedy v Velikoj Otečestvennoj vojne. 9 maja 2008 goda, 11:15 Moskva, Krasnaja ploščad’. Online: http://kremlin.ru/transcripts/30.

112 Ebd.

113 Die sukzessive Aufwertung südossetischer und abchasischer Institutionen und die Ausweitung der Zusammenarbeit mit ihnen in den Monaten nach der Anerkennung des Kosovo, ließ bereits damals Schlüsse darauf zu, wie die russländische Politik mit diesem erklärten >Präzedenzfallı umgehen würde. 
nationalen Beziehungen aufbrechen würde und unabsehbare Folgen haben werde, bezeichnet. ${ }^{114}$

Ein weiterer interessanter Aspekt der Rede betrifft die Modernisierung der Russländischen Armee. Auch Putin hatte die Modernisierung, Weiterentwicklung und Anpassung der Streitkräfte mehrfach in seinen Reden zum 9. Mai erwähnt. In der Rede Medvedevs wird die Modernisierung jedoch erinnerungspolitisch aufgeladen, indem auf die Erfahrung der Kriegsgeneration - was die wahre Bedeutung von Waffen und Militärtechnik angehe verwiesen wird. ${ }^{115}$ Aus der Erfahrung der Frontoviki des Großen Vaterländischen Krieges wird somit die Notwendigkeit der Modernisierung abgeleitet und die verteidigungspolitischen Ausgaben werden legitimiert.

Insgesamt fällt Medvedevs Rede zwar hinter die konfrontativen Zuspitzungen der Rede Putins im Vorjahr zurück. Die Berücksichtigung von Wendungen wie »historischer Ruhm der russischen Waffen« oder "Siegestraditionen unserer Armee ${ }^{116}$ zeigt jedoch die tiefe Verwurzelung in den rhetorischen Traditionen der 9. Mai-Reden.

In der Inszenierung der Parade wird im Jahr 2008 eine weitere Tradition wieder aufgenommen: Erstmals seit dem 7. November 1990 rollte wieder schweres militärisches Gerät über den Platz. ${ }^{117}$ In Medvedevs Rede wird dieser Aspekt durch die beschriebene erinnerungspolitische Unterfütterung von Modernisierung der Armee und Investitionen in Militärgerät berücksichtigt.

In einem breiteren Kontext betrachtet lässt sich die Wiedereinführung der Militärtechnik jedoch eher als Teil der im Vorjahr begonnenen konfrontativen Positionierung gegenüber den USA verstehen. Auch wenn Premierminister Putin betonte, es handele sich nicht um "Säbelrasseln « und der Charakter der Demonstration sei rein defensiv, ${ }^{118}$ so war die grundsätzliche Intention deutlich: Russland positioniert sich als internationaler Akteur, der seine sicherheitspolitischen Interessen auch im Dissens mit den Staaten Westeuropas und den USA verfolgen kann. Symbolpolitischer Ausdruck dieses Selbstverständnisses ist die Demonstration militärischer Stärke im Rahmen der Siegesfeier-

114 Vgl. Lenta: Putin nazval provozglašenie nezavisimosti Kosovo »strašnym precedentom«. 23.02.2008. Online: http://lenta.ru/news/2008/02/23/putin.

115 Medvedev, Dmitrij: Vystuplenie na Voennom parade v čest' 63-j godovščiny Pobedy v Velikoj Otečestvennoj vojne. 9 maja 2008 goda. Moskva, Krasnaja ploščad'. Online: http://kremlin.ru/transcripts/30.

116 Ebd.

117 Auch die Siegesparaden 1965, 1985, 1990 und 1995 präsentierten militärisches Gerät. Die Parade 1995 war jedoch zweigeteilt und militärische Fahrzeuge blieben auf den Teil auf dem Kutuzovskij Prospekt beschränkt, während auf dem Roten Platz primär historische Uniformen präsentiert wurden.

118 Vgl. Putin, Vladimir: Parad Pobedy prodemonstriruet oboronnyj potencial Rossii. In: Vesti.ru, 5 maja 2008. Online: http://www.vesti.ru/doc.html?id=179425. 
lichkeiten. Im Jahr 2008 wurde nicht nur in Moskau Militärtechnik präsentiert und dadurch in die Tradition des militärischen Ruhms gestellt - auch in vielen weiteren Städten der Russländischen Föderation ${ }^{119}$ war militärisches Gerät Teil der Inszenierungen am 9. Mai. ${ }^{120}$ Dass die Wiedereinführung der Militärtechnik in die Paraden ein auf Dauer angelegtes Projekt ist, zeigte sich im Februar 2009 als durch eine Änderung des Gesetzes über die >Verewigung des Sieges des Sowjetischen Volkes im Großen Vaterländischen Krieg 1941-1945 die Präsentation von Bewaffnung und Militärtechnik im Rahmen der Paraden zum 9. Mai festgeschrieben wurde. ${ }^{21}$

Auch bei Medvedevs zweiter Rede spielte ein konkretes Geschehen eine wichtige Rolle: der Georgienkrieg des Sommers 2008. Wie schon im Vorjahr wurde das zeitgeschichtliche Ereignis unter dem Begriff >militärisches Abenteuer ${ }^{122}$ thematisiert, ohne jedoch konkret Länder oder Namen zu nennen:

»Der Sieg über den Faschismus ist ein großes Beispiel und eine große Lehre für alle Völker. Eine Lehre, die auch heute aktuell ist, wenn es wieder jene gibt, die militärische Abenteuer suchen. ${ }^{123}$

Ebenfalls wie im Vorjahr ist diese erinnerungspolitische die Warnung vor militärischen Abenteuern als Lehre aus dem Großen Vaterländischen Krieg, der Einstieg in ein Plädoyer für die Einhaltung internationalen Rechts, friedlicher Regulierung von Konflikten, Waffenkontrolle und der Notwendigkeit einer neuen europäischen Sicherheitsarchitektur. ${ }^{124}$

Auch die für diese Veranstaltungen typische patriotische Tonart ist in dieser zweiten Rede Medvedevs präsent. ${ }^{125}$

Die Parade des Jahres 2010 wurde als >rundes` Jubiläum ähnlich wie schon beispielsweise 2005 oder auch 1995 im Beisein vieler internationaler Staatsund Regierungschefs abgehalten. Wie anlässlich der vorangegangenen runden Jubiläen trug dem auch 2010 die Rede Medvedevs Rechnung: Ein Schwerpunkt

119 So beispielweise in Sankt Petersburg, Kaliningrad, Chabarovsk, Vladivostok, Severomorsk, Tomsk, Kemerovo, Volgograd, Rostov na Donu, Ekaterinburg und Čeljabinsk.

120 Vgl. Newsru: Parady s učastiem voennoj techniki prochodjat 9 maja vo mnogich krupnych gorodach Rossii. 9 maja 2008 g. Online: http://www.newsru.com/russia/09may 2008/paradvezde.html.

121 Federal'nyj zakon ot 19.05.1995 N 80-FZ (Redakcija N 3 ot 09.02.2009)»Ob uvekovečenii Pobedy sovetskogo naroda v Velikoj Otečestvennoj vojne 1941-1945 godov«.

122 Der Begriff `militärisches Abenteuer` war zentral bei der Beschreibung des Vorgehens Georgiens gegen Abchasien und Südossetien in vielen russländischen Medien.

123 Medvedev, Dmitrij: Vystuplenie na voennom parade v čest' 64-j godovščiny Pobedy v Velikoj Otečestvennoj vojne. 9 maja 2009 goda. Moskva, Krasnaja ploščad'. Online: http://kremlin.ru/transcripts/4015

124 Ebd.

125 Vgl. ebd. 
lag auf der Notwendigkeit der Solidarität in der internationalen Staatenwelt. ${ }^{126}$ Wie beschrieben, hatte Vladimir Putin fünf Jahre zuvor die Notwendigkeit der Zusammenarbeit sowie der Aussöhnung betont ${ }^{127}$ und El'cin im Jahr 1995 die Vereinigung der Kräfte der internationalen Staatenwelt für gemeinsame Ziele gefordert. ${ }^{128}$

Die Teilnahme von Soldaten aus den GUS-Staaten wie auch aus Staaten der Anti-Hitler-Koalition an der Parade interpretierte Medvedev als Zeichen gegen Revisionismus und für die gemeinsame Bereitschaft, den Frieden zu verteidigen und keine neuen Tragödien zuzulassen. ${ }^{129}$

Medvedevs Rede 2011 ist in erinnerungspolitischer Hinsicht demgegenüber deutlich zurückgenommen. Prinzipien der internationalen Zusammenarbeit und das Eintreten für ein gemeinsames Sicherheitssystem sowie globale Stabilität stehen im Zentrum der Rede. Diese Ausführungen zur internationalen Politik oder auch zu Peace-Keeping-Missionen der Russländischen Streitkräfte sind aber erinnerungspolitisch kaum eingebunden und dienen eher als Überleitung, um die Modernisierung der Streitkräfte zu thematisieren.

\subsubsection{Putins Rückkehr 2012: Eine patriotische Wende?}

Im Jahr 2012 wurde die Rede zum 9. Mai wieder von Vladimir Putin gehalten, der zwei Tage zuvor seine dritte Amtszeit als Präsident angetreten hatte. In Bezug auf die erinnerungspolitischen Schwerpunkte knüpfte er an seine letzten Reden anlässlich der Parade in den Jahren bis 2008 und an die Reden Medvedevs aus den Jahren 2008 und 2009 an. 2012 ist es der militärisch eskalierte Konflikt in Syrien, vor dessen Hintergrund Putin die Achtung internationalen Rechts sowie nationalstaatlicher Souveränität und die Nichteinmischung in innere Angelegenheiten von Staaten als Lehre aus dem Kampf der Anti-HitlerKoalition fordert. ${ }^{130}$

126 Vgl. Medvedev, Dmitrij: Vystuplenie Prezidenta Rossii na parade, posvjaščënnom 65-letiju Pobedy v Velikoj Otečestvennoj vojne. 9 maja 2010 goda. Moskva, Krasnaja ploščad'. Online: http://kremlin.ru/transcripts/7685.

127 Vgl. Putin, Vladimir: Vystuplenie na Voennom parade v čest' 60-j godovščiny Pobedy v Velikoj Otečestvennoj vojne. 9 maja 2005 goda. Moskva, Krasnaja ploščad'. Online: http://kremlin.ru/transcripts/22959.

128 Vgl. Fernsehübertragung. 1-j kanal Ostankino: Moskva, Krasnaja Ploščad'. Parad v čest' 50-letija pobedy. 09.05.1995, $8.50 \mathrm{Uhr}$.

129 Vgl. Medvedev, Dmitrij: Vystuplenie Prezidenta Rossii na parade, posvjaščënnom 65letiju Pobedy v Velikoj Otečestvennoj vojne. 9 maja 2010 goda. Moskva, Krasnaja ploščad'. Online: http://kremlin.ru/transcripts/7685.

130 Vgl. Putin, Vladimir: Voennyj parad v čest' 67-j godovščiny Velikoj Pobedy. 9 maja 2012 goda. Moskva. Online: http://kremlin.ru/transcripts/15271. 
In Bezug auf die Tonlage knüpfte Putin ebenfalls eher bei den Jahren 2008 und 2009 als an seine letzte zugespitzte Rede des Jahres 2007 an. Gegen wen sich die Vorwürfe, das internationale Recht zu verletzen und sich in die inneren Angelegenheiten anderer Staaten einzumischen, richten, wird wie 2007 nicht explizit formuliert. Anders als 2007 unterbleibt 2012 jedoch die Parallelisierung der den USA zugeschriebenen Politik mit der nationalsozialistischen Kriegspolitik. Die `Lehren` des Krieges werden wieder als Appell zur Kooperation präsentiert.

Die Rede anlässlich der Parade zum 9. Mai 2012 hebt sich jedoch aus einem anderen Grund von ihren Vorgängern ab. Vladimir Putin leitet aus der Kriegserfahrung ein besonderes moralisches Recht ab, die eigenen Positionen mit Nachdruck zu vertreten:

»Und wir haben ein großes moralisches Recht, grundsätzlich und beharrlich unsere Positionen zu verteidigen; Weil gerade unser Land den Hauptschlag des Nazismus auf sich genommen hat..131

Damit liefert er eine erinnerungspolitische Fundierung für eine russländische Politik, die sich unabhängig geriert, aber vor allem Legitimationsquellen in der Geschichte als Ersatz oder Ergänzung zu politischen Argumentationen erschließt. Im Kern macht sich dieser Ansatz - unabhängig von den problematischen Implikationen, die sich daraus entwickeln, ob mit `unser Land die Sowjetunion, die RSFSR, oder eine im Prinzip russische Sowjetunion gemeint ist, einen ähnlichen Exzeptionalismus zu eigen, wie ihn Putin 2007 den USA vorgeworfen hatte.

Dieser Ansatz lässt sich als ein deutlicher Hinweis auf die mit der Wiederwahl beginnende Betonung von patriotischen Wendungen interpretieren. Dementsprechend hebt Putin den bis dahin in diesem Format sehr seltenen Begriff des $>$ Patriotismus auch auf eine Stufe mit moralischen Werten hervor. ${ }^{132}$

Im folgenden Jahr rückte die Lage der internationalen Politik wieder stärker in den Mittelpunkt der Rede: Die deutlichen Verweise auf die Bedeutung von Frieden und Unabhängigkeit können als Positionierungen bzw. Appelle in Bezug auf den endgültig eskalierten syrischen Bürgerkrieg interpretiert werden. Die Verweise auf die innere Geschlossenheit und die Wahrung der Interessen der Heimat lassen sich ebenfalls in Hinblick auf die immer deutlicher werdende Konfrontation mit NATO-Staaten im Zusammenhang mit dem syrischen Bürgerkrieg lesen. Der Hinweis auf die selbstlose Befreiung Europas durch

131 Ebd.

132 Vgl. Putin, Vladimir: Voennyj parad v čest' 67-j godovščiny Velikoj Pobedy. 9 maja 2012 goda. Moskva. Online: http://kremlin.ru/transcripts/15271. Den Begriff Patriotismus benutzte Medvedev in seiner Rede anlässlich des 9. Mai 2008. Ab 2012 hat er seinen festen Platz im rhetorischen Repertoire der Reden anlässlich der Parade zum 9. Mai. 
die >unsrigen` Soldaten hebt Russlands Rolle als unverzichtbare und positive Ordnungsmacht in der internationalen Welt auch für die Gegenwart hervor. ${ }^{133}$

Die Rede betont abschließend besonders den Wert des \Lebens in Frieden . Die entsprechende Passage stellt in ihrer beinahe lyrischen Formulierung eine Innovation dar:

»Der Sieg im Mai 1945 ist ein Sturmläuten für ein Leben ohne Krieg, er ist ein heiliges Symbol der Treue zur Heimat[...]..134

Insbesondere der Begriff des »heiligen Symbols der Treue zur Heimat« erinnert an die wortgewaltigen Formulierungen des neo-stalinistisch-orthodoxen Publizisten Aleksandr Prochanov in der Zvezda und gibt damit einen Hinweis darauf, dass die konservativ-patriotische Neuausrichtung sich auch in ihrer Rhetorik auf das u. a. von Prochanov repräsentierte Milieu zubewegt.

\subsubsection{Wende nach innen 2014}

Der im Mai 2014 aktuelle Konflikt innerhalb der Ukraine sowie zwischen Russland und der Ukraine und damit einhergehend die Verschlechterung der Beziehungen zu den Ländern Westeuropas und den USA spiegeln sich deutlich im erinnerungspolitischen Teil der Rede zum 9. Mai 2014: Mit den Verteidigern von Sewastopol und der Schlacht am Dnepr werden zwei geographische und historische Bezugspunkte gesetzt, die auf den aktuellen Konflikt verweisen. Nach einer Einführung des 9. Mai als »Tag des nationalen Triumphes, des Volksstolzes, der Trauer und des ewigen Andenkens « $^{135}$, die in ihrer national-patriotischen Formulierung an Reden Boris El'cins in den 1990er Jahren erinnert, hebt Putin die besondere erinnerungspolitische Bedeutung des Tages für die Formierung von Patriotismus und den Beweis von Loyalität gerade in Krisenzeiten hervor:

»Dies ist der Feiertag, an dem die überwältigende Kraft des Patriotismus triumphiert, an dem wir besonders deutlich fühlen, was Treue zur Heimat bedeutet und wie wichtig es ist, ihre Interessen verteidigen zu können. ${ }^{136}$

In den 2000er Jahren war der 9. Mai meist das erinnerungspolitische Datum, um auf die Notwendigkeit der internationalen Solidarität und Zusammen-

133 Vgl. Putin, Vladimir: Voennyj parad v čest' 68-j godovščiny Velikoj Pobedy. 9 maja 2013 goda. Moskva. Online: http://kremlin.ru/transcripts/18089.

134 Ebd.

135 Vgl. Putin, Vladimir: Parad Pobedy na Krasnoj ploščadi. 9 maja 2014 goda. Moskva. Online: http://kremlin.ru/transcripts/20989.

136 Ebd. 
arbeit gegen gemeinsame äußere Bedrohungen zu verweisen. In der Rede 2014 wird dieses Prinzip nun nach innen gewendet: Die Kraft des Patriotismus und die Loyalität zur Heimat ersetzen die Solidarität, an die Stelle der internationalen Kooperation in Sicherheitsfragen tritt die Fähigkeit, eigenständig für die Interessen der Heimat einstehen zu können. Die erinnerungspolitische Funktion, die Notwendigkeit innerer Einigkeit aus der Geschichte abzuleiten, kam ansonsten primär dem 4. November zu, dem Tag der Einheit des Volkes.

In der Wortwahl auffällig ist die erstmalige Verwendung des Begriffs »sowjetisches Volk« durch Vladimir Putin.

»Der eiserne Wille des sowjetischen Volkes, seine Furchtlosigkeit und Standhaftigkeit retteten Europa vor der Sklaverei.. ${ }^{137}$

Letztmalig gebraucht am 9. Mai 1996 von Boris El'cin, ist der Begriff eher typisch für die Reden der sowjetischen Verteidigungsminister. Das zitierte Motiv des Retters Europas vor der Versklavung weist keinen besonderen Bezug zum aktuellen Konflikt auf, da es auch zuvor verwendet wurde. Auch wird im weiteren Verlauf der Rede am neueren Sprachgebrauch des Nazismus anstelle des Faschismus festgehalten. Der Begriff des Faschismus wurde in den Reden zum 9. Mai bis 2009 parallel zum Begriff des Nazismus verwendet, danach taucht er nicht mehr auf. Eine Verwendung des abgelösten Begriffs hätte als eine Unterstützung des Narrativs von der `Faschistischen Junta ( gewertet werden können, das zeitweilig in russländischen Medien in Bezug auf die Kiewer Übergangsregierung ab Ende Februar 2014 verbreitet wurde.

In der symbolischen Ausgestaltung der Parade fällt auf, dass 2014 erstmals nicht nur Zuschauer und offizielle Vertreter der Politik fast ausnahmslos das Georgsbändchen tragen, sondern auch die Soldaten und die Militärfahrzeuge der Parade.

\subsubsection{Rückkehr zu appellativen Traditionen 2015}

Lässt sich die Parade von 2014 in vielen Bereichen als eine national-patriotische Wendung nach Innen lesen, so kehrt sich die Rhetorik 2015 in vielen Bereichen wieder nach außen und greift bestehende Traditionen wieder auf. Die erste dieser Traditionen betrifft die stärkere Berücksichtigung der internationalen Komponente des Sieges im Rahmen der rrunden< Feierlichkeiten, bei denen regelmäßig eine große Zahl von Staats- und Regierungschefs anwesend ist. 2015 fällt diese Berücksichtigung noch deutlicher aus als in den Jahren 2005 und 1995; dies betrifft zum einen die damaligen Verbündeten: 
»Aber wir erinnern uns auch an unsere Verbündeten der Anti-Hitler-Koalition. Wir danken den Völkern Großbritanniens, Frankreichs und der Vereinigten Staaten für ihren Beitrag zum Sieg. ${ }^{138}$

Ebenfalls ausführlich und an verschiedenen Stellen der Rede wird die Rolle der Sowjetunion und der Roten Armee, vor allem in ihrer multinationalen Charakteristik, thematisiert: »Für die Freiheit der Heimaterde kämpfte das ganze multinationale Volk. « ${ }^{139}$ Am Ende der Rede wird noch einmal herausgestellt, dass die Großväter und Urgroßväter der paradierenden Soldaten aus Russland, Aserbaidschan, Armenien, Belarus, Kirgisien, Kasachstan und Tadschikistan an der Front und im Hinterland Schulter an Schulter gekämpft hätten. ${ }^{140}$

Die hier beschriebene Schwerpunktsetzung fand auch im Umfeld der Feierlichkeiten einen deutlichen Niederschlag. So wurde im Vorfeld am 28. April 2015 im Zentralen Museum des Großen Vaterländischen Krieges im Siegespark in Moskau die Ausstellung »Im Kampf gegen den Nazismus waren wir zusammen ${ }^{141}$ eröffnet, die in 15 Abteilungen Aspekte des Krieges und der Erinnerung aus der Perspektive von 15 Sowjetrepubliken darstellte.

Die zweite Tradition, die 2015 wiederbelebt wurde, war der erinnerungspolitisch im Großen Vaterländischen Krieg begründete Appell zu internationaler Sicherheitskooperation und zur Verrechtlichung der internationalen Beziehungen. Die am Anfang der Passage stehende Analyse des andauernden Konflikts zwischen der Russländischen Föderation und den Staaten der EU sowie den USA hatte mahnenden Charakter: Unipolarität und Blockdenken stünden einer nachhaltigen globalen Entwicklung im Weg. ${ }^{142}$ Die folgende Forderung nach einer Sicherheitsarchitektur unterscheidet sich nur in einem Punkt von den entsprechenden Passagen der Reden der 2000er Jahre bis 2007: Die Basis für diese Architektur solle Blockfreiheit sein. ${ }^{143}$

Neben diesen wiederaufgelegten Traditionen fällt ein neuer Schwerpunkt auf. Erstmals in diesem Umfang wird über das `klassische‘ Heldengedenken hinaus auch der zivilen und nicht-heroischen Opfer gedacht:

»Wir verneigen uns vor allen, die bis zum Tode für jede Straße, jedes Haus und jede Grenze des Vaterlandes einstanden; die in den grausamen Kämpfen bei Moskau und

138 Putin, Vladimir: Vystuplenie Prezidenta Rossii na parade, posvjaščënnom 70-letiju Pobedy v Velikoj Otečestvennoj vojne. 9 maja 2015 goda. Online: http://kremlin.ru/ events/president/transcripts/49438.

139 Ebd.

140 Vgl. ebd.

141 Vgl.Central'nyjmuzejVelikojOtečestvennojvojny:Vbor'beprotivnacizmamybylivmeste (Ausstellung). Online: http://www.poklonnayagora.ru/?part=57\&id_single=1983.

142 Vgl. Putin, Vladimir: Vystuplenie Prezidenta Rossii na parade, posvjaščënnom 70-letiju Pobedy v Velikoj Otečestvennoj vojne. 9 maja 2015 goda 10:20 Online: http://kremlin.ru/ events/president/transcripts/49438.

143 Vgl. ebd. 
Stalingrad, am Kursker Bogen und am Dnepr umkamen; die an Hunger und Kälte im nicht unterworfenen Leningrad starben; die in den Konzentrationslagern, in der Gefangenschaft, in der Okkupation zu Tode gequält wurden. « ${ }^{144}$

Im Anschluss folgte erstmals eine Schweigeminute im Rahmen der Siegesparade am 9. Mai. Auch dieses Ritual ist eher im Opfer- als im Heldengedenken verwurzelt. ${ }^{145}$ Der neue Schwerpunkt, über ein `klassisches` KriegsheldenGedenken hinauszugehen, zeigte sich auch im weiteren Verlauf des Siegestages im Marsch des `Unsterblichen Regiments`: Diese verhältnismäßig junge Tradition, die das abstrakte und militärisch geprägte Kriegsgedenken auf eine persönliche, auf eine Familienebene holt, wurde erstmals in großem Umfang in Moskau durchgeführt und nahm auch in der Berichterstattung über den Tag großen Raum ein. ${ }^{146}$ Mehrere hunderttausend Menschen trugen nach der Parade Fotos ihrer Angehörigen durch die Straßen. ${ }^{147}$

Zu Beginn der Parade des Jahres 2015 fiel zudem ein christliches Symbol auf: Bei der Ausfahrt aus dem Tor des Spasskij Turms bekreuzigte sich der buddhistische Verteidigungsminister Sergej Šojgu unter der 2010 freigelegten und restaurierten Tor-Ikone. ${ }^{148}$

\subsubsection{Kriegsnarrativ und Inszenierung}

Neben diesen direkten erinnerungspolitischen Bezügen, die aus der Geschichte Handlungsmaximen für die Gegenwart ableiten, sind die Reden zum 9. Mai aber auch ein zentraler Ort, an dem die russländische Geschichte >geschrieben` wird. Durchgängig referieren die Präsidenten Medvedev und Putin Geschichtsnarrative - primär mit Bezug zum Großen Vaterländischen Krieg und

144 Ebd.

145 Vgl. Lichau, Carsten: `The moving, awe-inspiring silencer. Zum semotionalen Potenzial der Schweigeminute. In: Jarzebowski, Claudia/Kwaschik, Anne (Hg.): Performing emotions: interdisziplinäre Perspektiven auf das Verhältnis von Politik und Emotion in der Frühen Neuzeit und in der Moderne. Göttingen 2013, 69 ff. Zur Bedeutung der Schweigeminute für das Weltkriegsgedenken vgl. Danilova, Nataliya: The Politics of War Commemoration in the UK and Russia. London 2015, 99-103.

146 Vgl. z. B. Fernsehübertragung. Pervy Kanal: Vesti. 9. Mai 2015, 21 Uhr.

147 Zum Marsch des `Unsterblichen Regiments` vgl. Andreev, Dmitrij: Znaki Putina. jubilej Pobedy kak prostranstvo simvoličeskich akcij vlasti. In: Bordjugov, Gennadij (Hg.): Pobeda-70: rekonstrukcija jubileja. Moskau 2015, 150; Gabowitsch, Mischa/Gdaniec, Cordula/Makhotina, Ekaterina (Hg.): Kriegsgedenken als Event. Der 9. Mai im postsozialistischen Europa. Paderborn 2016 (In Vorbereitung).

148 Zur Einordnung dieser Geste vgl. Andreev, Dmitrij: Znaki Putina. jubilej Pobedy kak prostranstvo simvoličeskich akcij vlasti. In: Bordjugov, Gennadij (Hg.): Pobeda-70: rekonstrukcija jubileja. Moskau 2015, $152 \mathrm{f}$. 
in einem breiteren Fokus zum Zweiten Weltkrieg, aber teilweise auch darüber hinaus.

Eine Konstante der Reden im Rahmen der Paraden ist, dass der Krieg, oder auch die Umstände des Sieges, nur selten ausführlich erzählt werden. Während am 24. Juni 1945 durch Žukov vor allem die Rolle Stalins als Organisator des Sieges betont wurde, ${ }^{149}$ wird diese Rolle bei der nächsten großen Siegesparade 1965 bereits durch die Partei und den Marxismus-Leninismus eingenommen. Daneben steht aber bereits das Narrativ vom patriotischen Sieg des Volkes an der Front und im Hinterland: Nicht nur die Soldaten, sondern auch die Arbeiter, die Bauern, die Intelligenzija, die sowjetischen Frauen und die Jugend sind Schmiede des Sieges. ${ }^{150}$ Dieses Narrativ vom "Sieg des sowjetischen Volkes und seiner Streitkräfte « ${ }^{151}$ prägt die Reden anlässlich der Siegesparaden bis zum Ende der Sowjetunion.

In den Reden Boris El'cins bekommt das Kriegsnarrativ zunächst eine ambivalente Ausrichtung. Zum einen wird der militärische Ruhm hervorgehoben. In den Jahren 1995 und 1996 werden zugleich das Leid des Krieges und das Grauen der deutschen Verbrechen detailliert erzählt. Dieser Aspekt nimmt in den folgenden Jahren ab 1997 wieder geringeren Raum ein. Stattdessen werden neben dem militärischen Ruhm Tugenden, Werte und zunehmend der Patriotismus als kriegsentscheidend akzentuiert. In seiner Rede am 9. Mai 1999 erklärte El'cin, dass der Patriotismus den Sieg ermöglicht habe. ${ }^{152}$ Zumindest zum Teil nimmt der Patriotismus in den Reden die Stellung ein, die zur Sowjetzeit dem Marxismus-Leninismus zukam. ${ }^{153}$

Ab dem Jahr 2000 wird der zuletzt sehr pathetische Stil El'cins wieder zurückgenommen. Die Reden enthalten durchgängig die Bezeichnung »der schreckliche Krieg«. Auch das Grauen der deutschen Verbrechen wird wieder öfter thematisiert. In dieser Ausrichtung bleibt das Kriegsnarrativ über die Jahre stabil und wird nur in Teilbereichen ergänzt. So wird ab dem Jahr 2003 der gemeinsame Kampf der Völker der Sowjetunion in das Kriegsnarrativ integriert. Ebenfalls integriert - wenn auch nicht in jedem Jahr enthalten - wird die Erwähnung einzelner Kriegsereignisse, die mit den Tagen des militärischen Ruhmes verbunden sind: Erwähnt werden die Schlacht um Moskau, die Schlacht um Stalingrad und die Schlacht am Kursker Bogen. Seltener berücksichtigt werden die Blockade Leningrads oder die Schlacht am Dnepr.

Insgesamt werden Kriegsnarrative kaum entfaltet. Die Rede zum 9. Mai ist kein Anlass für eine Präsentation von Kriegsgeschehen. In den Jahren ab 2012 lässt sich in den Reden Putins teilweise eine ähnliche Orientierung fest-

149 Vgl. Pravda. Nr. 151 (9922) vom 25.06.1945, 3.

150 Vgl. Pravda Nr. 130 (17082) vom 10.05.1965, 2.

151 Pravda. Nr. 130 (24387) vom 10.05.1985., 1.

152 Vgl. Fernsehübertragung. Telekanal ORT: Voennyj parad. 09.05.1999, 9.50 Uhr.

153 Vgl. Kapitel: Der 9. Mai in Präsidentenreden: Die Siegesparaden bis 1999. 
stellen wie bei El'cin ab 1997: Die Reden werden abstrakter und die Schwerpunkte verlagern sich von einem Ereignisnarrativ hin zu einem Wertediskurs. Wie schon bei El'cin wird das Kriegsnarrativ heroischer präsentiert und die Schwerpunkte liegen zunehmend auf dem Patriotismus der Kriegsgeneration - mit einem Fokus auf die Soldaten und ihre Vorbildhaftigkeit.

Der Sieg wird in den Reden nicht »russisch « vereinnahmt, d. h. nicht als Sieg der Russen, des Russischen Volkes oder Russlands erzählt. ${ }^{154}$ Entsprechend der sowjetischen Tradition wird der Sieg den Soldaten und Arbeitern, »unserem Land «, dem Volk allgemein oder den Völkern der Sowjetunion zugeschrieben. Zudem wird häufig an den runden Jubiläen besonders auf den Beitrag der Verbündeten und Alliierten hingewiesen. Dieses Narrativ des gemeinsamen Sieges ist nicht nur in den Reden präsent, sondern findet auch im Umfeld der Feierlichkeiten seinen Niederschlag: So wurde 2010 im Park des Sieges das Denkmal »Im Kampf gegen den Faschismus waren wir zusammen« eingeweiht, das die Kriegserinnerung in verschiedenen Ländern thematisiert, und im Jahr 2015 wurde im Vorfeld des Siegestags eine thematisch entsprechende Ausstellung im Museum des Großen Vaterländischen Krieges eröffnet. Die Betonung des gemeinsamen Erbes steht häufig im Zusammenhang mit der Verteidigung der GUS-Strukturen und weist damit einen geopolitischen Bezug auf. Die Sowjetunion wird in den Reden nicht als politischer sozialistischer Staat, sondern als die Klammer präsentiert, die den Völkern die gemeinsame Abwehr der nazistischen Bedrohung ermöglichte.

Im Gegensatz zu den Paraden der 1990er Jahre ist die Gestaltung des Roten Platzes in den 2000er Jahren weniger wechselhaft. Die großen Dekorationen am Historischen Museum und am GUM wechseln zwar jedes Jahr, sie sind jedoch in ihrer Gestaltung ähnlich: Die Jahreszahlen 1941 und 1945 auf buntem Grund, häufig ergänzt durch das schwarz-orange Georgs-Band. Der Orden des Sieges ist wechselnd am Haupteingang des GUM oder am Historischen Museum angebracht.

Eine tatsächliche Veränderung stellt über die Jahre das Lenin-Mausoleum dar. Bis zum Jahr 2004 bleibt es im Rücken der Rednertribüne ungeschmückt. Im Jahr 2004 wird seine Silhouette an der Vorderseite durch gestufte russische Trikoloren verdeckt. Ab dem Jahr 2005 wird es dann zunehmend mit Dekorationselementen umbaut, die in der Regel die russische Trikolore, das GeorgsBand und den Schriftzug "9. Mai« enthalten. Ab 2007 wird das Mausoleum durchgängig zu allen Seiten mit umfangreicher Dekoration umbaut, sodass

154 In der Rede am 9. Mai 2013 gibt es eine Abweichung, die vermutlich einen Versprecher darstellt: »Wir werden uns immer erinnern, dass gerade Russland, die Sowjetunion die [...] Pläne der Nazisten zerstörte.« Vgl. Putin, Vladimir: Voennyj parad v čest' 68-j godovščiny Velikoj Pobedy. 9 maja 2013 goda. Moskva. Online: http://kremlin.ru/ transcripts/18089. 
es für den Tag der Parade faktisch aus dem architektonischen Ensemble des Platzes ausgeblendet wird.

Auffällig ist die über die Jahre zunehmende Verbreitung des Georgsbändchens als Anstecker. Auf den Großplakaten und Dekorationen war das Symbol schon zu Zeiten der sowjetischen Paraden und in den 1990er Jahren präsent gewesen. Im Zuge der 2005 gestarteten Aktion »Georgsbändchen« wird es auch als Anstecker am Revers Teil der Paraden. 2007 tragen es erstmals Präsident und Premierminister, ${ }^{155}$ ab 2014 sind dann auch ausnahmslos die paradierenden Soldaten und Fahrzeuge mit dem Symbol bestückt.

Im Ablauf der Parade stellen lediglich die Wiedereinführung der schweren Technik im Jahr 2008 und die Schweigeminute 2015 eine deutliche Veränderung dar. Ansonsten beschränkt sich die Regie auf kleinere Umgestaltungen. ${ }^{156}$

\subsubsection{Resümee: Reden und Siegesparaden}

Die Rede im Rahmen der Siegesparade stellt einen der wichtigsten Orte dar, an dem bestimmte Politikkomplexe erinnerungspolitisch bearbeitet werden. Diese Nutzung stellt keine Innovation der 2000er Jahre dar, sondern hat mit Malinovskij, Gorbačëv und El'cin prominente Vorläufer. Auffällig ist die Konsequenz und Regelmäßigkeit, mit der der geschichtliche Bezugspunkt mit einer Bedeutung für die gegenwärtige Politik gedeutet wird.

In den ersten Jahren stellen der Terrorismus und die Kooperationen gegen den Terrorismus die zentralen Themen der erinnerungspolitischen Bezüge dar, später folgt das Werben für die wirtschaftliche Integration im post-sowjetischen Bereich. Aber auch jeweils aktuelle Themen, wie rassistische Gewalt, der Geschichtsstreit mit Estland und die militärischen Konflikte in Georgien und Syrien, werden erinnerungspolitisch aufgeladen.

Neben dem Werben für Sicherheitskooperationen werden ab Mitte der 2000er Jahre auch zunehmend die divergierenden Sicherheitsinteressen gegenüber den Nato-Staaten thematisiert, in der Regel im Zusammenhang mit Plädoyers für die Stärkung des internationalen Rechts auf Grundlage der Vereinten Nationen. Eine Zuspitzung findet diese Entwicklung am 9. Mai 2007 in der Rede Vladimir Putins, der die Außenpolitik und Ideologie der USA partiell mit NS-Politik gleichsetzt.

155 Ende Februar 2007 hatte die Russländische Regierung eine Verordnung über die Verwendeung des Bändchens durch Teilnehmer und Gäste der Parade auf dem Roten Platz erlassen. Vgl. Postanovlenie Pravitel'stva RF ot 26.02.2007 g. N 128 »Ob učreždenii pamjatnogo nagrudnogo znaka učastnikam i gostjam voennogo parada na Krasnoj ploščadi«.

156 So trägt beispielsweise von 2006 bis 2014 die Ehrenformation die russische Trikolore vor dem Banner des Sieges, 2015 wird wieder das Banner an erster Stelle getragen. 
Nach einer Phase der rhetorischen Zurückhaltung unter Dmitrij Medvedev folgt ab 2012 eine patriotische Wendung nach innen. Das Werben für internationale Kooperation wird durch einen nach innen gerichteten Werte- und Traditionsdiskurs ersetzt. Betont werden die eigenen Traditionen der Stärke und der erkämpften und verteidigten Autonomie. In der Rhetorik wird zudem die Annäherung an das national-patriotische Lager deutlich. Das Jahr 2015 revidiert diese Wendung nach innen und betont wieder die Potenziale von Kooperationen. Gleichzeitig werden die Feierlichkeiten umgestellt, neben dem heroischen Kriegsgedenken werden auch Elemente eines Opfergedenkens integriert.

Das in den Reden präsentierte Kriegsnarrativ bleibt über die Jahre relativ statisch. Von großer erinnerungspolitischer Dynamik ist dagegen die Bedeutung, die dem geschichtlichen Bezugspunkt für die Gegenwart zugeschrieben wird.

\subsection{Reden vor der Föderalversammlung}

Die Tradition der Rede vor der Russländischen Föderalversammlung wurzelt noch in der letzten Phase der Sowjetunion. Mit der Einführung des Amtes des Präsidenten wurde auch die Institution der Rede vor dem Volksdeputiertenkongress der UdSSR eingeführt: Der Präsident sollte der Versammlung jährlich einen Bericht zur $»$ Lage des Landes ${ }^{157}$ erstatten - wozu es jedoch bis zur Aussetzung des Kongresses im September 1991 nicht kam.

Zur jährlichen Institution wurde die Rede vor der Föderalversammlung der Russländischen Föderation durch die Verfassung von 1993, die einen Bericht des Präsidenten über »die Lage des Landes und die Grundrichtungen der Innen- und Außenpolitik des Staates « $^{158}$ vorsah. Boris El'cin hielt die erste dieser Reden 1994 unter dem Titel »Über die Stärkung des russländischen Staates ${ }^{159}$

El'cin argumentiert in seinen Ansprachen selten erinnerungspolitisch, auch wenn er im Gegensatz zu seinen Nachfolgern durchaus häufig Bezüge zur UdSSR oder zu sowjetischen Institutionen herstellt. Eine Ausnahme stellt

157 Konstitucija SSSR prinjata VS SSSR 07.10.1977. Stat'ja 127.3. (5) geändert durch: Zakon SSSR ot 14 marta 1990 g. N 1360-I »Ob učreždenii posta Prezidenta SSSR i vnesenii izmenenij i dopolnenij v Konstituciju (Osnovnoj Zakon) SSSR“

158 Konstitucija Rossijskoj Federacija. Prinjata vsenarodnym golosovaniem. 12.12.1993.

159 El'cin,Boris:PoslaniePrezidentaRossiiBorisaEl'cinaFederal'nomuSobranijuRF:»Obukreplenii Rossijskogo Gosudarstva« 1994 god. Online: http://www.intelros.ru/strategy/gos_ rf/psl_prezident_rf_old/58-poslanija_prezidenta_rossii_borisa_elcina_federalnomu_ sobraniju_rf_1994_god.html. 
beispielsweise seine Argumentation für die Stärkung der kommunalen Selbstverwaltung mit dem Hinweis auf die »tiefen historischen Wurzeln in Form der Zemstvo ${ }^{160}$ des 19. Jahrhunderts dar.

Seine Reden enthalten vereinzelt geschichtliche Exkurse und Deutungen, wie z. B. der Abschnitt "Von der Revolution zur Perestroika ${ }^{161}$ in der Rede 1996, in dem er der Sowjetunion im Gegensatz zum Zarismus attestiert, einen Weg von der autoritären Führung zur Demokratie gefunden zu haben. In seiner letzten Rede 1999 spricht er auch über die historischen Erfahrungen der russländischen Völker, Politik und Wertewandel. ${ }^{162}$

Insgesamt unterscheiden sich die Ansprachen El'cins und die seines Nachfolgers in ihren grundsätzlichen geschichtlichen Bezugspunkten: Während sich Boris El'cin in der erinnerungspolitischen Begründung seiner Politik auf die Zeit der Sowjetunion, ihre Politik und ihre Institutionen bezieht, so verringern sich diese Bezugnahmen nach seiner letzten Ansprache 1999 deutlich. Für die Begründung von Politik ist für Vladimir Putin, der seine erste Rede vor der Föderalversammlung am 8. Juli 2000 hielt, nicht mehr die Zeit der Sowjetunion der entscheidende Bezugspunkt, sondern die Zeit der 1990er Jahre.

Bei den Reden sind nicht nur die beiden durch die Verfassung vorgesehenen Parlamentskammern anwesend, sondern eine Vielzahl weiterer staatlicher Organe und gesellschaftlicher Gruppen, wie Angehörige der Regierung, der obersten Gerichte, der Generalstaatsanwaltschaft, Oberhäupter der sogenannten traditionellen Religionen, Vertreter der Bürgergesellschaft und der Massenmedien.

Das für die Reden etablierte Format ermöglicht eine breite thematische Ausrichtung sowie in Teilen detaillierte Ausführungen. Die Reden Boris El'cins dauerten eine knappe Stunde und wurden durch eine wesentlich umfangreichere Schriftfassung von knapp 100 Seiten begleitet. ${ }^{163}$ Die Reden Putins aus den ersten Präsidentschaften waren etwas kürzer. Medvedevs Reden ab 2008 hatten eine ungefähre Länge von einer Stunde, ab 2012 behält Putin dieses längere Format bei.

Anders als etwa die Reden zum 9. Mai handelt es sich jedoch nicht um ein geschichtsnahes Redeformat. Dominierend in allen Reden ist die Beschreibung der Ausrichtung von staatlicher Politik und deren Begründung. Dabei stehen

160 Ebd.

161 El'cin,Boris: PoslaniePrezidenta Rossii BorisaEl'cina Federal'nomu Sobraniju RF:»Rossija za kotoruju my v otvete« 1996 god. Online: http://www.intelros.ru/strategy/gos_rf/psl_ prezident_rf_old/73-poslanie_prezidenta_rosii_borisa_elcina_federalnomu_sobraniju_ rf_rossija_za_kotoruju_my_v_otvete_1996_god.html.

162 Vgl. El'cin, Boris: Poslanie Prezidenta RF Federal'nomu Sobraniju ot 30.03.1999. Online: http://www.lawinrussia.ru/kabinet-yurista/zakoni-i-normativnie-akti/1999-03-30/ poslanie-prezidenta-rf-federalnomu-sobraniyu-ot-30031999.html oder Kommersant» Nr. 51 vom 30.03.1999, 1.

163 Vgl. Izvestiia, Nr. 37 (24144) vom 25.02.1994, 1 und 4. 
regelmäßig Fragen der Wirtschaftspolitik oder auch in geringerem Umfang der Sozialpolitik im Zentrum. Die Begründung der politischen Ausrichtung erfolgt in der Regel nicht durch erinnerungspolitische Bezugnahmen auf die Geschichte. So findet beispielsweise der Große Vaterländische Krieg so gut wie keine Erwähnung: El'cin führt ihn 1995 an, um auf die Notwendigkeit von Maßnahmen gegen faschistische Organisationen im Land hinzuweisen, ${ }^{164}$ 2006 liefert der Krieg eine Begründung für die Reform und Instandhaltung der Streitkräfte ${ }^{165}$ und 2014 dient er Putin als Ausgangspunkt für einen geschichtlichen Exkurs zu den Folgen einer Konfrontation mit Russland. ${ }^{166}$

\subsubsection{Die 1990er und die "Stabil'nost'»}

In den frühen 2000er Jahren sind vor allem die Deutungen der 1990er Jahre und die damit verbundenen Einordnungen der Gegenwart von erinnerungspolitischer Bedeutung.

Von Beginn an wird der Wechsel an der Staatsspitze und die Wahl Vladimir Putins von ihm selbst als ein Umbruch bzw. eine neue Periode beschrieben. ${ }^{167}$ Der Beginn dieser neuen Epoche wird jedoch nicht in klarer Abgrenzung zu den 1990ern beschrieben. Die 1990er werden als progressive Reformzeit beschrieben, in der die Freiheitsrechte, das demokratische System und das Mehrparteiensystem geschaffen wurden. Maßnahmen in Problembereichen, wie etwa die Föderalisierung, werden gegen Kritik in Schutz genommen, da sie im Sinne von höheren Zielen, wie der territorialen Integrität, notwendig gewesen seien. ${ }^{168}$

Der Schlusssatz dieser Passage im Jahr 2000 macht deutlich, dass hier keine inszenierte Abgrenzung oder ein konstruierter Bruch vorgenommen werden soll: Es sei immer leicht, die Vorgänger zu kritisieren. ${ }^{169}$ Die kritische Betrachtung der 1990er findet vor allem im motivierenden Teil der Rede Raum, in dem es um die >Wende zum Besseren` geht. So heißt es, zehn Jahre schweres

164 Vgl. El'cin, Boris: Poslanie Prezidenta Rossii Borisa El'cina Federal'nomu Sobraniju RF: »O dejstvennosti gosudarstvennoj vlasti v Rossii« 1995 god. Online: http://www.intelros. ru/strategy/gos_rf/psl_prezident_rf_old/72-poslanie_prezidenta_rosii_borisa_elcina_ federalnomu_sobraniju_rf_o_dejjstvennosti_gosudarstvennojj_vlasti_v_rossii_1995_ god.html.

165 Vgl. Putin, Vladimir: Poslanie Federal'nomu Sobraniju Rossijskoj Federacii. 10 maja 2006 goda. Moskva, Kreml', Mramornyj zal. Online: http://kremlin.ru/events/president/ transcripts/23577.

166 Vgl. Putin, Vladimir: Poslanie Prezidenta Federal'nomu Sobraniju. 4 dekabrja 2014 goda. Moskva, Kreml'. Online: http://kremlin.ru/transcripts/47173.

167 Vgl. Putin, Vladimir: Poslanie Federal'nomu Sobraniju Rossijskoj Federacii. 8 ijulja 2000 goda. Moskva, Kreml'. Online: http://kremlin.ru/events/president/transcripts/21480.

168 Vgl. ebd.

169 Vgl. ebd. 
und instabiles Leben seien genug, und die Macht sei verpflichtet Verbesserungen herbeizuführen. ${ }^{170}$

Einen Hinweis darauf, warum die 1990er Jahre in den Präsidentenreden zwar kritisch erzählt, aber nicht externalisiert oder in kritischer Abgrenzung erzählt werden, geben die ersten Anlässe der Präsentation dieses Narrativs: Kurz nachdem Vladimir Putin Anfang 2000 die Amtsgeschäfte von El'cin übernommen hatte, hielt er am 24. Februar eine Rede auf der Beerdigung seines früheren Vorgesetzten und Mentors, des ehemaligen St. Petersburger Bürgermeisters Anatolij Sobčak. ${ }^{171}$ In dieser kurzen Rede sind bereits die Eckpunkte des Narrativs präsent, das später im Rahmen der oben genannten Formate über die Jahre ausgebaut wurde. Putin charakterisiert in der Beschreibung des Wirkens des Verstorbenen die frühen 1990er als eine sehr schwierige und entbehrungsreiche Zeit, in der es jedoch durch das persönliche Engagement Sobčaks gelungen sei, beispielsweise im Zusammenhang mit dem Zusammenbruch der Versorgung der Stadt Leningrad/Sankt Petersburg in der Wendephase oder während der politischen Krisen 1991 und 1993 noch Schlimmeres $\mathrm{zu}$ verhindern. ${ }^{172}$ Die weitgehend apologetische Interpretation von politischen Fehlern, die sich durch die meisten späteren Reden zu diesem Thema zieht, ist ebenfalls hier begründet. Putin beschreibt die damalige politische Situation als präzedenzlos und deshalb die Fehler als zwangsläufig: Sobčak habe zu einer Politikergeneration gezählt, die nicht von der Erfahrung oder den Fehlern anderer hätte lernen können. ${ }^{173}$

Boris El'cin greift dieses Narrativ einer präzedenzlosen Zeit, in der Fehler gemacht wurden, jedoch die Grundlagen für die weitere Entwicklung des Landes gelegt wurden, einige Monate später im Rahmen der Inaugurationszeremonie Putins wieder auf. ${ }^{174}$

Auch bei der Einweihung des Denkmals für Anatolij Sobčak am 12. Juni 2006 - dem Tag Russlands - präsentiert Putin diese Interpretation.

»Der Erste zu sein ist immer schwer. Und noch schwerer ist es, in einer Epoche des Wandels und der Umgestaltung Verantwortung zu tragen; wenn alles wirklich neu ist, wenn man niemanden um Rat fragen kann, aber auch Warten unmöglich ist. ${ }^{175}$

170 Vgl. ebd.

171 Vladimir Putin war von 1994 bis 1996 stellvertretender Bürgermeister unter Anatolij Sobčak. Vgl. Sakwa, Richard: Putin. Russia's choice. London 2008, 11.

172 Vgl. Putin, Vladimir: Reč' na pochoronach Anatolija Sobčaka. 24 fevralja 2000 goda. Sankt-Peterburg. Online: http://kremlin.ru/events/president/transcripts/24142.

173 Vgl. ebd.

174 Vgl.El'cin, Boris: Reč' Borisa El'cina na ceremoniivstuplenija Vladimira Putinav dolžnost' Prezidenta Rossii 7 maja 2000 goda. Online: http://archive.kremlin.ru/events/articles/ 2007/04/125066/125149.shtml.

175 Putin, Vladimir: Vystuplenie na ceremonii otkrytija pamjatnika Anatoliju Sobčaku. 12 ijunja 2006 goda. Sankt-Peterburg. Online: http://news.kremlin.ru/transcripts/23627. 
Ein ganz ähnlicher Ansatz zeigte sich auch im Gedenken an Boris El'cin. Im Rahmen der offiziellen Trauerfeier lobte Putin das politische Werk El'cins uneingeschränkt und betonte dessen Mut, die Verantwortung auch für härteste, aber notwendige politische Entscheidungen zu übernehmen. ${ }^{176}$

Der frühe Zeitpunkt der Ausbildung des beschriebenen Narrativs in Bezug auf die 1990er Anfang des Jahres 2000 lässt die These zu, dass in diesem Fall die persönliche Verbundenheit Putins mit Anatolij Sobčak, aber auch Putins allgemeiner biografischer Bezug als politischer Akteur in der Umbruchszeit Einfluss auf die Ausgestaltung des Narrativs hatte. In rein strategischer und funktionaler Hinsicht wäre auch die kontrastive Konstruktion eines Bruches mit anschließender Begründung einer neuen Herrschaft für die erinnerungspolitische Einordnung der 1990er in Frage gekommen.

In der zweiten Rede vor der Föderalversammlung im Jahr 2001 fällt die Einordnung der 1990er Jahre mit Begriffen wie »Desintegration « oder "Zerfall der Staatlichkeit« schon kritischer aus. ${ }^{177}$ Diese kritische Beschreibung der 1990er geht mit einer relational positiven Beschreibung der Gegenwart einher: Die Abwesenheit von politischen Spannungen und wiederholten Krisen wird betont.

Die Gegenwart wird vor dem Hintergrund der krisenhaften Vergangenheit positiv gedeutet: Schon das Ruhige, die Abwesenheit von politischen Spannungen und wiederholten Krisen, ${ }^{178}$ wird zum Desideratum und zur Zielvorstellung. In dieser Konstellation leitet Vladimir Putin dann aus der shistorischen Erfahrung des 20. Jahrhunderts das politische Schlagwort seiner ersten Präsidentschaft ab, Stabilität - Stabil'nost. Putin deutet die Geschichte Russlands als einen Zyklus von Revolution, Konterrevolution und Bestrafung der 'Schuldigen ‘, den es zu überwinden gelte. An die Stelle dieses Zyklus müsse Stabilität im Sinne eines `Lebens nach normaler menschlicher Logik treten:

"Dieser Zyklus ist erledigt, es wird weder Revolutionen noch Konterrevolutionen geben. Die dauerhafte und ökonomisch begründete staatliche Stabilität ist eine Wohltat für Russland und für seine Menschen, und es ist schon lange höchste Zeit zu lernen, in dieser normalen menschlichen Logik zu leben, es ist höchste Zeit, sich bewusst zu machen, dass eine langwierige und schwierige Arbeit bevorsteht.. ${ }^{179}$

Einen interessanten Bezug - wenn auch in Abgrenzung - stellt Putin direkt im Anschluss her: A priori verteidigt er seinen Ansatz der Stabilität und des

176 Vgl. Putin, Vladimir: Vystuplenie na traurnom prieme posle proščanija s pervym Prezidentom Rossii Borisom Nikolaevičem El'cinym. 25 aprelja 2007 goda. Moskva, Kreml'. Online: http://kremlin.ru/events/president/transcripts/24196.

177 Vgl.Putin, Vladimir: Poslanie Federal'nomu Sobraniju Rossijskoj Federacii. 3 aprelja 2001 goda. Moskva, Kreml'. Online: http://kremlin.ru/events/president/transcripts/21216.

178 Vgl. ebd.

179 Ebd. 
langsamen, qualifizierten und täglichen Werkes gegen den Vorwurf der Stagnation, "Zastoj ${ }^{180}$ - ein Begriff, mit dem retrospektiv der politische, ökonomische und soziale Stillstand in den 20 Jahren bis zum Beginn der PerestrojkaReformen beschrieben wird. ${ }^{181}$

Auch im Folgejahr bleibt die Beschreibung der 1990er Jahre ambivalent: Zum einen werden die 1990er Jahre als Jahrzehnt »der Stagnation und der Krisen ${ }^{182}$ bezeichnet, zum anderen deutet man wie schon in den Vorjahren umstrittene Entscheidungen, wie beispielsweise die Praxis, den Regionen über Abkommen weitreichende Entscheidungskompetenzen zu ermöglichen, als verfassungsgemäß, erforderlich und notwendig. ${ }^{183}$

Im Jahr 2003 verschieben sich der Bezugspunkt der erinnerungspolitischen Passagen und der Tonfall. Der Akzent liegt nun weniger auf der Einordnung der 1990er Jahre als auf einer generalisierten Bezugnahme auf shistorische Erfahrung oder einen `tausendjährigen historischen Weg` des Landes. Gleichzeitig erscheinen Wendungen wie `Stolz auf das eigene Land ‘ oder `Respekt vor der eigenen großen Geschichte in der Rede. ${ }^{184}$

Politik wird nun weniger funktional »von den Umständen gerechtfertigt « ${ }^{185}$ und mehr aus der Geschichte begründet:

»Unsere gesamte historische Erfahrung bezeugt: Ein Land wie Russland kann in den bestehenden Grenzen nur leben und sich entwickeln, wenn es ein starker Staat ist. In allen Perioden eines geschwächten Landes - politisch oder ökonomisch - war Russland immer vom Zerfall bedroht. «"186

Diese Begründung des »starken Staates« ist einer der zentralen erinnerungspolitischen Aspekte der Rede des Jahres 2003 und wird an anderer Stelle durch einen Verweis auf einen » 1000 jährigen historischen Pfad Russlands « ${ }^{187}$ wiederholt.

Unverhohlen werden die 1990er Jahre in diesem Zusammenhang als Periode der »Schwächung des Landes« charakterisiert. Die wiederholte Erwäh-

180 Vgl. Putin, Vladimir: Poslanie Federal'nomu Sobraniju Rossijskoj Federacii. 3 aprelja 2001 goda. Moskva, Kreml'. Online: http://kremlin.ru/events/president/transcripts/21216.

181 Vgl. Yurchak, Alexei: Everything was forever, until it was no more: the last Soviet generation. Princeton 2005, 7 u. $31 \mathrm{f}$.

182 Putin, Vladimir: Poslanie Federal'nomu Sobraniju Rossijskoj Federacii. 18 aprelja 2002 goda. Moskva, Kreml'. Online: http://kremlin.ru/events/president/transcripts/21567.

183 Vgl. ebd.

184 Vgl. Putin, Vladimir: Poslanie Federal'nomu Sobraniju Rossijskoj Federacii. 16 maja 2003 goda. Moskva, Kreml'. Online: http://kremlin.ru/events/president/transcripts/21998.

185 Putin, Vladimir: Poslanie Federal'nomu Sobraniju Rossijskoj Federacii. 3 aprelja 2001 goda. Moskva, Kreml'. Online: http://kremlin.ru/events/president/transcripts/21216.

186 Putin, Vladimir: Poslanie Federal'nomu Sobraniju Rossijskoj Federacii. 16 maja 2003 goda. Moskva, Kreml'. Online: http://kremlin.ru/events/president/transcripts/21998.

187 Ebd. 
nung von Heldentaten und Opfern der Bevölkerung für das Land im Laufe Geschichte macht die Veränderung der Tonlage hin zu pathetisch-patriotischen Formulierungen deutlich. ${ }^{188}$

Die Verbindung von `historischer Heldentat` und `Opfern des Volkes` in diesem Abschnitt, in dem es primär um Stabilität und territoriale Integrität geht, hat einen ähnlichen Klang wie Passagen aus Reden des Kriegsgedenkens. ${ }^{189}$ Der patriotische Stil und die Ausrichtung auf Geschichtlichkeit lassen sich in verschiedenen Redeformaten in den Monaten vor der Duma-Wahl 2003 und bis zur Präsidentenwahl 2004 feststellen. ${ }^{190}$

An einem Beispiel aus der Rede des Jahres 2004 lässt sich zeigen, wie konkret die Deutung der Russländischen Geschichte seit Anfang der 1990er vorangetrieben wurde. Putin entwirft hier, kurz nach seiner ersten Wiederwahl als Präsident, eine dreistufige Periodisierung, die das Land durchlaufen habe. Die erste angeführte Etappe ist in ihrer Beschreibung als sozial und politisch konflikthaft sowie gesellschaftlich schmerzhaft unschwer als die Zeit der frühen 1990er Jahre zu erkennen. ${ }^{191}$ Die zweite Etappe, die Putin in der Beschreibung bereits sich bzw. den Seinen zuschreibt, wird als konservative Phase eingeordnet, die mit Altlasten der Vorgänger aufräumen und in der Fehlentwicklungen zunächst einmal aufgehalten werden mussten. Dies lässt sich als Beschreibung der 1990er Jahre ab Beginn des Jahres 1994 lesen, wobei die Beschreibung Interpretationsspielräume lässt. ${ }^{192}$ Die dritte Etappe - klar als die Präsidentschaft Vladimir Putins zu erkennen - wird als Zeit der Progression beschrieben. Nach der Beseitigung der >Altlasten`, soll in dieser Phase das eigentliche Ziel angegangen werden: die langfristige Entwicklung des `modernen russischen Staates ${ }^{193}$

Obwohl in dieser Gedankenfigur die 1990er Jahre teilweise sehr negativ beschrieben werden, findet keine Abgrenzung statt, stattdessen werden Teile sogar als >eigene Zeit charakterisiert. Darüber hinaus sind in den entsprechenden Passagen rechtfertigende Elemente über die besonderen politischen Umstände enthalten. ${ }^{194}$

188 Vgl. ebd.

189 Vgl. beispielsweise die Rede zum 9. Mai eine Woche vor der Rede vor der Föderalversammlung. Putin, Vladimir: Vystuplenie na parade v čest' 58 -j godovščiny Pobedy v Velikoj Otečestvennoj vojne. 9 maja 2003 goda, Moskva, Krasnaja ploščad'. Online: http://kremlin.ru/transcripts/21991.

190 So z.B. in der Rede zum Tag Russlands Juni 2003 und in der Rede zum Tag des Vaterlandsverteidigers Februar 2004.

191 Vgl. Putin, Vladimir: Poslanie Federal'nomu Sobraniju Rossijskoj Federacii. 26 maja 2004 goda. Moskva, Kreml'. Online: http://kremlin.ru/events/president/transcripts/22494.

192 Vgl. ebd.

193 Vgl. ebd.

194 Vgl. ebd. 
Diese Periodisierung der jüngsten russländischen Geschichte wurde im Jahr 2013 im historisch-kulturellen Standard für die Ausarbeitung der neuen Schulbücher für den Geschichtsunterricht festgeschrieben. ${ }^{195}$

\subsubsection{Patriotismus und Katharsis?}

Auch die Rede 2005 ist hinsichtlich der Deutung des Umbruchs und der 1990er Jahre interessant. In diesem erinnerungspolitischen Teil der Rede stellt Putin vor allem die Folgen des Umbruchs für die russischstämmige Bevölkerung der Sowjetunion heraus. Einem breiten internationalen Publikum bekannt wurde vor allem der erste Satz dieses Teils der Rede:

»Zunächst muss man anerkennen, dass der Zerfall der Sowjetunion zur größten geopolitischen Katastrophe des Jahrhunderts wurde. Für das russische Volk wurde er zu einem richtigen Drama. Dutzende Millionen unserer Mitbürger fanden sich außerhalb des russländischen Gebietes wieder. Die Epidemie des Zerfalls erstreckte sich auch auf Russland selbst. ${ }^{196}$

Anschließend geht er weitaus detaillierter als in den Vorjahren auf die prekäre Lage Russlands in den 1990er Jahren ein. ${ }^{197}$ Auffällig ist, dass erstmals in diesem Zusammenhang die Rolle der Oligarchen in den Medien und bei der Verfolgung ökonomischer Partikularinteressen als negativ hervorgehoben wird. ${ }^{198}$

Doch auch auf diesen Mängelkatalog folgt keine erinnerungspolitische Abgrenzung. Putin verweist explizit darauf, dass er die Geschichte der 1990er nicht ausschließlich negativ als "fortgesetzte Agonie des sowjetischen Systems « ${ }^{199}$ gedeutet sehen will. Stattdessen entfaltet er für die 1990er Jahre ein kathartisches Narrativ von einer schwierigen, aber besonders bedeutsamen Zeit, in der das Volk nicht nur »die Energie zum Selbsterhalt, sondern auch den Willen

195 Vgl. Konzept Lehrmethoden-Komplex, 74

196 Putin, Vladimir: Poslanie Federal'nomu Sobraniju Rossijskoj Federacii. 25 aprelja 2005 goda. Moskva, Kreml'. Online: http://kremlin.ru/events/president/transcripts/22931.

197 In dieser Passage zu den 1990er Jahren deutet er beispielsweise das Abkommen von Chasawjurt über die wechselseitigen Beziehungen zwischen der Russländischen Föderation und der Tschetschenischen Republik, mit dem 1996 der erste Tschetschenienkrieg beendet wurde, als Kapitulation. Das ist bemerkenswert, da sich diese Deutung zum einen klar von den üblichen offiziellen Beschreibungen abhebt und zum anderen in den Präsidentenreden bis heute nicht mehr wiederholt wurde.

198 Vgl. Putin, Vladimir: Poslanie Federal'nomu Sobraniju Rossijskoj Federacii. 25 aprelja 2005 goda. Moskva, Kreml'. Online: http://kremlin.ru/events/president/transcripts/ 22931.

199 Ebd. 
zu einem neuen freien Leben ${ }^{200}$ entwickelt habe. Gleichzeitig habe Russland in dieser Phase die staatliche Souveränität verteidigt und »fehlerlos einen neuen Vektor in seiner tausendjährigen Geschichte $\aleph^{201}$ gewählt. Die Aufgaben dieser Zeit seien gewesen, »die eigenen Werte zu bewahren, unbestreitbare Errungenschaften zu erhalten und die Lebensfähigkeit der russländischen Demokratie zu belegen. « $^{202}$

Als Lehre aus den Schwierigkeiten der 1990er Jahre postuliert Vladimir Putin am Ende dieses erinnerungspolitischen Teils der Rede, dass es eine Notwendigkeit gewesen sei, einen eigenen, russländischen Weg zu finden, um Staat und Gesellschaft demokratisch, frei und gerecht aufzubauen. ${ }^{203}$

Es scheint jedoch ein Anliegen der Rede zu sein, dass der herausgestellte reigener Entwicklungsweg nicht als Exzeptionalismus verstanden wird. Im Anschluss an die Passage über die Weichenstellungen der 1990er Jahre folgt ein Exkurs über europäische Kultur und Werte. »Zuallererst war Russland, ist Russland und wird Russland die größte europäische Nation sein. $\aleph^{204}$ Die europäischen Ideale von Freiheit, Menschenrechten, Gerechtigkeit und Demokratie seien über Jahrhunderte für die russische Gesellschaft in Bezug auf Werte die bestimmenden Orientierungspunkte gewesen. Von der Aufklärung über die Entstehung des Parlamentarismus und der Anerkennung von Menschenrechten bis hin zur Emanzipation der Frauen und sozialen Errungenschaften habe man einen gemeinsamen europäischen Weg beschritten. ${ }^{205}$

"All dies haben wir gemeinsam vollbracht - in manchem zurückbleibend und manchmal in manchem die europäischen Standards überholend. $^{206}$

Die Rede zeigt deutlich den Versuch, seigener Werte, Zielvorstellungen und Entwicklungsoptionen zu legitimieren, ohne sich jedoch aus dem europäischen Kontext zu lösen oder gar einen Gegenentwurf zu begründen.

Eine weitere Besonderheit der Rede vor der Föderalversammlung 2005 ist dem 60. Jubiläum des Kriegsendes und den anstehenden Feierlichkeiten zum Tag des Sieges geschuldet. Gleich in zwei Passagen wird der Große Vaterländische Krieg thematisiert: Zum einen, um aufgrund »des gemeinsamen historischen Schicksals, der russischen Sprache und der großen Kultur ${ }^{207}$ die Notwendigkeit des Zusammenhalts der Staaten der ehemaligen Sowjetunion in allen Bereichen und das gemeinsame Streben nach Freiheit herauszustellen. 
Zum anderen wird der Krieg im zukunftsweisenden Abschluss der Rede thematisiert, um auf die Verbindung des Sieges mit der Gegenwart hinzuweisen. Dabei wird neben dem Motiv der Solidarität mit der Kriegsgeneration - "Wir leben, weil sie siegten! ${ }^{208}$ - auch wieder der Begriff der eigenen Entwicklung aufgegriffen und damit das Kriegsnarrativ mit dem Reformnarrativ verbunden:

»Unser Volk kämpfte gegen die Sklaverei, kämpfte für das Recht, auf dem eigenen Boden zu leben, für das Recht, die eigene Sprache zu sprechen, seine eigene Staatlichkeit, Kultur und Traditionen zu haben. Es verteidigte sein Recht auf eine eigenständige Entwicklung. Es hat unserer Heimat damals eine Zukunft gegeben. Und von der heutigen Generation, von uns und Ihnen hängt ab, welche dies sein wird. ( $^{209}$

Im Jahr 2006 sind es erneut die 1990er, die im Zentrum des erinnerungspolitischen Teils der Rede stehen. Anders als in den Vorjahren werden die negativen Aspekte ohne apologetischen Zusatz referiert. Die 1990er Jahre seien, so Putin, verantwortlich für das geringe Vertrauen der Bürger in die Wirtschaft und die einzelnen Institutionen der staatlichen Macht, da weder der Staat noch die Wirtschaft die Hoffnungen der Menschen hätten erfüllen können. ${ }^{210}$

Diese Einschätzung ergänzt Putin mit einem Satz, der auf die legitimierende Funktion dieses Narrativs im Rahmen der Rede verweist: Er prangert die beispiellose, "amoralische« und widerrechtliche Bereicherung einiger Weniger auf Kosten der Mehrheit der Bürger an. ${ }^{211}$

Die ungewöhnliche deutliche Ausdrucksweise dient der Legitimierung des Vorgehens gegen einzelne Oligarchen und eines Staates, der postuliertes $>\mathrm{Ge}-$ meinwohl auch autoritär durchsetzt. Um diesen Ansatz auch in einem weiteren Kontext zu rechtfertigen, greift Putin - untypisch für dieses Format - auf ein längeres Zitat zurück:

"In unserer Arbeit an dem großen gesamtnationalen Programm, das den breiten Massen das Notwendigste geben soll, sind wir in der Tat einigen auf die Zehen getreten, und wir werden es weiterhin tun. Aber dies sind die Zehen derer, die nach einem hohen Posten oder großem Reichtum streben [...]. Gute Worte. Leider nicht von mir. Franklin Delano Roosevelt, 1934. « $^{212}$

Das Zitat soll belegen, dass Russland mit seiner Politik keinen Sonderweg beschreiten würde, sondern sich am Vorbild der USA orientiere und somit legitim handle.

208 Vgl. ebd.

209 Ebd.

210 Vgl. Putin, Vladimir: Poslanie Federal'nomu Sobraniju Rossijskoj Federacii. 10 maja 2006 goda. Moskva. Online: http://kremlin.ru/events/president/transcripts/23577.

211 Vgl. ebd.

212 Ebd. 
Im Folgejahr wird in der Rede wieder das Narrativ von den 1990ern als »schwierige Zeit der inneren Konflikte« präsentiert, in denen jedoch gleichzeitig die Fundamente für »zukünftige Reformen ${ }^{213}$ und ein »neues Leben « ${ }^{214}$ gelegt wurden.

\subsubsection{Dmitrij Medvedev und die 1990er}

Im November $2008^{215}$ hielt Dmitrij Medvedev seine erste Rede vor der Föderalversammlung. Die Rede weist weniger erinnerungspolitische Bezüge auf als die Reden seines Vorgängers. Ein Beispiel dafür ist die Herleitung von Werten. In den Reden der Vorjahre wurden Werte mit der Geschichte referenziert. So war beispielsweise von »den Werten unserer Vorfahren ${ }^{216}$ oder von »den moralischen Werten, die unser Volk in seiner mehr als tausendjährigen Geschichte entwickelt hat ${ }^{217}$ die Rede. Medvedev dagegen referenziert Werte mit der Verfassung. Gleich in mehreren Passagen der Rede von 2008 betont er diese Verortung: »Ziele und Werte unserer Gesellschaft sind in der Verfassung fixiert $[. ..] . \ll^{218}$

Aber auch Medvedev arbeitet in der Rede 2008 an der Deutung von Geschichte. So beklagt er eine geschichtliche Tradition der Staatszentrierung in Russland, die in den Rechten und Freiheiten der Bürger ein Hemmnis für die Macht des Staates sehe. Gegen diese Fehlstellungen >über Jahrhunderte hebt er die russländische Verfassung von 1993 als präzedenzlosen Fortschritt hervor. ${ }^{219}$

Die Gegenwart ist für Medvedev bereits eine weitere »Etappe des Fortschritts $\ll^{220}$, in der das `neue Russland bereits bewiesen habe, dass es die sozialen Verpflichtungen erfüllen, das Wirtschaftswachstum gewährleisten, die Rechte der Bürger garantieren, die Beachtung der Gesetze einfordern sowie sich erfolgreich mit dem Terrorismus und mit äußeren Aggressionen auseinandersetzen könne.

213 Putin, Vladimir: Poslanie Federal'nomu Sobraniju Rossijskoj Federacii. 26 aprelja 2007 goda. Moskva, Kreml'. Online: http://kremlin.ru/events/president/transcripts/24203.

214 Ebd.

215 Seit 2008 finden die Reden vor der Föderalversammlung nicht mehr im April oder Mai, sondern am Ende des Jahres - im November oder Dezember - statt.

216 Putin, Vladimir: Poslanie Federal'nomu Sobraniju Rossijskoj Federacii. 25 aprelja 2005 goda. Moskva, Kreml'. Online: http://kremlin.ru/events/president/transcripts/22931.

217 Putin, Vladimir: Poslanie Federal'nomu Sobraniju Rossijskoj Federacii. 26 aprelja 2007 goda. Moskva, Kreml'. Online: http://kremlin.ru/events/president/transcripts/24203.

218 Medvedev, Dmitrij: Poslanie Federal'nomu Sobraniju Rossijskoj Federacii. 5 nojabrja 2008 goda. Moskva, Bol’šoj Kremlëvskij dvorec. Online: http://kremlin.ru/events/ president/transcripts/1968.

219 Vgl. ebd.

220 Ebd. 
Alle diese Errungenschaften hätten bewirkt, dass Demokratie nicht mehr wie noch in den 1990er Jahren - mit Chaos, Hilflosigkeit und Erniedrigung assoziiert, sondern als sakrosankt wahrgenommen werde. ${ }^{221}$

Insgesamt ist der rhetorische Stil der Reden Medvedevs weniger patriotisch und pathetisch als der Stil der Reden Putins in diesem Format. An vielen Stellen nehmen legalistische Argumentationen die Stelle von historischen Bezügen ein und patriotische Töne werden teilweise durch Motivationsrhetorik ersetzt, die am ehesten dem Genre des Social Advertising zuzurechnen ist: »Letztendlich machen wir alles, was wir machen, für diejenigen, die wir am meisten lieben - unsere Kinder [...]...122

Geschichte spielt, anders als in den Reden Putins, eine weit geringere Rolle. So kommen die Reden 2010 und 2011 ohne nennenswerte Rückgriffe auf die Geschichte aus. Die Rede Medvedevs 2009 enthält lediglich eine konzise und interessante Deutung der jüngeren russisch-sowjetischen Geschichte: Im 20. Jahrhundert sei unter enormen Anstrengungen aus einem agrarischen und faktisch analphabetischen Land eine führende Industrie- und Technologiemacht geworden. Unter den Bedingungen des totalitären Regimes sei diese Position nicht zu halten gewesen und die Sowjetunion ein nicht-konkurrenzfähiger Rohstoffriese geblieben. ${ }^{223}$ Die Botschaft Medvedevs ist klar: Ohne die Fesseln des politischen Regimes könnte Russland wieder mindestens konkurrenzfähig, wenn nicht führend werden. Im Umkehrschluss könnte man seine Argumentation jedoch auch so interpretieren, dass ein totalitäres Regime funktional sei, um führend zu werden, aber eine liberalere Gesellschaft dann notwendig, um die Position zu halten.

\subsubsection{Die Rückkehr Putins}

Mit der Rückkehr Vladimir Putins ins Amt des Präsidenten 2012 kehrt auch der patriotisch-geschichtsbezogene Stil zurück in die Reden vor der Föderalversammlung. Diesmal jedoch mit einer gesteigerten Vehemenz und Dichte, die es nahelegt, so Hans-Henning Schröder, dass »die Putin-Administration eine Wende vollzogen hat und sich dem nationalen Lager annähert. « $^{224}$ Diese

221 Vgl. ebd.

222 Medvedev, Dmitrij: Poslanie Prezidenta Federal'nomu Sobraniju. 30 nojabrja 2010 goda. Moskva, Kreml'. Online: http://kremlin.ru/events/president/news/9637.

223 Vgl. Medvedev, Dmitrij: Poslanie Federal'nomu Sobraniju Rossijskoj Federacii. 12 nojabrja 2009 goda. Moskva, Bol'šoj Kremlëvskij dvorec. Online: http://kremlin.ru/events/ president/transcripts/5979.

224 Schröder, Hans-Henning: Vorwärts Russland! Die Botschaft des Präsidenten an die Nationalversammlung. In: Russland-Analysen Nr. 249 vom 14.12.2012, 4. 
Annäherung lässt sich als national-patriotisches Gegenkonzept zu der städtisch-liberalen Protestbewegung im Winter 2011/2012 lesen. ${ }^{225}$

Viele Passagen der Rede sind von Begriffen wie Patriotismus - »wie Solženizyn sagte: `Patriotismus ist ein organisches, natürliches Gefühl«« ${ }^{226}$ oder Wendungen wie »Wiedergeburt des Nationalbewusstsein ${ }^{227}$ geprägt. Diese Begriffe und Wendungen werden dabei häufig mit einer geschichtlichen Dimension referenziert: Man müsse begreifen, dass Russland nicht 1917 oder 1991 begann, sondern eine einheitliche, unverbrüchliche 1000 jährige Geschichte habe. ${ }^{228}$

Auch Werte haben nicht mehr nur eine legale Begründung wie in den vorangegangenen Jahren, sondern ebenfalls eine geschichtliche:

»Gegenwärtig erlebt die russische Gesellschaft einen klaren Mangel an geistigem Zusammenhalt: an Barmherzigkeit, an Mitgefühl zueinander, an Unterstützung und gegenseitiger Hilfe, ein Mangel dessen, was uns in allen Zeiten stärker gemacht hat, worauf wir stets stolz waren. ${ }^{229}$

Diese Veränderungen deuten darauf hin, dass sich die ideengeschichtlichen Bezugspunkte geändert haben. In den Reden vor der Föderalversammlung, die in seinen ersten Amtszeiten stattfinden, legt Putin seine Referenzpunkte selten offen. ${ }^{230} 2012$ verbindet Putin in einem der ersten Absätze eine Passage über globale Entwicklungspotenziale direkt mit den Ethnogenese-Theorien des Eurasisten Lev Gumilëv ${ }^{231}$ und spricht über Selbstständigkeit, Willen und innerer Energie von Nationen. ${ }^{232}$ Diese Ethnogenese-Theorien Gumilëvs genießen heute vor allem bei den neuen Rechten und den Neo-Eurasisten große Unterstützung. ${ }^{233}$ Die Rede greift in Teilen die Themen und die Sprache dieses Spektrums auf:

225 Zur Ausbildung einer sintrasystemischen` national-patriotischen Strömung vgl. Umland, Andreas: Neue rechtsextreme Intellektuellenzirkel in Putins Russland: das AntiOrange Komitee, der Isborsk-Klub und der Florian-Geyer-Klub. In: Russland-Analysen. Nr. 256 vom 03.05.2013, 2-5.

226 Putin, Vladimir: Poslanie Prezidenta Federal'nomu Sobraniju. 12 dekabrja 2012 goda. Moskva, Kreml'. Online: http://kremlin.ru/events/president/news/17118.

227 Ebd.

228 Vgl. ebd.

229 Ebd.

230 Eine Ausnahme ist vielleicht die Nennung des Philologen Dmitrij Lichačëv im Jahr 2007.

$231 \mathrm{Zu} \mathrm{Lev} \mathrm{Gumilëvs} \mathrm{Ethnogenesetheorien} \mathrm{im} \mathrm{Kontext} \mathrm{des} \mathrm{Eurasismus} \mathrm{vgl.} \mathrm{Wiederkehr,}$ Stefan: Die eurasische Bewegung: Wissenschaft und Politik in der russischen Emigration der Zwischenkriegszeit und im postsowjetischen Russland. Köln 2007, 195 ff.

232 Vgl. Putin, Vladimir: Poslanie Prezidenta Federal'nomu Sobraniju. 12 dekabrja 2012 goda. Moskva, Kreml'. Online: http://kremlin.ru/events/president/news/17118.

233 Vgl. z. B. die Bewegung der neuen Skythen, Online: http://newskif.su, oder das GumilëvZentrum: Online: http://www.gumilev-center.ru. 
»Und wenn eine Nation nicht fähig ist sich zu bewahren und zu reproduzieren, wenn sie die lebenswichtigen Orientierungen und Ideale verliert, dann braucht sie keinen äußeren Feind und wird auch so zerfallen. ${ }^{234}$

Auch der starke Staat wird nicht mehr aus der Verfassung abgeleitet, sondern findet seine Legitimation in der >charakteristischen Tradition ${ }^{235}$

Demgegenüber verändert sich die Deutung der 1990er Jahre kaum. Auch wenn Putin sie als eine Phase mit einer übersteigerten Bedeutung von `Privatinteressen deutet: Er erklärt sie als eine »natürliche Etappe ${ }^{236}$ im Übergang nach 70 Jahren sowjetischer Periode.

Im Zusammenhang mit der Forderung Putins nach einer stärkeren Würdigung der »Helden des Ersten Weltkriegs ${ }^{237}$ enthält die Rede eine weitere erinnerungspolitische Passage, die die Motivation der Putin-Administration für die Erinnerungsarbeit im Bereich des »historischen militärischen Gedächtnisses des Vaterlandes « ${ }^{238}$ offenlegt: Der Kampfgeist der Streitkräfte beruhe unter anderem auf Traditionen, der lebendigen Beziehung zur Geschichte und den Beispielen des Mutes und der Selbstaufopferung der Helden. ${ }^{239}$

Um diesen Ansatz zur Steigerung des Kampfgeistes der Streitkräfte umzusetzen, schlägt Putin anschließend die »Wiederherstellung der Namen der berühmtesten Militäreinheiten« vor: des Preobraženskij- und des Semënovskij-Regiments. Explizit geht es ihm dabei darum, »vergangene Epochen zu verbinden, die sowjetische und die noch älteren Epochen «. ${ }^{240}$

Bei aller offen nationalen Rhetorik im Rahmen der Rede des Jahres 2012 greift es zu kurz, diese mit völkisch-nationaler Rhetorik, wie sie in vielen Ländern Europas gebraucht wird, gleichzusetzen. Die Tonlage und auch die geschichtlichen Bezugspunkte mögen sich ähneln, die Bezugsgruppe ist jedoch keine ethnisch fassbare - es handelt sich nicht um einen russischen, sondern um einen russländischen Nationalismus. Nicht die Homogenität des Landes, sondern seine Heterogenität und Multiethnizität wird zum Ideal erhoben: »In unserer Vielfalt lag schon immer und liegt unsere Schönheit und unsere Stärke. ${ }^{241}$ Nationalismus und Chauvinismus werden als schädlich benannt und das Propagieren von »sogenannten >einfachen und endgültigen « Lösungen« durch Nationalisten zur Gefahr für Russland erklärt. ${ }^{242}$

234 Putin, Vladimir: Poslanie Prezidenta Federal'nomu Sobraniju. 12 dekabrja 2012 goda. Moskva, Kreml'. Online: http://kremlin.ru/events/president/news/17118.

235 Vgl. ebd.

236 Ebd.

237 Ebd.

238 Ebd.

239 Ebd.

240 Ebd.

241 Ebd.

242 Vgl. ebd. 
Damit bleibt der Ansatz zwiespältig: nationalistische Wirkmechanismen werden zwar getriggert, können aber dann nicht klassisch auf einer ethnischen Exklusionsebene wirken. Eine mögliche und nicht ungefährliche Substitution sieht Hans-Henning Schröder in der Projektion des Feindbildes auf »die Außenwelt und deren Agenten im eigenen Land ${ }^{243}$.

Im Jahr 2013 ist die nationale Rhetorik deutlich zurückgenommener. Interessanterweise ist jedoch die umfangreichste Passage, die sich mit Werten beschäftigt, im außenpolitischen Teil der Rede verortet. Vladimir Putin formuliert als Ziel russländischer Außenpolitik unter anderem das Recht auf Selbstständigkeit und nationale Eigenart ${ }^{244}$ für alle Länder. Er setzt dem als 'westlich erkennbaren Begriff von "geschlechtsloser und unfruchtbarer« Toleranz, ein Konzept des gemeinsamen »organischen Zusammenlebens« von Völkern entgegen, das auf den Erfahrungen von vielen Jahrhunderten russländischer Geschichte beruhe. ${ }^{245}$

Darüber hinaus bezeichnet er diese stoleranten westlichen Werte als einen im Grunde undemokratischen - weil gegen den Willen des Volkes gerichteten - Versuch, »traditionelle Werte >von oben` zu zerstören. ${ }^{246}$

Dem stellt er straditionelle Werte gegenüber, »die seit Jahrtausenden die geistige, moralische Grundlage der Zivilisation jeden Volkes ${ }^{247}$ jenseits vom ausschließlichen Materialismus gebildet hätten.

In dieser Passage sind - von einzelnen Begriffen bis hin zum Gegensatz zwischen >geistigem Osten $<$ und 'materialistischem Westen - viele Elemente des konservativen, anti-westlichen Diskurses des 19. Jahrhunderts und dem damit verbundenen messianischen Entwurf einer $>$ Russischen Idee enthalten. Dies könnte auch der Grund dafür sein, dass die Passage im Bereich der Außenpolitik verortet ist: Die formulierten Werte sind nicht nur für den Binnengebrauch nützlich. Sie lassen sich auch als verbindendes, nach außen gerichtetes Element in einer international ausgetragenen Auseinandersetzung mit snicht-traditionellen< Werten bzw. deren Vertretern einsetzen. Putin erklärt: „Und wir wissen, dass auf der Welt immer mehr Menschen unsere Position zur Verteidigung traditioneller Werte vertreten[...]. ${ }^{248}$

243 Schröder, Hans-Henning: Vorwärts Russland! Die Botschaft des Präsidenten an die Nationalversammlung. In: Russland-Analysen Nr. 249 vom 14.12.2012, 5.

244 Hier benutzt Putin den Begriff ,Samobytnost'` der seit dem 19. Jahrhundert zentral in der Debatte um russische Identität und Russische Idee ist. Vgl. Sukhov, Andrej: Stoletnjaja diskussija. Zapadnichestvo i samobytnost'v russkoj filosofii. Moskva 1998, $11 \mathrm{f}$;; Samochwalowa, V.I.: Na perekrestke kult'tur. O kul'turnoj samobytnosti Rossii. In: Akopjan, K. Z. (Hg.): Russkaja kul'tura i mir, Niznij Novgorod, 1994, Bd. 1, 7-9.

245 Vgl. Putin, Vladimir: Poslanie Prezidenta Federal'nomu Sobraniju. 12 dekabrja 2013 goda. Moskva, Kreml'. Online: http://www.kremlin.ru/events/president/news/19825.

246 Ebd.

247 Ebd.

248 Ebd. 
Dass Putin diesen Exkurs in das 19. Jahrhundert der Slawophilen mit einem Zitat Nikolaj Berdjaevs zum Sinn des Konservatismus - nicht »Bewegung nach vorne und oben, aber Bewegung zurück und nach unten in die chaotische Finsternis zu verhindern ${ }^{249}$ - beschließt, kann verwundern. So sieht Berdjaev Diskontinuität als Charakteristikum der russischen Geschichte an und wirft den Slawophilen vor, in ihrer Ablehnung petrinischer Reformen die sübelste Periode russischer Geschichte - die Moskauer - zu idealisieren. ${ }^{250}$

In der Rede vor der Föderalversammlung am 4. Dezember 2014 rückt neben den `traditionellen Werten « wieder nationale Rhetorik - ähnlich wie schon 2012 - ins Zentrum der Rede. Ein erheblicher Teil der Rede beschäftigt sich mit der Aufnahme der Krim in die Russländische Föderation, sodass zur Einordnung ein Exkurs auf eine weitere, jedoch außerplanmäßige Rede vor der Föderalversammlung notwendig erscheint. Am 18. März 2014 hatte Vladimir Putin, bevor er den »Vertrag zwischen der Russländischen Föderation und der Republik Krim über die Aufnahme der Republik Krim in die Russländische Föderation ${ }^{251}$ unterzeichnete, eine Rede vor den Abgeordneten der Duma, den Angehörigen des Föderationsrates, den Führungen der Föderationssubjekte sowie Vertretern der Zivilgesellschaft gehalten. Das Publikum entsprach somit weitgehend dem Publikum der Ansprachen vor der Föderalversammlung. Auch die Inszenierung der Rede im Georgssaal des Kremls und die Dekoration nahm sich dieses Format zum Vorbild. ${ }^{252}$

In dieser Rede, die zu einem großen Teil aus Geschichtsinterpretation besteht, leitet er erinnerungspolitisch einen Anspruch auf die Krim ab. Die Geschichte der Krim - am Beispiel des Gründungsmythos der Taufe Vladimirs wird dabei jedoch auch als vereinigende kulturelle, zivilisatorische Grundlage der Völker Weißrusslands, Russlands und der Ukraine beschrieben. ${ }^{253}$

Als wichtigstes erinnerungspolitisches Argument führt Putin - ganz im Geiste der Programme zur Patriotischen Erziehung der Bürger - die Krim als 'heiliges` Symbol des militärischen Ruhmes Russlands an:

"Auf der Krim sind die Gräber der Soldaten, durch deren Mut die Krim 1783 unter russländische Herrschaft kam. Krim, das ist Sewastopol, legendäre Stadt, Schicksalsstadt, Festungsstadt und Heimat der Schwarzmeerflotte. Krim, das ist Balaklava und

249 Ebd.

250 Vgl. Berdjaev, Nikolaj: Die russische Idee: Grundprobleme des russischen Denkens im 19. Jahrhundert und zu Beginn des 20. Jahrhunderts. Sankt Augustin 1983, 31.

251 Dogovor meždu Rossijskoj Federaciej i Respublikoj Krym o prinjatii v Rossijskuju Federaciju Respubliki Krym i obrazovanii v sostave Rossijskoj Federacii novych sub"ektov. 18. März 2014. Online: http://www.kremlin.ru/events/president/news/20605.

252 Lediglich die Anzahl der russländischen Fahnen hinter dem Rednerpult wurde von zwei auf acht erhöht.

253 Vgl. Putin, Vladimir: Obraščenie Prezidenta Rossijskoj Federacii. 18 marta 2014 goda. Moskva, Kreml'. Online: http://kremlin.ru/events/president/news/20603. 
Kertsch, Malachov Kurgan und Sapun-Gora. Jeder dieser Orte ist für uns heilig, ist ein Symbol des russischen militärischen Ruhmes und des beispiellosen Heldenmutes. ${ }^{254}$

Aufgezählt werden die beiden Heldenstädte Sewastopol und Kertsch sowie die Orte wichtiger Schlachten an, denen sich heute - z. B. am Sapun-Gora oder Malachov-Kurgan - bekannte Memorialkomplexe und ewige Feuer befinden.

In der ordentlichen Rede vor der Föderalversammlung am 4. Dezember neun Monate später gibt es eine ähnliche Passage, die sich mit der Bedeutung der Krim für Russland beschäftigt.

Im Gegensatz zur Rede im März wird die Krim nicht mehr als vereinigende kulturelle Grundlage heutiger Staaten, sondern als geistiger Ursprung des russländischen Staates und der russischen Nation benannt und damit erinnerungspolitisch nationalisiert. ${ }^{255}$

Gleichzeitig fehlt der Schwerpunkt auf den Traditionen des militärischen Ruhmes. An dessen Stelle argumentiert Putin zivilisatorisch-national und rückt den christlichen Gründungsmythos ins Zentrum: Das Christentum als »mächtige vereinigende geistige Kraft, die es erlaubte, eine einheitliche russische Nation zu bilden [...].« ${ }^{256}$ Die Passage gipfelt in den vielzitierten Sätzen von der Krim als russischem Tempelberg:

"Das gibt uns allen Grund zu sagen, dass für Russland die Krim, das altertümliche Korsun', Chersones und Sewastopol, eine große zivilisatorische und sakrale Bedeutung hat. Genauso wie der Tempelberg in Jerusalem für die, die sich zum Islam oder Judentum bekennen. ${ }^{257}$

Auffällig an dieser Passage des Jahres 2014 ist die Zuspitzung der Rede im Vergleich zu der Rede zur Krim im vorangegangenen März. Sie ist durch eine Verengung auf eine russisch-nationale Perspektive und durch eine Sakralisierung der Rhetorik gekennzeichnet. ${ }^{258}$

Auch andere Teile der Rede sind konfrontativ angelegt. So sind Geschichtsdeutungen in Bezug auf die Tschetschenienkriege enthalten, die zum Teil in seltener Deutlichkeit westliche Staaten beschuldigen, Separatismus und Terrorismus unterstützt zu haben. ${ }^{259}$ Man habe damals den Zerfall und die Auf-

254 Ebd.

255 Vgl. Putin, Vladimir: Poslanie Prezidenta Federal'nomu Sobraniju. 4 dekabrja 2014 goda. Moskva, Kreml'. Online: http://kremlin.ru/transcripts/47173.

256 Ebd.

257 Ebd.

258 Die Passage weist zudem Ähnlichkeit mit dem Text Prochanovs auf, der 2013 im Rahmen der Bike-Show in Volgograd präsentiert wurde. Dort wird Stalingrad als heiliger Ort mit Jerusalem verglichen.

259 Die Deutlichkeit dieser Passage kann durch den Umstand bedingt sein, dass in der Nacht ein Überfall von Islamisten im Zentrum Grosnys begonnen hatte, der während der Rede 
teilung des Landes nach jugoslawischem Drehbuch verhindert. ${ }^{260}$ In diesem Zusammenhang und unter Hinweis auf den Vernichtungskrieg Hitlers warnt Putin davor, wie es ende, wenn man versuche Russland zu vernichten. ${ }^{261}$

Insgesamt erscheint die Rede inhaltlich und in Rhetorik noch einmal gesteigert gegenüber der Rede zur Aufnahme der Krim, aber auch zu der Vorjahresrede. Inhaltlich stechen die Erklärung zum verhinderten JugoslawienSzenario und der damit verbundene Vorwurf an westliche Staaten hervor, Terroristen und die Zerschlagung Russlands unterstützt zu haben. Die rhetorische Steigerung ist in vielen Passagen präsent. Sinnbildlich dafür kann die Passage stehen, in der an Stelle des gängigen Elements des militärischen Ruhmes Russlands in allen Zeiten ein christlicher, national-russischer Gründungsmythos entfaltet und die Bedeutung der Krim für Russland mit der Bedeutung des Tempelbergs für Juden und Moslems gleichgesetzt wird.

Diese Radikalisierung und Sakralisierung der Rhetorik erscheint ungewöhnlich für ein funktionales, nicht festliches Redeformat, das im weitesten Sinne eine Rede zur Lage der Nation darstellt. Es ist der Versuch, erinnerungspolitisch und durch äußere Feindbildprojektion nach innen zu konsolidieren auch wenn dadurch der eigene Handlungsspielraum innen- wie außenpolitisch beschnitten wird: »Den `Tempelberg` gibt man nicht auf, einem `Hitler macht man keine Zugeständnisse. ${ }^{262}$

\subsubsection{Resümee: Reden vor der Föderalversammlung}

Die Reden vor der Föderalversammlung sind, obwohl der Anlass keinen direkten Geschichtsbezug aufweist, in erinnerungspolitischer Perspektive von großer Bedeutung. Das liegt zum einen daran, dass in dem jährlichen Format wichtige Ereignisse des Jahres aufgegriffen, interpretiert und historisch eingeordnet werden. Zum anderen ist diese Rede einer der zentralen Orte, an denen Politik begründet wird.

Wie häufig und in welcher Art die Geschichtsbezüge konstruiert werden, variiert stark. Auch wenn El'cin, im Gegensatz zu Putin, durchaus häufig auf die Zeit der Sowjetunion Bezug nimmt, spielt Geschichte in seinen Reden keine größere Rolle.

andauerte. Vgl. Muradov, Musa/Sergeev, Nikolaj: V Groznyj vernulis' smertniki. In: Kommersant« Nr. 221 vom 05.12.2014, 1. Online: http://kommersant.ru/doc/2625733.

260 Vgl. Putin, Vladimir: Poslanie Prezidenta Federal'nomu Sobraniju. 4 dekabrja 2014 goda. Moskva, Kreml'. Online: http://kremlin.ru/transcripts/47173.

261 Vgl. ebd.

262 Schröder, Hans-Henning: Politik in Zeiten nationaler Verzückung. Putins Botschaft zur Lage der Nation im Jahre 2014.. In: Russland-Analysen Nr. 288 vom 19.12.2014, 9. 
Das ändert sich im Jahr 2000 mit der ersten Rede Putins. Insbesondere die Deutung der 1990er Jahre spielt von Anfang an eine durchgehende Rolle - die 1990er sind der neue Referenzpunkt, an dem die Begründung von Politik ausgerichtet wird.

Mit der Rede 2003, die das letzte Jahr Putins erster Präsidentschaft einläutete, verändert sich die Rhetorik deutlich. Der Stil wird pathetischer und patriotischer im Sinne der Programme zur Patriotischen Erziehung der Bürger. Hier hält auch die Geschichte in ihrer erinnerungspolitischen Funktion Einzug: Politik und Werte werden nun zunehmend mit shistorischer Erfahrung, oder stausendjähriger Tradition` etc. begründet - Russland wird geschichtsphilosophisch zum Akteur erklärt, der sein Schicksal in der Zeit selbst bestimmt - seine `Vektoren in der tausendjährigen Geschichte` wählt.

In den Reden Medvedevs ab 2008 wird diese Entwicklung wieder zurückgenommen. Seine Reden sind eher funktionsorientiert und Geschichte spielt eine weit geringere Rolle. So begründet er, anders als in den Jahren zuvor $\mathrm{Pu}$ tin, Werte nicht aus der Geschichte, der Tradition, sondern aus der Verfassung der Russländischen Föderation.

Mit Putin kehrt 2012 auch der pathetisch-patriotische Stil zurück in die Reden vor der Föderalversammlung. Jedoch werden die bereits vor 2008 vorhandenen Elemente, erkennbar gesteigert: Die Sprache weist nun deutliche Anleihen beim national-konservativen und eurasistischen Spektrum ${ }^{263}$ auf und eigene, unterscheidbare Werte sowie das Postulat nationaler Eigenart allgemein nehmen breiten Raum ein. Neue Elemente stellen die Betonung des christlichen Glaubens und sakralisierende Wendungen in der Rhetorik dar. Die inhaltlichen Referenzen und Zitate in diesen Reden zeigen eine klare Annäherung an neue und alte Eurasisten, Nationalisten und das konservativchristlichen Spektrum.

Ein durchgängiges geschichtliches Deutungsobjekt der Reden von 2000 bis 2015 - ein Narrativ, an dem gearbeitet wird - stellen die 1990er Jahre dar. Bemerkenswerterweise dienen sie fast nie als reines Negativbeispiel. Gerade in den ersten Jahren wird die naheliegende erinnerungspolitische Möglichkeit, sich kontrastiv von der jüngeren Vergangenheit zu distanzieren, nicht genutzt. Auch später während der zweiten Amtszeit Putins werden Verweise auf Probleme und Fehlentscheidungen der 1990er Jahre in aller Regel von exkulpatorischen Passagen begleitet. 2005 entfaltet Putin sogar ein fast kathartisches Narrativ von den 1990ern als notwendig schwierige Leidenszeit, in der das Volk sich bewiesen habe und die Weichen für die Zukunft fehlerlos gestellt habe.

263 Zur eurasischen Bewegung und Aleksandr Dugin vgl. z. B. Dunlop, John: Aleksandr Dugin's `Neo-Eurasian` Textbook and Dmitrii Trenin's Ambivalent Response. In: Harvard Ukrainian Studies 25/1-2 (2001), 91-127. 
Im Jahr 2014 wird dann mit dem Tschetschenienkrieg ein Problemkomplex der 1990er Jahre - unter dem Vorwurf des von außen gewollten Jugoslawien-Szenarios - nach außen gewendet, um nach innen zu konsolidieren. So bleibt diese Epoche - in welchem Deutungszusammenhang auch immer - einer der wichtigen geschichtlichen Bezugspunkte der Reden vor der Föderalversammlung.

\subsection{Reden zum Tag des Vaterlandsverteidigers}

Eingeführt wurde der Tag 1922 als $>$ Tag der Roten Armee und Flotte ${ }^{264}, 1946$ wurde er in Tag der sowjetischen Armee und Seekriegsflotte Nach dem Ende der Sowjetunion wurde der Tag auch 1992 begangen. Jedoch zeigte sich von Beginn an eine Spaltung zwischen den offiziellen Feierlichkeiten der El'cin-Administration auf der einen und denen der kommunistischen Opposition und Veteranenverbänden auf der anderen Seite. Die Zeitung "Izvestija s stellte 1992 lakonisch fest: »Es scheint, nichts trennt uns heute so sehr wie die ehemaligen sowjetischen Feste. [...] Nun, so leben wir jetzt: zwei unterschiedliche Feste aus Anlass eines Datums. ${ }^{265}$

1993 wurde am 23. Februar zum ersten Mal der Tag der Verteidiger des Vaterlandes gefeiert. ${ }^{266}$ El'cin hatte kurz zuvor das $>$ Gesetz zur Verewigung des Andenkens an die Verteidiger des Vaterlandes« unterzeichnet. ${ }^{267}$ Stärker noch als im Vorjahr wurde der Tag durch die Opposition in Beschlag genommen. Während Aleksandr Ruckoj, Valerij Zor'kin und andere führende Politiker Blumen am Grab des unbekannten Soldaten niederlegten und zehntausende Nationalisten und Kommunisten auf dem Manege-Platz zusammenkamen, zeigte sich Boris El'cin nicht: Nach Angaben Ruckojs verbrachte er den Tag im Urlaub. ${ }^{268}$

Auch 1994 blieb der Tag politisiert und polarisiert. Die unterlegene Seite der Verfassungskrise vom September und Oktober 1993 nutzte den Tag des Vaterlandsverteidigers, um ihn mit dem Gedenken an die Verteidiger des Weißen Hauses zu verbinden. So wurde am 23. Februar nicht nur, wie auch in den vorangegangenen Jahren am Tag der Vaterlandsverteidiger, zu oppositionellen Gedenkveranstaltungen mobilisiert, sondern es wurden darüber

264 Offiziell sollte der Tag an die Gründung der Roten Armee im Jahr 1918 erinnern, das Datum ist jedoch nicht exakt gewählt.

265 Izvestia. Nr. 46 (23620) vom 24.02.1992, 1.

266 Izvestia. Nr. 34 (23889) vom 23.02.1993, 1.

267 Vgl. Zakon RF ot 14 janvarja 1993 g. N 4292-1 »Ob uvekovečenii pamjati pogibšich pri zaščite Otečestva«.

268 Vgl. Rossijskaja Gazeta. Nr. 37(653) vom 24.02.1993, 1. 
hinaus öffentlichkeitswirksam weitere vier Tote der Verteidigung des Weißen Hauses beerdigt und in der Staatsduma die Amnestie für die Beteiligten der Verfassungskrise - im Sprachgebrauch der Opposition: Verteidiger der Verfassung und des Vaterlands - beschlossen. ${ }^{269}$

1995 rückte der Tag wieder mehr in den Fokus der El'cin-Administration und wurde mit großen Feuerwerken in vielen Städten begangen, begleitet von Gratulationen El'cins und Gračëvs. ${ }^{270}$ Weniger der Tag selbst als die Verewigung des Andenkens und die Suche nach sterblichen Überresten der Verteidiger des Vaterlandes, wie es durch das Gesetz El'cins von 1993 intendiert war, wurde in der liberalen Presse gewürdigt. ${ }^{271}$

Kurz darauf, am 13. März 1995, unterschrieb Boris El'cin das Gesetz über die Tage des militärischen Ruhmes und brachte damit das erste große geschichtspolitische Projekt seiner Amtszeiten auf den Weg. In dem Gesetz war der 23. Februar als »Tag des Sieges der Roten Armee über die Kaiserlichen Truppen Deutschlands (1918) - Tag der Verteidiger des Vaterlands« festgeschrieben. ${ }^{272}$ Diese Bezeichnung als Tag des Sieges über die Kaiserlichen Truppen Deutschlands schrieb eine prekäre Geschichtsinterpretation aus dem stalinschen `Kurzen Lehrgang der Geschichte der VKP(B)< (Kratkij kurs istorii VKP(b) fort. Das Kriegsgeschehen, das Lenin 1918 in der Pravda noch als »quälend-schändlich « ${ }^{273}$, als Chaos und Flucht bezeichnet hatte, wurde in der stalinschen Geschichtsinterpretation zum entscheidenden Widerstand und das entsprechende Datum zum Geburtstag der Roten Armee erklärt. ${ }^{274}$

Wie die meisten erinnerungspolitischen Projekte der El'cin-Jahre wurde auch der Tag der Vaterlandsverteidiger nicht konsequent und öffentlichkeitswirksam umgesetzt. Da die Reden des Präsidenten vor der Föderalversammlung in den 1990er Jahren immer ungefähr in den gleichen Zeitabschnitt fielen, kam dem Feiertag wenig Beachtung zu. Als 1996 El'cin die Rede vor der Föderalversammlung genau am 23. Februar hielt, würdigte er den Feiertag mit keinem Wort. ${ }^{275}$ In einigen der Jahre legte El'cin anlässlich des Tages Blumen am Grab des unbekannten Soldaten nieder.

269 Vgl. Pravda. 29 (27204) vom 24.02.1994, $1 \mathrm{f}$.

270 Vgl. Izvestia. Nr. 35 (24394) vom 23.02.1995, 1.

271 Vgl. ebd., 1.

272 Vgl. Federal'nyj zakon ot 13.03.1995 N 32-FZ »O dnjach voinskoj slavy (pobednych Dnjach) Rossii

273 Pravda Nr. 35 (261) vom 25.02.1918 In: Lenin, Vladimir Il’ič: Polnoe sobranie sočinenij Том 35: Oktjabr' 1917 - mart 1918. 5. Aufl. - Moskva 1962, 394.

274 Vgl. Pravda Nr. 254 (7579) vom 14.09.1938, 4

275 Das geht zumindest aus der ausführlichen Schriftfassung der Rede hervor: Vgl. El'cin, Boris: Poslanie Prezidenta Rossijskoj Federacii ot 23.02.1996 g. b/n. Rossija, za kotoruju my v otvete (O položenii v strane i osnovnych napravlenijach politiki Rossijskoj Federacii). Online: http://www.kremlin.ru/acts/bank/36349/page/1. 
In Vladimir Putins erster Ansprache als Präsident am Tag des Vaterlandsverteidigers im Jahr 2000 ist noch keine klare erinnerungspolitische Linie zu erkennen. Es dominieren Themen, die durch den Tschetschenienkrieg vorgegeben werden, wie Sicherheit, Stabilität und staatliche Integrität. ${ }^{276}$

Ab dem Jahr 2001 wird dem Tag durch eine regelmäßige Festveranstaltung im Kreml ein größerer Stellenwert eingeräumt; er wird jetzt erinnerungspolitisch genutzt.

In den ersten Jahren ist ein Narrativ prägend, in dem die Geschichte Russlands als eine Geschichte der erfolgreichen Verteidigung darstellt wird - ohne jedoch auf ein konkretes geschichtliches Ereignis zu fokussieren: Der Tag des Vaterlandsverteidigers wird, wie hier im Jahr 2001, als Tag des sich verteidigenden Vaterlandes interpretiert: "Sie griffen die >Rus« häufig an - und sie verteidigte sich gegen die ganze Welt. ${ }^{277}$

Dieses Narrativ wird auch an die Gegenwart angebunden und dient hier, um erinnerungspolitisch eine Position der Stärke zu legitimieren:

"Die Ereignisse der vergangenen Jahre haben gezeigt - die Alternative für unser Land ist sehr einfach: Entweder Russland wird stark sein, oder es wird überhaupt nicht sein $[\ldots] . \aleph^{278}$

Das Narrativ des sich verteidigenden Landes bleibt bis einschließlich der Rede 2003 bestimmend und wird in verschiedenen Facetten ausgeführt. Der 23. Februar wird ab 2002 zum arbeitsfreien Tag und erfährt somit eine Aufwertung.

Ab 2004 verschieben sich die Schwerpunkte. Zum einen halten, dem Programm zur Patriotischen Erziehung entsprechend, Themen wie die historisch enge Verbundenheit zwischen Militär und Gesellschaft، sowie die militärischen Werte als `Schule des Lebens« Einzug in die Reden. ${ }^{279}$

Zum anderen rücken, unter dem Hinweis, Russland habe »nicht nur einmal die Welt vor Eroberern gerettet«, Themen wie globale Stabilität und Verantwortung für die Sicherheit auf dem Eurasischen Kontinent in den Fokus. ${ }^{280}$

2005 wird zusätzlich, ebenfalls im Einklang mit dem Programm zur Patriotischen Erziehung, das Narrativ des militärischen Ruhmes in allen Zeiten in die Rede integriert:

276 Vgl. Putin, Vladimir: Toržestvennyj večer, posvjaščennyj Dnju zaščitnika Otečestva. 22 fevralja 2000 goda. Moskva, Central'nyj Akademičeskij Teatr Rossijskoj Armii. Online: http://kremlin.ru/events/president/news/37992.

277 Putin, Vladimir: Vystuplenie na toržestvennom večere, posvjaščennom Dnju zaščitnika Otečestva. 23 fevralja 2001 goda. Moskva, Kreml'. Online: http://news.kremlin.ru/ transcripts/21193.

278 Ebd.

279 Vgl. Putin, Vladimir: Vystuplenie na toržestvennom večere, posvjaščennom Dnju zaščitnika Otečestva. 22 fevralja 2004 goda. Moskva. Online: http://news.kremlin.ru/trans cripts/22360.

280 Vgl. ebd. 
»Russland hat tatsächlich eine ruhmreiche, militärische Geschichte [...] Wir verneigen uns vor den Kämpfern Dmitrij Donskojs und Aleksandr Nevskijs, den Aufständischen Minins und Požarskijs, den Helden der Schlacht von Borodino; wir neigen das Haupt vor dem Mut und der Selbstaufopferung, der Selbstaufopferung der Soldaten des Großen Vaterländischen Krieges. « ${ }^{21}$

Im Zusammenhang mit den anstehenden Feierlichkeiten zum 60. Jahrestag des Sieges lassen sich zudem, im Vergleich zu den Vorjahren, pathetischere Formulierungen feststellen: So ist von Kraft und Würde sowie von Stolz und heiligem Andenken die Rede. ${ }^{282}$

Nach dem 60. Jubiläum, in den Jahren 2006 und 2007, sind kaum noch geschichtliche Bezüge in den Reden enthalten. Einen neuen Schwerpunkt, auch für die folgenden Jahre, bildet die Armeereform.

Vor der Rede des Jahres 2006 war auf Initiative der Staatsduma der Name des Feiertags geändert worden. Der erste Teil - `Tag des Sieges der Roten Armee über die Kaiserlichen Truppen Deutschlands (1918) - wurde gestrichen, der >Verteidiger des Vaterlandes blieb im Singular erhalten. ${ }^{283}$ In der Begründung des Antrags wurde angemerkt, dass die Behauptung eines Sieges über die kaiserlichen Truppen Deutschlands 1918 nicht den historischen Fakten entsprechen würde. ${ }^{284}$

Im Jahr 2008, kurz vor den Präsidentschaftswahlen, nehmen die erinnerungspolitischen Bezüge wieder eine wichtige Position in der Rede ein. Das Narrativ eines Landes, das sich in seiner langen Geschichte immer verteidigen musste, wird zusätzlich mit einem anschließenden Hinweis auf den Großen Vaterländischen Krieg und die damit verbundene Mission zur Befreiung auch anderer Völker verstärkt. ${ }^{285}$ Als besonderes Verdienst der Veteranen wird die Verteidigung von Freiheit und Souveränität betont, wie schon in den Reden vor 2006 werden auch die ruhmreichen Militärtraditionen bis in die Gegenwart fortgeschrieben.

Die Rückkehr der erinnerungspolitischen Elemente im Allgemeinen und die Betonung von territorialer Integrität und staatlicher Souveränität im Be-

281 Putin, Vladimir: Vystuplenie na toržestvennom večere, posvjaščennom Dnju zaščitnika Otečestva. 22 fevralja 2005 goda. Moskva, Gosudarstvennyj Kremlevskij dvorec. Online: http://news.kremlin.ru/transcripts/22839.

282 Vgl. ebd.

283 Vgl. Federal'nyj zakon ot 15.04.2006 N 48-FZ »O vnesenii izmenenija v stat'ju 1 Federal'nogo zakona »O dnjach voinskoj slavy i pamjatnych datach Rossii«.

284 Vgl. Newsru: Deputaty Gosdumy rešili iz" jat' istoričeskij mif iz nazvanija prazdnika 23 fevralja. 18.01.2006. Online: http://www.newsru.com/arch/russia/18jan2006/takoiprazdnik.html.

285 Vgl. Putin, Vladimir: Vystuplenie na toržestvennom večere, posvjaščënnom Dnju zaščitnika Otečestva. 22 fevralja 2008 goda. Moskva, Kremk. Online: http://news.kremlin.ru/ transcripts/24857. 
sonderen könnte der von Russland abgelehnten Unabhängigkeitserklärung des Kosovo und einem gesteigerten Mobilisierungsbedarf hinsichtlich der anstehenden Präsidentschaftswahlen geschuldet sein. In den Tagen vor der Rede, seit dem 17. Februar 2008, hatten unter der Führung von Frankreich, Großbritannien und den USA ein Teil der NATO-Staaten und Verbündete wie Afghanistan die Unabhängigkeit des Kosovo von der Republik Serbien anerkannt. Die Russländische Föderation hatte dies als Verletzung der Souveränität und der territorialen Integrität Serbiens eingestuft.

In den Reden des neuen Präsidenten Medvedev in den folgenden Jahren 2009 bis 2012 - sind kaum erinnerungspolitische Ansätze enthalten und die Rhetorik ist gegenüber den Vorjahren deutlich zurückhaltender. So stellt Medvedev 2009 zum Georgien-Krieg des Vorjahres lakonisch fest: »Wir haben den Aggressor gestoppt, Menschenleben geschützt und eine humanitäre Katastrophe verhindert. ${ }^{286}$

Anstelle von militärischen Ruhmestraditionen liegt ein Schwerpunkt der Reden auf den Bemühungen zur Modernisierung des Militärs. Auch die symbolische Bedeutung der Feier wird reduziert. Anstatt im großen Kreml-Palast finden die Reden wie schon vor dem Jahr 2002 wieder im Theater der Roten Armee statt.

Mit Vladimir Putins Rückkehr ins Amt des Präsidenten wird auch seine erste Rede am Tag des Vaterlandsverteidigers wieder im Kreml-Palast inszeniert. Auch der pathetische Stil und die häufigen geschichtlichen Bezüge knüpfen nahtlos an die letzte Rede seiner vorangegangenen Amtszeit an.

Beispielhaft ist folgende Passage, die von tausendjähriger Tradition über militärischen Ruhm in allen Zeiten bis hin zum Patriotismus als nationalem Charakter die wichtigsten Eckpunkte der putinschen Patriotischen Erziehung und der Erinnerungspolitik in sich vereint:

»In diesem Feiertag verwirklichen sich die historischen und militärischen Traditionen, der tausendjährige Weg der russländischen Staatlichkeit, das heilige Gedächtnis an die Heldentaten unserer Vorfahren. Von Generation zu Generation wird der Stolz auf den militärischen Ruhm Russlands, das tiefe Verständnis der hohen Bedeutsamkeit des militärischen Könnens und die Pflicht, die Heimat zu bewahren, weitergegeben. Solche patriotischen Gefühle sind im Blut unseres Volkes, in seinem nationalen Charakter; sie sind durch die Geschichte geprägt, die ausgefüllt ist mit Beispielen der Tapferkeit und des Mutes der Verteidiger des Vaterlandes. ${ }^{287}$

286 Medvedev, Dmitrij: Toržestvennyj večer, posvjaščënnyj Dnju zaščitnika Otečestva. 21 fevralja 2009 goda. Moskva, teatr Rossijskoj Armii. Online: http://news.kremlin.ru/ transcripts/3270.

287 Putin, Vladimir: Koncert po slučaju Dnja zaščitnika Otečestva. 23 fevralja 2013 goda. Moskva. Online: http://news.kremlin.ru/transcripts/17569. 
Auch die Fokussierung auf das Motiv der Bedrohung von außen kehrt - wie zuletzt 2008 - zurück. Dieses Mal richtet sich die erinnerungspolitische Botschaft auf eine ständige Mobilisierung, um den Staat und seine Bürger zu schützen: Man müsse in jedem Moment bereit sein, das Land und seine Bürger zu beschützen. ${ }^{288}$

Die Festveranstaltung im Jahr 2014 fand bereits einige Tage früher, am 20. Februar, statt. Tagsüber war die gewaltsame Konfrontation zwischen Sicherheitskräften und Maidan-Aktivisten in Kiew erneut eskaliert. Putin war sowohl vor als auch nach der abendlichen Rede anlässlich des Tages des Vaterlandsverteidigers mit Telefonaten u. a. mit Angela Merkel, David Cameron und Viktor Janukovič befasst. Obwohl sich die bewaffnete Konfrontation in Kiew bereits seit dem 18. Februar deutlich abzeichnete und auch die Berichterstattung der russländischen Medien bestimmte, findet sich in der Rede kein expliziter Hinweis auf die Geschehnisse. Lediglich eine kurze Passage über die Bereitschaft, in jeder Situation Russland und seine Bürger zu schützen, ließe sich im Kontext der aktuellen politischen Lage deuten. ${ }^{289}$

Es scheint, als habe es zu diesem Zeitpunkt weder eine klare Haltung noch eine klare Vorstellung über die Entwicklung der Situation gegeben und somit auch noch keine Strategie, die eigene Position zu den Ereignissen im Nachbarland in einem geschichtlichen Kontext zu präsentieren. Stattdessen wird ähnlich dem Jahr 2008 ausführlich das Narrativ des russländischen militärischen Ruhms in allen Zeiten referiert. ${ }^{290}$

Die dabei enthaltene Erwähnung der Soldaten und Offiziere des Ersten Weltkriegs entspricht der geschichtspolitischen Schwerpunktsetzung des Jahres 2014 - 100 Jahre Beginn des ersten Weltkriegs. ${ }^{291}$

Auch in der Rede 2015 steht der militärische Ruhm im Zentrum der Ausführungen - diesmal in Verbindung mit dem Narrativ einer defensiven Geschichte.

Einen weiteren Schwerpunkt nimmt - entsprechend den anstehenden Feierlichkeiten des 70. Jahrestages des Sieges - der Große Vaterländische Krieg ein. Dabei wird besonders die Rolle der Streitkräfte als Befreier Europas und der Krieg im Fernen Osten betont. ${ }^{292}$ Im Abschnitt über den Fernen Osten zeich-

288 Vgl. ebd.

289 Vgl. Putin, Vladimir: Toržestvennyj večer, posvjaščënnyj Dnju zaščitnika Otečestva. 20 fevralja 2014 goda. Moskva. Online: http://news.kremlin.ru/transcripts/20293.

290 Vgl. ebd.

291 Es gab 2014 eine große Anzahl von Veranstaltungen und Ereignissen wie beispielweise die Einweihung des Denkmals für die Helden des Ersten Weltkriegs am 1. August in Moskau im Siegespark durch Vladimir Putin. Pamjatnik gerojam Pervoj mirovoj vojny (Moskva).

292 Putin, Vladimir: Toržestvennyj večer, posvjaščënnyj Dnju zaščitnika Otečestva. 20 fevralja 2015 goda. Moskva, Kreml'. Online: http://kremlin.ru/events/president/news/ 47720. 
net sich bereits die für den 9. Mai 2015 erstmals in großem Umfang geplante Integration Chinas in die Siegesfeierlichkeiten und damit in das Kriegsgedenken ab.

Anders als bei den Siegesfeierlichkeiten am 9. Mai gab es für den Tag des Vaterlandsverteidigers im ersten Jahr keinen Kanon und keine Tradition, an welche Putin bei seinem Vorgänger El'cin hätte anknüpfen können. Trotzdem präsentieren seine Reden bereits ab dem Jahr 2001 eine konsistente Linie. Zunächst wird im Rahmen der Reden durchgängig das Narrativ eines Russlands entwickelt, das sich in seiner Geschichte immer mit Bedrohungen von außen konfrontiert sah und sich verteidigen musste. Die Reden entsprechen zunächst den legitimatorischen Erfordernissen des zweiten Tschetschenienkrieges. In den Jahren 2004 und 2005 wird dieses Narrativ durch weitere Elemente aus den Programmen zur Patriotischen Erziehung der Bürger wie beispielsweise dem Narrativ des militärischen Ruhms in allen Zeiten ergänzt. Zudem gewinnt die internationale Sicherheitspolitik - unter Hinweis auf das Narrativ vom Befreier Europas - an Raum.

Nach dem Jahr 2005 - dem 60. Jubiläum des Sieges - und bis zum Ende der Amtszeit von Dmitrij Medvedev im Jahr 2012 spielen geschichtliche Bezüge in den Reden eine weitaus geringere Rolle. ${ }^{293}$ Bei Medvedev stellt der Tag vor allem ein Instrument zur erinnerungspolitischen Unterfütterung der Armeereformen dar.

Im Jahr 2013 - nach Putins dritter Wahl zum Präsidenten im Vorjahr - kehren auch die Geschichtsbezüge in die Reden zurück. Der Tag des Vaterlandsverteidigers, der nicht zuletzt durch seine Tradition als Tag der sowjetischen Streitkräfte einen engen Bezug zu den militärischen Institutionen des Landes hat und zudem durch seine erinnerungspolitische Nutzung durch die antiliberale Opposition in den 1990er Jahren auch in diesem Spektrum bis heute über großen Rückhalt verfügt, hat sich in den letzten Jahren als ein dankbares Medium für Vladimir Putins national-patriotischen Schwenk erwiesen. Von »1000-jährigen Siegestraditionen« bis zum »besonderen nationalen Charakter" des Patriotismus sind die Eckpunkte der Patriotischen Erziehung, aber auch der patriotischen Wende enthalten und richten sich auf die Schaffung einer permanenten inneren Mobilisierung.

293 Eine Ausnahme bildet die Rede Putins im Jahr 2008. Die umfangreichen geschichtlichen Bezüge und die erinnerungspolitische Konstruktion einer ständigen Mobilisierung könnten dem speziellen Zeitpunkt der Rede unmittelbar zwischen der Anerkennung des Kosovo durch westliche Staaten und den Präsidentschaftswahlen geschuldet sein. 


\subsection{Reden am Tag der Einheit des Volkes}

Der Tag der Einheit des Volkes am 4. November zählt zu den jüngsten Russländischen Feiertagen, auch wenn er an lange Feiertagstraditionen anknüpft. Als Folge der Neuordnung der Novemberfeiertage entsprechend der Programme zur Patriotischen Erziehung wurde er im Jahr 2005 erstmals begangen. ${ }^{294}$

Obwohl im Zuge der Reform der vorrevolutionäre und von El'cin wieder aufgegriffene Hinweis auf die Befreiung Moskaus von den polnischen Invasoren ${ }^{295}$ aus dem Titel des Feiertages gestrichen worden war, ${ }^{296}$ wurde seine Einführung sehr kritisch begleitet. So berichtete die Frankfurter Allgemeine Zeitung unter dem Titel »Rußland feiert die Befreiung von Polen $\aleph^{297}$ über die Feierlichkeiten in Moskau. In Russland selbst fand diese Deutung keinen nennenswerten Niederschlag - der Tag wurde in seiner innerrussischen Dimension gedeutet. ${ }^{298}$

In der ersten Rede im Jahr 2005 wird zunächst der geschichtliche Bezugspunkt des neuen Festes erläutert, dessen »Sinn und Bedeutung tiefe geistige und historische Wurzeln ${ }^{299}$ habe:

»Vor fast vier Jahrhunderten, Anfang November 1612, befreite der Aufstand Minins und Požarskijs Moskau von den fremden Besatzern. $\aleph^{300}$

Als Nächstes erfolgt eine erste Deutung des Bezugspunktes:

»Es war das Ende der Zeit der Wirren in Russland, das Ende von inneren Unruhen und Streit, von Uneinigkeit und dem Verfall, der mit alledem einherging.." ${ }^{301}$

Dann folgt eine Einordnung in einen größeren geschichtlichen Zusammenhang, der den geschichtlichen Bezugspunkt an gegenwärtige Diskurse - von Patriotismus über Zentralisierung bis hin zu Souveränität - anbindet:

294 Vgl. Kapitel: Neugestaltung der Feiertage.

295 Vgl. Bulgakov, Sergej: Nastol'naja kniga dlja svjaščenno-cerkovno-služitelej. Kiev 1913, 419 und Federal'nyj zakon ot 13.03.1995 N 32-FZ »O dnjach voinskoj slavy (pobednych dnjach) Rossii

296 Federal'nyj zakon ot 13.03.1995 N 32-FZ »O dnjach voinskoj slavy (pobednych Dnjach) Rossii« v red. Federal'nych zakonov ot 22.08.2004 N 122-FZ.

297 Veser, Reinhard: Rußland feiert die Befreiung von Polen. In: Frankfurter Allgemeine Zeitung, Nr. 258 vom 05.11.2005, 6.

$298 \mathrm{Zu}$ innerrussischen Deutungskontexten, abseits der These von der antipolnischen Stoßrichtung des Tages vgl. Aust, Martin: Polen und Russland im Streit um die Ukraine. Konkurrierende Erinnerungen an die Kriege des 17. Jahrhunderts in den Jahren 1934 bis 2006. Wiesbaden 2009, 275.

299 Putin, Vladimir: Vystuplenie na toržestvennom prieme, posvjaščennom Dnju narodnogo edinstva. 4 nojabrja 2005 goda. Moskva, Kreml'. Online: http://news.kremlin.ru/trans cripts/23252.

300 Ebd.

301 Ebd. 
»Es war der Sieg der patriotischen Kräfte, der Sieg des Kurses auf die Stärkung des Staates durch den Zusammenschluss, die Zentralisierung und die Vereinigung der Kräfte. Mit diesen heroischen Ereignissen begann die geistige Wiedergeburt des Vaterlandes, begann das Entstehen eines großen und souveränen Staates. ${ }^{302}$

Die erinnerungspolitische Legitimationsfunktion wird am Ende der Passage präsentiert:

Das Volkhabe, nicht aufBefehlvon oben, sondern seinem Herzen folgend, die Staatlichkeit verteidigt, Bürgersinn und Verantwortung gezeigt und das eigene Schicksal entschieden. Der Aufruf Minins "Zusammen für eine Sache» habe die besten Seiten des russländischen Nationalcharakters hervorgerufen: in Friedens- und Kriegszeiten zusammenzustehen und sich gegenseitig zu helfen. ${ }^{303}$

In der erinnerungspolitischen Funktion soll das neue Fest der Volkseinheit vor allem ein freiwilliges bürgergesellschaftliches Engagement, gesellschaftliche Solidarität und Patriotismus fördern und legitimieren. Selbstständiger Einsatz für den Staat, aber auch für die Gesellschaft wird zum nationalen Charakterzug erklärt.

Dieser erinnerungspolitische Ansatz wird in der Folge durch eine längere Passage über die geschichtlichen Traditionen der russischen Philanthropie und des russischen Mäzenatentums weiter ausgebaut.

Die Inszenierung des neuen Feiertags als eines Tages der Philanthropie und des bürgergesellschaftlichen Engagements kommt noch einmal im abschließenden Toast der Rede auf die »besten Traditionen bürgerlicher Solidarität « ${ }^{304}$ zum Ausdruck.

$\mathrm{Zu}$ dieser Ausrichtung des 4. Novembers passt auch die begleitende Berichterstattung vor allem im Fernsehen. Die Vertreter der Konfessionen und Jugendorganisationen wie die >Unsrigen (Naši)< riefen im Vorfeld dazu auf, den 4 . November als $>$ Tag der guten Taten $>$ zu begehen. ${ }^{305}$

Dieser Ansatz einer geschichtlich aus dem Jahr 1612 begründeten Verbindung von Bürgergesellschaft und Patriotismus ist auch im Jahr 2006 das zentrale Thema der Rede. ${ }^{306}$ Es kommt jedoch ein neuer Aspekt hinzu - die Konstruktion einer geschichtlich begründeten und sich im gemeinsamen Gedächtnis manifestierenden Nation:

302 Ebd.

303 Vgl. ebd.

304 Ebd.

305 Vgl. Alekseev, Aleksandr: Pomoč’ okružajuščim. 4 nojabrja 2005. Online: http://www. vesti.ru/doc.html?id=110448\&tid=31568; Vesti: Religioznye dejateli prizyvajut sdelat' 4 nojabrja Dnem dobrych del. 16 sentjabrja 2005. Online: http://www.vesti.ru/doc.html? id $=68776 \&$ tid $=31568$.

306 Vgl. Putin, Vladimir: Vystuplenie na gosudarstvennom prieme, posvjaščennom Dnju narodnogo edinstva. 4 nojabrja 2006 goda. Moskva, Bol’šoj Kremlevskij dvorec. Online: http://news.kremlin.ru/transcripts/23882. 
»Und wo die Söhne und Töchter Russlands auch leben, uns alle vereint das historische Gedächtnis. Russland ist heute offen für alle, die sich mit seinem Schicksal identifizieren. ${ }^{307}$

Die Einführung dieses Aspektes steht mit dem >II. Weltkongress der russländischen Landsleute, die im Ausland leben` im Zusammenhang, der kurz vor der Rede - Ende Oktober 2006 - in St. Petersburg stattgefunden hatte. ${ }^{308}$ Die Bedeutung des Tags der Volkseinheit wird somit erweitert: Die Wir-Gemeinschaft, auf die sich der Tag bezieht, wird als Erinnerungsgemeinschaft präsentiert, die sich durch die Selbstzuschreibung des Einzelnen zum >Schicksal des Landes $<$ konstituiert. Diese Gemeinschaft ist die notwendige Institution, um die `Landsleute « unabhängig von Grenzen oder Staatsbürgerschaften weltweit zum Vorteile der >Heimat ‘ zu vereinen und in die Verantwortung zu nehmen. ${ }^{309}$

$\mathrm{Ab}$ der Rede 2007 verschwinden Philanthropie und bürgergesellschaftliches Engagement als erinnerungspolitische Ableitungen aus den Reden. Stattdessen rückt die Verbindung von Einigkeit als snationalem Charakter und die grenzüberschreitende Gemeinschaft der >Landsleute` weiter in den Mittelpunkt. Zugleich wird auch die Rhetorik pathetischer.

Die Geschlossenheit der >russländischen Gesellschaft $\_$- abgeleitet aus dem Narrativ von 1612 - wird als Bedingung für den Aufstieg zur Großmacht interpretiert.

»Es wurden die Grundlagen für den Aufbau eines gewaltigen, riesigen Staates vom Baltikum bis zum Pazifischen Ozean gelegt. ${ }^{310}$

Patriotische Bestrebungen werden als »Quelle von Macht und Stärke« dargestellt, die einer ewigen Tradition der geistigen Werte dienen sollten. Als Bewahrer dieser Werte werden wiederum die >Landsleute im Ausland ‘ besonders hervorgehoben. ${ }^{311}$

Auch Dmitrij Medvedev bleibt diesen Schwerpunkten in seiner ersten Rede zum Tag der Volkseinheit 2008 treu. Die erinnerungspolitische Argumenta-

307 Ebd.

308 Nach einem ersten kleinen Kongress im Jahr 2001 war der 2. Weltkongress 2006 mit ungefähr 600 Teilnehmern aus 100 Ländern der bis heute größte und medial sichtbarste. Vgl. Taratuta, Julija/Konfisachor, Aleksandra/Perl, Roman: Rodina trjachnula deržavnost'ju. Vsemirnyj kongress sootečestvennikov polučil gospodderžku. In: Kommersant « Nr. 200 vom 25.10.2006, 2. Online: http://www.kommersant.ru/doc/716076.

309 Vgl. Putin, Vladimir: Vystuplenie na gosudarstvennom prieme, posvjaščennom Dnju narodnogo edinstva. 4 nojabrja 2006 goda. Moskva, Bol'šoj Kremlevskij dvorec. Online: http://news.kremlin.ru/transcripts/23882.

310 Putin, Vladimir: Vystuplenie na prieme po slučaju Dnja narodnogo edinstva. 4 nojabrja 2007 goda. Moskva, Bol’šoj Kremlevskij dvorec. Online: http://news.kremlin.ru/ transcripts/24648.

311 Vgl. ebd. 
tion von der Geschlossenheit als höchstem Wert in der russländischen Geschichte, der die Generationen verbindet und eine Verpflichtung für Gegenwart und Zukunft darstellt, wird sogar noch deutlicher. ${ }^{312}$ Der zweite Teil der Rede ist zu einem großen Teil den >Landsleuten im Ausland`, den für sie aufgelegten Programmen und Initiativen sowie ihrem Beitrag zur Entwicklung des Landes gewidmet.

Die Reden der folgenden Jahre behalten diese Schwerpunkte bei. In der Rede 2011 wird noch einmal deutlich, dass auch Medvedev sich auf tausendjährige historische Werte als Grundlage des heutigen Staates bezieht:

»Patriotismus, Bürgersinn und Vaterlandsliebe sind die grundlegenden Werte, die den multinationalen russländischen Staat schon immer verbanden. Sie sind auch heute unsere moralische Stütze, das Erbe der Jahrtausende und zur gleichen Zeit eines der Symbole des jungen, demokratischen Russlands [...].."13

Obwohl sich, im Gegensatz zu anderen Redeformaten, Rhetorik und Geschichtsbezogenheit der Reden von Medvedev nicht wesentlich von denen Vladimir Putins bis 2008 unterscheiden, stellen die Reden Putins im Rahmen seiner neuen Präsidentschaft ab 2012 eine neue Qualität dar.

Besonders auffällig sind dabei zwei Aspekte. Erstens wird das Narrativ von 1612 verändert. Das Narrativ des Volkes, das die inneren Streitigkeiten beilegt und durch Geschlossenheit die Zeit der Wirren beendet, wird 2012 um eine Gefahrenprojektion erweitert: Jeder andere Ausgang der Smuta hätte die Unabhängigkeit Russlands bedroht und der Nation die historische Perspektive sowie die kulturelle und geistige Eigenart entziehen können. ${ }^{314}$

Gleichzeitig wird im weiteren Verlauf der Rede erstmals ein Schwerpunkt auf die Bedeutung von Souveränität und staatlicher Unabhängigkeit für den Frieden in der internationalen Staatenwelt gelegt. ${ }^{315}$

Im Jahr 2013 wird die erinnerungspolitische Funktion dieser neuen Gefahrenprojektion noch deutlicher und bereits in die Eingangsworte zur Bedeutung des Feiertags integriert. Durch die Erweiterung des Narrativs wird aus dem Fest der Einigkeit der Bevölkerung ein Fest, das sich, so die >Lehre der Geschichte`, auf die Souveränität und Unabhängigkeit des Staates richtet. ${ }^{316}$

312 Vgl. Medvedev, Dmitrij: Vystuplenie na toržestvennom priëme, posvjaščënnom Dnju narodnogo edinstva. 4 nojabrja 2008 goda. Moskva, Kreml'. Online: http://news.kremlin. $\mathrm{ru} /$ transcripts/1966.

313 Medvedev, Dmitrij: V Rossii otmečajut Den’ narodnogo edinstva. 4 nojabrja 2011 goda. Nižnij Novgorod. Online: http://news.kremlin.ru/transcripts/13340.

314 Vgl. Putin, Vladimir: Priëm po slučaju Dnja narodnogo edinstva. 4 nojabrja 2012 goda. Moskva, Kreml'. Online: http://news.kremlin.ru/transcripts/16752.

315 Vgl. ebd.

316 Vgl. Putin, Vladimir: Toržestvennyj priëm po slučaju Dnja narodnogo edinstva. 4 nojabrja 2013 goda. Moskva, Kreml’. Online: http://news.kremlin.ru/transcripts/19562. 
Anschließend wird diese erinnerungspolitische Ableitung für die Gegenwart zusätzlich auf `nationale Interessen`sowie `moralische Grundlagen` und die >nationalen Eigenarten< (samobytnost') ausgeweitet. ${ }^{317}$

Auch in der Rede 2014 wird die neue erinnerungspolitische Bedeutung des 4. Novembers hinsichtlich des Stellenwertes von Souveränität und nationalen Interessen noch einmal als »historische Lehrstunde, Mahnung an alle Generationen und Regel für uns ${ }^{318}$ formuliert.

Der zweite Aspekt, der neben der Erweiterung des Narrativs den Reden ab 2012 eine neue Qualität gibt, ist die Betonung von Geschichtlichkeit, Werten und Traditionen. Wie schon durch die Veränderung des Narrativs von 1612 wird auch in anderen Bereichen an der Bedeutung von Geschlossenheit und Einigkeit gearbeitet. Die Geschlossenheit wird nicht mehr - wie in den ersten Jahren ab 2005 - als Motivation interpretiert, als Gesellschaft Herausforderungen gemeinsam und solidarisch zu begegnen, sondern als geschichtsübergreifendes Instrument gegen Eroberung und nationale Erniedrigung:

»Der Geist von Einheit und Erschaffung zieht sich durch die gesamte russländische Geschichte. Die Macht schuf und einte den riesigen Staat. Vor dieser Macht wichen die Widersacher, innerer Streit und innere Unruhen zurück, zerschlugen sich Versuche, das Land zu erobern oder unser Land in die Knie zu zwingen.. ${ }^{319}$

Nicht mehr die Einigkeit und Geschlossenheit im Inneren werden in den Mittelpunkt gestellt, sondern deren Funktion als Mittel zur Verbesserung der Durchsetzungsfähigkeit nach außen. ${ }^{320}$ Durch diesen veränderten Fokus wird die Einigkeit im Inneren auf das `Schließen der Reihen nach Außen in schweren Zeiten reduziert.

Auch insgesamt wird in den Reden ab 2012 häufig auf die verpflichtende Geschichtlichkeit von Traditionen verwiesen:

»Heute, indem wir dieses Fest begehen, spüren wir alle die unverbrüchliche tausendjährige Geschichte, unseren tausendjährigen Weg und verstehen, dass wir direkte Erben einer gemeinsamen Sache unserer Vorfahren sind und dass wir unsere Traditionen ehren und bewahren sollen. ${ }^{321}$

317 Ebd.

318 Vgl. Putin, Vladimir: Priëm po slučaju Dnja narodnogo edinstva. 4 nojabrja 2014 goda. Moskva, Kreml'. Online: http://news.kremlin.ru/transcripts/46916.

319 Putin, Vladimir: Priëm po slučaju Dnja narodnogo edinstva. 4 nojabrja 2012 goda. Moskva, Kreml'. Online: http://news.kremlin.ru/transcripts/16752.

320 Vgl. Putin, Vladimir: Toržestvennyj priëm po slučaju Dnja narodnogo edinstva. 4 nojabrja 2013 goda. Moskva, Kreml'. Online: http://news.kremlin.ru/transcripts/19562.

321 Putin, Vladimir: Priëm po slučaju Dnja narodnogo edinstva. 4 nojabrja 2012 goda. Moskva, Kreml'. Online: http://news.kremlin.ru/transcripts/16752. 
Als Funktionen solcher Werte und Traditionen - zu denen beispielsweise ein "authentischer, tiefer Patriotismus « ${ }^{322}$ gezählt wird - werden in den Reden die Konsolidierung und Stärkung des Staates und der bürgerlichen Solidarität beschrieben. Die Stärkung des Staates und vor allem der >starke Staatı oder die sstarke Macht an sich sind ebenfalls wiederkehrende Motive und werden unter Hinweis auf den Volkswillen legitimiert. ${ }^{323}$

Auch in der Rede 2015 bleibt diese Ausrichtung bestehen. Unter Rückgriff auf Nikolaj Berdjaev erklärt Putin Stärke und Selbstständigkeit zur russischen Mission. Das Land, das eine eigene riesige Welt darstelle, müsse nach Harmonie und Partnerschaft zwischen Staaten und Menschen unterschiedlicher Kulturen und Traditionen streben. Die Heldentaten des Volkes bei der Rettung der Heimat seien Beispiele dafür, dass das Verfolgen von nationalen Interessen ein genauso wichtiger Wert sei wie Menschenrechte, Freiheit und Demokratie. ${ }^{324}$

Die ursprüngliche Interpretation des Tages der Volkseinheit in den Jahren 2005 und 2006, nicht den konfrontativen Charakter des Datums zu erzählen, sondern ein Narrativ zu entfalten,

das die Bürgergesellschaft vereinen und aktivieren sollte, wurde sukzessive zurückgenommen. Dieser ursprüngliche ‘vereinende` Ansatz entsprach vermutlich den Intentionen Boris El'cins bei der Umbenennung des Festes 1996 in >Tag der Eintracht und Harmonie`, die jedoch nie umgesetzt wurden. ${ }^{325}$

Über die Jahre wurde der Ansatz in zwei Schritten ins Gegenteil verkehrt: Zunächst wurde ab 2007 der erinnerungspolitisch abgeleitete Schwerpunkt auf die Aktivierung von bürgerlichem Engagement und auf die Förderung von Geschlossenheit und Patriotismus als den entscheidenden snationalen Charakterzügen verlegt. Die darin angelegte historische Notwendigkeit der Geschlossenheit nach innen impliziert bereits die Bedrohung von außen. Ab 2012 wird dieses Bedrohungsszenario explizit gemacht und rückt in den Mittelpunkt der Reden. Russlands Geschichte wird als eine Geschichte des Abwehrkampfes gegen seine Zerschlagung und die Vernichtung seiner historischen Werte und Traditionen erzählt. Die Bedeutungszunahme dieses Narrativs lässt sich als Reaktion auf den Aufschwung der Protestbewegung gegen den Kreml zur Jahreswende 2011/2012 erklären. ${ }^{326}$

322 Ebd.

323 Vgl. ebd.

324 Vgl. Putin, Vladimir: V Kremle vručeny gosnagrady Rossii inostrannym graždanam. 4 nojabrja 2015 goda. Moskva, Kreml'. Online: http://kremlin.ru/events/president/ news/50627.

325 El'cins Ansatz ist jedoch primär im Kontext der Revolutionserinnerung und des 80. Jahrestages der Oktoberrevolution zu sehen. Vgl. Kapitel zur Neugestaltung der Feiertage.

326 Zur Protestbewegung vgl. Gabowitsch, Mischa: Putin kaputt!? Russlands neue Protestkultur. Berlin 2013. 
So dient der 4. November nicht mehr, wie in den ersten Jahren, als positive Motivation, sich als Bürger für das Gemeinwohl zu engagieren und sich als Gesellschaft gemeinsam Herausforderungen zu stellen, sondern als Warnung, alles zu verlieren, wenn Souveränität und nationale Interessen nicht konsequent verteidigt werden.

Damit ergibt sich eine Bedeutungsverschiebung: Es wird nicht mehr auf die Bedeutung der Ereignisse von 1612 für das Innere der Gesellschaft fokussiert, sondern auf ihre Interpretation als Voraussetzung für die Entwicklung eines mächtigen Staates.

Angesichts der mit dieser Entwicklung einhergehenden rhetorischen Verschärfung in allen Bereichen ist es bemerkenswert, dass auch in den Jahren ab 2012 das grundlegende Narrativ, das immer schon in dem neuen Feiertag ab 2005 angelegt war, nicht explizit sscharf gemacht wird. Schon bei der Einführung war gemutmaßt worden, Putin wolle mit dem Tag vor allem eine Parallelität von Smuta und den 1990er Jahren inszenieren, um sich als Retter des Vaterlandes zu präsentieren, der die Fremdherrscher - die Oligarchen aus Moskau vertreibt und Russland wieder zu imperialer Größe führt. ${ }^{327}$ In der kulturellen Rezeption der Smuta gibt es deutliche Verweise in dieser Richtung $^{328}$ - die Reden der Präsidenten am Tag der Volkseinheit geben jedoch bisher keine belastbaren Anhaltspunkte für die Absicht, dieses Narrativ zu etablieren. Die 1990er Jahre finden keine Erwähnung - lediglich zwei Reden enthalten einen allgemeinen Hinweis darauf, dass Russland nicht nur einmal durch schwierige Zeiten gegangen sei. ${ }^{329}$

\subsection{Reden am Tag Russlands}

Obwohl der `Tag Russlands` der offizielle Nationalfeiertag der Russländischen Föderation ist, hat er im Bewusstsein der Bevölkerung einen weitaus geringeren

327 Martin Aust beschreibt dieses Metanarrativ als Fremdzuschreibung. Vgl. Aust, Martin: Polen und Russland im Streit um die Ukraine. Konkurrierende Erinnerungen an die Kriege des 17. Jahrhunderts in den Jahren 1934 bis 2006. Wiesbaden 2009, 281. Isabelle de Keghel beschreibt dieses Metanarrativ als implizit transportierte Aussage. Vgl. de Keghel, Isabelle: Verordneter Abschied von der revolutionären Tradition. Der \$Tag der nationalen Einheit in der Russländischen Föderation. In: Karl, Lars/Polianski, Igor J. (Hg.): Geschichtspolitik und Erinnerungskultur im neuen Russland. Göttingen 2009, 124 f..

328 So lässt sich die Darstellung der Bojaren im Film >1612: Chronik der Zeit der Wirren (1612: Chroniki smutnogo vremeni)<, Russland 2007, als Kritik an den Oligarchen der 1990er lesen.

329 So z.B. die Rede Medvedevs 2009. Medvedev, Dmitrij: Dmitrij Medvedev pozdravil graždan Rossii s obščenacional'nym prazdnikom - Dnëm narodnogo edinstva. 4 nojabrja 2009 goda. Suzdal'. Online: http://news.kremlin.ru/transcripts/5907. 
Stellenwert als andere Feiertage, wie zum Beispiel der Tag des Sieges oder auch der ähnlich junge Tag der Einheit des Volkes. ${ }^{330}$ Er bezieht sich auf die Souveränitätserklärung Russlands am 12. Juni 1990 durch den Volksdeputiertenkongress der RSFSR. Dementsprechend war seine offizielle Bezeichnung von seiner Einführung als arbeitsfreier Feiertag 1992 bis zum Jahr 2002 »Tag der Annahme der Deklaration über die staatliche Souveränität der Russländischen Föderation. ${ }^{331}$ Die Umbenennung in `Tag Russlands ging auf eine Fernsehansprache Boris El'cins am 12. Juni 1998 zurück und wurde 2002 durch die Änderung des Arbeitskodex vollzogen. ${ }^{332}$

Anlässlich des Tages gibt es jährlich einen Empfang im Kreml mit einer kurzen Ansprache des Präsidenten. Zusätzlich findet im Kreml die Verleihung der Staatsprämien für besondere Leistungen in den Bereichen Wissenschaft, Kultur und humanitäre Dienste statt.

Die Reden der ersten Jahre ab 2000 haben ganz ähnliche Schwerpunkte: Erstens werden die in der Frühphase der Russländischen Föderation erreichten Errungenschaften - Demokratie, Freiheitsrechte und Rechtstaatlichkeit positiv herausgestellt. ${ }^{333}$ Zweitens wird der grundsätzliche Charakter der Veränderungen als "gigantische Wende « Anfang der 1990er Jahre betont. ${ }^{334}$ Und drittens wird dabei immer wieder auf die 1990er Jahre als eine schwierige und für die Bevölkerung harte Zeit verwiesen, die man selbst überwunden habe. ${ }^{335}$

Dabei ist festzustellen, dass hier - wie auch am Tag der Verfassung, an dem ähnliche Themen verhandelt werden - keine Distanzierung vorgenommen wird. Die 2000er Jahre werden zwar als eine sneue Zeit charakterisiert, ohne jedoch die Härten der 1990er Jahre zu externalisieren. Es wird vielmehr ein Narrativ von einer schwierigen aber notwendigen Lernphase der staatlichen Entwicklung präsentiert. ${ }^{336}$

330 Vgl. Ivanov, Maksim: Den' Rossii ostaetsja dalekim ot graždan. Rossijane ne znajut, čto otmečajut 12 ijunja, no prazdnikom dovol'ny. In: Kommersant« vom 11.06.2015. Online: http://kommersant.ru/doc/2746090.

331 Vgl. Postanovlenie Verchovnogo Soveta RF ot 11 ijunja 1992 g. N 2981-I »O prazdničnom dne 12 ijunja«.

332 Vgl. Stat'ja 112. Nerabočie prazdničnye dni. Trudovogo kodeksa RF ot 30.12.2001 N 197-FZ.

333 Vgl. Putin, Vladimir: Vystuplenie na toržestvennom prieme po slučaju Dnja prinjatija Deklaracii o gosudarstvennom suverenitete Rossii. 12 ijunja 2001 goda. Moskva, Kreml'. Online: http://news.kremlin.ru/transcripts/21258.

334 Vgl. ebd.

335 Vgl. Putin, Vladimir: Vystuplenie na prieme po slučaju Dnja Rossii. 12 ijunja 2002 goda. Moskva, Kreml'. Online: http://news.kremlin.ru/transcripts/21641.

336 Vgl. Putin, Vladimir: Vystuplenie na toržestvennom prieme po slučaju Dnja prinjatija Deklaracii o gosudarstvennom suverenitete Rossii. 12 ijunja 2000 goda. Moskva, Kreml'. Online: http://news.kremlin.ru/transcripts/21465. 
In den Jahren 2003 und 2004 wird der Tag Russlands größer inszeniert. Die Reden finden im Rahmen von Paraden auf dem Roten Platz statt, bei denen Kostüme verschiedener Epochen der Moskauer Geschichte präsentiert werden. Dabei weist die Rede im Juni 2003 eine veränderte Rhetorik auf: ${ }^{337}$ Putin entwirft das Narrativ einer geschichtlich bedingten Schicksalsgemeinschaft.

"Jedes Jahr unserer jahrhundertealten Geschichte, sei es siegreich oder dramatisch, ist das Schicksal des Heimatlandes. Das heißt - unser gemeinsames Schicksal. Es ist das Schicksal von Millionen unserer Vorfahren, die Russland verteidigt und umgestaltet haben. . $^{338}$

Die folgende erinnerungspolitische Ableitung besteht in der Legitimation eines starken Staates: Die Lehre der Vorfahren sei, dass ein Land wie Russland stark sein müsse. ${ }^{339}$

Die Rede des Folgejahrs verzichtet bereits wieder auf erinnerungspolitische Ansätze und kehrt zu dem reduzierteren Ton der ersten Jahre zurück. ${ }^{340} \mathrm{Ab}$ dem Jahr 2005 finden die Reden wieder in einem kleineren Rahmen statt und werden teilweise mit der Verleihung der Staatspreise zusammengelegt. Auch die Reden Dmitrij Medvedevs am Tag Russlands setzen die zu Anfang skizzierten Schwerpunkte.

Eine deutliche Veränderung zeigt sich erst wieder in der Rede Putins 2012. Während in den vorangegangenen Reden ausschließlich das sneues, postsowjetische Russland gefeiert wurde, erweitert Putin nun den geschichtlichen Rahmen, wie schon 2003, um mehr als tausend Jahre:

Der Feiertag beziehe sich nicht nur auf die letzten 20 Jahre, sondern auf den gesamten historischen Weg, auf über elf Jahrhunderte. ${ }^{341}$

Diese geschichtliche Erweiterung soll das Bewusstsein für 'geerbter nationale, geistige Traditionen und ihre Bedeutung für die Gegenwart wecken:

»Für uns und für die kommenden Generationen ist es besonders wichtig, den großen schöpferischen Maßstab zu erkennen; die Vergangenheit und ihren tieferen Sinn wertschätzen zu können; das Erbe der nationalen, geistigen Traditionen zu bewahren; seine Bedeutung für die Lösung der heutigen Aufgaben. ॥ $^{342}$

337 Diese Veränderung der Rhetorik lässt sich paallel auch in einigen anderen Redeformaten - wie z. B. der Rede vor der Föderalversammlung 2003 - im Vorfeld der Dumawahlen 2003 beobachten.

338 Putin, Vladimir: Vystuplenie na toržestvach po slučaju Dnja Rossii. 12 ijunja 2003 goda. Moskva, Krasnaja ploščad'. Online: http://news.kremlin.ru/transcripts/22023.

339 Vgl. ebd.

340 Vgl. Putin, Vladimir: Vystuplenie na toržestvach, posvjaščennych Dnju Rossii. 12 ijunja 2004goda. Moskva,Krasnajaploščad'. Online:http://news.kremlin.ru/transcripts/22504.

341 Vgl. Putin, Vladimir: Vystuplenie na priëme v čest' Dnja Rossii. 12 ijunja 2012 goda. Moskva, Kreml'. Online: http://news.kremlin.ru/transcripts/15629.

342 Ebd. 
Die Bedeutung russischer Traditionen wird anschließend als vorbildhaft für die Welt ausgeweitet und als wichtiger Beitrag zum Fortschritt der gesamten Zivilisation gedeutet. ${ }^{343}$

Putin entwickelt in dieser Passage der Rede ein Narrativ einer staatlichen, kulturellen und moralischen Kontinuität über alle Brüche und Kontingenzen der Geschichte hinweg. Er beschreibt dies als eine ununterbrochene »Verbindung der Zeiten $\aleph^{344}$

In der Rede 2013 ist dieses nationale Pathos, aber vor allem das geschichtsphilosophische Sendungsbewusstsein wieder deutlich reduziert. Die Werte und Traditionen werden wieder primär auf die 1990er Jahre projiziert. ${ }^{345}$

2014 wird das Fest erneut im Kontext des "gesamten, mächtigen, Jahrhunderte alten Weges unseres eigenen Vaterlandes ${ }^{346}{ }^{46}$ gedeutet. Ähnlich wie 2012 legt Putin einen Schwerpunkt darauf, die Bedeutung eines retappenübergreifenden $<$ Geschichtsbewusstseins zu betonen. ${ }^{347}$ Die Essenz der Geschichte, das Vermächtnis der Vorfahren, sieht Putin im Patriotismus, der oftmals in der Praxis bewiesen habe, dass er helfen könne beliebige Herausforderungen zu meistern. Wie auch in seiner Rede 2012 beendet er die Passage mit dem Hinweis auf die Kontinuität, bzw. die ununterbrochene Verbindung der Zeiten. ${ }^{348}$

Auch in seiner Rede am 12. Juni 2015 spielt die >Verbindung der Zeiten wichtige Rolle: Sie ist das Instrument, um `den unschätzbaren Besitz‘ der Vergangenheit in die Gegenwart zu überführen und das Heute in die Jahrhunderte dauernde Kontinuität einzubinden. ${ }^{349}$ In der Gegenwart soll die Erfahrung der Geschichte dann zum Ratgeber und Motivator für die Zukunft werden. ${ }^{350}$

In den ersten Jahren der 2000er ist der Rahmen der Reden am Tag Russlands noch relativ unbestimmt. Der Name des Feiertags ändert sich genauso wie die Inszenierung. Typisch für die Reden in diesen Jahren ist ein Fokus auf die Umbruchsjahre als Aufbruch zu `Demokratie und Freiheit‘. Dabei werden die politischen Veränderungen Anfang der 1990er als grundlegend und positiv gewürdigt. Es findet keine klare Distanzierung von den Härten der 1990er statt. Die Zeit wird als notwendige, wenn auch schwierige Lernphase interpretiert. Bis auf die Ausnahme des Jahres 2003 - in dem die Rede in einem gro-

343 Vgl. ebd.

344 Ebd.

345 Vgl. Putin, Vladimir: Vystuplenie na priëme v čest' Dnja Rossii. 12 ijunja 2013 goda. Moskva, Kreml'. Online: http://news.kremlin.ru/transcripts/18325.

346 Putin, Vladimir: Vystuplenie na toržestvennom priëme po slučaju nacional'nogo prazdnika - Dnja Rossii. 12 ijunja 2014 goda. Moskva, Kreml'. Online: http://news.kremlin. $\mathrm{ru} /$ transcripts/45899.

347 Vgl. ebd.

348 Vgl. ebd.

349 Vgl. Putin, Vladimir: Toržestvennyj priëm po slučaju Dnja Rossii. 12 ijunja 2015 goda. Moskva, Kreml'. Online: http://kremlin.ru/events/president/news/49699.

350 Vgl. ebd. 
ßen Rahmen inszeniert wurde - weisen die Reden keine besonders pathetische oder patriotische Rhetorik auf.

Erst ab 2012 findet eine grundlegende Neujustierung statt: Der geschichtliche Bezugsrahmen wird von den Veränderungen der 1990er Jahre auf die Geschichte von elf Jahrhunderten erweitert. Die sjunge` Russländische Föderation wird in die Kontinuität einer Jahrhunderte alten geschichtlichen Kontinuität russländischer Staatlichkeit, Kultur und Werte eingebunden. Das Motiv der Verbindung der Zeiten rückt in den Vordergrund: Es symbolisiert eine politische, kulturelle und wertebezogene Kontinuität über alle Brüche und Kontingenzen hinweg. Mit der Rückkehr Vladimir Putins ins Amt des Präsidenten vollzieht sich nicht nur diese Veränderung des geschichtlichen Bezugsrahmens, auch die Tonlage wird deutlich patriotischer und pathetischer.

Geschichtsphilosophische Passagen über den ımächtigen Weg Russlands und seinen Beitrag zur menschlichen Zivilisation rücken genauso ins Zentrum der Reden wie Reflektionen über die Bedeutung von nationalen, geistigen Werten und Traditionen für die Gegenwart und Zukunft.

Diese Themen verdeutlichen eine klare Neupositionierung des Nationalfeiertags im Rahmen der patriotisch-konservativen Neuausrichtung ab den Wahlen 2012: Unter dem Topos der sununterbrochenen Verbindung der Zeiten soll vor allem eine alles integrierende Kontinuität präsentiert werden, die den demokratischen Aufbruch genauso mit einschließt wie militärischen Ruhm in allen Zeiten, Patriotismus und einen messianischen Geltungsdrang.

\subsection{Opfergedenken}

Opfergedenken steht allgemein und in Präsidentenreden im Besonderen nicht im Zentrum russländischer Erinnerungspolitik. Dennoch sind diese Bezüge, die dem heroischen Ruhmesgedenken weniger dienlich sind, durchaus präsent. Immer wieder wurden auch Elemente des Opfergedenkens in die Ansprachen am 9. Mai integriert, ${ }^{351}$ nach 2000 am deutlichsten in den Jahren 2003, 2010 und 2015. In der Rede 2015 würdigte Putin neben den Gefallenen der großen Schlachten auch diejenigen, »die im nichteroberten Leningrad an Hunger und Kälte starben. Die in den Konzentrationslagern, in Gefangenschaft und Okkupation zu Tode gequält wurden « ${ }^{352}$. Unterstrichen wurde diese Ausrichtung durch die erstmals im Rahmen der Parade abgehaltene Schweigeminute.

351 Schon in der Rede von Malinovskij 1965, aber noch deutlicher bei El'cin 1995 und 1996.

352 Putin, Vladimir: Vystuplenie Prezidenta Rossii na parade, posvjaščënnom 70-letiju Pobedy v Velikoj Otečestvennoj vojne. 9 maja 2015 goda. Moskva. Online: http://kremlin. $\mathrm{ru} /$ events/president/transcripts/49438. 
Die Gedenktage für die Opfer des Holocaust und die Opfer der Repression stehen weit weniger im Fokus der Öffentlichkeit und der staatlichen Erinnerungspolitik als andere Feiertage und verfügen zudem über kein festes Format, in dem regelmäßig Reden stattfinden. Dennoch ist der Blick auf diese Themen in den Reden aus verschiedenen Gründen von Relevanz. Das Thema der Repressionen in Präsidentenreden gewinnt seine Brisanz vor dem Hintergrund der immer wieder hitzig geführten Diskussionen in Russland um die Positionierung der heutigen Führung zu den stalinschen Verbrechen. ${ }^{353}$ Die erinnerungspolitische Thematisierung des Holocaust ist besonders mit Hinblick auf die Marginalisierung des Gedenkens und die Nichthervorhebung der jüdischen Identität der Opfer in der Sowjetunion interessant. ${ }^{354}$

Die Reden, die in verschiedenen Zusammenhängen anlässlich des Holocaust-Gedenkens durch Vladimir Putin und Dmitrij Medvedev gehalten wurden, haben einen durchgehenden Kern: Die Würdigung der Opfer des Holocaust, die Würdigung der Befreier der Konzentrationslager und die Würdigung der sowjetischen Soldaten und ihrer Verbündeten als Befreier Europas vom Nazismus. ${ }^{355}$

In der Rede am 60. Jahrestag der Befreiung des Lagers Auschwitz-Birkenau wird eine solche prägende Perspektive deutlich: Der Holocaust und seine Opfer werden in den Kontext des Weltkrieges allgemein und in den Kontext des Vernichtungskrieges im Osten im Besonderen gestellt. Die Opfer werden dabei auch als `Eigene $\prec$, als Landsleute beschrieben:

»Dem Material der Nürnberger Prozesse zufolge wurden in Europa während des Holocaust sechs Millionen Juden ermordet. [...] Darunter hunderttausende und Millionen unserer Landsleute. ${ }^{356}$

353 Zur Diskussion um Stalinismus und »Re-Stalinisierung« vgl. Khapaeva, Dina: Ocharovannye stalinizmom. Massovoe istoricheskoe soznanie v preddverii vyborov. In: Neprikosnovennyi zapas 55/5 (2007); Kindler, Robert: Kratzer auf dem `Autobus des Siegesく. Erinnerung an den Stalinismus in der Sowjetunion und in Russland. In: Baberowski, Jörg/Kindler, Robert (Hg.): Macht ohne Grenzen. Herrschaft und Terror im Stalinismus. Frankfurt a. M. 2014, 193-213.

354 Vgl. Makhotina, Ekaterina: Erinnerungen an den Krieg, Krieg der Erinnerungen. Litauen und der Zweite Weltkrieg. Göttingen 2017; Gitelman, Zvi: Politics and Historiography of the Holocaust in the Soviet Union. In: Gitelman, Zvi (Hg.): Bitter Legacy. Confronting the Holocaust in the USSR. Bloomington, Indianapolis 1997, 14-42; Gitelman, Zvi: Die sowjetische Holocaust-Politik. In: Young, James (Hg.): Mahnmale des Holocaust. Motive, Rituale und Stätten des Gedenkens. München 1994, 115-124.

355 Vgl. Putin, Vladimir: Vystuplenie na gosudarstvennoj ceremonii, posvjaščennoj 60letiju osvoboždenija sovetskimi vojskami konclagerja Aušvic-Birkenau. 27 janvarja 2005 goda. Pol'ša, Osvencim. Online: http://news.kremlin.ru/transcripts/22802.

356 Putin, Vladimir: Meždunarodnyj den' pamjati žertv Cholokosta. 27 janvarja 2015 goda. Moskva. Online: http://news.kremlin.ru/transcripts/47529. 
Ebenfalls zum Kern aller Reden anlässlich des Holocaust-Gedenkens gehört die Warnung vor der Umdeutung oder Fälschung der Geschichte:

»Jeder Versuch, die Geschichte umzuschreiben, zu versuchen, Opfer und Henker, Befreier und Besatzer in eine Reihe zu stellen, ist amoralisch und unvereinbar mit dem Bewusstsein der Menschen, die sich als Europäer sehen. » ${ }^{357}$

Der Hinweis auf die Unvereinbarkeit der gleichsetzenden Geschichtsbetrachtung mit seuropäischem Bewusstsein` ist ein interessanter Hinweis auf die Debatte um die Zentralität des Holocausts im europäischen Geschichtsbewusstsein und dessen Herausforderung durch das >nationale Geschichtsbewusstsein der neuen EU-Staaten in den 2000er Jahren. ${ }^{358}$

In seiner Botschaft an die Teilnehmer der Gedenkveranstaltungen zum 65. Jahrestag der Befreiung des Lagers Auschwitz-Birkenau 2010 verdeutlichte Dmitrij Medvedev diesen Verweis auf die Geschichtsperspektiven der neuen EU-Staaten des Baltikums ${ }^{359}$ mit dem Hinweis auf eine zunehmende Heroisierung von Kollaborateuren und einer zunehmenden Relativierung von nationalsozialistischen Verbrechen. ${ }^{360}$ Die unverfälschte Geschichte wird im Rahmen des Holocaust-Gedenkens immer wieder als Schutz vor dem Wiedererstarken nationalsozialistischer Ideologien interpretiert. ${ }^{361}$

Neben diesen Kernthemen, der Würdigung von Opfern und Befreiern sowie der Warnung vor Umdeutung der Geschichte, waren vor allem die Jahre der runden Jahrestage 2005 und 2015

Anlass, das Holocaust Gedenken am Tagder Befreiungdes Lagers AuschwitzBirkenau auch tagespolitisch zu kontextualisieren. Am 27. Januar 2005 verband Vladimir Putin im Rahmen des Forums "Let my people live ${ }^{362}$ das Holocaust-Gedenken mit der Warnung vor dem internationalen Terrorismus als ınicht weniger schrecklicher Gefahr $\triangleleft$ Die Rolle der Henker in schwarzen

357 Putin, Vladimir: Vystuplenie na gosudarstvennoj ceremonii, posvjaščennoj 60-letiju osvoboždenija sovetskimi vojskami konclagerja Aušvic-Birkenau. 27 janvarja 2005 goda. Pol'ša, Osvencim. Online: http://news.kremlin.ru/transcripts/22802.

358 Vgl. Schwelling, Birgit: Das Gedächtnis Europas. Eine Diagnose. In: Beichelt, Timm u.a. (Hg.): Europa Studien. Eine Einführung, Wiesbaden 2006, 81-94. Hier $85 \mathrm{ff}$.

359 Auch neue ukrainische Geschichtsperspektiven unter der Präsidentschaft Viktor Juščenkos dürften hier gemeint sein. Vgl. z. B. Schubert, Christiane: Dreizack und Roter Stern: Geschichtspolitik und historisches Gedächtnis in der Ukraine. Berlin 2015.

360 Vgl. Medvedev, Dmitrij: Poslanie učastnikam pamjatnych meroprijatij, posvjaščënnych 65-letiju osvoboždenija konclagerja Aušvic-Birkenau. Online: http://kremlin.ru/events/ president/news/6724.

361 Vgl. Putin, Vladimir: Privetstvie učastnikam Memorial'nogo večera-rekviema, posvjaščënnogo 70-letiju osvoboždenija Krasnoj armiej uznikov konclagerja Osvencim i Meždunarodnomu dnju pamjati žertv Cholokosta. 26 janvarja 2015 goda. Moskva. Online: http://kremlin.ru/events/president/news/47520.

362 Auch: World Holocaust Forum - Vsemirnyj Forum Pamjati Cholokosta: Online: http:// www.worldholocaustforum.org 
Uniformen sei an die Terroristen übergegangen, mit dem gleichen Hass auf Andersdenkende und der gleichen Verachtung für menschliches Leben. ${ }^{363}$

Auch in seiner späteren Rede bei der Gedenkveranstaltung auf dem Lagergelände am gleichen Tag stellte Putin diese Verbindung her und verwies auf den erinnerungspolitischen Kern dieser Analogiebildung: die Absolutheit der ‘tödlichen Bedrohung` des Terrorismus, die differenzierende Abwägungen ausschließe. ${ }^{364}$ Die Herstellung der Verbindung zwischen Nazismus und Terrorismus dient, wie auch in den Reden zum Tag des Sieges am 9. Mai, ${ }^{365}$ der Legitimation eines kompromisslosen Vorgehens und der grundsätzlichen Delegitimation der Gegner. ${ }^{366}$

Auch am 70. Jahrestag der Befreiung des Lagers Auschwitz-Birkenau enthält die Rede Vladimir Putins im Jüdischen Museum und Toleranzzentrum Moskau verschiedene tagespolitische Kontextualisierungen, die das HolocaustGedenken erinnerungspolitisch aufladen. So wird beispielsweise der vor allem ab dem Jahr 2012 in den Reden Putins häufige Topos der ,Vernichtung traditioneller Werte aufgegriffen und mit dem Thema Holocaust in Verbindung gebracht: Dort, wo die traditionellen Werte verhöhnt und vernichtet würden, führe der Zivilisationswandel schnell und unweigerlich in die Barbarei. ${ }^{367}$

Die in allen Reden zu diesem Thema enthaltenen Einlassungen gegen die Fälschung oder Umdeutung von Geschichte werden 2015 nochmals zusätzlich aufgeladen. Betont wird die Kollaboration und Teilnahme der örtlichen Bevölkerung am Holocaust oder auch an ethnischen Säuberungen:

"Die historischen Tatsachen sind unwiderlegbar. So bezeugen sie, dass die Banderovcy und andere Kollaborateure, Helfer Hitlers, selbst mitwirkten an der Vernichtung des jüdischen Volkes, an der Vernichtung der Juden L'vovs, Odessas, Kiews und anderer Orte der Ukraine, und die baltischen Nazisten führten `ethnische Säuberungen` in Vilnius und Riga, in Kaunas und Tallinn durch. ${ }^{368}$

Gerade die Betonung der Kollaboration national-ukrainischer Gruppierungen dient der Legitimation der eigenen Position in der Ukraine-Krise. Schon im Winter 2013 waren durch russische Medien vor allem nationalistische und

363 Vgl. Putin, Vladimir: Vystuplenie na forume »Žizn' narodu moemu!«, posvjaščennom pamjati žertv Osvencima. 27 janvarja 2005 goda. Pol'ša, Krakov. Online: http://news. kremlin.ru/transcripts/22800.

364 Vgl. ebd.

365 Die erinnerungspolitische Verknüpfung vom Kampf gegen den Nazismus und dem Kampf gegen den Terrorismus ist besonders in den Reden zum 9. Mai der Jahre 2002 bis 2004 präsent.

366 Vgl. Kapitel: Reden und Paraden am 9. Mai von 2000 bis 2015.

367 Vgl. Putin, Vladimir: Meždunarodnyj den' pamjati žertv Cholokosta. 27 janvarja 2015 goda. Moskva. Online: http://news.kremlin.ru/transcripts/47529.

368 Ebd. 
nationalsozialistische Kräfte als treibende Kräfte der Maidan-Bewegung in den Fokus der Berichterstattung gerückt worden, die sich positiv auf Stepan Bandera und dessen Gruppierung - die sogenannten Banderovcy - bezogen. Die Thematisierung in diesem Zusammenhang legitimiert den Widerstand gegen die neue politische Führung in Kiew, der in den russländischen Medien eine enge Verzahnung mit völkisch-nationalistischen Kräften und der Einsatz offen faschistischer Bataillone im Krieg in der Ostukraine vorgeworfen wurde.

Diese Betrachtung der politischen Verhältnisse im Nachbarland wird in der Folge - wenn auch implizit - weiter ausgeführt. Als Abschluss dieser Passage verweist Vladimir Putin explizit auf den Donbas als ein Beispiel dafür, dass doppelte moralische Standards zu Gleichgültigkeit gegenüber dem Schicksal von Menschen führen würden, und leitet daraus die Forderung nach einer Stärkung internationaler kollektiver Sicherheitssysteme ab. ${ }^{369}$

Das Beispiel dieser Rede am Gedenktag für die Opfer des Holocaust zeigt, dass die Reden zum Holocaust-Gedenken nicht nur ein Ort der Würdigung von Opfern und Befreiern sind, sondern auch immer wieder für die Tagespolitik instrumentalisiert werden.

Die stalinschen Repressionen und ihre Opfer zählen nicht zu den regelmäßigen Themen in den verschiedenen Redeformaten. Während sie in den Regierungserklärungen Boris El'cins regelmäßig im Zusammenhang mit den Rehabilitationsmaßnahmen erwähnt wurden, nahm die Aufmerksamkeit in den folgenden Jahren ab. Trotzdem besuchten sowohl Putin als auch Medvedev Denkmale für die Opfer der Repressionen: So besuchte beispielsweise Putin am 22. März 2003 die Gedenkstätte in Norilsk (Autonomer Kreis Taimyr) und Dmitrij Medvedev besuchte am 24. September 2008 die Gedenkstätte in Magadan und legte dort Blumen nieder. Auch in Interviews findet das Thema durchaus Berücksichtigung. ${ }^{370}$

Am >Tag des Gedenkens an die Opfer der politischen Repressionen ${ }^{371}$ am 30. Oktober 2007 besuchte Vladimir Putin die Erschießungsstädte >Memorialkomplex Butovo bei Moskau und gab vor Journalisten ein vorbereitetes Statement zum Thema Repressionen ab. Dabei führte er als Ursache der Repressionen an, dass "auf den ersten Blick attraktive, aber letztendlich leere

369 Vgl. ebd.

370 Vgl. Putin, Vladimir: Sovmestnoe interv'ju s Federal'nym kanclerom FRG Gerchardom Šrëderom gazete »Bil’d«. 7 maja 2005 goda,. Online: http://news.kremlin.ru/transcripts/ 22950.

371 Der Gedenktag geht auf den bis heute gültigen Beschluss des Obersten Sowjets der RSFSR vom 18. Oktober 1991 über die Einrichtung des Gedenktages an die Opfer der politischen Repressionen zurück. Vgl. Postanovlenie VS RSFSR ot 18.10.1991 N 1763/1-1 »Ob ustanovlenii Dnja pamjati žertv političeskich repressij«. 
Ideale höher gesetzt wurden als fundamentale Werte wie das menschliche Leben, die Rechte und die Freiheit der Menschen. $\aleph^{372}$

Die Repressierten beschreibt Putin sehr positiv als »Menschen mit eigener Meinung, die sich nicht fürchteten diese auszusprechen, höchst fähige Menschen, die Zierde der Nation. « $^{373}$

Seine Forderung, das Andenken an diese `Tragödie` zu bewahren, verbindet Putin mit einer erinnerungspolitischen Ableitung. Man müsse verstehen, dass für die Entwicklung des Landes, für die Wahl des effektivsten Weges zur Lösung der aktuellen Probleme des Landes politischer Streit und der Kampf der Meinungen notwendig sei. Die Opfer der Repressionen stünden genau für jene Eigenschaften, die für die heutige Entwicklung notwendig seien. ${ }^{374}$

Am 30. Oktober 2009 widmete Dmitrij Medvedev dem Gedenktag einen vielbeachteten Eintrag in seinem Video-Blog unter dem Titel »Die Erinnerung an die nationalen Tragödien ist genauso heilig wie die die Erinnerung an die Siege $\ll{ }^{375}$ Medvedev betonte darin den hohen Stellenwert der Erinnerung an die Repressionen und wies jegliche Rechtfertigung oder Relativierung der stalinistischen Verbrechen zurück:

"Aber bis heute hört man, dass die zahlreichen Opfer durch gewisse höhere staatliche Ziele gerechtfertigt gewesen seien. Ich bin überzeugt, dass keine Entwicklung des Landes, keiner seiner Erfolge und keine seiner Ambitionen auf Kosten von menschlichem Leid und Verlusten erreicht werden können. Nichts kann höher als der Wert des Menschenlebens eingestuft werden. Und für die Repressionen gibt es keine Rechtfertigung. ${ }^{376}$

Der hohe Stellenwert, den Medvedev dem Gedenken zubilligt, wird in der darauf folgenden Passage deutlich. Medvedev plädiert dafür, der Rechtfertigung der Repressionen genauso als Verfälschung der Geschichte entgegen zu treten wie im Bereich der Geschichte des Großen Vaterländischen Krieges. ${ }^{377}$

Auch einen Widerspruch zwischen der heroischen Erinnerung an den Krieg und dem Verweis auf die ,Verbrechen Stalins` weist Medvedev zurück: Der Sieg im Großen Vaterländischen Krieg, der Aufstieg als Industrienation, das Weltniveau in Wissenschaft, Kultur und Industrie seien die Errungenschaften

372 Putin, Vladimir: Podchod k presse posle poseščenija Butovskogo memorial'nogo kompleksa. 30 oktjabrja 2007 goda. Moskva, Butovo. Online: http://news.kremlin.ru/ transcripts/24627.

373 Ebd.

374 Vgl. ebd.

375 Medvedev, Dmitrij: Pamjat' o nacional'nych tragedijach tak že svjaščenna, kak pamjat' o pobedach. 30 oktjabrja 2009 goda,. Online: http://news.kremlin.ru/transcripts/5862 oder: Online: http://blog.da-medvedev.ru/post/35/transcript.

376 Ebd.

377 Vgl. ebd. 
des Volkes - Stalins Verbrechen könnten diese nicht herabsetzen. ${ }^{378}$ Medvedev schließt seinen Eintrag mit dem Appell, das Gedenken zu bewahren und zukünftig auszuweiten.

Dem Thema des kommunistischen Terrors kommt, vor allem im Umfeld des Tages der Opfer der Repressionen, immer wieder Aufmerksamkeit zu. Als Repressionen werden dabei vor allem die »Verbrechen Stalins« betrachtet. Eine breitere Perzeption, die etwa auch das Vorgehen gegen sowjetische Dissidenten nach Stalin mit einschließt, lässt sich - wenn überhaupt - nur in Andeutungen herauslesen. Putins Pluralitätsdiskurs, in dem er die Opfer der Repressionen erinnerungspolitisch als »Pioniere einer modernen, pluralistischen Gesellschaft « und damit als vorbildhaft für eine plural-verfasste Gegenwartsgesellschaft stilisiert, geht in diese Richtung; genauso wie die besondere Hervorhebung der Dissidenten in den Vorgaben für Schulbücher ab 2013. ${ }^{379}$

Die Redebeiträge sind in ihrer Verurteilung der Repressionen und im $\mathrm{Zu}$ rückweisen von Relativierungen somit klar und eindeutig, auch wenn das kritische Niveau von Medvedevs Äußerungen von 2009 in ihrer Deutlichkeit und Konsequenz bislang einmalig geblieben ist.

Dass es auf dieser Ebene bisher keine Zugeständnisse an neo-stalinistische Akteure gibt, zeigt auch die Umsetzung dieser Positionen in Regierungshandeln. Im August 2015 bestätigte die russländische Regierung eine Konzeption zur Verewigung des Andenkens der Opfer der politischen Repressionen. ${ }^{380}$

\subsection{Zusammenfassung: Erinnerungspolitik in Präsidentenreden}

Betrachtet man die verschiedenen Redeformate über die Jahre, so fallen drei wichtige erinnerungspolitische Themenkomplexe in den Präsidentenreden auf: der epochenübergreifende militärische Ruhm, die Einordnung der 1990er Jahre und die Neuausrichtung ab dem Jahr 2012

Der Rückgriff auf das Narrativ des militärischen Ruhms in allen Zeiten in Verbindung mit dem Großen Vaterländischen Krieg hat seine Wurzeln im Sowjetpatriotismus. Boris El'cin etablierte dieses Narrativ in einer auf das Militärische reduzierten Variante und gab damit seit der Mitte der 1990er Jahre wichtige Eckpunkte der heutigen Erinnerungspolitikvor. Was unter Boris El'cin noch fragmentarischen Charakter besaß, wurde unter seinem Nachfolger -

378 Vgl. ebd.

379 Vgl. Kapitel: Schulbücher, Bildungspolitik - Geschichtspolitik.

380 Vgl. Rasporjaženie Pravitel'stva RF ot 15.08.2015 N 1561-r: »Ob utverždenii Koncepcii gosudarstvennoj politiki po uvekovečeniju pamjati žertv političeskich repressij«. 
der bereits in seiner Inaugurationsrede klar gemacht hatte, dass die Geschichte ein primäres Instrument sein sollte, um gesamtgesellschaftliche Kohäsion zu generieren - zu einer konsistenten Politik ausgebaut.

Ein Beispiel hierfür ist der Tag des Vaterlandsverteidigers. Während El'cin diesen im weitesten Sinne von der Sowjetunion geerbten Tag nicht ausfüllen konnte oder wollte, nutzte Putin den Tag von Beginn an, um im Kontext des Krieges in Tschetschenien heroische Traditionen zu beschwören und für das Ansehen der Streitkräfte zu werben.

Der zentrale Anlass, um die militärischen Traditionen in allen Zeiten und die Vorbildhaftigkeit der heroischen Kriegsgenerationen zu würdigen, bleiben die Feiern zum Tag des Sieges. Das Narrativ der einfachen Soldaten und der Kommandeure, die uneigennützig und heldenhaft für die Einheit und Unabhängigkeit des Landes kämpften, wird auch über diese Formate hinaus regelmäßig als vorbildhaft für das dienstliche, aber auch zivile Engagement der Bürger gegenüber dem Staat fortgeschrieben. Weitere eindrückliche Beispiele, die sich nicht direkt auf den Großen Vaterländischen Krieg beziehen, sind die Präsidentenreden anlässlich der Feier zum 200. Jahrestag der Schlacht von Borodino $2012^{381}$ oder der Eröffnung des Denkmals für die Helden des Ersten Weltkriegs $2014^{382}$ in Moskau.

Die Ausrichtung auf militärischen Ruhm ist der prägnanteste Bezugspunkt der Präsidentenreden zu den Programmen zur Patriotischen Erziehung: Dieser Themenkomplex ist die zentrale Klammer, um die bruchlose Geschichte zu schreiben, die Putin bereits in seiner Antrittsrede im Jahr 2000 forderte, und derzeit von zentraler Bedeutung für Erinnerungspolitik in Russland.

Das Narrativ des militärischen Ruhmes in allen Zeiten funktioniert durch eine geschichtliche Entkontextualisierung beispielsweise in Bezug auf politische Rahmenbedingungen und eine gleichzeitige Fokussierung auf bestimmte Aspekte: den heldenhaften selbstlosen Einsatz für das Land oder das Volk. Dieses Heldentum als russländischer Nationalcharakter wird sogar mehrfach als genetisch oder vererbbar bezeichnet. Im übertragenen Sinne verweist das auf die notwendige Vorbildhaftigkeit der Helden für die Gegenwart. Dieses Narrativ findet in vielen Redeformaten, je nach Anlass in verschiedenem Umfang, Berücksichtigung.

Es besteht die Möglichkeit, dass diesem Komplex im Bereich der Reden in den nächsten Jahren noch größerer Raum gegeben wird: Mit dem Tag der Helden des Vaterlands` - eingeführt 2007 und ab 2013 mit Empfängen im

381 Vgl. Putin, Vladimir: Toržestva po slučaju 200-letija Borodinskogo sraženija. 2 sentjabrja 2012 goda. Moskovskaja oblast', Borodino. Online: http://news.kremlin.ru/transcripts/ 16346.

382 Vgl. Putin, Vladimir: Otkrytie pamjatnika gerojam Pervoj mirovoj vojny. 1 avgusta 2014 goda. Moskva. Online: http://news.kremlin.ru/transcripts/46385. 
Georgssaal des Kremls begangen ${ }^{383}$ - steht ein weiterer Anlass bereit, der nach Bedarf ausgebaut werden kann. ${ }^{384}$ Die Ehrung von lebenden Helden, mit Präsidentenreden vor der Kulisse des Georgssaales ${ }^{385}$ und damit im Kontext der militärischen Helden der Geschichte, weist erhebliches Potenzial für die Beförderung des Narrativs des militärischen Ruhmes in allen Zeiten auf. Der Einsatz des Georgsbändchens - das als Symbol eng mit der Geschichte des Feiertags verbunden ist - zeugt von diesen Potenzialen.

Der Arbeit an der geschichtspolitischen Einordnung der 1990er Jahre kommt in den 2000er Jahren eine große Bedeutung zu: Während El'cin seine Politik unter Bezugnahme auf die Sowjetunion begründete, sind es in den Reden Vladimir Putins die 1990er Jahre. Diese Bezugnahmen finden sich in vielen verschiedenen Redeformaten. Über die vorgestellten Anlässe hinaus findet das Thema auch am Verfassungstag regelmäßig Berücksichtigung. ${ }^{386}$ Die 1990er Jahre werden durchgängig als schwierige Zeit der Härten beschrieben. Sie werden jedoch nicht als fremde Zeit externalisiert und die Härten und Fehler der Zeit werden kaum Schuldigen zugeordnet. Nur wenn es tagespolitisch erforderlich erscheint, wird das Narrativ der 1990er vereinzelt gegen $>$ die Macht der Oligarchen` in Stellung gebracht. Die Reden beinhalten vielmehr

383 Der `Tag der Helden des Vaterlandes` am 9. Dezember wurde 2007 auf Initiative der Duma-Fraktion von Edinaja Rossija mit dem Status eines Gedenktages eingeführt. Vgl. Federal'nyj zakon Rossijskoj Federacii ot 28 fevralja 2007 g. N 22-FZO vnesenii izmenenija v stat'ju 11 Federal'nogo zakona $O \mathrm{O}$ dnjach voinskoj slavy i pamjatnych datach Rossii. Opublikovano: 3 marta 2007 g. v »RG» - Federal'nyj vypusk Nr. 4308. Online: http://www.rg.ru/2007/03/03/geroi-dok.html.

384 Das Datum des Tages bezieht sich auf die Stiftung des Ordens des Heiligen Georgs durch Ekaterina II. im Jahr 1769 und den vorrevolutionären Tag der Träger des Ordens. Der Sankt Georgs Orden wurde im Jahr 2000 als höchste militärische Auszeichnung wieder eingeführt und seine Verleihungsrichtlinien 2008 überarbeitet. Vgl. Ukaz Prezidenta RF ot 08.08.2000 N 1463 (red. ot 12.08.2008) »Ob utverždenii Statuta ordena Svjatogo Georgija, Položenija o znake otličija - Georgievskom Kreste i ich opisanij«.

385 Vgl. Putin, Vladimir: Priëm po slučaju prazdnovanija Dnja Geroev Otečestva. 9 dekabrja 2013 goda. Moskva, Kreml'. Online: http://kremlin.ru/events/president/news/19810. Putin, Vladimir: Toržestvennyj priëm po slučaju Dnja Geroev Otečestva. 9 dekabrja 2014 goda. Moskva, Kreml'. Online: http://kremlin.ru/events/president/news/47211/videos. Putin, Vladimir: Toržestvennyj priëm po slučaju Dnja Geroev Otečestva. 9 dekabrja 2015 goda. Moskva, Kreml'. Online: http://kremlin.ru/events/president/news/50901.

386 In der Sowjetunion wurde bis 1977 der 5. Dezember als Tag der Stalinschen 1936er Verfassung begangen, danach der 7. Oktober als Tag der Verfassung des entwickelten Sozialismus von 1977. Ab 1993 wurde der 12. Dezember als Tag der neuen Verfassung begangen. 2005 wurde der arbeitsfreie Status gestrichen und der Tag als Gedenktag in das Gesetz über die Tage des militärischen Ruhmes und Gedenktage aufgenommen. Die jährlichen Empfänge wurden beginnend 2004 durch ein Gespräch des Präsidenten mit den Richtern des Verfassungsgerichtes ersetzt. Lediglich an runden Jahrestagen, wie z. B. 2013, finden größere Empfänge statt. 
viel Verständnis und Apologetik für die sschwierigen Entscheidungen « in historisch einmaliger Situation.

Gleichzeitig werden die 1990er Jahre über diese Probleme hinaus als Beginn der Geschichte des neuen Russlands sehr positiv beschrieben:

»Damals im Jahr 1993 haben wir für den Rechtsstaat, Demokratie und Freiheit gestimmt. [...] Letztendlich haben wir am 12. Dezember 1993 die Zukunft Russlands gewählt. « ${ }^{387}$

Dieses Narrativ einer schwierigen Zeit, in der Fehler fast zwangsläufig geschahen, aber auch die Grundlagen eines prosperierenden Staates geschaffen wurden, war von Putin bereits Anfang des Jahres $2000 \mathrm{im}$ Rahmen der Trauerfeier für seinen ehemaligen Mentor Anatolij Sobčak geprägt worden und wurde bei seiner offiziellen Amtseinführung durch seinen Vorgänger Boris El'cin wiederholt.

Die ostentative Hervorhebung von Demokratie, Freiheit und Menschenrechten, die sich durch viele Formate von der Föderalversammlung über den Tag Russlands bis zum Verfassungstag zieht, wird über die Jahre sukzessive neu kontextualisiert: Spätestens mit der Rückkehr Putins ins Präsidentenamt 2012 werden diese Errungenschaften der Russländischen Föderation in einer eigenständigen Wertetradition verortet. Die Reden schreiben Freiheit, Menschenrechte und Demokratie mit zunehmender Tendenz nicht mehr als aufholende Entwicklung in eine universelle Tradition ein, sondern in eine Tradition der eigenen Werte - der samobytnost' - und beschreiben sie dabei als eine Rückkehr zu sich selbst, zur eigenen Tradition. Schon in der Rede vor der Föderalversammlung 2005 erklärte Putin, dass ein eigener Weg gefunden werden musste, um Staat und Gesellschaft demokratisch, frei und gerecht aufzubauen. $^{388}$

Neben den genannten Anlässen, existiert noch ein weiterer Feiertag, der mit dem 1990er-Narrativ in Verbindung steht: der Tag der Einheit des Volkes am 4. November. Das Narrativ von dem Volk, das sich unter neuer Führung vereinigt, die Fremdherrscher vertreibt, die Zeit der Wirren beendet und damit die Fundamente für ein starkes Russland legt, evoziert eine Parallelisierung mit den 1990er Jahren. Dennoch wird diese sich aufdrängende Parallele bisher - selbst in den Reden zum 4. November nach 2012 - nicht etabliert.

Die 1990er Jahre bleiben die »eigene" Zeit und begangene Fehler werden fast durchgängig apologetisch der Besonderheit der zeitlichen Umstände zugeschrieben. Dieser Umgang mit der Epoche - der Fokus auf die Härten und

387 Putin, Vladimir: Vystuplenie na prieme po slučaju Dnja Konstitucii. 12 dekabrja 2001 goda. Moskva, Kreml'. Online: http://news.kremlin.ru/transcripts/21441.

388 Putin, Vladimir: Poslanie Federal'nomu Sobraniju Rossijskoj Federacii. 25 aprelja 2005 goda. Moskva, Kreml'. Online: http://kremlin.ru/events/president/transcripts/22931. 
die fast notwendigen Fehler - macht es möglich, die immensen innergesellschaftlichen Konflikte der 1990er Jahre aus dem Fokus zu nehmen. Bezeichnend ist, dass der Höhepunkt dieser Konflikte - Konfrontationen zwischen liberalen Reformern und sowjetisch oder national orientierten Konservativen mit der blutigen Kulmination in der sogenannten Verfassungskrise 1993 - in den Reden nicht vorkommt. Die neue Verfassung, ihre Rechte und Freiheiten sowie ihre konsolidierende Wirkung werden gefeiert. Die Frage, wer gegen wen und warum in den Straßen Moskaus gekämpft hat, spielt keine Rolle.

$\mathrm{Ab}$ dem Jahr 2012 lässt sich eine deutliche Betonung konservativ-patriotischer Positionen feststellen. ${ }^{389}$ Dies zieht sich fast ausnahmslos durch alle Redeformate, mit einer besonderen Vehemenz in den Reden vor der Föderalversammlung.

Auch in den ersten beiden Präsidentschaften Putins gibt es einige Beispiele für auffällig patriotische Formulierungen oder indignierte Tonlagen, wie die Rede am 9. Mai $2007^{390}$ oder die Rede am Tag Russlands $2003^{391}$. Die jeweiligen Umstände weisen hier jedoch auf eine mehr taktische als strategische Motivation hin. Ab der Wiederwahl verkehrt sich dieses Verhältnis: Die konservativpatriotischen Positionen weisen einen konsistenten, strategischen Charakter auf, während konziliante Tonlagen eher taktisch motiviert zu sein scheinen, wie beispielsweise das Werben um Kooperation am 9. Mai 2015.

Der strategische Charakter der Neuausrichtung zeigt sich in dem beinahe alle Redeformate umfassenden Wandel der Rhetorik in der dritten Präsidentschaft. Schon die Inaugurationsrede im Mai 2012 veranschaulicht den Wandel:

"Wir sind gemeinsam einen großen und schweren Weg gegangen, haben an uns geglaubt, an unsere Stärke; wir haben das Land gestärkt und uns selbst die Würde einer großen Nation zurückgegeben, die hat die Wiedergeburt Russlands erlebt[...].« ${ }^{392}$

Diese Wendungen, von der Würde einer großen Nation oder der Wiedergeburt Russlands, sind bezeichnend für den Stil der dritten Amtszeit. Die sprachlichen Anleihen, sowohl bei rhetorisch radikaleren Reden Boris El'cins ${ }^{393}$ als

389 Vgl. Schröder, Hans-Henning: Vorwärts Russland! Die Botschaft des Präsidenten an die Nationalversammlung. In: Russland-Analysen Nr. 249 vom 14.12.2012, 4.

390 Vgl. Putin, Vladimir: Vystuplenie na voennom parade v čest' 62-j godovščiny Pobedy v Velikoj Otečestvennoj vojne. 9 maja 2007 goda. Moskva, Krasnaja ploščad'. Online: http://kremlin.ru/transcripts/24238.

391 Vgl. Putin, Vladimir: Vystuplenie na toržestvach po slučaju Dnja Rossii. 12 ijunja 2003 goda. Moskva, Krasnaja ploščad'. Online: http://news.kremlin.ru/transcripts/22023.

392 Putin, Vladimir: Vladimir Putin vstupil v dolžnost' Prezidenta Rossii. 7 maja 2012 goda. Moskva, Kreml'. Online: http://news.kremlin.ru/transcripts/15224.

393 Einen direkten Vorläufer hat die Passage in der Rede El'cins anlässlich seiner Amtseinführung 1991, in der er von der Wiederkehr Russlands sprach, das sich von seinen Knien erhebe. Vgl. Vystuplenie B. N. El'cina In: Rossijskaja gazeta (Federal'nyj vypusk) Nr. 144 (190) vom 11. Juli 1991,1. 
auch beim nationalistischen und neo-sowjetischen Milieu der Gegenwart, ${ }^{394}$ sind deutlich.

Einige der Neuerungen sind nicht in allen Redeformaten präsent. Dazu zählen formatspezifische Veränderungen des jeweiligen Narrativs oder auch die Thematisierung des Eurasismus. ${ }^{395}$ Durch alle Formate ziehen sich dagegen als Neuerungen zum einen die Betonung von Werten und Traditionen sowie teilweise damit verbunden das Herausstellen von Geschichtlichkeit.

Diese Neuerungen verbinden sich schon in der Inaugurationsrede 2012: Die Ausrichtung für die nächsten Jahre beschreibt Putin nicht in einer wirtschaftlichen oder politischen, sondern in einer geschichtlichen Perspektive. Es gehe um das »Schicksal Russlands« und um »das Leben zukünftiger Generationen und die historischen Perspektiven des Staates und unserer Nation « ${ }^{396}$. Im weiteren Verlauf verortet Putin die Regierungsarbeit der Gegenwart mit »Glaube« und »aufrichtigen und reinen Absichten" zwischen der "großen Geschichte" Russlands und seiner »nicht weniger großen Zukunft $\aleph^{397}$.

Solche Verortungen und andere Formen des Geschichtsbezugs ziehen sich durch alle Redeformate. Besonders auffällig ist dabei ab 2012 die vermehrte Präsentation einer langen Geschichte, das Betonen von 1000-jähriger, Jahrhunderte währender Geschichte. Die Ankündigung aus Putins erster Amtseinführung im Jahr 2000, die Verbindung der Zeiten wieder herzustellen, ${ }^{398}$ kommt hier endgültig zum Tragen.

Eng verbunden mit der Betonung von Geschichtlichkeit ist auch die Akzentuierung von Werten, Traditionen und nationalem Charakter ab 2012. Während in den Reden Medvedevs Werte vor allem aus der Verfassung abgeleitet werden, begründet Putin Werte und Traditionen aus der 1000-jährigen Geschichte. Dabei halten vermehrt Begriffe wie Samobytnost' Einzug, die in Diskursen der russischen Eigenständigkeit zu verorten sind. Die Betonung der eigenen Traditionen wird auch auf die Begriffe Freiheit, Demokratie und Menschenrechte angewandt. Sie werden, im Gegensatz zu den 1990er und mit Ausnahmen den 2000er Jahren, zunehmend aus einer universalen Tradition gelöst und in einen Diskurs der russischen Eigenart eingebunden. Die Verbindung von Werten und Traditionen mit der Samobytnost' findet auch in häufigeren Zitaten russischer Konservativer ihren Ausdruck, wie Ivan Il'in,

394 Vgl. Kapitel: Bike-Shows und Patriotische Erziehung.

395 Vgl. z. B. Putins Rede vor der Föderalversammlung 2012 oder seine Inaugurationsrede 2012.

396 Putin, Vladimir: Vladimir Putin vstupil v dolžnost' Prezidenta Rossii. 7 maja 2012 goda. Moskva, Kreml'. Online: http://news.kremlin.ru/transcripts/15224.

397 Ebd.

398 Putin, Vladimir: Vystuplenie na ceremonii vstuplenija v dolžnost' Prezidenta Rossii. 7 maja 2000 goda. Moskva, Bol’šoj Kremlevskij dvorec. Online: http://news.kremlin.ru/ transcripts/21399. 
Nikolaj Berdjaev, Lev Gumilëv oder Aleksandr Solženicyn. Sie werden als Sekundanten eines Konservatismus zitiert, der sich auf den traditionellen Werten von Familie und Religion gründen soll.

In einer diachronen Betrachtung der verschiedenen Redeformate fällt zusätzlich auf, dass sich Verschärfungen der Rhetorik oder auch der stärkere Einsatz von Geschichtlichkeit oder nationalem Pathos mit tagespolitischen Problemlagen kontextualisieren lassen.

Die Veränderungen in der Rhetorik verschiedener Redeformate im Jahr 2003 lassen sich so der breit aufgestellten Kampagne gegen die KPRF im Vorfeld der Duma-Wahlen zuordnen. ${ }^{399}$ Nach der Parlamentswahl und der Präsidentschaftswahl im März 2004 werden die rhetorischen Veränderungen wieder zurückgenommen.

Auch 2012 zeigt sich eine ähnliche Flexibilität: Die Veränderung der Rhetorik war bereits integraler Bestandteil der Wahlkampagne Putins für die Präsidentschaftswahlen. Während in den großen Städten gegen das Ergebnis der Dumawahlen protestiert wurde, versuchte Putin für die Präsidentschaftswahlen auf diese Weise das konservativere Elektorat in den Regionen des Landes zu gewinnen.

Im Gegensatz zu dem konstanten Druck auf westlich oder liberal orientierte Akteure und Medien in den folgenden Jahren variiert die rhetorische Tonlage der Präsidentenreden in dieser Zeit jedoch weiterhin deutlich.

399 Vgl. Siegert, Jens: Wahlkampf zur Russischen Staatsduma. In: Russland-Analysen Nr. 8 vom 05.11.2003, 2-5. 


\section{Verewigung und Schutz der Narrative}

Erinnerungspolitik richtet sich primär auf das Durchsetzen bestimmter Narrative und deren Einsatz zur Legitimierung gegenwärtiger Politik. In der Regel geschieht dies durch Popularisierung bestimmter Perspektiven. Es existiert jedoch eine Seite von Erinnerungspolitik, die sich in unterschiedlicher Intensität auf den Schutz bestimmter Narrative richtet. Dazu gehören drei Bereiche, die mit unterschiedlichen Mitteln auf dieses Ziel gerichtet sind:

Der erste Bereich lässt sich als konservierendes staatliches Handeln und konservierende Gesetzgebung bezeichnen. Ziel ist die Konservierung und Förderung einer `legitimen Geschichte. Weite Teile der Programme zur Patriotischen Erziehung der Bürger lassen sich hier einordnen, wie auch die Russländischen Verewigungsgesetze ${ }^{1}$.

Der zweite Bereich umfasst staatliche Eingriffe zur Durchsetzung einer srichtigen< Geschichte und damit auch die Delegitimierung ralternativer oder auch 'falscher Geschichte. Hier ist beispielhaft die Kommission beim Präsidenten gegen die Fälschung der Geschichte zum Nachteile Russlands zu erwähnen, aber auch die lange Tradition, nicht nur Falsches und Kontrafaktisches, sondern auch alternative Deutungen von Geschichte als Fälschung zu bezeichnen.

Der dritte Bereich umfasst staatliches Handeln, das sich konkret gegen Träger - Personen genauso wie Institutionen oder Gemeinschaften - konkurrierender Narrative richtet. Hier können die Maßnahmen von der Schaffung bürokratischer Belastungen über Publikationsverbote bis hin zu Strafandrohungen reichen.

Diese Bereiche werden, nach einer kurzen Beschreibung der geschichtlichen Entwicklung des Schutzes der Narrative, anhand von einigen Beispielen dargestellt.

1 Vgl. z.B. Federal'nyj zakon ot 19.05.1995 N 80-FZ $» O b$ uvekovečenii pobedy sovetskogo naroda v Velikoj Otečestvennoj vojne 1941-1945 godov« oder Federal'nyj zakon ot 19.05.1995 N 80-FZ »Ob uvekovečenii Pobedy sovetskogo naroda v Velikoj Otečestvennoj vojne 1941-1945 godov«. 


\subsection{Geschichtliche Entwicklung des Schutzes der Narrative}

In der Sowjetunion waren besondere Schutzmechanismen kaum von Bedeutung. Die institutionelle Struktur der Geschichtsschreibung als »hierarchisch gegliedertes Großunternehmen ${ }^{2}$ war in enger Verzahnung mit politischen Akteuren sowohl für die Geschichtsschreibung als auch für die Kontrolle zuständig. ${ }^{3}$ Auf der politischen Bühne konnten so die `Feinde` der Geschichte weitgehend im Ausland und in den Versuchen der bourgeoisen Propaganda verortet werden, die Geschichte und Bedeutung der Sowjetunion herabzuwürdigen. ${ }^{4}$ Unter den Bedingungen der Perestrojka erwies sich die Historiographie als besonders konservativ. Die wichtigen Diskussionen um die Geschichte der Sowjetunion und die weißen Flecken der Geschichte wurden von anderen Akteuren - vor allem von Schriftstellern und Journalisten - angestoßen. ${ }^{5}$

Besonders die Aspekte der Geschichte rückten Ende der 1980er Jahre in den Fokus, die zuvor einer offenen Diskussion oder sogar einer Thematisierung insgesamt entzogen waren. ${ }^{6}$ Mit dem Aufbrechen der alten sowjetischen Narrative und dem Sprechen über deren Leerstellen wurden zeitgleich die Legitimitätsgrundlagen der Sowjetunion in Frage gestellt und auch der Prozess der Verständigung über die gemeinsame Zukunft in Gang gesetzt.

Ein wichtiger Aspekt für das Verständnis der jungen Russländischen Föderation besteht jedoch darin, dass sich diese neue kritische Perspektive nur zum Teil durchsetzte. Das Lager derjenigen, die die Geschichte der Sowjetunion keiner grundsätzlichen Revision unterziehen wollten, blieb bestehen und manifestierte sich auch in großen Demonstrationen. ${ }^{7}$ Dieses Lager überschnitt sich weitgehend mit den Gegnern der Reformen von Boris El'cin. Die Losungen der Demonstrationen gegen die Reformpolitik beschrieben die Geschichte der Sowjetunion häufig als die bessere Zieloption. ${ }^{8}$

2 Geyer, Dietrich: Perestrojka in der sowjetischen Geschichtswissenschaft. In: Geyer, Dietrich (Hg.): Die Umwertung der sowjetischen Geschichte. Göttingen 1991,13.

3 Vgl. zur Historiographie vor der Perestroika und ihrer Organisations- und Kontrollstruktur: Davies, Robert: Perestroika und Geschichte. Die Wende in der sowjetischen Historiographie. München 1991, 11 ff; Geyer, Dietrich: Perestrojka in der sowjetischen Geschichtswissenschaft. In: Geyer, Dietrich (Hg.): Die Umwertung der sowjetischen Geschichte. Göttingen 1991,13 ff.

4 Vgl. die Rede des sowjetischen Verteidigungsministers Sergej Sokolov am 9. Mai 1985. Pravda. Nr. 130 (24387) vom 10.05.1985, 2.

5 Vgl. Davies, Robert: Perestroika und Geschichte. Die Wende in der sowjetischen Historiographie. München 1991, $201 \mathrm{ff}$.

6 So z.B. die hohen Verluste der Roten Armee oder das Zusatzprotokoll zum deutsch-sowjetischen Nichtangriffsvertrag.

7 Vgl. Kapitel: Erinnerungspolitik in Präsidentenreden.

8 Vgl. Kapitel: Der 9. Mai in Präsidentenreden: Die Siegesparaden bis 1999. 
Bei El'cin gab es im Rahmen der Identitätspolitik und des Bestrebens, dieser Opposition Legitimationsressourcen streitig zu machen, erste Ansätze, wieder eine staatliche Geschichte zu etablieren. ${ }^{9}$ Damit verbunden kehrte der traditionsreiche Verweis auf die Fälschung der Geschichte zurück. ${ }^{10}$ Auch unter Vladimir Putin soll Geschichte nicht nur bewahrt und erinnert, sondern auch verteidigt werden: In seiner Rede zum 60. Jahrestag des Beginns des Großen Vaterländischen Krieges betonte Putin, dass jeder Versuch, die Wahrheit über den Krieg zu verändern oder zu verzerren, bekämpft werden müsse. Besonders beklagte er die Perspektive, den Krieg als Kampf zweier totalitärer Ideologien um die Weltherrschaft zu betrachten. ${ }^{11}$

\subsection{Förderung und Fixierung der richtigen Geschichte}

Dem Bereich der Förderung und Fixierung einer bestimmten Perspektive auf die Geschichte sind ein großer Teil der bereits beschriebenen Maßnahmen aus den Patriotischen Programmen zuzuordnen. So richten sich diese Programme strukturell und in ihren einzelnen Maßnahmen überwiegend darauf, bestimmte Narrative zu fördern und zu popularisieren, um die Ziele der Programme zu erreichen. Dies geschieht beispielsweise durch die Inszenierungen der Paraden am 7. November in Moskau genauso wie durch Vorgaben für Schulbücher des Faches Geschichte oder Bildungsstandards. Das beschriebene öffentliche Engagement von Bildungsministerium und Präsidialadministration für die Lehrerausgabe des Schulbuches von Aleksandr Filippov ${ }^{12} 2007$ stellte einen besonders unmittelbaren Fall dar. Auch die beschriebenen Reformen des Festtagskalenders popularisierten bestimmte Narrative und fixierten sie in vielen Fällen in Gesetzen. Die Präsidentenreden sind ein Format mit enormer medialer Reichweite, in dem Narrative gefördert werden.

Neben diesen bereits beschriebenen Ansätzen gibt es eine lange russländisch-sowjetische Tradition der >Verewigung des Andenkens durch Gesetze oder Erlasse. Ein frühes Beispiel stellte die Einrichtung von Kommissionen

9 Vgl. Federal'nyj zakon ot 19.05.1995 N 80-FZ »Ob uvekovečenii pobedy sovetskogo naroda v Velikoj Otečestvennoj vojne 1941-1945 godov«; Federal'nyj zakon ot 13.03.1995 N 32-FZ »O dnjax voinskoj slavy Rossii«.

10 Vgl. die Rede des Verteidigungsministers Pavel Gračëv: Fernsehübertragung. 1-j kanal Ostankino: Voennyj parad, otkrytie Glavnogo monumenta i Central'nogo muzeja Velikoj Otečestvennoj vojny na Poklonnoj gore. 09.05.1995, 11.55 Uhr.

11 Vgl.Putin, Vladimir: Obraščeniev svjazi s 60-letiem načala Velikoj Otečestvennoj vojny. 22 ijunja 2001 goda. Moskva. Online: http://kremlin.ru/events/president/transcripts/21271.

12 Filippov, Aleksandr: Novejšaja istorija Rossii 1945-2006 gg. Kniga dlja učitelja. Prosveščenie, Moskva 2007. 
bei den Exekutivkomitees der Sowjetrepubliken und der Sowjetunion zur Verewigung des Andenkens an Vladimir Ul'janov Lenin im Juni 1924 dar. ${ }^{13}$ Auch sonst stand die Verewigung des Andenkens in der Sowjetunion in der Regel im Zusammenhang mit Personen: Typisch waren ehrende Erklärungen des Zentralkomitees oder des Ministerrates für Künstler, Politiker Militärs und Helden der Arbeit. Die Verewigung des Andenkens an Andrej Ždanov von $1948^{14}$ gehört zu den wenigen Ehrungen, die zurückgenommen wurden: 1989 revidierte der Ministerrat der UdSSR seine Verewigungserklärung. ${ }^{15}$ Anfang 1991 wurde das Instrument der Verewigung dann ausgeweitet. Michail Gorbačëv unterzeichnete als Präsident der Sowjetunion einen Erlass zur Verewigung des Andenkens an Bürger der Sowjetunion, die bei der Verteidigung der Heimat umkamen ${ }^{16}$, und einen Monat später unterzeichnete Boris El'cin als Vorsitzender des Obersten Sowjets der RSFSR eine Erklärung zur Verewigung des Andenkens derjenigen, die bei der Ausübung ihrer verfassungsgemäßen Pflichten umkamen. ${ }^{17}$

In der Russländischen Föderation wurde diese Verewigungsform bald aufgegriffen. 1993 wurde das "Gesetz zur Verewigung des Andenkens der Umgekommenen bei der Verteidigung des Vaterlandes ${ }^{18}{ }^{18}$ erlassen. 1995 folgten das »Gesetz über die Tage des militärischen Ruhmes « ${ }^{19}$ und das »Gesetz zur Verewigung des Sieges des sowjetischen Volkes im Großen Vaterländischen Krieg. ${ }^{20}$

Vor allem das Gesetz zur Verewigung des Sieges ist beispielhaft für die Festschreibung einer bestimmten Perspektive. Hier wurden der 9. Mai als Feiertag mit Militärparade und Artilleriesalut, die Ehrenwache am Grab des Unbekannten Soldaten in Moskau und die Stiftung verschiedener staatlicher Auszeichnungen wie beispielsweise des Žukov-Ordens verankert sowie nationale und internationale Maßnahmen zur Erhaltung der sowjetischen Kriegs-

13 Vgl. Dekret CIK SSSR ot 27.06.1924»O porjadke vosproizvedenija i rasprostranenija bjustov, barel'efov, kartin i t.p. s izobraženijami V.I. Lenina«.

14 Postanovlenie Sovmina SSSR ot 22.10.1948 N $3956 » O b$ uvekovečenii pamjati Andreja Aleksandroviča Ždanova«.

15 Vgl. Postanovlenie Sovmina SSSR ot 13.01.1989 N 46 »Ob otmene rešenij Pravitel'stva SSSR, svjazannych s uvekovečeniem pamjati A. A. Ždanova«.

16 Ukaz Prezidenta SSSR ot 08.02.1991 n UP-1440»O dopolnitel'nych merach po uvekovečeniju pamjati sovetskich graždan, pogibšich pri zaščite Rodiny v predvoennye gody i v period Velikoj Otečestvennoj vojny, a takže ispolnjavšich internacional'nyj dolg«.

17 Postanovlenie Prezidiuma VS RSFSR ot 15.03.1991»Ob uvekovečenii pamjati pogibšich pri vypolnenii konstitucionnoj objazannosti po zaščite Otečestva«.

18 Zakon RF ot 14.01 .1993 N 4292-1 »Ob uvekovečenii pamjati pogibšich pri zaščite Otečestva«.

19 Federal'nyj zakon ot 13.03.1995 N 32-FZ Zakon »O dnjach voinskoj slavy Rossii. Heute: Zakon O dnjach voinskoj slavy i pamjatnych datach Rossii«.

20 Federal'nyj zakon ot 19.05.1995 N 80-FZ »Ob uvekovečenii Pobedy sovetskogo naroda v Velikoj Otečestvennoj vojne 1941-1945 godov«. 
denkmale veranlasst. Alle diese Maßnahmen prägen bis heute das öffentliche Kriegsgedenken in seiner heroischen und manchmal martialischen Erscheinung. Zudem wurde der Staat in Paragraph sechs mit direktem Verweis auf den Krieg zur Bekämpfung jeglicher Erscheinungsformen des Faschismus verpflichtet und der Gebrauch jeglicher nazistischer Symbolik im Andenken an die Opfer verboten. ${ }^{21}$ Im Jahr 2014 wurde dieser Absatz deutlich ausgeweitet und richtet sich seitdem auch gegen Organisationen, die gemäß der Nürnberger Prozesse mit dem nationalsozialistischen Deutschland kollaborierten, sowie gegen die Revision der Ergebnisse der Nürnberger Prozesse. ${ }^{22}$

In den 2000er Jahren wurden diese Gesetze als Grundlage beibehalten und vielfältigen Änderungen im Sinne der Patriotischen Erziehung unterzogen. In der alten sowjetischen Tradition des personalen Gedenkens kam 2008 noch die Verewigung des Andenkens an Aleksandr Solženicyn hinzu.

Dass die Verewigung des Andenkens durch Rechtsakte nicht auf einzelne Personen wie in der Sowjetunion oder das Kriegsgedenken beschränkt bleiben muss, zeigte die Annahme eines Konzepts der Regierung aus dem Jahr 2015 zur Verewigung des Andenkens an die Opfer der politischen Repressionen. ${ }^{23}$ Die rechtliche Fixierung des Andenkens an die Opfer der Repressionen verlief zunächst parallel zu den Verewigungsansätzen. Zwischen 1989 und 1991 wurden zunächst die Rechte der von Repressionen Betroffenen wiederhergestellt. ${ }^{24}$ Wegweisend war dabei das »Gesetz zur Rehabilitation der Opfer der politischen Repressionen ${ }^{25}$ der RSFSR 1991, das in einer erweiterten Redaktion mit Veränderungen 1993 und 1995 in die Russländische Föderation übernommen wurde ${ }^{26}$ sowie die Einrichtung des Gedenktages der Opfer der Repressionen $1991 .^{27}$ Das Gesetz wurde vor allem in den 2000er Jahren immer wieder ergänzt und angepasst. Besondere Aufmerksamkeit bekam das Thema

21 Vgl. ebd.

22 Vgl. dazu siehe unten: Gesetze zum Schutz von Narrativen.

23 Rasporjaženie Pravitel'stva RF ot 15.08.2015 N 1561-r »Ob utverždenii Koncepcii gosudarstvennoj politiki po uvekovečeniju pamjati žertv političeskich repressij«.

24 Vgl. z. B. Ukaz Prezidiuma VS SSSR ot 16.01.1989»O dopolnitel'nych merach po vosstanovleniju spravedlivosti $v$ otnošenii žertv repressij, imevšich mesto v period 30-40-ch i načala 50-ch godov«; Ukaz Prezidenta SSSR ot 13.08.1990 N $556 » O$ vosstanovlenii prav vsech žertv političeskich repressij 20-50-ch godov«; Postanovlenie Sovmina SSSR ot 31.08.1990 N $871 » O$ merach po ispolneniju Ukaza Prezidenta SSSR »O vosstanovlenii prav vsech žertv političeskich repressij 20-50-ch godov«; Postanovlenie Kabineta Ministrov SSSR ot 06.06.1991 N 336 »Ob otmene postanovlenij byvšego Gosudarstvennogo komiteta oborony SSSR i rešenij Pravitel'stva SSSR v otnošenii sovetskich narodov, podvergšichsja repressijam i nasil'stvennomu pereseleniju«.

25 Zakon RSFSR ot 18.10.1991 N 1761-1 $O$ reabilitacii žertv političeskich repressij«.

26 Zakon RF ot 18.10.1991 N 1761-1 (red. ot 24.12.1993, s izm. ot 23.05.1995) »O reabilitacii žertv političeskich repressij«.

27 Postanovlenie VS RSFSR ot 18.10.1991 N 1763/1-1 »Ob ustanovlenii Dnja pamjati žertv političeskich repressij«. 
der Repressionen durch die Video-Botschaft des russländischen Präsidenten zum Tag der Opfer der Repressionen am 30. Oktober 2009. Dmitrij Medvedev erklärte darin, dass der Kampf gegen die Fälschung der Russländischen Geschichte sich nicht auf die Geschichte des Großen Vaterländischen Krieges beschränken dürfe. Auch gegen die Rechtfertigung und Reinwaschung derjenigen, die ihr eigenes Volk vernichteten, müsse im Sinne der Opfer und der historischen Gerechtigkeit vorgegangen werden. ${ }^{28}$

Die Konzeption der Regierung, die in den Jahren 2015 bis 2019 realisiert werden soll, richtet sich auf die Verewigung des Andenkens der Repressierten, jedoch ohne in ein eigenes Gesetz überführt zu werden. Dennoch wurde die Unterzeichnung allgemein als ein historisches Ereignis kommentiert. ${ }^{29}$ Das Konzept soll auf verschiedenen Ebenen die Bewahrung des Andenkens und die Verbreitung von Wissen über die Repressionen fördern. Ein interessanter Teilaspekt des Programms richtet sich explizit darauf, den Zugang zu Archiven zur Erforschung des Themas sicherzustellen. ${ }^{30}$

Am 30. Oktober 2015 unterzeichnete Vladimir Putin einen Erlass zur Errichtung eines Denkmals für die Opfer der politischen Repressionen in Moskau nach dem Projektentwurf "Wand der Trauer" von Georgij Vartanovič Franguljana. ${ }^{31}$ Die Umsetzung war das erste Großprojekt der im April 2016 gegründeten prominent besetzten Stiftung »Verewigung des Andenkens an die Opfer der politischen Repressionen ${ }^{32}$. Das Denkmal am Gartenring in Moskau wurde 2017 am Gedenktag für die Opfer der Repressionen durch Vladimir Putin eröffnet.

\subsection{Delegitimierung von Geschichte und Kampf gegen Fälschung}

Auch für staatliche Eingriffe, die sich auf die Durchsetzung eines srichtigen Geschichtsbildes richten, gibt es viele Beispiele. Dazu zählt das koordinierte und öffentliche Vorgehen gegen das Schulbuch »Vaterländische Geschichte

28 Vgl. Medvedev, Dmitrij: Pamjat' o nacional'nych tragedijach tak že svjaščenna, kak pamjat' o pobedach. 30 oktjabrja 2009 goda. Online: http://news.kremlin.ru/transcripts/5862 oder: http://blog.da-medvedev.ru/post/35/transcript

29 Vgl. Nagornych, Irina: Političeskie repressii polučili oficial'noe osuždenie. Podpisana koncepcija gospolitiki po uvekovečivaniju pamjati ich žertv. In: Kommersant « Nr. 149 vom 19.08.2015, 3. Online: http://kommersant.ru/doc/2791482.

30 Vgl. ebd.

31 Ukaz Prezidenta RF ot 30.09.2015 N 487 » vozvedenii memoriala žertvam političeskich repressij«.

32 Fond »Uvekovečenija pamjati žertv političeskich repressij«. 
des 20. Jahrhundert $\aleph^{33}$ von Igor' Doluckij im Jahr 2003, das die Empfehlung des Bildungsministeriums verlor und vom Markt genommen wurde.

Besonderes Aufsehen erregte im Jahr 2009 die Einrichtung der »Kommission beim Präsidenten gegen die Fälschung der Geschichte zum Nachteile Russlands « ${ }^{34}$ unter dem Vorsitz des Leiters der Präsidialadministration Sergej Naryškin. Schon der Name der Kommission evoziert den Blick auf eine lange Tradition. In den 1930er Jahren war die Abwehr von Fälschungen der Geschichte vor allem in der äußeren Auseinandersetzung mit dem Nationalsozialismus und dem Faschismus ein Thema. ${ }^{35}$ Nach dem Krieg richtete sich der Fälschungsvorwurf gegen die ‘bourgeoise Propaganda‘, die die Geschichte verzerre, um die Rolle der Sowjetunion bei der Zerschlagung des Faschismus im Zweiten Weltkrieg herabzusetzen. ${ }^{36}$ Auch nach dem Ende der Sowjetunion wurde diese Perspektive aufrechterhalten: Im Rahmen der Parade am Tag des Sieges 1995 auf dem Kutuzovskij-Prospekt verwies Verteidigungsminister Pavel Gračëv auf Versuche, die Geschichte des Sieges als einen gemeinsamen Besitz aller Brudervölker zu verfälschen. ${ }^{37}$

In diesem Sinne wurde einige Jahre später im ersten Programm zur Patriotischen Erziehung 2001 als Zielvorgabe formuliert, »der Verzerrung von Fakten und Verfälschungen der Geschichte des Vaterlandes aktiv entgegenzuwirken. ॥ $^{38}$ Als Medvedev 2009 die Kommission einrichtete, begründete er somit keine neue Politik, sondern gab einem der Ziele der Patriotischen Programme lediglich eine neue organisatorische Struktur.

Die tatsächliche Einrichtung der Kommission wurde auch als eine Reaktion auf Ehrenmärsche für Veteranen von SS-Divisionen in baltischen Staaten und die zunehmende Ehrung der Ukrainischen Aufständischen Armee (UPA) in der Westukraine kommuniziert. ${ }^{39}$ Medvedev äußerte sich im Laufe des Jahres mehrfach zu dem Thema, das Andenken an den Großen Vaterländischen Krieg zu bewahren und Versuchen der Fälschung der Geschichte entgegen-

33 Doluckij, Igor’: Otečestvennaja Istorija XX. Vek. Moskva 2003.

34 Ukaz Prezidenta RF ot 15.05.2009 N 549 (red. ot 08.09.2010) »O Komissii pri Prezidente Rossijskoj Federacii po protivodejstviju popytkam fal'sifikacii istorii v uščerb interesam Rossii«.

35 Vgl. Notovič, Filipp Iosifovič (Hg.): Protiv fašistskoj fal'sifikacii istorii. Sbornik statej. Moskau 1939.

36 Vgl. Rede des Verteidigungsministers Sergeij Sokolov bei der Parade zum Tag des Sieges 1985. In: Pravda. Nr. 130 (24387) vom 10.05.1985, 2.

37 Fernsehübertragung. 1-j kanal Ostankino: Voennyj parad, otkrytie Glavnogo monumenta i Central’nogo muzeja Velikoj Otečestvennoj vojny na Poklonnoj gore. 09.05.1995, 11.55 Uhr.

38 Programm 2001: Teil IV.

39 RIA Novosti: RF sozdaet komissiju po protivodejstviju popytkam fal'sifikacii istorii. 19.05.2009. Online: http://ria.ru/society/20090519/171517015.html. 
zutreten. ${ }^{40}$ Wie beschrieben, sprach sich Medvedev anlässlich des Tages der Opfer der politischen Repressionen zudem dafür aus, auch gegen die Rechtfertigung der Vernichtung des eigenen Volkes, gegen die Verharmlosung stalinistischer Verbrechen vorzugehen. ${ }^{41}$

Den Höhepunkt dieser Kampagne bildete im September 2009 Dmitrij Medvedevs Rede vor der 64. Vollversammlung der Vereinten Nationen, in der er sich unter Bezugnahme auf den kommenden 65. Jahrestags des Kriegsendes gegen Versuche aussprach, den Nationalsozialismus reinzuwaschen, den Holocaust zu leugnen und die Entscheidungen der Nürnberger Prozesse $\mathrm{zu}$ revidieren. ${ }^{42}$

Im Erlass zur Einrichtung der Kommission wurde als Hauptaufgabe festgelegt, dass die Kommission Informationen über die Fälschung historischer Fakten und Ereignisse zusammenführen und analysieren soll, die sich auf die Herabsetzung des internationalen Prestiges der Russländischen Föderation richten, und entsprechende Berichte für den Präsidenten vorbereiten soll. ${ }^{43}$ Weiter soll die Kommission Vorschläge zur Verhinderung solcher Fälschung erarbeiten und dem Präsidenten unterbreiten, Vorschläge von staatlichen Organen oder Organisationen in diesem Bereich koordinieren sowie Empfehlungen für angemessene Reaktionen auf Fälschungen der Geschichte und zur Abwendung möglicher negativer Folgen hieraus erarbeiten. ${ }^{44}$

Auch die Zusammensetzung der Kommission wurde durch den Erlass festgelegt. Die Zusammensetzung spiegelte sehr deutlich wieder, dass es sich um eine politische Kommission und nicht um eine `Historikerkommission $<$ handelte. Vertreten waren auf der Stellvertreter- oder Abteilungsleiterebene alle einschlägigen Ministerien und staatlichen Agenturen, der Föderationsrat, die Präsidialadministration, der Sicherheitsrat, die Gesellschaftskammer sowie das Militär und Sicherheitsdienste. Insgesamt fällt eine sehr große Übereinstimmung mit den Budgetzuweisungen der Patriotischen Programme ab 2006

40 Vor allem in den Monaten vor der Einrichtung der Kommission: Vgl. z. B. Medvedev, Dmitrij: Toržestvennyj večer, posvjaščënnyj Dnju zaščitnika Otečestva. 21 fevralja 2009 goda. Moskva, teatr Rossijskoj Armii. Online: http://kremlin.ru/events/president/news/3270; Medvedev, Dmitrij: O Velikoj Otečestvennoj vojne, istoričeskoj istine i o našej pamjati. Videoblog, 7. Mai 2009. Online: http://blog.da-medvedev.ru/post/11/transcript

41 Vgl. Medvedev, Dmitrij: Pamjat' o nacional'nych tragedijach tak že svjaščenna, kak pamjat' o pobedach. 30 oktjabrja 2009 goda. Online: http://news.kremlin.ru/transcripts/5862 oder: http://blog.da-medvedev.ru/post/35/transcript.

42 Medvedev, Dmitrij: Vystuplenie na 64-j sessii General'noj Assamblei OON. 24. September 2009. New York. Online: http://www.kremlin.ru/events/president/transcripts/5552.

43 Vgl. Ukaz Prezidenta RF ot 15.05.2009 N 549 (red. ot 08.09.2010) »O Komissii pri Prezidente Rossijskoj Federacii po protivodejstviju popytkam fal'sifikacii istorii v uščerb interesam Rossii«.

44 Vgl. ebd. 
auf. Die Kommission vereinigte die oberste staatliche Ebene der föderal budgetierten Patriotischen Erziehung. Geschichtswissenschaftliche Institutionen waren dagegen kaum vertreten. Lediglich die Akademie der Wissenschaften war durch Aleksandr Čubar'jan (Institut für allgemeine Geschichte) und Andrej Sacharov (Institut für Russländische Geschichte) prominent vertreten.

Die Einrichtung der Kommission wurde von viel Kritik sowohl aus der Wissenschaft als auch aus dem publizistischen und politischen Spektrum begleitet. ${ }^{45}$ Die Menschenrechtsorganisation Memorial schrieb in einer Erklärung:

»Vermutlich wird dieneueKommission nichtgegen Fälschungen historischer Tatsachen vorgehen, sondern gegen bestimmte Ansichten, Bewertungen und Konzeptionen, natürlich nur gegen jene, die im Widerspruch zur staatlichen Erinnerungspolitik stehen. ${ }^{46}$

Solche Befürchtungen schienen sich zu bestätigen, als im Juni 2009 eine E-Mail veröffentlicht wurde, in der der stellvertretende Sekretär der Akademie der Wissenschaften verbundene Institutionen aufforderte, Listen mit historisch-kulturellen Fälschungen sowie Berichte über die Tätigkeiten von Wissenschaftlern in ihren jeweiligen Fächern zu erstellen, um Fälschungen zu bekämpfen. ${ }^{47}$ Da diese Forderungen von einem eher kritischen Institutsdirektor kamen, wurde sie weniger als organisierte Kampagne, sondern mehr als ominöse und mysteriöse Umtriebe kommentiert. ${ }^{48}$

Aus der Arbeit der Kommission sind einige Protokolle zugänglich, die vor allem Eingangsstatements abbilden. In der ersten Sitzung skizzierte Sergej Naryškin die Gründe für die Einrichtung der Kommission: Der Russländischen Föderation als Nachfolgestaat der Sowjetunion werde kalkuliert und mit dem Ziel, eine ideologische Basis für politische, finanzielle und territoriale Ansprüche zu schaffen, die Schuld für Ereignisse und Tragödien vor allem während des Zweiten Weltkriegs zugeschrieben. Die Revision der Weltkriegsgeschichte habe zum Ziel, die geopolitischen Ergebnisse des Krieges zu revidieren. Die Aufgabe der Kommission sei es, dem entgegenzuwirken. Jedoch fügte er hinzu, dass die Kommission weder Geschichte umschreiben noch irgendeine Aufsichts- oder Zensurfunktion in diesem Bereich ausüben solle. Man stütze sich zuallererst auf die Freiheit der Geschichtswissenschaft in dem Sinne, dass historische Wahrheit - welche das auch sein möge - vor

45 Gorodeckaja, Natal'ja (u.a.): Rossii garantirovano prošloe. Prezident sozdal komissiju po bor'be s fal'sifikaciej istorii. In: Kommersant« Nr. 88 vom 20.05.2009, 1.

46 Zur neuen Kommission beim Präsidenten der Russländischen Föderation. Erklärung der Gesellschaft Memorial. In: Osteuropa 59/7-8 (2009), 278.

47 Vgl. From the Editors: Against Falsification, and a Changing of the Guard. In: Kritika. Explorations in Russian and Eurasian History 10/4 (2009), 749.

48 Vgl. Ebd., 749. 
allem auf der Grundlage von Primärquellen gefunden und verteidigt werden könne. $^{49}$

In den Sitzungen traten vor allem zwei große Themenkomplexe zu Tage: zum einen Bildung als Gegenmaßnahme zur Verfälschung der Geschichte und zum anderen die Zugänglichkeit von Primärquellen.

Die Bildung als Instrument gegen die Verfälschung der Geschichte stand besonders in der Augustsitzung 2009 im Zentrum der Diskussion. Als Vertreter des Bildungsministers referierte Isaak Kalina über Reformen im Bereich der Schulbuchzulassung und über die konsolidierende Kraft geschichtlichen Wissens für die Gesellschaft. ${ }^{50}$ Die Diskussion über Bildung im Rahmen der Kommission richtete sich vor allem darauf, wie auf verschiedenen Bildungsniveaus, aber auch im Bewusstsein der breiten Bevölkerung das geschichtliche Wissen verbessert und ein Bewusstsein für Verfälschungen der Geschichte geschaffen werden könne. Eines der greifbaren Ergebnisse in diesem Bereich war die Integration der Fälschungsthematik in die Bildungsstandards für das Fach Geschichte ab 2011. ${ }^{51}$

Der zweite große Themenkomplex - die Zugänglichkeit von Quellen als Mittel gegen Geschichtsfälschungen - wurde in der Sitzung im September 2010 behandelt. Die Kommission tagte zu diesem Thema gemeinsam mit der 'Kommission für den Schutz von Staatsgeheimnissen ${ }^{52}$. In seinem Eingangsstatement erklärte Sergej Naryškin, dass die Unzugänglichkeit von Archivquellen die Fälschung der Geschichte befördere und die Freigabe von Primärquellen sowohl dem Informationsrecht der Gesellschaft als auch der richtigen Darstellung der Russländischen Geschichte in der Welt diene. ${ }^{53}$

In einem Spannungsverhältnis zu Naryškins Forderung nach Archivfreigaben stand teilweise der zweite große Beitrag der Sitzung. Der Leiter der Föderalen Archivagentur referierte über die Arbeit und Freigabepraxis des russländischen Archivwesens. Haupttenor seiner Ausführungen war, dass im Prinzip fast alle Archivquellen für die Wissenschaft zur Verfügung stünden oder zumindest kurz davor stünden, zugänglich gemacht zu werden. Zudem

49 Vgl. Naryškin, Sergej: Zasedanie Komissii po protivodejstviju popytkam fal'sifikacii istorii v uščerb interesam Rossii. 28. August 2009. Moskau, Kreml. Online. http://kremlin. ru/events/administration/5336.

50 Vgl. ebd.

51 Vgl. Kapitel: Bildungspolitik und Schulbücher in den 2000er Jahren.

52 Eingerichtet 2004 Vgl. Ukaz Prezidenta RF ot 6 oktjabrja 2004 g. N 1286 „Voprosy Mežvedomstvennoj komissii po zaščite gosudarstvennoj tajny«.

53 Naryškin, Sergej: Sovmestnoe zasedanie Komissii po protivodejstviju popytkam fal'sifikacii istorii v uščerb interesam Rossii i Mežvedomstvennoj komissii po zaščite gosudarstvennoj tajny. 7 sentjabrja 2010 goda. Moskva, Kreml'. Online: http://kremlin.ru/events/ administration/8850. 
verwies er auf große Editionsprojekte der letzten Zeit. ${ }^{54}$ Er berichtete jedoch auch von regem Interesse der Bevölkerung an Archivquellen: Die Bevölkerung warte auf positive Veränderungen in der Arbeit der Archive. ${ }^{55}$ Welche Veränderungen hier gemeint sind, ließ er offen.

Über die Beiträge von Naryškin und Artizov hinaus liegen keine Protokolle vor, sodass sich nicht rekonstruieren lässt, wie das Thema diskutiert wurde. So bleibt eine Dissonanz bestehen zwischen der Forderung nach Öffnung der Archive und Freigabe von gesperrten Dokumenten und der Aussage, dass die Quellen ganz überwiegend zugänglich seien.

Die Rechtslage zum Archivrecht und zur Freigabe von Dokumenten allgemein und gesperrten Dokumenten im Besonderen ist unübersichtlich. ${ }^{56}$ Zwar sind, seitdem Mitte der 1990er Jahre der Zugang wieder eingeschränkt wurde, moderne Archivgesetze erlassen worden, wie das Gesetz für Archivangelegenheiten von 2004, ${ }^{57}$ sie enthalten jedoch vielfältige Möglichkeiten der Einschränkung von Freigaben. So verhindert beispielsweise der Regierungsbeschluss von $1995 \mathrm{zu}$ Verschlusssachen der Regierung der UdSSR ${ }^{58}$ auch heute einen ungehinderten Zugang zu Archivdokumenten. Aleksej Miller resümierte:

"Die tatsächliche Praxis in Russland ist aber, dass jedes Dokument durch besondere amtliche Kommissionen einzeln freigegeben wird. Dies wird auch in Zukunft so bleiben und nur ausgewählten Wissenschaftlern, die sauf Bestellung`arbeiten, wird der Zugang zu den Dokumenten gewährt werden. ${ }^{59}$

Kurz vor dem Ende seiner Amtszeit wurde die Kommission durch einen Erlass Dmitrij Medvedevs unauffällig aufgelöst. ${ }^{60}$ Neben dem Image-Schaden,

54 wie z. B. »Die Tragödie des sowjetischen Dorfes«, »Russland im 20. Jahrhundert«, »Die Geschichte des GULAG«, »Lubjanka an Stalin«, »Das Atomprojekt der UdSSR«, »Hunger in der Sowjetunion - Dokumente«.

55 Vgl. Artizov, Andrej: Iz doklada rukovoditelja Federal'nogo archivnogo agentstva A.N. Artizova. 7 sentjabrja 2010 goda. Online: http://archives.ru/press/comission_history_artizov_070910.shtml

56 Nach Angaben der Föderalen Archivagentur sind ca. 23 Regierungsverordnungen und -verfügungen, 20 Präsidialerlasse und 18 föderale Gesetze einschlägig. Online: http:// archives.ru/documents.shtml.

57 Federal'nyj zakon ot 22.10.2004 N 125-FZ »Ob archivnom dele v Rossijskoj Federacii«

58 Postanovlenie Pravitel'stva RF ot 20.02.1995 N $170 »$ Ob ustanovlenii porjadka rassekrečivanija i prodlenija srokov zasekrečivanija archivnych dokumentov Pravitel'stva SSSR«.

59 Miller, Alexei: Geschichtspolitik in Russland. In: Russland-Analysen Nr. 196 vom 12.02.2010, 2.

60 Versteckt in einem Erlass zur Zusammensetzung einer anderen Kommission wurde der Erlass zur Gründung der Kommission gegen die Fälschung der Geschichte im Unterpunkt 11 zusammen mit fünf weiteren Erlassen außer Kraft gesetzt. Vgl. Ukaz Prezidenta RF ot 14 fevralja 2012 g. N 183 »Ob utverždenii sostava Komissii pri Prezidente Rossijskoj Federacii po formirovaniju i podgotovke rezerva upravlenčeskich kadrov, izmenenii i priznanii utrativšimi silu nekotorych aktov Prezidenta Rossijskoj Federacii«. 
den die Einrichtung der Kommission angerichtet hatte, und dem Misstrauen, das durch Vorgänge wie die genannte Email erzeugt wurde, sowie einigen Spuren in den Bildungsstandards bleibt außerdem eine opulente, zunächst sechsbändige Buchreihe als Ergebnis. ${ }^{61}$ Sie entstand als Zusammenarbeit der Kommission mit dem Außenministerium und dem Staatlichen Moskauer Institut für Internationale Beziehungen (MGIMO) und eröffnet einen Blick auf die primäre praktische Ausrichtung der Kommission. Die Reihe beschäftigt sich unter dem Titel 65 Jahre Großer Sieg« mit dem Großen Vaterländischen Krieg. Die Bände mit übergreifenden Titeln wie »Vorabend der Tragödie I«, "Steh auf, Riesenland II" und "Sieg III" sind in Bücher untergliedert, die jeweils einige Aufsätze und eine Sammlung von Dokumenten zu einem Unterthema enthalten.

Besonders großen Raum nehmen in der Reihe Themen ein, die im weitesten Sinne geeignet sind, ein positives Selbstbild der russländischen Gesellschaft auf der Grundlage des Großen Vaterländischen Krieges zu stabilisieren. Das Thema der Fälschung der Geschichte, um die Rolle der Sowjetunion herabzuwürdigen, ist in vielen Bereichen präsent. ${ }^{62}$ Auch die Kollaboration nationaler Bewegungen mit den Nationalsozialisten und die Verstrickung in den Holocaust werden umfangreich thematisiert. ${ }^{63}$ Viele der Beiträger betten ihre Themen in einen gegenwartsbezogenen, geopolitischen Kontext ein. ${ }^{64}$

Die Publikation bildet damit den Arbeitsschwerpunkt der Kommission ab. Das gilt auch im Zusammenhang mit den freigegebenen Quellen. Die Absichtserklärungen, dass die freie Zugänglichkeit von Archivbeständen die wirksamste Maßnahme gegen die Fälschung der Geschichte darstelle, wurden nicht umgesetzt. Den Freigaben, die auch durch die Publikationsreihe dokumentiert wurden, bleiben enge Grenzen gesetzt. Hier bestätigt sich die Einschätzung von Aleksej Miller, dass nur handverlesene Dokumente freigegeben werden und in Bereichen, die als sensibel gelten, Wissenschaftler nur für Auftragsarbeiten Zugang erhalten.

61 Naryškin, Sergej: 65 let Velikoj pobedy. Moskau 2010. In sechs Bänden: Bd. 1: Kanun tragedii; Bd. 2: Vstavaj strana ogromnaja; Bd. 3: Pobeda; Bd. 4: Drugoe lico vojny; Bd. 5: Utračennye perspektivy; Bd. 6: Za čestnuju istoriju. Die Serie wurde später unter dem Titel Velikaja Pobeda fortgesetzt und umfasst inzwischen 11 Bände. Naryškin, Sergej: Velikaja pobeda. Bd. 7-8. Moskau 2011 und Naryškin, Sergej: Velikaja pobeda. Bd. 9-11. Moskau 2013.

62 Vgl. z.B. Bd. 6.

63 Vgl. z. B. Buch 10: Helden oder Verbrecher.

64 Vgl. z.B. Buch 33. 


\subsection{Staatliches Handeln gegen salternativer oder auch ıfalscher Geschichte}

Staatliches Handeln, das sich konkret gegen Personen oder Institutionen richtet, die bestimmte, von der staatlichen Erinnerungspolitik abweichende Narrative verbreiten, ist derzeit kein flächendeckendes Phänomen. Dennoch lohnt sich ein genauerer Blick auf diese Vorgänge, da es zum einen für Betroffene unerheblich ist, ob sie von einer durchgängigen Politik oder von einem seltenen Ereignis betroffen sind. Zum anderen können auch Einzelfälle eine einschüchternde Signalwirkung haben und den Blick dafür schärfen, welche Instrumente in den Bereichen des administrativen Handelns oder auch im Strafrecht bereitstehen, um bestimmte Narrative zu verteidigen.

Ein flächendeckendes Phänomen stellte das administrative Vorgehen gegen NGOs dar. Parallel zur staatlichen Förderung von staatsnahen, patriotischen Nichtregierungsorganisationen u. a. im Zuge der Patriotischen Programme begannen auch Maßnahmen gegen unabhängige NGOs. Als eine Reaktion auf die Orange Revolution in Kiew rückten vom Ausland finanzierte NGOs als treibende Kräfte für politische Veränderungen in den Fokus des Kremls. ${ }^{65}$ Die Folge waren zum einen mehrere Änderungen ${ }^{66}$ im Gesetz über gesellschaftliche Zusammenschlüsse ${ }^{67}$ im Januar 2006, wodurch die Organisationen einer umfassenden Berichtspflicht unterworfen wurden, und zum anderen die Verschärfung der Rhetorik gegenüber Organisationen, die ausländische Unterstützung erhalten: Putin verwies im Rahmen einer Wahlkampfveranstaltung darauf, dass es im Land jene gebe, die bei ausländische Botschaften hausieren ${ }^{68}$ gehen würden und sich auf die Unterstützung ausländischer Fonds und Regierungen anstatt auf die Unterstützung ihres eigenen Volkes verlassen würden. ${ }^{69}$ Nachdem unter der Präsidentschaft Medvedevs einige dieser Verschärfungen zurückgenommen oder abgeschwächt wurden, setzte Putin ab 2012 sein Vorgehen gegen NGOs fort. Im Juli 2012 trat eine

65 Vgl. Siegert, Jens: NGOs in Russland. In: Russland-Analysen Nr. 284 vom 24.10.2014, $16 \mathrm{f}$.

66 Federal'nyj zakon ot 10.01.2006 N 18-FZ O vnesenii izmenenij v nekotorye zakonodatel'nye akty Rossijskoj Federacii«.

67 Federal'nyj zakon ot 19.05.1995 N 82-FZ (red. ot 02.02.2006)»Ob obščestvennych ob"edinenijach«.

68 In seiner Rede benutzte Putin für »hausieren« das Wort »šakalit” - ein vom Substantiv Schakal abgeleitetes Verb, das wahrscheinlich dem Lager-Jargon zuzurechnen ist. Solženicyn benutzt das Wort in »Ein Tag im Leben des Iwan Denissowitsch«. In der deutschen Fassung wird der Schakal an entsprechender Stelle zum Luchs - »šakalit'« wird mit »abluchsen« übersetzt. Solschenizyn, Alexander: Ein Tag im Leben des Iwan Denissowitsch. München 1969.

69 Vgl. Putin, Vladimir: «Ničego u nich ne vyjdet«. Rossijskaja gazeta. Nr. 4525 vom 22.11.2007, 2. Online: http://rg.ru/2007/11/22/putin-forum.html. 
Reform in Kraft, die politisch tätige NGOs, die finanzielle Zuwendungen aus dem Ausland erhalten, zwang, sich als "ausländische Agenten" registrieren $\mathrm{zu}$ lassen. ${ }^{70}$ Die so registrierten Organisationen sind dann einer strengeren Berichtspflicht sowie häufigeren Überprüfungen unterworfen. Zudem sind sie verpflichtet ihren >Agentenstatus $<$ in ihren Publikationen, Materialien und im Internet offenzulegen. ${ }^{71}$ Diese Gesetzesverschärfung wurde vor allem mit der Rolle von NGOs wie beispielsweise >Golos bei der Begleitung der Wahlen 2011-2012 und den folgenden Massenprotesten in Verbindung gebracht. ${ }^{72} \mathrm{Im}$ Mai 2015 wurde zusätzlich eine Gesetzesänderung angenommen, die sich nominell gegen »unerwünschte ausländische und internationale NGOs « ${ }^{73}$ richtet, aber zusätzlich auch die Umgehung des Agentengesetzes z. B. durch Kooperationen oder individuelle Förderungen verhindert. ${ }^{74}$

Ein konkreter Zuschnitt der Maßnahmen auf Organisationen, die abweichende Geschichtsnarrative vertreten und popularisieren, lässt sich nicht feststellen. Das Ziel ist allgemeiner: Die Gesetzesänderungen und die folgenden Kampagnen richten sich gegen kritische Stimmen und die Organisation von Opposition.

Während sich das Vorgehen gegen rausländische Agenten großer öffentlicher Aufmerksamkeit vollzog, wurde einem anderen potenziellen Instrument, geschichtliche Narrative zu schützen, weit weniger Aufmerksamkeit zuteil: Seit einigen Jahren mehren sich Berichte über administrative Maßnahmen gegen ausländische Wissenschaftler. Manchmal wurden diese Maßnahmen durch die Medien begleitet oder ausgeschlachtet, was sogar im Vorwurf der Spionage münden konnte. ${ }^{75}$

Von diesem Vorwurf war im Jahr 2015 eine britische Historikerin und Doktorandin betroffen. Lifenews titelte »Nischni Nowgoroder Gericht weist britische Spionin aus Russland aus. ${ }^{76}$ Das eigentliche Vergehen ist in diesen Fällen immer das gleiche: wissenschaftliche Tätigkeit in Russland ohne entsprechendes Visum. Die weitverbreitete Praxis ausländischer Wissenschaftler,

70 Federal'nyj zakon ot 20.07.2012 N 121-FZ »O vnesenii izmenenij v otdel'nye zakonodatel'nye akty Rossijskoj Federacii v časti regulirovanija dejatel'nosti nekommerčeskich organizacij, vypolnjajuščich funkcii inostrannogo agenta«.

71 Ebd.

72 Vgl. Bowring, Bill: Gesetze und NGOs in Russland. In: Russland-Analysen Nr. 252 vom 22.02.2013, 5 .

73 Federal'nyj zakon ot 23.05.2015 N 129-FZ »O vnesenii izmenenij v otdel'nye zakonodatel'nye akty Rossijskoj Federacii«.

74 Vgl. Siegert, Jens: Von Agenten, unerwünschten Organisationen und ihren Folgen. In: Russland-Analysen Nr. 296 vom 22.05.2015, $18 \mathrm{f}$.

75 Goldberg, Otto (Pseudonym): Ich, der Spion. Russland verschließt sich westlichen Historikern. 20.5.2015. Online: http://www.nzz.ch/feuilleton/ich-der-spion-1.18545243.

76 Lifenews: Nižegorodskij sud vydvoril iz Rossii anglijskuju špionku. In: Lifenews, 1. April 2015. Online: http://lifenews.ru/news/152095. 
mit einem einfacher zu beantragenden Business- oder gar Touristenvisum einzureisen, wurde in den vergangenen Jahren zunehmend sanktioniert. Die ASEEES $^{77}$ befragte 2015 ihre Mitglieder zu diesen Vorkommnissen und kam zu dem Ergebnis, dass es sich gemessen an der Gesamtzahl der Forschungsaufenthalte um relativ wenige Ereignisse mit sehr unterschiedlichen Konsequenzen handelt. ${ }^{78}$ Die Sanktionen reichten von einer einfachen Ermahnung bis hin zur Annullierung des Visums und der Verhängung einer langjährigen Einreisesperre. Betroffen waren Wissenschaftler verschiedener Fachrichtungen. Die Herausgeber der Zeitschrift Kritika berichteten als Beispiele sowohl von einem verwarnten Historikerkollegen als auch von einem kontrollierten Kongress von Psychiatern und Problemen US-amerikanischer JournalistikProfessoren. ${ }^{79}$ Ein zentral orchestriertes Vorgehen gegen missliebige ausländische Historiker ist daher unwahrscheinlich. In den meisten der bekannten Fälle arbeiteten die Historiker nicht an Themen, die als erinnerungspolitisch sensibel gelten könnten. Die Fälle sind eher im Kontext der verschlechterten Beziehungen und gegenseitigen Sanktionen zwischen westlichen Staaten und Russland zu sehen. ${ }^{80}$ Da die Historiker gezielt bei ihrer Arbeit im Archiv kontrolliert wurden, zeigen diese Fälle zudem Zugriffs- und Abgleichsmöglichkeiten der Sicherheitsdienste und des Föderalen Migrationsdienstes auf.

Der Medienbericht zum oben genannten Fall der britischen Doktorandin verweist auf eine weitere Motivation für die Maßnahmen: Lifenews greift in seiner Berichterstattung auch die Betreuerin der Britin an, eine Professorin der Universität Nottingham. Ihre Themen, Revolutionen und Machtwechsel in Russland, seien im Kontext der derzeitigen Bemühungen des Westens zu sehen, Grundlagen für >farbige Revolutionen $>$ in Russland zu schaffen. ${ }^{81}$

Auch wenn es sich - so die Botschaft der USA in Moskau - in der Regel um Einzelfälle ohne direkten wissenschaftlichen Sachbezug handelte: ${ }^{82}$ Es gibt durchaus Einzelfälle, in denen das Forschungsthema ursächlich für administrative Sanktionen ist. Auch ohne Kampagnencharakter zeigt sich an ihnen, dass mit Visa- und Registrierungsvorschriften, aber auch durch den

77 Association for Slavic, East European, and Eurasian Studies (ASEEES)

78 Vgl. ASEEES: On Russian Visas for Researchers. 1. April 2015. Online: http://www.aseees. $\mathrm{org} /$ news-events/aseees-news-feed/russian-visas-researchers.

79 From the Editors: A New Chill? Foreign Scholars and the Russian Visa Question. In: Kritika: Explorations in Russian and Eurasian History. 16/2 (2015), $230 \mathrm{f}$.

80 Vgl. Schreck, Carl: Western Scholars Alarmed By Russian Deportations, Fines. 31. März 2015. Online: http://www.rferl.org/content/russia-western-scholars-alarmed-deportations/26929921.html

81 Vgl. Nižegorodskij sud vydvoril iz Rossii anglijskuju špionku. In: Lifenews, 1. April 2015. Online: http://lifenews.ru/news/152095.

82 Vgl. Schreck, Carl: Western Scholars Alarmed By Russian Deportations, Fines. 31. März 2015. Online: http://www.rferl.org/content/russia-western-scholars-alarmed-deportations/ 26929921.html 
Datenabgleich zwischen verschiedenen Diensten Instrumente bereitstehen, um gegen missliebige Forscher vorzugehen.

Ein Beispiel für administrative Sanktionen, die mit dem geschichtswissenschaftlichen Forschungsthema in Verbindung stehen, war der Fall eines deutschen Doktoranden, dessen Blogeinträge in die Liste der extremistischen Schriften des russländischen Justizministeriums aufgenommen wurden. Der Fall warf ein Schlaglicht auf verschiedene Rechtsgrundlagen die zum Schutz bestimmter Narrative eingesetzt werden können. Dazu zählt das Föderale Gesetz gegen extremistische Aktivitäten von $2002^{83}$ genauso wie die jüngere Strafbarkeit der Rehabilitation des Nazismus. ${ }^{84}$

Auf der Grundlage der Extremismus-Gesetzgebung führt das Justizministerium seit 2007 öffentlich eine umfangreiche Liste extremistischer Materialien, deren Verbreitung verboten ist. ${ }^{85}$ Als extremistisch werden Materialien definiert, die Verbrechen gegen soziale, ethnische oder religiöse Gruppen und rassische oder nationale Überlegenheit begründen oder rechtfertigen. ${ }^{86}$ Ausdrücklich eingeschlossen werden die Werke der Führung der NSDAP und der Nationalen Faschistischen Partei Italiens. ${ }^{87}$ Über die Jahre ist die Liste auf weit über 3000 Einträge angewachsen. ${ }^{88}$ Aufgenommen werden Materialien, Bücher, Internet-Ressourcen usw. auf der Grundlage von rechtskräftigen Gerichtsurteilen.

Der größte Teil der Einträge bezieht sich auf Musik, Filme und Schriften des russischen Rechtsradikalismus und Antisemitismus. Ein weiterer großer Teil bezieht sich auf den radikalen Islamismus. Inzwischen wurden auch einige Losungen wie beispielsweise »Orthodoxie oder Tod«, »Russland den Russen« und »Wir stoppen die Islamisierung - wir stoppen den Terrorismus" aufgenommen. ${ }^{89}$

Einträge, die sich auf Geschichtsdarstellungen beziehen, machen nur einen äußerst geringen Teil aus. Die meisten von ihnen sind geschichtlich verbrämte slawische Herrenrasse-Theorien.

83 Federal'nyj zakon ot 25 ijulja 2002 g. N 114-FZ »O protivodejstvii èkstremistskoj dejatel'nosti

84 Federal'nyj zakon ot 5 maja 2014 g. N 128-FZ $O$ vnesenii izmenenij v otdel'nye zakonodatel'nye akty Rossijskoj Federacii«.

85 Liste extremistischer Materialien des Justizministeriums. Federal'nyj spisok èkstremistskich materialov. Online: http://minjust.ru/node/41957.

86 Vgl. Federal'nyj zakon ot 25 ijulja 2002 g. N 114-FZ $» O$ protivodejstvii èkstremistskoj dejatel'nosti

87 Ausgeschlossen sind die grundlegenden Werke der russländischen `traditionellen Religionen: Seit einer Reform 2015 können Texte aus Bibel, Koran, Tanach und Gandschur nicht als extremistisch eingestuft werden. Vgl. Änderung vom 23.11.2015 in N 314-FZ.

88 Stand: Frühjahr 2016.

89 Vgl. Liste extremistischer Materialien des Justizministeriums. Einträge 865, 866 und 2032. Online: http://minjust.ru/node/41957. 
Der oben genannte Fall eines deutschen Wissenschaftlers, ${ }^{90}$ ging auf ein Gerichtsurteil des Amtsgerichts Brjansk zurück. ${ }^{91}$ Als extremistisch eingestuft wurden zwei Blogeinträge sowie eine Diskussion unter einem weiteren Eintrag im russischsprachigen Livejournal-Blog des Wissenschaftlers. Alle drei Seiten beziehen sich auf den Partisanenkampf im Brjansker Gebiet und damit auf ein Thema, das für die regionale staatliche Geschichtspolitik in Brjansk einen hohen Stellenwert hat, aber auch auf föderaler Ebene durch Reformen im Zuge der Patriotischen Programme ein höheres Gewicht bekam. ${ }^{92}$ In den Einträgen wurden Materialien präsentiert, die nahelegen, dass einige der Heldennarrative übertrieben sind oder sich so nicht zugetragen haben können.

Dass in diesem Zusammenhang ein lokales Gericht einen Fall von Extremismus festgestellt hat, zeigt zwei Dinge: Zum einen ist die Liste durch ihre Anlage weit offen für erstinstanzliche Eingaben, die, wenn nicht dagegen geklagt wird, auf Antrag ungeprüft aufgenommen werden. Zum anderen zeigt dieser Fall, dass hier - einen reinsichtigen Amtsrichter vorausgesetzt - ein sehr einfaches Instrument vorliegt, um gegen missliebige Geschichtsdeutungen vorzugehen. Im Moment zeigt die Liste noch eindeutig, dass das genannte Beispiel ein Einzelfall ist.

Die Strafbarkeit der Rehabilitation des Nazismus, ${ }^{93}$ die im Mai 2014 in das Strafgesetzbuch aufgenommen wurde, stellt bisher kein Instrument dar, mit dem gegen Historiker oder deren Arbeiten vorgegangen wird. Auch insgesamt findet der neue Paragraf kaum Anwendung, ${ }^{94}$ da er in der Rechtspraxis mit der etablierten Gesetzgebung zur Volksverhetzung konkurriert. ${ }^{95}$

Im Kern des neuen Paragrafen 354.1 des Strafgesetzbuches steht die Festschreibung der Ergebnisse der Nürnberger Prozesse. ${ }^{96}$ Die Leugnung der festgestellten Tatsachen und die Billigung der in den Prozessen nachgewiesenen Verbrechen werden unter Strafe gestellt. In dieser Intention ähnelt der Text

90 Vgl. ebd. Eintrag Nr. 2286.

91 Rešenie Sovetskogo rajonnogo suda g. Brjanska ot 05.11.2013.

92 Im Jahr 2010 wurde erstmals der Gedenktag der >Partisanen und der Angehörigen des Untergrundes` begangen. Die Änderung am Gesetz über die Tage des militärischen Ruhmes und Feiertage vom 10.04.2009 ging auf die Brjansker Gebietsduma zurück. Vgl. Federal'nyj zakon ot 13.03.1995 N 32-FZ; Redakcija N 7.

93 Federal'nyj zakon ot 5 maja $2014 \mathrm{~g}$. N 128-FZ »O vnesenii izmenenij v otdel'nye zakonodatel'nye akty Rossijskoj Federacii«.

94 Ein größeres Medienecho erfuhr lediglich der Fall eines Jugendlichen aus Astrachan, der sich positiv zum deutschen Überfall auf Polen geäußert hatte. Vgl. Percev, Andrej: Reabilitacija nacizma pošla v delo. Astrachanskogo podrostka zapodozrili v opravdanii dejstvij Germanii v Pol'še. 12.05.2015. Online: http://www.kommersant.ru/doc/2724813.

95 Vgl. ebd.

96 Vgl. Federal'nyj zakon ot 5 maja 2014 g. N 128-FZ $\mathrm{O}$ vnesenii izmenenij v otdel'nye zakonodatel'nye akty Rossijskoj Federacii«. 
der Gesetzgebung zur Holocaust-Leugnung in vielen Ländern. Der explizite Bezug auf die Nürnberger Prozesse in diesem Zusammenhang ist eher ungewöhnlich. Er findet sich jedoch auch in einem EU-Rahmenbeschluss zur strafrechtlichen Bekämpfung von Rassismus und Fremdenfeindlichkeit. ${ }^{97}$

Der erste Absatz enthält daneben noch einen Zusatz, der den Gegenstand erheblich erweitert: Auch die wissentliche, öffentliche Falschdarstellung des Vorgehens der UdSSR in den Jahren des Zweiten Weltkriegs wird unter Strafe gestellt. ${ }^{98}$ Ein Bezugspunkt, der die rrichtige Darstellung festlegen würde, fehlt hier - im Gegensatz zu den Bestimmungen zur Leugnung und Rechtfertigung.

Ein weiteres ungewöhnliches Instrument zum Schutz von Narrativen findet sich im letzten Absatz des Paragrafen: Die Verbreitung von explizit respektlosen Äußerungen über die Tage des militärischen Ruhmes und Gedenktage die mit der Verteidigung des Vaterlandes in Verbindung stehen, wird genauso unter Strafe gestellt wie die Schändung von Symbolen des militärischen Ruhmes. ${ }^{99}$ Auch wenn der Paragraf hier auf Tage mit Bezug zur Vaterlandsverteidigung beschränkt wird und somit z. B. respektlose Äußerungen über den Tag der Studenten ungeahndet bleiben sollten, ist er problematisch. Der Begriff »öffentliche respektlose Äußerungen« kann sehr weit gefasst werden - Gleiches gilt für die nicht näher bestimmten Symbole des militärischen Ruhmes. Zudem werden nicht etwa geschichtliche Narrative oder Fakten geschützt, sondern die Feiertage. Kritik an den Formen staatlicher Geschichtsinszenierung könnte dadurch als respektlos verurteilt werden.

\subsection{Zusammenfassung: Schutz der Geschichte oder Schutz der Narrative?}

Geschichte gegen Fälscher zu schützen, stellt eine weitverbreitete Praxis dar, die jedoch juristisch unterschiedlich angelegt wird. Die unterschiedliche Gesetzgebung gegen Holocaust-Leugnung in den deutschsprachigen Ländern ist ein Beispiel dafür. Diese Maßnahmen bewegen sich zwangsläufig in einem Spannungsfeld, da sie auf der einen Seite wichtige Rechtsgüter schützen, zum anderen jedoch auch den Diskursraum und damit die Meinungsfreiheit beschränken.

97 Rahmenbeschluss 2008/913/JI des Rates vom 28. November 2008 zur strafrechtlichen Bekämpfung bestimmter Formen und Ausdrucksweisen von Rassismus und Fremdenfeindlichkeit. Vgl. Amtsblatt der Europäischen Union, L 328, vom 06. Dezember 2008.

98 Vgl. Federal'nyj zakon ot 5 maja 2014 g. N 128-FZ $»$ v vnesenii izmenenij v otdel'nye zakonodatel'nye akty Rossijskoj Federacii«.

99 Vgl. ebd. 
Bei den vorgestellten Maßnahmen und Instrumenten in der Russländischen Föderation drängt sich teilweise der Eindruck auf, dass der Diskursraum beschränkt werden soll, ohne dass dadurch wichtige Rechtsgüter geschützt würden. Hier zeichnet sich möglicherweise eine neue geschichtspolitische Tendenz ab: Noch vor einigen Jahren wurde der Sieg der Roten Armee über die Kaiserlichen Truppen Deutschlands (1918) aus dem Gesetz über die Tage des militärischen Ruhmes gestrichen. ${ }^{100}$ Der Tag des Verteidigers des Vaterlandes kommt seitdem ohne diesen geschichtlichen Bezugspunkt aus. Die nachvollziehbare Begründung der Duma-Initiative war, dass die Behauptung des Sieges nicht den historischen Tatsachen entspreche. ${ }^{101}$

Einen Kontrapunkt dazu setzte eine öffentliche Debatte des Jahres 2015, die sich an einer Veröffentlichung des Staatsarchivs der Russländischen Föderation zur $>$ Heldentat der Panfilovcy ${ }^{102}$ entzündete. Das Russländische Staatsarchiv hatte einen Untersuchungsbericht des Militär-Oberstaatsanwalts Afanas'ev von 1948 über die 28 Panfilovcy` veröffentlicht ${ }^{103}$ der zwar kaum Neues enthielt, jedoch nochmals verdeutlichte, dass das Panfilovcy-Narrativ als Teil der motivierenden Kriegsberichterstattung wenig belegbare Übereinstimmungen mit den tatsächlichen Ereignissen im Zuge der Schlacht um Moskau aufweist.

Die Veröffentlichung und der Archiv-Leiter wurden von konservativ-patriotischer Seite massiv kritisiert - jedoch nicht, weil der Wahrheitsgehalt des Berichtes angezweifelt wurde, sondern weil sich die Veröffentlichung gegen positive Helden und Mythen richte. Der Rektor der Sankt Petersburger Universität der Gewerkschaften ${ }^{104}$ erklärte unter der Überschrift »Man darf nicht auf den Gräbern der Panfilov-Helden tanzen«, dass es eine schändliche Mode sei, die Heldentaten aus den Kriegsjahren anzuzweifeln. ${ }^{105}$ Er stellt dagegen die positive Bedeutung heraus, die diese Heldentaten für die Menschen bis heute hätten. Nicht das Ereignis an sich oder der Wahrheitsgehalt des Narrativs, steht im Zentrum der Argumentation und soll geschützt werden, sondern das Narrativ soll aufgrund seiner gesamtgesellschaftlichen Bedeutung unabhängig davon geschützt werden.

100 Vgl. Federal'nyj zakon ot 15.04.2006 N 48-FZ »O vnesenii izmenenija v stat'ju 1 Federal'nogo zakona O dnjach voinskoj slavy i pamjatnych datach Rossii«.

101 Newsru: Deputaty Gosdumy rešili iz"jat` istoričeskij mif iz nazvanija prazdnika 23 fevralja. http://www.newsru.com/arch/russia/18jan2006/takoiprazdnik.html.

102 Vgl. Kapitel: Schulbücher, Bildungspolitik - Geschichtspolitik.

103 Gosudarstvennyj archiv Rossijskoj Federacii: Spravka-doklad glavnogo voennogo prokurora N. Afanas'eva »O 28 panfilovcach«. (ГА РФ. Ф. P-8131). Online: http://www.state archive.ru/607.

104 Sankt-Peterburgskij gumanitarnyj universitet profsojuzov (SPBGUP). Auch Saint-Petersburg University of the Humanities and Social Sciences.

105 Vgl. Zapesockij, Aleksandr: Ne nado pljasat' na mogilach geroev-panfilovcev. In: Komsomol'skaja pravda, 22.06.2015. Online: http://www.kp.ru/daily/26396/3273591. 
Neben vielen weiteren konservativen Kommentatoren griff der russländische Kulturminister Vladimir Medinskij die Veröffentlichung und persönlich den Archivleiter Sergej Mironenko an. Dieser solle tun, wofür er bezahlt werde, und sich nicht als Kämpfer gegen die Fälschung von Geschichte gerieren. ${ }^{106}$ Medinskij hatte bereits 2011 in seinem Buch »Krieg. Mythen der UdSSR 1939-1945 « ${ }^{107}$ dargelegt, dass er Geschichte vor allem als eine Kampfarena der nationalen Mythen sieht, in der sich Russland gegen die »Kämpfer für historische Wahrheit der Oxford-Filiale von Langley ${ }^{108}{ }^{10}$ verteidigen müsse. »Fakten sind dabei an sich nicht von großer Bedeutung. [...] Alles beginnt nicht mit Fakten, sondern mit Interpretationen. Wenn sie ihre Heimat, ihr Volk lieben, so wird die Geschichte, die sie schreiben, immer positiv sein. Immer! « ${ }^{109}$

Es besteht die Möglichkeit, dass diese konservativ-patriotische Strömung, die Geschichte hauptsächlich als Reservoir für positive Geschichtsmythen ${ }^{110}$ betrachtet, weiter an Einfluss gewinnt und die Historiografie, die sich mit der Dekonstruktion von Mythen beschäftigt, ins Hintertreffen gerät. ${ }^{111}$ In diesem Falle könnten die skizzierten bereitstehenden Instrumente zum Schutz von Narrativen in der Breite zur Anwendung kommen. In der Gesetzgebung zu NGOs, der Extremismus-Gesetzgebung und im Strafrecht bestehen verschiedene Möglichkeiten, um gegen missliebige Geschichtsperspektiven vorzugehen. Dabei ginge es nicht um den Schutz von Geschichte zugunsten von tatsächlichen Rechtsgütern, sondern um den Schutz der Narrative der staatlichen Geschichtspolitik.

106 Vgl. Chamraev, Viktor: Gosarchivu veleno pokazyvat' dokumenty molča. In: Kommersant«, 31.07.2015. Online: http://kommersant.ru/doc/2778856.

107 Medinskij, Vladimir: Vojna. Mify SSSR. 1939-1945. Moskau 2011.

108 Ebd., 27. Medinskij benutzt Langley als Chiffre für den Hauptsitz des US-Auslandsnachrichtendienstes.

109 Ebd., 658.

110 Als Geschichtsmythen lassen sich geschichtliche Narrative betrachten, die abgekoppelt von einem tatsächlichen Wirklichkeitsbezug primär in einer sinnstiftenden Funktion aufgehen.

111 So wurde Sergej Mironenko, der im Zuge der Veröffentlichung immer wieder angegriffen wurde, im März 2016 als Leiter des Staatlichen Archivs entlassen und fungiert nun als sein wissenschaftlicher Leiter. Einen Zusammenhang mit der Veröffentlichung und dem Konflikt mit Medinskij wies er im Interview mit der Zeitung Kommersant zurück. Vgl. Chamraev, Viktor/Tichonov, Dmitrij: `Ničego strašnogo v moem uchode net. Sergej Mironenko uvolen s dolžnosti direktora Gosarchiva. In: Kommersant«, 16.03.2016. Online: http://kommersant.ru/doc/2939112. 


\section{Resümee: Geschichte im Dienst für das Vaterland}

Die Konsequenz, mit der sich die russländische Regierung unter Vladimir Putin ab dem Jahr 2000 dem Bereich Geschichts- und Erinnerungspolitik zuwendet, ist bemerkenswert. Nach weniger als einem Jahr Präsidentschaft war das erste Programm zur Patriotischen Erziehung ausgearbeitet und verabschiedet worden. Es wurde zum wichtigsten Organisationsrahmen für die geschichtspolitischen Reformen der folgenden Jahre. Dieses und die folgenden Programme sind ein deutliches Zeichen für den hohen Stellenwert, der der Geschichtspolitik beigemessen wird. Sie bilden die strukturelle Grundlage - die Ebene der materiellen Entscheidungen - für die Forderung aus Putins Antrittsrede, die Kontinuität der Geschichte wiederherzustellen und besonders das Andenken an die positiven Aspekte zu bewahren.

Die drei bislang realisierten Programme setzen inhaltlich jeweils ihre eigenen Schwerpunkte und bündeln entsprechende Kompetenzen und Akteure. Sie haben jedoch ein gemeinsames Ziel: Sie sollen die Aktualisierung von Geschichte organisieren, um gesamtgesellschaftliche Kohäsionskräfte sowie die Legitimität von Macht und Staat zu fördern. Als wichtigstes Instrument wird dabei die Hervorhebung der >ruhmreichen Seiten der Geschichter gesehen - ganz besonders geht es dabei um den militärischen Ruhm. Dieser Fokus ermöglicht es, die ^Verbindung der Zeiten über geschichtliche Brüche und politische Differenzen hinweg herzustellen. Ein gutes Beispiel liefert der 7. November, der ehemalige Tag der Oktoberrevolution: Semantisch und symbolpolitisch wurde er zum Symbol der Verteidigung der sowjetischen Hauptstadt in der Schlacht um Moskau 1941 umfunktioniert.

Die aufwendigen theatralischen Geschichtsinszenierungen am 7. November auf dem Roten Platz geben einen ersten Hinweis darauf, wie der Große Vaterländische Krieg auch über die Zeitzeugengeneration hinaus als integrierende Legitimations- und Sinnressource erhalten werden soll: Die exzessive ästhetische Autonomie der historischen Sinnstiftung soll die Herzen der jüngeren Generationen für den militärischen Ruhm in allen Zeiten erwärmen.

Gegenüber den von El'cin sgeerbten und in den 2000er Jahren ausgebauten militärischen Bezugspunkten konnten die nicht-militärischen Gedenktage und andere erinnerungspolitische Maßnahmen - einigen entsprechenden Ansätzen zum Trotz - nie ein echtes Gegengewicht entfalten. Dieser thematische Fokus zeigt sich auch anhand der Schwerpunktsetzungen des zweiten und 
dritten Patriotischen Programms: Sowohl in den Kooperationen mit nichtstaatlichen Akteuren als auch in der Ausrichtung auf das Web und jüngere Zielgruppen dominieren Kriegsnarrative.

Der Ansatz, die Patriotischen Programme als Ausgangspunkt der Analyse zu wählen, hat sich als sinnvoll erwiesen. Die vielfältigen Verflechtungen zwischen nicht-staatlichen Akteuren und der Patriotischen Erziehung sowie daraus resultierend - der staatsnahe Charakter von Geschichtsinszenierungen, beispielweise in Form der patriotischen Bike-Shows, erschließen sich vor dem Hintergrund der Programmstruktur und der Budgetzuweisungen. Auch der quasi-staatliche Charakter von viralen erinnerungspolitischen WebKampagnen lässt sich häufig nur im Kontext der Programme rekonstruieren. Die geschichtspolitische Analyse vervollständigt sich, wenn neben der ästhetisch-expressiven Seite zusätzlich die strukturellen Kontexte und rechtlichen Grundlagen auch in ihren Veränderungen mitbetrachtet werden.

Auch für die Betrachtung der Bildungspolitik erweist sich dieser Ansatz als gewinnbringend. Die Inhalte der russländischen Schulbücher des Faches Geschichte werden durch eine Reihe verschiedener Faktoren beeinflusst. Die staatliche Bildungspolitik definiert seit Beginn der 2000er Jahre grundlegende Anforderungen und Inhalte. Über die Bildungsstandards, Zulassungsverfahren und öffentlichkeitswirksame Interventionen hat die staatliche Geschichtspolitik hier einen klaren und in manchen Bereichen invasiven Gestaltungsanspruch deutlich gemacht.

Der Ausarbeitungsprozess des historisch-kulturellen Standards macht jedoch auch die derzeitigen Grenzen der staatlichen Einflussnahme deutlich. In Teilbereichen lassen sich bestimmte Narrative festschreiben - so z. B. die Progressionsgeschichte für die 2000er Jahre. Aber schon die Bewertung, inwieweit die Inhalte der Schulbücher diesem Narrativ ausreichend entsprechen, scheint schwierig. Zumindest bis zur letzten Schulbuchgeneration vor dem Schuljahr 2015/2016 lässt sich keine Vereinheitlichung der Deutungen in diesem Bereich feststellen. Über Teilbereiche hinaus tut sich die staatliche Geschichtspolitik entgegen mancher Befunde der Kritiker der Standards - schwer, eine eindeutige Perspektive auf die Geschichte verbindlich zu machen. Für einen umfassenden inhaltlichen Einfluss auf die Lehrbücher müsste zunächst eine staatliche Deutung der Geschichte vorgenommen werden. Die Ausarbeitung des historischkulturellen Standards ist als ein gescheiterter Versuch in diese Richtung zu betrachten. Verschiedene Akteure mit sehr unterschiedlichen Motivationen haben in diesem Fall die geforderte Eindeutigkeit und Widerspruchslosigkeit der Narrative verhindert. Demensprechend ist die aktuell sehr geringe Zahl an empfohlenen Büchern eher auf das neuen Zulassungs- und Prüfverfahren zurückzuführen als auf die inhaltlichen Vorgaben des Staates.

Auch für die erinnerungspolitische Analyse von Präsidentenreden wäre ein Blick auf die Aushandlungs- und Entstehungsprozesse interessant. Jedoch 
stehen keine Informationen darüber zur Verfügung, ob oder in welcher Form beispielsweise historiografische Expertise eingeholt wird. Dennoch lassen sich die Präsidentenreden als Gegenstand von Output-Analysen nutzen. Die Analyse der Reden hat gezeigt, dass im Bereich der Präsidentenreden die Arbeit an den Narrativen sehr deutlich zu Tage tritt. Häufig werden sowohl die Narrative als auch ihre Bedeutung für die Gegenwart an benennbare tagespolitische Erfordernisse angepasst.

Hier lassen sich die Zuspitzungen des Wahljahres 1996 als ein bis heute nachwirkender Katalysator für den Einsatz der Geschichte festmachen. Die Betonung des Patriotismus als Kondensat einer "geschichtlichen Schicksalsgemeinschaft « und der Rückgriff auf das Narrativ des militärischen Ruhmes, das sich maßgeblich auf den Großen Vaterländischen Krieg bezieht, wurden öffentlichkeitswirksam präsentiert. Einige Jahre später bildeten diese Elemente die Eckpunkte der Patriotischen Programme und der Präsidentenreden. Das Aufgreifen dieser Ansätze El'cins erleichterte es der Putin-Administration von Beginn an, das Feld der Geschichtspolitik für sich zu besetzen, und die nun vorhandene Unterstützung durch das Parlament ermöglichte eine wirksame Implementation.

Im Bereich der Präsidentenreden zu regelmäßigen Anlässen zeigt sich auch, dass nicht nur an militärische Ruhmestraditionen angeknüpft wurde. In den ersten Jahren ab 2005 standen beispielsweise am Tag der Einheit des Volkes keineswegs hermetisch-patriotische Narrative im Vordergrund. Der Tag war zunächst als ein bürgergesellschaftlicher Tag der Philanthropie angelegt - und entsprach damit in Vielem den Intentionen des el'cinschen Tages der Eintracht und Versöhnung. Auch der Tag Russlands und der Tag der Verfassung sind Anlässe, an denen die demokratischen Errungenschaften der Russländischen Föderation gefeiert werden. Hier zeigt sich: Nicht nur der heroischen Militärgeschichte wird größere Bedeutung zuteil, auch die Geschichte des jungen Staates wird umfangreicher als unter El'cin geschichtspolitisch inszeniert.

In diesen Formaten und noch deutlicher in den Reden vor der Föderalversammlung zeigt sich, dass die Präsidenten Medvedev und Putin die 2000er Jahre zwar als neue Epoche darstellen, eine erinnerungspolitisch kontrastive Abgrenzung jedoch nicht stattfindet. Demokratie, Rechtstaatlichkeit und Freiheiten werden als Errungenschaften dargestellt, die in schwierigen Zeiten durch das russländische Volk erstritten wurden. Narrative von Fremdherrschaft oder Chaos als Folge von Demokratie werden nicht kommuniziert.

Dem Opfergedenken kommt im Vergleich zu diesen Komplexen eine sehr geringe Bedeutung zu. Während die Opfer des deutschen Vernichtungskrieges und des Holocaust zumindest im Zusammenhang mit dem Kriegsgedenken immer wieder thematisiert werden, bleibt das Gedenken an die Opfer des Stalinismus auf den entsprechenden Tag beschränkt. Eine Rehabilitation Stalins oder positive erinnerungspolitische Bezugnahmen lassen sich in der 
staatlichen Geschichtspolitik jedoch nicht finden. Die Vorgaben für die Schulbücher wie auch die Redebeiträge der Präsidenten und die jüngste Regierungskonzeption zur Verewigung des Andenkens nehmen hier eine klare Position ein. In den Kooperationen der Patriotischen Erziehung mit Akteuren des rechten, sowjet-nostalgischen Spektrums ist diese Abgrenzung in manchen Fällen weit weniger deutlich.

Ab dem Jahr 2012, mit der erneuten Wahl Vladimir Putins zum Präsidenten, lässt sich in den Präsidentenreden eine deutliche Verschärfung der Rhetorik feststellen, die sich als Hinwendung zu eben diesem rechten, sowjet-nostalgischen Spektrum beschreiben lässt. Geschichtspolitisch zentral ist dabei vor allem die Betonung von Geschichtlichkeit. Werte werden geschichtlich begründet, Traditionen und Institutionen der Autorität einer 1000-jährigen Geschichte zugeschrieben. Tatsächlich neue geschichtliche Bezugspunkte lassen sich im Zuge dieser Entwicklung dagegen kaum ausmachen. Jedoch werden einzelne Narrative ausgeweitet, wie die Erweiterung des Bezugsrahmens des Russlandtages um 1000 Jahre, oder zugespitzt wie das Narrativ zum Tag der Einheit des Volkes. Aber auch in der geschichtlichen Begründung selbst ist potenziell eine Verschärfung angelegt, wie die Parallelisierung Sewastopols mit dem Tempelberg in Jerusalem deutlich macht.

Mit Narrativen von der `Würde einer großen Nation` oder der `Wiedergeburt Russlands` erinnert einiges an dieser Neuausrichtung an die Reden El'cins in den 1990er Jahren. Diese Rhetorik sollte nicht mit völkisch-nationalistischer Rhetorik gleichgesetzt werden: $\mathrm{Zu}$ den prominentesten traditionellen Werten der patriotischen Neuausrichtung zählt das Postulat von der historisch eingeübten Toleranz und Stärke durch Vielfalt in der Russländischen Föderation. Die nationale Rhetorik bezieht sich auf eine russländische, nicht auf eine russische Nation.

Als Eckpunkte der russländischen Geschichts- und Erinnerungspolitik in den ersten Jahren des 21. Jahrhunderts lassen sich so vor allem die Versuche feststellen, eine kohärente, bruchlose Geschichte über mehr als 1000 Jahre $\mathrm{zu}$ etablieren. Bisher zeichnet sich ab, dass das zentrale Instrument hierzu das Narrativ des militärischen Ruhmes in allen Zeiten darstellt. Ergänzend könnte in Zukunft der Ansatz einer im >Pathos der Erschaffung` verfassten Geschichte wirken, der im Bereich der Schulbücher bereits initialisiert wurde.

Neben dieser Arbeit an der Geschichte stellt der allgegenwärtige Begriff des Patriotismus ein zentrales geschichtspolitisches Element dar. In der Programm- und Konzeptprosa steht er im Zentrum eines auf Systemstabilisierung gerichteten Flussmodells: Der besondere Patriotismus der Vorfahren wird als Voraussetzung und Ursache für die großartige und heldenhafte russländische Geschichte referiert - Kenntnis dieser Geschichte und auf sie gerichtete sinnliche Affektion wiederum werden zur Voraussetzung für die Reproduktion des Patriotismus in der Gegenwart angeführt. Angelegt war dieser Geschichts- 
patriotismus bereits im ersten Patriotischen Programm 2001 und wurde 2004 umfassend in die Bildungsstandards integriert. Seinen Durchschlag in die politische Praxis fand er jedoch erst im Rahmen der Neuausrichtung 2012. Der geschichtlich begründete Patriotismus wurde zum Kern der konservativ-patriotischen Wende. Die Auseinandersetzungen um den Lehrmethoden-Standard 2013 machten jedoch auch deutlich, dass es einflussreiche Akteure gibt, die verhindern, dass diesem Geschichtspatriotismus alle Bereiche - auch die Geschichtswissenschaft und die Schulbildung - untergeordnet werden.

Im Zusammenhang mit der konservativ-patriotischen Wende stehen auch eine Reihe von Gesetzesänderungen, Gerichtsprozesse und administrative Vorgänge, die darauf hinweisen, dass die Narrative der staatlichen Geschichtspolitik in Zukunft öfter mit staatlichen Sanktionen als mit Argumenten geschützt bzw. durchgesetzt werden könnten - die Abwehr der >Fälschung der Geschichte wird als Frage der nationalen Sicherheit interpretiert.

Die Allgegenwärtigkeit und die Beschaffenheit des Begriffs `Patriotismus evozieren zwei Fragen für weitere Forschungen. Viele Studien zu Geschichte und Politik in Russland fragen nach einer neuen Identität für das Land. Die auffällige weitgehende Abwesenheit des Begriffes Identität in allen untersuchten Bereichen legt für weitere Forschungen die Frage nach dem Verhältnis von Identität und Patriotismus nahe - d. h. danach, inwieweit der in Hinsicht auf den vielgestaltigen Charakter des Landes weit weniger problematische Ansatz des Patriotismus Identität als Zuschreibungssystem zukünftig ersetzen soll. Ebenfalls naheliegend ist die Frage nach organisatorischen und inhaltlichen Gemeinsamkeiten und Unterschieden zwischen dem Sowjet-Patriotismus in seinen verschiedenen Ausprägungen und dem russländischen Patriotismus des 21. Jahrhunderts: So wie die sowjetische Geschichtspolitik nach einer Übergangszeit die russischen Helden zurückholte, stellte auch die russländische Geschichtspolitik nach wenigen Jahren die sowjetischen Helden wieder in Dienst - auch auf der organisatorischen Ebene und in den Inszenierungen scheinen sich Ähnlichkeiten abzuzeichnen.

Der Fokus dieser Arbeit auf das Politische - auf Sinnstiftung und instrumentelles staatliches Handeln - lenkt den Blick für zukünftige Forschungen auf Fragen nach nicht-staatlichen Akteuren und der gesellschaftlichen Durchdringung von Geschichtspolitik. Die Art und Weise, wie Menschen ihre Gegenwart geschichtlich perspektivieren, ist immer Teil und Ergebnis eines vielschichtigen und permanenten Aushandlungsprozesses - sie lässt sich nicht staatlich dekretieren. 



\section{Dank}

Dieses Buch stellt eine leicht überarbeitete Fassung meiner Dissertationsschrift dar, die im Rahmen des Kompetenznetzes »Institutionen und institutioneller Wandel im Postsozialismus« entstanden ist und 2016 an der LudwigMaximilians-Universität angenommen wurde.

Mein Dank gilt vor allem meinem Doktorvater Martin Schulze Wessel für seine wohlwollende und präzise Unterstützung und meinen Kollegen an der LMU für die klugen und offenen Gespräche. Großer Dank gilt auch Ursula Fries, die mein Manuskript Korrektur gelesen hat, und der Graduiertenschule für Ost- und Südosteuropastudien der Universitäten München und Regensburg für die finanzielle Unterstützung der Drucklegung.

Ich danke meiner Familie und besonders Katja für die viele Unterstützung und die Geduld während der Entstehung dieses Buches.

Bonn, 2017 



\section{Quellen- und Literaturverzeichnis}

\section{Quellen}

\section{Presseartikel}

Afanas'eva, Anna/Chamraev, Viktor: Odin predmet - odin učebnik. Deputaty vnov' pravjat zakon »Ob obrazovanii«. Kommersant«. Nr. 81 vom 13.05.2015, 4. Online: http://kommersant.ru/doc/2725058.

Alekseev, Aleksandr: Pomoč’ okružajuščim. 4 nojabrja 2005. Online: http://www.vesti. $\mathrm{ru} /$ doc.html?id=110448\&tid=31568.

Belavin, Pavel: Arkadij Rotenberg vzjalsja za učebniki. Predprinimatel'vchodit vbiznes izdatel’stv. »Prosveščenie« i »Olma Media Grupp«. In: Kommersant«. Nr. 200 vom 31.10.2013, 1. Online: http://kommersant.ru/doc/2332416.

Bogatyrenko, Zacharij: Kalendar' prazdničnych dnej, professional'nych prazdnikov, dnej voinskoj slavy i pamjatnych dat (dnej), otmečaemych na federal'nom urovne v Rossijskoj Federacii v 2012 godu. In: Rossiskaja Gazeta. 30.12.2011. Online: http:// www.rg.ru/2011/12/30/prazdniki-site.html.

Bojarskij, Aleksej: Učebnik čistoj pribyli. In: Kommersant« Den'gi. Nr. 39 vom 03.10.2011, 46. Online: http://www.kommersant.ru/doc/1773074.

Bol'šaja Moskva: Den' pamjati i skorbi. 22.06.2015. Online: http://b-m.info/novosti/ den_pamyati_i_skorbi.

Cavel'e, Oleg: $16 \%$ rossijan otprazdnujut Den' narodnogo edinstva 4 oktjabrja. Levada-Zentrum, 31.10.2012. Online: http://www.levada.ru/2012/10/31/16-rossiyanotprazdnuyut-den-narodnogo-edinstva-4-oktyabrya.

Cechmistrenko, Sergej: Slavu bol’ševikov razdelili Minin i Požarskij. In: Kommersant«. Nr. 25 vom 11.02.1995. Online: http://www.kommersant.ru/doc/101901.

Černych, Aleksandr: Vladimir Medinskij postavil točku v istorii. Razrabotan edinyj standart prošlogo Rossii. In: Kommersant«. Nr. 103 vom 18.06.2013, 5. Online: http://kommersant.ru/doc/2213690.

Chamraev, Viktor/Belavin, Pavel: Učenym razrešili pisat' novye učebniki istorii. Oni projdut mnogostupenčatuju fil’traciju. In: Kommersant«. Nr. 84 vom 20.05.2014, 3. Online: http://kommersant.ru/doc/2474758.

Chamraev, Viktor/Čerkasov, Gleb: 'Važno tol'ko ne politizirovat‘ istoriju, i togda mesto v nej najdetsja vsemu.く Akademik Aleksandr Čubar'jan o proekte istorikokul’turnogo standarta. In: Kommersant«. Nr. 200 vom 31.10.2013, 4. Online: http:// www.kommersant.ru/doc/2332034.

Chamraev, Viktor/Samochina, Sof'ja: Kulikovskuju bitvu vyveli na rossijskij rynok. Vtoroj variant istoriko-kul'turnogo standarta vynosjat na obsuždenie. In: Kommersant«. Nr. 174 vom 25.09.2013, 2. Online: http://kommersant.ru/doc/2304366. 
Chamraev, Viktor/Tichonov, Dmitrij: `Ničego strašnogo v moem uchode net«. Sergej Mironenko uvolen s dolžnosti direktora Gosarchiva. In: Kommersant«, 16.03.2016. Online: http://kommersant.ru/doc/2939112.

Chamraev, Viktor: »Razoblačenie fal'sifikatora i izgotovlennoj im fal'šivki neizbežno«. In: Kommersant«. Nr. 69 vom 20.04.2015, 4. Online: http://kommersant.ru/Doc/ 2712788.

Chamraev, Viktor: 2000-m godam podberut istoričeskij standart. V ocenke revoljucij i repressij u istorikov somnenij ne ostalos’. In: Kommersant«. Nr. 161 vom 06.09.2013, 4. Online: http://kommersant.ru/doc/2272303.

Chamraev, Viktor: Edinych učebnikov budet poka tri. Ministerstvo obrazovanija zakončilo otbor novych učebnikov po istorii Rossii. Kommersant«. Nr. 84 vom 18.05.2015, 5. Online: http://kommersant.ru/doc/2728740.

Chamraev, Viktor: Gosarchivu veleno pokazyvat' dokumenty molča. In: Kommersant«, 31.07.2015. Online: http://kommersant.ru/doc/2778856.

Delo istorikov. In: Vedomosti Nr. 1019 vom 28.11.2003. Online: http://www.vedomosti. ru/newspaper/articles/2003/11/28/ot-redakcii-delo-istorikov

Elkina, Marija: EGĖ okončatel'no razočaroval rossijan. Izvestija, 3. Juni 2015. Online: http://izvestia.ru/news/587305.

Goldberg, Otto (Pseudonym): Ich, der Spion. Russland verschließt sich westlichen Historikern. 20.5.2015. Online: http://www.nzz.ch/feuilleton/ich-der-spion-1.1854 5243.

Gorodeckaja, Natal'ja (u. a.): Rossii garantirovano prošloe. Prezident sozdal komissiju po bor'be s fal'sifikaciej istorii. In: Kommersant« Nr. 88 vom 20.05.2009, 1.

IA Regnum: Na Poklonnoj gore pojavilas' karta pamjatnikov Velikoj Otečestvennoj vojny. 22. Juni 2015. Online: http://regnum.ru/news/cultura/1935869.html.

Ivanov, Maksim/Muradov, Musa/Antonov, Kirill/Baširov, Bulat/Pavlova, Natal'ja: Rossiju izmerjat obščim učebnikom. Sergej Naryškin zanjalsja sozdaniem edinogo kursa otečestvennoj istorii. In: Kommersant«. Nr. 36 vom 28.02.2013, 3. Online: http://kommersant.ru/doc/2137507.

Ivanov, Maksim: Den' Rossii ostaetsja dalekim ot graždan. Rossijane ne znajut, čto otmečajut 12 ijunja, no prazdnikom dovol'ny. In: Kommersant« vom 11.06.2015. Online: http://kommersant.ru/doc/2746090.

Izsvestija: „Feierliche Manifestation der Jugend auf dem Roten Platz«. In: Izvestija Nr. 109(17952) vom 10.05.1975, 1-2.

Jakoreva, Anastasija: Skandaly, intrigi, učebniki. Komu vygodny novye pravila ocenki škol'noj literatury. In: Kommersant« Den'gi. Nr. 13 vom 07.04.2014, 27. Online: http://www.kommersant.ru/doc/2437844.

Kačurovskaja, Anna/Taratuta, Julija: Vladimiru Putinu napisali plochuju rol'. V škol’nom učebnike. In: Kommersant«. Nr. 218 vom 28.11.2003, 7. Online: http:// www.kommersant.ru/doc/431806.

Kačurovskaja, Anna: Istoričeskij pripadok. In: Kommersant« Vlast’. Nr. 27 vom 16.07.2007, 14. Online: http://www.kommersant.ru/doc/782464.

Kolesnikov, Andrej: Russkim jazykom otkazano. Vladimir Putin ob"javil biblioteku Šneersona nevyezdnoj. In: Kommersant«. Nr. 31 vom 20.02.2013, 1. Online: http:// kommersant.ru/doc/2130909 
Kolesnikov, Andrej: Spičrajtery prezidenta Vladimira Putina: „Začem nužny ėti 6 let?«. Novaja Gazeta. Nr. 104 vom 14.09.2012, 2-3.

Kutnij, Anželika/Coj, Julija: Koncepciju učebnika istorii »spisali«s sajtov s gotovymi referatami. Ėksperty Gosdumy raskritikovali podgotovlennyj Rossijskim istoričeskim obščestvom dokument. 11. Juli 2013. Online: http://izvestia.ru/news/553446 \#ixzz3s2gmi63n.

Lebedev, Sergej: Rynok učebnikov ostaetsja kriminal'noj sferoj. In: Pervoe sentjabrja. Učitel'skaja gazeta Nr.79 (1246), 11.11.2003, 1. Online: http://ps.1september.ru/ article.php?ID=200307903.

Lenta: Putin nazval provozglašenie nezavisimosti Kosovo »strašnym precedentom«. 23.02.2008. Online: http://lenta.ru/news/2008/02/23/putin.

Lifenews: Nižegorodskij sud vydvoril iz Rossii anglijskuju špionku. In: Lifenews, 1. April 2015. Online: http://lifenews.ru/news/152095.

Makarova, Elizaveta: Oleg Novikov dopolnil učebniki. Akcioner »Ėksmo« i AST konsolidiroval »Ventanu-Graf«. In: Kommersant«. Nr. 204 vom 06.11.2015, 12. Online: http://kommersant.ru/doc/2847419.

Muradov, Musa/Sergeev, Nikolaj: V Groznyj vernulis’ smertniki. In: Kommersant« Nr. 221 vom 05.12.2014, 1. Online: http://kommersant.ru/doc/2625733.

Nagornych, Irina: Političeskie repressii polučili oficial'noe osuždenie. Podpisana koncepcija gospolitiki po uvekovečivaniju pamjati ich žertv. In: Kommersant« Nr. 149 vom 19.08.2015, 3. Online: http://kommersant.ru/doc/2791482.

Netreba, Petr: Pravitel'stvo zaselo za učebniki. Bol'šoj pedsovet strany prodolžaetsja. In: Kommersant«. Nr. 157 vom 31.08.2001, 2. Online: http://www.kommersant.ru/ doc/280972.

Newsru: Deputaty Gosdumy rešili iz"jat‘ istoričeskij mif iz nazvanija prazdnika 23 fevralja. 18.01.2006. Online: http://www.newsru.com/arch/russia/18jan2006/takoi prazdnik.html.

Newsru: Minobrazovanija zapretit učebnik »Otečestvennaja istorija XX veka« za kritiku Putina. 27. November 2003. Online: http://www.newsru.com/russia/27Nov 2003/uchebnik.html.

Newsru: Parady s učastiem voennoj techniki prochodjat 9 maja vo mnogich krupnych gorodach Rossii. 9 maja 2008 g. Online: http://www.newsru.com/russia/09 may2008/paradvezde.html.

Oficial'nyj portal Gubernatora i Administracii Volgogradskoj oblasti: Sergej Boženov podderžal ideju provedenija $v$ regione masštabnogo bajk-šou. 30.03.2012. Online: http://www.volganet.ru/news/news/2012/03/news_00785.html.

Oficial'nyj portal Gubernatora i Administracii Volgogradskoj oblasti: Novosti. Online: http://ams.volganet.ru/news/news/2013/07/news_00233.html.

Oficial'nyj portal Gubernatora i Administracii Volgogradskoj oblasti: Novosti. Online: http://kdnk.volganet.ru/export/sites/kdk/folder_10/folder_03/kv2_2003.pdf.

Oficial'nyj portal Gubernatora i Administracii Volgogradskoj oblasti: Novosti. Online: http://www.volganet.ru/news/news/news_02647.html.

Oficial'nyj portal Gubernatora i Administracii Volgogradskoj oblasti: Novosti. Online: http://www.volganet.ru/news/news/news_02555.html. 
Oficial'nyj portal Gubernatora i Administracii Volgogradskoj oblasti: Novosti. Online: http://www.volganet.ru/news/news/news_02555.html.

Otdel politiki: Učebnikovye manevry. Sergej Naryškin priechal v Kazan' pogovorit’ pro istoriju. In: Kommersant«. Nr. 124 vom 17.07.2013, 1. Online: http://kommersant. $\mathrm{ru} / \mathrm{doc} / 2235283$.

Pavlova, Tat'jana: Bajk-Šou-Patriotizm. Ili Pominki po-volgogradski. In: Sovetskaja Rossija. 25. Juli 2013. Online: http://www.sovross.ru/modules.php?name=News\& file $=$ article \&sid $=594331$.

Percev, Andrej: Reabilitacija nacizma pošla v delo. Astrachanskogo podrostka zapodozrili v opravdanii dejstvij Germanii v Pol'še. 12.05.2015. Online: http://www. kommersant.ru/doc/2724813.

Pravda: Kljatva molodeži. Prinjata na Krasnoj ploščadi 11 sentjabrja 1966 goda. In: Pravda, Nr. 255 (17572) vom 12.09.1966, 1.

Pravda: Vrag pod maskoj učenogo. Pravda Nr. 354(6600) vom 25. Dezember 1935, 4.

Presseerklärung des Bildungsministeriums vom 05.03.2014: V Minobrnauki Rossii formirujut federal'nyj perečen' učebnikov soglasno novomu porjadku. Online: http:// минобрнауки.рф/новости/3995.

Presseerklärungdes Kremlsvom 2. November 2013:Vnesenoizmenenievzakon odnjach voinskoj slavy i pamjatnych datach Rossii. Online: http://www.kremlin.ru/acts/ 19536.

Presseerklärung des Kremls vom 27. Juni 2012: Ustanovlena novaja pamjatnaja data Den' rossijskogo parlamentarizma. Online: http://kremlin.ru/news/15779.

Presseerklärung des Kremls: Večnyj ogon' vnov’ zažžën na Mogile Neizvestnogo soldata u Kremlëvskoj steny. Moskva, 23.02.2010. Online: http://kremlin.ru/events/ president/news/6948.

Presseerklärung Prosveščenie: Ankündigung des Verlages. Online: http://www.prosv. ru/about.aspx?ob_no=222\&d_no=17139.

Prochanov, Aleksandr: Svjatoj Stalingrad. In: Gazeta Zavtra. Nr.53 (997) vom 26.12.2012. Online: http://www.zavtra.ru/content/view/svyatoj-stalingrad-2012-12-26-000000.

RIA Novosti: RF sozdaet komissiju po protivodejstviju popytkam fal'sifikacii istorii. 19.05.2009. Online: http://ria.ru/society/20090519/171517015.html.

Rosijskaja Gazeta: Vystuplenie B. N. El'cina In: Rossijskaja gazeta (Federal'nyj vypusk). Nr. 144 (190) vom 11. Juli 1991, 1.

Sacharov, Andrej: »Prazdniki ne naznačajutsja sverchu«. In: Ivestija, 23.11.2004. Online: http://izvestia.ru/news/296849.

Schreck, Carl: Western Scholars Alarmed By Russian Deportations, Fines. 31. März 2015. Online: http://www.rferl.org/content/russia-western-scholars-alarmed-deportations/26929921.html.

Smirnova, Ekaterina/Tjažlov, Ivan: Nacionalisty našli mesto podvigu. Aktivisty DPNI i ich storonniki otmetili Den’ geroev otečestva. In: Kommersant«. Nr. 227 vom 10.12.2007, 6. Online: http://kommersant.site/doc/834491.

Spiegel/ Ausland: `Wir haben sie vertrieben` In: Der Spiegel. 19/1990 vom 07.05.1990, $178-181$.

Spiegel/Panorama: Bonn Besuch. Nackter Tisch. In: Der Spiegel. Nr. 20/1996 vom 13.05.1996, 18 . 
Taratuta, Julija/Konfisachor, Aleksandra/Perl, Roman: Rodina trjachnula deržavnost' ju. Vsemirnyj kongress sootečestvennikov polučil gospodderžku. In:Kommersant« Nr. 200 vom 25.10.2006, 2. Online: http://www.kommersant.ru/doc/716076.

Varyvdin, Maksim: Pokušenie na činovnicu. Prestupniki deljat škol'nye den'gi. In: Kommersant«. Nr. 78 vom 28.05.1997, 7. Online: http://www.kommersant.ru/doc/ 178375.

Vesti: Religioznye dejateli prizyvajut sdelat' 4 nojabrja Dnem dobrych del. 16 sentjabrja 2005. Online: http://www.vesti.ru/doc.html?id=68776\&tid=31568.

Zapesockij, Aleksandr: Ne nado pljasat' na mogilach geroev-panfilovcev. In: Komsomol'skaja pravda, 22.06.2015. Online: http://www.kp.ru/daily/26396/3273591.

\section{Schulbücher}

Andreev, Igor': Istorija Rossii s drevnejšich vremën XVI v. 6 kl. Učebnik. Drofa, Moskau 2016.

Andreev, Igor’: Istorija Rossii. Konec XVII - XVIII v. 8 kl. Učebnik. Drofa, Moskau 2016.

Andreev, Igor': Istorija Rossii. XV - konec XVII v. 7 kl. Učebnik. Drofa, Moskau 2016. Arsent'ev, Nikolaj: Istorija Rossii. 6 kl. Učebnik. Čast' 1. Prosveščenie, Moskau 2016. Arsent'ev, Nikolaj: Istorija Rossii. 6 kl. Učebnik. Čast' 2. Prosveščenie, Moskau 2016. Arsent'ev, Nikolaj: Istorija Rossii. 7 kl. Učebnik. Čast' 1. Prosveščenie, Moskau 2016. Arsent'ev, Nikolaj: Istorija Rossii. 7 kl. Učebnik. Čast' 2. Prosveščenie, Moskau 2016. Arsent'ev, Nikolaj: Istorija Rossii. 8 kl. Učebnik. Čast' 1. Prosveščenie, Moskau 2016. Arsent'ev, Nikolaj: Istorija Rossii. 8 kl. Učebnik. Čast' 2. Prosveščenie, Moskau 2016. Arsent'ev, Nikolaj: Istorija Rossii. 9 kl. Učebnik. Čast' 1. Prosveščenie, Moskau 2016. Arsent'ev, Nikolaj: Istorija Rossii. 9 kl. Učebnik. Čast' 2. Prosveščenie, Moskau 2016. Danilov, Aleksandr: Istorija Rossii, 1900-1945, 11 klass. Prosveščenie. Moskau 2012. Danilov, Aleksandr: Istorija Rossii, 1945-2007, 11 klass. Prosveščenie, Moskau 2008. Danilov, Aleksandr: Istorija Rossii, 1945-2008, 11 klass. Prosveščenie. Moskau 2009. Danilov, Aleksandr: Istorija Rossii. XX vek. Moskau 1995.

Doluckij, Igor': Otečestvennaja Istorija XX. Vek. Čast' 1. Mnemozina, Moskau 2003. Doluckij, Igor': Otečestvennaja istorija. XX vek. Čast' 1. Mnemozina, Moskau 1994. Doluckij, Igor': Otečestvennaja Istorija XX. Vek. Čast' 2. Mnemozina, Moskau 2003. Filippov, Aleksandr: Istorija Rossii 1945-2008, Prosveščenie, Moskau 2009.

Filippov, Aleksandr: Novejšaja istorija Rossii 1945-2006 gg. Kniga dlja učitelja. Prosveščenie. Moskau 2007.

Gorinov, Michail: Istorija Rossii. 10 kl. Učebnik. Čast' 1. Prosveščenie, Moskau 2016. Gorinov, Michail: Istorija Rossii. 10 kl. Učebnik. Čast' 2. Prosveščenie, Moskau 2016. Gorinov, Michail: Istorija Rossii. 10 kl. Učebnik. Čast' 3. Prosveščenie, Moskau 2016. Izmozik, Vladlen/Rudnik, Sergej: Istorija Rossii. Ventana-Graf, Moskau 2011. Kiselev, Aleksandr: Istorija Rossii XX - načalo XXI veka. Drofa, Moskau 2012. Levandovskij, Andrej: Istorija Rossii XX - načalo XXI veka. Prosveščenie, Moskau 2011. 
Ljašenko, Leonid: Istorija Rossii. XIX - nacălo XX v. 9 kl. Učebnik. Drofa, Moskau 2016. Ostrovskij, Valerij: Istorija Otečestvo. 1939-1991. Moskau 1992.

Ostrovskij, Valerij: Istorija Rossii. XX vek. Moskau 1994.

Ostrovskij, Valerij: Istorija SSSR. Učebnik dlja 11 klassa. Moskau 1990.

Rybakov, Boris: Istorija SSSR. Moskau 1985.

Šestakov, Vladimir: Istorija Rossii XX - načalo XXI veka. Prosveščenie, Moskau 2011. Valev, Vasilij: Istorija SSSR 1938-1978. Učebnik dlja 10 klassa. Prosveščenie, Moskau 1980.

Vert, Nikolja: Istorija Sovetskogo gosudarstva. 1900-1991. Progress, Moskau 1992.

Volobuev, Oleg: Istorija Rossii. Načalo XX - načalo XI v. 10 kl. Učebnik. Drofa, Moskau 2016.

Volobuev, Oleg/Kulešov, Sergej: Istorija Rossii XX - načalo XXI veka. Mnemozina, Moskau 2008.

Volobuev, Oleg/Ponomarev, Michail/Rogožkin, Vasilij: Istorija. Vseobščaja istorija. 11 klass. Bazovyj i uglublënnyj urovni. Drofa, Moskau 2014.

Zagladin, Nikita: Istorija Rossii XX - načalo XXI veka. Russkoe slovo, Moskau 2011.

Žarova, Ljudmila / Mišina, Irina: Istorija Otečestva, 1900-1940. Prosveščenie, Moskau 1992.

\section{Transkripte und Protokolle}

Artizov, Andrej: Iz doklada rukovoditelja Federal'nogo archivnogo agentstva A.N. Artizova.7sentjabrja2010goda.Online:http://archives.ru/press/comission_history _artizov_070910.shtml.

El'cin, Boris: Poslanie Prezidenta Rossii Borisa El'cina Federal'nomu Sobraniju RF: »Ob ukreplenii Rossijskogo Gosudarstva« 1994 god. Online: http://www.intelros. ru/strategy/gos_rf/psl_prezident_rf_old/58-poslanija_prezidenta_rossii_borisa_ elcina_federalnomu_sobraniju_rf_1994_god.html.

El'cin, Boris: Reč' Borisa El'cina na ceremonii vstuplenija Vladimira Putina v dolžnost' Prezidenta Rossii 7 maja 2000 goda. Online: http://archive.kremlin.ru/events/articles/ 2007/04/125066/125149.shtml.

El'cin, Boris: Poslanie Prezidenta RF Federal'nomu Sobraniju ot 30.03.1999. Online: http://www.lawinrussia.ru/kabinet-yurista/zakoni-i-normativnie-akti/1999-0330/poslanie-prezidenta-rf-federalnomu-sobraniyu-ot-30031999.html.

El'cin, Boris: Poslanie Prezidenta Rossii Borisa El'cina Federal'nomu Sobraniju RF: »O dejstvennosti gosudarstvennoj vlasti v Rossii« 1995 god. Online: http://www. intelros.ru/strategy/gos_rf/psl_prezident_rf_old/72-poslanie_prezidenta_rosii_ borisa_elcina_federalnomu_sobraniju_rf_o_dejjstvennosti_gosudarstvennojj_ vlasti_v_rossii_1995_god.html.

El'cin, Boris: Poslanie Prezidenta Rossii Borisa El'cina Federal'nomu Sobraniju RF: »Rossija za kotoruju my v otvete« 1996 god. Online: http://www.intelros.ru/strategy/ gos_rf/psl_prezident_rf_old/73-poslanie_prezidenta_rosii_borisa_elcina_federal nomu_sobraniju_rf_rossija_za_kotoruju_my_v_otvete_1996_god.html.

El'cin, Boris: Poslanie Prezidenta Rossijskoj Federacii ot 23.02.1996 g. b/n. Rossija, za 
kotoruju my v otvete (O položenii v strane i osnovnych napravlenijach politiki Rossijskoj Federacii). Online: http://www.kremlin.ru/acts/bank/36349/page/1.

Gračëv, Pavel: Rede des Verteidigungsministers Gračëv: Fernsehübertragung. 1-j kanal Ostankino: Voennyj parad, otkrytie Glavnogo monumenta i Central'nogo muzeja Velikoj Otečestvennoj vojny na Poklonnoj gore. 09.05.1995, 11.55 Uhr.

Livanov, Dmitrij: Stenografičeskij otčët o zasedanii Soveta po mežnacional'nym otnošenijam. 19 fevralja 2013 goda, Moskva. Online: http://kremlin.ru/events/presi dent/news/17536.

Malinovskij, Rodion: Rede des sowjetischen Verteidigungsministers Malinovskij am 09. Mai 1965. Pravda. Nr. 130 (17082) vom 10.05.1965, 2.

Medvedev, Dmitrij: Dmitrij Medvedev pozdravil graždan Rossii s obščenacional'nym prazdnikom - Dnëm narodnogo edinstva. 4 nojabrja 2009 goda. Suzdal'. Online: http://news.kremlin.ru/transcripts/5907.

Medvedev, Dmitrij: O Velikoj Otečestvennoj vojne, istoričeskoj istine i o našej pamjati. Videoblog, 7. Mai 2009. Online: http://blog.da-medvedev.ru/post/11/trans cript.

Medvedev, Dmitrij: Pamjat' o nacional'nych tragedijach tak že svjaščenna, kak pamjat' o pobedach. 30 oktjabrja 2009 goda. Online: http://news.kremlin.ru/transcripts/ 5862 oder: http://blog.da-medvedev.ru/post/35/transcript.

Medvedev, Dmitrij: Poslanie Federal'nomu Sobraniju Rossijskoj Federacii. 12 nojabrja 2009 goda. Moskva, Bol’šoj Kremlëvskij dvorec. Online: http://kremlin.ru/events/ president/transcripts/5979.

Medvedev, Dmitrij: Poslanie Federal'nomu Sobraniju Rossijskoj Federacii. 5 nojabrja 2008 goda. Moskva, Bol’šoj Kremlëvskij dvorec. Online: http://kremlin.ru/events/ president/transcripts/1968.

Medvedev, Dmitrij: Poslanie Prezidenta Federal'nomu Sobraniju. 30 nojabrja 2010 goda. Moskva, Kreml'. Online: http://kremlin.ru/events/president/news/9637.

Medvedev, Dmitrij: Poslanie učastnikam pamjatnych meroprijatij, posvjaščënnych 65-letiju osvoboždenija konclagerja Aušvic-Birkenau. Online: http://kremlin.ru/ events/president/news/6724.

Medvedev, Dmitrij: Toržestvennyj večer, posvjaščënnyj Dnju zaščitnika Otečestva. 21 fevralja 2009 goda. Moskva, teatr Rossijskoj Armii. Online: http://kremlin.ru/ events/president/news/3270.

Medvedev, Dmitrij: V Rossii otmečajut Den’ narodnogo edinstva. 4 nojabrja 2011 goda. Nižnij Novgorod. Online: http://news.kremlin.ru/transcripts/13340.

Medvedev, Dmitrij: Vystuplenie na 64-j sessii General'noj Assamblei OON. 24. September 2009. New York. Online: http://www.kremlin.ru/events/president/tran scripts/5552.

Medvedev, Dmitrij: Vystuplenie na toržestvennom priëme, posvjaščënnom Dnju narodnogo edinstva. 4 nojabrja 2008 goda. Moskva, Kreml'. Online: http://news. kremlin.ru/transcripts/1966.

Medvedev, Dmitrij: Vystuplenie na Voennom parade v čest' 63-j godovščiny Pobedy v Velikoj Otečestvennoj vojne. 9 maja 2008 goda, 11:15 Moskva, Krasnaja ploščad'. Online: http://kremlin.ru/transcripts/30.

Medvedev, Dmitrij: Vystuplenie na voennom parade v čest' 64-j godovščiny Pobedy v 
Velikoj Otečestvennoj vojne. 9 maja 2009 goda. Moskva, Krasnaja ploščad'. Online: http://kremlin.ru/transcripts/4015

Medvedev, Dmitrij: Vystuplenie Prezidenta Rossii na parade, posvjaščënnom 65letiju Pobedy v Velikoj Otečestvennoj vojne. 9 maja 2010 goda. Moskva, Krasnaja ploščad'. Online: http://kremlin.ru/transcripts/7685.

Naryškin, Sergej: Sovmestnoe zasedanie Komissii po protivodejstviju popytkam fal'sifikacii istorii v uščerb interesam Rossii i Mežvedomstvennoj komissii po zaščite gosudarstvennoj tajny. 7 sentjabrja 2010 goda. Moskva, Kreml'. Online: http:// kremlin.ru/events/administration/8850.

Naryškin, Sergej: Zasedanie Komissii po protivodejstviju popytkam fal'sifikacii istorii v uščerb interesam Rossii. 28. August 2009. Moskau, Kreml. Online. http://kremlin. $\mathrm{ru} / \mathrm{events} / \mathrm{administration} / 5336$.

Putin, Vladimir: V Kremle vručeny gosnagrady Rossii inostrannym graždanam. 4 nojabrja 2015 goda. Moskva, Kreml'. Online: http://kremlin.ru/events/president/news/50627. Putin, Vladimir: »Ničego u nich ne vyjdet «. Rossijskaja gazeta. Nr. 4525 vom 22.11.2007, 2. Online: http://rg.ru/2007/11/22/putin-forum.html.

Putin, Vladimir: Koncert po slučaju Dnja zaščitnika Otečestva. 23 fevralja 2013 goda. Moskva. Online: http://news.kremlin.ru/transcripts/17569.

Putin, Vladimir: Meždunarodnyj den’ pamjati žertv Cholokosta. 27 janvarja 2015 goda. Moskva. Online: http://news.kremlin.ru/transcripts/47529.

Putin, Vladimir: Obraščenie Prezidenta Rossijskoj Federacii. 18 marta 2014 goda. Moskva, Kreml'. Online: http://kremlin.ru/events/president/news/20603.

Putin, Vladimir: Obraščenie v svjazi s 60-letiem načala Velikoj Otečestvennoj vojny. 22 ijunja 2001 goda. Moskva. Online: http://kremlin.ru/events/president/tran scripts/21271.

Putin, Vladimir: Otkrytie pamjatnika gerojam Pervoj mirovoj vojny. 1 avgusta 2014 goda. Moskva. Online: http://news.kremlin.ru/transcripts/46385.

Putin, Vladimir: Parad Pobedy na Krasnoj ploščadi. 9 maja 2014 goda. Moskva. Online: http://kremlin.ru/transcripts/20989.

Putin, Vladimir: Parad Pobedy prodemonstriruet oboronnyj potencial Rossii. In: Vesti.ru, 5 maja 2008. Online: http://www.vesti.ru/doc.html?id=179425.

Putin, Vladimir: Podchod k presse posle poseščenija Butovskogo memorial'nogo kompleksa. 30 oktjabrja 2007 goda. Moskva, Butovo. Online: http://news.kremlin. ru/transcripts/24627.

Putin, Vladimir: Poslanie Federal'nomu Sobraniju Rossijskoj Federacii. 10 maja 2006 goda. Moskva, Kreml', Mramornyj zal. Online: http://kremlin.ru/events/president/ transcripts/23577.

Putin, Vladimir: Poslanie Federal'nomu Sobraniju Rossijskoj Federacii. 8 ijulja 2000 goda. Moskva, Kreml'. Online: http://kremlin.ru/events/president/transcripts/21480.

Putin, Vladimir: Poslanie Federal'nomu Sobraniju Rossijskoj Federacii. 3 aprelja 2001 goda. Moskva, Kreml'. Online: http://kremlin.ru/events/president/transcripts/21216.

Putin, Vladimir: Poslanie Federal'nomu Sobraniju Rossijskoj Federacii. 16 maja 2003 goda. Moskva, Kreml'. Online: http://kremlin.ru/events/president/transcripts/21998.

Putin, Vladimir: Poslanie Federal'nomu Sobraniju Rossijskoj Federacii. 26 maja 2004 goda. Moskva, Kreml'. Online: http://kremlin.ru/events/president/transcripts/22494. 
Putin, Vladimir: Poslanie Federal'nomu Sobraniju Rossijskoj Federacii. 25 aprelja 2005 goda. Moskva, Kreml'. Online: http://kremlin.ru/events/president/transcripts/22931.

Putin, Vladimir: Poslanie Federal'nomu Sobraniju Rossijskoj Federacii. 10 maja 2006 goda. Moskva. Online: http://kremlin.ru/events/president/transcripts/23577.

Putin, Vladimir: Poslanie Federal'nomu Sobraniju Rossijskoj Federacii. 18 aprelja 2002 goda. Moskva, Kreml'. Online: http://kremlin.ru/events/president/transcripts/21567.

Putin, Vladimir: Poslanie Federal'nomu Sobraniju Rossijskoj Federacii. 3 aprelja 2001 goda. Moskva, Kreml'. Online: http://kremlin.ru/events/president/transcripts/21216.

Putin, Vladimir: Poslanie Federal'nomu Sobraniju Rossijskoj Federacii. 16 maja 2003 goda. Moskva, Kreml'. Online: http://kremlin.ru/events/president/transcripts/21998.

Putin, Vladimir: Poslanie Federal'nomu Sobraniju Rossijskoj Federacii. 26 aprelja 2007 goda. Moskva, Kreml'. Online: http://kremlin.ru/events/president/transcripts/24203.

Putin, Vladimir: Poslanie Federal'nomu Sobraniju Rossijskoj Federacii. 25 aprelja 2005 goda. Moskva, Kreml'. Online: http://kremlin.ru/events/president/transcripts/22931.

Putin, Vladimir: Poslanie Federal'nomu Sobraniju Rossijskoj Federacii. 26 aprelja 2007 goda. Moskva, Kreml'. Online: http://kremlin.ru/events/president/transcripts/24203.

Putin, Vladimir: Poslanie Prezidenta Federal'nomu Sobraniju. 12 dekabrja 2013 goda. Moskva, Kreml'. Online: http://www.kremlin.ru/events/president/news/19825.

Putin, Vladimir: Poslanie Prezidenta Federal'nomu Sobraniju. 12 dekabrja 2012 goda. Moskva, Kreml'. Online: http://kremlin.ru/events/president/news/17118.

Putin, Vladimir: Poslanie Prezidenta Federal'nomu Sobraniju. 4 dekabrja 2014 goda. Moskva, Kreml'. Online: http://kremlin.ru/transcripts/47173.

Putin, Vladimir: Priëm po slučaju Dnja narodnogo edinstva. 4 nojabrja 2012 goda. Moskva, Kreml'. Online: http://news.kremlin.ru/transcripts/16752.

Putin, Vladimir: Priëm po slučaju Dnja narodnogo edinstva. 4 nojabrja 2014 goda. Moskva, Kreml'. Online: http://news.kremlin.ru/transcripts/46916.

Putin, Vladimir: Priëm po slučaju Dnja narodnogo edinstva. 4 nojabrja 2012 goda. Moskva, Kreml'. Online: http://news.kremlin.ru/transcripts/16752.

Putin, Vladimir: Priëm po slučaju prazdnovanija Dnja Geroev Otečestva. 9 dekabrja 2013 goda. Moskva, Kreml'. Online: http://kremlin.ru/events/president/news/19810.

Putin, Vladimir: Privetstvie učastnikam Memorial'nogo večera-rekviema, posvjaščënnogo 70-letiju osvoboždenija Krasnoj armiej uznikov konclagerja Osvencim i Meždunarodnomu dnju pamjati žertv Cholokosta. 26 janvarja 2015 goda. Moskva. Online: http://kremlin.ru/events/president/news/47520.

Putin, Vladimir: Prjamaja linija s Vladimirom Putinym. 25. April 2013, Moskva. http://kremlin.ru/events/president/news/17976.

Putin, Vladimir: Reč na pochoronach Anatolija Sobčaka. 24 fevralja 2000 goda. Sankt-Peterburg. Online: http://kremlin.ru/events/president/transcripts/24142.

Putin, Vladimir: Sovmestnoe interv'ju s Federal'nym kanclerom FRG Gerchardom Šrëderom gazete »Bil'd«. 7 maja 2005 goda,. Online: http://news.kremlin.ru/tran scripts/22950.

Putin, Vladimir: Stenografičeskij otčet o press-konferencii dlja rossijskich i inostrannych žurnalistov. 1 fevralja 2007 goda. Moskva, Kreml', Kruglyj zal. Online: http:// kremlin.ru/events/president/transcripts/24026.

Putin, Vladimir: Stenografičeskij otčet o vstreče s delegatami Vserossijskoj konferen- 
cii prepodavatelej gumanitarnych i obščestvennych nauk. 21. Juni 2007, NovoOgarevo. Online: http://kremlin.ru/events/president/transcripts/24359.

Putin, Vladimir: Stenografičeskij otčët o zasedanii Soveta po mežnacional'nym otnošenijam. 19 fevralja 2013 goda, Moskva. Online: http://kremlin.ru/events/presi dent/news/17536.

Putin, Vladimir: Toržestva po slučaju 200-letija Borodinskogo sraženija. 2 sentjabrja 2012 goda. Moskovskaja oblast', Borodino. Online: http://news.kremlin.ru/tran scripts/16346.

Putin, Vladimir: Toržestvennyj priëm po slučaju Dnja Geroev Otečestva. 9 dekabrja 2014 goda. Moskva, Kreml'. Online: http://kremlin.ru/events/president/news/47 211/videos.

Putin, Vladimir: Toržestvennyj priëm po slučaju Dnja Geroev Otečestva. 9 dekabrja 2015 goda. Moskva, Kreml'. Online: http://kremlin.ru/events/president/news/50 901.

Putin, Vladimir: Toržestvennyj priëm po slučaju Dnja narodnogo edinstva. 4 nojabrja 2013 goda. Moskva, Kreml’. Online: http://news.kremlin.ru/transcripts/19562.

Putin, Vladimir: Toržestvennyj priëm po slučaju Dnja Rossii. 12 ijunja 2015 goda. Moskva, Kreml'. Online: http://kremlin.ru/events/president/news/49699.

Putin, Vladimir: Toržestvennyj večer, posvjaščennyj Dnju zaščitnika Otečestva. 22 fevralja 2000 goda. Moskva, Central'nyj Akademičeskij Teatr Rossijskoj Armii. Online: http://kremlin.ru/events/president/news/37992.

Putin, Vladimir: Toržestvennyj večer, posvjaščënnyj Dnju zaščitnika Otečestva. 20 fevralja 2014 goda. Moskva. Online: http://news.kremlin.ru/transcripts/20293.

Putin, Vladimir: Toržestvennyj večer, posvjaščënnyj Dnju zaščitnika Otečestva. 20 fevralja 2015 goda. Moskva, Kreml'. Online: http://kremlin.ru/events/president/ news/47720.

Putin, Vladimir: Vladimir Putin vstupil v dolžnost' Prezidenta Rossii. 7 maja 2012 goda. Moskva, Kreml'. Online: http://news.kremlin.ru/transcripts/15224.

Putin, Vladimir: Voennyj parad v čest' 67-j godovščiny Velikoj Pobedy. 9 maja 2012 goda. Moskva. Online: http://kremlin.ru/transcripts/15271.

Putin, Vladimir: Voennyj parad v čest' 68-j godovščiny Velikoj Pobedy. 9 maja 2013 goda. Moskva. Online: http://kremlin.ru/transcripts/18089.

Putin, Vladimir: Vstreča s avtorami koncepcii novogo učebnika istorii. 16 janvarja 2014 goda, Moskva. Online: http://www.kremlin.ru/events/president/news/20071.

Putin, Vladimir: Vstupitel'noe slovo na vstreče s učenymi-istorikami. 27 nojabrja 2003 goda, 19:07. Moskva, Rossijskaja gosudarstvennaja biblioteka. Online: http://www. kremlin.ru/events/president/transcripts/22227.

Putin, Vladimir: Vystuplenie i diskussija na Mjunchenskoj konferencii po voprosam politiki bezopasnosti. 10 fevralja 2007 goda 17:37, Mjunchen. Online: http://kremlin.ru/events/president/transcripts/24034.

Putin, Vladimir: Vystuplenie na ceremonii otkrytija pamjatnika Anatoliju Sobčaku. 12 ijunja 2006goda. Sankt-Peterburg. Online: http://news.kremlin.ru/transcripts/23627.

Putin, Vladimir: Vystuplenie na ceremonii vstuplenija v dolžnost' Prezidenta Rossii. 7 maja 2000 goda. Moskva, Bol’šoj Kremlevskij dvorec. Online: http://news.kremlin. ru/transcripts/21399. 
Putin, Vladimir: Vystuplenie na forume "Žizn’ narodu moemu!«, posvjaščennom pamjati žertv Osvencima. 27 janvarja 2005 goda. Pol’ša, Krakov. Online: http:// news.kremlin.ru/transcripts/22800.

Putin, Vladimir: Vystuplenie na gosudarstvennoj ceremonii, posvjaščennoj 60-letiju osvoboždenija sovetskimi vojskami konclagerja Aušvic-Birkenau. 27 janvarja 2005 goda. Pol’ša, Osvencim. Online: http://news.kremlin.ru/transcripts/22802.

Putin, Vladimir: Vystuplenie na gosudarstvennom prieme, posvjaščennom Dnju narodnogo edinstva. 4 nojabrja 2006 goda. Moskva, Bol’šoj Kremlevskij dvorec. Online: http://news.kremlin.ru/transcripts/23882.

Putin, Vladimir: Vystuplenie na parade v čest' 58-j godovščiny Pobedy v Velikoj Otečestvennoj vojne. 9 maja 2003 goda. Moskva, Krasnaja ploščad'. Online: http:// kremlin.ru/transcripts/21991.

Putin, Vladimir: Vystuplenie na parade, posvjaščennom 55-j godovščine Pobedy v Velikoj Otečestvennoj vojne. Rede Vladimir Putins am 9. Mai 2000 auf dem Roten Platz, Moskau. Online: http://kremlin.ru/transcripts/21421.

Putin, Vladimir: Vystuplenie na prieme po slučaju Dnja Konstitucii. 12 dekabrja 2001 goda. Moskva, Kreml'. Online: http://news.kremlin.ru/transcripts/21441.

Putin, Vladimir: Vystuplenie na prieme po slučaju Dnja narodnogo edinstva. 4 nojabrja 2007 goda. Moskva, Bol'šoj Kremlevskij dvorec. Online: http://news.kremlin. ru/transcripts/24648.

Putin, Vladimir: Vystuplenie na prieme po slučaju Dnja Rossii. 12 ijunja 2002 goda. Moskva, Kreml'. Online: http://news.kremlin.ru/transcripts/21641.

Putin, Vladimir: Vystuplenie na priëme v čest' Dnja Rossii. 12 ijunja 2012 goda. Moskva, Kreml'. Online: http://news.kremlin.ru/transcripts/15629.

Putin, Vladimir: Vystuplenie na priëme v čest' Dnja Rossii. 12 ijunja 2013 goda. Moskva, Kreml'. Online: http://news.kremlin.ru/transcripts/18325.

Putin, Vladimir: Vystuplenie na toržestvach po slučaju Dnja Rossii. 12 ijunja 2003 goda. Moskva, Krasnaja ploščad'. Online: http://news.kremlin.ru/transcripts/22023.

Putin,Vladimir:Vystupleniena toržestvach, posvjaščennych Dnju Rossii. 12 ijunja 2004 goda. Moskva, Krasnaja ploščad'. Online: http://news.kremlin.ru/transcripts/22504.

Putin, Vladimir: Vystuplenie na toržestvennom prieme po slučaju Dnja prinjatija Deklaracii o gosudarstvennom suverenitete Rossii. 12 ijunja 2001 goda. Moskva, Kreml'. Online: http://news.kremlin.ru/transcripts/21258.

Putin, Vladimir: Vystuplenie na toržestvennom prieme po slučaju Dnja prinjatija Deklaracii o gosudarstvennom suverenitete Rossii. 12 ijunja 2000 goda. Moskva, Kreml'. Online: http://news.kremlin.ru/transcripts/21465.

Putin, Vladimir: Vystuplenie na toržestvennom priëme po slučaju nacional'nogo prazdnika - Dnja Rossii. 12 ijunja 2014 goda. Moskva, Kreml'. Online: http://news. kremlin.ru/transcripts/45899.

Putin, Vladimir: Vystuplenie na toržestvennom prieme, posvjaščennom Dnju narodnogo edinstva. 4 nojabrja 2005 goda. Moskva, Kreml'. Online: http://news.kremlin. ru/transcripts/23252.

Putin, Vladimir: Vystuplenie na toržestvennom večere, posvjaščennom Dnju zaščitnika Otečestva. 22 fevralja 2004 goda. Moskva. Online: http://news.kremlin.ru/ transcripts/22360. 
Putin, Vladimir: Vystuplenie na toržestvennom večere, posvjaščennom Dnju zaščitnika Otečestva. 23 fevralja 2001 goda. Moskva, Kreml'. Online: http://news.kremlin. $\mathrm{ru} /$ transcripts/21193.

Putin, Vladimir: Vystuplenie na toržestvennom večere, posvjaščennom Dnju zaščitnika Otečestva. 22 fevralja 2005 goda. Moskva, Gosudarstvennyj Kremlevskij dvorec. Online: http://news.kremlin.ru/transcripts/22839.

Putin, Vladimir: Vystuplenie na toržestvennom večere, posvjaščënnom Dnju zaščitnika Otečestva. 22 fevralja 2008 goda. Moskva, Kreml'. Online: http://news.kremlin. ru/transcripts/24857.

Putin, Vladimir: Vystuplenie na traurnom prieme posle proščanija s pervym Prezidentom Rossii Borisom Nikolaevičem El'cinym. 25 aprelja 2007 goda. Moskva, Kreml'. Online: http://kremlin.ru/events/president/transcripts/24196.

Putin, Vladimir: Vystuplenie na voennom parade v čest' 57-j godovščiny Pobedy v Velikoj Otečestvennoj vojne 9 maja 2002 goda. Moskva, Krasnaja ploščad'. Online: http://kremlin.ru/transcripts/21587.

Putin, Vladimir: Vystuplenie na Voennom parade v čest' 60 -j godovščiny Pobedy v Velikoj Otečestvennoj vojne. 9 maja 2005 goda. Moskva, Krasnaja ploščad'. Online: http://kremlin.ru/transcripts/22959.

Putin, Vladimir: Vystuplenie na voennom parade v čest' 61-j godovščiny Pobedy v Velikoj Otečestvennoj vojne. 9 maja 2006 goda. Moskva, Kreml'. Online: http:// kremlin.ru/transcripts/23576.

Putin, Vladimir: Vystuplenie na voennom parade v čest' 62-j godovščiny Pobedy v Velikoj Otečestvennoj vojne 9 maja 2007 goda, 11:27 Moskva, Krasnaja ploščad'. Online: http://kremlin.ru/transcripts/24238.

Putin, Vladimir: Vystuplenie Prezidenta Rossii na parade, posvjaščënnom 70-letiju Pobedyv Velikoj Otečestvennoj vojne. 9 maja 2015 goda 10:20 Online: http://kremlin. ru/events/president/transcripts/49438.

Sokolov, Sergej: Rede des sowjetischen Verteidigungsministers Sokolov am 9. Mai 1985. Pravda. Nr. 130 (24387) vom 10.05.1985, 2.

Stalin, Iosif: Reč’ Predsedatelja Gosudarstvennogo Komiteta Oborony i Narodnogo Komissara Oborony tov. I. V. Stalina na Krasnoj ploščadi v den' XXIV godovščiny Velikoj Oktjabr'skoj Socialističeskoj Revoljucii. In: Pravda, Nr. 310(8718) vom 08.11.1941, 1.

\section{Rechtsgrundlagen}

Dekret CIK SSSR ot 27.06.1924 g. »O porjadke vosproizvedenija i rasprostranenija bjustov, barel'efov, kartin i t.p. s izobraženijami V. I. Lenina«.

Direktiva Sovnarkoma SSSR i CK VKP(b) partijnym i sovetskim organizacijam prifrontovych oblastej o mobilizacii vsech sil i sredstv na razgrom fašistskich zachvatčikov. In: Bogoljubova, K. M./Smirtjukova, M.S. (Hg.): Rešenija partii i pravitel'stva po chozjajstvennym voprosam. Bd. 3. Moskau 1968, 38-39.

Dogovor meždu Rossijskoj Federaciej i Respublikoj Krym o prinjatii v Rossijskuju Federaciju Respubliki Krym i obrazovanii v sostave Rossijskoj Federacii novych sub"ektov. 18.04.2014. Online: http://www.kremlin.ru/events/president/news/20605. 
Federal'nyj komplekt učebnikov dlja obščeobrazovatel'nych učreždenij Rossijskoj Federacii na 1996/97 učebnyj god. (Priloženie 1 k prikazu Ministerstva obrazovanija RF ot 01.11.1995 g. N 564). In: Učitel'skaja gazeta Nr. 52 vom 26.12.1995.

Federal'nyj zakon RF ot 05.05.2014 g. N 128-FZ »O vnesenii izmenenij v otdel'nye zakonodatel'nye akty Rossijskoj Federacii«.

Federal'nyj zakon RF ot 06.10.2003 g. N 131-FZ »Ob obščich principach organizacii mestnogo samoupravlenija v Rossijskoj Federacii«.

Federal'nyj zakon RF ot 10.01.2006 g. N 18-FZ »O vnesenii izmenenij v nekotorye zakonodatel'nye akty Rossijskoj Federacii«.

Federal'nyj zakon RF ot 13.03.1995 g. N 32-FZ »O dnjach voinskoj slavy i pamjatnych datach Rossii«.

Federal'nyj zakon RF ot 13.03.1995 g. N 32-FZ »O dnjach voinskoj slavy i pamjatnych datach Rossii« (aktuelle Bezeichnung).

Federal'nyj zakon RF ot 14.01.1993 g. N 4292-1»Ob uvekovečenii pamjati pogibšich pri zaščite Otečestva«.

Federal'nyj zakon RF ot 15.04.2006 g. N 48-FZ »O vnesenii izmenenija v stat'ju 1 Federal'nogo zakona »O dnjach voinskoj slavy i pamjatnych datach Rossii«.

Federal'nyj zakon RF ot 19.05.1995 g. N 80-FZ »Ob uvekovečenii pobedy sovetskogo naroda v Velikoj Otečestvennoj vojne 1941-1945 godov«.

Federal'nyj zakon RF ot 19.05.1995 g. N 82-FZ (red. ot 02.02.2006) »Ob obščestvennych ob"edinenijach «.

Federal'nyj zakon RF ot 20.07.2012 g. N 121-FZ O vnesenii izmenenij v otdel'nye zakonodatel'nye akty Rossijskoj Federacii v časti regulirovanija dejatel'nosti nekommerčeskich organizacij, vypolnjajuščich funkcii inostrannogo agenta«.

Federal'nyj zakon RF ot 22.10.2004 g. N 125-FZ »Ob archivnom dele v Rossijskoj Federacii«.

Federal'nyj zakon RF ot 23.05.2015 g. N 129-FZ »O vnesenii izmenenij v otdel'nye zakonodatel'nye akty Rossijskoj Federacii«.

Federal'nyj zakon RF ot 25.07.2002 g. N 114-FZ »O protivodejstvii èkstremistskoj dejatel'nosti«.

Federal'nyj zakon RF ot 28.02.2007 g. N 22-FZ $\gg$ v vnesenii izmenenija v stat'ju 11 Federal'nogo zakona »O dnjach voinskoj slavy i pamjatnych datach Rossii«.

Federal'nyj zakon RF ot 28.03.1998 g. N 53-FZ »O voinskoj objazannosti i voennoj službe.

Federal'nyj zakon RF ot 29.12.2004 g. N 200-FZ »O vnesenii izmenenij v stat'ju 1 Federal'nogo zakona »O dnjach voinskoj slavy (pobednych dnjach) Rossii«.

Federal'nyj zakon RF ot 29.12.2012 g. N 273-FZ »Ob obrazovanii v Rossijskoj Federacii«. Koncepcija patriotičeskogo vospitanija graždan Rossijskoj Federacii (odobrena na zasedanii Pravitel'stvennoj komissii po social'nym voprosam voennoslužaščich, graždan, uvolennych s voennoj služby, i členov ich semej. Protokol N 2(12)-P4 ot 21.05.2003. In: Vedomosti ugolovno-ispolnitel'noj sistemy. 1 (2004).

Konstitucija Rossijskoj Federacija. Prinjata vsenarodnym golosovaniem. 12.12.1993.

Konstitucija SSSR prinjata VS SSSR 07.10.1977.

Liste extremistischer Materialien des Justizministeriums. Federal'nyj spisok èkstremistskich materialov. Online: http://minjust.ru/node/41957. 
Postanovlenie Administracii Volgogradskoj oblasti ot 28.11.2011 g. N 756-p »Ob utverždenii dolgosročnoj oblastnoj celevoj programmy Patriotičeskoe vospitanie graždan na 2012-2015 gody«.

Postanovlenie Kabineta Ministrov SSSR ot 06.06.1991 g. N 336 »Ob otmene postanovlenij byvšego Gosudarstvennogo komiteta oborony SSSR i rešenij Pravitel'stva SSSR v otnošenii sovetskich narodov, podvergšichsja repressijam i nasil'stvennomu pereseleniju«.

Postanovlenie Pravitel'stva Moskvy ot 29.03.2011 g. N 88-PP »O plane meroprijatij po patriotičeskomu vospitaniju naselenija goroda Moskvy na 2011 god «

Postanovlenie Pravitel'stva RF ot 05.10.2010 g. N 795 (red. ot 07.10.2013) »O gosudarstvennoj programme »Patriotičeskoe vospitanie graždan Rossijskoj Federacii na 2011-2015 gody«: Anlage 1 (Nr. 25).

Postanovlenie Pravitel'stva RF ot 11.07.2005 g. N $422 » O$ gosudarstvennoj programme »Patriotičeskoe vospitanie graždan Rossijskoj Federacii na 2006-2010 gody« (s izmenenijami ot 13.11.2006 g.). In: Sobranie zakonodatel'stva RF, 18.07.2005, N 29, 3064.

Postanovlenie Pravitel'stva RF ot 14.04.1995 g. N $328 » O$ podgotovke toržestvennogo otkrytija 8-9 maja 1995 g. pamjatnika G. K. Žukovu na Manežnoj ploščadi, glavnogo monumenta i Central'nogo muzeja Velikoj Otečestvennoj vojny 1941-1945 godov na Poklonnoj gore v g. Moskve«.

Postanovlenie Pravitel'stva RF ot 16.02.2001 g. N 122: Koncepcija patriotičeskogo vospitanija graždan Rossijskoj Federacii. In: Rossijskaja gazeta, Nr. 49 vom 12.03.2001. Künftig zitiert als: Programm 2001.

Postanovlenie Pravitel'stva RF ot 20.02.1995 g. N $170 » O b$ ustanovlenii porjadka rassekrečivanija i prodlenija srokov zasekrečivanija archivnych dokumentov Pravitel'stva SSSR".

Postanovlenie Pravitel'stva RF ot 26.02.2007 g. N 128 »Ob učreždenii pamjatnogo nagrudnogo znaka učastnikam i gostjam voennogo parada na Krasnoj ploščadi«.

Postanovlenie Pravitel'stva RF ot 05.10.2010 g. N 795 »O gosudarstvennoj programme »Patriotičeskoe vospitanie graždan Rossijskoj Federacii na 2011-2015 gody« (s izmenenijami i dopolnenijami): "Sobranie zakonodatel'stva RF«, 11.10.2010, N 41 (2 č.), 5250.

Postanovlenie Pravitel'stva RF ot 28.02.1994 g. N 174. »Ob utverždenii Porjadka razrabotki, utverždenija i vvedenija $\mathrm{v}$ dejstvie federal'nyx komponentov gosudarstvennyx obrazovatel'nyx standartov načal'nogo obščego, osnovnogo obščego, srednego (polnogo) obščego i načal'nogo professional'nogo obrazovanija«.

Postanovlenie Prezidiuma VS RSFSR ot 15.03.1991 ॥Ob uvekovečenii pamjati pogibšich pri vypolnenii konstitucionnoj objazannosti po zaščite Otečestva«.

Postanovlenie Sovmina SSSR ot 13.01.1989 g. N 46 »Ob otmene rešenij Pravitel'stva SSSR, svjazannych s uvekovečeniem pamjati A. A. Ždanova«.

Postanovlenie Sovmina SSSR ot 22.10.1948 g. N 3956 »Ob uvekovečenii pamjati Andreja Aleksandroviča Ždanova«.

Postanovlenie Sovmina SSSR ot 31.08 .1990 g. N $871 » O$ merach po ispolneniju Ukaza Prezidenta SSSR $\mathrm{O}$ vosstanovlenii prav vsech žertv političeskich repressij 20-50-ch godov«. 
Postanovlenie Verchovnogo Soveta RF ot 11.06.1992 g. N 2981-I »O prazdničnom dne 12 ijunja $\ll$.

Postanovlenie VS RF ot 06.05.1993 g. N 4930-1»O prazdnovanii 48-j godovščiny Pobedy v Velikoj Otečestvennoj vojne«.

Postanovlenie VS RF ot 13.05.1993 g. N 4963-1 $\mathrm{O}$ podgotovke k prazdnovaniju 50letija Pobedy v Velikoj Otečestvennoj vojne 1941-1945 godov«.

Postanovlenie VS RF ot 13.05.1993 g. N 4963-1 $O$ O podgotovke k prazdnovaniju 50letija Pobedy v Velikoj Otečestvennoj vojne 1941-1945 godov«.

Postanovlenie VS RSFSR ot 18.10.1991 g. N 1763/1-1»Ob ustanovlenii Dnja pamjati žertv političeskich repressij«.

Postanovlenija Pravitel'stva RF ot 16.02.2001 g. N $122 » O$ gosudarstvennoj programme »Patriotičeskoe vospitanie graždan Rossijskoj Federacii na 2001-2005 gody«.

Postanovlenija Pravitel'stva RF ot 31.12.1999 g. N 1441 »Ob utverždenii Položenija o podgotovke graždan Rossijskoj Federacii k voennoj službe«.

Prikaz Ministerstva obrazovanija i nauki RF ot 10.11.2011 g. N 2643 »O vnesenii izmenenij v Federal'nyj komponent gosudarstvennych obrazovatel'nych standartov načal'nogo obščego, osnovnogo obščego i srednego (polnogo) obščego obrazovanija, utverždennyj prikazom Ministerstva obrazovanija RF ot 5 marta $2004 \mathrm{~g}$. N 1089«.

Prikaz Ministerstva obrazovanija i nauki Rossijskoj Federacii (Minobrnauki Rossii) ot 24.12.2010 g. N 2080 g. Moskva »Ob utverždenii federal'nych perečnej učebnikov, rekomendovannych (dopuščennych) k ispol'zovaniju v obrazovatel'nom processe v obrazovatel'nych učreždenijach, realizujuščich obrazovatel'nye programmy obščego obrazovanija i imejuščich gosudarstvennuju akkreditaciju, na 2011/2012 učebnyj god«.

Prikaz Minobrazovanija RF ot 05.03.2004 g. N 1089 »Ob utverždenii federal'nogo komponenta gosudarstvennych obrazovatel'nych standartov načal'nogo obščego, osnovnogo obščego i srednego (polnogo) obščego obrazovanija«.

Prikaz Minobrazovanija RF ot 05.03.2004 g. N 1089 »Ob utverždenii federal'nogo komponenta gosudarstvennych obrazovatel'nych standartov načal'nogo obščego, osnovnogo obščego i srednego (polnogo) obščego obrazovanija«.

Prikaz Minobrazovanija RF ot 05.03.2004 g. N 1089 »Ob utverždenii federal'nogo komponenta gosudarstvennych obrazovatel'nych standartov načal'nogo obščego, osnovnogo obščego i srednego (polnogo) obščego obrazovanija«.

Prikaz Minobrazovanija RF ot 05.03.2004 g. N 1089 »Ob utverždenii federal'nogo komponenta gosudarstvennych obrazovatel'nych standartov načal'nogo obščego, osnovnogo obščego i srednego (polnogo) obščego obrazovanija".

Prikaz Minobrazovanija RF ot 12.11 .1999 g. N 865 »O pereimenovanii gosudarstvennogo učreždenija »Federal'nyj èkspertnyj sovet po obščemu obrazovaniju« Minobrazovanija Rossii«.

Prikaz Minobrazovanija RF ot 19.05.1998 g. N 1235 »Ob utverždenii Objazatel'nogo minimuma soderžanija «.

Prikaz Minobrazovanija RF ot 19.05.1998 g. N 1236 »Ob utverždenii Vremennych trebovanij k objazatel'nomu minimumu soderžanija osnovnogo obščego obrazovanija«. 
Prikaz Minobrazovanija RF ot 30.06.1999 g. N 56 »Ob utverždenii Objazatel'nogo minimuma soderžanija srednego (polnogo) obščego obrazovanija«.

Prikaz Minobrazovanija Rossii ot 05.03.2004 g. N 1089 (red. ot 31.01.2012) »Ob utverždenii federal'nogo komponenta gosudarstvennych obrazovatel'nych standartov načal'nogo obščego, osnovnogo obščego i srednego (polnogo) obščego obrazovanija«.

Prikaz Minobrnauki RF ot 24.01.2012 g. N 39 »O vnesenii izmenenij v federal'nyj komponent gosudarstvennych obrazovatel'nych standartov načal'nogo obščego, osnovnogo obščego i srednego (polnogo) obščego obrazovanija, utverždennyj Prikazom Ministerstva obrazovanija RF ot 5 marta 2004 g. N 1089«.

Prikaz Minobrnauki RF ot 31.08.2009 g. N $320 » O$ vnesenii izmenenij v federal'nyj komponent gosudarstvennych obrazovatel'nych standartov načal'nogo obščego, osnovnogo obščego i srednego (polnogo) obščego obrazovanija, utverždennyj Prikazom Ministerstva obrazovanija RF ot 5 marta 2004 g. n 1089 »Ob utverždenii federal'nogo komponenta gosudarstvennych obrazovatel'nych standartov načal'nogo obščego, osnovnogo obščego i srednego (polnogo) obščego obrazovanija«.

Prikaz Minobrnauki Rossii ot 08.06.2015 g. N 576 »O vnesenii izmenenij v federal'nyj perečen' učebnikov, rekomenduemych $\mathrm{k}$ ispol'zovaniju pri realizacii imejuščich gosudarstvennuju akkreditaciju obrazovatel'nych programm načal'nogo obščego, osnovnogo obščego, srednego obščego obrazovanija, utverždennyj prikazom Ministerstva obrazovanija i nauki RF ot 31 marta 2014 g. N 253«.

Rabočaja gruppa po podgotovke koncepcii novogo učebno-metodičeskogo kompleksa po otečestvennoj istorii: Istoriko-kul'turnyj-standart (Geschichtlich-Kultureller Standard). Auf der Seite des Bildungs- und Wissenschaftsministeriums in der Version vom 01.07.2013: http:/Минобрнауки.рф/документы/3483/файл/ 2325/13.07.01-Проект_Историко-культурного_стандарта.pdf.

Rabočaja gruppa po podgotovke koncepcii novogo učebno-metodičeskogo kompleksa po otečestvennoj istorii: Koncepcija novogo učebno-metodičeskogo kompleksa po otečestvennoj istorii (Konzeption des neuen Lehrmethoden-Komplex für vaterländische Geschichte). Auf der Seite des Bildungs- und Wissenschaftsministeriums in der Version vom 21.10.2013: http://минобрнауки.рф/документы/3721/ файл/2506/13.10.21-Проект_Концепции_уМК.pdf.

Rabočaja gruppa po podgotovke koncepcii novogo učebno-metodičeskogo kompleksa po otečestvennoj istorii: Koncepcija novogo učebno-metodičeskogo kompleksa po otečestvennoj istorii (Konzeption des neuen Lehrmethoden-Komplex für vaterländische Geschichte). Auf der Seite der Russischen Historischen Gesellschaft in der endgültigen Version: http://rushistory.org/images/documents/konsepsiyafinal.pdf.

Rahmenbeschluss 2008/913/JI des Rates vom 28. November 2008 zur "strafrechtlichen Bekämpfung bestimmter Formen und Ausdrucksweisen von Rassismus und Fremdenfeindlichkeit«. Amtsblatt der Europäischen Union, L 328, vom 06. Dezember 2008.

Rasporjaženie Pravitel'stva RF ot 15.08.2015 g. N 1561-r »Ob utverždenii Koncepcii gosudarstvennoj politiki po uvekovečeniju pamjati žertv političeskich repressij«.

Trudovogo kodeksa RF ot 30.12.2001 g. N 197-FZ. Stat' ja 112. „Nerabočie prazdničnye dni«.

Ukaz Prezidenta RF ot 08.06.1996 g. N 857 »O Dne pamjati i skorbi« (RG 96-109). 
Ukaz Prezidenta RF ot 08.08.2000 g. N 1463 (red. ot 12.08.2008) »Ob utverždenii Statuta ordena Svjatogo Georgija, Položenija o znake otličija - Georgievskom Kreste i ich opisanij«.

Ukaz Prezidenta RF ot 10.01.2000 g. N $24 » O$ Koncepcii nacional'noj bezopasnosti Rossijskoj Federacii«.

Ukaz Prezidenta RF ot 11.09.2009 g. N $1034 » O$ dne programmista«.

Ukaz Prezidenta RF ot 12.05.2009 g. N 537 »O Strategii nacional'noj bezopasnosti Rossijskoj Federacii do 2020 goda«.

Ukaz Prezidenta RF ot 12.03.2013 g. N $190 » O$ nagraždenii gosudarstvennymi nagradami Rossijskoj Federacii«.

Ukaz Prezidenta RF ot 14.02.2012 g. N 183 »Ob utverždenii sostava Komissii pri Prezidente Rossijskoj Federacii po formirovaniju i podgotovke rezerva upravlenčeskich kadrov, izmenenii i priznanii utrativšimi silu nekotorych aktov Prezidenta Rossijskoj Federacii«.

Ukaz Prezidenta RF ot 14.02.2012 g. N 183 (red. ot 09.02.2013) »Ob utverždenii sostava Komissii pri Prezidente Rossijskoj Federacii po formirovaniju i podgotovke rezerva upravlenčeskich kadrov, izmenenii i priznanii utrativšimi silu nekotorych aktov Prezidenta Rossijskoj Federacii«.

Ukaz prezidenta RF ot 15.04.1996 g. N $561 » O$ Znameni Pobedy«.

Ukaz Prezidenta RF ot 15.05.2009 g. N $549 » O$ Komissii pri Prezidente Rossijskoj Federacii po protivodejstviju popytkam fal'sifikacii istorii v uščerb interesam Rossii«.

Ukaz Prezidenta RF ot 16.11.2010 g. N 1433 »O Dne rabotnika ugolovno-ispolnitel'noj sistemy«.

Ukaz Prezidenta RF ot 18.10.2007 g. N 1381 »O Dne rossijskogo predprinimatel'stva«.

Ukaz Prezidenta RF ot 21.02.2012 g. N 223 »O nagraždenii ordenom Početa Rastorgueva N.V.«.

Ukaz Prezidenta RF ot 24.12.1993 g. N 2288 »O merach po privedeniju zakonodatel'stva Rossijskoj Federacii v sootvetstvie s Konstituciej Rossijskoj Federacii«.

Ukaz Prezidenta RF ot 31.05.2006 g. N 549 »Ob ustanovlenii professional'nych prazdnikov i pamjatnych dnej v Vooružennych Silach Rossijskoj Federacii«.

Ukaz Prezidenta RF ot 06.10.2004 g. N 1286 »Voprosy Mežvedomstvennoj komissii po zaščite gosudarstvennoj tajny«.

Ukaz Prezidenta RF ot 07.11.1996 g. N 1537 »O dne soglasija i primirenija«.

Ukaz Prezidenta RF ot 30.09.2015 N 487 » vozvedenii memoriala žertvam političeskich repressij«.

Ukaz Prezidenta SSSR ot 08.02.1991 g. N UP-1440»O dopolnitel'nych merach po uvekovečeniju pamjati sovetskich graždan, pogibšich pri zaščite Rodiny v predvoennye gody i v period Velikoj Otečestvennoj vojny, a takže ispolnjavšich internacional'nyj dolg«.

Ukaz Prezidenta SSSR ot 13.08.1990 g. N 556 »O vosstanovlenii prav vsech žertv političeskich repressij 20-50-ch godov«.

Ukaz Prezidiuma Verchovnogo Soveta SSSR ot 01.10.1980 g. N 3018-Ch »O prazdničnych i pamjatnych dnjach « (v red. Ukaza Prezidiuma Verchovnogo Soveta SSSR ot 01.11.1988 N 9724-XI $\cong \mathrm{O}$ vnesenii izmenenij v zakonodatel'stvo SSSR o prazdničnych i pamjatnych dnjach«). 
Ukaz Prezidiuma Verchovnogo Soveta SSSR ot 01.10.1980 g. N 3018-Ch »O prazdničnych i pamjatnych dnjach « (v red. Ukaza Prezidiuma Verchovnogo Soveta SSSR ot 01.11.1988 N 9724-XI »O vnesenii izmenenij v zakonodatel'stvo SSSR o prazdničnych i pamjatnych dnjach«).

Ukaz Prezidiuma Verchovnogo Soveta SSSR ot 08.05.1945 g. »Ob ob” javlenii 9 maja Prazdnikom Pobedy«.

Ukaz Prezidiuma VS SSSR ot 16.01.1989 „O dopolnitel'nych merach po vosstanovleniju spravedlivosti v otnošenii žertv repressij, imevšich mesto v period 30-40-ch i načala 50-ch godov«.

Ukaz Prezidiuma VS SSSR ot 02.09.1945 g. »Ob ob”javlenii 3 sentjabrja prazdnikom pobedy nad Japoniej. Data sozdanija: 2 sentjabrja 1945 goda«. In: Mandel’štam Ju. I.(Hg.): Sbornik zakonov SSSR i ukazov Prezidiuma Verchovnogo Soveta SSSR. 1938 g.- ijul' 1956. Moskau 1956.

Ukaz Prezidiuma VS SSSR ot 7.05.1947 g. »Ob izmenenii Ukaza Prezidiuma Verchovnogo Soveta SSSR ot 2 sentjabrja 1945 g Data sozdanija: 7 maja 1947 goda«. In: Mandel'štam Ju. I.(Hg.): Sbornik zakonov SSSR i ukazov Prezidiuma Verchovnogo Soveta SSSR. 1938 g.- ijul' 1956. Moskau 1956.

Zakon RF ot 10.07.1992 g. N 3266-1 »Ob obrazovanii«.

Zakon RF ot 14.01.1993 g. N 4292-1 »Ob uvekovečenii pamjati pogibšich pri zaščite Otečestva«.

Zakon RF ot 14.01.1993 g. N 4292-1 »Ob uvekovečenii pamjati pogibšich pri zaščite Otečestva«.

Zakon RF ot 18.10.1991 g. N 1761-1 (red. ot 24.12.1993, s izm. ot 23.05.1995) »O reabilitacii žertv političeskich repressij«.

Zakon RSFSR ot 18.10.1991 N 1761-1 »O reabilitacii žertv političeskich repressij«.

Zakon SSSR ot 14.03.1990 g. N 1360-I »Ob učreždenii posta Prezidenta SSSR i vnesenii izmenenij i dopolnenij v Konstituciju (Osnovnoj Zakon) SSSR .

\section{Fernsehbeiträge, Kinofilme, Online-Videos}

Fernsehübertragung. 1-j kanal Ostankino: Moskva, Krasnaja Ploščad'. Parad v čest' 50-letija pobedy. 09.05.1995, 8.50 Uhr.

Fernsehübertragung. 1-j kanal Ostankino: Voennyj parad, otkrytie Glavnogo monumenta i Central'nogo muzeja Velikoj Otečestvennoj vojny na Poklonnoj gore. 09.05.1995, 11.55 Uhr.

Fernsehübertragung. Kanal Rossija 2: Stalingrad. Bajk-Šou. 23.08.2013, 23.30 Uhr. Online: http://2.russia.tv/brand/show/brand_id/46444.

Fernsehübertragung. Kanal Televidenie SSSR: Vremja. 09.05.1975, 21.00 Uhr.

Fernsehübertragung. Kanal TV Centr: Prjamaja transljacija. Moskva, Krasnaja ploščad'. Parad Pervoj Pobedy. 07.11.2009, 10.00 Uhr. Online: http://www.tvc.ru.

Fernsehübertragung. Kanal TV Centr: Prjamaja transljacija. Moskva, Krasnaja ploščad'. Parad Pervoj Pobedy. 07.11.2010, 10.00 Uhr. Online: http://www.tvc.ru.

Fernsehübertragung. Kanal TV Centr: Prjamaja transljacija. Moskva, Krasnaja ploščad'. Parad Pervoj Pobedy. 07.11.2011, 10.00 Uhr. Online: http://www.tvc.ru. 
Fernsehübertragung. Kanal TV Centr: Prjamaja transljacija. Moskva, Krasnaja ploščad'. Toržestvennyj marš v čest' Pervoj Pobedy. 07.11.2012, 10.00 Uhr. Online: http://www.tvc.ru.

Fernsehübertragung. Pervy Kanal: Vesti. 09.05.2015, 21 Uhr.

Fernsehübertragung. Pervyj Kanal; Rossija 1; Rossija 24: Prjamaja linija s Vladimirom Putinym. 25.04.2013, 12.00 Uhr.

Fernsehübertragung. Pervyj Volgogradskij Kanal: Volgograd gotovitsja k provedeniju grandioznogo Meždunarodnogo bajk-šou. 03.07.2013. Online: http://1vtv.tv/news/ obshchestvo/6358.

Fernsehübertragung. Telekanal ORT. Voennyj parad na Krasnoj ploščadi, posvjašennyj Dnju Pobedy. 09.05.1997, 9.50 Uhr.

Fernsehübertragung. Telekanal ORT. Voennyj parad na Krasnoj ploščadi, posvjašennyj Dnju Pobedy. 09.05.1998, 9.50 Uhr.

Fernsehübertragung. Telekanal ORT. Voennyj parad vojsk na Krasnoj ploščadi. 09.05.1996, 9.00 Uhr.

Fernsehübertragung. Telekanal ORT: Voennyj parad. 09.05.1999, 9.50 Uhr.

Film. Basov, Vladimir: Tišina. Sowjetunion 1963.

Film. Chotinenko, Vladimir: 1612: Chroniki smutnogo vremeni. Russland 2007.

Film. Egiazarov, Gavriil: Ot zari do zari. Sowjetunion 1975.

Film. Miller, George: Mad Max - Jenseits der Donnerkuppel. Australien 1985.

Film. Ozerov, Jurij: Bitva za moskvu - Tajfun. Sowjetunion 1985.

Film. Pudovkin, Vsevolod / Doller, Michail: Minin i Požarskij. Sowjetunion 1939.

Film. Varlamov, Leonid / Kopalin, Ilja: Moscow strikes back. Sowjetunion 1942.

Film. Varlamov, Leonid: XXIV-yj Oktjabr, Reč’ I. V. Stalina. Sowjetunion 1941.

YouTube Kanal Igor' Juškov: My pomnim (Hochgeladen am 04.05.2013). Online: http://www.youtube.com/watch?v=uf1BINIaLRc.

YouTube Kanal Časovye Pamjati: Vlad Malenko - Sevastopol' (Hochgeladen am 19.07.2013). Online: https://www.youtube.com/watch?v=HiDImHX23Mg.

YouTube. Kanal FeoShow: Bajk šou - 2012 Sevastopol'. Kul'minacija (Hochgeladen am 29.07.2012). Online: https://www.youtube.com/watch?v=Um_DMJDNWzk.

YouTube Kanal NationalHeroChannel: Nastojaščij geroj: Konev (Hochgeladen am 09.12.2011). Online: https://www.youtube.com/watch?v=Phq9nIWSTxI.

YouTube Kanal NationalHeroChannel: Flotovodec (Hochgeladen 25.01.2011). Online: https://www.youtube.com/watch?v=vy8lNSkwN7g.

YouTube Kanal NationalHeroChannel: Nastojaščie Supergeroi - Real Superheroes (Hochgeladen am 17.12.2010). Online: https://www.youtube.com/watch?v=Zmk Cqs0O-wg.

YouTube Kanal NationalHeroChannel: Nastojaščij geroj: Bagration (Hochgeladen am 09.12.2011). Online: https://www.youtube.com/watch?v=_M2ZmSy_ofA.

YouTube Kanal NationalHeroChannel: Nastojaščij geroj: Donskoj (Hochgeladen am 09.12.2011). Online: https://www.youtube.com/watch?v=PDa00NoJlNo.

YouTube Kanal NationalHeroChannel: Nastojaščij geroj: Nachimov (Hochgeladen am 09.12.2011). Online: https://www.youtube.com/watch?v=k7Fad20xH10.

YouTube Kanal NationalHeroChannel: Nastojaščij geroj: Nevskij (Hochgeladen am 09.12.2011). Online: https://www.youtube.com/watch?v=lZ-bIl2zPDs. 
YouTube Kanal NationalHeroChannel: Nastojaščij geroj: Rokossovskij (Hochgeladen am 09.12.2011). Online: https://www.youtube.com/watch?v=W3rKrqdPNdg.

YouTube Kanal NationalHeroChannel: Samaja bol'šaja pobeda (Hochgeladen am 11.01.2011). Online: https://www.youtube.com/watch?v=z1BKVTlus_U.

YouTube Kanal NationalHeroChannel: Sraženie (Hochgeladen am 20.01.2011). Online: https://www.youtube.com/watch?v=KyCicNDsWZk.

YouTube Kanal NationalHeroChannel: Sraženie. Hochgeladen am 20.01.2011. Online: https://www.youtube.com/watch?v=KyCicNDsWZk.

YouTube Kanal NationalHeroChannel: Viktorina (Hochgeladen am 27.01.2011). Online: https://www.youtube.com/watch?v=a7Mh0ewjrNg.

YouTube Kanal NationalHeroChannel: Vozvraščenie (Hochgeladen am 21.09.2011). Online: https://www.youtube.com/watch?v=Opf1PvCK20k.

\section{Sonstige Quellen}

ASEEES: On Russian Visas for Researchers. 1. April 2015. Online: http://www.aseees. org/news-events/aseees-news-feed/russian-visas-researchers.

Berdjaev, Nikolaj: Die russische Idee: Grundprobleme des russischen Denkens im 19. Jahrhundert und zu Beginn des 20. Jahrhunderts. Sankt Augustin 1983.

Bulgakov, Sergej: Nastol'naja kniga dlja svjaščenno-cerkovno-služitelej. Kiev 1913.

Central'nyj muzej Velikoj Otečestvennoj vojny: V bor'be protiv nacizma my byli vmeste (Ausstellung: 28.04.-14.10.2015). 28.04.2015. Online: http://www.poklonnayagora. ru/?part=57\&id_single $=1983$.

Gosudarstvennyj archiv Rossijskoj Federacii: Spravka-doklad glavnogo voennogo prokurora N. Afanas'eva »O 28 panfilovcach«. (ГА РФ.Ф. P-8131). Online: http://www. statearchive.ru/607

Kaltachčjan, Suren Tigranovič: Internacionalizm. In: Bol’šaja sovetskaja ènciklopedija (BSĖ). 3. Auflage. Moskau 1969-1978.

Prosveščenie (Karta pamjati): ।Voin - osvoboditel’.. Online: http://memory-map.prosv. $\mathrm{ru} /$ ?item=2257.

Prosveščenie (Karta pamjati): Monument Večnaja slava aviatoram, pavšim v bojach za Rodinu. Online: http://memory-map.prosv.ru/?item=9635.

Prosveščenie (Karta pamjati): Pamjatnik biljar-ozërcam, ne vernuvšimsja s vojny. Online: http://memory-map.prosv.ru/?item $=5025$.

Prosveščenie (Karta pamjati): Voinam Velikoj Otečestvennoj vojny posvjaščaetsja. Online: http://memory-map.prosv.ru.

Lukaševič, A.: Viktorial'nye dni. Eintrag in: Kirill I. (Hg.): Orthodoxe Enzyklopädie. Online: http://www.pravenc.ru/text/158568.html.

Medinskij, Vladimir: Vojna. Mify SSSR. 1939-1945. Moskau 2011.

Memorial: Erklärung der Gesellschaft Memorial. In: Osteuropa 59/7-8 (2009), 277-278.

Naryškin, Sergej: 65 let Velikoj pobedy. Moskau 2010. In sechs Bänden: Bd. 1: Kanun tragedii; Bd. 2: Vstavaj strana ogromnaja; Bd. 3: Pobeda; Bd. 4: Drugoe lico vojny; Bd. 5: Utračennye perspektivy; Bd. 6: Za čestnuju istoriju; Bd. 7-8: Velikaja pobeda. (erschienen Moskau 2011); Bd.9-11: Velikaja pobeda (erschienen Moskau 2013). 
Notovič, Filipp Iosifovič (Hg.): Protiv fašistskoj fal'sifikacii istorii. Sbornik statej. Moskau 1939.

Renan, Ernest: Was ist eine Nation? Rede am 11. März 1882 an der Sorbonne. Hamburg 1996.

Solschenizyn, Alexander: Ein Tag im Leben des Iwan Denissowitsch. München 1969.

Stalin, Iosif: Sočinenija. Bd. 18. Tver' 2006.

Stalin, Iosif/Ždanov, Andrej/Kirov, Sergej: Zamečanija po povodu konspekta učebnika po »Istorija SSSR«. In: Pravda vom 27.01.1936 Nr. 26 (6632), 2.

\section{Forschungsliteratur}

Abramov, Aleksandr:PatriotičeskajaideologijavRossii:ètapyèvoljucii.In:Molodežnaja politika, vospitatel'naja i patriotičeskaja rabota: praktika XXI veka. Materialy Vserossijskoj naučno-praktičeskoj konferencii. RGUTiS, Moskau 2014, 6-14.

Alyševa, Julija: Rečevoj portret V.V. Putina. In: Vestnik. Volgogradskij gosudarstvennyj universitet.16/2 (2012), 171-174.

Andreev, Dmitrij: Znaki Putina. Jubilej Pobedy kak prostranstvo simvoličeskich akcij vlasti. In: Bordjugov, Gennadij (Hg.): Pobeda-70: rekonstrukcija jubileja. Moskau 2015, 143-158.

Assmann, Aleida: Der lange Schatten der Vergangenheit. Erinnerungskultur und Geschichtspolitik. Bonn 2007.

Assmann, Jan: Das kulturelle Gedächtnis: Schrift, Erinnerung und politische Identität in frühen Hochkulturen. München 1992.

Augstein, Rudolf (Hg.): Historikerstreit. Die Dokumentation der Kontroverse um die Einzigartigkeit der nationalsozialistischen Judenvernichtung. 8. Auflage. München 1991.

Aust, Martin: Polen und Russland im Streit um die Ukraine. Konkurrierende Erinnerungen an die Kriege des 17. Jahrhunderts in den Jahren 1934 bis 2006. Wiesbaden 2009.

Becker, Julia/Wagner, Ulrich/Christ, Oliver: Nationalismus und Patriotismus als Ursache von Fremdenfeindlichkeit. In: Heitmeyer, Wilhelm (Hg.): Deutsche Zustände. Folge 5. Frankfurt a.M. 2007, 131-149.

Belov, Michail: Maršaly pobedy: pobediteli germanskich fel'dmaršalov. Moskau 1995.

Binder, Beate/Niedermüller, Peter/Kaschuba, Wolfgang: Inszenierungen des Nationalen - einige einleitende Bemerkungen. In: Binder, Beate/Niedermüller, Peter / Kaschuba, Wolfgang (Hg.): Inszenierungen des Nationalen. Geschichte, Kultur und die Politik der Identitäten am Ende des 20. Jahrhunderts. Köln 2001, 7-15.

Bizeul, Yves: Nationalismus, Patriotismus und Loyalität zur offenen Republik. In: Aus Politik und Zeitgeschichte 1-2 (2007), 30-38.

Bordjugov, Gennadij (Hg.): Pobeda-70: rekonstrukcija jubileja. Moskau 2015.

Bordjugov, Gennadij: Oktjabr'. Stalin. Pobeda. Kul't jubileev v prostranstve pamjati. Moskau 2010. 
Bowring, Bill: Gesetze und NGOs in Russland. In: Russland-Analysen Nr. 252 vom 22.02.2013, 2-5.

Brandenberger, David: A New Short Course? A. V. Filippov and the Russian State's Search for a $>$ Usable Pastı. In: Kritika. Explorations in Russian and Eurasian History 10/4 (2009), 825-833.

Brandenberger, David: National Bolshevism. Stalinist Mass Culture and the Formation of Modern Russian National Identity, 1931-1956. Cambridge 2002.

Čapkovskij, Filipp: Učebnik istorii i ideologičeskij deficit. In: Pro et Contra. 15/1-2 (2011), 117-133;

Capoccia, Giovanni/Kelemen, R. Daniel: The Study of Critical Junctures: Theory, Narrative, and Counterfactuals in Historical Institutionalism. In: World Politics 59/3 (2007), 341-369.

Cornelißen, Christoph: Was heißt Erinnerungskultur? Begriff - Methoden - Perspektiven. In: Geschichte in Wissenschaft und Unterricht 54 (2003), 548-563.

Danilova, Nataliya: The Politics of War Commemoration in the UK and Russia. London 2015.

Dann, Otto: Nation und Nationalismus in Deutschland. 1770-1990. 2. Aufl. München 1994.

Davies, Robert: Perestroika und Geschichte. Die Wende in der sowjetischen Historiographie. München 1991.

Davies, Robert: Soviet History in the Gorbachev Revolution. Bloomington 1989.

Davies, Robert: Soviet History in the Yeltsin Era. London 1997.

Dneprov, Ėduard: Novejšaja političeskaja istorija rossijskogo obrazovanija. Marios, Moskva 2011.

Dneprov, Ėduard: Obrazovatel'nyj standart - instrument obnovlenija soderžanija obščego obrazovanija. In: Voprosy Obrazovanija. 3 (2004), 77-117.

Donat, Helmut: Vorbemerkung: Die Indienstnahme der Geschichte. In: Donat, Helmut/Wieland, Lothar (Hg.): Auschwitz erst möglich gemacht? Bremen 1991, 7-15.

Dörner, Andreas: Politischer Mythos und symbolische Politik. Sinnstiftung durch symbolische Formen. Opladen 1995.

Dunlop, John: Aleksandr Dugin's `Neo-Eurasian` Textbook and Dmitrii Trenin’s Ambivalent Response. In: Harvard Ukrainian Studies. 25/1-2 (2001), 91-127.

Durkheim, Emile: Über die Teilung der sozialen Arbeit. Frankfurt a. M. 1977.

Easton, David: A Re-Assesment of the Concept of Political Support. In: British Journal of Political Science. 5/4 (1975), 435-457.

Easton, David: A Systems Analysis of Political Life. New York 1967.

Edelmann, Murray: Politik als Ritual. Die symbolische Funktion staatlicher Institutionen und politischen Handelns. Frankfurt a. M. 1976.

Fein, Elke: Geschichtspolitik in Russland. Chancen und Schwierigkeiten einer demokratischen Aufarbeitung der sowjetischen Vergangenheit am Beispiel der Tätigkeit der Gesellschaft MEMORIAL. Hamburg 2000.

Editorial: A New Chill? Foreign Scholars and the Russian Visa Question. In: Editorial. Kritika: Explorations in Russian and Eurasian History. 16/2 (2015), 229-233.

Editorial: Against Falsification, and a Changing of the Guard. In: Editorial. Kritika. Explorations in Russian and Eurasian History. 10/4 (2009), 747-751. 
Ešev, Marat: Patriotizm v sovetskoj i postsovetskoj Rossii. In: Vlast' 5 (2014), 85-89.

Gabowitsch, Mischa/Gdaniec, Cordula/Makhotina, Ekaterina (Hg.): Kriegsgedenken als Event. Der 9. Mai im postsozialistischen Europa. Paderborn 2017.

Gabowitsch, Mischa: Putin kaputt!? Russlands neue Protestkultur. Berlin 2013.

Gavriljuk, Vera/Malenkov, Vjačeslav: Graždanstvennost', patriotizm i vospitanie molodeži. In: Sociologičeskie issledovanija 4 (2007), 44-50.

Gavrilova, Marina: Diskursivnyj portret V.V. Putina. In: Diskurs-Pi 10/3 (2013), 114-115.

Gavrilova, Marina: Nekotorye čerty rečevogo portreta pervogo prezidenta Rossii B. N. El'cina. In: Političeskaja lingvistika 42/4 (2012), 17-22.

Gavrilova, Marina: Nekotorye čerty rečevogo portreta prezidenta rossii D. A. Medvedeva. Vestnik TvGU. Serija »Filologija» 1 (2011), 4-10.

Geyer, Dietrich: Perestrojka in der sowjetischen Geschichtswissenschaft. In: Geyer, Dietrich (Hg.): Die Umwertung der sowjetischen Geschichte. Göttingen 1991, 9-31.

Gitelman, Zvi: Die sowjetische Holocaust-Politik. In: Young, James (Hg.): Mahnmale des Holocaust. Motive, Rituale und Stätten des Gedenkens. München 1994, $115-124$.

Gitelman, Zvi: Politics and Historiography of the Holocaust in the Soviet Union. In: Gitelman, Zvi (Hg.): Bitter Legacy. Confronting the Holocaust in the USSR. Bloomington, Indianapolis 1997, 14-42.

Gjerde, Kristian Lundby: The use of history in Russia 2000-2011: the Kremlin and the search for consensus. In: East European Politics 31/2 (2015), 149-169.

Golubev, Aleksandr: Das Bild der sowjetischen Vergangenheit in den rußländischen Schulbüchern der letzten Jahre. In: de Keghel, Isabelle / Maier, Robert(Hg.): Auf den Kehrichthaufen der Geschichte? Der Umgang mit der sozialistischen Vergangenheit. Hannover 1999, 103-113.

Golunov, Sergej: Patriotičeskoe vospitanie v Rossii: za i protiv. In: Voprosy obrazovanija 3 (2012), 258-273.

Gorjuchin, Jurij: Dopuščeno - ne značit rekomendovano. Na odnogo pjatiklassnika prichoditsja 8 učebnikov po fizike. In: Učitel'skaja gazeta Nr. 40 vom 25. September 2001, 10.

Grüner, Frank: Patrioten und Kosmopoliten: Juden im Sowjetstaat 1941-1953. Köln 2008.

Habermas, Jürgen: Vorstudien und Ergänzungen zur Theorie des kommunikativen Handelns. Frankfurt a. M. 1989.

Hahn, Alois: Inszenierung und Erinnerung. In: Paragrana. Internationale Zeitschrift für Historische Anthropologie. 9/2 (2000), 21-41.

Halbwachs, Maurice: Das Gedächtnis und seine sozialen Bindungen. Frankfurt a. M. 1985.

Halbwachs, Maurice: Das kollektive Gedächtnis. Frankfurt am Main 1991.

Harle, Vilho: The Enemy with a thousand faces: The tradition of the other in western political thought and history. Westport 2000.

Hobsbawm, Eric (Hg.): The Invention of Tradition. Cambridge 1983.

Husband, William: Secondary School History Texts in the USSR: Revising the Soviet Past, 1985-1989. In: The Russian Review 50/4 (1991), 458-480. 
Il'ičeva, Valerija: Inauguracionnaja reč' kak instrument formirovanija političeskogo imidža v kontekste russkoj ritoričeskoj tradicii. Moskau 2015.

Ivantsov, Dmitrij: Ideengeschichtliche Entwicklungslinien der `Russischen Idee $\prec$ In: Russland - Deutschland - Europa. Ost-West-Wissenschaftsforum. Münster 2004, 33-43.

Jakunin, Vladimir (Hg.): Škol'nyj učebnik istorii i gosudarstvennaja politika. Moskau 2009.

Jaworski, Rudolf: Jubiläen und Gedenktage im östlichen Europa - Versuch einer einordnenden Betrachtung. In: Jaworski, Rudolf/Kusber, Jan (Hg.): Erinnern mit Hindernissen. Osteuropäische Gedenktage und Jubiläen im 20. und zu Beginn des 21. Jahrhunderts. Münster 2011, 11-28.

Jeismann, Karl-Ernst: >Identität‘ statt `Emanzipation`? Zum Geschichtsbewußtsein in der Bundesrepublik. In: Aus Politik und Zeitgeschichte. 20-21 (1986), 3-16.

Karl, Lars: >Der Tag des Sieges in der Sowjetunion: Inszenierung eines politischen Mythos. Magisterarbeit. Tübingen 1999.

Kaschuba, Wolfgang: Geschichtspolitik und Identitätspolitik. In: Binder, Beate/Niedermüller, Peter/Kaschuba, Wolfgang (Hg.): Inszenierungen des Nationalen. Geschichte, Kultur und die Politik der Identitäten am Ende des 20. Jahrhunderts. Köln 2001, 19-42.

Kaspržak, Anatolij/Loginova, Ol'ga/Polivanova, Katerina: Standart obrazovanija: istorija razrabotki i itogi. Voprosy obrazovanija 3 (2004), 24-43.

de Keghel, Isabelle (Hg.): Auf den Kehrichthaufen der Geschichte? der Umgang mit der sozialistischen Vergangenheit. Hannover 1999.

de Keghel, Isabelle: Die Rekonstruktion der vorsowjetischen Geschichte. Identitätsdiskurse im neuen Russland. Hamburg 2006.

de Keghel, Isabelle: Die Staatssymbolik des neuen Russland im Wandel. Vom antisowjetischen Impetus zur russländisch-sowjetischen Mischidentität. Bremen 2003.

de Keghel, Isabelle: Die Staatssymbolik des neuen Russland. Traditionen - Integrationsstrategien - Identitätsdiskurse. Münster 2008.

de Keghel, Isabelle: Verordneter Abschied von der revolutionären Tradition. Der `Tag der nationalen Einheit in der Russländischen Föderation. In: Karl, Lars / Polianski, Igor J. (Hg.): Geschichtspolitik und Erinnerungskultur im neuen Russland. Göttingen 2009, 119-140.

Khapaeva, Dina: Ocharovannye stalinizmom. Massovoe istoricheskoe soznanie v preddverii vyborov. In: Neprikosnovennyi zapas 55/5 (2007), 48-59.

Kielmansegg, Peter: Legitimität als analytische Kategorie. In: Zeitschrift für Politikwissenschaft. 12/3 (1971), 367-401.

Kindler, Robert: Kratzer auf dem `Autobus des Sieges $`$. Erinnerung an den Stalinismus in der Sowjetunion und in Russland. In: Baberowski, Jörg/Kindler, Robert (Hg.): Macht ohne Grenzen. Herrschaft und Terror im Stalinismus. Frankfurt a. M. 2014, 193-213.

Kliems, Alfrun/Winkler, Martina: Einleitung. Sinnstiftung durch Narration. In: Kliems, Alfrun/ Winkler, Martina (Hg.): Sinnstiftung durch Narration in Ost-Mittel-Europa. Berlin 2005, 7-18. 
Klusmeyer, Douglas und Suhrke, Astri: Comprehending `Evilk: Challenges for Law and Policy. In Ethics \& International Affairs 16/1 (2002), 27-42.

Knoll, Joachim: `Heil dir im Siegerkranz` Nationale Feier- und Gedenktage als Formen kollektiver Identifikation. In: Zeitschrift für Religions- und Geistesgeschichte. 57/2 (2005), 150-171.

Kocka, Jürgen: Angemessenheitskriterien historischer Argumente. In: Koselleck, Reinhart/Mommsen, Wolfgang/Rüsen, Jörn (Hg.): Objektivität und Parteilichkeit in der Geschichtswissenschaft. München 1977, 469-475.

Kocka, Jürgen: Erinnerung und Politik. In: Oldenhage, Klaus (Hg.): Archiv und Geschichte. Düsseldorf 2000, 963-967.

Kohlstruck, Michael: Erinnerungspolitik. Kollektive Identität, Neue Ordnung, Diskurshegemonie. In: Schwelling, Birgit (Hg.): Politikwissenschaft als Kulturwissenschaft. Wiesbaden 2004, 173-193.

Kolesnikov, Andrej: Spičrajtery: chroniki professii, sočinjavšej i izmenjavšej mir Spičrajtery: chronika professii, sočinjavšej i izmenjavšej mir. Moskau 2007.

Koposov, Nikolaj: Pamyat' Strogogo Rezhima. Istoriya i politika Rossii. Moskva 2011. Kopp, Manfred / Müller, Hans-Peter: Herrschaft und Legitimität in modernen Industriegesellschaften. München 1980.

Korff, Gottfried: Bildwelt der Ausstellung - Die Darstellung von Geschichte im Museum. In: Borsdorf, Ulrich / Grütter, Heinrich Theodor (Hg.): Orte der Erinnerung. Denkmal, Gedenkstätte, Museum. Frankfurt a. M. 1999. 319-336.

Koselleck, Reinhart: Begriffsgeschichten. Frankfurt a. M. 2006.

Koselleck, Reinhart: Geschichte. In: Brunner, Otto/Conze, Werner/Koselleck, Reinhart (Hg.): Geschichtliche Grundbegriffe. Bd. 2. Stuttgart 1975, 593.

Landkammer, Jochen/Zimmerli, Walther: Erinnerungsmanagement und politische Systemwechsel. Kleine Versuche zur Erklärung eines großen Problems. In: Landkammer, Jochen/Noetzel, Thomas (Hg.): Erinnerungsmanagement. Systemtransformation und Vergangenheitspolitik im internationalen Vergleich. München 2006, 265-283.

Langenohl, Andreas: Erinnerung und Modernisierung. Die Rekonstruktion politischer Kollektivität am Beispiel des neuen Russland. Göttingen 2000.

Langenol', Andreas: Oficial'nye vizity. Internacionalizacija pamjati o Vtoroj mirovoj vojne v Rossii i Germanii. In: Neprikosnovennyj zapas 40-41/2-3 (2005), 403-418.

Leggewie, Claus/Meyer, Erik: `Ein Ort, an den man gerne geht . Das Holocaust-Mahnmal und die deutsche Geschichtspolitik nach 1989. München 2005.

Levintova, Ekaterina/Butterfield, Jim: Kak formiruetsja istorija i otnošenie k nej: škol'nye učebniki o novejšej rossijskoj istorii. Vestnik obščestvennogo mnenija 101/3 (2009), 103-115.

Lichau, Carsten: `The moving, awe-inspiring silence . Zum semotionalen Potenzial der Schweigeminute. In: Jarzebowski, Claudia/Kwaschik, Anne (Hg.): Performing emotions: interdisziplinäre Perspektiven auf das Verhältnis von Politik und Emotion in der Frühen Neuzeit und in der Moderne. Göttingen 2013, 69-92.

Luchterhand, Galina: Die politischen Parteien im neuen Rußland. Dokumente und Kommentare. Bremen 1993.

Luhmann, Niklas: Legitimation durch Verfahren. Frankfurt a.M. 1983. 
Lutz-Auras, Ludmila: >Auf Stalin, Sieg und Vaterland!.. Politisierung der kollektiven Erinnerung an den Zweiten Weltkrieg in Russland. Wiesbaden 2013.

Maier, Robert: Was ist ein gutes Schulbuch? In: Eckert Beiträge 2009/3. Online: http:// d-nb.info/1001808479/34, 1-3.

Makhotina, Ekaterina: Auf der Suche nach der verlorenen Heimat. Das gesellschaftliche Erinnern an das 20. Jahrhundert im heutigen Russland. In: Zedler, Jörg (Hg.): ,Was die Welt im Innersten zusammenhält‘. Gesellschaftlich-staatliche Kohäsionskräfte im 19. und 20. Jahrhundert. München 2014, 77-104.

Makhotina, Ekaterina: Der »Tag des Sieges« als ein erinnerungskulturelles Konfliktfeld: Der 9. Mai in Vilnius« (in russischer Übersetzung). In: Gabovič, Michail (Hg.): >Pamjatnik i prazdnikı. NLO, Moskau 2016. unveröff. Manuskript.

Makhotina, Ekaterina: Erinnerungen an den Krieg - Krieg der Erinnerungen. Litauen und der Zweite Weltkrieg. Göttingen 2016.

Makhotina, Ekaterina: Symbole der Macht, Orte der Trauer. Die Entwicklung der rituellen und symbolischen Ausgestaltung von Ehrenmalen des Zweiten Weltkriegs in Russland. In: Heinemann, Monika/Maischein, Hannah (Hg.): Medien zwischen Fiction-Making und Realitätsanspruch. Konstruktionen historischer Erinnerungen. München 2011, 279-306.

Malinova, Ol'ga: Aktual'noe prošloe. Simvoličeskaja politika vlastvujuščej èlity i dilemmy rossijskoj identičnosti. Moskau 2015.

Martinez, Matias/Scheffel, Michael: Einführung in die Erzähltheorie. München 2007.

McCalman, Iain/Pickering, Paul A. (Hg.): Historical reenactment: From realism to the affective turn. Basingstoke 2010.

Merriam, Charles E.: Political Power. New York 1934.

Mickiewicz, Ellen: Changing Channels. Television and the Struggle for Power in Russia. London 1999.

Mikula, Maja: Historical re-enactment: narrativity, affect and the sublime. In: Rethinking History 19/4 (2015), 583-601.

Miller, Aleksej: Rossija: vlast' i istorija. In: Pro et Contra, 13/3-4 (2009), 6-23.

Miller, Alexei: Geschichtspolitik in Russland. In: Russland-Analysen Nr. 196 vom 12.02.2010, 2-5.

Miller, Alexei: Introduction. Historical Politics: Eastern European Convolutions in 21st Century. In: Miller, Alexei/Lipman, Maria (Hg.): The convolutions of historical politics. Budapest 2012, 1-20.

Miller, Alexei/Lipman, Maria (Hg.): The convolutions of historical politics. Budapest 2012.

Miller, Alexei: The turn of Russian Historical Politics, from Perestroika to 2011. In: Miller, Alexei/Lipman, Maria (Hg.): The convolutions of historical politics. Budapest 2012, 253-278.

Mironov, Boris: The Fruits of a Bourgeois Education. In: Kritika: Explorations in Russian and Eurasian History. 10/4 (2009), 847-860.

Modržinskaja, Elena Dmitrievna: Kosmopolitizm. Bol’šaja sovetskaja ènciklopedija (BSĖ). 3. Auflage. Moskau 1969-1978.

Mosse, George: Gefallen für das Vaterland: nationales Heldentum und namenloses Sterben. Stuttgart 1993. 
Münch, Felix: Diskriminierung durch Geschichte? Der Deutungsstreit um den >Bronzenen Soldaten im postsowjetischen Estland. Marburg 2008.

Niethammer, Lutz: Kollektive Identität. Heimliche Quellen einer unheimlichen Konjunktur. Hamburg 2000.

Nora, Pierre (Hg.): Les lieux de mémoire. Bd. 1: La République. Paris 1984; Bd. 2.1-2.3: La nation. Paris 1986; Bd. 3.1-3.3: Les France. Paris 1992.

Oberländer, Erwin: Sowjetpatriotismus und Geschichte. Dokumentation. Köln 1967.

Olick, Jeffrey: Genre memories and memory genres. In: American Sociological Review 64 (1999), 381-402.

Oushakine, Serguei Alex: Emotional Blueprints: War Songs as an Affective Medium. In: Steinberg, Mark/Sobol, Valeria (Hg.): Interpreting Emotions in Russia and Eastern Europe. DeKalb 2011, 248-276.

Oushakine, Serguei: Remembering in Public: On the Affective Management of History. In: Ab Imperio 1 (2013), 269-302.

Rapoport, Anatoli: In search of identity: Competing models in Russia's civic education. In: Grumet, Madeleine/ Yates, Lyn (Hg.): World Yearbook of Education 2011. Curriculum in Today's World: Configuring Knowledge, Identities, Work and Politics. London 2011, 199-213.

Rapoport, Anatoli: Patriotic education in Russia: Stylistic move or the sign of substantive counter-reform? The Educational Forum 73/2 (2009), 141-153.

Rapoport, Anatoli: Similar Rhetoric, Different Goals: Contemporary Tendencies Patriotic Education in Russia and Ukraine. In: World Studies in Education 10/1 (2009), 27-40.

Ro'i, Yaakov: The Transformation of Historiography on the >Punished Peoples $\triangleleft$ In: History and Memory 21/2 (2009), 150-176.

Rolf, Malte: Das Sowjetische Massenfest. Hamburg 2006.

Rolofs, Oliver: Ein Hauch von Kaltem Krieg. Putins Brandrede verschreckt die Münchner Sicherheitskonferenz 2007 und warnt die USA und NATO. Online: https://www.securityconference.de/ueber-uns/muenchner-momente/ein-hauchvon-kaltem-krieg.

Rüsen, Jörn: Das ideale Schulbuch. Überlegungen zum Leitmedium des Geschichtsunterrichts. In: Internationale Schulbuchforschung. Zeitschrift des Georg-EckertInstituts. 14/3 (1992), 237-250.

Rüsen, Jörn: Für eine Didaktik historischer Museen. In: Rüsen, Jörn / Ernst, Wolfgang / Grütter, Heinrich Theodor (Hg.): Geschichte sehen. Beiträge zur Ästhetik historischer Museen. Pfaffenweiler 1988, 9-20.

Rüsen, Jörn: Geschichtskultur. In: Geschichte in Wissenschaft und Unterricht 46 (1995), 513-521.

Rüsen, Jörn: Kultur macht Sinn. Orientierung zwischen Gestern und Morgen. Köln 2006.

Rüsen, Jörn: Vernunftpotenziale der Geschichtskultur. In: Rüsen, Jörn/Lämmert, Eberhard/Glotz, Peter (Hg.): Die Zukunft der Aufklärung. Frankfurt a. M. 1988, 105-114.

Sakwa, Richard: Putin. Russia’s choice. London 2008. 
Samochwalowa, V.I.: Na perekrestke kult'tur. O kul'turnoj samobytnosti Rossii. In: Akopjan, K.Z. (Hg.): Russkaja kul'tura i mir. Bd. 1. Niznij Novgorod, 1994, 7-9.

Sanina, Anna: Patriotizm i patriotičeskoe vospitanie v sovremennoj Rossii. In: Sociologičeskie issledovanija 5 (2016), 44-53.

Sanina, Anna/Migunova, Dar'ja/Zuev, Daniil: Patriotičeskoe vospitanie kak ob"ekt gosudarstvennoj politiki. Doklad. XVIII Aprel'skaja meždunarodnaja naučnaja konferencija po problemam razvitija èkonomiki i obščestva. Online: https://eventsfiles-bpm.hse.ru/files/_reports/86241926-EEB6-4267-8A20-00C8A314FDE7/ Sanina_Migunova_Zuev.pdf.

Scheliha, Wolfram von: Analyse. Staatliche Geschichtsschreibung im Post-Imperium. Putins Einheitslehrbuch für den Geschichtsunterricht. In: Russland-Analysen Nr. 271 vom 14.02.2014, 2-6. Online: http://www.laender-analysen.de/russland/ pdf/RusslandAnalysen271.pdf.

Scherrer, Jutta: Ideologie, Identität und Erinnerung. Eine neue Russische Idee für Rußland? In: Osteuropa. Zeitschrift für Gegenwartsfragen des Ostens 54/8 (2004), 27-42.

Schmid, Harald: Konstruktion, Bedeutung, Macht. Zum kulturwissenschaftlichen Profil einer Analyse von Geschichtspolitik. In: Heinrich, Horst-Alfred/Kohlstruck, Michael (Hg.): Geschichtspolitik und sozialwissenschaftliche Theorie. Stuttgart 2008, 75-98.

Schröder, Hans-Henning: Auf dem Boden der Tatsachen. Putins Rede zur Lage der Nation im Dezember 2013. In: Russland-Analysen. Nr. 269 vom 20.12.2013, 2-6.

Schröder, Hans-Henning: Der Terror, die Türkei und die alltäglichen Probleme... Die `Botschaft an die Föderalversammlung`zeigt, dass Putin ein politisches Konzept fehlt. In: Russland-Analysen. Nr. 307 vom 18.12.2015, 2-6.

Schröder, Hans-Henning: Politik in Zeiten nationaler Verzückung. Putins Botschaft zur Lage der Nation im Jahre 2014. In: Russland-Analysen Nr. 288 vom 19.12.2014, 7-9. Schröder, Hans-Henning: Vorwärts Russland! Die Botschaft des Präsidenten an die Nationalversammlung. In: Russland-Analysen Nr. 249 vom 14.12.2012, 2-5.

Schubert, Christiane: Dreizack und Roter Stern: Geschichtspolitik und historisches Gedächtnis in der Ukraine. Berlin 2015.

Schwelling, Birgit: Das Gedächtnis Europas. Eine Diagnose. In: Beichelt, Timm u.a. (Hg.): Europa Studien. Eine Einführung, Wiesbaden 2006, 81-94.

Schwelling, Birgit: Politische Erinnerung. Eine akteurs- und handlungsbezogene Perspektive auf den Zusammenhang von Gedächtnis, Erinnerung und Politik. In: Heinrich, Horst-Alfred/Kohlstruck, Michael (Hg.): Geschichtspolitik und sozialwissenschaftliche Theorie. Stuttgart 2008, 99-121.

Selunskaja, Nadežda: Sakral'nye mesta, investicii v pamjat' i srednevekovyj diskurs. Novacii istoričeskogo jazyka Vladimira Putina 2014 goda: vzgljad istorika-medievista. In: Gefter vom 29.12.2014. Online: http://gefter.ru/archive/13947.

Sereda, Viktoria: Osobennosti reprezentacii national'no-istoričeskich identičnostej v oficial'nom diskurse prezidentov Ukrainy i Rossii. Sociologija: teorija, metody, marketing 3 (2006), 191-212.

Ševyrev, Aleksandr: Das Bild Rußlands in heutigen russischen Geschichtslehrbüchern. In: Internationale Schulbuchforschung 17/4 (1995), 397-424. 
Shlapentokh, Dmitry: History and Interethnic Conflicts in Putin's Russia. Journal of Educational Media, Memory and Society 1/1 (2009), 165-179.

Shlapentokh, Dmitry: Kondopoga - Ethnic/Social Tension in Putin's Russia. European Review 18/2 (2010), 177-206.

Shnirelman, Victor: Stigmatized by History or by Historians? The peoples of Russia in School History Textbooks. In: History and Memory 21/2 (2009), 110-149.

Sieber, Bettina: >Russische Idee` und Identität. >Philosophisches Erbeく und Selbstthematisierung der Russen in der öffentlichen Diskussion 1985-1995. Bochum 1998.

Siegel, Jerry/Shuster, Joe: Action Comics featuring Superman. DC Comics, New York 1938.

Siegert, Jens: NGOs in Russland. In: Russland-Analysen Nr. 284 vom 24.10.2014, 16-19. Siegert, Jens: Von Agenten, unerwünschten Organisationen und ihren Folgen. In: Russland-Analysen Nr. 296 vom 22.05.2015, 17-21.

Siegert, Jens: Wahlkampf zur Russischen Staatsduma. In: Russland-Analysen Nr. 8 vom 05.11.2003, 2-5.

Simon, Gerhard: Auf der Suche nach der `Idee für Rußlandk. In: Osteuropa. Zeitschrift für Gegenwartsfragen des Ostens 47/12 (1997), 1169-1190.

Šnajder, Ėberchard: Vnešnjaja politika Ukrainy pri Viktore Juščenko. In: Vestnik Analitiki 21/3 (2005) vom 01.09.2005, 97-113.

Solonari, Vladimir: Normalizing Russia, Legitimizing Putin. In: Kritika: Explorations in Russian and Eurasian History 10/4 (2009), 835-846.

Stollberg-Rilinger, Barbara: Symbolische Kommunikation in der Vormoderne. Begriffe - Theorien - Forschungsperspektiven. In: Zeitschrift für historische Forschung 31/4 (2004), 489-529.

Straub, Jürgen: Identität. In: Jaeger, Friedrich/Liebisch, Burkhard (Hg.): Handbuch der Kulturwissenschaften. Band 1. Stuttgart 2004, 207-303.

Sukhov, Andrej: Stoletnjaja diskussija. Zapadnichestvo i samobytnost' v russkoj filosofii. Moskva 1998.

Surkov, Vladislav: Nacionalizacija buduščego. Paragrafy pro suverennuju demokratiju. In: Ėkspert Nr. 43 (537) vom 20. November 2006. Online: http://expert.ru/ expert/2006/43/nacionalizaciya_buduschego.

Tacke, Charlotte: Denkmal im sozialen Raum: Nationale Symbole in Deutschland und Frankreich im 19. Jahrhundert. Göttingen 1995.

Thijs, Krijn: Vom >master narrativ`zur `Meistererzählung`? Überlegungen zu einem Konzept der snarrativen Hierarchie`. In: Kliems, Alfrun/Winkler Martina (Hg.): Sinnstiftung durch Narration in Ost-Mittel-Europa. Berlin 2005, 21-53.

Tismaneanu, Vladimir: Fantasies of Salvation. Democracy, Nationalism and Myth in Post-Communist Europe. Princeton 1998.

Tjulaeva, Tamara: Die Reform der historischen und sozialkundlichen Bildung an russischen Schulen. In: Internationale Schulbuchforschung 17/4 (1995), 387-395.

Tsfasman, Arkadij: Die Darstellung der Rolle Stalins in sowjetischen Schulbüchern zur Geschichte der UdSSR. In: Bulletin 1- Systemumbrüche und historisches Gedächtnis in der deutschen und russischen Geschichte. Gemeinsame Kommission für die Erforschung der jüngeren deutsch-russischen Geschichte. Online-Publi- 
kation 2014. http://www.deutsch-russische-geschichtskommission.de/fileadmin/ user_upload/Dateien/Bulletin_1_deutsch.pdf, 43-50.

Umland, Andreas: Neue rechtsextreme Intellektuellenzirkel in Putins Russland: das Anti-Orange Komitee, der Isborsk-Klub und der Florian-Geyer-Klub. In: Russland-Analysen. Nr. 256 vom 03.05.2013, 2-5.

Veser, Reinhard: Rußland feiert die Befreiung von Polen. In: Frankfurter Allgemeine Zeitung, Nr. 258 vom 05.11.2005, 6.

Voigt, Rüdiger: Mythen, Rituale und Symbole in der Politik. In: Pribersky, Andreas/Unfried, Berthold (Hg.): Symbole und Rituale des Politischen. Frankfurt a. M. 1999, 55-72.

Voigt, Rüdiger: Mythen, Rituale und Symbole in der Politik. In: Voigt, Rüdiger (Hg.): Symbole der Politik - Politik der Symbole. Opladen 1989, 9-37.

Vorländer, Hans: Gründung und Geltung. Die Konstitution der Ordnung und die Legitimität der Konstitution. In: Melville, Gert/Vorländer, Hans (Hg.): Geltungsgeschichten. Über die Stabilisierung und Legitimierung institutioneller Ordnungen. Köln 2002, 243-263.

Vowinckel, Annette: Past Futures: From Re-enactment to the Simulation of History in Computer Games. In: Historical Social Research 34/2 (2009), 322-332.

Weber, Max: Wirtschaft und Gesellschaft. Grundriss der verstehenden Soziologie. 5. rev. Ausgabe. Tübingen 1995.

Wiederkehr, Stefan: Die eurasische Bewegung: Wissenschaft und Politik in der russischen Emigration der Zwischenkriegszeit und im postsowjetischen Russland. Köln 2007.

Wolffsohn, Michael: Ewige Schuld? 40 Jahre Deutsch-Jüdisch-Israelische Beziehungen. München 1988.

Wolfrum, Edgar: Erinnerungskultur und Geschichtspolitik als Forschungsfelder. In: Scheunemann, Jan (Hg.): Reformation und Bauernkrieg. Erinnerungskultur und Geschichtspolitik im geteilten Deutschland. Leipzig 2010, 13-47.

Wolfrum, Edgar: Geschichtspolitik in der Bundesrepublik Deutschland. Der Weg zur bundesrepublikanischen Erinnerung 1948-1990. Darmstadt 1999.

Wood, Elizabeth: Performing Memory: Vladimir Putin and the Celebration of World War II. in Russia. The Soviet and Post-Soviet Review 38 (2011), 172-200.

Yurchak, Alexei: Everything was forever, until it was no more: the last Soviet generation. Princeton 2005.

Zorn, Andrej: In search of a New Identity. Visions of Past and Present in Post-Communist Russia. In: Strath, Bo (Hg.): Myth and Memory in the Construction of Community. Brüssel 2000, 321-330.

Zubkova, Elena: The Filippov Syndrom. In: Kritika: Explorations in Russian and Eurasian History 10/4 (2009), 861-868. 


\section{Personenregister}

Afanas'ev, Nikolaj 299

Aleksei I. 63

Andreev, Igor' 181-183

Arsent'ev, Nikolaj $181 \mathrm{f}$.

Artizov, Andrej 291

Assmann, Aleida $12 \mathrm{f}$.

Assmann, Jan $12 \mathrm{f}$.

Bagration, Pëtr 84, 117

Bandera, Stepan 272

Belinskij, Vissarion 54

Berdjaev, Nikolaj 247, 263, 280

Boženov, Sergej 99

Brežnev, Leonid 170, 196

Butterfield, Jim 30

Čajkovskij, Pëtr 85

Cameron, David 254

Chakimov, Rafail' $150 \mathrm{f} ., 157,159 \mathrm{f}$.

Chasbulatov, Ruslan $203 \mathrm{f}$.

Chodkiewicz, Jan 181

Chruščëv, Nikita 170

Chutorskaja, Ekaterina 194

Čiževskij, Aleksandr 116

Čubar'jan, Aleksandr 136, 155, 159, $163 \mathrm{f} ., 172,289$

Danilin, Pavel 138, 146

Danilov, Aleksandr 141-146

Demakin, Igor' 96 f., 108

Dneprov, Ėduard 128

Doluckij, Igor' 135-137, 139, 145, 148, 155, 287

Donskoj, Dmitrij 59, 63, 117, 210, 212, 254

Dostoevskij, Fëdor 54

Easton, David 19, 77

Edelman, Murray 22
Ekaterina II. 72, 182

El'cin, Boris $10 \mathrm{f} ., 33,58,60,64 \mathrm{f}$., 72-74, 82 f., 105, 119f., 126, 170, 172, 174, 193 f., 197, 203-213, 223, 225 f., 229-236, 249, 251 f., 257 f., 263, 265, 272, 274-278, 282-284, 301, $303 \mathrm{f}$.

Elizaveta Petrovna 161

Ermolov, Aleksandr $87 \mathrm{f}$.

Evžerichin, Ėmmanuil 102

Filippov, Aleksandr 92, 135, 137, 145 f., 148, 187, 283

Franguljana, Georgij 286

Galuškin, Vasilij 98

Gogol', Nikolaj 54, 118

Gorbačëv, Michail 9, 170f., 198-203

Gorinov, Michail 180, 185-187

Gračëv, Pavel 205-209, 212, 252, 287

Gumilëv, Lev 244, 280

Halbwachs, Maurice $12 \mathrm{f}$.

Händel, Friedrich 113

Hitler, Adolf 81, 207, 249, 271

Hobsbawm, Eric 21

Il'in, Ivan 279

Izmozik, Vladlen 143 f., 147

Janukovič, Viktor 188, 256

Javlinskij, Grigorij 136

Jazov, Dmitrij 200-202

Jesus Christus 104

Juščenko, Viktor 217

Kalimulin, Dmitrij 194

Kalina, Isaak 290

Kaschuba, Wolfgang 24

Kas'janov, Michail 129, 136 
Kielmansegg, Peter 18

Kirill I. 98

Kirov, Sergej 151

Kiselev, Aleksandr 142, 144, 147

Kločkov, Vasilij 144

Kocka, Jürgen 16

Kohlstruck, Michael 18-21

Kolesnikov, Andrej 150

Kollontaj, Aleksandra 107

Konev, Ivan 117

Kožedub, Ivan 114

Kutuzov, Michail 63, 84, 210

Lenin, Vladimir 63, 80, 209, 252, 284

Levandovskij, Andrej 144, 146

Levintova, Ekaterina 30

Limonov, Eduard 109

Livanov, Andrej 149-151

Lužkov, Jurij 204

Malenko, Vladislav 96

Malinovskij, Rodion $196 \mathrm{f}$.

Maršal, Aleksandr $102 \mathrm{f}$.

Medinskij, Sergej 300

Medvedev, Dmitrij 73, 105, 172, 220-224, 228, 232 f., 242 f., 250, 255, 257, 260 f., 266, 269f., 272-274, 279, 286-288, 291, 293, 303

Melikova, Natal'ja 194

Merkel, Angela 256

Miller, Aleksej $291 \mathrm{f}$.

Minin, Kuz'ma 59, 63 f., 69, 82 f., 161, 209f., 254, $258 \mathrm{f}$.

Mironenko, Sergej 300

Mišustina, Larisa 194

Molotow, Vjačeslav 81, 204

Nachimov, Pavel 117

Napoleon Bonaparte 81, $83 \mathrm{f}$.

Naryškin, Sergej 150 f., 154, 178, 287, 289-291

Nevskij, Aleksandr 59, 63, 117 f., 210, 254

Oberländer, Erwin 154

Oktjabr'skaja, Marija 115
Okudžava, Bulat 203

Ostrovskij, Valerij 125

Panfilov, Ivan 144, 299

Paulus, Friedrich 104, 117

Pëtr I. 58, 210

Petrov, Andrej 178

Pokrovskij, Michail 154

Polosuchin, Viktor 85

Požarskij, Dmitrij 59, 63 f., 69, 82 f., 161, 209 f., 254, 258

Prilepin, Sachar 109

Prisekin, Sergej 209

Prochanov, Aleksandr 103-106, 108 f., 122,225

Putin, Vladimir 10, 27, $33 \mathrm{f} ., 61,65,72$, 95, 98, 102f., 105, 110, 120, $129 \mathrm{f}$., 135-137, 146, 149-151, 160, 172, 174-176, 178, 187, 190, 193, 213-221, 223-231, 233-250, 253, 255-257, 261, 263f., 266-280, 283, 286, 293, 301, $303 \mathrm{f}$.

Puškin, Aleksandr 116

Raevskij, Nikolaj 84

Rastorguev, Nikolaj 103

Renan, Ernest 83

Rokossovskij, Konstantin 117 f., 209

Roosevelt, Franklin 241

Rotenberg, Arkadij 135

Ruckoj, Aleksandr 204, 251

Rüsen, Jörn 13, 19 f., 22

Saakašvili, Michail 217

Šabanov, Jaroslav 194

Sacharov, Andrej Dmitrievič 54

Sacharov, Andrej Nikolaevič 289

Schmid, Harald 19

Schröder, Hans-Henning 31, 243, 246

Schwelling, Birgit 17

Šestakov, Andrej 151

Šestakov, Vladimir 144, 146

Solženicyn, Aleksandr 54, 132, 244, 280, 285

Sobčak, Anatolij 235f., 277 
Sobjanin, Sergej 82-84

Šojgu, Sergej 228

Šostakovič, Dmitrij 113

Sokolov, Sergej 198

Stalin, Iosif 53, 62, 91, 107-109, 141, $151,154,157,162,169,197,209,229$, $273 \mathrm{f} ., 303$

Stollberg-Rilinger, Barbara 17

Surkov, Vladislav $137 \mathrm{f}$.

Suvorov, Aleksandr 63, $116 \mathrm{f}$., 210

Svanidze, Nikolaj 150

Thijs, Krijn 20

Timošenko, Julija 188

Toidze, Iraklij 206

Tret'jak, Natal'ja 179

Trubinova, Tat'jana 194

Tsfasman, Arkadij 169

Ušakov, Fëdor 117
Ustinov, Viktor 60

Utkin, Anatolij 145

Voigt, Rüdiger 21, 78

Volobuev, Oleg 141, 143, 147, 180, 184-188

Weber, Max 18, 111

Wolffsohn, Michael 15

Wolfrum, Edgar 14f., 18, 21

Zagladin, Nikita 141, 143 f., 147

Zagot, Michail $87 \mathrm{f}$.

Zaldostanov, Aleksandr 95, $98 \mathrm{f}$, 102-104, 106-109

Ždanov, Andrej 151, 154, 284

Zjuganov, Gennadij 204, 211

Zor'kin, Valerij 204, 251

Žukov, Georgij 197, 209, 211, 229, 284

Žuravlev, Sergej 170, 172, 174 